\title{
The Influence of Religion on Armed Conflict Onset
}

\author{
Davis Lemay Brown II \\ Oxford, Mississippi
}

\author{
M.A., University of Virginia, 2008 \\ LL.M., George Washington University, 2003 \\ J.D., New York University, 1994 \\ B.A., University of Mississippi, 1989
}

A Dissertation presented to the Graduate Faculty of the University of Virginia in Candidacy for the Degree of

Doctor of Philosophy

Department of Politics

University of Virginia

May 2012

John M. Owen, IV

Todd S. Sechser

John Norton Moore

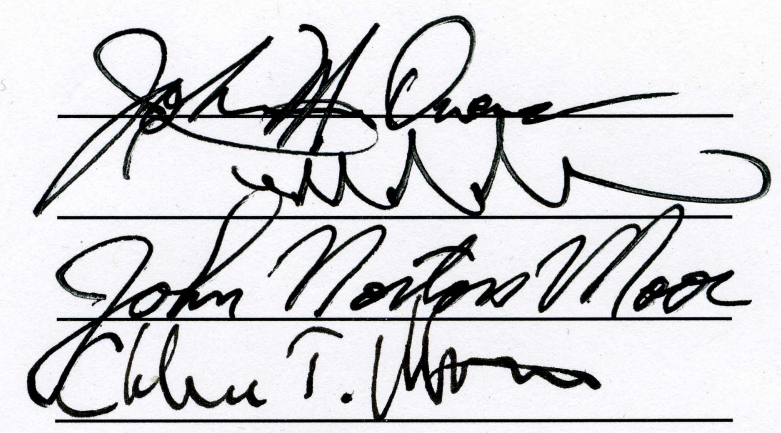

Charles Mathewes 
$\underline{\text { AbSTRACT }}$

This dissertation examines the effect of religion on the use of military force by states against other states. Despite a growing body of literature on religion and/in international relations, the topic remains under-studied and under-theorized; most of the literature focuses either on conflict associated with religious differences, or on religious identity or culture as a driver for civil and other non-state wars. In contrast, I treat religion as an effect on the ideological characteristics of a state, and argue that religious ideas influence the outcomes of war and peace. I argue that religion wields its effect through three media: religious scripture, the priesthood (or more precisely, the writings of the priesthood), and historical narrative. Through these media, each religion generates a war ethic that influences the decisions of states to use military force or not.

I measure that influence through a series of variables which capture the religious identities of chief executives of states, the preference for a particular religious category held by governing regimes of states, and the religious demographics of the citizenries of states. Having done this, and having controlled for the other conventional factors, I find that (1) religion does influence a state's propensity to use force against other states, and (2) different religions have different effects. I find that Christian states are less likely to initiate interstate armed conflicts than non-Christian states, Muslim states are more likely than non-Muslim states, and Buddhist states are no more or less likely than non-Buddhist states. In other words, Christianity has a negative effect on a state's propensity to use force, Islam a positive effect, and Buddhism no effect. 


\section{TABLE OF CONTENTS}

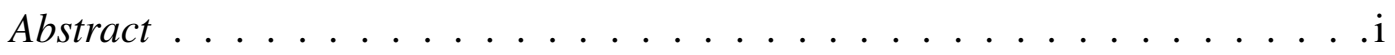

Table of Contents . . . . . . . . . . . . . . . . ii

Acknowledgements .................... iv

Table of Abbreviations . . . . . . . . . . . . . . v

Chapter 1: The Influence of Religion on Armed Conflict Onset . . . . . . . . 1

Chapter 2: Why and How Religion Affects Decisions for War or Peace . . . . .40

The Place of Religion in International Relations Theory . . . . . . .42

Religion in International Legal Theories of Armed Conflict Onset . .75

Chapter 3: Research Design . . . . . . . . . . . . . . . . 88

Chapter 4: The Effect of Religion Generally: Empirical Results . . . . . . . . 131

Chapter 5: The Effect of Christianity . . . . . . . . . . . 166

The Biblical Foundations of Christian Political Theory . . . . . . . 167

The Western Christian War Ethic . . . . . . . . . . . . . . 172

Empirical Testing of Christianity Overall and Western Christianity 211

The Eastern Christian War Ethic . . . . . . . . . . . . 225

Chapter 6: The Effect of Islam . . . . . . . . . . . . . . . 236

Islamic Scripture . . . . . . . . . . . . . . . . . . . . . . . . . . . . . . .

Islamic Political Theory and Law . . . . . . . . . . . . . . . 241

The Islamic War Ethic . . . . . . . . . . . . . . . . . . . 257

Empirical Testing of Islam . . . . . . . . . . . . . . . . . . . . . . . . . . . . . . 
Chapter 7: The Effect of Buddhism . . . . . . . . . . . . . . 301

Buddhist Scripture . . . . . . . . . . . . . . . . . 302

The War Ethic in the Pali Canon . . . . . . . . . . . . . . . . . 305

The War Ethic in Mahayana Buddhism . . . . . . . . . . . . . 332

Empirical Testing of Buddhism . . . . . . . . . . . . . . 339

Chapter 8: Bush and Sadat: Two Illustrations of the Effect of Religion . . . . 348

George Bush and the Gulf War . . . . . . . . . . . . . . . . . . 348

Anwar Sadat and War and Peace with Israel . . . . . . . . . . . . 369

Conclusion . . . . . . . . . . . . . . . . . . . . . . . . . . . . . . . . .

Appendix A: Code Book for Data Set . . . . . . . . . . . . . . . . 394

Appendix B: Tables . . . . . . . . . . . . . . . . 4436

Tables for Chapter 3 . . . . . . . . . . . . . . . . . . . 437

Tables for Chapter 4 . . . . . . . . . . . . . . . . . . . 439

Tables for Chapter 5 . . . . . . . . . . . . . . . . . . 495

Tables for Chapter 6 . . . . . . . . . . . . . . . . . . . 523

Tables for Chapter $7 \ldots$. . . . . . . . . . . . . . . . . . . 543

Appendix C: Organization of Religious Scriptures . . . . . . . . . . . . . 564

Bibliography . . . . . . . . . . . . . . . . . . . . . . 569 
ACKNOWLEDGEMENTS

In addition to my Committee members, I would like to thank the following persons for their helpful feedback and guidance on various components of this projects, at various stages: Victor Asal, Charles Brower, Darrell Cole, Dale Copeland, Walter Dorn, Brent Durbin, Heba El-Shazli, Dennis Foster, Jonathan Fox, Paul Freedman, Vsevolod "Seva" Gunitskiy, Daniel Heimbach, James Hentz, Patrick James, James Turner Johnson, Karen Mingst, Daniel Philpott, Howard Sanborn, Herman Schwartz, John Setear, Kendall Stiles, Gönül Tol, and Robert Turner. A special thanks also to Luther Atkinson for his assistance in Visual Basic programming. Apologies to anyone I may have missed.

I would also like to thank the many contributors to my dataset on the religious identities of chief executives of states, who are too numerous to list here.

Finally, I would like to thank Annette, Walker, Gemma, Tessa, George, and Margie for their steadfast love and support during times that at best have been trying for all of us. This work is dedicated to them. In addition, this dissertation is dedicated to Dad, and to Steve, who died three weeks before its defense. 


\section{TABLE OF ABBREVIATIONS}

A: Anguttara Nikaya of the Pali Canon, original PTS translation

AN: Anguttara Nikaya (for sutta references)

BFSP: British Foreign and State Papers

BGVVNS: Bodhisattva-gocaropaya-visaya-vikurvaṇa-nirdesa-sutra

CTS: Consolidated Treaty Series

D: Digha Nikaya of the Pali Canon, original PTS translation

DN: Digha Nikaya (for sutta references)

DR: Bible, Douay-Rheims Version

FHIG: Fontes Historiae Iuris Gentium

GAOR: U.N. General Assembly Official Records

ICJ: International Court of Justice Reports

J: Jataka of the Pali Canon (for sutta references)

Ja: Jataka, original PTS translation

JB: Jerusalem Bible

KJV: Bible, King James Version

LB: Living Bible

M: Majjhima Nikaya of the Pali Canon, original PTS translation

Mil: Milindapañha of the Pali Canon, original PTS translation

MN: Majjhima Nikaya (for sutta references)

MPT: Major Peace Treaties of Modern History

NAB: New American Bible 
NIV: Bible, New International Version

NLT: Bible, New Living Translation

NRSV: Bible, New Revised Standard Version

PTS: Pali Text Society

Q: Quran

RIAA: Reports of International Arbitral Awards

RSV: Bible, Revised Standard Version

RSV-CE: Bible, Revised Standard Version-Catholic Edition

S: Samyutta Nikaya of the Pali Canon, original PTS translation

SN: Samyutta Nikaya (for sutta references)

Sn: Suttanipata of the Pali Canon, original PTS translation

T: Taishō Tripitaka

UNTS: United Nations Treaty Series 


\section{Chapter 1}

\section{THE INFLUENCE OF RELIGION ON ARMED CONFLICT ONSET}

\section{Introduction and Puzzle}

In the last twenty years, an alternative to rational-choice theories in International Relations (IR) has begun to advance the proposition that ideas, norms, and rules matter in statecraft. The last ten years have also seen a growth in the literature on religion and politics. The increased awareness of the position of religion in IR has generated a puzzle for IR scholars. It has long been a commonly-held sentiment in the field, particularly on the rational-choice side, that religion has no place in the mechanics or study of modern statecraft. Beginning with the Enlightenment and continuing through the 1970s, the field of IR, along with the rest of the social sciences, increasingly banished religion from its purview. Realist IR theory, both classical and neorealist, has granted no place for law, morals, or ideas (let alone religious beliefs) in the conduct of modern international relations (Carr 1964; Morgenthau 2006; Waltz 1979; Mearsheimer 2001). ${ }^{1}$ Even the "Christian Realism" of Reinhold Niebuhr claimed that religious mores had to be set aside in matters of statecraft (Niebuhr 2001: 170-2; Niebuhr 1940, 1959; Tucker 1953; Lovin 1995, 2003). The neoliberal institutionalist literature has largely ignored the power of

\footnotetext{
${ }^{1}$ Morgenthau should not be misunderstood; his argument is that realism has displaced international law as the prevailing ethic of world politics whereas Waltz would assert that international law has never been relevant. Although Neoclassical Realists problematize the preferences of states, they do so according to the rational material interests of the constituents with the greatest power and influence, not according to norms. Snyder 1991; Rose 1998; Lobell Ripsman \& Taliaferro 2009. Snyder, having recently edited a volume on religion and IR theory, may have changed his views. Snyder 2011a, 2011b.
} 
norms as well, instead focusing on the long-term material benefits of cooperation (Krasner 1983; Keohane 1984, 1989). ${ }^{2}$ In these rational-choice sectors, religion is regarded at best as an instrument to be manipulated by states, and at worst entirely irrelevant, especially to the decisions of states to resort to military force. Furthermore, religion as a source of ideas largely has been overlooked even by constructivists; for example, the über-opus of constructivism devotes much attention to the role of psychology, anthropology, philosophy, and materialism in the formation of states' interests (Wendt 1999: chap. 3), but makes no mention of religion.

But if the pillars of IR thought are correct in that religion has no influence on such decisions, then how does one explain the rise of political Islam and the consequently greater militant tendencies of the Islamic Republic of Iran? Furthermore, how does one explain the intense soul-searching by U.S. President George H.W. Bush in his decision to undertake the Persian Gulf War? ${ }^{3}$ Neither of these cases is explained by material incentives or pressures, psychology, or philosophy alone. The time has come for the field not only to revisit the effect of ideology on national preferences and international outcomes, but also to recognize religion as an ideology that generates preferences and outcomes alongside secular ideologies such as liberalism and communism. As ideologies, religions

\footnotetext{
2 The exception is Gelpi 2003, which examines the institutionalist process by which states construct norms. An additional body of literature advances liberalism as the core concept around which modern international law and norms revolve, e.g. Franck 1999; Slaughter 2004. However, I argue that this literature is not so much "liberal institutionalist," outlining a process of rational cooperation to achieve rational goals, as it is simply "liberal," in that it advances and even privileges a normative idea.

${ }^{3}$ This particular case will be taken up in Chapter 8.
} 
are just as worthy of examination as the others just mentioned, and I submit are in even greater need of it.

This study will contribute to the field's understanding of the role of religion in generating and inhibiting armed conflict. My essential claim is that religious ideas influence the decisions of states to resort to or refrain from military force. Moreover, I claim that states tend to substitute the more permissive war ethics of their respective religions for the highly restrictive war ethic that is embodied in contemporary, secular jus ad bellum (the international law that regulates the resort to military force by states). I will show that states of some religions have a greater propensity than states of other religions to use military force in violation of jus ad bellum, and I will explore why this is the case. The dependent variable is the commission of an act of aggression by a state against another state (more on this momentarily). The independent variable is the religion of the state (and when called for, the religion of its target). It is operationalized in three ways: (1) the state's religious demographics, (2) the state's governing regime's institutional preference for a particular religion (or mix of religions), and (3) the religious identity of the chief executive of the state. Each of these independent variables will be measured separately, but all of them pertain to defining the religion "of" a state.

I claim that religion does influence the propensity of states to use military force, and that different religions do wield different influences on the same, i.e. some religions have a negative effect, others have a positive effect, and still others have no effect. However, unlike most of the religion and IR literature that treats religion as a preference-generating identity, or as an economic firm with rational, material interests, I argue that religion 
influences statecraft by instilling norms - and different religions influence statecraft differently by virtue of the different norms that they instill.

\section{Dependent Variable}

Because my dependent variable (DV) has applications to more than just the IR field and is somewhat less conventional than might be expected in an IR work, it warrants some early explanation. As a preliminary matter, it should be emphasized that this study covers only the years 1946 through 2001 (the reason for this is set forth below and more fully in Chapter 3). Therefore, despite the broad applications of my DV, my claims of the effect of religion (or lack of it) are limited to the post-Second World War international system.

The DV is the commission of an "act of aggression" by one state against another. An act of aggression is the first "use of military force" that is committed in "violation of jus ad bellum" (the norms of international law that regulate the resort to force). A use of force in response to a previous use of force, i.e. self-defense, is not an act of aggression because states are permitted (even expected) to defend themselves when a first use of military force is undertaken against them. Put another way, the activity that the DV is intended to capture is the "initiation of an [interstate] armed conflict." Furthermore, a first use of military force in compliance with jus ad bellum is also by definition not an act of aggression. International law today does legitimize some first uses of force within narrowly defined circumstances, and those few cases have been taken into account in constructing the DV used in this study. 
From 1946 through 2001, the cases in which states have been the first users of military force, but without violating jus ad bellum, number only five out of 1005 armed conflicts catalogued in the entire dataset (the five cases are listed in Chapter 3, note 15). They are so few in number that the DV "initiate an armed conflict" captures very nearly the same activity as the DV "violate jus ad bellum." This was not the case before the inauguration of the United Nations (just after World War II), but it is the case thereafter. Although strictly speaking the DV is the first use of force in violation of jus ad bellum, it so closely approximates the first use of force (regardless of the content of jus ad bellum) that the difference should be insignificant. Therefore, going forward, the terms "first use of force," "initiation of an armed conflict," and "violation of jus ad bellum" will be treated as interchangeable. Furthermore, the content of jus ad bellum, including the UN Charter and Definition of Aggression, ${ }^{4}$ are clearly intended to regulate all uses of force, from minor border incursions or low-level attacks on armed forces all the way to full-scale war. Any activity that falls within this range could trigger the right to self-defense (thereby initiating an armed conflict) and thus constitutes an act of aggression. For this reason, and also due to the stylistic need for several shorthand expressions of the activity being studied, the terms "use of force," "aggression," "armed conflict," and "war" will also be used interchangeably, both among themselves and with the other expressions already mentioned.

At this point an IR scholar might wonder why I chose a more complicated DV than the simple, straightforward "first use of force." The reason I did so is that I wish to address a broader audience than just the community of realists, the subfield of inter-

\footnotetext{
${ }^{4}$ General Assembly Resolution 3314.
} 
national security, or even the academy of IR as a whole. The state behavior that I seek to identify is that which is disliked; that which runs contrary to the expected conduct of good citizens within the community of states; that which the community of states as a whole would find objectionable. The baseline standard for the behavior of states of all religions is the content of jus ad bellum in contemporary international law. Like any other institution, jus ad bellum prescribes behavioral roles, constrains activity, and shapes expectations (Keohane 1989: 3), and from the legal perspective, jus ad bellum is like any other body of rules of positive international law, formulated by states themselves with the intent to be bound by them. I seek to identify the extent to which religious ideas (not merely material interests) generate compliance with or deviation from the institutional norms of jus ad bellum. I also seek to enrich the constructivist agenda of discovering how states' interests and behavior are socialized by ideas (e.g. Finnemore 1996), by suggesting an additional source of those ideas. ${ }^{5}$ I further wish to speak to the academy of international law, to which I still belong and whose work has been crucial to the crafting and problematizing of today's norms of jus ad bellum. Very little of the international legal scholarship in this area has sought to explain why states so often violate jus ad bellum, despite having largely agreed to its content; this work offers a partial answer. ${ }^{6}$

\footnotetext{
${ }^{5}$ However, unlike the constructivist agenda of showing how ideas are universalized, I am showing how a diversity of ideas generates a diversity of interests and outcomes.

${ }^{6}$ In addition, the choice of the time period 1946 through 2001 was also one of practical necessity: it is the date range on which the most comprehensive data could be marshaled. My preferred data source for the independent variables stops in 2001 and data on religious demographics and religious regime preferences were more difficult to obtain the further back in time, especially regime preferences. Until more data can be collected, we are limited to taking measurements of the post-Second World War international state system.
} 
Emphasis should be placed on the word partial. I do not claim that all armed conflicts are rooted in ideology, let alone religious ideology, nor do I argue that studying religious characteristics should displace the study of all other factors, structural and otherwise, that arguably may fuel or quench international conflict. Religious factors influence outcomes alongside other factors such as power, regime type, alliances, and others; my point is that religious factors must also be studied alongside those others.

Furthermore, I make no claim that the war ethics of specific religions remain constant over time. It seems plausible, even likely, that the war ethics of Christianity, Islam, and Buddhism today are different from those 500 or 1000 years ago. ${ }^{7}$ However, until sufficient data on the dependent, independent, and control variables can be marshaled (along with sufficient data on the international system itself), the effects of religion during those periods cannot be measured empirically. Nor do I claim that effect of religion overall on the propensity of states to use force remains constant. An inherent assumption of this study, which I now make explicit, is that jus ad bellum also influences

However, even if enough additional data could be collected further back in time to make it possible to simply control for the legal regime, doing so would seem to frustrate one of the goals of this work, which is to compare the war ethics of different religions with the baseline standard of jus ad bellum in contemporary, secular international law.

${ }^{7}$ I maintain that religious war ethics are rooted in scripture, the priesthood (especially classical priestly writings), and the historical narrative. Religious war ethics are not constant, despite the longevity of the sources just listed, because those must still be interpreted by people—and entire cultures—today. A culture may emphasize different scriptures, writings, and histories at different times, which is why I also examine modern treatments of the war ethics of various religions for evidence in how those sources are interpreted in the present. 
the propensity to use force; states will use force more often when jus ad bellum is permissive, and less often when it is restrictive. The effect of religion might have been different in the $19^{\text {th }}$ century, when jus ad bellum was quite permissive. But until data on religious characteristics of states can be gathered for this time period, and in such a way that accounts for the state system not being very diverse religiously, the effect of religion in earlier epochs of jus ad bellum cannot be empirically measured either. ${ }^{8} \mathrm{I}$ do offer two conjectures, despite their not being testable: (1) that states of all religions would use force more often when jus ad bellum is more permissive than it is today; and (2) that even in a more permissive legal environment, a state of a religion that has a more permissive war ethic would be more likely to use force than a state of a religion with a less permissive war ethic. However, I make no claim that these conjectures are supported by the evidence presented in this work. My claim is limited to the effect of religion after World War II, during which time the legal environment is highly restrictive.

\section{Structure and Impact of This Work}

The remainder of this chapter will be devoted to reviewing the pertinent literature. Chapter 2 will present a theory for how religion influences the outcome being studied in this work - the initiation of an armed conflict (and, strictly speaking, in violation of jus ad bellum). I will argue that religion transmits its ideas through three media (scripture; priesthood, especially the writings of the priesthood; and historical narrative), and influences three types of actors: chief executives of states individually, governing

\footnotetext{
${ }^{8}$ It may be easier to acquire sufficient data for the period 1919 through 1945; that development is expected to be introduced in the next version of this study.
} 
regimes of states, and entire national cultures. But beyond this framework, I am more inclined to treat religion as an overlooked factor in a great many pre-existing paradigms and theories of international outcomes, rather than something that necessitates inventing entirely new paradigms and theories.

The core of the empirical component of this dissertation is Chapters 3 and 4 . The research design is presented in Chapter 3, in which the dependent, independent, and control variables are all defined and operationalized. The results are presented in Chapter 4. They indicate that during the time period of the study (1946-2001), some religions influenced the propensities of states to initiate armed conflicts (but not all). The results further indicate that, overall, Christianity is negatively correlated with the propensity to use force and Islam and Atheism positively correlated. A category styled "Buddhist Mix" (Buddhism, Confucianism, Taoism, and Shinto combined) is also positively correlated, but further examination of the Buddhist war ethic in Chapter 7 will reveal that the correlation between Buddhist Mix states and greater propensity to use force is probably due to factors other than Buddhism.

The next three chapters present more in-depth examinations of the effects of Christianity, Islam, and Buddhism, respectively. Chapter 5 explores the Christian war ethic, particularly the just war tradition, and the differences in war ethic and practice between Catholic, Protestant, and Orthodox Christian states. Chapter 6 explores the Islamic war ethic, though because there are too few Shia Muslim states to validate a measurement of the effect of Shia Islam, the chapter is devoted almost entirely to the ethic and practice of Sunni Muslim states. Chapter 7 explores the Buddhist war ethic, weighing in on the ongoing debate as to whether Buddhism supports any war ethic at 
all—a long brewing question but precipitated most recently by the religious violence in Sri Lanka.

Chapter 8 presents two case studies on the effects of religion in decisions of states-or more accurately, states' leaders - to resort to war or not. The first case is the decision of the U.S. president to commit military troops to the liberation of Kuwait from Iraqi occupation during the Persian Gulf War of 1990-1991. The second case is the decision of the Egyptian president to launch the Yom Kippur War against Israel in 1973, and later to make peace with Israel in 1978.

The impact of this work is to contribute to the literature that seeks to determine whether religion influences international outcomes, and in a larger sense, whether ideas and norms influence them. Eva Bellin (2008) has called for the field to get on with the task of mid-level theorizing about the role of religion in IR, and this dissertation is partly an answer to that call. The results will impact both the fields of IR and international law. For IR, this work will offer an approach to addressing a problem that seems to continue to vex the constructivists: how to generate and test a falsifiable hypothesis in which the independent variable is an idea. The quantitative model used in this work should be adaptable to measuring other, non-religious ideologies as well. Furthermore, since several conventional state-level characteristics are included in the study as control variables (e.g. power differential, regime type), I will be able to make observations along the way about the effects of those characteristics on a state's preferences for using force or not.

For international law, this study will offer insight into the degree to which states comply with or deviate from jus ad bellum. In this case, especially in the epoch of 
international law from 1945 to the present, ${ }^{9}$ the propensity to initiate armed conflicts is virtually the same as the propensity to violate present-day jus ad bellum-interpreted in its restrictive, positivist sense as Ian Brownlie (1963), Oscar Schachter (1984), and Simon Chesterman (2001) would do. In terms that Thomas Franck (1990) would appreciate, religion influences all aspects of a rule's legitimacy and pull toward compliance, and a rule that regulates the resort to force is no different. In addition, religion influences the level of animosity between states, which directly affects the degree to which states comply with rules against their interests-in this case, rules that prohibit the use of force (see Wendt 1999: chap. 6).

Finally, this study will have implications for foreign policy-making, a major component of which is predicting and coping with the preferences of other states. In 2010, a study by the Chicago Council on Global Affairs, led in part by Scott Appleby, called for greater attention to the role of religion in U.S. foreign policy-making, noting that the "God gap" impedes the ability of the U.S. government to understand and influence other actors (Waters 2010). Apart from examining the influence of one source of ideas (religion) on one's own state's preferences, this study will examine the same influence on the preferences of other states. Armed with a better understanding of how certain state-level characteristics influence preferences for war or peace, states can improve their abilities to predict other states' preferences, and adjust their own policies accordingly.

\footnotetext{
${ }^{9}$ For expositions of the rationale for dividing periods of international law into epochs, see Grewe 2000; Ikenberry 2001.
} 


\section{Religion in International Relations: The State of the Field}

\section{$\underline{\text { The "Resurgence" of Religion in International Relations }}$}

Because the history of religion stretches back to antiquity, and nearly as far back as the history of war, one might expect the modern IR literature on religion and war to be quite voluminous. This turns out not to be the case. Until recently, Western thought has been characterized by the ejection of religion from international politics and international law. In the domain of international law, the Peace of Westphalia of $1648^{10}$ crystallized into a norm the state practice of non-interference in the religious affairs of other states (set into motion in 1555 by the principle cuius regio eius religio in the Peace of Augsburg $^{11}$ ). As Jeffrey Haynes (2005: 399) puts it, the Westphalian state system is "rooted in the predominance of secularism and the emphatic sidelining of religion amid dissemination of western-directed economic and political modernization." Scott Thomas (2005: 54-5) attributes the decline of religion in international thought partly to the "Westphalian presumption" that religion was the cause of conflict and therefore needed to be banished from politics. No longer within the realm of permissible state interaction, let alone interference, the treatment of religion declined in international legal treatises. Mark Janis (1999a, b) chronicles this decline and attributes it to two factors: (1) the expansion of the Westphalian state system to include non-Western states and thus nonWestern (i.e. non-Christian) cultures and traditions, and (2) the field's greater tendency to

\footnotetext{
${ }^{10}$ Treaty of Peace (Holy Roman Empire-Sweden), October 14, 1648 (“Treaty of Osnabrück), 1 CTS 198; Treaty of Peace (France-Holy Roman Empire), October 14, 1648 (“Treaty of Münster”), 1 CTS 271.

${ }^{11}$ Religious Peace of Augsburg, September 25, 1555, reprinted in Viorst 1965: 98-102.
} 
treat international law as a "science." In the natural and social sciences generally, the banishment of religion from matters political began largely with the Enlightenment; Edward Luttwak (1994: 8), for example, compares the Enlightenment's treatment of religion to the Catholic inquisitions. This phenomenon also may have been inspired by the hostility to religion of Karl Marx, Émile Durkheim, and Max Weber, who all viewed religion as a "premodern relic," destined to fade with modernization (Bellin 2008: 317). The theory of the impending death of religion, styled "secularization theory," 12 has begun to wane since its peak in the 1960s, but Jonathan Fox and Shmuel Sandler (2004: 17) argue that even now the West is still particularly "socialized" to the separation of religion and politics. ${ }^{13}$ In addition, since the 1960 s, the political science academy itself has contained disproportionately few individuals who are actually religious themselves, as opposed to the disproportionately large number of faculty who are not religious or even hostile to religion (Wald \& Wilcox 2006). Scholarship on religion in politics could hardly thrive in an academic environment in which the bias against religion was so strong. As a consequence, the role of religion in IR is still overlooked far too frequently today ${ }^{14}$ and the literature on religion in both IR specifically and political science generally remain comparatively scarce, despite repeated calls of attention to this fact (most recently Kettell 2012).

\footnotetext{
${ }^{12}$ For two excellent histories of the secularization of international relations and its theories, see Shah \& Philpott 2011; Hurd 2011.

${ }^{13}$ Elizabeth Shakman Hurd (2008) strongly implies the same in her treatment of secularism.

${ }^{14}$ For example, in his treatment of the "method-of-analysis" problem in IR, Alex Mintz (2005) lists seventeen "fundamental puzzles," yet none of them pertain to the role of religion.
} 
The scholarly movement to challenge this state of affairs began in 1991 with the appearance of the book La Revanche de Dieu [The Revenge of God] by the French Islam scholar Gilles Kepel. Kepel argued that the rise of the Likud party in Israel, the election of Pope John Paul II, and the Iranian Revolution posed a challenge to the commonly-held beliefs that religious conservatism was linked to anti-modernism. The same year that the English translation of Kepel's book was released (Kepel 1994), a new challenge to secularization theory appeared in the form of an edited volume provocatively titled Religion, the Missing Dimension of Statecraft, which examined the role of religious actors in promoting peace (Johnston \& Sampson 1994). In addition, the previous year saw the introduction of Samuel Huntington's $(1993,1996)$ celebrated “clash of civilizations" thesis; religion does not figure overtly into it but the correlation of his demarcation of civilizations with different religions is difficult to ignore.

These works inaugurated a strand of literature that illustrates a "resurgence" of religion and calls for greater attention to its role in shaping international relations. ${ }^{15}$ This trend began with the appearance of special issues on religion and IR in two international relations journals. The first, in Orbis in $1998,{ }^{16}$ surveyed the impact of major world religions, one by one, on the geopolitical behavior of states (see McDougall 1998). The second, in Millennium in 2000, was a series of treatments of the impact of religion in international society, such as questions of "multiple modernities," the legitimization or

\footnotetext{
${ }^{15}$ Eva Bellin (2008: 317) argues that the challenge to the axiom that modernization would doom religion actually began in the 1970s. That may be true for the field of comparative politics, but I submit that the resurgence of religion did not get the attention of the international relations field until later.

${ }^{16}$ Religion in World Affairs, Special Issue, Orbis 42, no. 2 (1998).
} 
de-legitimization of political conflict, "international political theology," and securitization theory. ${ }^{17}$ In 1999 , noted sociologist Peter Berger famously recanted his prediction, which he had made in 1968 during the peak of secularization theory, that by the $21^{\text {st }}$ century religious believers would exist only in small pockets among the masses (Berger 1968). Quite the opposite: he now writes of the "desecularization" of the world and concedes that the entire body of secularization theory literature was "essentially mistaken" (Berger 1999: 2). Journalist Lee Strobel (2004) argues that scientific inquiry—the results of which previously had undermined faith in the existence of God-today now supports that faith. ${ }^{18}$ The overall claim of this strand of literature is that religion has experienced a resurgence, and therefore a new paradigm in international relations theory is needed (Petito \& Hatzopoulos 2003; Fox \& Sandler 2004; Thomas 2005; Hanson 2006; Haynes 2007: 19-24; Bellin 2008; Hurd 2008). ${ }^{19}$

What precipitated the renewed interest in religion in international relations? I submit that it was the convergence of three events. The first event, beginning in the late 1980s but especially with the works of Alexander Wendt in the 1990s, is the emergence of the constructivist literature which prioritizes the role of ideas and norms shaping states'

\footnotetext{
${ }^{17}$ Special Issue, Millennium 29, no. 3 (2000). Many of these articles are reprinted in Petito \& Hatzopoulos 2003.

${ }^{18}$ This work is one of several sequels to Strobel's original opus, The Case for Christ (1998), in which he applies similar scientific methodology to conclude that accounts of Jesus Christ in the New Testament are fact and not myth. Interestingly, his findings induced him to convert from atheism to Christianity.

${ }^{19}$ But see Snyder 2011b and Nexon 2011: 161. Both acknowledge the greater visibility of religion and the need to take it seriously, but Snyder reacts to the call for a paradigm shift with caution and Nexon opposes it outright. For reasons outlined in Chapter 2, I am also skeptical that new theories are necessary.
} 
preferences and international outcomes (Wendt 1987; Kratochwil 1989; Onuf 1989;

Dessler 1989; Wendt 1992; Wendt 1995; Hopf 1998; Ruggie 1998a; Wendt 1999; see also Katzenstein 1996). Constructivists argue that ideas (along with identities) in fact do matter; ideas are at least $a$ component of the international structure alongside material capabilities, and at most the primary structural component that confers meaning to all others. Consequently, norms and rules influence the decisions and actions of states independently, not merely through or by material pressures. The broad, over-arching question that the constructivist literature brings to the table is whether ideas, norms, and rules generally exert any independent influence on the decisions of states (including whether to not to use military force). Accounts of religious ideas can fit within this larger category of scholarship.

The second event is the post-Cold War proliferation of ethnic conflict, which often has featured religious differences as a source or aggravator of animosity. Jonathan Fox (2001a) finds that ethnic conflicts with religious dimensions attract significantly greater foreign political intervention, and more military intervention as well when the conflicts involve Christian or Muslim minorities. ${ }^{20}$ Indeed, Fox argues that religion is one of the most influential aspects of ethnic identity, thus also ethnic behavior (2001a: 518).

The third event is $9 / 11$, which resulted in the dramatic rise in awareness of religiously based terrorism, particularly by radical Islam. The perpetrator of that attack, al-Qaeda, is noted for its use of religious imagery and appeals to justify attacks not merely on United States military forces in the Arabian peninsula, but on the United States and other

\footnotetext{
${ }^{20}$ Inter-religious ethnic conflict is also the focus of Fox and Samuel Shmuel's edited volume (2006).
} 
Western states themselves, including on civilians (bin Laden 1996, 1998). Thus this event has spawned a considerable body of literature on radical political Islam. ${ }^{21}$

A smaller, more multi-disciplinary strand of literature on religion and politics argues not that religion has been resurrected, but that it was never dead (or dying) in the first place. Kepel (1994) attributes the outburst of conservativism in Christianity, Islam, and Judaism to societal malaise and the popular rejection of secularism gone too far, rather than to the rediscovery of religion that was previously dormant. Arthur Waldron (1998) makes a similar observation for the growth of Christianity and Islam in China, even after (or more likely, as a consequence of) severe repression during the first 30 years of Communist rule there. Sociologist of religion Rodney Stark (1999) systematically debunks each of the five components of the "secularization thesis," with the goal of showing that the secularization thesis has never been consistent with empirical reality. ${ }^{22}$ A 2003 multi-disciplinary volume edited by John Carlson and Erik Owens (then divinity students) focuses on the challenges posed by religion to concepts such as human rights, political authority, and especially sovereignty. ${ }^{23}$ Such challenges did not surface with the

${ }^{21}$ Jeffrey Haynes (2005: 404-10) also attributes 9/11 to the influence of the New Christian Right on U.S. foreign policy.

${ }^{22}$ The five components of the secularization thesis are: (1) Modernization is the causal engine of secularization; (2) Secularization leads to not only the separation of church and state, but also a decline in individual belief; (3) Science has the most deadly implications for religion; (4) Secularization, once achieved, is irreversible; and (5) The secularization thesis applies to all religions, not just Christianity.

${ }^{23}$ Beyond that point, however, the work diminishes in utility, for it is essentially a collection of essays on the comportment of anti-terrorism and humanitarian intervention to just war theory, some with Responsibility to Protect overtones. 
so-called "resurgence" of religion; they were always there. ${ }^{24}$ IR scholar Daniel Philpott (2000: 220; 2001: chap. 4) shows that the very foundation of the concept of state sovereignty is rooted in Protestant thinking. In doing so, he extends the constructivist agenda; whereas the norm of sovereignty is usually treated as the determinant of states' identities and behavior (the structure socializing the agent), Philpott would treat the norm of sovereignty as the product of states' (religious) identity (the agents producing the structure). With the constructivist writers in IR having shown the need for, and utility of, reintroducing the idea as a unit of analysis, the multi-disciplinary literature just outlined in turn has laid the foundation for treating religious ideas in the same manner-as an explanatory variable that influences international outcomes.

\section{Classifying the Literature on Religion and Conflict in International Relations}

\section{Does Religion Precipitate Conflict?}

Within the body of literature on religion and IR, which as mentioned before is small, there are several categories that are not particularly relevant or useful to the present inquiry and thus may be set aside. One category examines the role of religion in conflict resolution, and first appears in Johnston and Sampson's edited volume (1994) previously mentioned. The series of essays in that book are all devoted to the contribution of

\footnotetext{
${ }^{24}$ On the question of whether religion has enjoyed genuine resurgence or simply renewed attention, Haynes (2005) takes an intermediate position, tracing religion's international political influence since the end of the Second World War. He chronicles the religious fueling of the anti-colonial movement, the association of secularism with dictatorship in the Muslim world, the introduction of the clash of civilizations thesis in the wake of the end of the Cold War, and the religious overtones of 9/11 and the United States' response.
} 
religion, and often specific religious institutions, in peace-making and/or conflict resolution. Edward Luttwak and Barry Rubin (both 1994), for example, illustrate how religious institutions are impervious to state power, a trait that facilitates their roles as vanguards of social change. Following this line of thought, James Nafziger (1999) theorizes five functions of religious institutions in international law, among which are its creation, its incorporation into the behavior of states' leaders, and its effect in dispute mediation. Jonathan Fox (1999) argues that religious institutions have a quietist effect, in that they tend to promote the status quo, provided that religion itself is not relevant to the conflict. ${ }^{25}$ Several other mostly non-political works, beginning in the $19^{\text {th }}$ century with those of Friedrich Schleiermacher (1976) and Søren Kierkegaard (1997), advance a related claim: that underneath the diversity of religions lies a single, undiscovered religious truth (Eliade 1954; Smith 1958; Smith 1991), or that a single, unified religion would eventually evolve from several diverse ones (Hocking 1928; van Leeuwen 1964; Küng 1997). Arnold Toynbee (1947), whose work is generally considered part of the early $20^{\text {th }}$-century corpus of IR literature, further imagined religion as contributing to the construction of a world society.

Others claim that religion can either stoke or stifle conflict. As Perry Schmidt-Leukel puts it:

Religions have always made their active contributions to war and to peace. In this regard the world religions are quite ambivalent — all of them. There

\footnotetext{
${ }^{25}$ Fox is writing in the context of civil conflicts. As will be seen in Chapter 4, the empirical results do not support such a conclusion for armed conflict between states (at least, those taking place from 1946 to 2001).
} 
is none among the world religions which does not proclaim and foster peace. But equally so, there is none among them which has not also justified and fostered war. (2004b: 4; emphasis in original)

Andreas Hasenclever and Volker Rittberger (2000) explore the potential for religion to suppress and/or delegitimize violence, but the functions and strategy they outline do not appear to be unique to religious institutions, and they themselves also show how religions can wield the opposite effect. Scott Thomas (2005: chap. 5) provides a treatment of religion within anthropological approaches to conflict; the purpose of religious rites or rituals of sacrifice is to substitute something else as the "scapegoat" for what would otherwise be the object or victim of violence. Scott Appleby (2000) contends that all religions have the same potential for charity, tolerance, and non-violence, and that the more knowledgeable believers are of their faiths, the more they will become peacemakers. ${ }^{26}$

Several other categories of literature will be set aside as well. One is that which treats religion as an instrument of political manipulation. ${ }^{27}$ It examines the control of religion by the state, as well as the state's control of public opinion through religious institutions. Jonathan Fox (2008) illustrates this process in several states through his development of the parameter he calls Government Involvement in Religion. Although it is not disputed that some such manipulation takes place in some states, that is the opposite of the causal

\footnotetext{
${ }^{26}$ Again, however, this assertion does not appear to be supported empirically for interstate armed conflicts during the time period of this study. In addition, Appleby later argues that the potential for religiously based peace-making is undermined by its exclusivity; the more a religion's truths, rights, and responsibilities are portrayed as inherently superior, the greater its potential to generate conflict (2003: 181).

${ }^{27}$ For a survey of such literature, see Hasenclever \& Rittberger 2000: 647.
} 
effect being examined in this study. This work focuses on the role of religion in influencing the behavior of the state, not the reverse.

Another question to be set aside is that which problematizes the definition of the term “religion” itself. Vendulka Kubálková (2000) and Pauletta Otis (2004), as well Nafziger (1999) and Philpott (2002), have all devoted pages to this problem. The following definitions of religion are typical in this strand of literature:

[Religion] may be described as a practice of ultimate concern about our nature and obligations as human beings, inspired by experience and typically expressed by members of a group of community sharing myths and doctrines whose authority transcends both individual conscience and the state. (Nafziger 1999: 158)

Religion is an integrated, systematized set of beliefs, behaviors, values, institutions, modes of communication, and leadership. (Otis 2004: 17)

The problems with such definitions are that (1) they minimize, or omit altogether, the transcendental element of religion (Otis is guilty of the former), and (2) they could equally well describe secular ideologies_a point that Nafziger concedes (1999: 158). I submit that efforts to define religion unduly emphasize a question that is not crucial to the study of the effect of religion on armed conflict. I therefore follow Fox and Sandler's (2004: 2) approach, in deliberately refraining from specifying any particular definition of the term. The classification of religions outlined in this study are relatively simple and straightforward, and I prefer to avoid getting mired in such questions as whether Confucianism and other East Asian religions are actually "religions" in the strictest sense. Such questions are unnecessarily distracting and will be set aside. 
The literature that is most relevant, on the other hand, is that which focuses on religion as a conflict driver. The most paradigmatic_-and most maligned-expression of this theory is the "clash of civilizations" thesis of Samuel Huntington (1993, 1996). Huntington hypothesizes that in the "next phase" of world politics (i.e., post-Cold War), the fundamental source of conflict ... will not be primarily ideological or primarily economic. The great divisions among humankind and the dominating source of conflict will be cultural. .. [T]he principal conflicts of global politics will occur between nations and groups of different civilizations. (1993: 24)

Huntington goes on to demarcate civilizations by "common language, history, religion, customs, institutions and by the subjective self-identification of people" (1993: 24), arriving at a typology of seven or eight major world civilizations (1993: $25 ; 1996: 45-7){ }^{28}$ These civilizations are divided largely along religious lines, as Huntington himself and other scholars have acknowledged. Huntington predicts that the flash points for future geopolitical crises will be the "fault lines" between civilizations, citing as evidence a new wave of ethnic and other inter-civilizational tensions and open conflicts since the end of the Cold War. Despite a considerable body of literature that claims to debunk Huntington's thesis, ${ }^{29}$ there is a strong ring of truth to the utility of classifying civilizations the

${ }^{28}$ They are: Sinic, Japanese, Hindu, Islamic, Western, Slavic-Orthodox, Latin American, and "possibly" African. The "Sinic" civilization he labels "Confucian" in his earlier work, and he does not explicitly separate Slavic-Orthodox from Western in his later work.

${ }^{29}$ Huntington's thesis often has been criticized for being long on anecdotal evidence and short on theories of causality and empirical testing. Most empirical tests of his thesis have failed to support it, leading their authors to proclaim it refuted (Russett Oneal \& Cox 2000; Henderson \& Tucker 2001; Fox 2002; Chiozza 
way he does. What lends further plausibility to Huntington's claim is the proliferation of non-Western states in the Westphalian state system and the gradual rise of non-Western powers, ${ }^{30}$ and the growing attention by Western IR scholars to non-Western theories of international relations (Acharya \& Buzan 2009; Tickner \& Wæver 2009). His groundbreaking contribution is the assertion that "[c]ultural commonalities and differences shape the interests, antagonisms, and associations of states" (1996: 29); he is in effect arguing that states of like civilizations are inherently friendly and peaceful toward each other and states of unlike civilizations inherently hostile. That specific claim will not be tested here, but suffice it to say that it is equally possible that some cultures' war ethics are simply more permissive, leading some states to be more hostile generally, even against their ethnic confreres. Essentially, the effect of civilizations may be monadic, not dyadic.

What Huntington claims is true for culture is also true for religion. Much less celebrated than Huntington's thesis but equally profound is Eric Hanson's (2006: 6) observation that "religion holds all social strata together in the name of a unified national culture." Religious commonalities and differences also shape states' interests, antagonisms, and associations. Several scholars have presented religion as inherently conflictual, whether it be religion generally or some specific religions, usually Christianity and/or Islam. Brian Lai (2006), for example, has found that religious differences between states'

2002; Tusicisny 2004). However, these refutations are often based on measurements that in my opinion are flawed. A defense and rehabilitation the clash of civilizations thesis falls outside the scope of this work, therefore none is offered here. For a survey of literature that supports Huntington's thesis, mostly in secondary and overtly conservative journals, see Fox \& Sandler 2004: 123.

${ }^{30}$ On the potential of China and India, for example, to challenge American hegemony, see Zakaria 2008. 
leaders contribute to militarization of disputes between their respective states. This category of literature tends to be especially harsh on monotheistic religions. Regina Schwartz (1997) expounds on the legacy of violence in Bible, though her approach is exposed to criticism that she defines violence far too broadly and is far more deconstructive than constructive. Carol Delaney (2010) also depicts the Abrahamic religions as all fundamentally violent. ${ }^{31}$ Mark Juergensmeyer (1993) writes of the impending confrontation of religious nationalism with secular authorities, and later (2000) casts religion and violence as oddly attracted to each other, focusing on religious-based terrorism and especially on the large religious communities of supporters of those individuals who actually carry out the acts. Scott Appleby (2000) is somewhat more even-handed, attributing religious militancy to embeddedness of the clergy in civil society, religious (il)literacy, and the degree of injustice, discrimination, etc. But even Appleby concludes that Judaism, Islam, Christianity tend to be more congenial to violent revolutionary movements, whereas Buddhism, Confucianism, and Hinduism (being less dualistic and more world-affirming) have been less hospitable to militancy. A particularly illconsidered piece by Andreas Osiander (2000) advances the claim that whereas pagan Greco-Roman culture is the root of Western concepts of human rights and liberty, JudeoChristianity is largely responsible for the aggressive side of Western culture; his piece, however, is completely devoid of any exploration of even the most basic Christian just-

\footnotetext{
${ }^{31}$ Her conclusion is flawed, in my view, because it inappropriately equates the Christian ethic of violence with the violence associated with Biblical accounts of Abraham (who was not only pre-Christian, but also pre-Judaic). Furthermore, her conclusion is supported almost solely by reference to her study of women's rights in the United States and Turkey, which is a grossly insufficient foundation for assessing the entire ethic of violence of three separate religions.
} 
war literature. Pauletta Otis takes a more detached approach, arguing that explicitly religious conflicts are more intense, severe, brutal and lethal than other forms of war. "Each and every religion," she writes, "is . . a an ideology that provides comprehensive ideals and principles that govern both life and death. Religions not only answer the question, 'How should I live?' but also the question, 'For what am I willing to kill and die?"' (2004: 12). Otis points out that a major function of religion is to explain the meaning and value of life, as well as the conditions under which taking life is justifiable (2004: 19). As religion counts life, death, just war, and justice in war among its matters of concern, it is relevant to all conflict (2004: 15). Susanna Pearce (2006: 55) offers a quantitative confirmation of this theory, finding that conflicts involving religion are more intense than other types of conflicts. ${ }^{32}$ A volume on religion in Europe edited by Timothy Byrnes and Peter Katzenstein (2006) finds religious factors to be "stumbling blocks" to further European integration. Another volume edited by John Owen and Judd Owen (2010) explores a related question: whether religious conflicts are too intractable for the Enlightenment model of liberalism to resolve.

Within the category of literature that treats religion as a conflict driver, two subcategories propound different theories as to how and why religion exerts such influence. Those theories essentially boil down to whether religions promote (1) rational material interests, or (2) ideas. Most authors appear to treat these theories as competing, ${ }^{33}$ but not all. Philpott (2000) argues that both have explanatory power, and Fox and Sandler (2004: chap. 1) suggest the same. Eric Hanson (2006: 50) also implies a complementary

\footnotetext{
${ }^{32}$ She concedes, however, that the evidence is "statistically much weaker than expected."

33 The two theories were first juxtaposed in Langan 1998.
} 
relationship between the two theories in delineating four types of relationships between religion and politics. Those relationships are: (1) legitimizing state power (ideas), (2) battle for institutional and expressive power (interests), (3) competition for influence (ideas and interests), and (4) control the national culture or defend it from threats (ideas).

\section{Why Does Religion Precipitate Conflict?}

Why does religion precipitate conflict? One possible answer is that religious institutions act like economic firms. They are overtly political actors, pursuing their rational material interests like any other. Eva Bellin (2008: 319) has dubbed this line of inquiry the "Religious Economy School." An early representative work is that of Stathis Kalyvas (1996), who examines the emergence of specifically Catholic political parties in Europe in the late $19^{\text {th }}$ and early $20^{\text {th }}$ centuries, why they emerged in some Catholic countries but not others, and why they gradually secularized over time. Kalyvas's answer is that the church supported confessional parties only in response to attempts to secularize public institutions that previously had been the exclusive domain the church (such as education and marriage), and that gradual secularization was necessary to facilitate alliances with other political forces (which was necessary to those parties' survival). Along the same line of inquiry, Carolyn Warner (2000) examines why the church tends to ally with "ideologically suboptimal" parties. Her answer: the cost of ideological purity frequently outweighs the benefits, which are access to rule (i.e. political strength)—and of course in realist politics, strength is a necessary condition of survival. On a different tack, Anthony Gill (1998) examines why some Catholic national episcopacies in Latin America denounced authoritarian rule after 1960 but others did not. He argues that the Catholic 
Church did so only in countries in which evangelical Protestant movements had broadly appealed to the poor and repressed, and thus challenged the Catholic monopoly over religious life on those countries. The commonality of these three works is that they all cast religious institutions as firms that seek to protect their survival and rationally calculate what is necessary to maintain their position in the market.

A different but related line of inquiry concerns the various levels of religiosity among states, i.e. what makes populations devout followers as opposed to merely nominal followers. Pippa Norris and Ronald Inglehart (2004) answer that question by resorting to economic metaphors, dividing theories of religiosity into "supply-side" and "demandside." On the demand side, they argue, religious institutions provide essential human services such as education, health care, and welfare, generating a human need for religion. ${ }^{34}$ Alternatively, they argue, existential threats (due to poverty, disasters, etc.) drive people toward religion for security (if only spiritual). On the supply side, they argue that religious pluralism in a society (i.e. competition between religions for followers) generates creativity and energy, as the campaigning institutions try to outdo each other in appealing to the masses. ${ }^{35}$ This leads to greater religious engagement and therefore greater religiosity. In contrast, religious monopoly breeds complacency and rigidity.

Other literature, labeled "instrumentalist" by Hasenclever and Rittberger, takes a Durkheim-like position that the resurgence of religious movements is the result of

\footnotetext{
${ }^{34}$ Cf. Eric Hanson's (2006: 6) argument that religion "serves as the ideological cohesion for the poor and frustrated lower and middle classes to demand social justice."

${ }^{35}$ Cf. Monica Duffy Toft's (2007) argument that "religious outbidding," in which competing actors vie to establish their religious credentials, plays a role in religious wars.
} 
growing political, economic, and social inequalities within and between states, which prompt the religious confreres of the unequal to mobilize and seek political change. ${ }^{36}$ Another branch of literature links religious freedom to stability and religious suppression to conflict (Hoover, Hasson, Saunders, all 2004); religious institutions and organizations fighting against suppression essentially are seeking to preserve their very existence. The works of Jonathan Fox and others examining ethnic conflict as the outcome of religious suppression also feed into this theory (Fox 1999, 2001a; see also Toft 2002/3, 2007). Finally, some work in religious studies has delved into the role of religion pertaining to security at the individual, psychological level. For example, Elizabeth Maynard et al. (2001) link concepts of God with psychological mechanisms for coping with threats, losses, and challenges. All of these inquiries are characterized by the underlying logic that religious organizations and institutions seek to augment their material needs and those of their constituents. The better off the institution or its contributors (materially speaking), the greater the institution's political power and security. In addition, the greater the number of followers, the greater the institution's influence and thus its political power (and again, its security).

The other theory as to why religion precipitates conflict is that religious institutions seek to promote their ideas, and the collision of competing ideas is what generates conflict. The literature in this subcategory is somewhat broader and more diverse than that of the others. One body of literature examines the role of religion (or sometimes specific religions) in shaping identities, interests, and preferences of states and/or cultures. Vendulka Kubálková (2000: 684) claims that religion provides a map of reality that

\footnotetext{
${ }^{36}$ For a survey, see Hasenclever \& Rittberger 2000: 644-5.
} 
orients the individual and fixes his/her identity. Scott Thomas, following Alasdair MacIntyre, argues that religion, as a social tradition, embodies values and ethical conceptions about goodness, justice, rightness, and obligation (2000b: 826). Rodney Stark (2001a) attributes religious conflict to religious "particularism" (the belief that one's own religion is the only true religion); such conflict between a few major groups (in this case, generally monotheistic groups) creates a general climate of antagonism and aggression. A related problem is that of conflicting claims on "sacred space," referring to the often intractable conflicts over religious sites, which do not lend themselves well to bargaining solutions (Hassner 2009). In another work analogous to the political psychological contribution of Maynard et al. mentioned above, Stark correlates belief in God with personal morality (2001b). For discussions of specific influences of specific religions, in addition to the anecdotal evidence presented in Huntington's works, representative works include studies of the Protestant origins of American foreign policy (Kurth 1998), and the Protestant origins of Westphalian sovereignty (Philpott 2000, 2001). As mentioned above, James Nafziger (1999) outlines five functions of religion in the formation and implementation of international law; to the extent that religions propound certain ideas of exclusivity or superiority, it is not difficult to ascertain their role in precipitating conflict. Scott Thomas (2000a: 18) turns that thesis around, illustrating how religion can pose a challenge to international society by promoting beliefs that are incompatible with rules, practices, norms of that society. As to specifics, Thomas argues that Buddhism, Islam, and Christianity are the only three main world religions that have universalistic aspirations and as such, pose the greatest challenge to the state as the basic political unit of international society. Of these three, he argues, Islam has the most 
potential for mounting such a challenge, for Buddhism has not expressed itself politically and the seat of Christianity (the West) has separated church and state (2000a: 15).

As to how religion promotes those ideas, one branch of literature focuses on the political power and influence of (often transnational) religious institutions, from providing incentives to state officials to support their preferences to organizing activist movements (Thomas 2005: chap. 4; Katzenstein \& Byrnes 2006; Philpott 2007). ${ }^{37}$ The other branch focuses on the normative power of religiously-grounded ideas about the relationship of man with God, from which flow further ideas about the legitimacy of governments and military force, or lack thereof (Hasenclever \& Rittberger 2000: 642ff; Fox 2001b: 63-67; Otis 2004; Thomas 2005: chap. 3). This body of literature supplements the standard constructivist argument that social conflicts are embedded in cognitive sources such as ethnicities and ideologies, of which religion is one. ${ }^{38}$ It also fits well within the broader constructivist literature that examines the same effects of ideas generally. It spans across the Waltzian images, examining effects of religion in shaping identities, interests, and preferences of people, populations, and ultimately states: for example, the effects of religious ideas in shaping the state structure (Philpott), defining foreign policy (Fox and Sandler), and constructing the individual ethos (Stark). Fox and Sandler (2004) and Scott Thomas (2005) contend that religion wields both political and normative power.

\footnotetext{
${ }^{37}$ On transnational activism generally, see Keck \& Sikkink 1998; Dai 2008.

${ }^{38}$ For a survey of constructivist literature on religion, see Hasenclever \& Rittberger 2000: 642-9.
} 


\section{$\underline{\text { Religious War Ethics }}$}

Within the same category of religion precipitating conflict because of competing ideas, another body of literature, dating back to about the 1950s, consists of expositive and/or comparative studies of the ethics of war in specific religions. This category of literature is quite voluminous, but most of it is written by scholars of religious studies and political theory; little of it is written by political scientists or international lawyers. ${ }^{39}$ Among the general comparative studies of war in ethics and political theory are edited collections by Terry Nardin (1996), Paul Robinson (2003), Perry Schmidt-Leukel (2004a), Torkel Brekke (2006), Richard Sorabji and David Rodin (2006), Vesselin Popovski, Greg Reichberg, and Nicholas Turner (2009), and about half of a volume edited by J.I. Coffey and Charles Mathewes (2002). Mark Janis and Carolyn Evans (1999) have edited a similar collection for international law. Several works compare the content of just war theory in Christianity and Islam specifically; e.g. two volumes edited by James Turner Johnson and John Kelsay (Johnson \& Kelsay 1990; Kelsay \& Johnson 1991) and an examination of the holy war ethic in both faiths by Johnson alone (1997).

Most of the literature in this category, however, examines the ethic of war, or of specific wars, from the perspective of specific religions. For Christianity, these works tend to follow two separate paths. One is the pacifist argument, which is that the use of force is incompatible with Christian tenets, as exemplified by the works of H. Richard

\footnotetext{
${ }^{39}$ Exceptions include Vesselin Popovski, Frances Harbour, and Walter Dorn (for international relations), and Mark Janis (for international law). The assertion above is not necessarily true for scholarship on the Middle East, North Africa, and Islamic South Asia, for Islam is generally more ingrained in those societies.
} 
Niebuhr (1992a, b, c), Roland Bainton (1960), John Howard Yoder (1984, 1994), ${ }^{40}$

Stanley Hauerwas (1985, 1988, 2011), Lisa Sowle Cahill (1994), and Andrew Fiala (2008). Valerie Morkevicius (2011) makes a related claim: that the just war tradition is not ambitious enough to effectively prevent war (see also Yoder 1984: 22). The other path is the just war argument - that the use of force may be justly undertaken given sufficient cause. Foreshadowed by works by John Eppstein (1935), Reinhold Niebuhr (1940, 1992a, b), John C. Ford (1944), the Calhoun and Dun Commissions (1944, 1946; 1950), and John Courtney Murray (1959a, b), the resurgence of the just war tradition in Western thought is generally attributed to Paul Ramsey $(1961,1968)$, with the tradition explored most comprehensively by James Turner Johnson (1975, 1981, 1984, 1987, 1999) and William V. O’Brien (1967, 1969, 1979, 1981, 1983, 1991). In addition, James Childress $(1982,1991)$ and Richard Miller (1991) claim that the pacifist and just war ethics can be reconciled, as both begin with a presumption against doing harm (see also Yoder 2009). Oliver O’Donovan (2003) treats just war as a form of “judgement." The overall effect of these works has been to reclaim the just war tradition, which until their generation had fallen into desuetude since the end of the $18^{\text {th }}$ century in both political circles and the church.

Several authors have approached the Christian just war tradition from the perspective of specific denominations or specific problems or events. From the Catholic tradition, John Langan (1984, 1991, 1998; O’Brien \& Langan 1986: chaps. 1, 6; Weigel \& Langan

\footnotetext{
${ }^{40}$ But see Yoder 2009, a posthumous work in which he argues that the just war tradition and pacifism are compatible.
} 
1991: chaps. 2, 7, 9) and Bryan Hehir $(1982,1992)^{41}$ tend to write from a more theological perspective, whereas George Weigel (1987, 1989, 1994, 2003, 2007a, b; Johnson \& Weigel 1991) applies Catholic just war theory to American foreign policy. From the Protestant (Reformed) perspective write Edward Long (1967), Daryl Charles (2005; Charles \& Demy 2010), Darrell Cole (1999, 2002, 2011; Webster \& Cole 2004), and Daniel Bell (2009); Charles and Cole tend toward more hawkish views than Long; and Bell, like Childress and Miller, seeks to synthesize the just war ethic with the pacifist ethic. From the Eastern Orthodox perspective, Stanley Harakas (1981, 1999: 154-7, 2002) and Alexander Webster (1986, 1999, 2003; Webster \& Cole 2004: chaps. 2-5) are more reluctant just war theorists than the others mentioned here, although the mainstream Orthodox position appears to condemn war unequivocally, especially outside the United States (Limouris 1990). A volume jointly authored by Webster and Cole (2004) open the dialog between the Western and Eastern Christian perspectives. Valerie Hudson and Kerry Kartchner have edited two volumes on just war theory from the Mormon perspective, which overall tends to more hawkish than most of the other denominations (Hudson \& Kartchner 1995; Kartchner \& Hudson 2004). Finally, I have synthesized the Catholic, Protestant, and Mormon approaches in an exploration of just war theory in the United States specifically (Brown 2008).

Literature on the just war tradition as applied to specific problems include a work by Johnson and Weigel (1991) on the Persian Gulf War, works by Jean Bethke Elshtain (2003) and George Weigel (2007a) on responding to the 9/11 attacks, and by Johnson

\footnotetext{
${ }^{41}$ Hehir was also the principal drafter of the U.S. Catholic Bishops' 1983 pastoral letter, The Challenge of Peace (National Conference of Catholic Bishops 1983).
} 
(2005) on the Iraq War. In addition, a volume edited by Sorabji and Rodin (2006) takes up contemporary problems such as preventive war and humanitarian intervention, as does a special issue of the Journal of Military Ethics (Brown 2011). Two notable collections of essays apply the just war tradition to a variety of post-Cold War issues, one before 9/11 (Lugo 1996) and one after (Reed \& Ryall 2007). The Reed and Ryall volume also offers a comparison of the American and British perspectives.

Literature on the Muslim world, including "political Islam," is quite voluminous, especially after $9 / 11$, and any scholarly treatment of the domestic or international politics of the Middle East, North Africa, and South Asia must necessarily devote some attention to Islam, since its influence in the law and politics of these regions is pervasive. Representative contemporary authors on the phenomenon of political Islam include Gilles Kepel (Kepel \& Roberts 2002), Graham Fuller (2004), Mohammed Ayoob (2008), Joseph Skelley (2009), and Bassam Tibi (2002, 2007). Tibi (2009) and Bernard Lewis (2002) write on the conflict between Islam and modernity, and Abdulaziz Sachedina writes mostly on Islam and democracy, liberalism, and human rights.

English-language works that specifically cover the Islamic ethics of war and statecraft are not as extensive as for Christianity, and that body of literature is written from the viewpoints of many disciplines. Major English-language Islamic legal texts include works by Muhammad Abu Zahra (1961), Mohammad Talaat al-Ghunaimi (1968), Christopher Weeramantry (1988), and especially Majid Khadduri $(1955,1984) .{ }^{42}$ Historical accounts of the rise of the early Islamic state include works by Fred Donner

\footnotetext{
${ }^{42}$ Khadduri is also noted for having translated the classic treatise on the Islamic law of nations by Shaybani (Shaybani 1966). For a further exposition of Shaybani's classic see Kelsay 2003.
} 
(1981, 2010; see also Kelsay \& Johnson 1991), who depicts the early Muslims as militant, and Thomas Sizgorich (2008, 2009), who situates early Muslim militarism within what he claims is an environment of militarism among Arabia's neighbors. Lewis (2003), John Esposito (2002), and recently Alia Brahimi (2011) have all examined radical Islamic terrorism, usually with the claim that Islamic terrorism falls well outside the Islamic normative mainstream. ${ }^{43}$

Works on the Islamic war ethic specifically include chapters by Sachedina in Johnson \& Kelsay 1990 and Coffey \& Mathewes 2002; chapters by Tibi and Sohail Hashmi in Terry Nardin's (1996) edited volume of comparative war ethics; treatments by David Cook of jihad (2005), martyrdom (2004, 2007), and Islamic apocalyptic (1997, 2003); and several chapters within the context of Islamic political ethics as a whole (Hashmi 2002; see also Hashmi \& Lee 2004). James Turner Johnson and John Kelsay have edited volumes that compare the Christian and Islamic war ethics specifically (Johnson \& Kelsay 1990; Kelsay \& Johnson 1991), and Johnson (1997) compares the respective ethics of war for religion in Christianity and Islam. Kelsay (2007) explores the Islamic war ethic specifically, focusing on the scripture, interpretation, and historical tradition (see also Kelsay 1990, 1993; Johnson \& Kelsay 1990; Robinson 2003; Brekke 2006). The treatment of Islam in this work largely will follow Kelsay's approach. Bernard Lewis (2003) uses a similar approach to explain the Muslim grievances that have given rise to terrorism, as does Reza Aslan (2005) in his treatment of Islamic political ethics generally.

\footnotetext{
${ }^{43}$ Khaled Abou el Fadl (2005), a law professor, makes such a claim in his treatment of Islamic extremism generally, not just in the context of terrorism. For a related claim, see Kepel 2004, arguing that radical Islamists have failed to win over the Islamic mainstream.
} 
In contrast to the historical-tradition approach just mentioned, Paul Heck's (2004) treatment of jihad strives to account for the changing needs and conditions of the Muslim community.

The literature on Buddhism and war (or Buddhism and peace), is sharply divided as to whether the resort to any form of violence whatsoever can be justified in the Buddhist ideal of ethical behavior. Literature from the first few decades after World War II usually maintains, occasionally with a tinge of chauvinism, that Buddhism (especially Theravada Buddhism) is exclusively a religion of peace (Rahula 1997; Jayatilleke 1962; Dissanayake 1977; see also Ramaiah Ravi \& Rao 1991). The few exceptions to this trend, by Paul Demiéville (2010) and Hajime Nakamura (1974) and dealing with Mahayana Buddhism, remained in relative obscurity until the appearance of Demiéville's piece in Jerryson and Juergensmeyer's new edited volume (2010; to be mentioned again below).

The idea that Buddhism could be anything but pacifist did not begin to take hold until 1983, when ethnic violence erupted in Sri Lanka between the majority Buddhist Sinhalas and the minority Hindu Tamils. The religious dimension of that conflict appears to have taken the scholarly community by surprise, and the events spawned a large body of literature on the Buddhist war ethic in Sri Lanka within the larger context of the politics of that country and South Asia generally (Manor 1984; Allen 1992; Houben \& van Kooij 1999; Deegalle 2006; Hinnells \& King 2007). As to Buddhism specifically, some works have treated the more militant Buddhist thought in Sri Lanka as a value-neutral "transformation" (Gombrich \& Obeyesekere 1988; Grant 2009), whereas others have taken more normative positions. Gananath Obeyesekere (1992, 2006), Stanley Tambiah (1992), P.D. Premasiri (2003, 2006), and Mahinda Deegalle (2003a, b, 2009) take the position that the 
recent militarism of Sinhala Buddhism is an unacceptable aberration of the Buddhist norm of absolute pacifism, whereas Tessa Bartholomeusz (1999, 2002), Elizabeth Harris (2003), Rupert Gethin (2007), and Daniel Kent $(2008,2010)$ argue that some use of force is actually permitted in Buddhist scripture.

The attention to Buddhism in Sri Lanka has recently prompted more thorough examinations of the war ethics in Mahayana and Tibetan Buddhism. In the comparatively sparse literature that seems to exist on this subject (at least, in English), there seems to be much greater consensus that some variant of a justifiable war ethic exists within the scriptures of both schools. Lambert Schmithausen (1999) and Perry Schmidt-Leukel (2004c) examine the Mahayana war ethic generally, Xue Yu $(2005,2010)$ examines China, and Winston King (1993) and especially Brian Victoria (2006a, 2003, 2006b, 2010) focus on Japan. The ethic of political violence in Tibetan Buddhism and its Mongolian variant are the subject of studies by Michael Zimmermann (2000, 2006b) and three chapters in Jerryson and Juergensmeyer's (2010) edited volume. In recent years, several edited volumes have lent greater support to the existence of a Buddhist war ethic than in years past (Brekke 2006; Zimmermann 2006a; Jerryson \& Juergensmeyer 2010). Their appearance has led to claims, especially by Jerryson and Juergensmeyer, that the Buddhist war ethic is consistently less pacifist than is often acknowledged in the conventional, even stereotypical image of Buddhism held by the academy today. I agree with Jerryson and Juergensmeyer's claim, but I also maintain that contrary to that conventional, stereotypical image, the Buddhist war ethic is not consistently pacifist, militant, or moderated, and as a result it lacks the relative coherency that the Christian and Islamic war ethics have. 
Further literature explores the war ethics in Judaism, Hinduism, Sikhism, Jainism, Confucianism, and Shinto. However, since the influences of those religions will not be studied in this work, they are not included in this literature review.

\section{Conclusion: Religion as the Undertheorized Dimension of Statecraft}

The thinness of the survey of IR literature on how religion precipitates conflict, as opposed to why, is evidence that the role of religion in IR has been "undertheorized," as Eva Bellin put it (2008: 339). Bellin complains that much of the literature is written by non-IR faculty (historians, sociologists, and religious studies faculty) and focuses too much on individual cases or religions at the expense of normative assessments and structured comparisons that yield hypotheses as to when and how religion influences state behavior. The role of religion in IR, she argues, needs greater mid-level theorizingsomething beyond simply that "religion matters" in statecraft. She calls upon the field to address whether religious ideas systematically trump material interests in international outcomes (2008: 341$)^{44}$ _and I will argue in Chapter 4 that the data shows that religious ideas do exactly that. Bellin places a tall order; the field is replete with literature on ideas in world politics, but seldom religious ideas. For example, Christian Reus-Smit (1997, 1999) links the structure of the state system (the "organizing principle of sovereignty") to ideas as to what constitutes the "moral purpose" of the state; and Victoria Tin-bor Hui (2004) problematizes the state system according to the strategic choices of individual

\footnotetext{
${ }^{44}$ Michael Desch (1998) argues the opposite: that security and economic welfare both consistently override ideological and humanitarian concerns.
} 
states. ${ }^{45}$ Martha Finnemore (2003) attributes the rise of humanitarian intervention to changing ideas about the nature of state sovereignty, and John Owen (2010), though not a constructivist per se, attributes the role of ideas in precipitating regime change. Of these works, only Owen explores the religious dimensions of these ideas, and then in only two instances (the Reformation and Counter-Reformation, and political Islam after the demise of the Ottoman Empire). A number of other works examine the role of culture in determining outcomes (including conflict outcomes), but usually in the context of identity and the interests that flow from identity, rather than the context of norms (Katzenstein 1996; Lapid \& Kratochwil 1996).

In this study I present the claim, which even Fox and Sandler seem to shy away from, ${ }^{46}$ that religious norms are a major driver of the international outcome of war and peace. This does not mean that they are the only driver, but the empirical results shown in Chapter 4 will show that the religion of a state often has an effect that is as strong as or stronger than many of the traditional variables feature in the security literature. In the next chapter, I will flesh out my theory for why and how religion influences the onset of armed conflict.

\footnotetext{
${ }^{45}$ Hui attributes the ancient Chinese domination of its system to certain particularly ruthless strategies that Western domination-seekers did not employ, but I would attribute the relative restraint in tactics in the West to the influence of restraining norms in Christianity.

${ }^{46}$ Fox and Sandler (2004: 7) contend that religion "is not the main driving force behind international relations."
} 


\section{CHAPTER 2}

\section{WHY AND HoW RELIGION AFFECTS DECISIONS FOR WAR OR PEACE}

\section{Introduction}

Now that the "resurgence" of religion in international politics has been sufficiently well documented, the next great question for the realm of religion and IR is: do religious ideas ever override material interests, and if so, when and how (Bellin 2008: 341-2)? It is only very recently that the mainstream of the IR field has begun to take this question seriously (Snyder 2011a; Toft Philpott \& Shah 2011).

A debate over how to respond to the resurgence of religion in $\mathrm{IR}^{1}$ is brewing within the most recent body of literature on that topic. Vendulka Kubálková (2000) calls for the construction of an "international political theology" and Timothy Shah and Daniel Philpott (2011: 51) go as far as to call for a "Kuhnian paradigm shift" in the study of IR. In contrast, Nukhet Sandal and Patrick James (2011) and Daniel Nexon (2011) argue that no paradigm shift is necessary, and Eva Bellin (2008: 316) expresses with frustration the need for scholars to just "get on with" the theorizing. I am inclined to place myself in the latter camp — that the study of religion in IR requires no fundamental revision or reevaluation of the field. Rather than attempt to craft a new grand theory, this chapter will explore the role or function of religion in a variety of existing theories of state behavior in both international relations and international law, and ultimately theories on the causes of conflict and war.

\footnotetext{
${ }^{1}$ Assuming it was ever dormant in the first place; see Chapter 1.
} 
Robert Art (1980: 5) has theorized there to be four functions of force (defend, deter, compel, and "swagger"). ${ }^{2}$ But in my view the ideal classification of the purposes of using force is reducible to something that is simpler than Art's four functions, yet more complex than mere human beastliness. Force is fundamentally either defensive or offensive. The New Haven School classifies force into two basic types. The first is value extension: extension or expansion of one's utility, be it territory, material wealth, control, or some other form of power. The second is value conservation: defense of territory, wealth, etc., for oneself or for others (McDougal \& Feliciano 1961). This classification is quite useful, in that it fleshes out (if in an abstract way) the meanings of "offensive" and "defensive."

Contemporary theories of armed conflict in IR normally do not problematize the purpose of force in this way (i.e., whether it is offensive or defensive). There are two likely explanations for this. One is that the two categories themselves have normative connotations and many theories are oblivious to norms. Another is that the field is primarily interested in the cause of offensive force only. This is logical most of the time, for a state almost always undertakes a defensive use of force in response to an offensive one. It is generally expected and assumed that a state rightly uses defensive force because some other state has used offensive force against it, thus the use of defensive force is easily explained much of the time. What the field strives to understand is what causes a state to be the first to resort to force.

In the field of international law, most scholarly treatments of jus ad bellum have been devoted to the content of the rules and to case studies that analyze whether a particular

\footnotetext{
${ }^{2}$ I would characterize these functions better as to compel, deter, deny to others, and benefit to self. A particular use of force may have one or more these objectives.
} 
state has acted in compliance with the rules in a particular instance. They do not often attempt to address the question of why states violate jus ad bellum, ${ }^{3}$ but instead make arguments that certain acts that would appear prima facie to be unlawful are actually lawful—works that support the justifiability of humanitarian intervention often fit into this category (e.g. Wheeler 2001; Tesón 2005).

As explained more fully in Chapter 1, my dependent variable is the first use of force in violation of jus ad bellum (which in today's legal environment is nearly synonymous with simply the first use of force). As such, the DV responds to both of the questions just set forth: to IR, what causes a state to use force first in an interstate dispute, and to international law, what causes a state to deviate from the rule the prohibits using force, despite its previous agreement to be bound by that rule. Because the DV is responding to questions in both IR and international law, it is necessary to address the theory underlying my claims in both fields.

\section{The Place of Religion in International Relations Theory}

Contemporary theories of international relations, as well as of armed conflict, are quite numerous and diverse. A generation before many of today's theories were developed, Kenneth Waltz usefully classified them into three divisions, or "images" of international relations (1959; see also Cashman 1993). In the first image, the root of war lies largely in the nature and behavior of man; in the second, it lies in the internal organization of states; in the third, war is bound to occur due to lack of an enforceable

\footnotetext{
${ }^{3}$ For an exception, see Franck 2002.
} 
system of law among states, forcing every state to rely on its own devices. ${ }^{4}$ In placing religion within the many theories of causes of international armed conflict, this section will treat those theories along similar lines: systemic, domestic, and psychological.

\section{Third Image: Religion in Systemic Theories of Armed Conflict}

$\underline{\text { Realism }}$

The oldest theory of international relations, today styled Classical Realism, posits that war ensues because states (or more precisely, individuals) crave power and fear the intentions of other states, which also crave power (Thucydides 1998; Machiavelli 1950a, b; Hobbes 1985; Morgenthau 2006; see also Kauppi \& Viotti 1992: chap. 4 \& 147-67). But also in classical realism, individuals crave power because of their human depravities; to Plato, for example, the purpose of war is to satisfy human appetites for honor, wealth, or baser desires (1992: bks. viii-ix). ${ }^{5}$ Religion may participate in defining those appetites, particularly what constitutes "honor" and "power," but beyond that the monotheistic religions, at least, would seem to play little part in classical realist theory-for it is usually supposed that leaders of states must act in accordance with their human depravities, which would appear to eliminate any significant possibility of choice. ${ }^{6}$

\footnotetext{
${ }^{4}$ Waltz settles on the third image as the one with the most explanatory power. See also Waltz 1979.

${ }^{5}$ Modern IR theory typically eschews honor as a driver of international outcomes, preferring to focus on material capabilities only, but Richard Ned Lebow (2008) attempts to reclaim the classical role of honor in IR theory.

${ }^{6}$ For a more optimist view of the potential to incorporate religion into Classical Realism, see Sandal \& James 2011. Their optimism appears to be based on the potential contributions of religion to theories of
} 
In the same vein, Neorealism denies the role of choice. Its founder, Kenneth Waltz (1979), outlines three defining features of the modern state system: (1) an ordering principle of anarchy, as opposed to hierarchy or some other ordering principle; (2) lack of differentiation of functions or preferences of the actors (states); and (3) and differentiation of capabilities of the states. ${ }^{7}$ Assuming states to be unitary and rational actors, Waltz then analogizes their behavior to that of economic firms in the marketplace. States being rational, they seek to augment their utility, but above all seek security from threat. The state system, however, is inherently threatening because some states have greater capabilities than others. The marketplace requires states to resort to self-help in order to protect themselves, for if they do not, they die. States must therefore occasionally force other states to do their bidding, and armed conflict ensues. In Defensive Realism, states merely seek security (they are content to leave others alone provided they are left alone also) and only use force to protect themselves against threats (Walt 1987). Offensive Realists, on the other hand, go further, arguing that the uneven distribution of power in the system gives states incentives to seek not just security, but power. States have offensive capability (the power to hurt) and their primary fear is not for their security but for their very survival. They must, therefore, augment their power at any opportunity

misperceptions, as well as their quite correct insight that religion often is employed as a source of legitimacy. These, however, are first- and second-image theories of armed conflict onset, not third.

${ }^{7}$ To these three features Helen Milner (1991) adds a fourth: the actors in the system must interact. John Ruggie (1983) criticizes Waltz's dropping the second feature (because all states have the same function and preferences), on the basis that doing so renders unexplainable the change from the feudal system to the Westphalian system. Ruggie is probably correct but his criticism seems largely irrelevant to the state system today. 
(Mearsheimer 2001). ${ }^{8}$ States' preferences are not problematized; they are assumed to be to augment or retain power, and dynamic theories of war attribute this preference to the onset of major war, to the virtual exclusion of all other factors. ${ }^{9}$

The neorealist depiction of international interactions leaves no place for norms, religious or otherwise. For religion to influence outcomes at the structural level, it would have to take the form of an actor in the international system, wielding its power alongside the rest of them. The models of Robert Gilpin (1981) and John Mearsheimer (1990, 2001) suggest that religions would have to assume great power status. This paradigm, as applied to religion, might have had considerably more explanatory power in the distant past than it does today. In the European system during the Middle Ages, the Roman Catholic Church emerged as a formidable political power, by itself and later alongside the Holy Roman Empire. In the early Muslim system, the Islamic Caliphate wielded political power in a similar way, and the material power of the Caliphate was probably even greater than that of the Catholic Church, given the profound intermingling of religious and political authority in Islam during that period. However, no religious institution has anything close to such material or political capability today. The last Caliphate to enjoy any genuine political power was overrun by the Mongols in the $13^{\text {th }}$ century, and the closest thing to its political successor, the Ottoman Empire, met its demise in the 1920s with the secularization of Turkey. Since that time, no single state has emerged as the

\footnotetext{
${ }^{8}$ Eric Labs (1997) argues that this craving for power is actually unconscious; states expand simply when the opportunity presents itself.

${ }^{9}$ In Power Transition Theory, wars are theorized to be started by rising challengers to the hegemon (Organski \& Kugler 1981). Dynamic Differentials Theory predicts the opposite: that wars are started by hegemons against potential rising challengers (Copeland 2000b).
} 
hegemon of the Muslim world and the Caliphate itself was purportedly abolished constitutionally in 1924, by the new Republic of Turkey. The Roman Catholic Church, despite its claim of over one billion members and its special status as a politically independent entity, ${ }^{10}$ has but a tiny amount of territory, no permanent population, and no military capability apart from an internal security force. The prospect of religious institutions having influence in the neorealist paradigm would appear to have little empirical support today.

However, one way in which religion might influence outcomes in this seemingly deterministic model is through James Fearon's theory of why rational states undertake wars that are objectively irrational. Fearon (1995) argues that states' otherwise rational calculations of the costs and benefits of war are impaired by private information with incentives to misrepresent, commitment problems, and (less often) issue indivisibility. Religion especially may hamper issue divisibility, e.g. the question of the ownership of Jerusalem in the larger Israeli-Palestinian dispute. Ron Hassner (2009), for example, catalogs and analyzes several conflicts over indivisible religious sites. Religion may also create or resolve commitment problems; for example, religious tenets may foster trust between religious confreres on opposite sides of the dispute, and distrust between adherents of a different religion. Other than through this avenue (and Fearon's work is not easily classified into a particular realist variant), religion would appear to have little

\footnotetext{
${ }^{10}$ Treaty Establishing the Vatican State, with Financial Convention (Holy See-Italy), February 11, 1929 ("Lateran Treaty"), 130 BFSP 791, partially reprinted in 3 FHIG 895 (establishing the sovereign status of Vatican City). For a discussion of Vatican statehood as a special case in the international system, see Shaw 2003: 218-9.
} 
to contribute to neorealist explanations of armed conflict onset, in which the favored causal mechanisms are almost entirely material.

Yet I contend that while the neorealist paradigm is elegant and powerful, its explanatory power is severely limited by the key assumptions that (1) norms are irrelevant, and (2) a state's actions are induced by the structure, rather than chosen by the state. The second of these assumptions has been challenged by the emergence of Neoclassical Realism (Rose 1998), successfully in my view. Randall Schweller (1994) makes the case that the preferences of states are divisible into the categories of status quo-seeking and revisionist, and further theorizes that international outcomes vary not only according to distributions of power, but also—in fact, primarily—with distributions of preferences (1994, 1996). In his book Unanswered Threats (2006), he shows that some states are less willing (as well as less able) than others to undertake highly risky ventures in order to balance against other states. However, in traditional neoclassical realism, the ability of a state to realize its preferences is limited by its position in the larger state system. The preferences of states act as temporary, short-term filters for the long-term pressures, incentives, and constraints on states' behavior that are imposed by the system. In this model, the system ontologically precedes the state, so the preferences induced by the system are prioritized over those of the state. Unless religion influences the preferences induced by the state system (already shown to be a doubtful proposition), religion would not significantly enrich this model of state behavior. We shall, however, revisit the influence of religion on neoclassical realism in the section on domestic theories of armed conflict. 
$\underline{\text { Institutionalism }}$

The world politics of today is considerably more institutionalized since the creation of the United Nations. As Robert Keohane (1989: 1) puts it, “[M]uch behavior is recognized by participants as reflecting established rules, norms, and conventions, and its meaning is interpreted in light of these understandings." Institutionalists, especially Neoliberal Institutionalists, ${ }^{11}$ challenge several realist assumptions and contend that states are more inclined to cooperate than realists predict. States will enter into cooperative relationships so long as the long-term benefits of doing so outweigh the long-term costs. Once the states are brought together to address a common problem, the machinery of institutionbuilding is set into motion: States form institutions, here conceptualized as a set of behavioral expectations, in order to alleviate uncertainty. This is accomplished by providing a clear standard of behavior, alleviating asymmetries of information between states, and mitigating the collective action problem by centralizing the function of ruleenforcement. Institutions also incentivize compliance with rules by lengthening the shadow of the future; they do this by forcing states into an indefinite cycle of interaction (the iterated game) in which states acquire reputations for cooperating or not, and by promoting retaliation for cheating (Keohane 1984; Hobson 2000: 96-9). Backed up by the institution, which enforces compliance through various means, an aggrieved state no longer need resort to self-help measures, including military force, to remediate an injury when another state deviates from the expected behavior. This theory breaks down,

\footnotetext{
${ }^{11}$ As opposed to Liberal Institutionalists, who unlike neoliberals, challenge the realist assumptions that states are unitary and rational, are the primary actors, and that states are most concerned about power/security (Grieco 1988).
} 
however, under two possible conditions. One is when a state no longer perceives any long-term net benefit to cooperation. The other, which may partly result from the first, is when a state has the power to unilaterally change the status quo, thereby forcing other states to cooperate even when doing so confers no benefit (the other states then cooperate because not doing so entails even greater costs; Gruber 2000).

While the causes of the formation of institutions are largely material, ${ }^{12}$ the institutions themselves take a variety of forms that are not necessarily concrete. Keohane (1989: 3) defines an "institution" as a "persistent and connected set[] of rules (formal and informal) that prescribe behavioral roles, constrain activity, and shape expectations." ${ }^{\text {"13 }}$ Such entities can take the form of formal organizations (inter-governmental or non-governmental); they may also take the form of "regimes," which Keohane defines as sets of explicit rules, agreed to by governments, that pertain to particular sets of issues. ${ }^{14}$ Furthermore, institutions may take the form of "conventions," which Keohane defines as informal, implicit rules and understandings that shape the expectations of the actors.

\footnotetext{
${ }^{12}$ According to Keohane $(1982,1984)$, demand for institutions are generated by (1) absence of clear legal framework for establishing liability between the actors, (2) high cost and low reliability of information, and (3) transaction costs associated with making agreements. When an institution can alleviate these problems in ways that an ad hoc agreement cannot, a demand ensues for that institution.

${ }^{13}$ Cf. Stephen Krasner's (1982: 185) definition of "regime" as "a set of implicit or explicit principles, norms, rules, and decision-making procedures around which actors' expectations converge." What Krasner calls a "regime" Keohane calls an "institution."

${ }^{14} \mathrm{Cf}$. the definition of "positive international law" as the rules of state behavior explicitly drawn up by states with the intent to be bound by them.
} 
Religion can perform the functions of all of these forms of institutions. An religious organization may act as a central institution to enforce behaviors and adjudicate or mediate disputes, as the Catholic Church once did in Europe, e.g. over possession of the New World. ${ }^{15}$ However, like the hypothetical of religion acting as a great power in the realist paradigm, this explanation also has little empirical support today. Only one contemporary international political organization is overtly religious (the Organization of the Islamic Conference); the rest are secular. In addition, as a result of the institutionalization of groups of states with common religious identities (e.g. the OIC, Arab League, the OAS, EU, and most of NATO), one would expect those states to cooperate with each other to a greater degree, thus leading to peace within those groupings, e.g. a "Christian peace" or "Islamic peace" analogous to the democratic peace. That expectation also has little empirical support, for modern history is replete with cases of Christian states fighting each other and Muslim states fighting each other, with the belligerents often being members of the same organization. However, within these organizations, religion may also inspire the content of their regimes (sets of rules), or even provide them directly; the Quran, for example, is the primary source of the richly sophisticated legal system used in and between many Muslim states today. Religion may be used as a tool to de-legitimize a regime as well (Sandal \& James 2011: 14).

But I suggest that the strongest influence of religion on institutionalism may be in shaping the conventions that provide the necessary foundations to shape states' expectations of each other. Prior to genuine, meaningful negotiation of rules, the "conventions"

\footnotetext{
${ }^{15}$ See Bull Inter caetera of Pope Alexander VI, May 4, 1493, 2 FHIG 103; Treaty of Tordesillas (SpainPortugal), June 7, 1494, 2 FHIG 110.
} 
or common frames of reference for interaction must first be in place. A common religion between states could provide these. Indeed, the lack of formal conventions for interaction could explain why independent non-Western — and non-Christian—-states were not admitted into the Westphalian system until long after European and American states; Turkey was not admitted into the European "family" until 1856 despite constant interaction with it for centuries, ${ }^{16}$ and the Correlates of War dataset does not include Persia or China in the state system until 1855 and 1860, respectively (Correlates of War Project 2004). The fact that the Westphalian system today is so religiously diverse compared to that of the $19^{\text {th }}$ century suggests that secular conventions of interaction have now supplanted religious conventions. In the international relations of today, the influence of religion in the institutionalist paradigm would also seem to be fairly limited.

\section{$\underline{\text { Constructivism }}$}

The most fundamental challenge to the neorealist paradigm—and John Ruggie (1998b) argues, to the institutionalist paradigm as well-is Constructivism. The core features of the constructivist approach to IR theory are that (1) global politics is guided by intersubjectively shared ideas, norms, and values of the actors; (2) ideational structures exert not only a regulative effect on the actors, but a constitutive effect as well; and (3) ideational structures and actor co-constitute and co-determine each other (Copeland 2000a). The state structure is analogous to an office building, in which the exterior walls and internal configuration of space generates broad behavioral pattern, e.g. its occupants

\footnotetext{
${ }^{16}$ Treaty of Peace [ending the Crimean War] (France, Great Britain, Ottoman Empire, Sardinia-Russia), March 30, 1856 (“Treaty of Paris”), 2 MPT 947, partially reprinted at 3 FHIG 19.
} 
do not walk through the walls or exit through the windows (Dessler 1989). Where interaction is concerned, constructivism begins from the core principle that people act toward others on the basis of the meanings those others have for them, and those meanings arise out of interaction (Wendt 1992). The actor's conceptions of itself and its interests tend to mirror the practice of significant others over time, in a cycle of reinforcement which could be characterized as vicious if that cycle is conflictual, or virtuous if it is cooperative. The structure, or rule, is instantiated in the actor or action, and the actor/ action in turn reproduces the structure/rule (Dessler 1989). In this way, structures of human association are determined primarily by shared ideas rather than material forces, and the identities and interests of actors are constructed by these shared ideas, rather than given to them by nature (Wendt 1999). The immediate consequence of this construction of shared ideas is that states base their behavior on the logic of appropriateness, rather than consequences. Confronted with a situation, states' decisions of what to do are guided by norms, not utility (Checkel 1998). To Alexander Wendt, whom the field regards as the most prominent purveyor of constructivism in IR, it is these shared ideas that explain the preferences of states to be revisionist or status quo-seeking with respect to each othersomething that neorealism, for all its explanatory power, cannot explain. Variations in states' preferences leads Wendt to the conclusion that more than one type of anarchy-therefore more than one set of behavioral norms-exist between states. These types of anarchy are fundamentally distinguished by whether states view each other as enemies, rivals, or friends (Wendt 1999: chap. 6). Furthermore, these types of anarchies can coexist with each other, leading to a richer diversity of international outcomes than a single paradigm of IR theory could predict. 
At first glance, the influence of religion in international outcomes would seem more plausible in the constructivist paradigm, for religious ideas would be socialized into state structures and into the identities and interests of states themselves, just like ideas from other sources. Structural, systemic concepts such as anarchy, sovereignty, power, wealth, and security are all beholden to the ideas that give those terms meaning. ${ }^{17}$ For example, Daniel Philpott $(2000,2001)$ argues that the Westphalian concept of sovereignty is rooted in Protestantism.

But upon deeper inquiry, we find that a traditional constructivist theory of the impact of religion does not appear to explain much, at least at the systemic level. Non-Western, non-Christian states also have embraced the concept of sovereignty that Philpott outlines (sometimes even more vigorously than Western states!). In addition, several concepts or goals are (or are claimed to be) universal; for example, all states would seem to have roughly the same idea of what it means to be wealthy or powerful. Because the world is religiously diverse, the only way for religion to have given meaning to certain concepts is for different religions to have inculcated the same meanings. If that is the case, then different religions should not be generating different preferences among states for war or peace, and the empirical results presented in Chapter 4 show otherwise. Whereas constructiveism is a theory of how norms are diffused through the system, and how that diffusion leads states' preferences to eventually converge, the empirical findings indicate a divergence of preferences, with different religions leading states to adopt different norms and thus different preferences.

\footnotetext{
${ }^{17}$ Though Wendt would contest the assertion that material forces are completely irrelevant ("ideas not all the way down"; 1999: chap. 3).
} 
In sum, the potential of religion to significantly enrich systemic theories of international relations, hence also theories of armed conflict onset, appears doubtful. Its potential, however, appears more promising for domestic theories of states' preferences, and for theories of political psychology, i.e. in the second and first images.

\section{Second Image: Religion in Domestic Theories of Armed Conflict}

In this section we examine the influence of religion on the domestic characteristics of states that induce preferences (thus outcomes). In contrast to the third image, the relationship of religion to IR in the second image appears to be stronger and more relevant.

\section{$\underline{\text { Religion and Neoclassical Realism }}$}

As discussed earlier, neoclassical realists take the preferences of states into account, e.g. Schweller's division of states into status quo-seeking and revisionist. In this model, it would appear that states often do choose their actions, including whether to use force against another state and when. However, many neoclassical realists would claim that the role of states' preferences is somewhat predetermined, in two ways. The first way is that those preferences act merely as temporary filters for the pressures and incentives that are dictated by the systemic distribution of states' power; preferences are intervening variables, but only in the short term (as discussed above). But suppose that it were not the systemic pressures and incentives being filtered through states' preferences to generate outcomes, but instead the reverse: their preferences being filtered through the pressures, incentives, and constraints of the system. States' decisions may actually begin with their 
own desires rather than being incentivized by the system, and those desires are then filtered through the systemic pressures and constraints, which in turn determine which desires are possible for the state to realize.

The second way in which states' preferences are arguably predetermined is the theory, articulated most notably by Jack Snyder (1991), that the preferences are determined by the interests of rent-seeking domestic groups. This supposition is a formidable challenge to the place of religion in neoclassical realism because if it is correct, then the interests that drive states' preferences are material, not ideational, even if the interest group generating those preferences is religious in character. To borrow an example from history: the "civilizing mission" of European states from the $16^{\text {th }}$ to the $19^{\text {th }}$ centuries may have been motivated genuinely by the desire to propagate Christianity, or it may have been simply a veneer of legitimacy for material acquisition (Pagden 2003: chaps. 5 \& 10). The Spanish Jesuit theologians Francisco de Vitoria and Francisco Suárez professed there to be a right to preach the Gospel to the natives in the New World, as well as the prerogative of the Spanish conquistadors to use force to defend that right (Vitoria 1991a: q. 3, art. 2; Suárez 1944b: sec. 1(2)). On the other hand, Roland Bainton (1960: 165-6) quotes both Spanish conquistadors Hernando Cortez and Francisco Pizarro as frankly admitting that their motives were to acquire gold, not save souls. It is not implausible that overall church support of the Spanish conquest in the New World, and even missionary activity during the scramble for Africa in the $19^{\text {th }}$ century, were actually motivated more by material concerns than spiritual. Tony Smith (2000) illustrates a more contemporary tension in the foreign policy advocacy of ethnically-based interest groups in the United States. Smith argues that ethnic groups lobby for policies that promote human rights and 
economic aid for their ethnic confreres. Carried over to religion, the inference is that religious institutions will rent-seek in favor of the material interests of themselves and their members (the greater number of members and the wealthier those members, the more powerful the religious institution). In this respect, religious institutions would act no differently than secular interest groups (recall the approach of the Religious Economy School recounted in Chapter 1). By this logic, it is not religious ideas that influence foreign policy preferences, but the material interests of religious institutions.

Although this alternative explanation for the foreign policy preferences of religion might seem reasonable prima facie, it seems excessively and inappropriately cynical upon deeper reflection. Let us assume for the moment that Bainton's attributions of motives to Cortez and Pizarro are factually true (we might even assume that their motives were shared by the Spanish crown). That is evidence not that they conquered at the behest of the church or with the church's support, but that the church's motivation for supporting the Spanish presence in the New World, along with its protests of abuse, did not sway the conquistadors or their political leadership. To claim that the Spanish plundered the New World with church support is to choose not to take the writings and preachings of Vitoria, Suárez, and other church authorities at their word, yet without any evidence of disingenuity on their part. In addition, the genesis of the practice of humanitarian intervention by European countries in the $19^{\text {th }}$ century was the perceived need to protect Christians from oppression at the hands of non-Christian rulers, not the material interests of the interveners (Murphy 1996: 49-57). Furthermore, Tony Smith's claim is that ethnic groups seek to influence American foreign policy not wholly for the sake of their own 
material interest, but also to improve the human rights of their ethnic confreres outside the country (rather than their own rights).

In addition, contemporary world events frequently suggest that the claim that materialism is the primary explanation for war or peace today is overstated. As the final chapter of this work will show, material interest was a weak factor at best in the decision of the U.S. to use force to liberate Kuwait from Iraqi occupation in 1990-91; indeed, many material concerns weighed against doing so. The decision of the U.S. to invade Iraq itself in 2003 also appears to have been driven primarily by ideological, not material, concerns (the war-for-oil conspiracy theories notwithstanding). These were both wars of choice, with the U.S. under no pressure or incentive from the international system to embark on them, material or otherwise. It would appear that states' preferences are only partly determined by the interests of domestic groups, not wholly determined, and those interests are not exclusively material. I would thus contend that neoclassical realism actually is a persuasive model of international outcomes, but not always in the ways that it is traditionally propounded. The sections that follow will illustrate other ways in which religion contributes to the formation of domestic preferences.

\section{The Influence of Religion on States' Ideologies}

Max Weber conceptualized the existence of "practical religion" as the vehicle by which religious precepts are translated into action or restraint. Such action or restraint can be political. As early as the 1960s, Gabriel Almond, Sidney Verba, and Lucian Pye formulated the premise that "deeply embedded beliefs ... lead to certain probabilistic political attitudes and actions" (Laitin 1978: 563, citing Almond 1956; Almond \& Verba 
1963; Pye \& Verba 1965). In more recent scholarship, K.R. Dark (2000: ix) reminds us that religious factors affect human decision-making and actions, and because states are comprised of people, religious beliefs and affiliations can affect the states' decisionmaking and actions as well. Studies of the influence of religion on political outcomes have articulated the process several ways. The standard constructivist explanation, summarized by Andreas Hasenclever and Volker Rittberger (2000: 647-8), is that "Social conflicts are embedded in cognitive structures such as ideology, nationalism, ethnicity, or religion. These structures, which consist of 'shared understandings, expectations, and social knowledge', provide social actors with value-laden conceptions of the self and others and consequently affect their strategic choices." Although power and interests do play a crucial role in explaining politics, constructivists argue that they are embedded in cognitive structures that give them meaning. Furthermore, although political leaders do exercise some degree of agency in the outbreak of conflict, the religious traditions that influence them are intersubjective structures with lives of their own, and political leaders cannot simply manipulate those religious traditions at will.

But just how does the "religious tradition" come about? Weber theorized that religion emerges by way of a charismatic prophet who systematizes the culture's beliefs in gods, magic, and other supernatural phenomena that are attractive to the culture. A sense of celestial stability, regularity, and authority is usually appealing to the masses, who are victims of the impetuosity and caprice of human authority and the forces of nature. The oppressed masses take comfort in the promise that their earthly suffering will be rewarded in the afterlife (Weber 1958a, 1963). The emergence of religion, to Weber, was a 
response to unmet needs, ${ }^{18}$ and as rational society progressed to the point at which material human needs would be satisfied, the need for religion would wane and eventually disappear. Religion, in essence, was a pre-modern relic (see Bellin 2008: 317). Two events, however, have shed doubts on the Weberian theory of the origin of religion. One has already been noted in Chapter 1: scholars have realized that religion overall has not waned, despite improvements in material circumstances. The other event is an archeological discovery of evidence of organized religion from 11,600 years ago, at the site of Göbekli Tepe in southern Turkey (Mann 2011). Anthropologists had believed organized religion to be a manmade phenomenon, developed in the first civilizations as a response to the newly discovered social tensions associated with the larger communities that were necessary to sustain agriculture. The ruins at Göbekli Tepe, however, are evidence of the existence of organized religion by hunter-gathers, five thousand years before the development of agriculture or its sustaining communities.

These two events suggest a more apt explanation for the emergence of religion. Following the philosopher of religion Mircea Eliade (1959), Kevin Hasson (2004: 153) notes that "Human beings typically come with a built-in thirst for the transcendent,"19 or put another way, that man needs something larger than itself to make its existence meaningful. Religion can provide meaning to human existence in several ways. First, the primary concern of many religions is the condition of souls in the afterlife. In Christian thought, for example, the soul may go to heaven (a place of eternal blessing) or hell (a

\footnotetext{
${ }^{18}$ In Maslovian terms, these needs would range from biological to self-actualization (Maslow 1943).

${ }^{19}$ This assertion does not necessarily mean that humans have a psychological need to create a god for themselves; it could also mean that humans have a psychological need to find one.
} 
place of eternal torment). Religions prescribe certain behavior during one's lifetime, with most of them prescribing such behavior as a prerequisite to earning a happy afterlife (the exception is Christianity). Some prescriptions of individual behavior, such as a duty of charity, may spill into the rubric of statecraft. A second way religion may provide meaning to human existence is through the worship of an entity that inspires awe in humans - a god. Humans may find existential meaning in worshipping an awesome god and obeying that god's commands, including its prescriptions of behavior (and potentially of statecraft). A third view, suggested by Pauletta Otis (2004), treats religious prescripttions more as personal benefits than commands or personal incentives; because obeying religious behavioral prescriptions is a condition of a happy afterlife, such obedience is materially rational, even if the "material" itself is otherworldly.

The process by which religion provides meaning to human existence is to instill values, priorities, cognitions and prescriptions—in other words, norms—which assist people in understanding the meaning and value of their lives. In explaining the meaning and value of life, religion also prescribes the conditions under which taking life is justifiable. Otis (2004: 19) asserts that this is the role of religion in precipitating deadly conflict. One immediate benefit of norms governing state behavior is that they simplify the decision-making process: By prescribing the preferred choice in advance, norms reduce the complexity of the choice-situation (Kratochwil 1989). Another benefit of norms may be to assist actors in discovering what actions confer long-term benefits to both sides; Christopher Gelpi (2003) adopts this approach in his study of the construction of normative standards of behavior in militarized disputes by states themselves, via settlement agreements. Applied to religion, however, these arguments miss the point 
(even though they are logical and plausible on their own). The point is that through any of the alternatives described here (or perhaps all of them), individuals adopt standards of behavior acquired from transcendental sources, and carry those standards with them when conducting statecraft.

Having identified how religiously based standards of behavior are acquired, we may now turn to the process by which the standards are transmitted. Weber theorized that the prescriptions for taking life, along with all the rest of the meanings, values, prescriptions, etc., are first conveyed to the masses through a charismatic prophet, and the prescribed behavior is induced through psychological sanctions (Weber 1958b; see also Laitin 1978: 565-6). Weber went on to propose that the priesthood would systematize the two types of social influences (the charismatic prophet and the enduring habits of the masses). As religion expands, the religious doctrine and the culture (the totality of the political and socio-economic conditions) interact with each other (Laitin 1978: 572). That may be true to some extent, but as Peter Berger (1999) rightly points out, religions have developed their own identities, and as such they influence cultural norms, values, priorities, and cognitions independently. As evidence of this, Daniel Philpott's $(2000,2001)$ treatment of the Protestant influence on the modern concept of state sovereignty has already been mentioned; in addition, Rodney Stark (2005) has attributed the success of Western capitalism to Christian faith in progress and Christian concepts of human rights including property rights. These works are accounts of how religion has changed entire cultures, and they serve to corroborate Berger's claim. Weber is right to attribute social influence to a charismatic prophet (as evidence of this claim we need not look further than the 
examples of Jesus and Mohammed), but as to how the religion endures after the prophet is gone, I suggest the media of transmission are broader than those articulated by Weber.

Stanley Hauerwas calls attention to the role of cultural and religious "narratives" in shaping moral decisions, and the Tessa Bartholomeusz (2002) uses that approach in examining the just-war ideology in Sri Lankan Buddhism. Adopting that approach, I argue that religious principles, i.e. religiously-instilled beliefs of fact, causation, and rectitude (see Krasner 1982: 186), are transmitted through the persuasive power of three forms of narratives. The first is religious scripture, such as the Bible, Quran, or Pali Canon. Scripture provides a written record of the teachings of the prophet, plus accounts of historical events, circumstances, and environments that are relevant to interpreting the prophet's teachings. A basic principle of biblical exegesis, for example, is to take into account whom the prophet is addressing and why. As a written record, scripture memorializes the prophet's teachings in a more permanent fashion than oral histories do, and the more widely disseminated the scripture, the more resistant it becomes to meaningaltering changes. The scripture may influence people directly, i.e. by being widely read, or its content may be disseminated through the second (but by no means secondary) narrative by which religious principles are transmitted.

The second type of narrative is generated by what loosely may be characterized as the priesthood, or more accurately, the writings of the priesthood. Weber is right to point out that the role of the priesthood is to systematize the prophet's teachings. But once that work is completed, the function of the priesthood is to interpret the prophet's teachings in light of new events and circumstances; otherwise, the religion becomes fossilized and soon loses its relevance and eventually its persuasive power. Furthermore, it takes a 
charismatic priesthood to continue to persuade people to adhere to the religious principles and behavior prescriptions long after the prophet is gone. An enduring priesthood is necessary to perpetuate the religious tradition, but the priestly teachings that enjoy the most durable persuasive power are those that are written down, so that they, like scripture, are accessible to a much wider audience during and after the priests' lifetimes. Examples of such writings include the works of Augustine, Thomas Aquinas, Martin Luther, John Calvin, and classical Islamic scholars (especially legal scholars, given the centrality of law to so many facets of Islamic life).

The third type of narrative is historical tradition. Some religions, including Islam and various forms of Buddhism, emphasize events and actions and the stories that emerge from them. Examples of this medium include compilations of Islamic hadith (nonscriptural compilations of the words, actions, and decisions of the Prophet Muhammad), traditional biographies of the Prophet and histories of the early expansion of Islam, and classical historical sagas in Buddhist tradition. These narratives serve as the bases for analogizing current events to past events, and thus assist in prescribing the appropriate reactions. Yuen Foong Khong (1992) shows how states' leaders make decisions in crises by analogizing those crises to previous crises and their outcomes; I argue that in religion traditions, such analogizing takes place within entire cultures.

Through these three media (scripture, priesthood, and historical tradition), the meanings, values, priorities, cognitions and prescriptions of human life are instilled into whole societies and cultures, one person at a time. The result is not unlike that which forms the "operational code" in the so-named literature. An "operational code" consists of the "values, world view, and response repertoire which an individual acquires and 
shares with other members of an organization" (Walker 1990: 403; see also Walker Schafer \& Young 1999). In this way, the individuals within an organization internalize certain rules of conduct and norms of behavior, and those rules and norms become their identity (George 1969), and thus the organization's identity as well (see Feng 2005). The focus of the original operational code literature was on the Bolshevik ideology (Leites 1953), but the same process applies to any ideology, including a religion, and for any grouping of people, including a state. In this way, a state acquires characteristics that amount to a religiously-rooted ideology.

Scott Thomas (2005: 87-90), drawing upon the works of Alasdair MacIntyre, offers an alternative approach to explaining the emergence of a religious tradition. He argues that a religious tradition actually emerges as a social tradition, and that values and ethical conceptions about the nature of good, justice, rightness, and obligation, as well as the rationality upon which these things are based, "are socially embodied in particular social traditions and communities." Religion is reduced to "a set of practices that constitutes a social tradition" and rationality is the "conception of the good embodied in a particular social tradition or community." To Thomas, there is no rationality independent of tradition; there is "no view from nowhere." This approach might have support in works such as that of Thomas Sizgorich (2009), who argues that Islamic militancy is the product of early Islam's socialization to it by the equally militant practices of the neighboring Byzantine and Persian empires. In addition, Thomas adopts a "narrative approach" to identity and social action, rejecting the idea that individuals can be understood as separate or autonomous actors in a larger social system. Human life, he argues, is something 
more than a sequence of discrete or separate actions. A social action is only an episode [within a larger narrative of social action], and so it must be understood in this way. ... [T] he self in MacIntyre's account is a 'situated self' of practice, narrative, and social, cultural, or religious tradition." (Thomas 2005: 91)

In sum, one's rationality depends on his or her identity. In IR theory, such rationality is treated in accounts of Social Identity Theory, in which the in-group naturally acquires a latent hostility toward the out-group (Tajfel \& Turner 1979; Mercer 1995). It is also treated in accounts of the origin of nationalism, in which individuals who need greater self-fulfillment turn to their national identity for that fulfillment (Lebow 2008: 17; see also Levy 1989b: 271-2). And it does seem intuitive that the role of religion in the formation of social and/or political identity would be strong (see Seul 1999).

Notwithstanding the logic of Social Identity Theory, I have two objections to Thomas's approach. First, it does not problematize the preferences associated with social identity; for example, it does not explain why Islam prescribes death for apostasy but Christianity does not. Second, the claim that there is no rationality independent of tradition does not ring true: the core meanings, values, priorities, cognitions, and prescriptions in most religions do not arise out of practice, but from the teachings and scripture that speak for a higher, transcendent or divine entity. Indeed, those teachings often radically depart from the prevailing tradition, which is why societies tend to be hostile to the original prophets of a religion (the cases of Jesus with respect to the Jews and Muhammad with respect to Mecca serve as examples). From their adherents' perspectives, religious prescriptions really do come from "nowhere"-at least, from no 
temporal, physical location. Furthermore, people often follow religious behavioral prescriptions not simply because that behavior is socialized, but also out of love for (or awe of) a godlike or other charismatic figure, or because of the incentives or punishments that originate from that same "nowhere."

In the ways just described, religion exerts a broader influence on conflict than simply as a clash of cultures with mutually exclusive universal aspirations. Religion, like any other ideology, affects the preferences of states in conflicts overall, without necessarily being the root cause of any specific conflict. This is not to say that regime elites' religiously-inspired value sets will always override material incentives, pressures, and constraints (which admittedly are very strong). There is empirical support, however, for the proposition that not all states seek material power to the exclusion of all else. The Caribbean micro-states have not been swallowed up by larger states, and some humanitarian interventions have been undertaken by states that had no genuine material interest in doing so. State behavior is not always strictly egoist, not even in security matters; some ideology is mixed into the internal deliberations of states as to whether to use force or not (see Haas 2005). Such ideology includes religious principles.

Those religious principles, transmitted through the media of scripture, (writings of) the priesthood, and historical tradition, influence three types of actors, which correspond to the independent variables constructed for this study (see Chapter 3). The first type of actor is the individual "chief executive" of the state. The place of religion in first-image theories of international outcomes will be taken up in the section that follows. The second type of actor is the governing regime of the state, treated as an institution. Governments consist of people, and most people follow one particular religion or another. Over time, 
the religious inclinations of the executives, lawmakers, judges, and bureaucrats are manifested in preferences toward one or more particular religious categories, at an institutional, corporate level. There may be a constitutional establishment of religion; the government may fund or provide religious education in the public schools; government officials may be particularly amenable to advice or influence of officials from one religious denomination but not others; the preferred religion may have privileges that others do not; the government may have low tolerance for the practice (not including political activity) of religious other than the preferred one(s). As an institution, a government with a preference toward a particular religion is more likely to carry out its foreign relations in accordance with the prescriptions of that religion, and governments with preferences for religions that have different war ethics are likely to resort to military force under different circumstances, therefore at different rates.

The third type of actor is the state's population, or to be more precise, its citizenry. Again, states and their governments consist of people, and most people have a particular religious identity. ${ }^{20}$ The same religious principles that influence the actions and decisions of professionals, laborers, scholars, and everyone else in a particular culture also influence the actions and decisions of the governments that are made up of people of that culture. ${ }^{21}$ For example, a state that is $95 \%$ Catholic is highly likely to have Catholic

\footnotetext{
${ }^{20}$ In this study, religious identity is separated from religiosity, which is a measurement how strongly or devoutly people adhere to a particular religion. These are different variables. It is hoped that eventually, the World Values Survey Association (2009) will acquire enough data on enough states to enable the construction of a measurement for religiosity. However, there is insufficient data to do so at the time of this writing. ${ }^{21}$ The "Cultural Theory" of politics posits that many large-scale political preferences can be predicted according to a fourfold typology of cultures. That typology is defined the strength of group boundaries
} 
lawmakers, Catholic civil and military officials, and a Catholic head of state/government. Therefore it is highly likely that Catholic principles will influence the statecraft of that state, including decisions to make war or peace. Another way that the religion of a culture influences the preferences of the state is through public opinion, which Jessica Weeks (2008) has argued can influence the decisions of all states, not just democracies. ${ }^{22}$ By informing the principles of right behavior (and right statecraft) that are held by the public, religion may influence public preferences for certain decisions of their political elites. For example, Michael Koplow (2011) argues that U.S. governmental support for Israel is the result of American public support, which itself is generated by ideological affinities for Israel, especially among conservative Christians. Joseph Daniels (2005) observes an empirical relationship between a person's religious affiliation and his or her international policy preferences. Mira Sucharov (2011) makes the case that Diaspora Jews are more likely to invoke specifically Jewish values when critiquing Israeli policy.

Finally, although this study explores the direct effect of religion on states' decisions to use military force, it should be acknowledged that religion may influence such decisions

(weak and strong) and the number and variety of prescriptions (numerous/varied and few/similar). Individual decisions are simultaneously choices of culture, and those decisions are all rooted in the choice to support or oppose certain institutions (Wildavsky 1987). The four ways of life enumerated in Cultural Theory specify four different ways of making decisions, constituting authority, and exercising political power (Swedlow 2011: 705). It is not the purpose of this work to classify religions into Cultural Theory's fourfold typology, assuming that such an undertaking is even possible. Rather, the focus on religious prescriptions will be considerably narrower.

${ }^{22}$ Weeks focuses on the generation and effects of audience costs on autocratic leaders, finding that they have the same effect as those on democratic leaders. 
through other, intervening variables as well. Greg Cashman (1993: chap. 5) has surveyed the various characteristics of states that may contribute to their conflict-proneness. Of those that he lists, regime type and economic system could potentially be influenced by the religion of the state. Religion tends to legitimize certain sources of political authority and de-legitimize others; if democracy were correlated with particular religious categories (a supposition beyond the scope of this study and therefore not tested here), then it is possible that religion is a partial explanatory variable for the democratic peace.

\section{First Image: The Role of Religion in Political Psychology}

In this section we briefly survey the potential of religion to enrich theories of political psychology. Every state's central government has one individual (and very occasionally, more than one) who acts as the final authority to decide whether the state will undertake a military operation, particularly an operation that results in violating the territorial integrity and political independence of another state in ways so fundamental as to invite retaliation—-thus initiating an armed conflict. Despite Barry Rubin's (1994) claim that national elites are often more cosmopolitan and cynical, and better educated, than the masses, and thus less susceptible to the direct influence of religious ideas, I contend the states' national elites, including their chief executives, are influenced by religiously based beliefs of fact, causation, and rectitude the same way that the rest of a state's population is. ${ }^{23}$ If it is true, for example, that Christian prescriptions regarding the use of

\footnotetext{
${ }^{23}$ Christopher Eberle (2006) makes a normative argument: that the most common arguments in favor of the doctrine of restraint—-the claim that political leaders should restrain themselves from making political decisions solely on religious grounds—are not persuasive.
} 
military force are different from those of Islam (and I will show in Chapters 5 and 6 that it is true), then states with chief executives of different religions should initiate armed conflicts at different rates. ${ }^{24}$

Kenneth Waltz's (1959) treatment of the first image in international relations is situated within pathologies of human behavior. Security studies is incomplete without the psychological element, which is useful not just for understanding and applying concepts such as misperception and Social Identity Theory, but also the deeper dimensions of ideas, beliefs, perceptions, and identities (Goldgeier 1997).

One aspect of these ideas, beliefs, and perceptions is that human beings have different priorities of psychological needs, and when one category of needs is satisfied, human nature is to crave the next higher category (Maslow 1943). These needs are, in order of priority: physical/biological, safety, affection or belonging (e.g. love), self-esteem, and self-actualization. The relationship between self-esteem and politics is that people with higher self-esteem are more trusting, therefore more opposed to using force, but are also more risk-acceptant because they have greater confidence in their abilities (see Cashman 1993: 39). David Winter and Abagail Stewart (1977) write of a different relationship between psychological needs and propensity to go to war: a leader with a greater need for affiliation or achievement is more cooperative and less inclined to resort to force, whereas a leader with a greater need for power is more inclined. Religion may influence

\footnotetext{
${ }^{24}$ Cf. Lai 2006, finding that religious differences between states' leaders increase the likelihood of militarized disputes between their respective states; this piece is one of the seemingly very few quantitative measurements of the religious identity of state leaders in the IR literature. My dependent variable, however, is different: the likelihood of a state initiating an armed conflict, regardless of the religion of the other state.
} 
leaders' propensities to resort to force by defining their needs, i.e. instilling meaning into the psychological needs of love and affiliation, enhancing or detracting from self-esteem, and defining the parameters of self-actualization.

Religion may also insert itself into the mechanics of cognitive dissonance. When new information about a situation does not fit within a leader's own image of realty, the leader processes that new information in a variety of ways designed to suppress it, including ignoring it, discrediting the source, or distorting it so that it fits within the leader's preconceptions (Holsti 1967). It is possible to change the leader's image of reality, but only by presenting information that is new and unambiguous in large quantities, or alternatively from sources with the same backgrounds and concerns as the receiver (Jervis 1968). Religion shapes the leader's image of reality, including beliefs of fact and causation, and someone with a religious background similar to the leader's may be able to convey new information more effectively than otherwise. Religion may also influence the practice of "perceptual satisficing," in which a leader, having recognized the need to reformulate an image of reality, adopts the first formulation that minimally fits (Lebow 1981: 105). Religion shapes the leader's perception of reality, and it shapes the nature of that minimal requirement that the new information must satisfy in order to fit within the leader's perception of reality.

Much has been written on misperceptions, which are caused by cognitive and motivational biases. Cognitive bias is caused by the human psychological need for information to comport with one's image of reality (discussed above); motivational bias is caused by the human need to construct and maintain a positive image of oneself and the environment. For example, prior to the outbreak of World War I, the German Kaiser 
wanted to diffuse the July Crisis so badly that he failed to recognize the plain warning signs that Germany likely would be defeated in war (Lebow 1981: chap. 5). This is the phenomenon of defensive avoidance, in which the leader tries to avoid fear-arousing warnings in situations in which his current policy entails serious risks but no better alternative is known (Janis \& Mann 1977). In security matters, misperceptions may lead to war because the leader over- or under-estimates the capabilities, but more importantly, the intentions of other actors (Levy 1983b). An over-estimation of capabilities or of aggressive intentions sets into motion the pathology of the security dilemma (Jervis 1978). When a leader sitting on the brink of war believes that his adversary will strike him, war is more likely_and most likely when the leaders on each side harbor the same belief about the other (Stoessinger 2010). Religion may introduce cognitive bias by assigning different meanings to words and actions, causing leaders to misperceive each others' intentions. It may also contribute to motivational bias by setting priorities and goals, and by defining the limits of acceptable adverse consequences (e.g. losses). Speaking of losses, prospect theory theorizes that leaders will be more risk-acceptant to avoid losses and more risk-averse in seeking gains, for a loss hurts psychologically more than a gain pleases (Kahneman \& Tversky 1979; see also McDermott 2004). Again, religion may impact prospect theory by setting the priorities of loss or gain, e.g. a "loss" of something may be more painful in one religion than another.

These various motives of human behavior-cognitions, perceptions, satisfaction of gain, pain of loss-all are products of the under-theorized effects of emotion in international relations (Mercer 2006; see also Ross 2006: 197-204). In a challenge to the conventional supposition that actors are rational, Neta Crawford (2000) presents emotion 
as an under-studied factor in the practices of diplomacy and negotiation, the eruption of war, the failure of peacebuilding, and the fear that drives the security dilemma (see also Bleiker \& Hutchison 2008: 116). In the wake of the 9/11 attacks, several works have examined the effect of trauma in generating political outcomes (Edkins 2003; Ross 2006: 212-4; Hutchison 2010). Others have explored the effect of emotion in formulating identity and interests (Bleiker \& Hutchison 2008; Hutchison 2010) and the related outcome of group reactions, perceptions, and behavior (Sasley 2011). As Roland Bleiker and Emma Hutchison (2008: 123) put it, "Emotions help us make sense of ourselves, and situate us in relation to others and the world that surrounds us. They frame forms of personal and social understanding, and are thus inclinations that lead individuals to locate their identity within a wider collective." This body of literature also explores the effects of emotions on perceptions, cognitions, and rationality (Bleiker \& Hutchison 2008; McDermott 2011), with Jonathan Mercer $(2006,2010)$ taking the extraordinary position that rationality itself is dependent on emotion, ${ }^{25}$ and that cognition and emotion are indistinguishable in the human brain. Emotions drive prospect theory, and they contribute to the "feeling" of identity, the formation of norms, and the fostering of trust (Mercer 2006: 296-9).

Different emotions wield different effects on political decisions. Rose McDermott (2011) surveys the effects of anger on the decisions of U.S. presidents (and by extension, the leaders of all states):

\footnotetext{
${ }^{25}$ Citing medical evidence presented by Antonio Damasio (1994), Mercer (2006: 294) argues that the lack of emotion causes people to be irrational; without it, they lose the ability to make effective choices, engaging in endless cost-benefit analyses in even trivial decisions.
} 
[W]hen individuals feel that some standard of purity has been violated, they are more likely to feel disgust, just as when they feel some standard of justice has been violated, they are more likely to feel anger. . . . When someone has been treated unjustly, anger can motivate observers or victims to try to right that wrong (2011: 8).

She argues that anger influences constructions of morality and induces misperceptions of capability (Mercer [2006, 2010] makes a related claim). Paul Saurette (2006) and Khaled Fattah and K.M. Fierke (2009) explore the effect of the related emotion of humiliation; Saurette on U.S. foreign policy, and Fattah and Fierke on the framework for meanings in international interactions in the Middle East and the subsequent emergence of Islam as a basis for identity. ${ }^{26}$ Such negative emotions influence specifically the onset of armed conflict by fostering desires for revenge, which itself may be emotionally satisfying (Löwenheim \& Heimann 2008). Religious principles may influence the onset of anger or humiliation, by informing those very standards of behavior or honor, the violation of which is likely to induce such emotions, and by prescribing certain remediations. ${ }^{27}$ Furthermore, by setting standards of empathy and charity (i.e. toward whom and for what), religious principles may also influence the amount of trauma that is felt by populations and governments when people are victimized. Religion may have similar

\footnotetext{
${ }^{26}$ Fattah and Fierke take the position that the humiliation of the Islamic world, especially after 1967 , is a major factor in the resurgence of Islam in an area that had become secularized. As mentioned in Chapter 1, however, others take the position that religion was never dormant in the first place.

${ }^{27}$ For an illustration of all three of these emotional aspects, see Löwenheim \& Heimann 2008.
} 
influences on other emotions that influence elites' political decisions, such as pride (Hymans 2006), shame (Mercer 2006: 298), awe, empathy, or joy.

Finally, it should be noted that, in the United States at least, political leaders have acknowledged that religion guides their politics consciously, not just unconsciously. The New York Times recently hosted a debate on the nature and content of a Christian Presidential platform; what is noteworthy is that the debate begins with the unproblematized assertion that politicians openly acknowledge that religion guides them (Novak et al. 2011).

To conclude this section: The arsenal of theories predicting the onset of armed conflict between states is vast indeed, and religion is an overlooked and under-theorized element in many of them, in all three Waltzian images of international relations. But in addition to religion, the field tends to neglect one other factor in armed conflict onset, one that plays an especially important role in both the decisions of states to undertake military force and those of the international community in responding to it. That factor is the norms and prescriptions of international law, which will be taken up in the next section.

\section{$\underline{\text { Religion in International Legal Theories Pertaining to Armed Conflict }}$}

So far, this chapter has addressed the relationship of religion to the incentives, pressures, constraints, and human frailties that induce states to use military force in spite of the normative restrictions that contemporary jus ad bellum has placed on them. The previous section catalogued factors that are believed to override what this work assumes to be states' preferences to comply with jus ad bellum along with the rest of international law. Because the dependent variable of this work is not only the initiation of interstate 
armed conflict, but also the violation of today's jus ad bellum, this section will take up the relationship of religion to international law and jus ad bellum directly.

\section{Theory of International Law}

By identifying the type of relationship, or "culture," within any dyad, one should be able to predict roughly the content of the rule regulating the preferences of those two states, and the circumstances under which either state will comply with or violate that rule. The essential claim in my theory of international law is that the content of international law, and the degree of compliance with it, both depend on whether states are enemies, rivals, or friends. The international law field does not address what causes states to be enemies, rivals, or friends; that question lies in the domains of other disciplines. International relations theory is one such discipline — and so is religion.

Let us conceptualize the international system as the totality of the relationships of all the dyads in the system, in all issue areas. Within each dyad-issue, the nature of the relationship influences the expectation of behavior between the states, as well as the expectations of the consequences of deviating from the expected behavior. The set of expectations over all dyads and all issue areas constitutes international law. In this way, the norms and rules of international law regulate the interactions between states. For each issue area, the rule that emerges at the systemic level reflects the totality of the rules within all the dyads. But within each dyad, the expectation of behavior may be different (because different dyads have different types of relationship), and compliance with the systemic rule will vary according to that relationship. Religion may contribute to the formation of these expectations in several ways. First, religious scripture or influential 
priestly writings may prescribe certain political institutions or behavior directly. Second, scripture and the priesthood may instill in the lawmakers certain meanings, values, and behavioral norms that manifest themselves in the content of the laws and the degree of punishment for infractions—and the scripture and priesthood of different religions will instill different values and norms.

Much (though not all) of the contemporary theoretical literature on international law is aligned with the three major paradigms of IR theory. In realism, rules are imposed from above and states comply with them only because they are coerced into doing so. In institutionalism, states negotiate rules among themselves and comply with them for as long as their self-interests dictate. In constructivism, rules emerge from repetitive behavior and states comply out of a sense of duty or logic of appropriateness. Each paradigm presents a unique conception of the process of rule formation and compliance in international law. I submit that all three of these approaches are necessary and sufficient to explain the same.

The relationship of the three approaches is evident in Alexander Wendt's model for classifying the three basic types or "cultures" of anarchy in Social Theory of International Politics (1999: chap. 6). The three cultures, which he labels Hobbesian, Lockean, and Kantian, ${ }^{28}$ correspond to three degrees to which a state identifies other states with itself, and are roughly analogous to enmity, rivalry, and friendship. Religion has a role in defining the identities of enemies, rivals, or friends, and/or the actions that other states must undertake in order to be designated the same. Religion also has a role in

\footnotetext{
${ }^{28}$ Wendt gives the cultures those labels with the understanding that they oversimplify somewhat the political theories of Hobbes, Locke, and Kant, respectively. However, as general labels they are reasonably well descriptive and I shall adopt them.
} 
prescribing how those enemies, rivals, and friends, respectively, are to be treated, e.g. whether their rights to fair dealing, or even to existence, are to be respected.

In the Hobbesian culture, states exist in enmity: each state assumes that the others do not recognize its right to exist autonomously. This is the culture of state systems prior to the Westphalian state system and the rise of international law, and it still characterizes the current relationship between Israel and several Arab states. In this culture, each state perceives the others as hostile, i.e. unwilling to limit their violence toward it, and it reciprocates that hostility. This culture is the quintessentially self-help, dog-eat-dog system that Hobbes (1985: chap. xiii) envisions as the state of nature of man. It is typically characterized as an environment in which the acquisition of material power is the highest priority of any state, or in which benefit to the Self is the paramount consideration above all others. Religion may permit or even prescribe such an ethic, but it is more likely that if a religious tradition does prescribes this level of hostility toward another, it does so because such hostility is to serve some higher purpose or higher good than coexisting with that enemy would serve.

In the Lockean culture, states exist in rivalry: each state assumes that others will act as if they recognize its sovereignty, but that does not include any right to be totally free from violence, i.e. states have a right to exist but little else. This culture best characterizes the Westphalian state system; indeed, Wendt (1999: 279-85) asserts that of the three cultures, the Lockean one best models the majority of the international system today. States often find themselves in disputes with other states over scarce resources and notwithstanding the general prohibition of force in the UN Charter and in customary international law, the system places no significant constraints on the use of force to resolve 
those disputes, save one: states continue to respect the existence of other states and the system will usually (though not always) act to prevent a state from "dying" at the hands of another. As with enemies, religion has a role in defining rivals as well as setting the boundaries of their treatment.

In the Kantian culture, states exist in friendship: each state identifies the others with itself, i.e. they are a single group. Because no rational state would use military force to damage itself or willingly submit to such treatment from other states, the state refrains from using force against the others, even when disputes arise. Wendt (1999: 297) argues that the collective membership of NATO has progressed into this phase. Material power no longer matters to the outcome of those disputes, as it does in the Hobbesian or Lockean cultures, because the stronger states and even the hegemon would view attacking the weaker states no differently than being attacked themselves. Religion also has a role in defining the identities and/or actions of friends.

The division of dyads into relationships of enmity, rivalry, and friendship is not the end of the story, however. In addition to the three cultures, Wendt proposes three levels of cultural internalization, i.e. the degree to which actors comply with the rules, norms, and expectations of behavior within their society. Whereas the culture itself is a major determinant of the formation and content of international law, the levels of internalization is the primary determinant for explaining compliance, especially when doing so runs counter to the state's short-term interest. Put another way, this model can explain why states do not always succumb to the temptation to violate every agreement in which doing so promises material gains at the expense of other states. In the first level of internalization, states obey rules only when they are forced to do so. In the second level, states obey 
rules because they find it to be in their self-interest to do so. In the third level, states obey rules even when it is against their interest, out of a sense of "rightness." Unlike Wendt, who claims that all combinations of cultures of anarchy and degrees of rule internalization exist (1999: 254), I theorize that the degree of rule internalization is itself dependent on the culture of anarchy; in human nature, enmity breeds coercion, rivalry self-interested cooperation, and friendship altruistic cooperation. Thus the Hobbesian culture is associated with the first degree of rule internalization, the Lockean culture with the second, and the Kantian with the third.

This typology is relevant to the use of force in two ways. First, compliance with rules that regulate the resort to force depends on the culture of anarchy that defines the relationship between the states, just as compliance with any other rules of statecraft depends on the same. Second, there is an inherent "live and let live" rule associated with any society (see Bull 1977), not necessarily stated overtly, and the bond between members of the society gets stronger as the relationship grows friendlier. Enemy states are most likely to use force against each other, for neither respects the rights or even the existence of the other (at least, in the absence of religion). Rivals are somewhat less likely to use force; they will not seek the destruction of the other, but they will use force in order to acquire or maintain their relative power over the other (or from another perspective, to weaken the other). Friendly states will seldom use force against each other, for each state is much closer to identifying the other with itself. The relationship of religion to this theory, as already stated is mainly in religion's influence in the identification and treatment of enemies, rivals, and friends. 
Rights, Remedies, and the Use of Force

Having proposed that states form and comply with rules of international law in accordance with the nature of their anarchical relationships with other states, including rules of jus ad bellum, it now remains to present a theory for why states violate the highly restrictive form of jus ad bellum that is firmly entrenched in international law today. As Thomas Franck (1970: 810) once lamented, states "violate[] it, ignore[] it, run roughshod over it, and explain[] it away." This is a puzzle in international law, especially in the institutionalist paradigm, for an absolute prohibition of the use of force would seem to have vast benefits in both the short term and the long.

The reason that states violate jus ad bellum, especially its present-day highly restrictive form, is twofold. First, states resort to force because they believe that the benefits of doing so outweigh the benefits of complying with the rule. This formulation is a further indicator that the overall culture in the state system today is one of rivalry (Wendt 1999: 279-85), which is associated with the second level of rule internalization. The second reason is that a state may occasionally find the content of jus ad bellum morally deficient as guidance in the crisis before it, and on that occasion choose to set aside international law in favor of what it believes to be a higher morality, or in the present context, a higher form of jus ad bellum. Contrary to the wording of the UN Charter, the conduct of states has repeatedly shown that when the stakes are high enough, they in fact prefer justice over peace, not the reverse. This practice has presented itself in a variety of forms: anticipatory and preemptive self-defense, intervention to evacuate a state's nationals or rescue hostages, interventions in support of democracy, and especially humanitarian intervention. Sometimes there is a contradiction between the conventional legal norm 
proscribing the use of force and the values, including religious values, that prompt states to violate that norm.

There is precedent in international law for the proposition that when a state inflicts an injury on another state, the latter has the right to a remedy and the former has the obligation to furnish it. Legal scholars from Grotius and Vattel to Oppenheim and the $\mathrm{ICJ}^{29}$ have all shown that the consequence of the injured state's legal right, in customary international law, is to confer on it the option not merely to demand a remedy, but to take it (Grotius 1925: bk. ii, chap. xvii, sec. 1 \& bk. iii, chap. ii, secs. 3-4; Vattel 1995: bk. ii, chap. v, secs. 63-70; Oppenheim 1912: vol. 1, secs. 148-51). Without such a prerogative, the right to remedy is meaningless.

Many legal scholars would probably take issue with my likening jus ad bellum to tort law, arguing that a right to self-help in remediating an injury has been explicitly extinguished in contemporary international law, specifically in the UN Charter and Definition of Aggression, which make no exception for doctrines such as humanitarian intervention, and the Articles on State Responsibility. ${ }^{30}$ A full-fledged defense of my tort-based theory of jus ad bellum is beyond the scope of this work, but I ask the reader to indulge a brief digression. First, the prohibition of the use of force in Article 2(4) of the UN Charter is a piece of positive international law placed within the constitution of an international organization. It was assumed at the UN's founding that the Security Council would be

\footnotetext{
${ }^{29}$ The Gabcikovo-Nagymaros Project (Hung. v. Slovk.), paras. 83-87, 1997 ICJ 7 (Sep. 25).

${ }^{30}$ Draft Articles on State Responsibility for Internationally Wrongful Acts, art. 49, in Report of the International Law Commission on the Work of Its Fifty-Third Session, GAOR, $56^{\text {th }}$ Sess., Supp. No. 10, chap. IV, sec. E.1, U.N. Doc. A/56/10 (2001) [hereinafter Articles on State Responsibility].
} 
effective in fulfilling its function to maintain international peace and security, but such has frequently not been the case. Sometimes the use of force in violation of the Charter may be viewed as Lockean-style reclaiming of that state's sovereign prerogative to use force, in the wake of the central institution not having lived up to its obligations. In addition, although the prohibition of force has entered the body of customary international law, customary international law itself is not static. The practice of states, undertaken with a sense of legal obligation, can and does evolve, and several international legal scholars have argued that a post-Charter legal right of humanitarian intervention has emerged (Murphy 1996; Tesón 2005: esp. chap. 8; see also Franck 2002: chaps. 9-10; Brown 2004: 7-12); such a right supersedes the strict confines of the UN Charter. ${ }^{31}$ For the reasons just set forth, the content of the UN Charter does not debunk my theory.

The other basis for my antagonist's argument, the Articles on State Responsibility, is also unpersuasive. The Articles do acknowledge an injured state's right of self-help, to employ peaceful means of inducing a delinquent state to cease the delinquent act and make reparation (the law of counter-measures; article 49). The Articles do, on their face, prohibit the use of force as a counter-measure (art. 50(a)). But they do not take into consideration an injury that involves the use of force, or otherwise threatens international peace and security. Some obligations of states to other states are so vital to the mainten-

\footnotetext{
${ }^{31}$ Tesón overstates this claim, in my opinion, when he asserts that the U.S. invasion of Grenada was a legitimate humanitarian intervention. I would classify Grenada as a "pro-democratic" intervention, not "humanitarian," because no gross, large-scale violation of human rights appeared to have been in progress or imminent. For reasons beyond the scope of this work, I contend that the legality of pro-democratic intervention, in contemporary jus ad bellum, is doubtful.
} 
ance of peace and security, and the breach of such obligations so gravely injurious, that the appropriate remedy can only be achieved by the use of force. When an injury is severe enough to justify it, the use of force is simply a counter-measure.

Most religions have theories of justice, and when a theory of justice is applied to the use of force, the resulting principle is as follows: a state may resort to force when force is a necessary and proportionate remedy to an injury committed by another state in breach of its obligations. ${ }^{32}$ The relevance of religion to this theory is that obligations in treatybased international law evolve from obligations in customary international law, which in turn develop first as obligations in natural law. Norms and principles in natural law develop from the cultural ethos of the society that they govern, and that cultural ethos is strongly influenced by religion-hence the intuitively correct logic of Samuel Huntington's $(1993,1996)$ demarcation of major world civilizations largely along religious lines. Religion also influences the range of appropriate responses to breaches of those obligations.

\section{Conclusion: How Religion Influences Armed Conflict Onset}

How, then, does religion impact the decisions of states to use force against other states? Daniel Philpott (2007: 518) suggests two ways: (1) it shapes the identities and loyalties of warring communities, and (2) it defines the political goals of those communi-

\footnotetext{
${ }^{32}$ This tort-based approach to jus ad bellum can be applied to self-defense, anticipatory and preemptive self-defense, defense against terrorism, intervention to protect nationals, interventions in civil conflicts, humanitarian intervention, intervention to support certain forms of government, intervention to depose a criminal regime, use of force for self-determination, and belligerent reprisals.
} 
ties. Philpott is intuitively correct, and the purpose of this chapter has been to flesh out the identities and goals germane to armed conflict that are influenced by religion. The purpose of this section will be to summarize the chapter and tie up a few loose ends.

One way that religion influences conflict is that as a set of ideas, it gives meaning to other, more traditional political factors such as power and security. Just as one may ask what makes gold and platinum more valuable, ounce for ounce, than iron and aluminum, one may also ask what precisely makes a state more "powerful" relative to others, and why states would want more of it. The obvious answer (greater power confers greater security) leads us in turn to problematize the concept of security. Religion has the potential to undermine the traditional concept of security as freedom from material wants or constraints, in favor of a less tangible kind of security, e.g. assurance of a pleasant afterlife. The promise of heavenly rewards is a tool that secular ideologies cannot wield. But this is a problematique better suited for a study in political theory or theology.

A more concrete impact of religion on conflict is its ability to define enemies, rivals, and friends, and prescribe the proper treatment of them. A religion with a strong delimitation of Self and Other may be more likely to define the Other as the enemy. Examples include the divine direction to the ancient Israelites that the Canaanites and Amalekites were enemies to be eradicated without question or hesitation (Numbers 33:50-3; Deuteronomy 25:17), and the early Muslim distinction of the dar al-islam (house of peace/Islam) from the dar al-harb (house of war). ${ }^{33}$ On the other hand, a religion need not necessarily prescribe perpetual hostility toward an enemy; illustrations of prescriptions of equitable and even charitable treatment of enemies may be found in the ancient

\footnotetext{
${ }^{33}$ The literature on Islam contains many accounts of this distinction. See, for example, Kelsay 2007: 99.
} 
Greek distinction between themselves and non-Greeks ("barbarians"; Bederman 2001: 36-8) and the Christian admonition to love one's enemies (Matthew 5:43-44). As to the identification of friends, different religions may harbor different sentiments, depending on the degree to which the Self is distinguished from the Other. However, even if a religion clearly demarcates enemies and friends, it does not necessarily follow that they are to be treated differently; a religion may prescribe specific sanctions against nonadherents, such as the Islamic poll tax assessed against non-Muslims, or it may mandate equitable treatment of all. The identification and proper treatment of rivals may also vary among religions.

Religious war ethics may also be examined through the lens of tort theory. In a tortbased approach to the resort to force, the legitimacy of using force may be evaluated as a remediation of an injury that has been caused by another state's breach of its obligations. Religions may define those obligations, what constitutes a breach of them, and even what is and is not an injury, i.e. what is a "just cause" for war. Religions may also prescribe the form and amount of remediation to be exacted; this is the function of rules of proportionality such as the ancient Jewish lex talionis (an eye for an eye, a tooth for a tooth). ${ }^{34}$

Finally, religion may stoke or snuff conflict by legitimizing or de-legitimizing egoistic or aggrandizing behavior-behavior that the New Haven School would characterize as value-extension vice value-conservation. A religion that venerates domination through strength is more likely to permit (or even mandate) force when the configuration of power makes doing so expedient. An example of such behavior being legitimized is the

\footnotetext{
${ }^{34}$ The lex talionis was actually considered an advancement in its time, as it required the punishment be commensurate to the offense, not excessive (Brown 2008: 27).
} 
Arthasastra of Kautilya, an ancient Hindu treatise on statecraft. Kautilya was very much a proponent of the stronger wielding their power to subordinate the weak (Ramaswamy 2007: 109).${ }^{35}$ On the other hand, a religion that de-legitimizes aggrandizement by eschewing material power in favor of a more transcendental type of power is more likely to prescribe restraint or even pacifist non-resistance. An illustration of such restraint may be found in Christian scripture, in which Jesus turns down opportunities for political power (John 6:15).

These are several ways in which religious teachings and scripture may affect a state's propensity to use military force, or put another way, to substitute an alternative jus ad bellum for the jus ad bellum of secular international law. In each instance, religion wields its influence as a state-level characteristic in the first and second images of international relations. The central hypotheses generated by the theories above are that (1) religion affects the propensities of states to initiate armed conflicts against other states, and (2) different religions have different effects on those propensities. Religions exert their influence through their scriptures, priesthoods, and historical traditions, and wield that influence on three types of actors: individual decision-makers at the highest echelons of statecraft, governing regimes of states including their executive, legislative, and judicial branches, and through the behavioral norms instilled in the cultures of which states' populations are members. The next two chapters will present a model for testing these hypotheses and the overall results of those tests.

\footnotetext{
${ }^{35}$ Along with the rights of the strong to dominate the weak, however, also came duties to treat them well (Viswanatha 1925; Nawaz 1957). On the ancient Hindu cultural rooting of the principle of the strong dominating the weak, see Modelski 1964.
} 


\section{CHAPTER 3}

\section{RESEARCH DESIGN}

This chapter presents the research design used in this study to measure the effect of religion on a state's propensity to use military force in violation of jus ad bellum (which after 1945 , is nearly the same as simply the propensity to use military force). The time period of the study will be explained, as well as the unit of observation. The dependent variable, which is the initiation of an interstate armed conflict, will be constructed. The independent variable, the religion "of" the state, will be operationalized in three ways: the religious identity of the chief executive of the central government of the state, the institutional preference of the state's governing regime for a particular religion (or religions), and the religious demographics of the population of the state. Finally, this chapter will introduce a series of control variables and present a rationale for the selection of some over others in the standard models that will be used in the rest of this work.

\section{Scope: Time Period and Unit of Observation}

\section{Time Period of Study}

This study examines the practice of states from January 1, 1946 through December 31, 2001. The rationale for limiting the study to this range will now be explained.

The purpose of the research design presented here, strictly speaking, is to measure the effect of certain state-level characteristics on states' compliance with jus ad bellum. Because jus ad bellum is more easily observable in its breach than in its compliance, it is 
appropriate to measure instead the propensity of a state to commit an act that violates jus ad bellum. The clearest indicator of a violation of jus ad bellum is an act that directly contravenes the plain meaning of the text of the international law that regulates states' decisions to resort to military force, at a time when that international law is particularly restrictive. In the last 500 years, jus ad bellum has fluctuated between varying degrees of restrictiveness and permissiveness; its most restrictive epoch is in the present (see Nussbaum 1954; Grewe 2000; Neff 2005). Today's highly restrictive jus ad bellum is embodied in the article 2(4) of the UN Charter, which states: "All Members shall refrain in their international relations from the threat or use of force against the territorial integrity or political independence of any state, or in any other manner inconsistent with the Purposes of the United Nations." A use of military force under this legal regime is presumed unlawful and thus illegitimate, with only three exceptions: self-defense (article 51), Security Council authorization (article 42), and regional action (article 52, but which also requires Security Council authorization). ${ }^{1}$ Notwithstanding the present-day debates between restrictionist and counter-restrictionist interpretations of the Charter (Arend \& Beck 1993), or whether exceptions should be made for anticipatory self-defense and/or humanitarian intervention (Brown 2011), the plain text of the UN Charter (along with the UN Definition of Aggression of 1974) provide the clearest indicators today of what it means to commit an act of aggression, thereby precipitating an armed conflict in violation

\footnotetext{
${ }^{1}$ A first use of force (without authorization) cannot be "self-defense," because the inherent right of selfdefense presupposes the occurrence of an armed attack. Article 2 of the Definition of Aggression, G.A. Res. 3314, further creates a presumption that the first use of force constitutes "aggression." Thus we need not be concerned whether the first use of force can be in self-defense, because by definition it cannot be.
} 
of jus ad bellum. In essence, we wish to specify "who started the fight," and a restrictive interpretation of the Charter is the best bright-line rule for doing so. Since the Charter entered into force on October 24, 1945, and since the convention of observing dyad-years is well established in the field, January 1, 1946 is chosen as the most appropriate starting date, in order to avoid partial-year observations. The study ends on December 31, 2001, because the most comprehensive data set for the dependent variable (the Militarized Interstate Disputes dataset) ends in that year.

In addition to the above (primary) rationale for the time period selected for this study, there are several secondary reasons and advantages as well. One is that several other data sources, and especially those on states' religious characteristics, are less precise the further back in time they go (and for some variables, data before 1945 is simply not available). Another rationale (and advantage) is that states are considerably more diverse after 1945 than before. Bruce Russett (1993: 73) makes this claim for control variables such as regime type, wealth, and power differential, i.e. that states are more diverse in these characteristics after 1945, and I make this claim for the religious characteristics of states as well. The modern state system had few non-Christian states before the end of World War I; by 1980, in contrast, when de-colonialism was largely completed, states were far more diverse in their religious characteristics.

Finally, in my view, limiting this study to the current epoch of jus ad bellum is the best approach for generating findings in the here and now. Although studies that go far back in history can yield valuable information and insights (e.g. Levy 1983a; Holsti 1991; Reus-Smit 1999; Levy \& Thompson 2005; Owen 2010), I still maintain that the most immediately valuable studies of political behavior are those that tell us how states 
are behaving in the present and predict how they will behave in the near future. Many empirical studies of the causes of war and/or the democratic peace employ the entire Correlates of War dataset, which begins in 1816, and one disadvantage of doing so is the failure to control for the legal regime. From 1816 to 1918, for example, states were generally more prone to armed conflicts (if not full-scale wars) than they are today simply because the resort to force was regarded as lying outside the domain of international law_there were no legal norms against doing so (Wheaton 1936: sec. 295; Hall 1890: sec. 1.3.16; Westlake 1907: 3; Oppenheim 1912: vol. 2, sec. 54). ${ }^{2}$ The best possible measurement of states' propensities to use force in the present and near future is to measure their propensities not in the 1800 s, but in the recent past, in a similar environment and under the same legal regime (see King Keohane \& Verba 1994: 43). ${ }^{3}$ Such a measurement is not possible in the time period before the current legal regime came into effect.

Finally, it should be noted that although my rationale for limiting this study to after 1945 is different from the other works about to be cited, doing so does not put it out of place with other measurements of the frequency of using force, such as those by Erich Weede (1984), Zeev Maoz and Bruce Russett (1993), John Oneal \& James Lee Ray

\footnotetext{
${ }^{2}$ Bonfils (1914: sec. 1002), Lawrence (1915: sec. 3.1.135), and Davis (1916: 272) also rejected the role of international law in determining whether or not a war was right, with Lawrence specifically repudiating just war as a legal requirement. Several other contemporaneous treatises even omitted the subject altogether (Walker 1895; Wilson \& Tucker 1901; Smith 1911).

${ }^{3}$ King Keohane \& Verba (1994: 43) advocate the study of systematic patterns in similar parallel events in order to arrive at scientific inferences of the particular event being examined.
} 
(1997), Jeffery Pickering and William Thompson (1998), Mark Souva \& Brandon Prins (2006), and Michael Mousseau (2009). ${ }^{4}$

\section{$\underline{\text { Unit of Observation }}$}

The trend in the field is to take annual measurements of the examined phenomena, and the phenomena being examined is the behavior of states. Therefore the identity of states must figure into the unit of observation, as opposed to individuals, interest groups, or other non-state actors. However, in many well-supported theories in the field a state's decision to use force or not is determined often by the characteristics of other states. A state, according to the logic of Realism, is more likely to militarize a dispute with a significantly weaker state than a significantly stronger one ("the strong do what they can and the weak suffer what they must”; Thucydides 1998: bk. v, sec. 89). A democratic state, according to the logic of the democratic peace, is far less likely, if ever, to militarize a dispute with another democratic state (Kant 1991; Doyle 1983); and so on. It is not enough, therefore, merely to examine the propensity to use force across monads; a rigorous study of the influence of monadic characteristics must, in this instance, take into account dyadic characteristics. The unit of observation must therefore be the dyad-year. Furthermore, because the outcome is armed conflict initiation rather than simply occurrence, and because some of the other influencing characteristics are directed in nature (e.g. the stronger versus the weaker, in contrast to the weaker versus the stronger),

\footnotetext{
${ }^{4}$ Weede (1984: 654) curiously begins his study in 1960, for fear that he would end up replicating his earlier results from the 1950s. I do not include R.J. Rummel (1983) in this list, for many of his empirical measurements only cover the period 1976-1980, which in my view is too short a time span for validity.
} 
I follow Reiter and Stam (2002: 48) in observing directed dyads (see also Quackenbush \& Rudy 2009: 281), therefore the unit of observation in this work is the directed dyadyear.

There are advantages and disadvantages to this approach. The advantage of a dyadyear dataset is that it does not select on the dependent variable (see King Keohane \& Verba 1994: 129-37), and therefore accounts for the possibility that some types of states may be more likely than others to be involved in militarized disputes in the first place (which in turn affects their propensity to initiate actual armed conflicts). One disadvantage is that the data set is very large and contains a rare event, though a test of the rareevent bias documented at the end of Chapter 4 will show that the rare-event bias is insignificant. A further disadvantage is that even a unit of observation as narrow as the dyad-year undercounts the armed conflicts; of 1729 directed dyad-years in which one state militarized a dispute, 72 contained more than one militarized dispute; i.e. the same state militarized more than one dispute against the same other state in the same year 72 times. As a result, about $4 \%$ of the militarized disputes go uncounted. I consider this disadvantage to be relatively minor. ${ }^{5}$

A somewhat more serious disadvantage of the dyad-year data set results from the convention of measuring only politically relevant dyads. The total number of dyad-years in the state system from 1946 to 2001 (when the data ends) exceeds 1.1 million, which is beyond the capacity of many computers (mine included) to manipulate and process. Because of this problem, and also to mitigate the rare-event bias, a convention has

\footnotetext{
${ }^{5}$ Souva and Prins (2006) claim, in their study, that no state initiated more than one MID with fatalities during the time period they examine (1950-1999).
} 
emerged to limit the observations to "politically relevant" dyads, consisting of all dyads that are contiguous (by land, or within a certain distance by sea) or contain any major power (Bremer 1992; Maoz \& Russett 1993). That convention reduces the dyad-year data set to about 116,000 observations, which is a more manageable size. However, it also masks out actual and potential armed conflicts between dyads that are neither contiguous nor contain a major power but are still at significant risk of armed conflict, such as noncontiguous intra-regional dyads, dyads of minor powers that are close allies with the opposing poles in a severely bipolarized system, or dyads involving a state and its former colony. For example, the risk of armed conflict between Colombia and Sri Lanka may be so insignificant as to warrant that dyad's omission, but the risk of armed conflict between Colombia and Nicaragua is not. Yet both dyads are treated as equally "irrelevant" and both are omitted from the dyad-year data set. This bias has real consequences for the completeness of a dyad-year data set. For example, the dyad of Belgium and the DRC is excluded and yet the two states have had three MIDs between 1960 and 1993. I call for the field to reevaluate the definition of "political relevance" of dyads; however, a detailed rationale and proposal for such an undertaking is beyond the scope of this study.

\section{Dependent Variables}

It is possible to construct a series of dependent variables that capture the initiation of an armed conflict by a state, in violation of jus ad bellum. A conservative interpretation of jus ad bellum is that a state violates it by meeting all three of the following conditions: 
(1) it uses force, (2) it is the first to use force (or it joins the conflict on the side of the first user of force), and (3) it does so without Security Council authorization. ${ }^{6}$

\section{$\underline{\text { Data Source }}$}

The candidates for a data source for the activity being measured consisted of two widely available datasets: the Militarized Interstate Dispute (MID) dataset of the Correlates of War Project (Ghosn Palmer \& Bremer 2004), ${ }^{7}$ and the International Crisis Behavior dataset (Brecher \& Wilkenfeld 2000). After weighing the totality of advantages and disadvantages of each, I found the MID dataset to be more suitable for this study. The ICB dataset identifies the first actor, state or non-state, to trigger the overall crisis, but it does not identify the first state to use force in a given crisis, thus rendering it unsuitable for coding the dependent variables needed here. In addition, the ICB dataset tends to disaggregate conflicts, e.g. the Korean War, in ways that require the data to be reconstructed-a cumbersome process. ${ }^{8}$ For these reasons, the dependent variables in this study are constructed using data from the MID dataset. The observations themselves were generated using EUGene software v.3.2 (Bennett \& Stam 2000). For each dyad-year, EUGene records the "Key MID" as the MID with the most severe militarized action (i.e. with the greatest Highest Activity level). I further have specified the coding of initiating-

\footnotetext{
${ }^{6}$ In the section on control variables, I will address the potential objection that jus ad bellum is biased against Muslim states because no Muslim state is a permanent member of the Security Council.

${ }^{7}$ The article of record for the MID Code Book is Jones Bremer \& Singer 1996.

${ }^{8}$ For an illustration of such a reconstruction, see Rousseau Gelpi Reiter \& Huth 1996.
} 
side joiners of conflicts as initiators and target-side joiners as targets (the dependent variable includes joiner dyads as well as the dyads of the original disputants).

\section{“Use" Force}

What does it mean for a state to "use" force? The UN General Assembly offered a conservative legal answer in 1974, when it passed the Definition of Aggression (UN General Assembly Res. 3314). In a nutshell, an attack, bombardment, blockade, or movement of troops into another state's territory constitutes an "act of aggression" and thus a "use of force." (We assume that the above acts are intentional, and with respect to troop movements, that the troops enter the territory of the target state with the intent to exert their state's sovereignty or control over that territory.) In the MID dataset, the

\footnotetext{
${ }^{9}$ Recall from Chapter 1 that terms of this sort will be used interchangeably throughout this work. This work brackets the question of whether humanitarian interventions and similar uses of force, undertaken without Security Council authorization, violate jus ad bellum. Several international legal scholars take the position that they do not, including Thomas Franck (2002), Fernando Tesón (2005), and Nicholas Wheeler (2001). But for every Franck, Tesón, and Wheeler, there is an Oscar Schachter (1991: 117-9), Ian Brownlie (1963, 2001), and Simon Chesterman (2001) to arrive at the opposite conclusion. This study also brackets the issue of legality of threats of force. Strictly speaking, a threat of force is as much a violation of article 2(4) of the Charter as a use of force, but both the fields of international relations and international law tend to focus heavily on the use of force, so this study shall follow suit. As a supporter of the right of humanitarian intervention alongside Franck, Tesón, Wheeler, and John Norton Moore (2004: passim), I object to the characterization of such operations as "aggression" in the legal sense, in which the term is used pejoratively to de-legitimize a first use of force. However, as a statement of the meaning of the term "use force" against another state, the Definition of Aggression is quite useful. That is the purpose for which the Definition is employed in this study.
} 
Highest Activity variable (HiAct; labeled cwhiact in the dataset constructed for this study) enumerates several types of threats and uses of force, including verbal threats, alerts, shows of force (e.g. troop movements or naval exercises), border violations, blockades, attacks, and major war. Comparing the types of military force enumerated in the Definition of Aggression with those listed in the MID dataset, ${ }^{10}$ we find that a HiAct value lower than 12 corresponds to a threat of force but not an actual use, and a HiAct value of 12 or higher (from "border violation" to "interstate war") corresponds to an actual use of force. A participant in a MID in which the HiAct coded as 12 or higher has "used" force.

\section{“First” Use of Force}

To commit the activity that is being captured by the dependent variable, the state must be the first user of force, i.e. it must be the initiator of an armed conflict. Many empirical measurements of the democratic peace, especially the early ones, have measured conflict involvement as a proxy for conflict proneness (Singer \& Small 1972; Small \& Singer

\footnotetext{
${ }^{10}$ Article 3 of the Definition of Aggression defines "aggression" as any of the following acts: (a) invasion, attack, or military occupation of any part of another state, however temporary; (b) bombardment or use of any weapons against the territory of another state; (c) blockade of another state; (d) armed attack on land, sea or forces, or marine or air fleets, of another state; (e) use of visiting forces in another state (which are there originally by consent) in contravention of the consenting agreement, or keeping them there beyond the termination of that agreement; (f) allowing one's territory to be used by another state to attack a third state; and (g) sending by or on behalf of a state of armed bands, groups, irregulars or mercenaries, to commit attacks on another state. For detailed documentation of the coding of cwhiact and other variables, see Appendix A of this work.
} 
1976; Chan 1984; Weede 1984; Moaz \& Abdolali 1989; Bremer 1992; Ray 1993; Russett 1993; Maoz 1997). ${ }^{11}$ Such an approach was useful for measuring dyadic effects, but the dependent variable of interest here is the probability of a state forming the preference or making the decision to enter into an armed conflict (the initiator chooses to fight, vice the target being forced into a fight that it did not choose). The state that is not the first to use force is presumed to be acting in response to first use of force-acting in self-defense (which is permitted under Article 51 of the UN Charter and thus does not violate jus ad bellum). Following the monadic democratic peace literature (e.g. Rousseau et al.1996; Russett \& Oneal 2001), this study is interested only in armed conflict initiation.

In this study, the first user of force is identified by reference to both the HiAct variable mentioned above and the Side A variable in the MID dataset (labeled cwsidea in the dataset constructed here; see Souva \& Prins 2006: 191). The cwsidea variable is binary, coded 1 if the observed state is the first to militarize the dispute, i.e. escalate the dispute to any HiAct value higher than 0 (or put another way, convert the dispute from nonmilitarized to militarized).

The baseline dependent variable for this study is whether the observed state was the first user of force or not, and that variable is labeled init12. The observed state "Initiates" an armed conflict if one of two events takes place: (1) the state is on Side A of a MID and it militarized the dispute at a HiAct value of 12 or higher (meaning it "used" force); or (2) the state is not on Side A, but the other state(s) only threatened force (HiAct

\footnotetext{
${ }^{11}$ The exception is the First Use of Violent Force dataset introduced by Mary Caprioli and Peter Trumbore (2006). However, their dataset goes back only to 1980, whereas the first user of force in a dispute can be derived for the entire MID dataset (which is done here).
} 
11 or lower) and the observed state responded by using force (at HiAct 12 or higher). In this way, the dependent variable is more refined than those of research designs that measure initiation of a militarized dispute, but do not indicate whether those disputes escalated into actual armed conflicts (e.g. Souva \& Prins 2006).

This brings us to the most commonly voiced concern over using the MID dataset: too much information. The MID dataset is quite large, listing several thousand militarized interstate disputes from 1946 to 2001 alone, which exposes it to criticism that too many of its cases are trivial and/or irrelevant, or that too many low-intensity conflicts that ought to be aggregated are disaggregated. In approaching cases this way, the criticism goes, the MID dataset obscures the cases with which the field is really concerned, such as major wars, large-scale military operations short of war, and "close calls" which might have erupted into wars but did not. To that criticism I reply that the function of the dependent variable is to capture only whether or not the state initiated an armed conflicts (in violation of jus ad bellum), and the severity of that violation is not as important. When the observed state sends its military forces across the border to exert that state's sovereignty or control over any territory of the other state, however temporary, the observed state has used force against the other and thus violated jus ad bellum. ${ }^{12}$ Even the trivial cases matter, if they constitute a use of force. However, in order to alleviate the concern just voiced, a series of other dependent variables was constructed in which the

\footnotetext{
${ }^{12}$ Article 2 of the Definition of Aggression excludes from the Definition cases that the Security Council determines lack sufficient gravity. However, the Council has never made such a determination in any case that it has taken up, and the clause just mentioned may have been intended to exclude cases of unauthorized or accident incursions or weapon discharges. No state seems likely to treat any intentional border violation as a "trivial" matter, especially by the armed forces of another state.
} 
threshold for a "use" of force is gradually raised (for a similar design, see Rauchhaus 2009).

Thus the model using the dependent variable init12 just described is only the first of five models, each one using a dependent variable with a gradually higher threshold of militarized activity necessary to trigger it. In the second model, the dependent variable init13 denotes the use of force at HiAct 13 ("blockade") or higher. Another way to answer the criticism is to eliminate cases in which HiAct is coded 15 ("seizure"); the corresponding dependent variables are labeled init12no15 and init13no15. This approach is offered to mitigate the possibility that too many MIDs consist of seizures of vessels in fishing disputes, such as the Cod Wars between Iceland and Great Britain in the 1950s and 1970s; such cases potentially could be construed as more akin to law enforcement activity than a military confrontation. ${ }^{13} \mathrm{~A}$ third approach, implemented by Mark Souva and Brandon Prins (2006), is to count only the initiation of armed conflicts in which fatalities occur (initfatal). This approach reduces the "attention bias" on lowlevel disputes (Wollebæk Toset, Gleditsch \& Hegre 2000: 984) and is made possible by the Fatality Level variable provided in the MID dataset (here labeled cwfatal); any Fatality Level higher than 1 ("none") results in an armed conflict Initiation, provided also that the Initiating state used force at HiAct 12 or higher. Using this variable eliminates many of the so-called "armed conflicts" in which a very low level of force is used.

\footnotetext{
${ }^{13}$ See Russett 1993: 12. Although I offer these alternative variables, I still maintain that such cases should be included in the study, for the fundamental political issue in such cases is the extension (or overextension) of the state's territorial rights. In term of what activity constitutes an "act of aggression," the Cod Wars are not much different from other militarized territorial disputes.
} 


\section{Without Security Council Authorization}

The event being measured is not the first use of force absolutely, but the use of force in violation of jus ad bellum. For the sake of maximizing objectivity, a conservative, restrictionist interpretation of jus ad bellum, as embodied in the UN Charter and Definition of Aggression, is adopted. ${ }^{14}$ A first use of force undertaken without Security Council authorization (which would legitimize it under article 42 of the Charter) constitutes a violation of jus ad bellum. The reason for adopting this approach goes to one of the fundamental premises of the theory behind this work: that norms (including especially norms of peace) matter to states and their leaders, and that states generally comply with international norms (Henkin 1979: 47)—or at least wish to (Chayes \& Chayes 1995). The dependent variable seeks to capture instances in which religion and other factors induce militant behavior by states in spite of those norms of peace. Furthermore, I do not share the widely-held view among my Realist colleagues that both sides are (often) equally blameworthy for the onset of an armed conflict. Contrary to views of Vitoria (1991b: 313), Vattel (1995: bk. iii, chap. 1, sec. 40), and others on the problem of invincible ignorance in the just war context, I hold the view that one side is always objectively the aggressor (though one may not know which one until all the facts are known, which could be years later). It is inappropriate to code as the "aggressor" a state that is the first user of force but is acting with the clear, unequivocal authority of the

\footnotetext{
${ }^{14}$ Again, we must bracket the question of whether humanitarian interventions and similar operations, when conducted without Security Council authorization, run afoul of the Definition of Aggression. In the most restrictive interpretation of jus ad bellum, even humanitarian cases constitute "acts of aggression" for the purpose of this study, despite many protests in the international legal field that they should not (including from myself).
} 
institution that by international law is expressly charged with the maintenance of international peace and security (the Security Council).

In the restrictionist interpretation of today's jus ad bellum used for this study, such legitimacy can only be conferred by the Security Council. This information is contained in the binary variable scauth, which indicates whether the state(s) on Side A of the MID (i.e. the first user of force) had such authorization. If it did, then Side A did not violate jus ad bellum. For this reason, the last refinement to the five dependent variables is to add the suffix noauth to the Initiation variables outlined above. Thus the binary variable init12noauth indicates whether the observed state Initiated an armed conflict at HiAct level 12 or higher, without Security Council authorization. The variables init13noauth, init12no15noauth, init13no15noauth, and initfatalnoauth are analogous. From 1946 to 2001, only five first uses of force have been authorized by the Council, ${ }^{15}$ thus a measurement of first use of force in violation of jus ad bellum is also a very close approximation to measuring simply first use of force.

\section{Five Models}

Going forward, the default approach for reporting quantitative results will be to report on five models, corresponding to five dependent variables for the Initiation of an armed

\footnotetext{
${ }^{15}$ The cases are: (1) by NATO and other states against Bosnian Serbs in 1993 (S.C. Res. 836; MID \# 3551); (2) by the U.S. against Haiti in 1993 (S.C. Res. 873; MID \# 4016); (3 \& 4) by an Australian-led force in East Timor prior to its independence (S.C. Res. 1264; MID \# 4264 \& 4265); and (5) by the U.S. and other states against Afghanistan following the 9/11 attacks in 2001 (S.C. Res. 1386 with authorization further implied in S.C. Res. 1368; MID \# 4283).
} 
conflict at graduating thresholds of force; i.e. each definition for "using" force is more stringent than the last. Those five variables are as follows:

Model 1: init12noauth (Initiated armed conflict at HiAct 12 or higher)

Model 2: init13noauth (at HiAct 13 or higher)

Model 3: init12no15noauth (at HiAct 12 or higher, seizure cases [HiAct 15] removed) Model 4: init12no15noauth (at HiAct 13 or higher, seizure cases [HiAct 15] removed) Model 5: initfatalnoauth (Initiated armed conflict that resulted in fatalities)

\section{Independent Variables}

The independent variable of this study, the religion of the observed state, is operationalized in three ways: (1) religious identity of the leader (the "chief executive") of the state; (2) religious Preference of the governing regime; and (3) religious Prevalence among the state's citizenry. These two latter terms of art, religious Preference and Prevalence, will be introduced shortly and are employed throughout this work.

\section{$\underline{\text { Religious Categories }}$}

Although at least one attempt has been made to compare religious war ethics using a scaled variable (Dorn 2010), the sheer complexity of religious war ethics may preclude assigning them definitively to points on a sliding scale, or even one of ordered categories. Therefore, religion shall be operationalized as a series of variables (some binary, some scaled) that are dedicated to each religious category for which data has been collected. The specific categories are enumerated in Table 3-1. 
world religion is quite recently). In addition, many of their political ethics are similar, and their war ethics have virtually identical origins (see Chapter 5 for greater detail). ${ }^{16}$

The other two categories warranting explanation are styled "East Asian" and "Buddhist Mix." Despite the incompatibility of many of the philosophies and worldviews of Buddhism, Confucianism, Tao, and Shinto, it is appropriate for these purposes to amalgamate them for two reasons. One is that Buddhism (in its Mahayana form) has been imported into and widely accepted in the countries in which the other three religions have thrived; the sheer volume of the Mahayana Buddhist literature (Conza 1997: 295) discourages unity in belief or canon, and a variety of sects have emerged in China, Korea, Japan, and Vietnam, each flavored by the background of other, indigenous religiophilosophical traditions. In turn, Buddhism has influenced those indigenous traditions as well (Bownas, Conza, Graham, Robinson, all 1997; Kitagawa 1990: 154; McGreal 1995 passim). ${ }^{17}$ In China specifically, traditional society is often characterized as being a syncretic of Buddhism, Taoism, and Confucianism (Nyitray 2006); interestingly, the new Oxford volume on global religions edited by Mark Juergensmeyer (2006) groups the three religions together. In Japan, Buddhist and Shinto, and by extension, their war ethics, have become so closely intertwined as to form a "single religious complex" (Kisala 2009:

\footnotetext{
${ }^{16}$ The inclusion of the Mormon Church within Christianity is widely disputed, as many Christians contend that the Mormon church is not truly Christian. However, because the Mormon Church self-identifies as Christian and does treat the Bible as canon (albeit alongside the Book of Mormon), this dataset will do likewise (see Brown 2008: 10). However, the Mormon war ethic will not be studied in this work for lack of any states with a Mormon chief executive, Preference, or Prevalence.

${ }^{17}$ In addition, according to McGreal 1995, many of the great thinkers in East Asia and India were versed in more than one religion.
} 
89). Furthermore, Confucianist philosophy has also been influential outside China at times; for example, it was the official theology of the Tokugawa shogunate in Japan (1603-1868) (Kitagawa 1990: 153), and of the Choson dynasty in Korea (1392-1897), where Buddhism had once flourished and would flourish again (Lancaster 2006). The second reason for amalgamating these four religions is that the religious demographic data reveal that in East Asia, especially in China and Japan, individuals often affiliate with more than one religion—usually Buddhism or Confucianism mixed with something else (CIA 1981-2008; Graham 1997: 357; Juergensmeyer 2006: 69-172 passim). In states that are not purely Buddhist, this situation makes it nearly impossible to separate one component of the East Asian and Buddhist Mix categories from another. ${ }^{18}$

\section{Religion of the Chief Executive}

It has already been theorized in Chapter 2 that the religious identity of a state's leader can influence that person's decisions, including political decisions. Such decisions canand do-include whether to resort to military force. In this study, the leader of the state is defined as the "chief executive" of the central government of that state. That office, whether styled President, Prime Minister, General Secretary, or something else, is held by the one (and very rarely, more than one) person who is the final approval authority in decisions of the state to use military force.

\footnotetext{
${ }^{18}$ The label Pure or Mix denotes whether or not the Buddhism in that state is mixed with the other East Asian religions. It is not intended to label Mahayana Buddhism as a mixture or "impure" form of Buddhism, although it so happens that the Buddhism practiced in all of the Buddhist Mix states is Mahayana Buddhism.
} 
While the Archigos dataset was the first systematic compilation of data on states' chief executives worldwide over the time range used for this study (Goemans Gleditsch \& Chiozza 2009), their dataset does not provide the religious affiliations of those individuals. I have therefore constructed my own dataset with that information. ${ }^{19}$ Furthermore, in my opinion, the Archigos dataset occasionally misidentifies the official who has the final authority to commit the state's armed forces to combat operations.

The variable itself, the religion of the state's chief executive, is codified as a series of binary variables, one for each religious category. The variable names employ the root from Table 3-1 above, with the suffix chief added. Hence christallchief1 indicates whether or not the observed state in the dyad (State 1) has a Christian chief executive, buddmixchief1 a Buddhist Mix chief executive, and so on. It should be noted that this variable does not capture the devoutness or religiosity of the individual, only that person's religious identity. A devout, "born-again" Christian, for example, is coded the same way as a nominal Christian who attends church services only on Christmas and Easter. A consequence of operationalizing the chief executive's religion this way is that occasionally persons who are officially Atheist (such as members of the Communist party) will be coded as a having another religious identity, because they have harbored a

\footnotetext{
${ }^{19}$ The data sources, largely online, are too numerous to name individually. Furthermore, I have consulted with many scholars and professionals who are more knowledgeable in the politics and governance of each individual state than I. Occasionally, however, I have had to estimate the religious identity of states' leaders given the religious demographics of the state. I have only done so when my data on religious demographics indicates that $90 \%$ or more of the state's population adheres to a particular religious category and no better source is available.
} 
latent individual preference or sympathy toward that religion or have reconciled with that religion later in life (e.g. Stalin with the Orthodox church during and after World War II).

\section{$\underline{\text { Religious Preference }}$}

The religious Preference of a state is the favorable institutional disposition of the state's governing regime toward one religious category (or mixture) above others. Every state's regime harbors some amount of religious Preference, ${ }^{20}$ however small-a trait that goes under-appreciated in the United States due to the political culture of separation of church and state (see Fox 2001b). A regime's religious Preference may be manifested in financial support, education mandates, selection of or close relationships with religious officials, discriminatory granting of privileges or licenses, and intolerance of other religions. Or, the regime may be neutral toward religion (which usually works to the advantage of the majority religion), or even hostile to religion. Jonathan Fox has brought this state-level characteristic to light in his book A World Survey of Religion and the State (2008), in which he provides considerable data on the religious policies of states' regimes. Most of the data used for this study originated from his book. ${ }^{21}$

The function of the religious Preference variable in this study is to identify the religion with the greatest political power in the observed state (which may be different from the majority religion of the population, as was the case of the Idi Amin regime in Uganda).

\footnotetext{
${ }^{20}$ In communist regimes, that Preference may be for Atheism, which I treat as a "religion" alongside the other categories.

${ }^{21}$ Fox 2008 only covers the period from 1990 to 2002. I have extrapolated his data as far back as 1946 when appropriate.
} 
The religion with the greatest political power is expected to be also the most influential on the key decision-makers; the ethical norms and processes of the Preferred religion should sway the regime elites more than the ethics of any other religion (save the religion of the chief executive personally). The identity of the Preferred religion is coded in the unordered categorical variable prefrelid.

In order to operationalize the Preferred religion to be suitable for quantitative analysis, it was necessary to codify it as a series of binary variables, one for each religious category. The variable names employ the root from Table 3-1 above, with the suffix pref added. Hence christallprefl denotes whether or not the observed state in the dyad (State 1) has a Christian regime Preference, buddmixpref1 a Buddhist Mix regime Preference, and so on. The identities of the religious Preferences (prefrelid) of some states are coded as mixtures, e.g. Christian-Muslim Mix, when no single religious category listed in Table 3-1 dominates the religious Preference of the governing regime. In those cases, the binary variables specific to the religions within those mixtures are coded as missing. For example, for a Christian-Muslim Mix state in which the Christians were known to be Protestant and Muslims known to be Sunni, the binary variables for the Christian (all), Western Christian, Protestant, Muslim (all), and Sunni Muslim categories would be coded as missing. However, the variables for the Catholic, Orthodox, Shia Muslim, and Other Muslim categories would be coded as 0 .

The degree of the state's regime Preference for each religious category can also be quantified. For this task, I have devised a Government Religious Preference (GRP) scale using data mostly from the narratives in Fox's (2008) book. Fox himself devises a measurement of "Government Involvement in Religion," which quantifies the degree to 
which a state's government is intertwined with religion or religious institutions. His construct, while useful in a comparative context, is not conducive to the measurement of religion's influence on a state's foreign policy preferences, including for war or peace, because it conflates the influence of religion on the government (which is the focus of this study) with the influence of the government on religion (which is not the focus).

However, the wealth of data in Fox's book makes it possible to construct a variable that is more suitable for the purpose needed here. The GRP scale examines the government's policies in five areas: constitutional establishment of religion (constest), religious education (releduc), amenability of government officials to religious influence (amen), general privileges to the Preferred religion (genpriv), and intolerance of the practice (not political activity) of religions other than the Preferred one (intol). Each state is assigned a score ranging from 0 to 4 in each of these areas for which data is available; the scores roughly correspond to the ordered categories Strongly Negative (0), Somewhat Negative (1), Low or No Preference (2), Moderate (3), and High (4). ${ }^{22}$ The GRP score is the mean of all non-missing scores just described, converted from a scale of 0 to 4 to a scale of 0 to 100 (though for the purpose of work, the percentage scale has been reconverted to a scale of 0 to 10 in order to more easily see the effect of a $10 \%$ increase in GRP score). The GRP scores are operationalized as a series of variables for each religious category, e.g. christallpref110 is the GRP score for Christianity for State 1 on a scale from 0 to 10 , etc.

It is possible for states to have non-zero GRP scores for more than one religion; for example, the government of Nigeria has a roughly equal Preference for Christianity and

\footnotetext{
${ }^{22}$ See Appendix A for detailed descriptions of scores for specific components of the GRP scale.
} 
Islam. In addition, many states with a primary religious Preference for Atheism also have acquired a secondary Preference for some other religion after the Cold War (this was seldom the case during it). Secondary religious Preferences are also recorded in the data set. When the GRP score of one religious category is greater than that of any other, that category is coded as the Preferred religion using the binary pref variables described above, but if two or more GRP scores are equal, the applicable binary variables are coded as missing.

\section{$\underline{\text { Religious Prevalence }}$}

The third way this study operationalizes the religion of a state is by capturing the religious affiliations of the state's population. It should be emphasized that this series of variables captures only a population's religious identity, not the amount of religiosity (on which insufficient data was available). ${ }^{23}$ Furthermore, it should be made clear that going forward, any reference to a state's population denotes specifically the population of the nationals (or citizens) of that state. This clarification is important for the few states that have expatriate populations that number as great as or greater than their own nationals, e.g. Kuwait and the United Arab Emirates. It is assumed that the cultural standards and public opinion that influence a state's leadership's decision for war or peace will be those held by its nationals rather than its guest workers.

\footnotetext{
${ }^{23}$ A dataset from which the religiosity of the general population could be constructed, the World Values Survey, was rejected for use in this study on the ground that it does not cover enough states (World Values Survey Association 2009).
} 
Data on religious demographics of states is obtained from various annual almanacs and government reports (Central Intelligence Agency 1976-1980, 1981-2008; Information Please Almanac 1947-1981; U.S. Department of State 1999-2009; World Almanac 1968-1995). ${ }^{24}$ Each observation contains the percentage of the state's population that follows each of the religious categories listed in Table 3-1. For ease in viewing the effect of $10 \%$ increases of percentages of populations, the variables themselves are scaled $0-10$, with each unit representing $10 \%$ of the population. The variable christall110 denotes the portion of State 1 that is Christian, hindu110 denotes the portion that is Hindu, and so on.

Each observation also records the religion that is "Prevalent" in the population (or occasionally, the mixture of the two religions that are most Prevalent). The threshold of Prevalence is set at $66.5 \%$. This figure was selected for two reasons: (1) it represents a supermajority that would seem to be sufficient for the Prevalent demographic to impose its preferences on religious minorities; and (2) it demarcates what appears to be a "salient empirical break" in the data (Rousseau et al. 1996: 519-20). At a threshold of $66.5 \%$ there appear to be few borderline cases. An exception to this rule is when not enough of the population follows any religion or mixture (because they are coded Atheist or Not

\footnotetext{
${ }^{24}$ The preferred data source for any given range of years is that which appears to provide the most precise and accurate information, a criterion which sometimes must be judged according to common sense and knowledge of the ways of the world. If no source appears to be more precise or accurate than any other, then the order of preference is the CIA World Factbook/National Basic Intelligence Factbook, State Dept. International Religious Freedom Report, Information Please Almanac, World Almanac. Rationales for the use of specific sources for specific entries is documented in the original Excel spreadsheet from which state-year observations were later generated.
} 
Religious) for a religion to be coded as Prevalent; i.e. the coding of any Prevalent religion would be thwarted. In such a case, the religion (or mixture) that is followed by at least two-thirds of the religious population is coded as Prevalent. Occasionally this rule results in a religion being coded as Prevalent even though less than $66.5 \%$ of the population follows it.

\section{Control Variables}

Because it is necessary to separate the effects of religion from the effects of other characteristics that may influence the propensities of states to armed conflict, data has been collected on a variety of control variables. The controls can be placed essentially into seven categories: power, regime type, alliances, wealth, trade dependence, the peacelearning process, and proximity. This section will present those controls and explain why some have been weeded out of the final research design.

\section{Power Differential}

The central tenet of the Realist paradigm in international relations is that international outcomes are determined by configurations of power (Morganthau 2006; Waltz 1979; Mearsheimer 2001). By that logic, a party to an interstate dispute should be more likely to initiate an armed conflict if it is more powerful than the other party (we shall assume that the more powerful state perceives this) and therefore in a better position to compel the weaker states to do its will (Clauswitz 1993: bk. 1, chap. 1, sec. 2; Singer \& Small 1972; Bremer 1980; Cashman 1993: 137). 


\section{$\underline{\text { National Capabilities }}$}

Data on the material power of states was generated from the COW National Material Capabilities dataset using EUGene (Singer Bremer \& Stuckey 1972; Singer 1988; Correlates of War Project 2010). ${ }^{25}$ Each observed directed direct-year includes variables on the military personnel (milper), military expenditures (milex), energy consumption (energy), iron and steel production (irst), total population (tpop), and urban population (upop) for each state in the directed dyad. These components are combined into a Composite Index of National Capability (CINC) score (cinc) for each state, which is the average of the ratio of each component to the total material capability of the state system in the observed year. Thus the CINC score for each state is between 0 and 1 . But because the unit of observation for this study is based on dyads, the configuration of power between the two states is what must be taken into consideration. In their testing of the democratic peace, Bruce Russett and John Oneal (2001: 103) use the logarithm (we assume the natural logarithm) of the ratio of the CINC score of the stronger state to that of the weaker state. However, since my study examines the behavior of observed states (State 1) in directed dyads, it is more appropriate to use the logarithm of the directed CINC ratio (logdircincratio), which is the ratio of the CINC score of State 1 to that of State $2 .^{26}$

${ }^{25}$ EUGene does not specify the version of the National Military Capabilities dataset, but it is presumably 3.02, which is last version released before the most recent version of EUGene. The data was superseded by version 4.0 in June 2010.

${ }^{26}$ Certainly the directed CINC ratio is not the only way to quantify the power differential between states. Rousseau Gelpi Reiter \& Huth (1996: 520) construct a Balance of Forces variable as the average of the ratios of the state's number of troops to the global total number of troops, the state's military expenditures 
Troop Quality

Dan Reiter and Allan Stam (2002: 41) propose also taking the differential of "troop quality" into account, under the theory that a fighting force that is better trained, soldier for soldier, enjoys an a priori military advantage and thus has greater power. ${ }^{27}$ The variable Troop Quality (troopqual) is the state's military expenditures divided by the number of its military personnel. Relative troop quality in the directed dyad is then operationalized as the natural logarithm of the directed ratio of Troop Quality between State 1 and State 2 (logdirtroopqualratio), in a manner similar to the directed CINC ratio described above.

\section{Nuclear Capability}

The possession of nuclear weapons on either side also affects a state's propensity to militarize a dispute, apart from the effect of power differential (which is more a measure-

to the global military expenditures, and the state's military expenditures per soldier to the global total of the same, all discounted by Bruce Bueno de Mesquita's (1981: 41-4) loss of strength gradient. Dan Reiter and Allan Stam (2002: 41) use the CINC ratio of the state to all participants of the MID. These approaches are not necessarily wrong-headed, but EUGene (Bennett \& Stam 2000) generates data in a way that makes using the directed CINC ratio a far more convenient way to operationalize power differential within a directed dyad. Finally, should the occasion arise to operationalize power differential as a binary variable, the variable dircincsuperior is constructed, in order to code whether the observed state's CINC is at least three times that of the other state (following the Rule of 3; see Biddle 1994: 15, Liddell Hart 1939: 545; Mearsheimer 1989).

${ }^{27}$ See Biddle 1994 on the specifics of a winning strategy for ground forces, the implementation of which requires considerable resources. 
ment of conventional power than nuclear). ${ }^{28}$ But beyond the general proposition that nuclear capability is relevant, scholars disagree on the nature of its effect. Kenneth Waltz $(1981,2003)$ famously argues that nuclear weapons actually have a stabilizing effect, on the ground that the risk of nuclear war tempers direct military confrontation between nuclear powers. Robert Rauchhaus (2009), on the other hand, argues that nuclear states are more likely to engage in low-level armed conflict, because mutual nuclear capability is a guarantee that the violence will not escalate. Scholars also disagree on the effect of only one side having nuclear capability. Michael Horowitz (2009) argues that experienced nuclear powers reciprocate military disputes less often (they learn when and when not to play the "nuclear card"), whereas Kyle Beardsley and Victor Asal (2009) claim that the nuclear side is more likely to win against the non-nuclear side (which in turn seems to suggest that the nuclear side will assert itself more forcefully). The binary variables nuke1, nuke2, and bothnuke capture the nuclear capability of State 1, State 2, and both states, respectively. ${ }^{29}$

\section{Permanent Security Council Membership}

Finally, I would like to address the hypothetical argument that my dependent variable is systematically biased against religions that are not Prevalent or Preferred in states that are permanent members of the UN Security Council. The dependent variable, strictly speaking, is the violation of jus ad bellum, and each permanent member of the Council

\footnotetext{
${ }^{28}$ I am indebted to Victor Asal for suggesting this line of inquiry.

${ }^{29}$ For coding the specific years in which states are nuclear capable, I follow the dates in Beardsley \& Asal 2009: 285 .
} 
has the power to block an authorization to use force (thereby preventing a first use of force from being in compliance with jus ad bellum), by virtue of that member's veto power (UN Charter, art. 27, para. 3). ${ }^{30}$ A majority of those states are Christian, and no Muslim state has veto power in the Security Council. The results in Chapter 4 show that Christian states have a lower propensity to violate jus ad bellum and Muslim states a higher propensity, and might be construed as creating the appearance that Christianity is less aggressive by virtue of its privileged position a gatekeeper for the legitimacy of using force. The argument would then be that P5 members are more inclined to legitimize uses of force by their religious confreres but not by states of other religions. For this reason, the binary variable perm5 denotes whether or not the state has that status on December $31^{\text {st }}$ of the observed directed dyad-year (perm51 for State 1, perm52 for State 2 ). ${ }^{31}$

\section{$\underline{\text { Regime Type }}$}

A large body of literature advances and tests the theory that democracies do not, or are less likely to, enter into armed conflicts with each other (the dyadic thesis), with some literature going even further to suggest that democracies are less aggressive, i.e. have a lower propensity to initiate armed conflicts, than non-democracies (the monadic thesis). ${ }^{32}$

\footnotetext{
${ }^{30}$ I thank John Owen for pointing out this argument to me.

${ }^{31}$ The United States, United Kingdom, France, and Russia are all coded as P5 members for the entire time period of the study. China is coded as a P5 member from 1946 through 1948 and 1971 through 2001 and Taiwan, as the recognized representative of China, from 1949 through 1970.

32 On the dyadic thesis, see Kant 1991; Doyle 1983; Ray 1993; Russett 1993; Owen 1994, 1997; Lipson 2003; Mousseau 2009. On the monadic thesis, see Rummel 1983, 1995 (associating libertarianism with the absence of conflict-proneness); Maoz \& Abdolali 1989 (finding a tendency of autocracies to initiate more
} 
Although the dyadic thesis has greater support in the literature than the monadic thesis, along with a greater effect on the outcome of war or peace (Russett \& Oneal 2001), it seems appropriate to incorporate both theses as control variables in this study.

The most commonly used measurement for regime type is the Polity score from the Polity Project (Marshall Gurr \& Jaggers 2010). On any given date, the Polity score of a state (labeled polity in this study) is the composite of a series of scores that measure competitiveness and openness of executive recruitment, institutional constraints on the chief executive, and regulation and competitiveness of political participation. The final score is an integer ranging from -10 (the maximum level of autocracy) to +10 (the maximum level of democracy). ${ }^{33}$ The Polity IV Project adds a Polity2 score (labeled polity 2 in this study) that recodes some of the missing data in the original dataset. In

disputes, but only if anocracies are separated from democracies and autocracies); Bueno de Mesquita \& Lalman 1992 (finding force more likely to be avoided if either the initiator or the target is democratic); Rousseau et al. 1996 (suggesting a monadic effect on the emergence of crises, working in tandem with the dyadic effect); Rummel 1997 (arguing that the more democratic a state, the less severe its "foreign violence"); Russett \& Oneal 2001 (finding that autocracies initiate more crises than democracies); Bueno de Mesquita et al. 1999, 2004 (finding that democracies are more selective in initiating war, thus strongly implying a lower propensity thereto). Stephen Quackenbush and Michael Rudy (2009) find insufficient empirical support for the monadic democratic peace, but their finding may be the result of (1) making their dependent variable the initiation of a MID as opposed to an armed conflict, and (2) covering the entire period of the MID data set (1816-2001) as opposed to starting after 1945.

${ }^{33}$ The other alternative data source for regime type, Freedom House (2011), was considered but rejected on the grounds that (1) Freedom House scores regimes in only three types whereas Polity's 21-point scale reflects finer variations; and (2) Freedom House does not cover the entire time period used in this study, whereas Polity IV does. 
cases of transition from one Polity score to another, the difference in Polity2 score at the beginning and end of the transition is prorated from year to year during that transition period. In addition, missing data scores attributable to "interregnum" (which the Polity IV code book casts as "anarchy" but which I would cast as insurgency or civil war) are recoded to a Polity score of 0 , and missing data scores attributable to foreign “interruption" (i.e. occupation) are recoded as truly missing (i.e. without any value).

However, further refinements to the Polity score are possible to make it even more suitable for the needs of this study. The behavior being examined is the militarization of a dispute by a state; in international law and diplomatic practice, the behavior of the state and its government are virtually synonymous. Whereas the "interregnum" code in the Polity and Polity2 scores denote that the state's government is not in full control of its territory, that characteristic has little or no relevance to the state's (government's) decision-making processes in the area of foreign policy, especially for using military force. I submit that during such an "interregnum" period, the last non-missing Polity score of the state is a reasonably good indicator of the democratic or autocratic traits of its central government, even if that government does not exercise full control over all of the state's territory. I have therefore generated a third type of Polity score (labeled politydlb) to reflect my own adjustments, which consist of recoding an "interregnum" score to the state's last non-missing score, and correcting what appear to have been several typographical errors in the original Polity IV data set. A further refinement was to rescale all of these variables to 0 to 20 vice -10 to +10 , in order to facilitate their manipulation in Stata (following Rousseau et al. 1996: 519). Polity scores that are rescaled in this manner are labeled with the suffix 20. 
In operationalizing the dyadic thesis, two approaches are possible. One is to simply assign values to binary variables that indicate whether or not the state is a democracy, and whether or not the dyad consists of two democracies. The variables labeled democ 7 , democ8, democdyad7, and democdyad8 perform this function (the suffix 7 denotes a Polity score of +7 as the threshold for coding a state as a democracy, 8 denotes that the threshold is +8 ). However, the field has not arrived at a consensus as to the dividing line between a democracy and non-democracy, let alone a democracy, anocracy, and autocracy. A better approach, in my view, is to use the 21-point scaled variables; this approach makes it possible to observe the change in state behavior resulting from each single-point increase or decrease in Polity score. This approach is used by Russett and Oneal (2001: 99) in their testing of the democratic peace. They test on the lower Polity score of the two states in the dyad, as an indicator of whether the dyad is democratic or not. Following their lead, I have constructed the variable dyadlowpolitydlb20 for this purpose (the lower adjusted Polity score in the dyad, rescaled to $0-20) .^{34}$

As to the monadic effect, the most direct measurement is the Polity score of the observed state itself (in this case, politydlb120, which is the adjusted Polity score for State 1 , rescaled to $0-20$ ). A high correlation between the variables politydlb120 and dyadlowpolitydlb20 poses some concern when the two variables are regressed

\footnotetext{
${ }^{34}$ Russett \& Oneal also test on the political distance between the states using the higher Polity score of the states in the dyad, following the premise that the difference in regime types affects the likelihood of conflict (2001: 100). However, as I wish to be careful not to overly dilute the effects of control variables by including too many of them, I have elected not to include Polity difference as a standard control.
} 
simultaneously (as they will be), but no better alternative to including both theses in the standard model seems to be available. ${ }^{35}$

\section{$\underline{\text { Alliances }}$}

Neorealism predicts balancing behavior by states against potential threats and Neoclassical Realism predicts that status quo-seeking and revisionist states will align themselves with other states of like preferences (Waltz 1979; Weede 1989; Schweller 1994; Farber \& Gowa 1994). It follows that allied states should be significantly less likely to enter into armed conflicts with each other (see Gibler \& Wolford 2006). On the other hand, Bruce Bueno de Mesquita (1981: 159-64), James Lee Ray (1990: 86), Ido Oren (1990), and Stuart Bremer (1992: 315) all claim that, counter-intuitively, war is actually more likely between allies than enemies. Either way, the parameter appears to be worth controlling for.

Data on alliance types is generated from the Correlates of War Formal Alliances dataset, version 3.03 (Gibler \& Sarkees 2004; Gibler 2008), via EUGene. Rousseau and his colleagues (1996: 520) test the effect of alliances using a dummy variable for whether the dyad has entered into any form of alliance during the observed year (defense pact, neutrality pact, or merely an entente). I submit, however, that their measurement is far too broad, for a pact of neutrality or entente a priori would not seem to enjoy the same

\footnotetext{
${ }^{35}$ The democratic peace has been measured in many different ways. In reply to the inevitable question of why democracy was measured one way and not another, the reader is directed to Oneal \& Ray 1997; that article tests the democratic peace in several ways (some dichotomous variables, others continuous) and different measurements of democracy made no difference in the overall findings.
} 
degree of pull toward either non-aggressive behavior or a relationship that is close enough to generate the potential for spats, as a mutual defense pact against a third-party attacker would. I therefore follow the approach of Russett and Oneal (2001: 104), controlling for defensive alliances only, using the binary variable defenseallies, which denotes whether or not a defense pact is in effect between the states in the directed dyad.

\section{$\underline{\text { Wealth }}$}

Bruce Russett (1993: 25ff, 82) suggests that wealth leads to peace, i.e. a wealthier state has a lower propensity to initiate an armed conflict. However, Michael Haas (1980) argues the reverse: that greater wealth bestows greater relative material power on a state, making it more likely to resort to force to realize its preferences because it can bear the cost of the effort and its risk of defeat is lower. Furthermore, Joshua Goldstein (1988) correlates the severity of war with sustained and stable economic growth (i.e. wealthbuilding), with Geoffrey Blainey (1988: 93) making the inverse argument that economic downturns (wealth-loss) constrain the use of force. Either way, wealth would seem to have an effect.

Data on Gross Domestic Product (GDP) and GDP per capita were obtained from the Quality of Government Institute (Teorell et al. 2011; Ledet 2006). Of the three readily accessible alternatives, the dataset of Angus Maddison (2003) was selected for use in this study because it appears to contain the least amount of missing data for the time period examined herein. ${ }^{36}$ The values of states' GDPs and GDPs per capita, both adjusted for

\footnotetext{
${ }^{36}$ The alternative sources were from Kristian Gleditsch (2002) and the United Nations Statistics Division (2009).
} 
currency and inflation, are captured in the dataset used for this work by the variables maddisongdp and maddisongdppc. But because it is relative power that determines state behavior in the Realist paradigm, it is again more appropriate to examine the directed ratio of those values between the observed state (State 1) and the other state in the dyad (State 2). In keeping with Russett \& Oneal 2001, this study uses the logarithm of that ratio (logdirmaddisongdpratio and logdirmaddisongdppcratio).

\section{$\underline{\text { Trade Dependence }}$}

In some literature, armed conflict is linked with international trade dependence. The typical conclusion is that trading partners are less likely to enter into armed conflicts with each other; ${ }^{37}$ they realize that the overall (or long-term) benefit of trade relations outweighs the short-term benefit of victory in battle, because the negative impact on trade that results from the armed conflict significantly reduces the state's prosperity (Angell 1913; Mueller 1989: 219; Copeland 1996). ${ }^{38}$ Russett and Oneal (2001: 140-1) conceptualize two indicators of trade dependence. The first is the observed state's economic dependence on trade with the other state (econdepend), which is sum of the value of all exports to and imports from the other state in the observed year, divided by the observed state's GDP. ${ }^{39}$ The second indicator is the amount of symmetry of trade dependence

${ }^{37}$ Souva and Prins (2006: 184) argue that a state that is more dependent on the global market as a whole, not just on another specific state, is less likely to enter into a militarized conflict with any other state.

${ }^{38}$ Dale Copeland's (1996) version of this thesis adds a twist: he argues that it is not present trade, but expectations of future trade that reduces a state's propensity to armed conflict.

${ }^{39}$ Russett and Oneal (2001), incidentally, also use Maddison's (2003) figures as their preferred source of GDP data. 
between the observed state in the dyad and the other state (the Directed Economic Dependence Ratio). This variable, labeled direcondependratio, is simply the directed ratio of the economic dependence of State 1 on trade with State 2 to that of State 2 on trade with State 1 (Russett \& Oneal 2001: 143), though in keeping with practices elsewhere in this study, the natural logarithm is used instead (logdirecondependratio). In either case, argue Russett and Oneal, greater economic dependence should reduce the observed state's propensity to armed conflict with the other state.

However, I would go further and suggest that measuring the directed ratio of economic dependence by itself is sufficient to capture the effect of trade, for the following reasons. First, assuming it is true that both absolute trade importance and asymmetric trade dependence positively affect a state's propensity to armed conflict, the effect of the former is embedded in the latter, making it more efficient to use only the latter. Second, the latter variable measures the $d y a d$, and like many of the other dyadic variables described in this chapter, is therefore more appropriate for a dataset in which the unit of observation is the dyad-year rather than the state-year. Data on dyadic and national trade, suitable for deriving the variables mentioned here, was generated from the COW Trade Data Set, version 2.0 (Barbieri Keshk \& Pollins 2008, 2009), via EUGene.

Russett and Oneal (2001: 144) also offer a measurement of "economic openness," which is the sum of the observed state's total exports and imports in the observed year, divided by its GDP (here labeled econopen). ${ }^{40}$ The lower the economic openness, they argue, the greater the chance of armed conflict, because the disincentive imposed by trade

\footnotetext{
${ }^{40}$ Similarly, Souva and Prins (2006) measure foreign direct investment (FDI) dependence as the amount of FDI a state receives divided by its GDP.
} 
dependence on using military force is not present. Although this seems intuitive, it also seems redundant to measure this variable alongside trade interdependence. It therefore seems apropos to confine the measurement of this phenomenon to a single variable.

\section{Peace Learning}

Lars-Erik Cederman (2001) proposes that the dyadic democratic peace is at least partly attributable to the "learning process" of pacific relations, which democratic dyads learn quickly but which non-democratic and mixed dyads are able to learn also. It follows that the longer a dyad has been at peace, the less likely the dyad will enter into an armed conflict. Data on "peace-years" was generated from the COW MID data set, version 3.10 (Ghosn Palmer \& Bremer 2004), via EUGene. However, in keeping with the practice of other variables, and in order to account for the diminishing effects of each of many individual peace-years over time, the logarithm of peace-years is used instead (logcwpeaceyrs). ${ }^{41}$

\section{Proximity}

The notion that proximity breeds conflict is well supported in the literature of the field (Richardson 1960; Midlarsky 1974; Diehl 1985; Starr 1978, 2005; Starr \& Most 1976, 1978). Without proximity the opportunity for interactions and therefore disputes is greatly diminished; the closer the proximity of two states, the greater the likelihood of

\footnotetext{
${ }^{41}$ David Carter and Curtis Signorino (2010) suggest a better approach to modeling time: regressing on time $\mathrm{t}, \mathrm{t}^{2}$, and $\mathrm{t}^{3}$. Such a regression was attempted but could not be carried out due to lack of convergence in Stata.
} 
armed conflict between them. ${ }^{42}$ Proximity has been operationalized in several ways. First, as an ordered categorical variable of geographic contiguity (Starr \& Most 1976; Bremer 1992; Henderson 1997). ${ }^{43}$ Second, as a binary variable; the states are either contiguous or not (Maoz \& Russett 1993; Farber \& Gowa 1995; Mousseau 2009; Vasquez 1995; Senese 2005; Rasler \& Thompson 2000; Diehl 1985). ${ }^{44}$ Third, as the distance between capitals (or ports) of states; the greater the distance, the lower the probability of armed conflict due to the difficulty of projecting military power over long distances (the "lossof-strength gradient"; Boulding 1962; Bueno de Mesquita 1981: 103-9). Data on proximity as an ordered categorical variable was more readily available at the time the datasets used for this work were being constructed. Between the first two alternatives, the first one (an ordered categorical variable) is better suited than the binary variable for regressing contiguity in a dataset of politically relevant dyads; to do otherwise would bias the results by overlooking the ability of non-major powers to project their power over a short distance of water.

Raw data on contiguity was generated from the COW Direct Contiguity and Colonial/ Dependency Contiguity Data Sets, versions 3.1 and 3.0, respectively, (Stinnett et al.

\footnotetext{
${ }^{42}$ But see Senese 2005 (arguing that territorial disputes have greater explanatory power for the onset of armed conflict than simply contiguity); Rasler \& Thompson 2000 (arguing that for major powers, "positional" issues are as important as geographic proximity).

${ }^{43}$ The ordered category with the highest contiguity is land contiguity, and lower categories of category are by sea with stratified distances between the nearest land points of the two states. In Bremer's work, states cease to be contiguous when separated by more than 150 miles of water, but the Correlates of War Project's latest contiguity dataset extends sea contiguity up to 400 miles.

${ }^{44}$ Diehl 1985 uses land contiguity only.
} 
2002; Correlates of War 2 Project 2003). The raw data, however, separates "direct" contiguity between two metropoles and "colonial" contiguity in which at least one territory is a "colony." 45 To arrive at a true measurement of contiguity, particularly those involving a great or colonial power, I submit that it is appropriate to combine the two variables into a single identifier of the Closest Contiguity within the dyad (here labeled closestcontig) ${ }^{46}$ For the sake of thoroughness, I have also entertained introducing a binary variable to denote land contiguity specifically (direct or colonial), labeled anylandcontig.

\section{Correlated Controls}

All the control variables discussed above have the potential to affect a state's propensity to initiate armed conflict. However, to control for all of them, even simultaneously, would be unduly cumbersome—and James Lee Ray (2003) even suggests that doing so is inappropriate- therefore it is behooving to eliminate those controls that are

${ }^{45}$ In this context the word "colony" is used to identify the territory not as lacking autonomy or full representation in the national government, but as geographically separated from the metropole, generally by more than 400 miles of sea (e.g. French Guiana, an overseas department of and fully incorporated into France, is considered a "colony" for these purposes).

${ }^{46}$ Starr and Most (1978) suggest that having many colonial frontiers leads to more wars, and many direct frontiers to fewer wars, but Diehl and Goertz (1988) argue the opposite. A brief series of regressions on contig and colcontig, the results of which are not reported, supported Diehl and Goertz's claim. Since the effect of colonial frontiers is at best inconclusive, I submit that the variable closestcontig offers the best compromise between the competing claims, consistent with the approach that all armed conflicts are important to this study. 
most correlated with others. ${ }^{47}$ The results of a pairwise correlation of control variables, using the Bonferroni multiple-comparison procedure (Acock 2008: 172-4), are reproduced in Appendix B, Table B-1. Table 3-2 summarizes those results to show which variables are highly correlated with the core controls.

${ }^{47}$ I take a different approach to weeding out controls then Ray (2003) does. Ray argues against automatically adding control variables in multivariate analyses merely because they (might) have some impact on the outcome variable, because doing so obscures the distinctions between competing causal variables (which he labels "confounding"), intervening variables, and alternative causal factors. The immediate difficulty in applying this guideline is that it is not usually apparent which variables are which. Ray also cautions against controlling for variables that are related by definition to each other or to the key explanatory variable. This seems like good advice generally speaking, but in one respect it goes too far and in another not far enough. Ray is under-cautious in that he makes no mention of eliminating controls that are highly correlated with each other statistically but not by definition. These are the types of variables that should be labeled "confounding" in my view, for their correlation raises the possibility that they are proxies for a third factor. Including controls that are highly correlated with each other increases substantially the risk that that unknown third factor will be given more weight than it is due. But in another way, Ray is over-cautious, in that two variables may be related definitionally but not excessively correlated. The Polity and Low Polity variables used in this model are such a case: the latter is related definitionally to the former, but they measure different effects (the dyadic and monadic theses of the democratic peace, respectively). 
Table 3-2. Highly Correlated Control Variables.

$\begin{array}{ll}\text { Core Variable } & \text { Highly Correlated Controls } \\ \text { Log of Directed CINC Ratio } & \begin{array}{l}\text { Log of Directed Troop Quality Ratio } \\ \text { Nuclear Capability (State 1) } \\ \text { Permanent Member of Security Council (State 1) } \\ \text { Log of Directed GDP Ratio } \\ \text { Log of Directed GDP Per Capita Ratio } \\ \text { Log of Directed Economic Dependence Ratio }\end{array} \\ \text { Low Polity Score } & \text { Polity Score (State 1) } \\ \text { Polity Score (State 1) } & \text { Log of Directed GDP Per Capita Ratio } \\ \text { Defensive Allies } & \text { (none) } \\ \text { Log of Peace-Years } & \text { (none) } \\ \text { Closest Contiguity } & \text { Any Land Contiguity }\end{array}$

Variables that are highly correlated with the core controls will not be included in the standard models going forward, with the exception of the Polity score of the observed state in the dyad (State 1); this variable will be included because it measures a different effect of the democratic peace than the lower Polity score in the dyad. A few of these controls will be reintroduced in Chapter 4, as robustness checks of the research design.

\section{$\underline{\text { Summary of Research Design }}$}

The primary research design consists of five binary dependent variables that denote whether or not the observed state in the dyad (State 1) initiated an armed conflict against the other state (State 2), in violation of jus ad bellum. This is nearly the same measurement as whether or not State 1 initiated an armed conflict against State 2, regardless of the legality of doing so. The independent variables consist of a series of binary and scaled 
variables on the religious identity of the chief executive, the regime Preference, and Prevalence among the population, of a variety of specific religious categories. The standard control variables going forward will consist of national material capability, the dyadic and monadic democratic peace, defensive alliances, peace-learning, and proximity. Some of the other control variables will be reintroduced at the end of Chapter 4 for the purpose of robustness checks. A preliminary set of empirical results is presented in the next chapter. 


\section{CHAPTER 4}

\section{THE EFFECT OF RELIGION GENERALLY: EMPIRICAL RESULTS}

\section{$\underline{\text { Introduction }}$}

The previous chapter presented a research design for empirically measuring the effect of religion on the propensities to states to initiate armed conflicts (in violation of $j u s$ ad bellum, after 1945). This chapter will present some general results of those measurements. The overall finding is that religion does have an effect, and that effect is frequently as strong as or stronger than the conventional explanations for using military force in the field. As to specific religions, Christianity is found overall to have a negative effect on the propensity of a state to commit an act of aggression and Islam a positive effect. The effects Atheism and the "Buddhist Mix" category are mixed, and the results for those categories are not as conclusive as those for Christianity and Islam.

\section{Which Religions To Test?}

A test of every single religious category for which data has been collected would be unduly cumbersome and the validity of the results would questionable for some of them, for lack of diversity among states of those religions. For example, the practices of Jewish and Shia Muslim states are driven by a single state for each religion (Israel and Iran, respectively), and the practice of Hindu states is similarly limited to India, Nepal, and a handful of states with mixed populations that are partly Hindu. The effects of those religions cannot be isolated from those of the other domestic and geopolitical features of 
those states, and any behavioral predictions resulting from this research design for states of those religions would not be generalizable to the larger population of states.

Several other religions, on the other hand, are Prevalent or Preferred in a large number of states with diverse other characteristics. Table 4-1 shows the frequencies of religions that are Prevalent or Preferred in all monadic state-years in the system from 1946 to 2001 (mixtures of two religions are not included). The table shows that Christianity, Islam, and Buddhism Mix are the Prevalent religions in $91 \%$ of the state-years during that period, and the Preferred religions in $87.5 \%$ of them. Those are the three religious categories that will be tested in this chapter. In addition, since Atheism is Preferred in about $9 \%$ of the state-years, the Atheist Preference will be tested also.

Table 4-1. Religions of State-Years.

\begin{tabular}{|c|c|c|}
\hline$\underline{\text { Religion }}$ & Prevalent & Preferred \\
\hline Christian (combined) & 3724 (59.15\%) & 3700 (55.45\%) \\
\hline Western Christian (combined) & 3380 (53.68\%) & 3488 (52.27\%) \\
\hline Catholic & 2037 (32.35\%) & 1932 (28.95\%) \\
\hline Muslim (combined) & 1543 (24.51\%) & $1583(23.72 \%)$ \\
\hline Sunni & 1271 (20.19\%) & $1461(21.89 \%)$ \\
\hline Protestant & $555(8.82 \%)$ & 637 (9.55\%) \\
\hline Atheist & & $613(9.19 \%)$ \\
\hline Buddhist Mix & 472 (7.50\%) & 557 (8.35\%) \\
\hline Buddhist (pure) & 311 (4.94\%) & $294(4.41 \%)$ \\
\hline East Asian & & $263(3.94 \%)$ \\
\hline Eastern Christian & 287 (4.56\%) & $212(3.18 \%)$ \\
\hline Indigenous (all) & $215(3.41 \%)$ & \\
\hline East Asian & $161(2.58 \%)$ & \\
\hline Not Religious/Atheist & $139(2.21 \%)$ & \\
\hline Hindu & $112(1.78 \%)$ & $112(1.68 \%)$ \\
\hline Other Muslim (not Sunni/Shia) & $73(1.16 \%)$ & \\
\hline Shia & $57(0.91 \%)$ & $68(1.02 \%)$ \\
\hline Indigenous (all) & & $54(0.81 \%)$ \\
\hline Jewish & $54(0.86 \%)$ & $54(0.81 \%)$ \\
\hline Other Muslim (not Sunni/Shia) & & $42(0.63 \%)$ \\
\hline Syncretic & $37(0.59 \%)$ & $0(0.00 \%)$ \\
\hline TOTAL STATE-YEARS & $6296(100 \%)$ & $6673(100 \%)$ \\
\hline
\end{tabular}




\section{$\underline{\text { Cross-Tabulations }}$}

We begin with a rough measurement of association between the major religious categories and the dependent variable. A series of cross-tabulations and Cramér's V-tests (reproduced in Appendix B, Tables B-2 to B-5) suggests that there is such an association. Depending on the dependent variable tested, Christian states initiated armed conflicts at $33-50 \%$ below the expected rates, Muslim states at 60-94\% above the expected rates, and Buddhist Mix and Atheist-Preference states at 48-65\% above the expected rates. In these tests, the associations are statistically significant $(\mathrm{p}<.001)$. The Cramér's V values are low $(\mathrm{V}<.08)$, which at first glance would insinuate a weak relationship between religion and armed conflict initiation (see Acock 2008: 118). However, when compared to similar cross-tabulations of control variables, we find that the Cramér's V values of the controls are just as low. Table 4-2 summarizes a series of cross-tabulations performed on Models 1 and 5, in which the dependent variables are defined at the lowest and highest thresholds (the full tables are reproduced in Appendix B). The observed and expected outcomes are reproduced only for the cell in which both the predictor and outcome are coded 1. 
Table 4-2. Summary of Cross-Tabulations.

\begin{tabular}{|c|c|c|c|c|c|c|}
\hline Predictor & $\begin{array}{c}\text { MODEL } 1 \\
\text { Observed (Expected) }\end{array}$ & $\mathrm{V}$ & $\begin{array}{l}\text { Append. } \\
\text { Table }\end{array}$ & $\begin{array}{c}\text { MODEL } 5 \\
\text { Observed (Expected) }\end{array}$ & V & $\begin{array}{l}\text { Append. } \\
\text { Table }\end{array}$ \\
\hline $\begin{array}{l}\text { Christian Chief } \\
\text { Muslim Chief } \\
\text { Buddhist Mix Chief } \\
\text { Atheist Chief }\end{array}$ & $\begin{array}{c}579(973.0)^{\star} \\
504(304.5)^{\star} \\
94(33.3)^{\star} \\
344(277.7)^{*} \\
\end{array}$ & .0653 & B-2 & $\begin{array}{c}154(384.4)^{\star} \\
218(119.4)^{\star} \\
42(12.9)^{\star} \\
141(106.3)^{\star} \\
\end{array}$ & .0609 & B-3 \\
\hline $\begin{array}{l}\text { Christian Pref. } \\
\text { Muslim Pref. } \\
\text { Buddhist Mix Pref. } \\
\text { Atheist Pref. }\end{array}$ & $\begin{array}{l}494(945.5)^{\star} \\
463(288.9)^{*} \\
138(84.6)^{*} \\
444(300.0)^{*} \\
\end{array}$ & .0757 & B-4 & $\begin{array}{c}127(378.2)^{\star} \\
215(114.8)^{\star} \\
52(33.5)^{\star} \\
197(119.3)^{\star} \\
\end{array}$ & .0707 & B-5 \\
\hline $\begin{array}{l}\text { Christian Prev. } \\
\text { Muslim Prev. } \\
\text { Buddhist Mix Prev. }\end{array}$ & $\begin{array}{l}495(954.4)^{*} \\
496(277.4)^{\star} \\
296(197.4)^{*}\end{array}$ & .0750 & $\mathrm{~B}-6$ & $\begin{array}{l}141(387.3)^{*} \\
217(111.6)^{*} \\
131(79.3)^{*} \\
\end{array}$ & .0639 & $\mathrm{~B}-7$ \\
\hline $\begin{array}{l}\text { irected CINC } \\
\text { Superiority† }\end{array}$ & $615(743.7)^{\star}$ & -.0183 & B-8 & $242(293.8)^{\star}$ & -.0117 & B-9 \\
\hline Democratic Dyad†† & $91(302.4)^{\star}$ & -.0419 & $B-10$ & $34(120.3)^{\star}$ & -.0271 & B-11 \\
\hline Defensive Alliance & 309 (337.8) & -.0052 & B-12 & $85(133.5)^{\star}$ & -.0140 & B-13 \\
\hline 25 Peace-Years $† \dagger \dagger$ & $92(666.0)^{\star}$ & -.0832 & B-14 & $31(264.4)^{*}$ & -.0537 & B-15 \\
\hline Iny Land Contiguity & $1105(389.3)^{*}$ & .1213 & B-16 & $468(151.8)^{\star}$ & .0855 & B-17 \\
\hline
\end{tabular}

${ }^{*} p<.001$

† Directed CINC Superiority: whether the CINC of State 1 is 3 times that of State 2 (Rule of 3).

t† Democratic Dyad: whether both states' adjusted Polity score is +7 or higher.

††† 25 Peace-Years: whether the dyad has 25 Peace-Years or more (this number chosen because the mean value in the data set is 24.6).

The Cramér's V values for the religious predictors are not out of place with those of the other predictors. Based on the table above, I submit that that the religious variables are about as good predictors of states' behavior as the other conventional variables used in the field—and sometimes they are better. 


\section{$\underline{\text { Logit Regressions }}$}

A series of logit regressions yields more insight on the strength of the effects of religion. For the dependent variables that are binary (coded 1 if the observed state initiated an armed conflict [in violation of jus ad bellum] and 0 if it did not), the estimate of probability $\pi$ of the outcome $Y=1$ is a logistic function of one or more explanatory variables (the independent and control variables tested here), mathematically expressed as follows:

$$
\pi=\frac{1}{1+e^{-\beta_{0}-\beta_{1} X_{1} \ldots-\beta_{\mathrm{n}} X_{\mathrm{n}}}},
$$

where:

$e$ is the base of the natural logarithm (approximately 2.718),

$\mathrm{X}_{1}$ is the measurement of religious Preference or Prevalence,

$\mathrm{X}_{2}$ is the logarithm of the Directed CINC Ratio,

$\mathrm{X}_{3}$ is the lower adjusted Polity score in the dyad;

$\mathrm{X}_{4}$ is the adjusted Polity score of the observed state (State 1);

$\mathrm{X}_{5}$ is a dummy variable for Defensive Alliance;

$\mathrm{X}_{6}$ is the logarithm of Peace-Years in the dyad;

$\mathrm{X}_{7}$ is the ordered category of the closest contiguity in the dyad (direct or colonial);

$\beta_{1}$ through $\beta_{7}$ are the coefficients for $X_{1}$ through $X_{7}$ above; and

$\beta_{0}$ is a constant $y$-intercept.

A positive coefficient denotes a positive effect of a unit increase in a variable on $\pi$ (the probability of $Y=1$ ); a negative coefficient denotes a negative effect. The higher the absolute value of the coefficient, the stronger the effect (positive or negative). 


\section{Effect of Religion Generally}

The remainder of this chapter will be devoted to testing the four largest religious categories: Christian, Muslim, Buddhist Mix, and Atheist. Logit regressions on those four categories simultaneously suggest that religion does have an effect on the propensity of a state to be the first user of force in a dispute with another state. Those four categories of religions appear to have the strongest effect when the DV is the state's chief executive and the weakest effect when the DV is the religion of the state's citizenry. In addition, when regressed simultaneously, Christianity would appear to the have strongest effect and Atheism the weakest (Appendix B, Tables B-18 through B-20).

A logit regression on the Government Religious Preference (GRP) score generally (i.e. the score for the Preferred religion, whatever religion that is) shows a significant relationship between it and the state's propensity to use force. A similar regression on the proportion of the Prevalent religion in the state's citizenry also shows a relationship, but that relationship is not as statistically significant. Table $4-3$ shows the increase in probability of initiating an armed conflict (in violation of jus ad bellum) for every $10 \%$ increase in (1) the GRP score, and (2) the proportion of citizenry that follows the Prevalent religion. 
Table 4-3. Odds Ratios for Effect of Religion Generally. ${ }^{1}$

\begin{tabular}{|c|c|c|c|c|c|c|}
\hline & Model 1 & Model 2 & Model 3 & Model 4 & Model 5 & $\begin{array}{l}\text { Appeno } \\
\text { Table }\end{array}$ \\
\hline $\begin{array}{l}\text { For every } 10 \% \text { increase } \\
\text { in GRP, probability of } \\
\text { initiation increases by: }\end{array}$ & $7.1 \%$ *** & $8.8 \%$ *** & $7.4 \%$ *** & $9.2 \%$ *** & $10.9 \%$ *** & B-21 \\
\hline $\begin{array}{l}\text { For every } 10 \% \text { increase in } \\
\text { religiously Prevalent pop'n, } \\
\text { initiation increases by: }\end{array}$ & $4.7 \%$ & $4.9 \%$ & $8.6 \% *$ & $9.4 \% *$ & $13.7 \%$ * & B-23 \\
\hline
\end{tabular}

${ }^{\circ} p<.10{ }^{*} p<.05{ }^{* *} p<.01{ }^{* * *} p<.001$

These results lend strong support to the hypothesis that the stronger the religious Preference of the governing regime, the more likely the state is to use force. It may be inferred from this finding that religious extremism is at least a catalyst for political violence. There is precedent for this phenomenon in all religions; radical Islam has in recent years been most notable for violent tendencies (e.g. bin Laden 1996, 1998), but there have also been cases of violence by Hindu and Buddhist extremists (Banerjee 1999; Shani 2007; Cady 2006; Tambiah 1992; Obeyesekere 2006: 134-7; Schmidt-Leukel 2004b) as well as by Christian extremists, as the 2011 terrorist attack in Oslo has demonstrated (Erlanger \& Shane 2011). The above results lend mild support to the hypothesis that the more religiously homogeneous its citizenry, the more likely the state is to use force.

This section provides a convenient opportunity to revisit Errol Henderson's (1997) claim that ethnic similarity leads to more war. When regimes' religious Preferences are compared, my results support the opposite conclusion. States with the same religious

\footnotetext{
${ }^{1}$ The logit coefficients are reproduced in Appendix B, Table B-22 for GRP score and Table B-24 for percentage of the population.
} 
Preferences are less likely to use force on one another, with logit coefficients uniformly negative (Appendix B, Tables B-27 \& B-28). States in which the chief executives are of the same religion are similarly less likely to use force on each other (Appendix B, Tables B-25 \& B-26). ${ }^{2}$ Measurements of similar religious demographics of states' citizenries also result in negative coefficients, but none of them are statistically significant (Appendix B, Tables B-29 \& B-30). These results may not refute Henderson's claim conclusively, but they do at least undermine it.

\section{Effect of Christianity}

Regressions on individual religious categories provide much useful insight. The number of tables of logit regressions necessary for the findings of the next few sections could quite overwhelm the reader, and for that reason this chapter shall summarize the contents of those tables rather than reproduce them in full (they are reproduced in full in

\section{Appendix B).}

We begin with Christianity. The results support the conclusion that a Christian state is less likely_sometimes much less likely_to initiate an interstate armed conflict than a non-Christian state. The logit coefficients associated with each of the Christian independent variables (all denominations combined) are summarized in Table 4-4; odds ratios are compiled in Table 4-5. The tables reveal a strong negative effect of Christianity on the

\footnotetext{
${ }^{2}$ For both religious Preference and the religion of the chief executive, the logit coefficients are statistically more significant at lower thresholds of initiating armed conflict than at higher thresholds, and they are stronger and far more significant when the religious categories are simplified to Christian (all), Muslim (all), Buddhist Mix, and Atheist.
} 
propensity of states to use force. The effect of a Christian regime Preference is nearly twice as strong as that of a Christian population (in both the binary and scaled variables). The statistical significance for Preference is stronger than that for the population, but no coefficient has a $\mathrm{p}$ value greater than 0.10 . The negative effect of Christianity grows stronger as the threshold of force necessary to "initiate an armed conflict" is raised; the coefficients are nearly three times as strong in Model 5 (initiating an armed conflict with fatalities) as in Model 1 (initiating an armed conflict merely by crossing the border).

Table 4-4. Summary of Logit Coefficients for Christian States.

\begin{tabular}{|c|c|c|c|c|c|c|}
\hline Variable & Model 1 & Model 2 & Model 3 & Model 4 & Model 5 & $\begin{array}{l}\text { App. } \\
\text { Table }\end{array}$ \\
\hline & (Robust SE) & & & & & \\
\hline $\begin{array}{l}\text { Christian } \\
\text { Chief Exec. (binary) }\end{array}$ & $\begin{array}{l}-.2958^{* *} \\
(.0915)\end{array}$ & $\begin{array}{r}-.3362^{* * *} \\
(.0972)\end{array}$ & $\begin{array}{r}-.3942^{* * *} \\
(.1022)\end{array}$ & $\begin{array}{r}-.4468^{\star \star *} \\
(.1108)\end{array}$ & $\begin{array}{r}-.8108^{\star * *} \\
(.1839)\end{array}$ & B-31 \\
\hline $\begin{array}{l}\text { Christian } \\
\text { Preference (binary) }\end{array}$ & $\begin{array}{l}-.3544^{* *} \\
(.1103)\end{array}$ & $\begin{array}{r}-.4254^{* * *} \\
(.1157)\end{array}$ & $\begin{array}{r}-.4096^{* * *} \\
(.1239)\end{array}$ & $\begin{array}{r}-.4935^{\star * *} \\
(.1324)\end{array}$ & $\begin{array}{r}-.9542^{* * *} \\
(.2207)\end{array}$ & B-32 \\
\hline $\begin{array}{l}\text { Christian } \\
\text { GRP (every 10\%) }\end{array}$ & $\begin{array}{c}-.0620^{* *} \\
(.0234)\end{array}$ & $\begin{array}{r}-.0671^{\star *} \\
(.0246)\end{array}$ & $\begin{array}{r}-.0781^{\star *} \\
(.0261)\end{array}$ & $\begin{array}{r}-.0842^{\star *} \\
(.0278)\end{array}$ & $\begin{array}{r}-.2013^{\star \star *} \\
(.0480)\end{array}$ & B-33 \\
\hline $\begin{array}{l}\text { Christian } \\
\text { Prevalence (binary) }\end{array}$ & $\begin{array}{l}-.2085^{\circ} \\
(.1121)\end{array}$ & $\begin{array}{l}-.2082^{\circ} \\
(.1182)\end{array}$ & $\begin{array}{l}-.2788^{*} \\
(.1250)\end{array}$ & $\begin{array}{l}-.2907^{*} \\
(.1338)\end{array}$ & $\begin{array}{l}-.5973^{*} \\
(.2329)\end{array}$ & B-34 \\
\hline $\begin{array}{l}\text { Christian } \\
\text { Pop. (every 10\%) }\end{array}$ & $\begin{array}{r}-.0341^{* *} \\
(.0132) \\
\end{array}$ & $\begin{array}{r}-.0342^{\star} \\
(.0140) \\
\end{array}$ & $\begin{array}{c}-.0459^{\star *} \\
(.0148) \\
\end{array}$ & $\begin{array}{c}-.0478^{\star \star} \\
(.0158) \\
\end{array}$ & $\begin{array}{r}-.0814^{\star *} \\
(.0265) \\
\end{array}$ & B-35 \\
\hline
\end{tabular}

${ }^{\circ} p<.10 \quad{ }^{*} p<.05 \quad{ }^{* *} p<.01{ }^{* * *} p<.001$

Table 4-5. Summary of Odds Ratios for Christian States.

\begin{tabular}{lllllll}
\multirow{2}{*}{$\begin{array}{l}\text { Cariable } \\
\text { Model 1 }\end{array}$} & Model 2 & $\underline{\text { Model 3 }}$ & Model 4 & Model 5 \\
Christian Chief. Exec. (binary) & $-25.6 \%^{* *}$ & $-28.6 \%^{* *}$ & $-32.6 \%^{* * *}$ & $-36.0 \%^{* * *}$ & $-55.6 \%^{* * *}$ \\
Christian Preference (binary) & $-29.9 \%^{* *}$ & $-34.7 \%^{* * *}$ & $-33.6 \%^{* *}$ & $-39.0 \%^{* * *}$ & $-61.5 \%^{* * *}$ \\
Christian GRP (every 10\%) & $-6.0 \%^{* *}$ & $-6.5 \%^{* *}$ & $-7.5 \%^{* *}$ & $-8.1 \%^{* *}$ & $-18.2 \%^{* * *}$ \\
Christian Prevalence (binary) & $-18.8 \%^{\circ}$ & $-18.8 \%^{\circ}$ & $-24.3 \%^{*}$ & $-25.2 \%^{*}$ & $-45.0 \%^{*}$ \\
Christian Pop. (every 10\%) & $-3.4 \%^{*}$ & $-3.4 \%^{*}$ & $-4.5 \%^{* *}$ & $-4.7 \%^{* *}$ & $-7.8 \%^{* *}$ \\
\hline
\end{tabular}

${ }^{\circ} p<.10{ }^{*} p<.05{ }^{* *} p<.01{ }^{* * *} p<.001$ 
Figures 4A and 4B graph the effects of a Christian religious Preference and Christian population, respectively, on the predicted probabilities of initiating an armed conflict.

Figure 4A. Graph of Christian GRP Score.

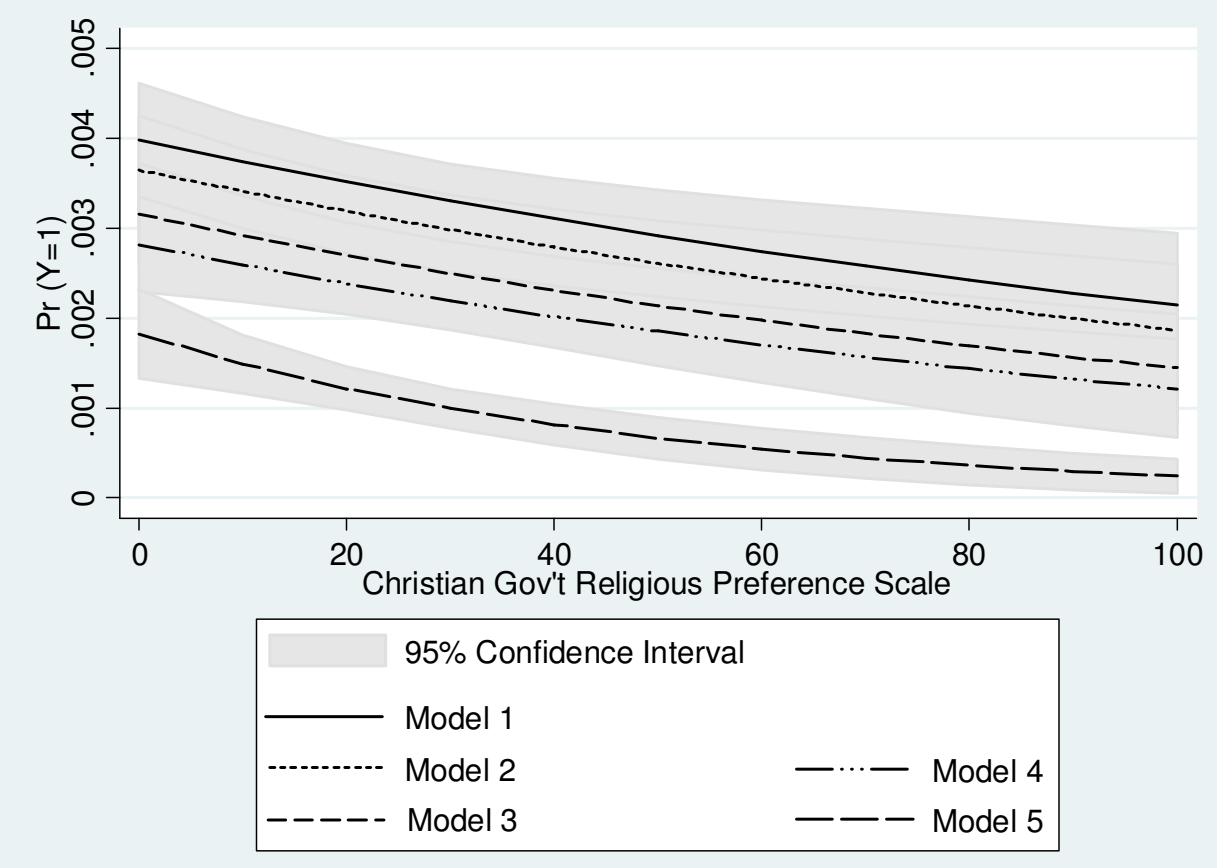

Figure 4B. Graph of Christian Population.

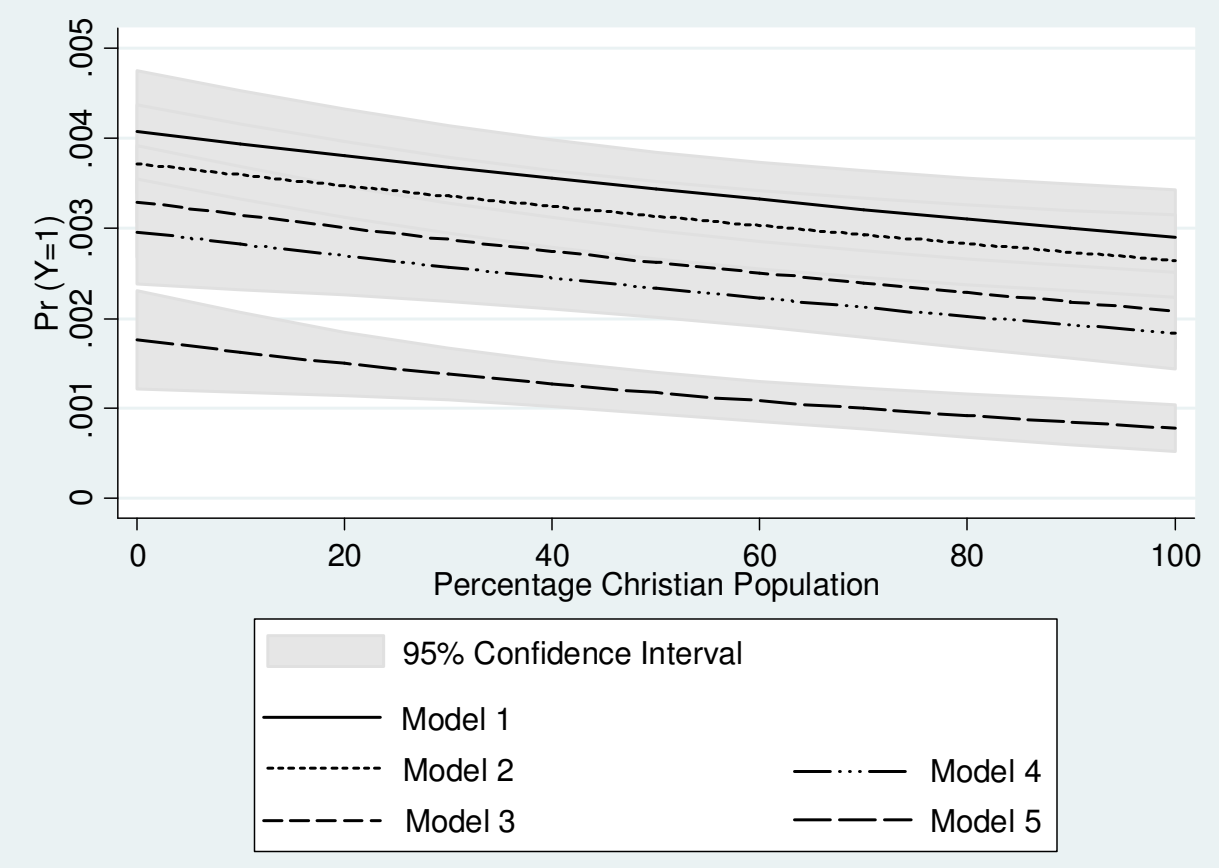


These graphs show a steady decline in the propensity to use force as the Christian GRP score and Christian population increase, with the former having a stronger negative effect than the latter. The lines depicting the probabilities of initiating armed conflicts with fatalities (Model 5) are somewhat more curvilinear, reflecting a sharper decline in probability when the Christian GRP or percentage of population increases from 0 to $40 \%$, but the confidence intervals are wider in that range as well, making it possible that the actual lines for Model 5 are shaped more like those of Models 1 through 4.

\section{Effect of Islam}

Whereas the results for Christianity above suggest that Christian states are less likely to use force than non-Christian states, the results for Islam suggest that Muslim states are somewhat more likely to use force than non-Muslim states. The logit coefficients associated with each of the Muslim independent variables (all branches combined) are summarized in Table 4-6; odds ratios are compiled in Table 4-7. Every coefficient is positive, but not all of them are statistically significant. We cannot conclude with sufficient certainty that Muslim states are more or less likely than non-Muslim states to use force at a low level, i.e. when the threshold for defining an "armed conflict" is low. When the threshold is raised, however, we are more certain of an effect. At higher thresholds, Muslim states are 20 to 30 percent more likely to use force, with the effect of Muslim Prevalence within the population being slightly stronger than that of a Muslim regime Preference. At the highest threshold, the increase in propensity is sudden and even a bit startling: Muslim states are roughly $70 \%$ more likely to initiate an interstate armed 
conflict with fatalities than non-Muslim states, with the likelihood increasing roughly $7 \%$ for every $10 \%$ increase in GRP score or Muslim population.

Table 4-6. Summary of Logit Coefficients for Muslim States.

\begin{tabular}{|c|c|c|c|c|c|c|}
\hline Variable & Model 1 & Model 2 & Model 3 & Model 4 & Model 5 & $\begin{array}{l}\text { App. } \\
\text { Table }\end{array}$ \\
\hline $\begin{array}{l}\text { Muslim } \\
\text { Chief Exec. (binary) }\end{array}$ & $\begin{array}{l}.0564 \\
(.0972)\end{array}$ & $\begin{array}{l}.0534 \\
(.1001)\end{array}$ & $\begin{array}{l}.2222^{*} \\
(.1051)\end{array}$ & $\begin{array}{l}.2373^{*} \\
(.1094)\end{array}$ & $\begin{array}{r}.5767^{* *} \\
(.1774)\end{array}$ & B-36 \\
\hline $\begin{array}{l}\text { Muslim } \\
\text { Preference (binary) }\end{array}$ & $\begin{array}{l}.0167 \\
(.0992)\end{array}$ & $\begin{array}{l}.0120 \\
(.1022)\end{array}$ & $\begin{array}{l}.1862^{\circ} \\
(.1070)\end{array}$ & $\begin{array}{l}.1990^{\circ} \\
(.1112)\end{array}$ & $\begin{array}{r}.5423^{* *} \\
(.1759)\end{array}$ & B-37 \\
\hline $\begin{array}{l}\text { Muslim } \\
\text { GRP (every 10\%) }\end{array}$ & $\begin{array}{l}.0100 \\
(.0134)\end{array}$ & $\begin{array}{l}.0103 \\
(.0138)\end{array}$ & $\begin{array}{l}.0318^{*} \\
(.0142)\end{array}$ & $\begin{array}{l}.0344^{*} \\
(.0147)\end{array}$ & $\begin{array}{l}.0632^{* *} \\
(.0222)\end{array}$ & B-38 \\
\hline $\begin{array}{l}\text { Muslim } \\
\text { Prevalence (binary) }\end{array}$ & $\begin{array}{l}.0738 \\
(.0993)\end{array}$ & $\begin{array}{l}.0625 \\
(.1022)\end{array}$ & $\begin{array}{l}.2540^{\star} \\
(.1067)\end{array}$ & $\begin{array}{l}.2593^{*} \\
(.1108)\end{array}$ & $\begin{array}{r}.5368^{* *} \\
(.1782)\end{array}$ & B-39 \\
\hline $\begin{array}{l}\text { Muslim } \\
\text { Pop. (every 10\%) }\end{array}$ & $\begin{array}{r}.0142 \\
(.0115)\end{array}$ & $\begin{array}{l}.0127 \\
(.0119)\end{array}$ & $\begin{array}{r}.0346^{\star \star} \\
(.0125) \\
\end{array}$ & $\begin{array}{r}.0349^{\star *} \\
(.0130) \\
\end{array}$ & $\begin{array}{r}.0696^{* * *} \\
(.0206) \\
\end{array}$ & B-40 \\
\hline
\end{tabular}

${ }^{\circ} p<.10 \quad{ }^{*} p<.05 \quad{ }^{* *} p<.01{ }^{* * *} p<.001$

Table 4-7. Summary of Odds Ratios for Muslim States.

\begin{tabular}{llllll}
\multirow{2}{*}{$\begin{array}{l}\text { Variable } \\
\text { CHANGE IN PROBABILITY OF INITIATION }\end{array}$} & \multicolumn{1}{l}{ Model 1 } & Model 2 & $\underline{\text { Model 3 }}$ & Model 4 & Model 5 \\
Muslim Chief. Exec. (binary) & $+5.8 \%$ & $+5.5 \%$ & $+24.9 \%^{*}$ & $+26.8 \%^{*}$ & $+78.0 \%^{* *}$ \\
Muslim Preference (binary) & $+1.7 \%$ & $+1.2 \%$ & $+20.5 \%^{\circ}$ & $+22.0 \%^{\circ}$ & $+72.0 \%^{* *}$ \\
Muslim GRP (every 10\%) & $+1.0 \%$ & $+1.0 \%$ & $+3.2 \%^{*}$ & $+3.5 \%^{*}$ & $+6.5 \%^{* *}$ \\
Muslim Prevalence (binary) & $+7.7 \%$ & $+6.4 \%$ & $+28.9 \%^{*}$ & $+29.6 \%^{*}$ & $+71.1 \%^{* *}$ \\
Muslim Pop. (every 10\%) & $+1.4 \%$ & $+1.3 \%$ & $+3.5 \%^{* *}$ & $+3.6 \%^{* *}$ & $+7.2 \%^{* *}$ \\
\hline
\end{tabular}

${ }^{\circ} \mathrm{p}<.10{ }^{*} \mathrm{p}<.05 \quad{ }^{* *} \mathrm{p}<.01{ }^{* * *} \mathrm{p}<.001$

Figures 4C and 4D graph the effects of a Muslim religious Preference and Muslim population, respectively, on the predicted probabilities of initiating an interstate armed conflict. 
Figure 4C. Graph of Muslim GRP Score.

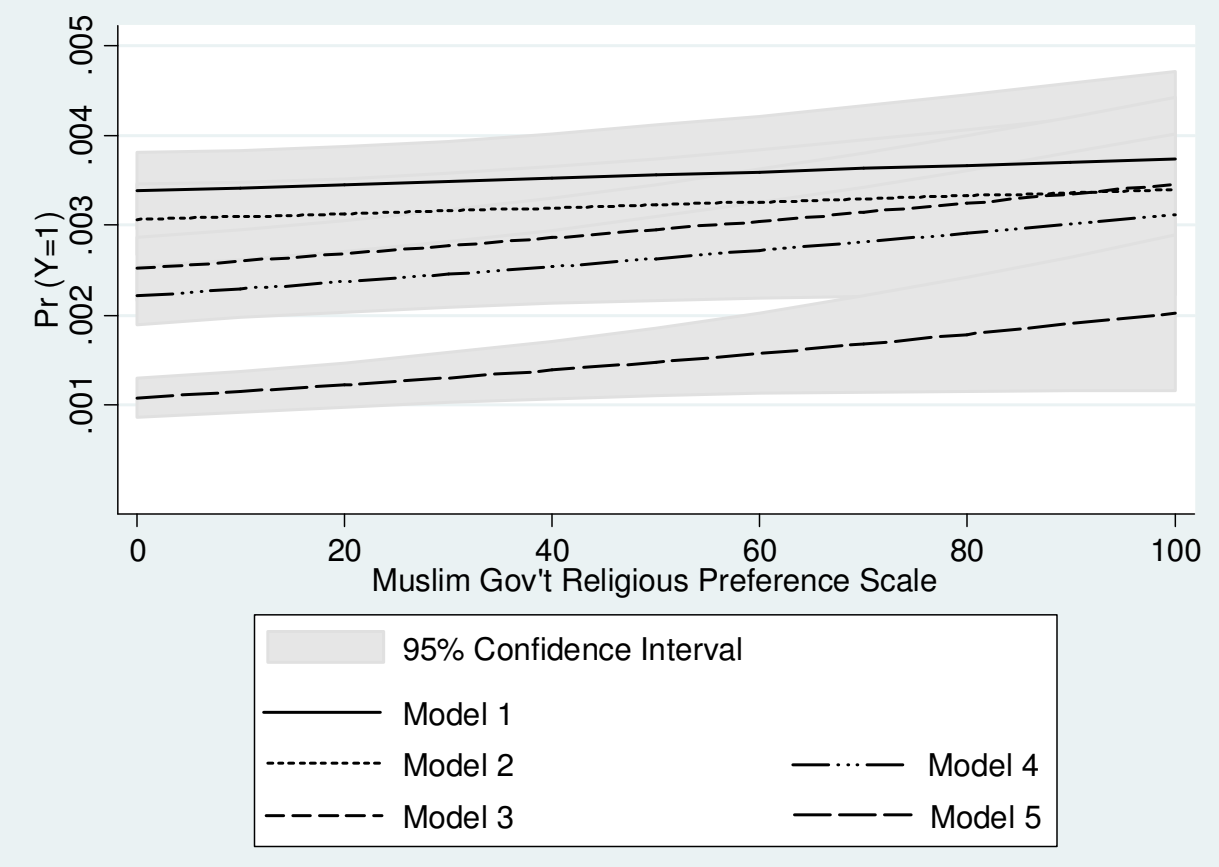

Figure 4D. Graph of Muslim Population.

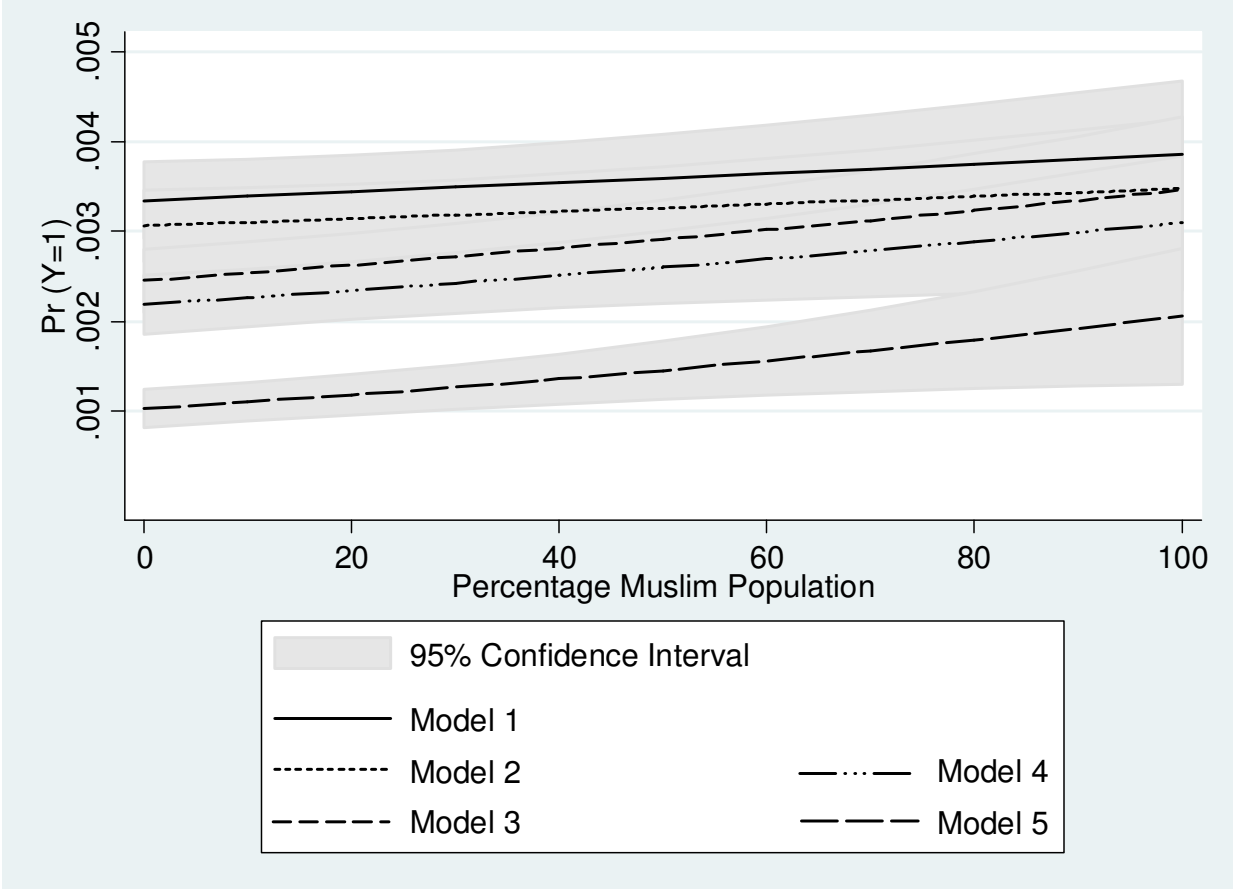

These graphs show a steady increase in probability as the Muslim GRP score and population increase. Although the confidence intervals for Models 1 and 2 (the lower 
thresholds) are very large (large enough to negate their statistical significance), it appears nevertheless that the graphs for the lower thresholds have shallower slopes than those for the higher thresholds. This finding is also noticeable in Table 4-7, which shows that the odds ratios for Models 3 and 4 are roughly three times those for Models 1 and 2. Given the markedly larger odd ratios for Model 5, it was expected that the slopes for Model 5 on the graphs would be the highest of all, but the large confidence intervals in the range of 70 to 100 percent Muslim GRP Score and population may negate those larger slopes. It is also noticed that at high Muslim regime GRP Scores and percentages of populations, the likelihoods of initiating interstate armed conflicts for Models 3 and 4 approach those for the lower thresholds of force (Models 1 and 2). In Model 5 (fatalities, the highest threshold), the absolute likelihood of using force is significantly lower than in the rest of the models, but the effect of an increase in the Muslim GRP Score/population is stronger.

\section{Effect of Buddhism Mix}

The effect of the Buddhist Mix category on a state's propensity to use force appears to be the inverse of that of Islam. Like that of Islam, the Buddhist Mix effect is generally positive, if not always statistically significant. But whereas the Muslim effect is stronger and more significant at higher thresholds of force (Models 3-5), the Buddhist effect is stronger and more significant at lower thresholds (Models 1-2). Table 4-8 summarizes the logit coefficients for the Buddhist Mix category; Table 4-9 compiles the odds ratios. Despite the strong coefficients in the higher thresholds, the confidence intervals are too high to conclude with confidence that Buddhist Mix states are any more likely than nonBuddhist Mix states to use force at high degrees of severity (especially those with fatal- 
ities). For low-level conflicts, however, the positive effect of a Buddhist Mix Prevalence is strong-stronger and more significant than that of a Buddhist Mix regime Preference (which is the opposite of the trend for Christianity and Islam).

Table 4-8. Summary of Logit Coefficients for Buddhist Mix States.

\begin{tabular}{|c|c|c|c|c|c|c|}
\hline Variable & Model 1 & Model 2 & Model 3 & Model 4 & Model 5 & $\begin{array}{l}\text { App. } \\
\text { Table }\end{array}$ \\
\hline $\begin{array}{l}\text { Buddhist Mix } \\
\text { Chief Exec. (binary) }\end{array}$ & $\begin{aligned}-.0652 \\
(.2258)\end{aligned}$ & $\begin{aligned}-.0343 \\
(.2320)\end{aligned}$ & $\begin{array}{r}-.2702 \\
(.2751)\end{array}$ & $\begin{array}{l}-.2417 \\
(.2863)\end{array}$ & $\begin{array}{l}-.8603 \dagger \\
(.5848)\end{array}$ & B-41 \\
\hline $\begin{array}{l}\text { Buddhist Mix } \\
\text { Preference }\end{array}$ & $\begin{array}{l}.2538 \dagger \\
(.1764)\end{array}$ & $\begin{array}{l}.3005^{\circ} \\
(.1794)\end{array}$ & $\begin{array}{l}.1272 \\
(.2062)\end{array}$ & $\begin{array}{c}.1850 \\
(.2108)\end{array}$ & $\begin{array}{l}-.4460 \\
\quad(.4197)\end{array}$ & B-42 \\
\hline $\begin{array}{l}\text { Buddhist Mix } \\
\text { GRP }(0-10)\end{array}$ & $\begin{array}{l}.0631^{\circ} \\
(.0324)\end{array}$ & $\begin{array}{l}.0649^{*} \\
(.0329)\end{array}$ & $\begin{array}{l}.0485 \\
(.0387)\end{array}$ & $\begin{array}{l}.0512 \\
(.0397)\end{array}$ & $\begin{array}{l}-.0233 \\
(.0701)\end{array}$ & B-43 \\
\hline $\begin{array}{l}\text { Buddhist Mix } \\
\text { Prevalence }\end{array}$ & $\begin{array}{l}.3804^{\star *} \\
(.1247)\end{array}$ & $\begin{array}{l}.3916^{\star *} \\
(.1292)\end{array}$ & $\begin{aligned} .2534^{\circ} \\
(.1386)\end{aligned}$ & $\begin{array}{l}.2579^{\circ} \\
(.1450)\end{array}$ & $\begin{array}{c}.1954 \\
(.2209)\end{array}$ & B-44 \\
\hline $\begin{array}{l}\text { Buddhist Mix } \\
\text { Population (10\%) }\end{array}$ & $\begin{array}{r}.0374^{\star *} \\
(.0136) \\
\end{array}$ & $\begin{array}{r}.0402^{* *} \\
(.0140) \\
\end{array}$ & $\begin{array}{c}.0230 \dagger \\
(.0152) \\
\end{array}$ & $\begin{array}{r}.0256 \dagger \\
(.0158) \\
\end{array}$ & $\begin{array}{r}.0140 \\
(.0250) \\
\end{array}$ & B-45 \\
\hline
\end{tabular}

${ }^{\circ} \mathrm{p}<.10 \quad{ }^{*} \mathrm{p}<.05 \quad{ }^{* *} \mathrm{p}<.01{ }^{* * *} \mathrm{p}<.001$

$\dagger p<.15$

Table 4-9. Summary of Odds Ratios for Buddhist Mix States.

\begin{tabular}{|c|c|c|c|c|c|}
\hline & \multicolumn{5}{|c|}{ CHANGE IN PROBABILITY OF INITIATION } \\
\hline Variable & Model 1 & Model 2 & Model 3 & Model 4 & Model 5 \\
\hline Buddhist Mix Chief (binary) & $-6.3 \%$ & $-3.4 \%$ & $-23.7 \%$ & $-21.5 \%$ & $-57.7 \% \dagger$ \\
\hline Buddhist Mix Pref. (binary) & $+28.9 \% \dagger$ & $+35.0 \%{ }^{\circ}$ & $+13.6 \%$ & $+20.3 \%$ & $-36.0 \%$ \\
\hline Buddhist Mix GRP (every 10\%) & $+6.5 \%^{\circ}$ & $+6.7 \%{ }^{*}$ & $+5.0 \%$ & $+5.3 \%$ & $-2.3 \%$ \\
\hline Buddhist Mix Prev. (binary) & $+46.3 \%$ ** & $+47.9 \%$ ** & $+28.8 \%^{\circ}$ & $+29.4 \%^{\circ}$ & $+21.6 \%$ \\
\hline Buddhist Mix Pop. (every 10\%) & $+3.8 \%$ ** & $+4.1 \%{ }^{* *}$ & $+2.3 \%$ & $+2.6 \%$ & $+1.4 \%$ \\
\hline
\end{tabular}

${ }^{\circ} p<.10{ }^{*} p<.05 \quad{ }^{* *} p<.01{ }^{* * *} p<.001$

$+p<.15$ 
The causes of these trends are not entirely clear. One possibility is that the East Asian (all) category is diluting the otherwise stronger effect of Buddhism itself. ${ }^{3}$ Another possibility, given that some Buddhist Mix states are Communist (with primarily Atheist Preferences) and that the most frequent aggressors in the Buddhist Mix category are Communist states, is that the Atheist regime Preference is having a stronger effect on the Buddhist Mix states than Buddhism itself. A third possible explanation for these results is the geopolitical effect of the Asia-Pacific region-perhaps that region is more conflict prone than other regions. This effect, however, cannot be isolated completely from the effects of the Buddhist Mix category, for all Buddhist Mix states are located within the Asia-Pacific region.

Figures 4E and 4F graph the effects of a Buddhist Mix religious Preference and Buddhist Mix population, respectively, on the predicted probabilities of initiating an interstate armed conflict.

\footnotetext{
${ }^{3}$ Tables for the Buddhist (Pure) category are not reproduced here, but that category will be taken up in Chapter 7.
} 
Figure 4E. Graph of Buddhist Mix GRP Score.

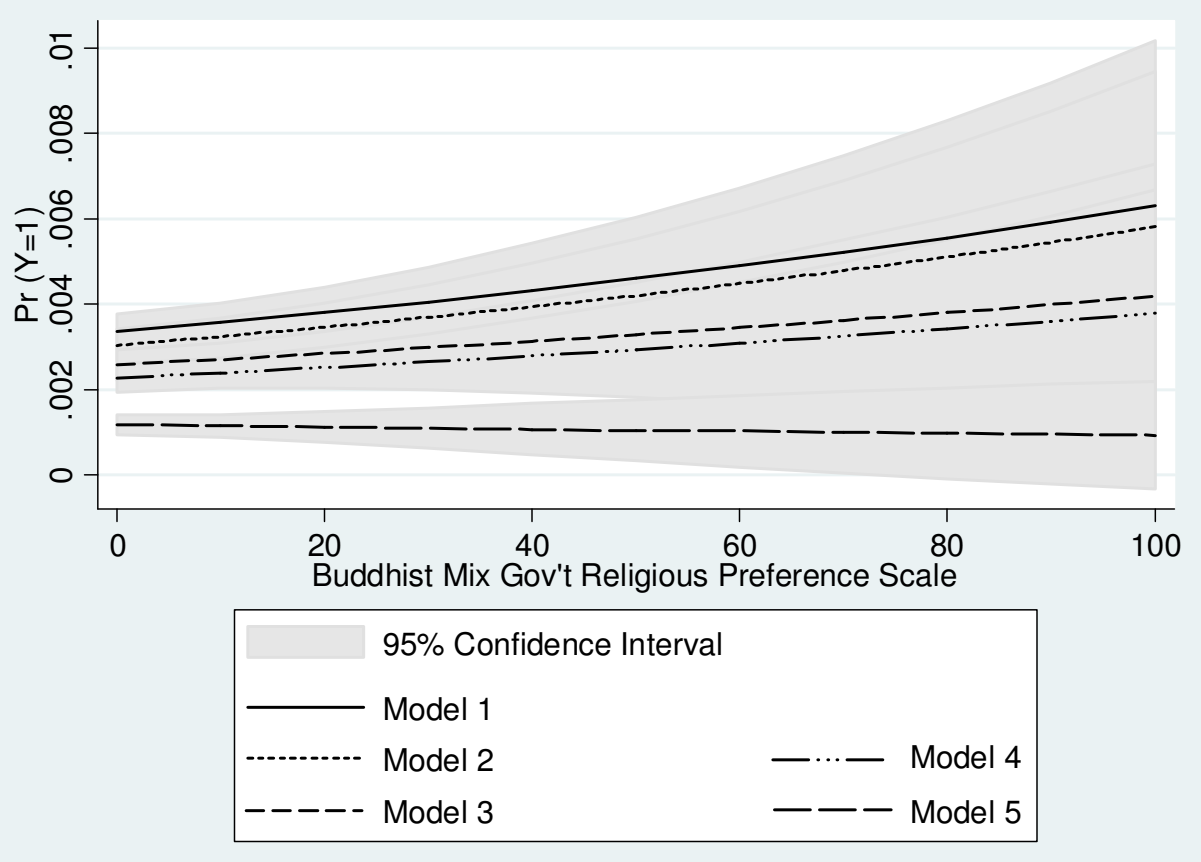

Figure 4F. Graph of Buddhist Mix Population.

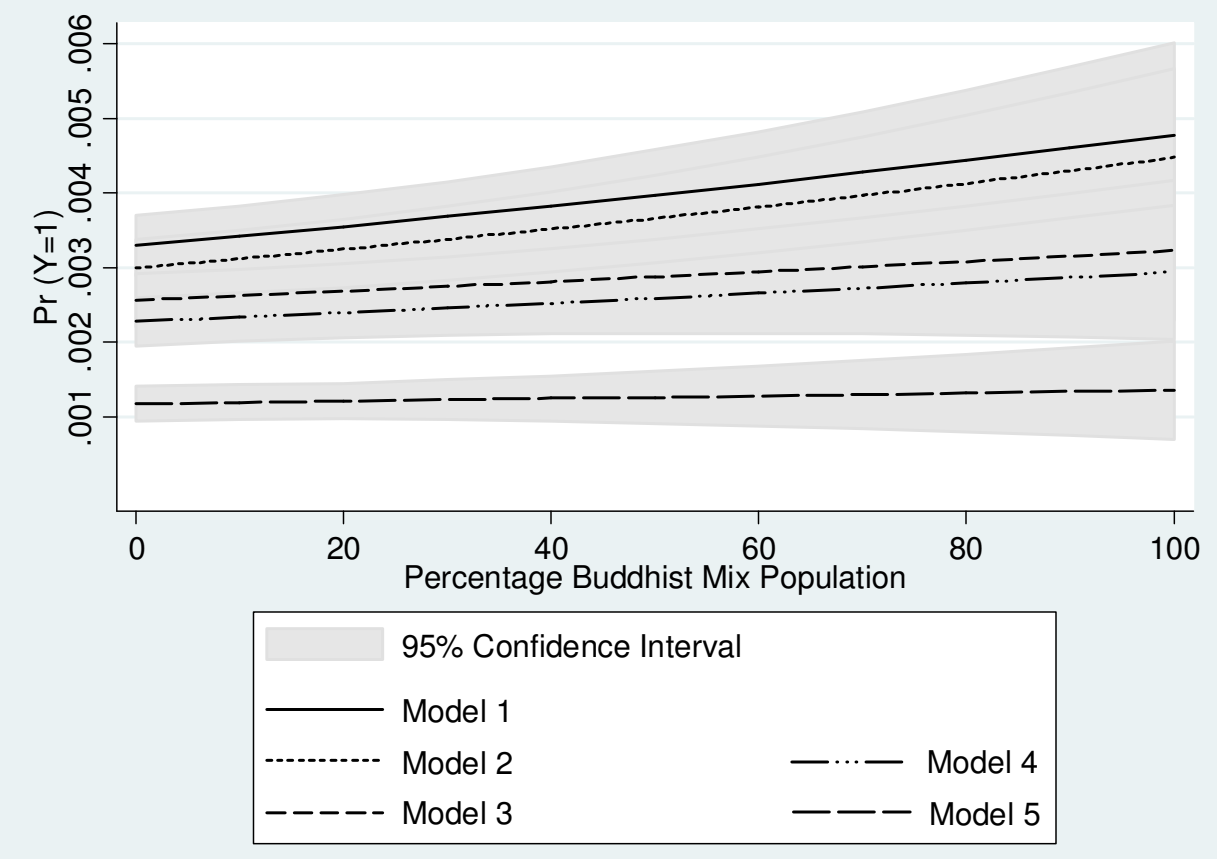

Each line shows an increase in propensity to use force as the Buddhist Mix Preference or population increases. The slopes of the lines for the two lower thresholds (Models 1 and 
2) are steepest; the slopes for the higher thresholds (Models 3-5) are shallow. This suggests that the effect of the Buddhist Mix category is strong in Models 1 and 2 but weak in the others, though the wide confidence intervals call into question whether the category has any statistically significant effect at all, especially in the higher ranges of the Buddhist Mix GRP Scores and populations.

\section{Effect of Atheist Preference}

In one respect, states with Atheist Preferences (of which nearly all are Communist) behave like Buddhist Mix states; they are one-fourth to one-third more likely to initiate an interstate armed conflict at a low threshold of force (Models 1 and 2). These results are statistically significant. In another respect, however, Atheist states behave differently: at the highest threshold (Model 5, with fatalities), they are nearly one-third more likely to use force, whereas states with Buddhist Mix Preferences were much less likely to do so (but without statistical significance). However, most of the confidence intervals for the higher thresholds are slightly too wide to confer statistical significance on their results according to the convention of the field - though they does not miss significance by much. Having an Atheist chief executive appears to have no statistically significant effect. Table 4-10 summarizes the logit coefficients for states with Atheist Preferences; Table 4-11 compiles the odds ratios. 
Table 4-10. Summary of Logit Coefficients for Atheist States.

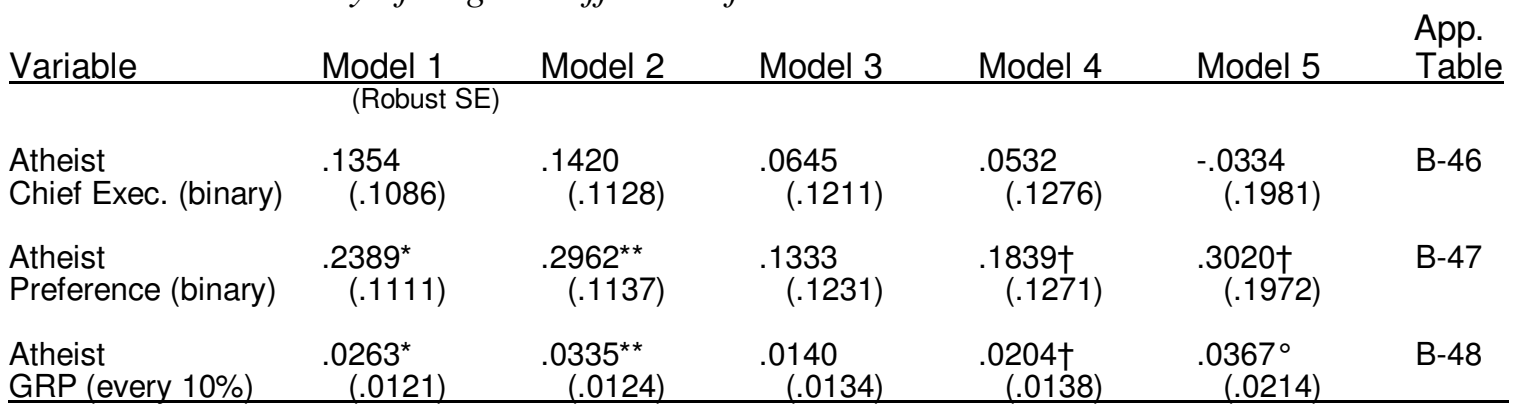

${ }^{\circ} p<.10 \quad{ }^{*} p<.05 \quad{ }^{* *} p<.01{ }^{* * *} p<.001$

$\dagger p<.15$

Table 4-11. Summary of Odds Ratios for Atheist States.

\begin{tabular}{llllll}
\multirow{2}{*}{$\begin{array}{l}\text { Cariable } \\
\text { CHANGE IN PROBABILITY OF INITIATION }\end{array}$} & Model 1 & $\underline{\text { Model 2 }}$ & $\underline{\text { Model 3 }}$ & $\underline{\text { Model 4 }}$ & Model 5 \\
Atheist Chief Exec. (binary) & $+14.5 \%$ & $+15.3 \%$ & $+6.7 \%$ & $+5.5 \%$ & $+3.3 \%$ \\
Atheist Preference (binary) & $+27.0 \%^{*}$ & $+34.5 \% \%^{* *}$ & $+14.3 \%$ & $+20.2 \% \dagger$ & $+35.3 \% \dagger$ \\
Atheist GRP (every 10\%) & $+2.7 \%^{*}$ & $+3.4 \%^{* *}$ & $+1.4 \%$ & $+2.1 \% \dagger$ & $+3.7 \%{ }^{\circ}$ \\
\hline
\end{tabular}

${ }^{\circ} \mathrm{p}<.10 \quad{ }^{*} \mathrm{p}<.05 \quad{ }^{* *} \mathrm{p}<.01{ }^{* * *} \mathrm{p}<.001$

$\dagger p<.15$

What is curious about these figures is that they indicate a greater propensity of Atheist states to use force at lower thresholds, and a faint-heartedly greater propensity at the higher thresholds as well, but not at the middle threshold.

Figure 4G graphs the effect on the predicted probabilities of initiating an armed conflict, of an Atheist Preference. 
Figure 4G. Graph of Atheist GRP Score.

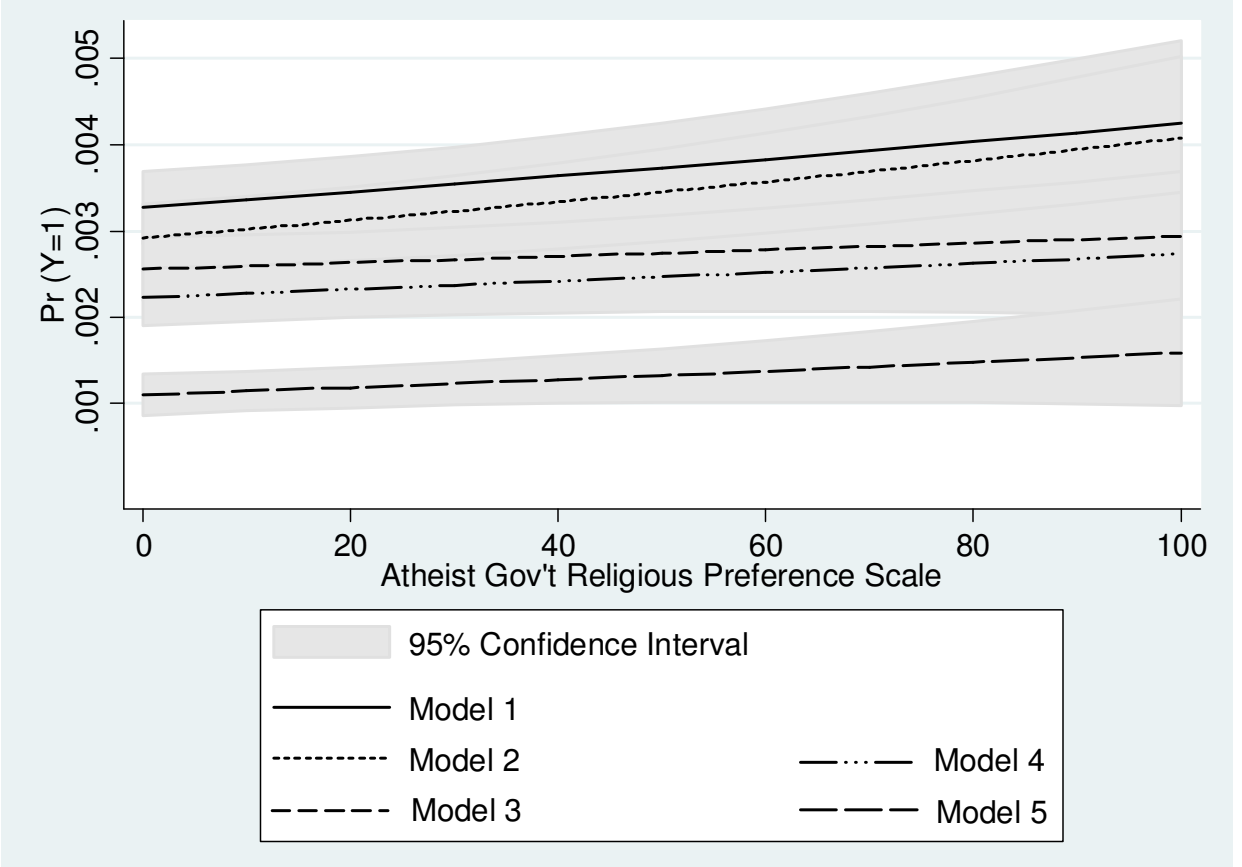

The slope of the line for Model 3 is the shallowest, indicating a minimal effect of Atheism, if any, in that Model. The slope is steepest in Models 1 and 2 (the lower thresholds), indicating that the effect of Atheism is strongest in those models.

\section{Comparing Effects of Religions}

Tables 4-12 through 4-16 summarize the logit coefficients for each religious category, of the religion of the chief executive, religious Preference, GRP Score, religious Prevalence, and percentage of population, respectively. The strongest findings are that Christianity is associated with a dramatic reduction in propensity to initiate interstate armed conflicts (compared to non-Christianity), especially armed conflicts with fatalities. The other religious categories are associated generally with a moderate to large increase 
in the same, but not uniformly across all models, and without the consistently high confidence that characterize the findings for Christianity.

Table 4-12. Summary of Logit Coefficients for Religion of Chief Executive.

\begin{tabular}{|c|c|c|c|c|c|c|}
\hline Variable & $\frac{\text { Model } 1}{\text { (Robust }}$ & Model 2 & Model 3 & Model 4 & Model 5 & Table \\
\hline $\begin{array}{l}\text { Christian } \\
\text { Chief Exec. (binary) }\end{array}$ & $\begin{array}{r}-.2958^{* *} \\
(.0915)\end{array}$ & $\begin{array}{r}-.3362^{* * *} \\
(.0972)\end{array}$ & $\begin{array}{r}-.3942^{* * *} \\
(.1022)\end{array}$ & $\begin{array}{r}-.4468^{* * *} \\
(.1108)\end{array}$ & $\begin{array}{r}-.8108^{* * *} \\
(.1839)\end{array}$ & B-31 \\
\hline $\begin{array}{l}\text { Muslim } \\
\text { Chief Exec. (binary) }\end{array}$ & $\begin{array}{l}.0564 \\
(.0972)\end{array}$ & $\begin{array}{l}.0534 \\
(.1001)\end{array}$ & $\begin{array}{l}.2222^{*} \\
(.1051)\end{array}$ & $\begin{array}{l}.2373^{*} \\
(.1094)\end{array}$ & $\begin{array}{l}.5767^{\star *} \\
(.1774)\end{array}$ & B-36 \\
\hline $\begin{array}{l}\text { Buddhist Mix } \\
\text { Chief Exec. (binary) }\end{array}$ & $\begin{array}{l}-.0652 \\
(.2258)\end{array}$ & $\begin{array}{l}-.0343 \\
(.2320)\end{array}$ & $\begin{array}{l}-.2702 \\
(.2751)\end{array}$ & $\begin{array}{l}-.2417 \\
(.2863)\end{array}$ & $\begin{array}{l}-.8603 \dagger \\
(.5848)\end{array}$ & B-41 \\
\hline $\begin{array}{l}\text { Atheist } \\
\text { Chief Exec. (binary) }\end{array}$ & $\begin{array}{r}.1354 \\
(.1086)\end{array}$ & $\begin{array}{l}.1420 \\
(.1128) \\
\end{array}$ & $\begin{array}{l}.0645 \\
(.1211) \\
\end{array}$ & $\begin{array}{l}.0532 \\
(.1276) \\
\end{array}$ & $\begin{aligned}-.0334 \\
(.1981) \\
\end{aligned}$ & B-46 \\
\hline
\end{tabular}

${ }^{\circ} \mathrm{p}<.10{ }^{*} \mathrm{p}<.05{ }^{* *} \mathrm{p}<.01{ }^{* * *} \mathrm{p}<.001$

$\dagger p<.15$

Table 4-13. Summary of Logit Coefficients for Religious Preference.

\begin{tabular}{|c|c|c|c|c|c|c|}
\hline Variable & Model 1 & Model 2 & Model 3 & Model 4 & Model 5 & Table \\
\hline & (Robust & & & & & \\
\hline $\begin{array}{l}\text { Christian } \\
\text { Preference (binary) }\end{array}$ & $\begin{array}{r}-.3544^{\star *} \\
(.1103)\end{array}$ & $\begin{array}{r}-.4254^{\star * *} \\
(.1157)\end{array}$ & $\begin{array}{r}-.4096^{\star * *} \\
(.1239)\end{array}$ & $\begin{array}{r}-.4935^{\star \star \star} \\
(.1324)\end{array}$ & $\begin{array}{r}-.9542^{\star * \star} \\
(.2207)\end{array}$ & B-32 \\
\hline $\begin{array}{l}\text { Muslim } \\
\text { Preference (binary) }\end{array}$ & $\begin{array}{l}.0167 \\
(.0992)\end{array}$ & $\begin{array}{l}.0120 \\
(.1022)\end{array}$ & $\begin{array}{r}.1862^{\circ} \\
(.1070)\end{array}$ & $\begin{array}{l}.1990^{\circ} \\
(.1112)\end{array}$ & $\begin{array}{l}.5423^{\star *} \\
(.1759)\end{array}$ & B-37 \\
\hline $\begin{array}{l}\text { Buddhist Mix } \\
\text { Preference (binary) }\end{array}$ & $\begin{array}{l}.2538+ \\
(.1764)\end{array}$ & $\begin{array}{l}.3005^{\circ} \\
(.1794)\end{array}$ & $\begin{array}{r}.1272 \\
(.2062)\end{array}$ & $\begin{array}{l}.1850 \\
(.2108)\end{array}$ & $\begin{array}{l}-.4460 \\
(.4197)\end{array}$ & B-42 \\
\hline $\begin{array}{l}\text { Atheist } \\
\text { Preference (binary) }\end{array}$ & $\begin{array}{r}.2389^{\star} \\
(.1111) \\
\end{array}$ & $\begin{array}{r}.2962^{* *} \\
(.1137)\end{array}$ & $\begin{array}{r}.1333 \\
(.1231) \\
\end{array}$ & $\begin{array}{r}.1839 \\
(.1271) \\
\end{array}$ & $\begin{array}{r}.3020 \dagger \\
(.1972)\end{array}$ & B-47 \\
\hline
\end{tabular}

${ }^{\circ} p<.10 \quad{ }^{*} p<.05 \quad{ }^{* *} p<.01{ }^{* * *} p<.001$

$\dagger p<.15$ 
Table 4-14. Summary of Logit Coefficients for Government Religious Preference Score.

\begin{tabular}{|c|c|c|c|c|c|c|}
\hline Variable & Model 1 & Model 2 & Model 3 & Model 4 & Model 5 & Table \\
\hline $\begin{array}{l}\text { Christian } \\
\text { GRP (every 10\%) }\end{array}$ & $\begin{array}{c}-.0620^{* *} \\
(.0234)\end{array}$ & $\begin{array}{r}-.0671^{* *} \\
(.0246)\end{array}$ & $\begin{array}{r}-.0781^{\star *} \\
(.0261)\end{array}$ & $\begin{array}{r}-.0842^{* *} \\
(.0278)\end{array}$ & $\begin{array}{r}-.2013^{* * *} \\
(.0480)\end{array}$ & B-33 \\
\hline $\begin{array}{l}\text { Muslim } \\
\text { GRP (every 10\%) }\end{array}$ & $\begin{array}{l}.0100 \\
(.0134)\end{array}$ & $\begin{array}{r}.0103 \\
(.0138)\end{array}$ & $\begin{array}{r}.0318^{\star} \\
(.0142)\end{array}$ & $\begin{array}{c}.0344^{*} \\
(.0147)\end{array}$ & $\begin{array}{l}.0632^{\star *} \\
(.0222)\end{array}$ & B-38 \\
\hline $\begin{array}{l}\text { Buddhist Mix } \\
\text { GRP (every 10\%) }\end{array}$ & $\begin{array}{l}.0631^{\circ} \\
(.0324)\end{array}$ & $\begin{array}{r}.0649^{*} \\
(.0329)\end{array}$ & $\begin{array}{l}.0485 \\
(.0387)\end{array}$ & $\begin{array}{l}.0512 \\
(.0397)\end{array}$ & $\begin{array}{r}-.0233 \\
(.0701)\end{array}$ & B-43 \\
\hline $\begin{array}{l}\text { Atheist } \\
\text { GRP (every 10\%) }\end{array}$ & $\begin{array}{l}.0263^{*} \\
(.0121)\end{array}$ & $\begin{array}{l}.0335^{\star *} \\
(.0124)\end{array}$ & $\begin{array}{r}.0140 \\
(.0134)\end{array}$ & $\begin{array}{l}.0204 \dagger \\
(.0138)\end{array}$ & $\begin{array}{l}.0367^{\circ} \\
(.0214)\end{array}$ & B-48 \\
\hline
\end{tabular}

${ }^{\circ} p<.10{ }^{*} p<.05{ }^{* *} p<.01{ }^{* * *} p<.001$

$+p<.15$

Table 4-15. Summary of Logit Coefficients for Religious Prevalence.

\begin{tabular}{lcccccc} 
Variable & Model 1 & Model 2 & Model 3 & Model 4 & Model 5 & Table \\
\hline & (Robust SE) & & & & & \\
Christian & $-.2085^{\circ}$ & $-.2082^{\circ}$ & $-.2788^{*}$ & $-.2907^{\star}$ & $-.5973^{\star}$ & B-34 \\
Prevalence (binary) & $(.1121)$ & $(.1182)$ & $(.1250)$ & $(.1338)$ & $(.2329)$ & \\
Muslim & .0738 & .0625 & $.2540^{*}$ & $.2593^{*}$ & $.5368^{* *}$ & B-39 \\
Prevalence (binary) & $(.0993)$ & $(.1022)$ & $(.1067)$ & $(.1108)$ & $(.1782)$ & \\
& & & & .39 & \\
Buddhist Mix & $.3804^{* *}$ & $.3916^{* *}$ & $.2534^{\circ}$ & $.2579^{\circ}$ & .1954 & B-44 \\
Prevalence (binary) & $(.1247)$ & $(.1292)$ & $(.1386)$ & $(.1450)$ & $(.2209)$ & \\
\hline
\end{tabular}

${ }^{\circ} \mathrm{p}<.10{ }^{*} \mathrm{p}<.05{ }^{* *} \mathrm{p}<.01{ }^{* * *} \mathrm{p}<.001$

Table 4-16. Summary of Logit Coefficients for Religious Population.

\begin{tabular}{|c|c|c|c|c|c|c|}
\hline Variable & Model 1 & Model 2 & Model 3 & Model 4 & Model 5 & Table \\
\hline & (Robust S & & & & & \\
\hline $\begin{array}{l}\text { Christian } \\
\text { Pop. (every 10\%) }\end{array}$ & $\begin{array}{r}-.0341^{\star *} \\
(.0132)\end{array}$ & $\begin{array}{r}-.0342^{*} \\
(.0140)\end{array}$ & $\begin{array}{r}-.0459^{\star *} \\
(.0148)\end{array}$ & $\begin{array}{r}-.0478^{* \star} \\
(.0158)\end{array}$ & $\begin{array}{r}-.0814^{\star *} \\
(.0265)\end{array}$ & B-35 \\
\hline $\begin{array}{l}\text { Muslim } \\
\text { Pop. (every 10\%) }\end{array}$ & $\begin{array}{l}.0142 \\
(.0115)\end{array}$ & $\begin{array}{l}.0127 \\
(.0119)\end{array}$ & $\begin{array}{r}.0346^{\star *} \\
(.0125)\end{array}$ & $\begin{array}{r}.0349^{* *} \\
(.0130)\end{array}$ & $\begin{array}{r}.0696^{\star \star *} \\
(.0206)\end{array}$ & B-40 \\
\hline $\begin{array}{l}\text { Buddhist Mix } \\
\text { Pop. (every 10\%) }\end{array}$ & $\begin{array}{r}.0374^{\star *} \\
(.0136) \\
\end{array}$ & $\begin{array}{c}.0402^{\star *} \\
(.0140) \\
\end{array}$ & $\begin{array}{c}.0230 \dagger \\
(.0152)\end{array}$ & $\begin{array}{c}.0256 \dagger \\
(.0158) \\
\end{array}$ & $\begin{array}{r}.0140 \\
(.0250) \\
\end{array}$ & B-45 \\
\hline
\end{tabular}

${ }^{\circ} p<.10 \quad{ }^{*} p<.05 \quad{ }^{* *} p<.01{ }^{* * *} p<.001$

$\dagger p<.15$ 
In addition to the uniformly negative effect of Christianity, these tables indicate that a Muslim state is no more or less likely than a non-Muslim state to use low-level force against another state, but is moderately more likely to use higher levels of force and much more likely to use deadly force. In contrast, a Buddhist Mix state is more likely than a non-Buddhist Mix state to use low-level force, but not conclusively more or less likely to do so at higher thresholds (though the strongly negative coefficient for the Buddhist Mix chief executive and government religious Preference in Model 5 is interesting). An Atheist state is moderately more likely than a non-Atheist state to use force, but that result is more significant statistically at lower thresholds than higher.

The comparative effects of the different religious categories can be seen in the series of graphs below, which show the effects of all four religious categories, at the lowest and highest thresholds of defining an armed conflict. Figures $4 \mathrm{H}$ and $4 \mathrm{I}$ show the effects of GRP scores for each religious category for Models 1 and 5, respectively. Figures 4J and $4 \mathrm{~K}$ show the effects of religions of populations for the same models. In comparing these graphs, the negative effects of Christianity and positive effects of Islam are quite noticeable. 
Figure 4H. Graph of GRP Scores, Model 1.

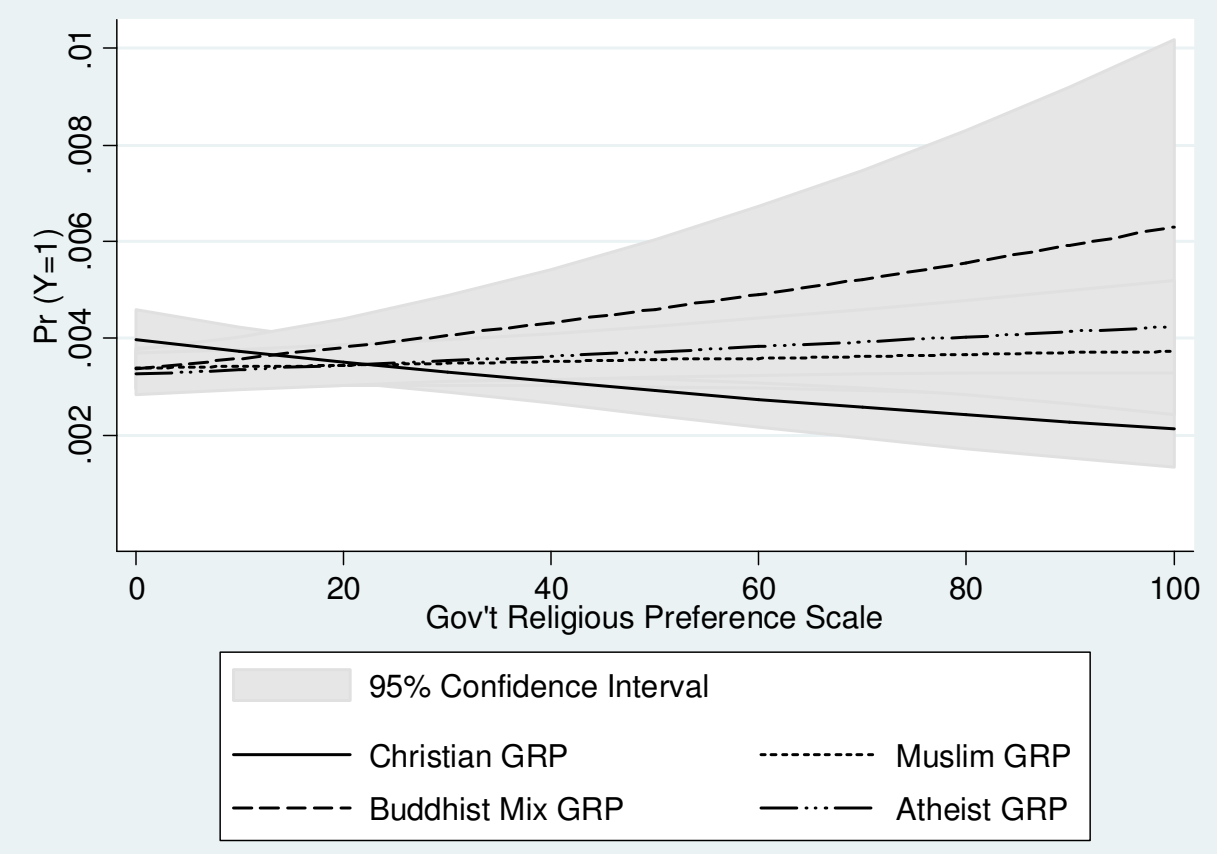

Figure 4I. Graph of GRP Scores, Model 5.

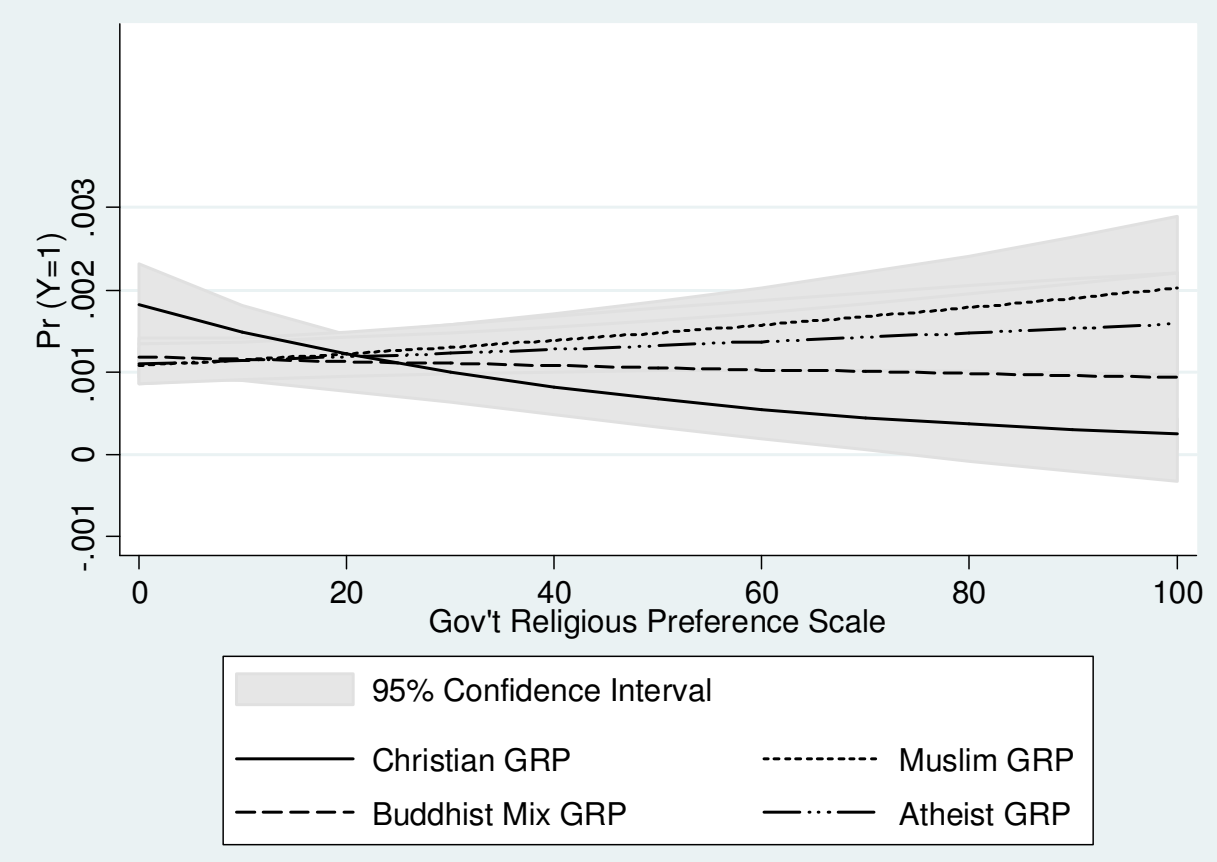


Figure 4J. Graph of Religions of Populations, Model 1.

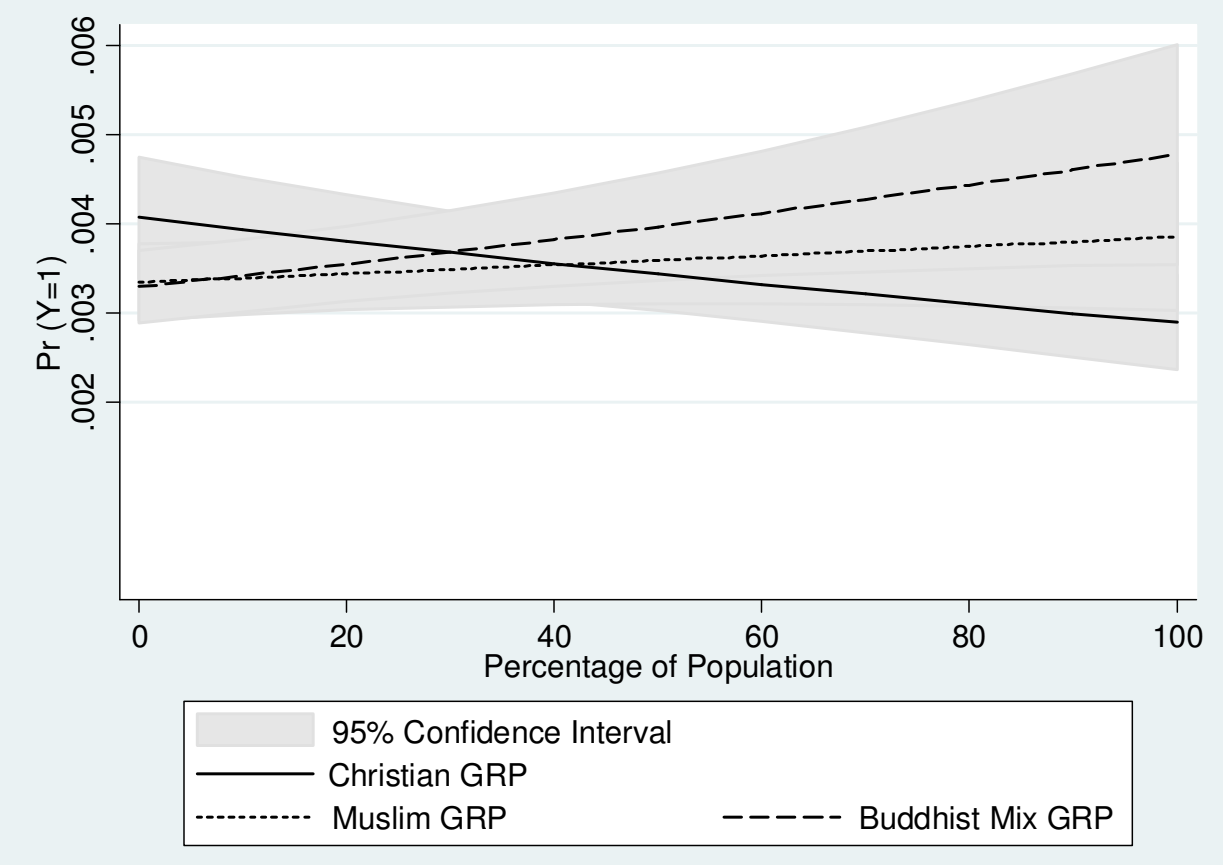

Figure 4K. Graph of Religions of Populations, Model 5.

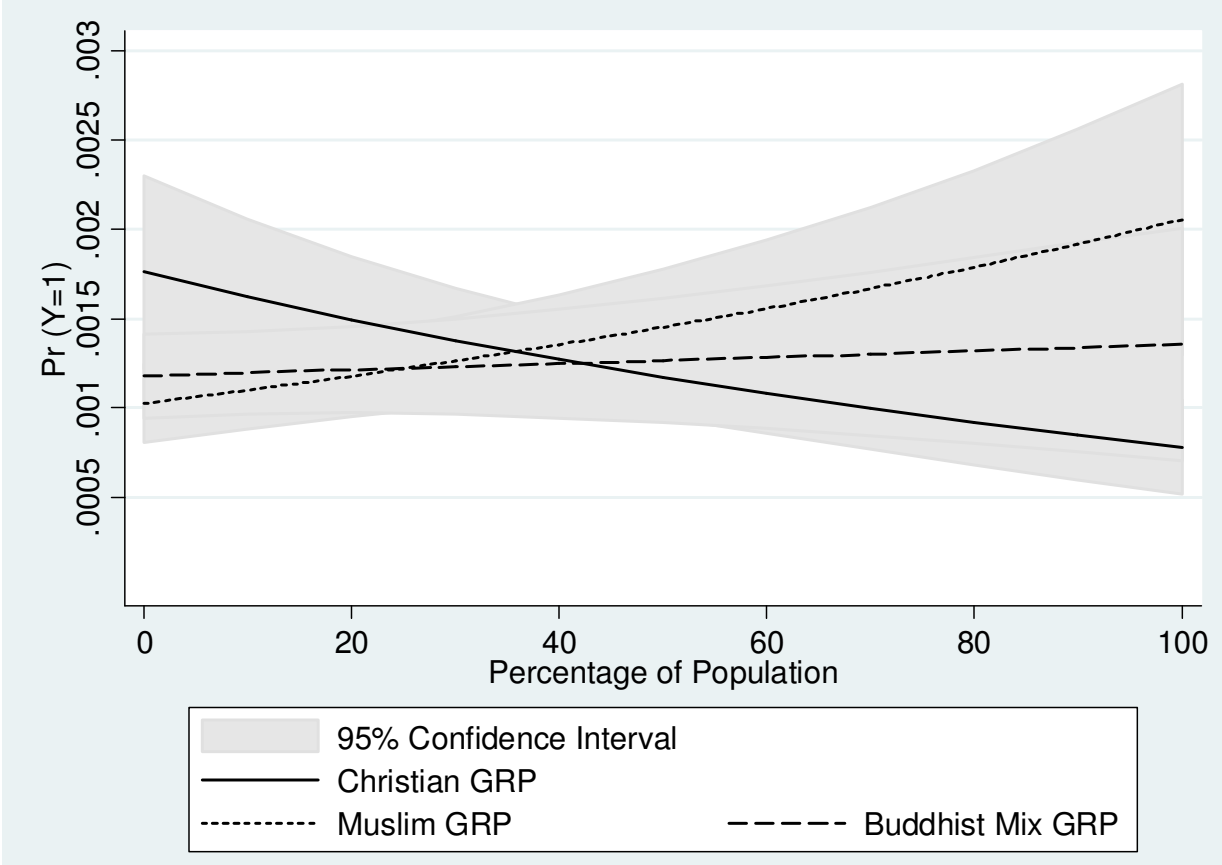




\section{$\underline{\text { Effects of Control Variables }}$}

At this point it may be useful to make a few observations concerning the control variables. The control variables with the consistently strongest and most significant associations are peace-learning and contiguity, and their trends are as expected: the longer a dyad goes without a war, and the farther away the two states are from each other, the less likely the onset of armed conflict between them. The two theses of the democratic peace (dyadic and monadic) also appear to have the expected effects: the greater the Polity score of the less democratic state in the dyad (i.e. the more democratic the dyad), the less likely the dyad is to experience an armed conflict, and the greater the Polity score of the observed state, the less likely it is to initiate an armed conflict. These effects are readily observable in the tables in Appendix B from which the tables in this chapter are extracted. As predicted by Russett and Oneal (2001), the dyadic effect is stronger and more significant than the monadic effect. The coefficients for the Polity variables are small compared to those of other controls, but that is likely the consequence of measuring the effect of a single-unit increase in Polity score in a 21-point scale. I submit that Jack Levy's (1989a: 88) famous characterization of the democratic peace as being as the closest thing to an "empirical law in international relations" still holds.

The controls for defensive alliance and power differential, on the other hand, appear to have little or no association with the propensity of a state to initiate an interstate armed conflict (in violation of jus ad bellum). Out of 130 logit regressions performed up to this point, the defensive alliance variable is statistically significant in only one of them, and the coefficients themselves are not uniformly positive or negative; this study therefore cannot support or refute either of the competing claims made on the effects of alliances. 
The coefficients for power differential were not uniformly positive or negative, and were statistically significant at $90 \%$ confidence in only 37 of the 90 regressions performed in Tables B-31 to B-48. Those coefficients that are significant are also weak. These results appear to support a finding that power differential has little effect on the propensity of a state to use force against another state, at least after 1945.

\section{Conclusion}

The many tables and graphs just presented form the basis for concluding that individual religious categories are associated with higher and lower propensities of states to initiate interstate armed conflicts (in violation of jus ad bellum). The associations are not significant in every case; they often depend on the threshold of force necessary to satisfy the definition of an "armed conflict" in each model. However, many of them are statistically significant even after the introduction of control variables.

\section{$\underline{\text { Robustness Checks and Diagnostics }}$}

In this section, the effects of some of the independent variables will be retested using different methods and with different parameters, in order to test the possibility of inadvertent bias in the controls due to omitted variables, or in the construction of the research design itself.

\section{$\underline{\text { Rare Events Bias }}$}

Armed conflicts are rare events in the international system; out of over 116,000 observations of dyad-years in the dataset made for this study, fewer than $2 \%$ of them 
contain the event being analyzed (the initiation of an armed conflict in violation of jus ad bellum). Standard logit analyses tend to underestimate the event probabilities and are more error prone in finite samples of rare-events data (King \& Zeng 2001a: 693, 703). Gary King and Langche Zeng (2001a, 2001b) have introduced an alternative method of performing logistic regressions, the RELogit, which is tailored to correct the rare-events bias.

Six independent variables measuring religious Preference and Prevalence were chosen for testing using RELogit, all from Model 5 because that is the model in which the dependent variable is the rarest event. The six chosen were those with coefficients that were: (1) the strongest and most significant; (2) also strong and significant; (3) the weakest and least significant; (4) also weak and insignificant; (5) near the median and highly significant; and (6) near the median and highly insignificant. Tables B-49 to B-51 of Appendix B show the logit and RElogit coefficients for each independent variable along with its controls. ${ }^{4}$ The greatest difference between any corresponding coefficients is less than 0.02. We may infer that the rare events bias, although present, does not threaten the overall validity of the research design.

\section{$\underline{\text { Alternative Controls }}$}

The possibility that the confluence of several specific control variables has biased the results of this study must be considered. In that vein, selected independent variables (again, measuring religious Preference and Prevalence) were regressed with several alternative controls_-six variables each in Models 1 and 5 (the lowest and highest

\footnotetext{
${ }^{4}$ No diagnostics are included in those tables because the RELogit function in Stata does not provide any.
} 
thresholds of force to constitute an armed conflict). The criteria for selection were: two with strong and highly significant coefficients, two with weak and insignificant coefficients, and two with coefficients in the middle. Each religious category and each independent variable (Preference, GRP Score, etc.) is included at least once.

The alternative controls were selected as follows. As an alternative to the logarithm of the Directed CINC Ratio, the following variables are introduced together: logarithm of the Directed GDP Per Capita ratio, nuclear capability (binary), and permanent membership on the UN Security Council (binary). ${ }^{5}$ In place of the Low Polity score in the dyad and Polity score of the observed state, a binary variable for whether the dyad is democratic (both states having an adjusted Polity score of +7 or higher) is used. For the Closest Contiguity level in the dyad, a binary variable of Land Contiguity (whether direct or colonial) is substituted. Table 4-16 summarizes the extent to which using an alternative model changes the coefficients for each selected independent variable. Using the alternative controls appears to render the effect of Christianity less strong overall, but the effect remains strong nevertheless. Strong effects of Islam are not changed significantly, but weak effects of Islam are made stronger and more significant. The effect of Atheism is moderately strengthened. The most radical changes are in the effects of the Buddhist Mix category; a strong and significant coefficient is weakened and rendered insignificant, but two weaker and insignificant coefficients are not made significant (and one is strengthened yet the other weakened).

\footnotetext{
${ }^{5}$ The logarithm of the Directed GDP Ratio was not used, because according to Table B-1 of Appendix B, that variable is nearly perfectly correlated with the logarithm of the Directed CINC Ratio.
} 
Table 4-17. Summary of Comparison of Standard and Alternative Controls.

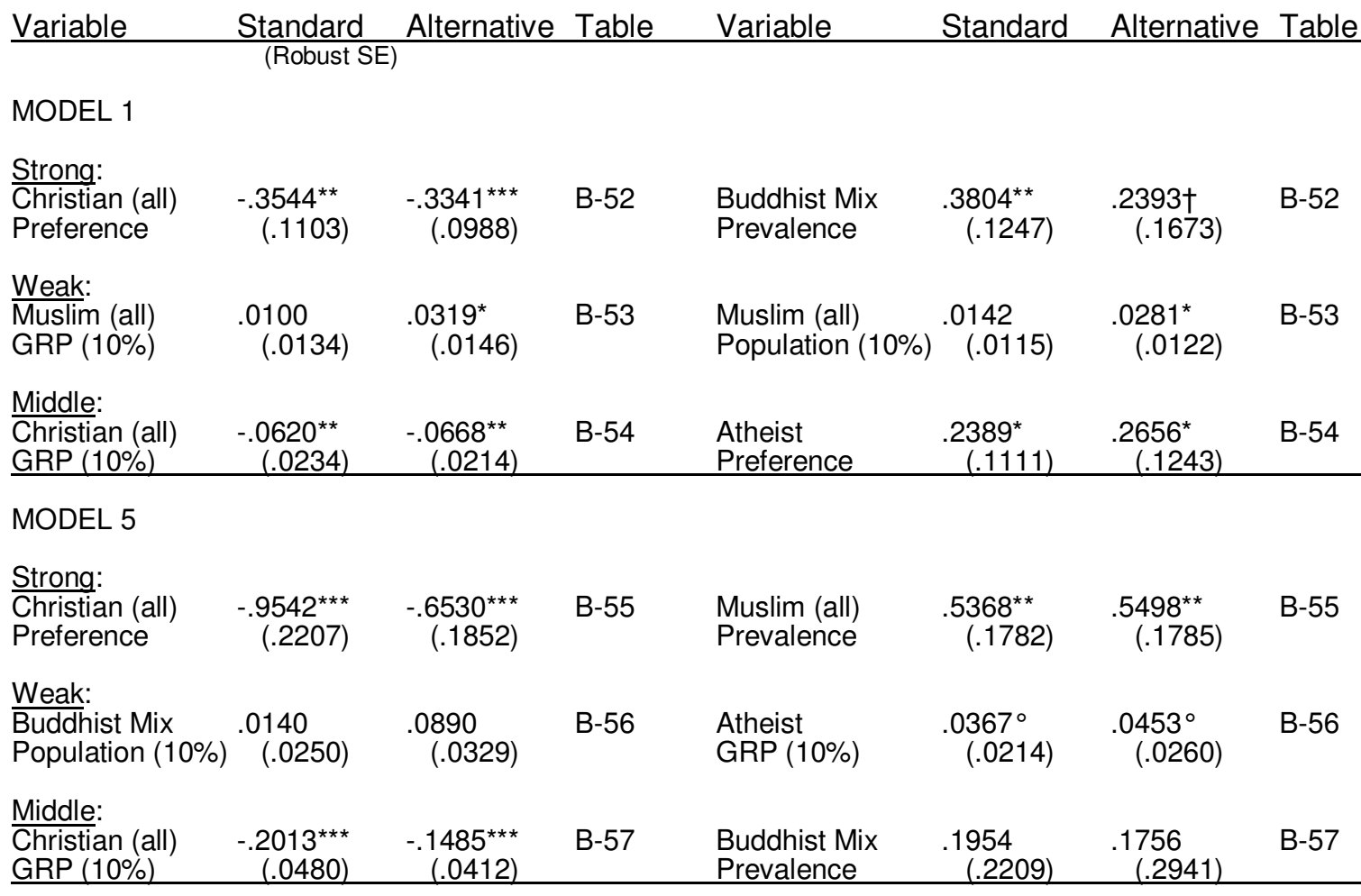

${ }^{\circ} p<.10 \quad{ }^{*} p<.05 \quad{ }^{* *} p<.01{ }^{* * *} p<.001$

$+p<.20$

I submit that the differences in the Buddhist Mix category raise doubts about the significance its effect overall (and in Chapter 7 those doubts are confirmed), but my conclusions for Christianity, Islam, and Atheism hold. I am confident that there are no significant biases or errors attributable to the selection of the specific control variables used for this study.

\section{$\underline{\text { Regional Effects }}$}

One further bias should be considered: the possibility that the results of the standard models are at least partly driven by regional effects. Some regions may be more conflict- 
prone than others, and some religions are concentrated in certain regions and not in others. It is conceivable that the power of the religious variables is overestimated, or even that the relationships between religion and armed conflict onset are spurious. That possibility will now be tested by adding a series of binary control variables for each region (americandyad, europeandyad, africandyad, mideastdyad, and asiapacificdyad).

This potential bias is tested in the same manner as the alternative controls, using the same independent variables selected in the previous subsection, in Models 1 and 5. Table 4-18 summarizes the changes in coefficients resulting from adding regional controls. Again, the overall trend appears to be that adding regional controls weakens strong coefficients and strengthens weak ones, with the same pattern for middle coefficients as for the experiment with alternative controls. The major exception is for the Buddhist Mix coefficients, which are uniformly weakened. This result is not unexpected; all Buddhist Mix are in the Asia-Pacific region, which makes disaggregating the effects of the Buddhist Mix category from those of the region difficult. However, none of the signs of coefficients are changed. 
Table 4-18. Summary of Comparison of Regressions After Adding Regional Controls. $\underset{\text { Variable } \quad \text { Standard } w / \text { Regions Table Variable }}{\text { (Robust SE) }}$ MODEL 1

\begin{tabular}{|c|c|c|c|c|c|c|c|}
\hline \\
\hline $\begin{array}{l}\text { Christian (all) } \\
\text { Preference }\end{array}$ & $\begin{array}{c}-.3544^{\star \star} \\
(.1103)\end{array}$ & $\begin{array}{r}-.3484^{* *} \\
(.1331)\end{array}$ & B-58 & $\begin{array}{l}\text { Buddhist Mix } \\
\text { Prevalence }\end{array}$ & $\begin{array}{l}.3804^{* *} \\
(.1247)\end{array}$ & $\begin{array}{l}.1241 \\
(.1433)\end{array}$ & B-58 \\
\hline $\begin{array}{l}\text { Weak: } \\
\text { Muslim (all) } \\
\text { GRP }(0-10)\end{array}$ & $\begin{array}{l}.0100 \\
(.0134)\end{array}$ & $\begin{array}{c}.0049 \\
(.0180)\end{array}$ & B-59 & $\begin{array}{l}\text { Muslim (all) } \\
\text { Population (10\%) }\end{array}$ & $\begin{array}{l}.0142 \\
(.0115)\end{array}$ & $\begin{array}{l}.0199 \\
(.0144)\end{array}$ & B-59 \\
\hline $\begin{array}{l}\text { Middle: } \\
\text { Christian (all) } \\
\text { GRP }(0-10) \\
\end{array}$ & $\begin{array}{r}-.0620^{\star *} \\
(.0234) \\
\end{array}$ & $\begin{array}{c}-.0573^{*} \\
(.0263) \\
\end{array}$ & B-60 & $\begin{array}{l}\text { Atheist } \\
\text { Preference }\end{array}$ & $\begin{array}{c}.2389^{*} \\
(.1111) \\
\end{array}$ & $\begin{array}{l}.3047^{\star} \\
(.1337) \\
\end{array}$ & B-60 \\
\hline \multicolumn{8}{|l|}{$\underline{\text { MODEL } 5}$} \\
\hline $\begin{array}{l}\text { Strong: } \\
\text { Christian (all) } \\
\text { Preference }\end{array}$ & $\begin{array}{r}-.9542^{\star * *} \\
(.2207)\end{array}$ & $\begin{array}{r}-.9178^{* * *} \\
(.2521)\end{array}$ & B-61 & $\begin{array}{l}\text { Muslim (all) } \\
\text { Prevalence }\end{array}$ & $\begin{array}{c}.5368^{\star *} \\
(.1782)\end{array}$ & $\begin{array}{c}.4514^{\star} \\
(.2236)\end{array}$ & B-61 \\
\hline $\begin{array}{l}\text { Weak: } \\
\text { Buddhist Mix } \\
\text { Population (10\%) }\end{array}$ & $\begin{array}{c}.0140 \\
(.0250)\end{array}$ & $\begin{array}{l}.0033 \\
(.0298)\end{array}$ & B-62 & $\begin{array}{l}\text { Atheist } \\
\text { GRP }(0-10)\end{array}$ & $\begin{array}{l}.0367^{\circ} \\
(.0214)\end{array}$ & $\begin{array}{l}.0585^{\circ} \\
(.0306)\end{array}$ & B-62 \\
\hline $\begin{array}{l}\text { Middle: } \\
\text { Christian (all) } \\
\operatorname{GRP}(0-10)\end{array}$ & $\begin{array}{r}-.2013^{* * *} \\
(.0480) \\
\end{array}$ & $\begin{array}{r}-.1866^{* * *} \\
(.0524) \\
\end{array}$ & B-63 & $\begin{array}{l}\text { Buddhist Mix } \\
\text { Prevalence }\end{array}$ & $\begin{array}{r}.1954 \\
(.2209) \\
\end{array}$ & $\begin{array}{r}.0813 \\
(.2572) \\
\end{array}$ & B-63 \\
\hline
\end{tabular}

${ }^{\circ} \mathrm{p}<.10 \quad{ }^{*} \mathrm{p}<.05 \quad{ }^{* *} \mathrm{p}<.01{ }^{* \star *} \mathrm{p}<.001$

The above findings further weaken the claim that the Buddhist Mix actually has an effect on the propensity of states to use force (again, this is addressed in Chapter 7). For the other categories, it may be inferred that although regional location appears to have a modest effect on the strength of the religion variables, that effect is not so great that the validity of the research design is threatened.

\section{$\underline{\text { Fit }}$}

At first glance, the pseudo- $\mathrm{R}^{2}$ statistics for the models reproduced in Tables B-18 through B-63 of Appendix B would appear to undermine my claim that the effects of 
some religions are strong and significant, for those statistics are congregated around 0.10 , suggesting a relatively low explanatory power for the models. However, that is probably because the outcome is a rare event. When the diagnostics of the religious explanatory variables are compared to those of the control variables, many of the former appear to have greater explanatory power than many of the latter. Table 4-19 summarizes the pseudo- $\mathrm{R}^{2}$ statistics for individual regressions of the strongest and most significant religious variables, compared to the standard control variables, for Models 1 and 5 (the full set of diagnostics are reproduced in Appendix B, Tables B-64 and B-65).

\begin{tabular}{|c|c|c|}
\hline Variable & $\begin{array}{l}\text { MODEL } 1 \\
\text { Pseudo-R } \\
\text { (Table B-64) }\end{array}$ & $\begin{array}{l}\text { MODEL } 5 \\
\text { Pseudo-R } \\
\text { (Table B-65) }\end{array}$ \\
\hline Christian Chief Exec. & .0194 & .0364 \\
\hline Christian Preference & .0293 & .0497 \\
\hline Christian GRP & .0258 & .0488 \\
\hline Christian Prevalence & .0301 & .0463 \\
\hline Christian Population & .0296 & .0464 \\
\hline Muslim Chief Exec. & & .0104 \\
\hline Muslim Preference & & .0114 \\
\hline Muslim GRP & & .0106 \\
\hline Muslim Prevalence & & .0126 \\
\hline Muslim Population & & .0131 \\
\hline Log CINC Ratio & $<.0001$ & .0001 \\
\hline Low Polity Score & .0203 & .0189 \\
\hline Polity Score & .0155 & .0129 \\
\hline Defensive Allies & .0002 & .0029 \\
\hline Log Peace-Years & .0734 & .0502 \\
\hline Closest Contiguity & .0899 & .0761 \\
\hline
\end{tabular}


The religious variables that are shown to actually have strong, significant effects have pseudo- $\mathrm{R}^{2}$ values that are also strong compared to the controls. The reverse is true for religious variables that have been shown to have weak or insignificant effects (those values are reproduced in the full tables in Appendix B). It should be noted also that the $\mathrm{p}$ values for the regressions are almost always less than 0.0001 (as shown in Appendix B, Tables B-55 and B-56). This, however, is likely a consequence of the very large number of observations in the dataset that is used for this study (over 116,000).

A further consequence of the large number of observations is that it is not possible to ascertain the percentage of outcomes correctly predicted. Because the outcome is a rare event, Stata predicts the dependent variable to be 0 (non-initiation of an armed conflict) in every observation. For this reason, no such diagnostics are provided.

\section{Conclusion}

The central, overall conclusion of this chapter is that religion does have a definite, measurable effect on the propensity of a state to violate jus ad bellum (as well as, I infer, to initiate an armed conflict irrespective of jus ad bellum). This conclusion holds despite the introduction of a variety of controls; indeed, the effect of religion is as strong as or stronger than the effects of several conventional control variables such as power differential and the democratic peace. As to the effect of specific religions, the strongest finding is that Christian states have a lower propensity than non-Christian states to use force. Findings also include that Muslim states have a higher propensity than non-Muslim states to use deadly force (but not to use low-level force), and Atheist states have a higher propensity than non-Atheist states to use force at most levels. The effect of the Buddhist 
Mix category, though seemingly positive, if weak, in initial results, is not as conclusive after running robustness checks.

The chapters that follow will explore the effects of individual religions in greater detail, including examinations of specific branches or denominations of those religions and the war ethics associated with them. 


\section{Chapter 5}

\section{THE EFFECT OF ChRistianity}

\section{Introduction}

Since Christianity is the Prevalent or Preferred religion of a preponderance of stateyears from 1946 to 2001 (about 57\% of them), it is the appropriate starting point for an exploration of the effects of specific religions. This chapter explores the war ethic in Christianity, as set forth by scripture and the most prominent writings of the priesthood (which as I argued in Chapter 2, are two of the primary media by which religion propagates its norms). The dependent variable (the propensity of a state to use force in violation of jus ad bellum) is then subjected to further testing of the effects of several specific branches of Christianity: Catholic, Protestant, Eastern Christian (primarily constituting Orthodox), along with a category styled Western Christian (Catholic, Protestant, and Mormon combined). ${ }^{1}$ I find that Christianity is nearly always negatively correlated with a state's propensity to use force, with Protestantism having the strongest negative effect and Eastern Christianity having the weakest negative effect (and occasionally, a positive effect). I further find that for Christianity generally, and for Western Christianity,

\footnotetext{
${ }^{1}$ Many Catholics and Protestants consider the Church of Jesus Christ of Latter-Day Saints (the Mormon Church) as not Christian, given the Mormons' treatment of the Book of Mormon as canon alongside the Bible, among other reasons. However, the Mormon Church self-identifies as Christian, and its war ethic is fully compatible with the Catholic and Protestant war ethics, therefore it is included in the categories of Christian and Western Christian for the purpose of this work (see Brown 2008: 10). However, because no state is Mormon in Prevalence or Preference and no chief executive of any state from 1946 to 2001 is known to have been Mormon, the Mormon war ethic will not be given further treatment here.
} 
Catholicism, and Protestantism specifically, the negative effect grows stronger as the threshold for defining an "armed conflict" increases from Model 1 to Model 5 (the five models are outlined in Chapter 3). Interestingly, though, I find that the negative effect of Eastern Christianity grows weaker as the threshold increases.

\section{The Biblical Foundations of Christian Political Theory}

Christian political theory ultimately can be traced back to several key passages of the Bible, specifically the New Testament. As a preliminary matter, a translation of the Bible must be selected, and this is no small matter. For the organization of the books of the Bible in both Western and Orthodox Christianity, see Appendix C.

The Christian Bible is a compilation of works written over hundreds of years, in ancient Hebrew and Aramaic (the Old Testament) and ancient Greek (the New Testament). One major challenge to analyzing the content and meaning of religious scripture, particularly in the English language, is that the same passage often appears differently in translation; indeed, every translation is itself an interpretation, so every translation is thus tinged by the experiences and even ideology of the translator (Fee \& Stuart 2003: 19). Every passage must be interpreted according to its historical and literary context, and its meaning at the time and place of its original composition must be interpreted in light of the time and place of its reading (these are the disciplines of exegesis and hermeneutics, respectively; Fee \& Stuart 2003: 25-31). Further complicating the matter of translating the Bible into modern languages is that until relatively recently, most modern translations

were themselves translated from other translations, usually the Septuagint (the $3^{\text {rd }}$-century 
BCE Greek translation of the Old Testament) and the Vulgate (the Latin translation of the entire Bible completed in the early $5^{\text {th }}$ century CE).

Gordon Fee and Douglas Stuart (2003: 42) classify several English translations on a scale ranging from literal to free. At the extreme literal end are the Douay-Rheims translation of 1609-1610 and Bishop Challoner's 1749-1752 revision of it (DR), used in the Catholic church, and the 1611 King James Version (KJV) of the Anglican church, which until the $20^{\text {th }}$ century was the authoritative translation in most Anglophone Protestant denominations. These translations are noteworthy for their "formal equivalence," attempting to keep as close to the form of the original language as possible while still making the English translation understandable. ${ }^{2}$ At the extreme free end of the scale, the Living Bible of 1971 (LB) translates the ideas into the modern idiom by paraphrasing them, in an attempt to lessen the historical distance between the ancient scripture and the modern reader.

Between these two extremes, most contemporary English translations seek to achieve "functional" or "dynamic" equivalence; they strive to retain the meaning of the original Hebrew/Greek while using words and idioms in the everyday English language. As Fee and Stuart put it, "Such translations keep historical distance on all historical and factual matters but 'update' matters of language, grammar, and style" (2003: 41). This middle ground is quite broad, however, with some translations leaning more toward formal equivalence and others leaning more toward paraphrasing. Among Catholic translations,

\footnotetext{
${ }^{2}$ Whereas the KJV was translated from the original Hebrew and Greek, the DR was translated from the Latin Vulgate, which erodes the accuracy of that translation somewhat further.
} 
the Knox translation of 1944-1950 (Knox) and the Jerusalem Bible of $1966(\mathrm{JB}){ }^{3}$ both produced in Great Britain, are relatively free. Among the American Catholic translations, the 1966 Revised Standard Version-Catholic Edition (RSV-CE) and the later New Revised Standard Version (NRSV) are relatively literal and the 1970 New American Bible (NAB), approved by the U.S. Conference of Catholic Bishops, stands right in the middle. Among Protestant translations, the 1952 Revised Standard Version (RSV) and 1991 New Revised Standard Version (NRSV) are more literal, the 1997 New Living Translation (NLT) is freer, and the 1984 New International Version (NIV) is roughly in the middle. Undoubtedly translations into other modern languages are fraught with the same problems.

Among the various translations of the three Biblical passages that are of primary interest here, there are considerable variations in wording but fortunately not in meaning. The first passage is that which defines the two fundamental duties of Christians: to love God, and more importantly for these purposes, to love their neighbors as themselves (Luke 10:27). Christians have a moral duty of charity-to advance the well-being of others and to place that well-being of others minimally at the same priority at which they would place their own well-being. The same duty applies to Christians who are in positions of political authority.

The second passage is from the Apostle Paul's letter to the Romans (Romans 13:1-4), on the relationship of Christians to the state:

\footnotetext{
${ }^{3}$ The JB is itself a translation of the French Bible de Jérusalem (1956), which was the outcome of an encyclical by Pope Pius XII urging a modern translation from the original Hebrew and Greek, rather than from the Latin Vulgate.
} 
Let every person be subject to the governing authorities; for there is no authority except from God, and those authorities that exist have been instituted by God. Therefore whoever resists authority resists what God has appointed, and those who resist will incur judgment. For rulers are not a terror to good conduct, but to bad. Do you wish to have no fear of the authority? Then do what is good, and you will receive its approval; for it is God's servant for your good. But if you do what is wrong, you should be afraid, for the authority does not bear the sword in vain! It is the servant of God to execute wrath on the wrongdoer. (NRSV)

Several variants include "higher powers" or "higher authorities" in place of "governing authorities" (DR, NAB, KJV), "established" or "ordained" by God instead of "instituted" (DR, Knox, NAB, KJV, NIV), and "rebels against" or "opposes" authority in place of "resists" authority (Knox, NIV). The phrase "it is God's servant for your good" appears in other translations as "he is God's minister to thee, for good" (DR, KJV), "For he is God's servant to do you good" (NIV), and "the magistrate is God's minister, working for thy good" (Knox). The much freer translation in the Jerusalem Bible warrants reproduction in full:

You must all obey the governing authority. Since all government comes from God, the civil authorities were appointed by God, and so anyone who resists authority is rebelling against God's decision, and such an act is bound to be punished. Good behavior is not afraid of magistrates; only criminals have anything to fear. If you want to live without being afraid of authority, you must live honestly and authority may even honor you. The 
state is there to serve God for your benefit. If you break the law, however, you may well have fear: the bearing of the sword has its significance. The authorities are there to serve God: they carry out God's revenge by punishing wrongdoers. (Romans 13:1-4, JB)

In addition, the Knox translation, which begins "Every soul must be submissive to its lawful superiors" (emphasis added), calls into the question the legitimacy of usurpers and other political authorities who assume power by extraconstitutional means. That question, however, is not germane to the immediate problem at hand (the legitimacy of using military force against other states) and will therefore be set aside.

The passage from Romans 13:1-4 above, in all its translations, sets forth the function of the state in Christian thought: to protect the individual from injury that is caused by the wrongdoing of others. It would follow from the Christian duty of charity that if the political authorities were Christian, they would have the duty to provide such protection (i.e. police power). Furthermore, the state is responsible for protecting its people from threats not only from within, but also from without. The state has the duty to ensure the security of the people from attack by or from other states, and by extension, the duty also to ensure its own (i.e. the state's) security. This passage serves as the Christian basis for the inherent right of self-defense in Western legal thought.

The third passage is the vignette of the coin. Challenged by the Pharisees with the question of whether the Jews should pay taxes to the Roman occupiers, Jesus calls attention to the image of the Emperor on a Roman coin and replies, "Give to the emperor the things that are the emperor's, and to God the things that are God's" (Mark 12:17, 
NRSV). ${ }^{4}$ This otherwise cryptic response is actually quite telling, because it sets limits on the Christian's duty to submit to the authority of the state (Christians are not to give the state that which is God's) and in doing so, sets limits on the state's authority. The most immediate limitation is that the state may not infringe the right of its citizens to worship God and obey God's laws (such as not worshipping idols, murdering, stealing, etc.), but this passage also serves as the biblical basis for civil liberties and human rights-and by extension, limits the range of legitimate causes for making war against other peoples. From these three passages, much if not all of Christian political theory can be derived, including the ethic of war.

\section{The Western Christian War Ethic}

When we speak of the "Christian" war ethic, we must do so with the qualification that historically there are three: Holy War, Just War, and Pacifism (Bainton 1960: 14). The first one appears to have more pervasive in Christian thought 1000 years ago, but is well repudiated in mainstream Christian thought today. There remain tensions between the second and third. In the pages that follow, the scriptural basis and doctrinal development of each of these ethics will be presented in detail. For the moment we shall focus on the development of ethics of war in Western Christianity, as the Eastern Christian war ethics, such as they are, developed differently.

\footnotetext{
${ }^{4}$ The more poetic KJV and DR both read, "Render to Caesar the things that are Caesar's, and to God the things that are God's."
} 


\section{$\underline{\text { Pacifism }}$}

Jesus is never recorded as supporting war or revolt against the Roman authorities (he preached at a time when the present-day Holy Land was a province of the Roman Empire). The strongest scriptural basis for the pacifist ethic is the Sermon on the Mount, which he begins by extolling the oppressed and powerless:

Blessed are the meek, for they will inherit the earth... Blessed are the peacemakers, for they will be called children of God. ... Blessed are you when people revile you and persecute you ... on my account. (Matthew 5:5-10, NRSV)

He continues by preaching an ethic of non-violence:

You have heard that it was said, "An eye for an eye and a tooth for a tooth." But I say to you, Do not resist an evildoer. But if any one strikes you on the right cheek, turn to him the other also; and if anyone wants to sue you and take your coat, give your cloak as well; and if any one forces you to go one mile, go also the second mile. (Matthew 5:38-41, NRSV)

He further admonishes his followers that the duty of love (or charity) is absolute: You have heard that it was said, "You shall love your neighbor and hate your enemy.” But I say to you, Love your enemies and pray for those who persecute you. (Matthew 5:43-4, NRSV)

These and other preachings, along with the performance of miracles, gained Jesus many followers, some of whom went as far as to offer him kingship (John 6:15). Jesus turned down such offers, and also turned down Satan's offer of much greater political dominion ("all the kingdoms of the world and their splendors"; Matthew 4:8-10, NSRV). His 
ultimate gesture of non-violence came when he eschewed any possibility of resisting his own arrest, even though he knew he would be tortured, crucified, and killed (Matthew 26:50-4).

The vignettes presented above form the scriptural basis for the ethic of pacifism, in which the duty of non-violence is treated as absolute. ${ }^{5}$ Jesus did not address directly the morality of political violence, but in the first three centuries of Christianity many others did. Since Jesus had ruled out the legitimacy of violence against others on a personal level, the argument goes, violence against others on a corporate level must be illegitimate also. The quintessential purveyor of this position in the second and third centuries $\mathrm{CE}$, Tertullian, condemned war absolutely and unequivocally. He advocates complete and total submission to persecution and execution, even though Christians were in his time sufficiently numerous to successfully revolt against oppression (Apologeticus, sec. 37, in Cadoux 1982: 79; De Corona Militis, sec. 11, in Eppstein 1935: 36). For Tertullian, the defining moment of pacifism is the biblical vignette in which Jesus rebukes Peter for trying to protect him from arrest, cutting off the ear of a Roman soldier in the process, saying "Put your sword back into its place; for all who take the sword will perish by the sword" (Matthew 26:52, NRSV). Tertullian argues that in doing so, Jesus "cursed the

\footnotetext{
${ }^{5}$ Until recently, the conventional wisdom among scholars of Christian just war theory had been that in the earliest period of Christianity, in which its adherents were mostly poor and powerless, pacifism was the only acceptable ethic of behavior, both personally and in statecraft. This belief appears to be due largely to the influence of Roland Bainton (1960). Since Bainton's work, many authors have fallen into that trap, myself included (Brown 2008: 18, 28). But Daryl Charles (2010) argues, persuasively in my view, that the early Christian pacifist writings were prescriptive, not descriptive, thus indicating pacifism had to compete against a more permissive war ethic in Tertullian's day. I thank Daniel Heimbach for raising this point.
} 
works of the sword for ever after" (De Patienta, sec. 3, in Cadoux 1982: 51); in disarming Peter, he further writes, he "unbelted every soldier" (De Idolotria, chap. 19, in Eppstein 1935: 37). In the passage from De Corona Militis mentioned above, Tertullian even advises Christians to leave military service (see also Cadoux 1982: 113-4), which is something that not even Jesus or others did. ${ }^{6}$

Although Tertullian's articulation of pacifism is most often cited today, the pacifist ethic had other proponents as well, both before and after Tertullian. Aristeides attributes the warlike nature of man to that of ancient Greek gods and writes of the Christian repudiation of the ways of Ares, the god of war (Apology, sec. 8, in Cadoux 1982: 50). ${ }^{7}$ Justin Martyr renounces the right "to answer fighting with fighting" (Apologia I pro Christianis, secs. 16 \& 34, in Eppstein 1935: 32; see also Bainton 1960: 72), and further blamed wars, murders, and other wickedness on evil angels (Apologia II pro Christianis, v. 4, in Cadoux 1982: 50). Tatianus equates war with murder (Oratio ad Graecos, sec. 19, in Cadoux 1982: 50) and Athenagoras categorizes unjust war as among the worst of sins (Legatio pro Christianis, sec. 35, in Cadoux 1982: 50). Athenagoras appears particularly concerned about the effects of war- "the slaughter of myriads of men, the razing of cities, ... the destruction of entire populations." Post-Tertullian pacifists include Cyprian, who would leave vengeance to God (Testimonia adversus Judaesos (ad Quirinum), in

\footnotetext{
${ }^{6}$ Not once is Jesus recorded as advising anyone to leave the military, not even the Roman soldiers with whom he interacted (Matthew 8:8-10). In another vignette, Jesus's predecessor John the Baptist, asked by soldiers what they should do, counsels them not to resign their military service, but simply to comport themselves professionally and charitably (Luke 3:14).

${ }^{7}$ A century and a half later, Eusebios took a similar stance. Praeparatio Evangelica, sec. 192c, in Cadoux 1982: 57.
} 
Cadoux 1982: 81), ${ }^{8}$ and Lactantius, who equates a just man with a non-violent one (Divinae Institutiones, passim, in Cadoux 1982: 83-4). All of the foregoing authors consider the imposition of war to be a form of divine justice for transgressions, yet Christians were forbidden to take part. $^{9}$

\section{$\underline{\text { Just War Tradition }}$}

The scriptural basis for a more permissive war ethic in the New Testament is more obscure than for pacifism. In the Gospels themselves, the Christian war ethic is more evident in what is not said than what is. Jesus's immediate predecessor John the Baptist, asked by soldiers what behavior is righteous for them, replies "Do not extort money from anyone by threats or false accusation, and be satisfied with your wages" (Luke 3:14, NRSV). In essence, he tells them to comport themselves professionally and responsibly, but does not advise them to resign from military service. Neither does Jesus in his encounters with Roman soldiers. At Capernaum, a Roman centurion appeals to him to heal his servant, and Jesus agrees to do so, saying to his followers, "Truly I tell you, in no one in Israel have I found such faith" (Matthew 8:10, NRSV). He seems to have gone out of his way to praise the centurion's submission to authority. But the duty of submission to authority has boundaries; in the vignette of the coin presented in the previous section, Jesus advises submission to the earthly sovereign in earthly matters and to God in spiri-

\footnotetext{
${ }^{8}$ Cyprian follows Tertullian's lead in preaching non-violence notwithstanding Christians' strength in numbers. Ad Demetrianum, secs. 17 \& 25, in Cadoux 1982: 82.

${ }^{9}$ See Cadoux 1982: 191-3. Bainton (1960: 73-4) argues that the early Christian prohibition of military service was partially motivated by the proscription of idolatry, for officers were required to perform sacrifices in honor of the deified Emperor.
} 
tual matters; but he is also referring to giving the earthly sovereign other, less tangible things than mere taxes, such as loyalty, honor, or obedience. In this context, what is most significant is what Jesus does not say: he does not advise rendering to Caesar that which is not Caesar's. Jesus is allowing for the possibility of disloyalty, disobedience, and resistance, in cases in which no duty of loyalty, obedience, or submission ensues.

Other biblical passages suggest more overtly that the duty of submission to authority has limitations. In John 8:3-11, Jesus shames the Pharisees into letting an adulteress go free, although Jewish law prescribes stoning for her offense. In John 2:13-6, Jesus fashions a whip and angrily drives the money-changers and vendors from the Temple. ${ }^{10}$ Scholars disagree as to whether this episode constitutes an example of Jesus actually using force; John Eppstein (1935: 14) argues that it does, whereas John Cadoux (1982: 34-5) argues that it is more likely that Jesus expelled them by the force of his authority rather than by physical force. The point, however, is that in this vignette Jesus is unmistakably flouting authority, for their presence in the Temple was specifically permitted in rabbinic law. The function of the money-changers and vendors was to supply the halfshekels used to pay the Temple tax, and to supply the oxen, sheep and birds that worshippers would sacrifice at the altar (Watson 1996: 76-7). Jesus clearly did not submit to authority in these cases and was willing to resort to "force" (physical or authoritative) to right what he claimed was a wrong.

As to precepts of statecraft, the most direct biblical guidance comes not from Jesus, but from the Apostle Paul, in Romans 13:1-7 which is partly reproduced earlier in this chapter. Paul, like Jesus, teaches Christians to maintain peace and order, writing "Pay to

\footnotetext{
${ }^{10}$ See also Matthew 21:12-3; Mark 11:15-7; Luke 19:45.
} 
all what is due them-taxes to whom taxes are due, revenue to whom revenue is due, respect to whom respect is due, honor to whom honor is due" (Romans 13:7, NRSV). But again, this duty to submit is not unlimited; Paul does not advocate paying taxes, revenue, respect, or honor to those whom those things are not due. The passage also states clearly, in verse 4 , that the state enjoys not merely the right to use force to maintain order, but also the responsibility to protect the people from harm. Moreover, in making no distinction between the harm posed by internal threats to public order (i.e. from crime and rioting) and external threats (i.e. foreign invasion), the passage indicates that the state has the right and duty of self-defense. This is the scriptural foundation for the just war ethic in Christian thought.

Although there is no record of any Christians serving in the Roman military from 50 to $170 \mathrm{CE}$ (see Cadoux 1982: 97; Bainton 1960: 67-9), subsequent writings indicate that by the third century many soldiers were converting to Christianity. Among the contemporaneous Christian scholars, Clement of Alexandria advises Christian converts in military service to "obey the Captain who giveth just commands," instead of condemning military service outright (quoted in Eppstein 1935: 40). Origen continues to support Christian abstention from military service, but takes the pragmatic view that righteous wars such as defense of the nation are distinguishable from unrighteous wars, and further that Christians should pray for victory in a righteous war (Contra Celsum, quoted in Eppstein 1935: 43-4; see also Cadoux 1982: 137, Bainton 1960: 69).

Historical circumstances also contribute to the tensions between the ethics of nonviolence and limited protective violence. In the West, the Pax Romana made an ethic of pacifism possible. In the East, however, the constant border threats rendered such an ethic 
unsustainable. Christians are known to have participated in the Thundering Legion of the province of Melitene (in present-day Armenia) as early as $173 \mathrm{CE}$, about twenty years before Tertullian's writings. In $202 \mathrm{CE}$, while Christians were still being persecuted in the West, King Abgar IX of Edessa converted to Christianity and made it the official religion of his kingdom; his forces must therefore have included Christians at the highest level (Bainton 1960: 70).

In the West, two political events set the stage for a more permanent reconciliation of the just-war ethic with Christian thought. The first was the conversion of Emperor Constantine. In $312 \mathrm{CE}$, according to the legend recounted by Eusebios, the then-pagan but tolerant emperor had visions of his army fighting under the Christian banner against the rival emperor Maxentius, who was not tolerant of Christianity and whom Constantine would meet in battle the following day. Constantine obeyed the divine command to have his soldiers mark crosses on their shields ("in this sign conquer") and his forces were victorious at the Battle of the Milvian Bridge (Durant 1944: 654, citing Eusebios, Life of Constantine, bk. 1, sec. 28). By 323, Constantine had legalized Christianity in the Roman Empire and had himself converted and invited the rest of the Empire to convert with him, thus setting the stage for Emperor Theodosius to make Christianity the official religion of the Empire near the end of that century. In stark contrast to the days when military converts to Christianity had been executed, military service by the year 416 was restricted to Christians (Bainton 1960: 68; Cadoux 1982: 257). Christianity had been transformed from a religion of the oppressed and martyred into a religion with material power.

The other historical event shaping Western Christian attitudes toward war was the threat posed to Italy in the late $4^{\text {th }}$ and early $5^{\text {th }}$ centuries by the Goths from the north, 
which culminated in the sacking of Rome itself by the Visigoths in 410 . To a number of Christians of this era, the Christianization of the Roman Empire had fulfilled Isaiah's prophecy of swords beaten into plowshares (Isaiah 2:3) in an unintended way: the horde of marauders holding itself out as the Roman army had become a professional military organization whose purpose was to maintain the Pax Romana against the onslaught of the barbarians from outside (Russell 1975: 12; Bainton 1960: 86-8). The literature on war in Christian thought reflected this. John Chrysostom, Bishop of Constantinople, considers it proper to make war "when the soldiers on our side are attacked by the barbarians" (Homily [VII] on the First Epistle to Timothy, in Eppstein 1935: 53). Ambrose, an Italian government official and Bishop of Milan, merges Christian ethics with the Ciceronian tradition of public and private duties and derives rationales for self-preservation, defense of others, and intervention. "Fortitude," he writes, "which in war preserves the country from the barbarians . . . or defends one's neighbours from robbers, is full of justice" ( $D e$ Officiis, bk. 1, chap. 27, sec. 129, in Eppstein 1935: 58). Such infusions of the duty of charity into the laws of war, coupled with the need for the newly Christian empire to deal with very real threats to its survival, paved the way for the foundational works of Western just war theory by Augustine, Bishop of Hippo.

Augustine never offers a systematic treatment of war despite his massive body of writings, but a common thread runs through his piecemeal reconciliation of war with Christianity: that war, as a divine punishment for sin, is an act of charity. Just as the preChristian Greeks personified the dual nature of war in the persons of Ares and Athena, Augustine recognizes that war could be either sinful or charitable. The evil of war, he writes in Contra Faustum in 398, is not the death and destruction that accompanies it, but 
rather the love of these things: "The desire to do harm, cruelty in taking vengeance, ... the lust of domination ... these are the things that are rightly blamed in wars" (1990: bk. 12, ch. 74).

A legitimate war, to Augustine, can be prosecuted without passion or hatred, but for the loving purpose of maintaining a just order. Hence Augustine points out how John the Baptist did not urge soldiers to leave the profession, in the vignette mentioned earlier, because John understood that by virtue of their military service, they were ministers of the law and defenders of public safety, not murderers or avengers of their own wrongs (id.). The just warrior, in restraining the sinner from committing acts of evil, is actually acting in the best interest of the sinner, which is an act of charity. To Augustine, those who turned to the sword in this manner, "in obedience to the divine command, or in conformity with His laws, have represented in their persons the public justice or the wisdom of government, and in this capacity have put to death wicked men" and are thus exempted from the divine commandment prohibiting murder (De Civitate Dei; Augustine 1952: bk. 1, chap. 21). ${ }^{11}$ Love for one's enemies do not preclude physical punishment for their transgressions and hatred, only the malice in inflicting it (Sermon 302, Augustine 2001b: sec. 15; Letter 138, Augustine 2001c: sec. 2(15)). The charitable nature of Augustine's just war theory lies in the notion that it saves more souls. As Roland Bainton (1960: 92) puts it, "Killing and love could the more readily be squared by Augustine

\footnotetext{
${ }^{11}$ However, Augustine would apply this principle only to the professional soldier acting within the scope of his duties; a private person, i.e. one without the authority to enforce the law, was not permitted to kill, even in self-defense, because to do so would be to act upon the very hatred and passion that was absent in a just warrior. See Russell 1975: 18.
} 
because in his judgment life in the body is not of extreme importance. What matters is eternal salvation. The destruction of the body may actually be of benefit to the soul of the sinner."

The just war tradition in Christian thought begins with Augustine, though the concept was not new in the Roman cultural and political thought of his day. The Roman legal precept of bellum justum (just war) had long since developed from the jus fetiale of the Roman republic ${ }^{12}$ and culminated in the works of Cicero (De Officiis, Cicero 1961: bk. 3, sec. 23; De Re Publica, Cicero 1998b: bk. 1, chap. 11, secs. 35-8). Augustine's theory of just war shares some commonalities with that of Cicero. One commonality is that peace is preferable to war $^{13}$ and that the goal of war should always be peace. Augustine writes in 418:

Peace should be the object of your desire. War should be waged only as a necessity and waged only that through it God may deliver men from that necessity and preserve them in peace. For peace is not to be sought in order to kindle war, but war is to be waged in order to obtain peace. (Epistle 189, sec. 6, in Eppstein 1935: 78) ${ }^{14}$

But he goes further in De Civitate Dei, lamenting the misery of even a necessary war: For it is the wrongdoing of the opposing party which compels the wise man to wage just wars; and this wrong-doing, even though it gave rise to

\footnotetext{
${ }^{12}$ See Bederman 2001: 231-3; Nussbaum 1954: 10-11; Phillipson 2001, Vol. 2: 332-9. The ceremonial procedures of the jus fetiale itself are documented largely in the works of Livy and Servius. 1 FHIG 187.

${ }^{13}$ Augustine places the glory of peace higher than that of war. Epistle ad Darium [Epistle 229], in Eppstein 1935: 79.

${ }^{14}$ For Cicero's view, see Cicero 1961: bk. 1, chap. 11, sec. 35.
} 
no war, would still be matter of grief to man because it is man's wrongdoing. Let every one, then, who thinks with on all these great evils . . . acknowledge that this is misery. (Augustine 1952: bk. 19, chap. 7)

Augustine's broad affirmation of peace raises the question of what manner of event should constitute a breach of the peace, necessitating its restoration. His approach is to equate a breach of peace with a breach of justice, and this equation is the second commonality of the Augustinian and Ciceronian theories. A just war, to Augustine, is that which redresses an injury. ${ }^{15}$ In 419 , nine years after the sacking of Rome, Augustine writes,

Just wars are usually defined as those which avenge injuries, when the nation or city against which warlike action is to be directed has neglected either to punish wrongs committed by its own citizens or to restore what has been unjustly taken by it. (Quastiones in Heptateuchum, bk. 6, sec. 10b, in Eppstein 1935: 74)

Thus was born the principle justa bella ulciscuntur injurias - just wars avenge injuries (see Russell 1975: 18). A war undertaken with an evil purpose, such as love of killing or destruction, anger, or lust for power, would be an unjust cause and precipitating war with such motives inflicts injury. Conquest for conquest's sake would be considered unjust, but defense of the homeland, its people and their property would be considered just causes for war (De Civitate Dei, Augustine 1952: bk. 4, chap. 6; id. bk. 3, chap. 10). ${ }^{16}$

\footnotetext{
${ }^{15}$ For Cicero's summary of just causes for war, see Cicero 1998b: bk. 3, chap. 23.

${ }^{16}$ Augustine does not appear to be applying that principle to Roman expansion, for he considers the Pax Romana to have been accomplished by God's design (De Civitate Dei, Augustine 1952: bk. 18, chap. 22).
} 
The authority to wage war is the third commonality of the Augustinian and Ciceronian just war theories. To Augustine, the authority to make war and impose punishment should rest with the political ruler (Contra Faustum, Augustine 1990: bk. 12, chap. 75). ${ }^{17}$ This is consistent with his conception of war as a divine punishment for sin; a sovereign ruler is answerable to none except God, who carries out his work through the sovereign. A war undertaken without the authority of the sovereign usurps the sovereign's function, and indirectly that of God. Consequently, the authority for executing the war rests with the officials of the sovereign—his soldiers—and no one else (see Russell 1975: 18).

After the fall of the Roman Empire in the West in 476, the Augustinian conception of war as a charitable punishment for sin gradually evolved into a more militant ethic, the details of which will be presented in the section on Holy War. The doctrine of just war to eradicate heresy and defend (or even propagate) the faith remained prevalent until the $13^{\text {th }}$ century, when members of the Decretalist school finally began to incorporate a coherent solution to the Muslim problem into the church's existing canon legal structure. Raymond of Peñafort in 1234 places great emphasis on whether war was necessary, and even accepts the notion of punishment of Christians who commit sins against Muslims (Summa de casibus poenitentiae ii, secs. 17-18, in Reichberg Syse \& Begby 2006: 13444).

But the real reining-in of the holy war ethic begins with the just war theory of Thomas Aquinas. Thomas writes at a time when the theological literature is moving from expositions and analyses of individual rulings to comprehensive, encyclopedic-length

\footnotetext{
${ }^{17}$ Cicero, in De Officiis, does not state this principle explicitly, but he implies it in including proper procedure as a necessary criterion for a just war. Cicero 1961: bk. 1, chap. 11, sec. 36.
} 
compilations of Christian philosophy. Thus the treatment of war in his mammoth Summa Theologica takes place in the broad context of fraternal correction of the sins of hatred, apathy, and envy. War is situated in a treatment of sins contrary to peace, which in addition to war include discord, contention, schism, strife, and sedition.

Thomas reduces just war theory to three essential criteria, all of which must be satisfied for the war to be just. Those criteria are here reproduced in full:

In order for a war to be just, three things are necessary. First, the authority of the sovereign by whose command the war is to be waged. ... And as the care of the common weal is committed to those who are in authority, it is their business to watch over the common weal of the city, kingdom or province subject to them. And just as it is lawful for them to have recourse to the material sword in defending that common weal against internal disturbances, when they punish evil-doers, [here follows a passage from Romans $13: 4]$. . . so too, it is their business to have recourse to the sword of war in defending the common weal against external enemies. . .

Secondly, a just cause is required, namely that those who are attacked should be attacked because they deserve it on account of some fault. Therefore Augustine says . . . "A just war is usually described as one that avenges wrongs, when a nation or state has to be punished, for refusing to make amends for the wrongs inflicted by its subjects, or to restore what is has seized unjustly."

Thirdly, it is necessary that the belligerents should have a right intention, so that they intend the advancement of good, or the avoidance of 
the evil. Hence Augustine says . ... "True religion does not look upon as sinful those wars that ware waged not for motives of aggrandizement, or cruelty, but with the object of securing peace, of punishing evil-doers, and of uplifting the good." For it may happen that the war is declared by the legitimate authority, and for a just cause, and yet be rendered unlawful through a wicked intention. (Aquinas 1952: pt. ii-ii, q. 40, art. 1; citations omitted)

In articulating these three celebrated just-war criteria, Proper Authority, Just Cause, and Right Intent, Aquinas reclaims the Augustinian conception of war as a means of securing peace and justice. $^{18}$

The writings of Thomas Aquinas's contemporaries reflect his strong influence. Albertus Magnus writes of the goal of war being peace; Vincent of Beauvais treats war as necessary to preserve liberty and territory and increase dignity; Thomas's student Peter of Auvergne criticizes wars of domination in which domination is the end rather than the means to the end (Russell 1975: 264-5). Another of his students, Ptolemy of Lucca (1997: paras. 1101, 1104), argues that maintaining an army for the purpose of defending against external aggression and preserving justice is simply part of exercising good government. Yet another of his students, Giles of Rome, goes as far as to characterize war as a divine

\footnotetext{
${ }^{18}$ In the modern form of just war theory, two separate criteria may be discerned from Thomas Aquinas's formulation of "just cause." One is that there must be injury ("because they deserve it on account of some fault"); the other is that the use of force must be a proportionate remediation of the injury ("because they deserve it on account of some fault"; emphasis added). I have labeled the latter criterion "proportionality of cause" (Brown 2008: chap. 7), but it has also been labeled proportionality of "ends."
} 
virtue, when resorted to defend against aggression or to preserve order (De Regimine Principum, bk. 3, chap. 3, sec. 23, in Russell 1975: 266).

The Thomist just war tradition, at this point largely reclaimed from its more militant cousin (the holy war tradition), has served as the foundation not only for most subsequent treatments of war in Christian ethics all the way to today, but also for the evolution of secular jus ad bellum. During the Renaissance, as the Holy Roman Empire's hold over Italian cities weakened and Italy ascended to cultural supremacy, so too did Italian jurisconsults emerge as the foremost authorities on the justice of war. And being Catholic, their writings reflect a strong infusion of the Catholic (and at this time in history, Western Christian) just war tradition. But among the lay authors of this literature, the prevailing attitude that only the Pope and the Holy Roman Emperor had the authority to go to war (being the only ones with no earthly superior) began to break down as stronger and more independent nations and city-states emerged. Bartoli of Sassoferato claims in the $14^{\text {th }}$ century that since various Italian cities no longer have any de facto superior, they have the right to wage war (1 FHIG 343 \& 574-5; see also Sereni 1943: 87). ${ }^{19}$ Albericus of Rosate similarly argues that by virtue of France, England, and Aragon lying outside the Empire, they also have such a right (Sereni 1943: 87), and Giovanni da Legnano (1917) regards any declaration of war by an authority with no de facto superior as lawful (see also Sereni 1943: 88-91). ${ }^{20}$ Martino da Lodi (Martinus Laudensis), writing

\footnotetext{
${ }^{19}$ But Bartolus' protégé Baldeschi of Ubaldis [Baldus], on the other hand, maintained that even though a king was "emperor within his realm," only the Pope and the Emperor had the legal authority to wage war. See Sereni 1943: 86-7; Nussbaum 1954: 40.

${ }^{20}$ Legnano. Summaries taken from Sereni 88-91.
} 
in the following century, regards war as lawful if the belligerent is unable to enforce his rights in any other way and after due warning (Sereni 1943: 91). ${ }^{21}$

\section{The Catholic Just War Tradition after the Split in Western Christianity}

The legal treatises on just war theory after Lodi's are roughly evenly divided between those authored by the clergy (thus under the direct auspices of the Church) and those authored by lay lawyers. We begin with the clergy. The works of Tommaso de Vio, aka Cardinal Cajetan, take an extreme approach of war as an instrument of punishment of wrongdoing (Reichberg Syse \& Begby 2006: 240-50). But the trajectory of just war thinking is forever altered in two short works by the Spanish Jesuit law professor Francisco de Vitoria, De Indis (On the Indians) and De Iure Belli (On the Law of War) (Vitoria 1991a, b). ${ }^{22}$ Taking the Spanish conquest of the New World as its entry point (and subjecting the Spanish subjugation of the natives to devastating scrutiny), Vitoria treats war not merely as a punishment for wrongdoing (as is Cajetan's focus), but also as an instrument of self-defense, defense of others, recovery of things wrongfully taken, and eradication of evil. In the most comprehensive treatment of war since Thomas Aquinas, he presents all of these facets of war in a single package, together with an exposition of righteous means for accomplishing these goals. Even more importantly, Vitoria is the

\footnotetext{
${ }^{21}$ Lodi's work, De bello (1455), is not available in English.

22 These two works were first delivered as lectures in 1539 and first published in 1557.
} 
first to link just war theory to natural law, and in doing so he provides a foundation for the formation of modern international law. ${ }^{23}$

The following century, another Spanish Jesuit professor, Francisco Suárez, treats war within the larger framework of the three theological virtues (faith, hope, and charity), with just war falling under charity (De Bello, Suárez 1944c). In doing so, he continues the approach of war as an instrument of justice, but goes further in the conversion of that "justice" from retributive (simple punishment, or eradication of evil) to vindicative (remediation of faults or injuries). Suárez also goes further even than Thomas Aquinas, in that he introduces the broad criterion "right manner" in place of the traditional Thomist criterion "right intent" (1944c: chap. 1, sec. 7). Suárez thus sets the stage for the introduction of several additional just war criteria that are not inherent in the Thomist formula. One is that the war must be necessary (that is, that the injury giving rise to war cannot be remediated in any other way); this is the forerunner of the modern criterion "last resort." Another, which Suárez regards as more important for judging offensive wars, is that the likelihood of victory must be balanced against the risk of further suffering in the event of failure; this principle has evolved into the modern criterion "reasonable prospect of success." Finally, although he is not the first to examine the execution of war alongside its justification (Vitoria is), Suárez successfully merges the two by linking charitable conduct in warfare to the overall justice of the war effort (1944c: chap. 7). Thus is born the criterion that today is labeled "just means." Thus I submit that the real father of modern just war theory in Christian thought is Suárez, with Thomas Aquinas and

\footnotetext{
${ }^{23}$ Indeed, James Brown Scott (1934) argues that Vitoria is the founding father of international law, rather than Hugo Grotius as the mainstream of the legal field claims.
} 
Augustine as grandfather and great-grandfather, respectively, and Vitoria akin to an influential great uncle.

Unlike Vitoria's work, which focuses on the natives of the New World, Suárez's work is more philosophical, systematic, and dispassionate-a perfect legal treatise, which is how the piece is regarded in international law today. But Christian thought, and the Christian just war theory specifically, is well infused into the early scholarship of international law written by the laity as well. A prime example of this trait is the 1563 treatise on war by Pierino Belli (1936), a lawyer and counselor to the Spanish crown. His work is concerned as much with the details of executing armed conflict as with its legal legitimacy, but all the while his rationale is based on religious premises such as the theological distinction between just and unjust wars (indeed, Angelo Sereni [1943: 97] criticizes him for not conceiving of international law as a system of rules distinct from religious precepts). ${ }^{24}$ After Vitoria, most treatises on the law of nations during this era begin with an orthodox treatment of the religious sources of just war theory, including the Bible, Augustine, and Thomas Aquinas, and they often cite theological works. Even the first and venerated systematic treatise of international law by Hugo Grotius (1925), who is often regarded as the father of international law, takes this approach. Grotius writes in the early $17^{\text {th }}$ century, at a time when the naturalist approach to the law of nations prevails, so his use of the Bible is expected. But his use of works by Catholic theologians to construct the foundation for an international law of war is remarkable, for Grotius is Protestant, writing at a time when Protestantism was well entrenched, and in an

\footnotetext{
${ }^{24}$ In addition, Sereni criticizes the work for broadening the concept of just war to the point that nearly any war is just (1943: 93-9).
} 
environment of relative freedom to express his Protestantism. In contrast, Grotius does not mention the writings pertinent to just war theory of the major founders of the Protestant movement, Martin Luther and John Calvin. ${ }^{25}$

\section{The Protestant Just War Tradition}

Speaking of Luther and Calvin, mention should be made of the positions of those two founders of Protestantism on the legitimacy of military force. Martin Luther and John Calvin ${ }^{26}$ were both raised and trained in the Catholic Church, with the Catholic just war tradition firmly entrenched in their ideologies. Luther and Calvin both broke from Rome and established separate denominations (Lutheran and Reformed, respectively) within the newly emerged Protestant branch of Christianity. ${ }^{27}$ Both were strongly influenced by the political thought of Augustine, and neither departed radically from his writings, though both viewed the use of force somewhat less contritely than Augustine did.

There are several differences between the early Lutheran and Calvinist theories of just war, however. To Luther, law and "the sword" (i.e. government) are essential for contain-

${ }^{25}$ Perhaps Grotius was hostile to Calvinism due to its status as a rival sect within the Reformed branch of Protestantism (Grotius was an Arminian); perhaps he believed that the Catholic outlook on the law of nations had a certain pedigree and longevity, and had withstood the test of time, that the relatively new Protestant movements lacked. I prefer not to speculate further, however.

${ }^{26}$ The name John Calvin is Anglicized from the Latin Ioannes Calvinus; his native French name was Jean Cauvin.

${ }^{27}$ The third major branch of Protestantism, the Anglican Church, broke from Rome largely for political reasons, not theological, and the war ethic in the 1571 Anglican Confession reflects the influence of its Lutheran counterparts (Morkevicius 2009: 228). 
ing human wickedness and society/community cannot survive without them (Porter 1974b: 8). True Christians (those living in the Kingdom of God), who abide by God's law of love, have no need for the law or the sword, but the Kingdom of the World (everyone else, which practically speaking is everyone) needs both in order to restrain sinners from actualizing their wicked thoughts. Luther therefore encourages Christians to participate in temporal authority structures (Luther 1974a: 53-8). Those authority structures have a duty to deal justly with evildoers (punishing them without injuring the innocent) and make war only for the public interest, never private (id. 65-6). Likening war to amputation, whereby a part must be destroyed in order to preserve the greater whole, Luther concludes that God created the institution of war as a means to enforce peace and goodness:

For the very fact that the sword has been instituted by God to punish the evil, protect the good, and preserve peace ... is powerful and sufficient proof that war and killing along with all the things that accompany wartime and martial law have been instituted by God. What else is war but the punishment of wrong and evil? [Why] does anyone go to war, except because he desires peace and obedience? (1974b: 102, citing Romans 13: $1-4 \& 1$ Peter $2: 13-4)$

These and other writings form the basis for a relatively curt, unequivocal endorsement of the just war tradition in the founding documents of the Lutheran church. Section 181 of the Larger Catechism of 1529 affirms the divine ordination of the function of the state to punish wrongdoing ("God has delegated his authority to punish evil-doers to civil magistrates"; Tappert 1959: 389). Article 16 of the Augsburg Confession of 1530 states it more 
plainly: "Christians may without sin occupy civil offices . . punish evildoers with the sword, engage in just wars, serve as soldiers" (id. 37; emphasis added).

In contrast, early Calvinist thought takes a more expansive view on the legitimacy of force, sometimes even venturing into holy war territory. Whereas Luther treats the power of the sword as simply a constituent part of political authority (which is ordained by God for the sake of restraining sin), Calvin treats the power of the sword itself as divinely ordained, calling upon Christian civil magistrates to take up arms if necessary to discharge their official functions (1948: bk. 4, chap. 20, sec. 11). Those official functions include defense from enemy attack and judicial punishment of wrongdoing, but as Calvin articulated them, they also could be interpreted to include suppressing doctrines which the state views as heretical, or otherwise inimical to the state's conception of order (id. secs. 11-12). This view of the role of the state constitutes a more militant war ethic than Luther's, and is a symptom of Calvin's ambition to create a political society directly inspired by his religious beliefs. Whereas Luther (1974b: 108-10) argues that true Christians will be passive, leaving God to punish tyrants by having others rise up and depose or kill him, Calvin (1948: bk. 4, chap. 20, sec. 6) asserts that God may depose tyrants by calling up his own servants. Furthermore, in Calvinist political theory, the civil magistrate is responsible for protecting not only the physical well-being of the people but also the moral fabric of society. Because civil magistrates hold their offices in accordance with divine law and are ordained with God's wisdom, ${ }^{28}$ the first duty of civil authority is to

\footnotetext{
${ }^{28}$ Calvin 1948: bk. 4, chap. 20, sec. 10. This outlook is further reflected in the Westminster Confession, chap. 25 (PCUS)/23 (UPCUSA), sec. 1, which views the purpose of the civil magistrate as "for the defense
} 
uphold God's law. Calvin writes, "No government can be happily constituted, unless its first object be the promotion of piety" (1948: bk. 4, chap. 20, sec. 11). The militant streak of early Calvinism is also evident is the works of John Knox (Mason 1994), the founder of the Presbyterian in Scotland, from which the Presbyterian churches of North America trace their roots. Curiously, the earliest confessional documents of the Reformed church (the Scots Confession of 1560 and the Heidelberg Catechism of 1562) contain no doctrine of just war; the first appearance of such a doctrine in any Reformed confessional document is in the Westminster Standards of the Presbyterian Church in 1647 (Presbyterian Church (USA) 2004). Like the foundational documents of the Lutheran church, the Westminster Standards' formula is rather curt and unassuming:

It is lawful for Christians to accept and execute the office of a magistrate, when called thereunto; ... as they ought especially to maintain piety, justice, and peace, ... so, for that end, they may lawfully ... wage war upon just and necessary occasion. (Chap. 25 (PCUS)/23 (UPCUSA), sec. 2, in Presbyterian Church (USA) 2004: sec. 6.128)

But unlike its Lutheran counterparts, the Westminster Standards include the maintenance of piety as a function of government. This ethic, strictly applied, strays into holy war territory, though as the second half of this chapter will show, there appears to be no empirical evidence that this particular piece of the Protestant war ethic is applied by states today.

and encouragement of them that are good, and for the punishment of evildoers." Presbyterian Church (USA) 2004: sec. 6.127. 
The emergence of Protestant independence during the Thirty Years War (1618-1648) and the demise of the political authority of the central Catholic Church set the stage for the secularization of international law, a task begun by Protestants such as Alberico Gentili (1933) and Hugo Grotius (1925). But although Grotius in particular is venerated for his systematic, secularized treatise on international law, a precursory glance of that work reveals the strong influence of Christian thought. Grotius himself had been a theology student before entering into the legal profession, and his treatise is replete with citations of biblical passages as proof of his propositions. He evens ends the treatise with a prayer. The use of Christianity to undergird the rationale for the efficiency of international law is also evident in the legal works of John Austin (1959) and Henry Wheaton (1936) in the $19^{\text {th }}$ century, and Lassa Oppenheim (1912) in the early $20^{\text {th }}$ century notes the contribution of the religious bond between Christian states to the formation of the Westphalian state system (see also Janis 1999b). ${ }^{29}$

\section{Holy War}

The third major war ethic in Christian thought is that of Holy War, which as mentioned before, was pervasive in Christian thought around the time of the Crusades and possibly the Reformation and Counter-Reformation, but is repudiated today. As a result, the Christian war ethic of those eras likely was more permissive than it is today. A full

\footnotetext{
${ }^{29}$ Valerie Morkevicius (2009) has also taken note of the Christian influence on the development of international law, though she focuses on the Protestant contribution, and Daniel Philpott $(2000,2001)$ attributes the modern concept of state sovereignty directly to Protestant thought.
} 
exposition of the holy war ethic in Christianity will be presented nevertheless, for the sake of completeness.

Holy war is fought at the command of God specifically; its proponents may even consider such a war to be fought by God, through his warriors. Holy war is fought not for the purpose of attaining an earthly, material objective (though that may be the effect), but rather to bring about an outcome that its proponents believe is pleasing to God. Edward Long (1968: 33-41) identifies four common characteristics of holy war: (1) it is primarily or solely motivated by religion; (2) its partisans are promised spiritual rewards; (3) restraint on the methods and means of war is often eroded; and (4) the cause is absolute and not open to question, even if its result would be immoral in other contexts.

The holy war ethic is distinguishable from the just war ethic in several ways: Holy war seeks to remediate what its proponents believe are injuries or offenses against God, not necessarily earthly injuries, whereas the concern of just war is confined to earthly injuries. The warfare itself is constrained in just war but not in holy war. In addition, because holy war is prosecuted by divine mandate, it does not allow for the possibility that the injustices caused by the remediation might outweigh the injustices caused by the injury, while just war does allow for that possibility. ${ }^{30}$ Because the two war ethics both pursue the remediation of a (perceived) injury, there is admittedly some overlap between them, and it is conceivable that a just war ethic carried too far can assume holy war character-

\footnotetext{
${ }^{30}$ I have defined the criterion Proportionality of Cause as a requirement that the foreseeable good in curing the injustice that gives rise to war must outweigh the foreseeable harm that is expected to be inflicted in the process, on both sides (Brown 2008: chap. 7). Cf. National Conference of Catholic Bishops 1983: sec. 92, a pastoral letter introducing the criterion "comparative justice," in which the justness of the belligerent's cause must outweigh that of the other party_one side must be more "right" than the other (1983: sec. 92).
} 
istics, as Daniel Heimbach (2008) has argued in his assessment of war for regime change. But I submit that the same is true for the relationship of just war to pacifism; the just war ethic becomes a pacific ethic when the constraints on warmaking are taken to extremes, as John Howard Yoder (1984: 22) and Andrew Fiala (2008) have done. Just war occupies a middle ground between holy war and pacifism, and the boundaries that separate just war from the more extreme ethics are a little fuzzy.

The Judeo-Christian scriptural basis for holy war is grounded in God's covenant with Abraham to give the Promised Land (Canaan) to Abraham's descendents (Genesis 17:68). When Israel emerges as a nation, God fulfills that covenant by instructing the Israelites to conquer Canaan completely, leaving no survivors (Deuteronomy 7:1-5, 24-5; id. 20:16-7). Further historical narratives on the Israelites in the Old Testament reveal a pattern in which faith in and obedience to God guarantees victory, and turning away from God leads to defeat and conquest.

Like the just war doctrine, the holy war doctrine owes its heritage to the works of Augustine. The central tenet of his theory is that a war to avenge an injury is just. But to Augustine, a just war includes not merely the restoration of the status quo ante, but also punishment for the injurious act. Frederick Russell (1975: 19) likens the difference to awarding punitive damages as opposed to merely compensatory damages; the just war "not only avenge[s] the violation of existing legal rights but also avenge[s] the moral order injured by the sins of the guilty party regardless of the injuries done to the just party acting as a defender of that order." Augustine considers total war against the offending party to be permitted, regardless of the nature of the offense; applying such an ethic of war could result in the total annihilation of the offending party. In addition, Augustine's 
view of justice goes beyond avenging earthly injuries. To him, war is a form of punishment for sin, and as such is divinely sanctioned. ${ }^{31}$ This principle serves as the foundation for his belief that heresy is a threat to the common belief and as such warrants punishment (see Russell 1975: 23). ${ }^{32}$ As Moses punished the Israelites for their wickedness, so too may orthodoxy use force to return heretics to the fold. Both are charitable acts, carried out by divine authority (Letter 93, in Augustine 1962: 193-9). ${ }^{33}$

Taken to extremes, this theory could (and did) result in considerable violence against breakaway sects of Christianity, as well as non-Christian faiths. This trend began not long after Augustine's death (Russell 1975: 26-8). An epistle that was once attributed to Augustine but which scholars believe now was not his, claims that God will grant victory

${ }^{31}$ Augustine affirms the justness of a war when commanded by God, and also affirms the notion that God imposes war as a form of punishment for sin. Quaestiones in Heptateuchum, bk. 6, chap. 10, in Eppstein 1935: 74; De Civitate Dei, Augustine 1952: bk. 1, chap. 21; id. bk. 19, chap. 15.

${ }^{32}$ Augustine interprets the stories of Jesus driving the merchants out of the Temple and of God's persecution of Saul (later Paul) as examples of God using coercive measures to achieve his goals (see Russell 1975: 24).

${ }^{33}$ The fact that both the just war and holy war ethics are rooted in the works of Augustine might raise the question of whether Augustine's war ethic itself is coherent, especially in light of my conclusions on the Buddhist war ethic in Chapter 7. My claim in Chapter 7 is that the mainstream Buddhist war ethic is internally inconsistent, especially for Theravada Buddhism, and impractical for application in temporal statecraft. In contrast, Augustine's war ethic is not inconsistent; he simply takes a broader view of the scope of "injury" that could warrant war. In addition, Augustine's war ethic straddles the fuzzy boundary between the holy war and just war ethics, whereas the war ethic in Mahayana Buddhism attempts to straddle a boundary between holy war and pacifism - and cannot do so because the gulf between the two ethics is far too wide. 
in war to the side fighting a just cause (Gravi de pugna). Gregory of Tours, writing in the late sixth century, extends the Augustinian concept of Providence determining the outcome of history to the idea that the justness of war is linked to, and determinable by, its result (Historia Francorum, bk. 8, sec. 32). Pope Gregory I (Gregory the Great) also supports the propriety of persecution and war against heretical sects, as well as the duty of secular rulers to make war at the behest of the Church (Registrum Epistolarum, bk. 2, sec. 35); the context of his writing is the threat to mainstream Rome by the warlike-and in his eyes, heretical (though Christian) — rulers of the Lombards to the north. ${ }^{34}$ God would come to the aid of righteous and obedient rulers, and punish those who refused his will, as transmitted to them by the clergy (id. bk. 8 , sec. 4 ; bk. 2 , sec. 7). In this way the holy war ethic began to work its way into Christian thought, as the Church ascended to power to fill the vacuum left by the demise of the Roman Empire.

The first Holy Roman Emperor, Charlemagne, was influenced heavily by the Church's position on the role of a just king: to drive out the impious and defend the kingdom — and the Church-against their adversaries. As King of the Franks, he invaded Spain in 777 to do battle with the Moors in the name of Christianity. He also warred against the pagan Saxons for 32 years and forcibly converted them to Christianity, and protected Rome from the heretic Lombards. Charlemagne tied the fate of his kingdom to Christianity, and the Church thus linked its own success with that of Charlemagne.

After his death, with the newly constituted Holy Roman Empire plagued by invasions from outside and strife from within, clergy of the ninth century write of the need for the

\footnotetext{
${ }^{34}$ The Lombards espoused the Arian sect of Christianity, which had been rejected by the Church nearly three centuries beforehand.
} 
Church to maintain order by force. Agobard, Archbishop of Lyon, views internal dissension as unjust, advocating the forcible pacification of barbarians both within the Empire and on its borders. Hincmar, Archbishop of Reims, favors war against the pagans, as well as war to quell strife between Christian rulers and officials within the Empire, which Hincmar sees as unjust and unworthy of Christianity (Russell 1975: 30).

Although other writers during this period advocate temperance, that temperance reaches its limit when Muslim pirates (the Saracens) began to raid southern Italy. After they sack Rome and desecrate St. Peter's basilica (in 846), Pope Leo IV takes an active role in combating these raids, promising in 853 eternal life to those who die fighting the Saracens:

Put off all fear and horror, fight valiantly against these enemies of the holy faith, these adversaries of all religions. If one of you should fall, the Almighty will know that he died for the truth of the faith, for the salvation of the fatherland, and for the defence of Christians; he will therefore receive celestial reward from His hand. (1 FHIG 241)

Pope John VIII similarly promises eternal salvation to those who die in wars against infidels and pagans (Russell 1973: 33).

This theme resonates for centuries afterward. By the $11^{\text {th }}$ century, the Church had acquired a strong interest in the fate of Christian lands in the east, which had been chipped away by Muslim expansion, and that of their peoples, whom the Western Christians believed have been forcibly converted to Islam or killed or enslaved. Pope Gregory VII issued a general call to arms to reverse this trend: "for as He [Jesus] laid down His life for us, so we also ought to lay down our lives for our brethren" (Epistle 49, 
Ad Omnes Christianos, in Eppstein 1935: 94). In 1095, Pope Urban II solidifies both of Gregory's movements, preaching a holy war to liberate the Holy Land from the Muslims, thus inaugurating the Crusades (1 FHIG 242). In the late $12^{\text {th }}$ century, Huguccio views war as punishment on peoples who deserve it; just as the Jews deserved the wars inflicted on them by Nebuchadnezzar, so do the wars between the Christians and Saracens serve to punish each other for their respective sins (Commentary to Decretum Gratiani, C. 23, q. 5, c. 13, in Russell 1975: 113). ${ }^{35}$ In Huguccio's eyes, the most direct justification for war to recover the Holy Land is the need to eradicate heresy. Huguccio supports war against heretical sects, not only on account of their offense to God but also because they have usurped territories held by Christians by divine right. Accordingly, the property of heretics is subject to confiscation (Russell 1975: 114). By analogy, as Saracen control of the Holy Land deeply offends the Church, Christians have the right to repossess it. Therefore to Huguccio, the Crusades are God's war. ${ }^{36}$ His influence had far reaching resultsPope Innocent III, who inaugurated the Fourth Crusade, had been a pupil of Huguccio's (Russell 1975: 119-22). The need for legitimate defense against a pattern of raids, incursions, and invasions had evolved into an ethic of holy war.

In the $13^{\text {th }}$ century, Johannes de Deo ties the Crusades to defense of property, working from the premise that the Muslims are unjustly occupying lands that rightfully belong to Christians. Pope Innocent IV regards Muslim occupation of the Holy Land as an offense

\footnotetext{
${ }^{35}$ Such as position is remarkably even-handed for its day; he may have in mind the Crusaders' violation of their truce with the Saracens in 1187, which precipitated Saladin's Holy War.

${ }^{36}$ Huguccio, however, breaks with his contemporaries when he argues that the primary justification for the Crusades is infidel occupation of the Holy Land, and not their beliefs.
} 
to all Christians, and thus considers war to liberate the Holy Land to be just (Russell 1975: 199). Hostiensis divides war into seven categories, placing wars against infidels at the top of the list of just wars, solely on account of their faith (1 FHIG 572; see also Russell 1975: 129). However, several authors, including Innocent IV, also take position that Muslims who pose no threat to Christendom should be left alone. Raymond of Peñafort takes such a stance; he is willing to tolerate Muslims' control over their own lands (though not those which previously have been under Christian control), and even goes as far as accepting the notion of punishment of Christians who committed sins against them (Russell 198-9, 207).

As the Crusaders suffered defeat after defeat, and with the Crusades themselves winding down in the $13^{\text {th }}$ century, Christendom began to turn its attention more toward heresy, sometimes treating that threat as more urgent even than the recovery of Christian lands from Islam. ${ }^{37}$ Pope Innocent III issued a decretal directing the Church to order secular princes to persecute heretics and confiscate their property (1 FHIG 590). ${ }^{38}$ At the Church's behest, northern French forces launched the Albigensian Crusade (1208-1229) to wipe out a breakaway sect in southern France, the Cathars or Albigenses, whom the Church has branded as heretics (Bainton 1960: 115ff). In 1233, Pope Gregory IX issued a

\footnotetext{
${ }^{37}$ Wars to propagate Christianity were not new to the $13^{\text {th }}$ century; the Danes forced the pagan Wends to convert in a war from 1160 to 1168, and the Teutonic Knights embarked on a fifty-year military campaign in the $13^{\text {th }}$ century to Christianize the pagan Prussians. What is different about the $13^{\text {th }}$ century is that it inaugurated a pattern of eradicating unorthodox beliefs and doctrine within the faith.

${ }^{38}$ In 1215, the Fourth Lateran Council affirmed the requirement that princes confiscate the property of heretics, on pain of excommunication (1 FHIG 591; see also Russell 1975: 180).
} 
bull authorizing the Dominican friars to call upon secular forces if necessary to carry out their function of eradicating heresy (Harsanyi 1989: 45).

The Church's holy war against internal dissension (in its view, heresy) was escalated in the $16^{\text {th }}$ century. When Martin Luther inaugurated a movement for churches to break away from Rome in 1517 (the Reformation), the central church militarized the conflict and Catholic political authorities frequently responded with force, thus the battle lines between Catholics and the breakaway Protestants formed quickly. Wars between Catholic and Protestant partisans during this period include the Counts' War in Denmark (15331536), which was a war for the Danish throne; Dacke's War in Sweden (1542-1543), which was a peasant revolt; and a series of Spanish interferences in the religious affairs of other kingdoms, including Scotland (1559), France (First War of Religion, 1562), and England (Tyrone's Rebellion, 1595). Meanwhile in Germany, nine Protestant states formed the Schmalkaldic League, a defensive alliance against Holy Roman Emperor Charles V, a Catholic. In 1618, Austrian Emperor Ferdinand II (a Hapsburg and Catholic) went to war in response to being passed over for the throne of Bohemia in favor of a Protestant. This was the spark that ignited the Thirty Years War (1618-1648), which is widely regarded as Protestantism's great war of independence from the Catholic Church.

The highly permissive war ethic that dominated during this era was not confined to the Catholics, however. Some Protestant sects were equally militant against Catholics and against rival Protestants. In Germany, the hostility of the Radical Reformationists Thomas Müntzer and Andreas Karlstadt toward authorities who in their view were unChristian (Reichberg Syse \& Begby 2006: 280-3) culminated in the Peasants' Rebellion 
(1524-1526). ${ }^{39}$ In Switzerland, the militant Reformationist leader Ulrich Zwingli formed an alliance of Protestant cantons, prompting Catholic cantons to do the same and two wars ensued (the Kappel Wars, 1529-1531).

\section{The Western Christian War Ethic Today}

Despite its longevity, the holy war ethic in Christianity has died out today. The reason for this is not clear. Roland Bainton (1960: 174), in his exploration of the three war ethics in Christianity, attributes the abandonment of holy war to the return of pity during the Enlightenment. Furthermore, though Bainton himself does not argue this, to link the end of holy war with the Enlightenment is to imply also linking its demise with the rise of an ideology of tolerance, which itself could be rooted in charitable respect for the differences of others (e.g. Locke 2003) or in secularization generally (e.g. "civil religion"; Rousseau 2002: bk. 4, chap. 8). I would argue, however, that the cause of the decline of holy war runs deeper and begins earlier than Bainton claims. What ultimately sets its decline into motion is the pattern of failure of holy wars to achieve their goals. The early successes of the Crusades were eventually rolled back, and the later Crusades were unsuccessful (and sometimes disastrous). Furthermore, although campaigns to Christianize northern Europe were successful, the ultimate cause célèbre against heresy, the Counter-Reformation, was unsuccessful and very costly. Bainton (1960: 173) may be right to call attention to war exhaustion in Europe, but the exhaustion was largely on the part of the side whose goals went unrealized. Bainton (1960: 178) may also be correct to

\footnotetext{
${ }^{39}$ The rebellion lacked support from the more moderate Protestants, including Luther who roundly condemned it (1974c), and it was subsequently put down.
} 
point out that the "universal peace" conceived during the Enlightenment could not be exclusively Christian, but it is important to note that Christian states did not begin to espouse such universalism until after it was clear that Christian holy wars had been failures. It was not until the mid- $16^{\text {th }}$ century, well after the last Crusade, that European states, including the Pope, began to recognize the Ottoman Empire as a major power in Europe ${ }^{40}$ Furthermore, Catholic political entities did not finally recognize Protestantism as co-equal until the 1648 Peace of Westphalia ${ }^{41}$ (except in England where civil war between religious partisans lasted until 1651), when it was apparent that the effort to stamp it out was futile. None of these sentiments of toleration would have emerged but for the string of defeats for the central church, first in the Middle East and then within Europe.

The holy war ethic was not repudiated formally, but instead withered away from desuetude. ${ }^{42}$ After Suárez, the Western church had little to say about the ethics of war. This is evident in Bainton's (1960) account history of Christian attitudes toward war and peace after Westphalia, for very little of the $18^{\text {th }}$ - and $19^{\text {th }}$-century literature cited in his

${ }^{40}$ First Franco-Turkish Capitulation (France-Turkey), Feb. 1535, 2 FHIG 71; see also Nussbaum 1954: 645. George Childs Kohn (1999: 215) argues that the first general acceptance of Turkish influence and power in Europe took place with a 1547 truce that ended the Hungarian Civil War of 1540-1547.

${ }^{41}$ Treaty of Peace (Holy Roman Empire-Sweden), Oct. 14(24), 1648 (“Treaty of Osnabruck”), 1 CTS 12; Treaty of Peace (France-Holy Roman Empire), Oct. 14(24), 1648 (“Treaty of Münster”), 1 CTS 271.

${ }^{42}$ The first unequivocal repudiation of the holy war ethic by the Catholic Church was in 2006, by Pope Benedict XVI at a lecture at the University of Regensburg, in which he asserted that "spreading the faith through violence ... in incompatible with the nature of God and nature of the soul" (quoted in Popovski Reichberg \& Turner 2009: 156). 
work is religious in character. The question that arises is, with the holy war ethic no longer dominant in Christian thought, what replaced it?

The answer is not so clear, for neither the pacifist nor the just-war traditions have emerged as completely dominant within contemporary Western Christianity, in either the Catholic on Protestant traditions. The entry "War" in the 1912 Catholic Encyclopedia defines the "right of war" in terms of necessary defense and recovery, with reference to purveyors of the just war doctrine such as Thomas Aquinas, Francisco Suárez, and Hugo Grotius (Macksey 1912). The works of the Methodist theologian Paul Ramsey (1961, 1968) in the 1960s were highly influential in reclaiming the Augustinian just war ethic in contemporary religious studies. But since that time, Catholic iterations of the just war ethic have been diluted—or as some might argue, polluted—by expressions of the pacifist ethic (Webster \& Cole 2004: chap. 6). The modern edition of the Catechism of the Catholic Church (1994: secs. 2308-9) concedes the justifiability of war for selfnecessity, but under sections with titles such as "avoiding war" and "safeguarding peace" and without direct reference to Thomas Aquinas. ${ }^{43}$ In 1983, the National Conference of Catholic Bishops (now the U.S. Conference of Catholic Bishops) issued a pastoral letter titled The Challenge of Peace, which imposes a heavy burden for overcoming the "presumption against war" that they claim permeates the moral obligations of statecraft today (National Conference of Catholic Bishops 1983: sec. ii(D)(2)). ${ }^{44}$ They go on to

\footnotetext{
${ }^{43}$ Indeed, the list of "strict conditions for legitimate defense" in section 2309 do not restate completely the Thomist just war tradition.

${ }^{44}$ Darrell Cole's objection is that the Catholic bishops misstate the moral presumption, which is actually against injustice, not war (Webster \& Cole 2004: 138).
} 
restate the just war tradition, including the modern, non-Thomist criteria that emerged from Suárez's recasting of "right intent" as "right manner," 45 but they also introduce another: "comparative justice," in which no cause is recognized as absolutely just or unjust and the values at stake must override the presumption against war (id. para. 92). One may conclude simply from the number of additional criteria (eight, vice the original three) that the threshold for legitimizing the use of force in the contemporary just war tradition is significantly higher than before. In addition, pacifism is reflected in other treatments of the Catholic war ethic, both official and scholarly. For example, a tenthanniversary follow-up to The Challenge of Peace, titled The Harvest of Justice is Sown in Peace, is virtually devoid of any just war thinking (United States Conference of Catholic Bishops 1993). Writings such as these introduce tension between the pacifist and just war ethics in Catholic thought.

The same tension is evident in many contemporary Protestant treatments of the just war tradition, especially official treatments in the United States. The 1983 Catholic pastoral letter spawned a series of publications by other prominent American denominations, which unanimously railed against nuclear warfare and the nuclear arms race. For example, documents of the United Methodist Council of Bishops (1986) and the General Assembly of the Presbyterian Church (USA) (1988) purport to maintain the just war tradition alongside pacifism, but like their Catholic counterparts, they begin with the presumption against war (i.e. that war is unjust), and are so fixated on the unjustness of

\footnotetext{
${ }^{45}$ Those criteria are last resort, reasonable prospect of success, and just means (Brown 2008: 31). The criterion of proportionality of cause, which is articulately separately today, is derived directly from the Thomist formula for just cause (Brown 2008: 97).
} 
nuclear warfare that they do not seriously engage the possibility of a just war given the proper circumstances. ${ }^{46}$ The Methodist church, in its Book of Discipline, even goes as far as making the sweeping assertion that "war is incompatible with the teaching and example of Christ" (United Methodist Church 2004: sec. 165; emphasis added). All of the major American Protestant denominations situate the just war ethic among theories and/or ethics of peace or "just peace." ${ }^{, 47}$ Yet tensions ensue within the Protestant denominations as well. For example, the Methodist Book of Discipline goes on to concede the justifiability of war in cases of genocide and unprovoked aggression (United Methodist Church 2004: sec. 165). In addition, several churches' responses to the Kosovo War of 1999, in which NATO bombed Yugoslavia to induce its regime to stop its ethnic cleansing campaign against Albanians in Kosovo, were so equivocal that they were paralyzed (United States Conference of Catholic Bishops, Evangelical Lutheran Church in America, Episcopal Church, all 1999). Thus, Valerie Morkevicius's (2009) claim that the just war tradition is dominant among Protestant churches, on the basis that very few of them espouse pacifism as an official policy (as do the Amish, Mennonites, and Quakers), is overstated; for it does not take into account the pattern of hesitance, reluctance, or outright hostility to the just war ethic expressed by much of the American ecclesiastical leadership.

\footnotetext{
46 The publication by the Episcopal Diocese of Washington (1987) is somewhat more even-handed, if too charitable in its assessment of Soviet intentions during the Cold War, and reluctantly concedes the moral acceptability of the policy of nuclear deterrence.

${ }^{47}$ In addition to the documents cited above, see Lutheran Church in America 1984. For an attempt to reclaim the just war tradition in the Lutheran Church, on the other hand, see Stelmachowicz 1986.
} 
Scholarly treatments of the Christian war ethic are similarly divided. The treatment of the Catholic just war tradition in Paul Robinson's edited volume reads as repudiation of the just war ethic, and even asserts that the Catholic Catechism merely enumerates the traditional just war criteria without affirming them (Dearey 2003: 29). Despite several attempts to reconcile the pacifist and just war ethics (Childress 1982; Miller 1991), other scholarly treatments are quite defensive of the just war ethic (Webster \& Cole 2004: chap. 8; Reichberg 2009). The parallel (at best) treatment of these two ethics leads to the conclusion that the war ethic that dominates Western Christian political thought today is actually a blend of pacifism and the just war ethic. This blending would seem to render it less permissive than the classical just war tradition—a supportable position if today's war ethic is compared with that of Suárez, who embraced just war to vindicate honor. Although it is more restrictive than the original just war ethic, the Western Christian war ethic of today is less restrictive than pacifism, by definition. If depicted on a scale of permissiveness in which the just war tradition were at the center, the Western Christian war ethic would lie somewhere between the center and the pacifist end.

Although the Western Christian war ethic is restrictive today, it is still more permissive than the jus ad bellum that is currently in effect (according to jus ad bellum's restrictive interpretation). In the just war ethic, if State A has a sufficiently just cause to use force against State B, than attacking State B is morally permissible. State B need not have actually attacked State A; it need only have committed some fault that warrants resorting to the drastic remediation of military force-for example, a military intervention to restore basic human rights, as some just war theorists have argued. The range of permissible actions under the Western Christian war ethic is broader than the range of 
permissible actions according to the letter of secular international law. The latter makes no provision for the first use of force by a state that has not been the object of an armed attack and has not secured the approval of the Security Council to attack first. It is never certain that the Council will authorize a first attack against a state that, under just war theory, has committed an act that confers a just cause against it - as the failure of the Council to authorize the humanitarian interventions conducted in Uganda in 1979, Kosovo in 1999, and elsewhere attests. Therefore it may be concluded that the Western Christian war ethic is more permissive than jus ad bellum. If states do substitute the war ethics of their respective religions for the war ethic of jus ad bellum as I have suggested, than the probability of Western Christian states using force in violation of jus ad bellum should be non-zero, but low. ${ }^{48}$ This is in fact the case, as shown in the section that follows. Furthermore, assuming that religious war ethics cover a broad range on the scale of permissiveness to restrictiveness, than it follows that states with highly restrictive war ethics should have lower propensities to violate jus ad bellum than other states. This is shown empirically to be the case also, for the results below indicate that Christian states are less likely to use force (in violation of jus ad bellum) than non-Christian states.

\footnotetext{
${ }^{48}$ It is expected that the propensity of any state to violate jus ad bellum should be non-zero, regardless of its religion or religiosity, for it would be unreasonable to assume that states never violate the rules of conduct they even they believe apply to them. We therefore cannot conclude, solely on the basis of the results shown in this chapter, that states substitute their religious war ethics for that of secular jus ad bellum. However, more evidence will follow in later chapters.
} 


\section{Empirical Testing of Western Christianity}

Some empirical results for Christianity overall were presented in Chapter 4, in the context of comparing the effects of Christianity relative to those of other religious categories. The purpose of the remainder of this chapter is to dig deeper into the empirical effects of Christianity overall and its major branches individually.

We begin by enumerating the states that are identified as "Christian" according to criteria set forth in Chapter 3. Table 5-1 lists all the states that have had a Christian chief executive, Christian Preference, or Christian Prevalence (all denominations combined), along with the number of interstate armed conflicts they initiated in violation of $j u s$ ad bellum (if any) at the lowest threshold (cwhiact=12) and at the highest (cwfatal=1), while holding the Christian characteristic(s) they did. 
Table 5-1. List of Christian (All) States, with Number of Armed Conflicts Initiated at Lowest Threshold (Model 1) and Highest Threshold (Model 5).

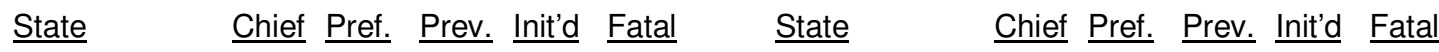

\begin{tabular}{|c|c|c|c|c|c|c|c|c|c|c|c|}
\hline Albania & * & & & 2 & 1 & Germany, East & & & * & 9 & 4 \\
\hline Andorra & * & * & * & -- & -- & Germany, West & * & * & * & 4 & 1 \\
\hline Angola & * & * & & 6 & 4 & Ghana & * & * & * & 4 & 1 \\
\hline Antigua \& Barb. & * & & * & 1 & 1 & Great Britain & * & * & * & 26 & 8 \\
\hline Argentina & * & * & * & 17 & 1 & Greece & * & * & * & 9 & 3 \\
\hline Armenia & * & * & * & 11 & 9 & Grenada & * & & * & -- & -- \\
\hline Australia & * & * & * & 10 & 2 & Guatemala & * & * & * & 8 & 2 \\
\hline Austria & * & * & * & 2 & -- & Guyana & * & * & & 2 & - \\
\hline Bahamas & * & * & * & -- & -- & Haiti & * & * & & 3 & -- \\
\hline Barbados & * & * & * & 1 & 1 & Honduras & * & * & * & 8 & 1 \\
\hline Belarus & & * & * & -- & -- & Hungary & * & * & * & 6 & 6 \\
\hline Belgium & * & * & * & -- & -- & Iceland & * & * & * & 8 & 2 \\
\hline Belize & * & * & * & 5 & -- & Ireland & * & * & * & -- & - \\
\hline Benin & * & & & 2 & -- & Italy & * & * & * & 3 & 2 \\
\hline Bolivia & * & * & * & -- & -- & Jamaica & * & * & * & 1 & 1 \\
\hline Bosnia \& Herz. & * & & & -- & -- & Japan & * & & & -- & -- \\
\hline Botswana & * & & * & 3 & -- & Kenya & * & * & * & 2 & -- \\
\hline Brazil & * & * & * & 3 & -- & Kiribati & * & & * & - & -- \\
\hline Bulgaria & * & * & * & 6 & 4 & Korea, South & * & & & 7 & 1 \\
\hline Burkina Faso & * & & & -- & -- & Latvia & & * & * & -- & -- \\
\hline Burundi & & * & * & 3 & -- & Lebanon & * & & & 3 & 3 \\
\hline Cameroon & * & & & 6 & 3 & Lesotho & * & * & * & -- & -- \\
\hline Canada & * & * & * & 4 & -- & Liberia & * & & & -- & -- \\
\hline Cape Verde & * & * & * & -- & -- & Liechtenstein & * & * & * & -- & -- \\
\hline Central Afr. Rep. & * & * & * & 2 & -- & Lithuania & * & * & * & -- & -- \\
\hline Chile & * & * & * & 7 & 1 & Luxembourg & * & * & * & -- & -- \\
\hline China† & * & & & -- & -- & Macedonia & * & * & * & -- & 2 \\
\hline Colombia & * & * & * & 2 & -- & Madagascar & * & & & -- & - \\
\hline Congo, D.R. of & * & * & * & 16 & 3 & Malawi & * & * & * & -- & -- \\
\hline Congo, Rep. of & * & * & & -- & -- & Malta & * & * & * & -- & -- \\
\hline Costa Rica & * & * & * & 1 & -- & Marshall Is. & * & & * & -- & -- \\
\hline Cote d'Ivoire & * & * & & -- & -- & Mexico & * & * & * & 1 & -- \\
\hline Croatia & * & * & * & 5 & 4 & Moldova & * & * & * & -- & -- \\
\hline Cuba & * & * & * & 7 & 1 & Monaco & * & & * & -- & -- \\
\hline Cyprus & * & * & * & 1 & -- & Mozambique & * & & & 1 & -- \\
\hline Czech Rep. & & * & * & -- & -- & Namibia & * & * & * & -- & -- \\
\hline Czechoslovakia & & * & * & 7 & 2 & Nauru & * & & * & -- & -- \\
\hline Denmark & * & * & * & 1 & - & Netherlands & * & * & * & -- & -- \\
\hline Dominica & * & & * & 1 & 1 & New Zealand & * & * & * & 7 & -- \\
\hline Dominican Rep. & * & * & * & -- & -- & Nicaragua & * & * & * & 31 & 2 \\
\hline Ecuador & * & * & * & 15 & 4 & Nigeria & * & & & 1 & - \\
\hline Equat'l Guinea & * & * & * & -- & -- & Norway & * & * & * & 7 & -- \\
\hline El Salvador & * & * & * & 3 & 2 & Palau & & & * & 1 & -- \\
\hline Eritrea & * & & & 13 & 3 & Panama & * & * & * & 5 & 1 \\
\hline Estonia & & * & & -- & -- & Papua New G. & * & * & * & 2 & -- \\
\hline Ethiopia & * & & & 7 & 1 & Paraguay & * & * & * & 2 & 2 \\
\hline F.S. Micronesia & * & & * & -- & -- & Peru & * & * & * & 14 & 3 \\
\hline Fiji & * & * & & -- & -- & Philippines & * & * & * & 14 & -- \\
\hline Finland & * & * & * & -- & -- & Poland & * & * & * & 2 & -- \\
\hline France & * & * & * & 23 & 10 & Portugal & * & * & * & -- & -- \\
\hline Gabon & * & * & & -- & -- & Romania & * & * & * & 3 & 4 \\
\hline Georgia & * & * & * & -- & -- & Russia/USSR †† & * & * & * & 35 & 12 \\
\hline Germany & & * & * & 2 & 2 & Rwanda & * & * & * & 2 & -- \\
\hline
\end{tabular}


State $\quad \underline{\text { Chief Pref. }} \underline{\text { Prev. Init'd Fatal }} \underline{\text { State }} \quad \underline{\text { Chief Pref. Prev. Init'd Fatal }}$

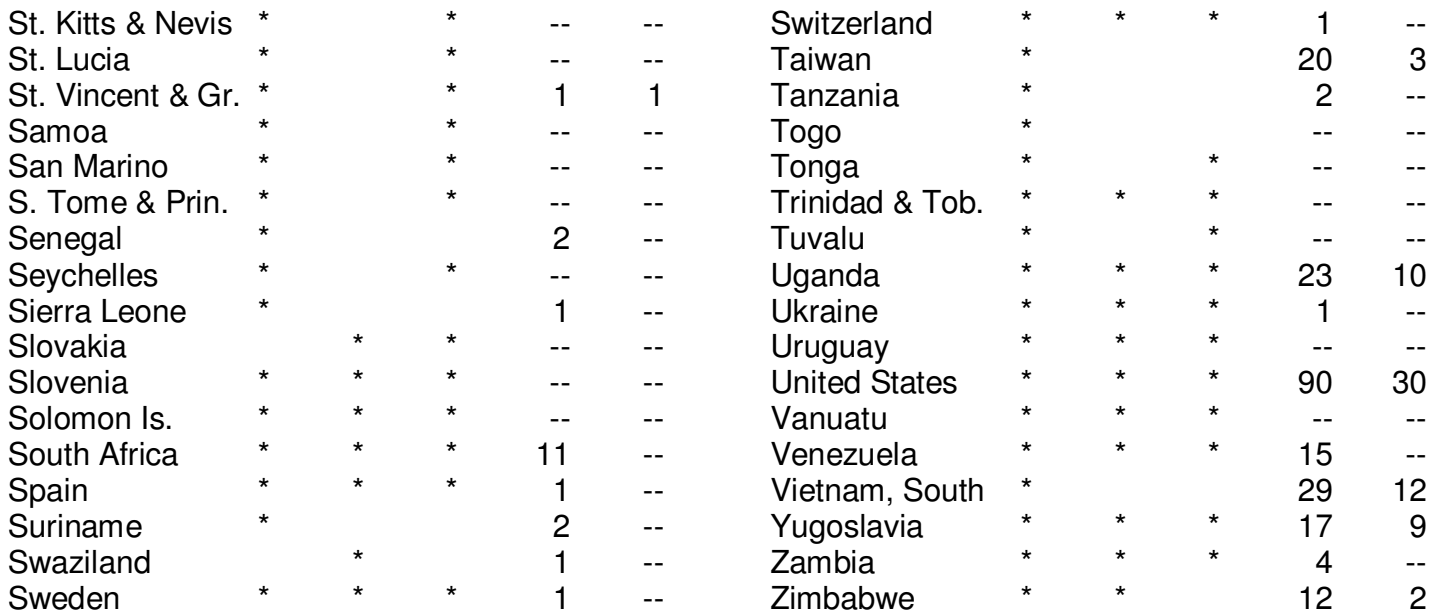

† Chief executive was Chiang Kai-Shek, prior to breakaway of Taiwan.

†† Stalin coded as Orthodox after 1942; Gorbachev coded as Orthodox.

We can compare the relative effects of a Christian chief executive, Preference, and

Prevalent by reiterating the results of testing Christianity overall from Chapter 4,

reproduced below as Table 5-2.

Table 5-2. Summary of Logit Coefficients for Christian (All) States.

\begin{tabular}{|c|c|c|c|c|c|c|}
\hline Variable & Model 1 & Model 2 & Model 3 & Model 4 & Model 5 & $\begin{array}{l}\text { App. } \\
\text { Table }\end{array}$ \\
\hline & (Robust SE) & & & & & \\
\hline $\begin{array}{l}\text { Christian (all) } \\
\text { Chief Exec. (binary) }\end{array}$ & $\begin{array}{l}-.2958^{* *} \\
(.0915)\end{array}$ & $\begin{array}{r}-.3362^{\star \star *} \\
(.0972)\end{array}$ & $\begin{array}{r}-.3942^{* \star *} \\
(.1022)\end{array}$ & $\begin{array}{r}-.4468^{* * *} \\
(.1108)\end{array}$ & $\begin{array}{r}-.8108^{* * *} \\
(.1839)\end{array}$ & B-31 \\
\hline $\begin{array}{l}\text { Christian (all) } \\
\text { Preference (binary) }\end{array}$ & $\begin{array}{c}-.3544^{* *} \\
(.1103)\end{array}$ & $\begin{array}{r}-.4254^{\star * *} \\
(.1157)\end{array}$ & $\begin{array}{r}-.4096^{\star * *} \\
(.1239)\end{array}$ & $\begin{array}{r}-.4935^{\star \star *} \\
(.1324)\end{array}$ & $\begin{array}{r}-.9542^{* * *} \\
(.2207)\end{array}$ & B-32 \\
\hline $\begin{array}{l}\text { Christian (all) } \\
\text { GRP (every 10\%) }\end{array}$ & $\begin{array}{r}-.0620^{* *} \\
(.0234)\end{array}$ & $\begin{array}{r}-.0671^{\star *} \\
(.0246)\end{array}$ & $\begin{array}{r}-.0781^{\star *} \\
(.0261)\end{array}$ & $\begin{array}{c}-.0842^{* *} \\
(.0278)\end{array}$ & $\begin{array}{r}-.2013^{\star * *} \\
(.0480)\end{array}$ & B-33 \\
\hline $\begin{array}{l}\text { Christian (all) } \\
\text { Prevalence (binary) }\end{array}$ & $\begin{array}{r}-.2085^{\circ} \\
(.1121)\end{array}$ & $\begin{array}{c}-.2082^{\circ} \\
(.1182)\end{array}$ & $\begin{array}{c}-.2788^{*} \\
(.1250)\end{array}$ & $\begin{array}{l}-.2907^{*} \\
(.1338)\end{array}$ & $\begin{array}{c}-.5973^{*} \\
(.2329)\end{array}$ & B-34 \\
\hline $\begin{array}{l}\text { Christian (all) } \\
\text { Pop. (every 10\%) }\end{array}$ & $\begin{array}{r}-.0341^{* *} \\
(.0132) \\
\end{array}$ & $\begin{array}{c}-.0342^{*} \\
(.0140) \\
\end{array}$ & $\begin{array}{c}-.0459^{* *} \\
(.0148) \\
\end{array}$ & $\begin{array}{c}-.0478^{\star *} \\
(.0158) \\
\end{array}$ & $\begin{array}{r}-.0814^{* *} \\
(.0265) \\
\end{array}$ & B-35 \\
\hline
\end{tabular}

${ }^{\circ} p<.10 \quad{ }^{*} p<.05 \quad{ }^{* *} p<.01{ }^{* * *} p<.001$ 
Of any religious category measured in this work, Christian states have the lowest propensity to use force. States that are Christian are less likely to use force than states that are not Christian, and in some models they are much less likely. Furthermore, the percentage of Christian population and GRP scores also have the most strongly negative effects as they increase. Every coefficient in the table above is negative and statistically significant, across data sets and across dependent variables. This result shows that Christian states, taken as a whole, are restrained in their undertaking of armed conflict, and as I have argued earlier in this chapter, the cause of this restraint is traceable to a war ethic that today is more restrictive overall than the war ethics of non-Christian states.

Two other interesting trends are identifiable. One trend, at least for Christianity overall (and as will be seen, usually for the individual branches), is that a Christian regime Preference has a stronger (negative) effect than a Christian chief executive or population. The negative effect of a Christian Preference is about one-third stronger than that of Christian Prevalence, and one-fourth stronger than that of a Christian chief executive. Additionally, the negative effect of an increase in a Christian GRP is between 2 and $2 \frac{1}{2}$ times stronger than that of the same increase in Christian population. This could be a reflection of the influence of population's religion on state practice being intuitively less direct than the influence of the religion of the governing regime.

The other, even more interesting trend is that the higher the threshold for defining an armed conflict, the stronger the negative effect of Christianity. The coefficients in Model 1, in which the threshold is the lowest (cwhiact=12), are uniformly the least negative, and those for Model 5, in which the threshold is highest (cwfatal=1), are almost always the most negative. In most models across most independent variables, the coefficients are 
gradually more negative as the threshold increases, and those in Model 5 are sharply more negative than in the other models. This trend appears to reflect a high regard in the contemporary Christian war ethic for the life and well-being of the Other, as well as for treating the Other in an equal manner as treating the Self (recall the Christian duty to love one's neighbor as oneself).

This section, however, is specifically devoted to the empirics of Western Christianity, for the Catholic and Protestant war ethics appear to be similar enough to warrant testing them together. ${ }^{49}$ Table 5-3 lists the states that have had Western Christian chief executives, regime Preferences, and population Prevalences, along with the number of interstate armed conflicts that they initiated (if any) at the lowest and highest thresholds, while they had those Western Christian characteristics.

\footnotetext{
${ }^{49}$ The Mormon branch is also included in Western Christianity, as indicated in Chapter 3.
} 
Table 5-3. List of Western Christian States, with Number of Armed Conflicts Initiated at Lowest Threshold (Model 1) and Highest Threshold (Model 5).

\begin{tabular}{|c|c|c|c|c|c|c|c|c|c|c|c|}
\hline State & Chief & Pref. & Prev. & Init'd & Fatal & $\underline{\text { State }}$ & Chief & Pref. & Prev. & Init'd & Fatal \\
\hline Andorra & * & * & * & -- & -- & Guatemala & * & * & * & 8 & 2 \\
\hline Angola & * & * & & 6 & 4 & Guyana & * & * & & 2 & -- \\
\hline Antigua \& Barb. & * & & * & 1 & 1 & Haiti & * & * & & 3 & -- \\
\hline Argentina & * & * & * & 17 & 1 & Honduras & * & * & * & 8 & 1 \\
\hline Australia & * & * & * & 10 & 2 & Hungary & * & * & * & 6 & 6 \\
\hline Austria & * & * & * & 2 & -- & Iceland & * & * & * & 8 & 2 \\
\hline Bahamas & * & * & * & -- & -- & Ireland & * & * & * & -- & -- \\
\hline Barbados & * & * & * & 1 & 1 & Italy & * & * & * & 3 & 2 \\
\hline Belgium & * & * & * & -- & -- & Jamaica & * & * & * & 1 & 1 \\
\hline Belize & * & * & * & 5 & -- & Japan & * & & & -- & -- \\
\hline Benin & * & & & 2 & -- & Kenya & * & * & * & 2 & -- \\
\hline Bolivia & * & * & * & -- & -- & Kiribati & * & & * & -- & -- \\
\hline Bosnia \& Herz. & * & & & -- & -- & Korea, South & * & & & 7 & 1 \\
\hline Botswana & * & & * & 3 & -- & Latvia & & * & * & -- & -- \\
\hline Brazil & * & * & * & 3 & -- & Lebanon & * & & & 3 & 3 \\
\hline Bulgaria & * & & & 5 & 4 & Lesotho & * & * & * & -- & -- \\
\hline Burkina Faso & * & & & -- & -- & Liberia & * & & & -- & -- \\
\hline Burundi & & * & * & 3 & -- & Liechtenstein & * & * & * & -- & -- \\
\hline Cameroon & * & & & 6 & 3 & Lithuania & * & * & * & -- & -- \\
\hline Canada & * & * & * & 4 & -- & Luxembourg & * & * & * & -- & -- \\
\hline Cape Verde & * & * & * & -- & -- & Madagascar & * & & & -- & -- \\
\hline Central Afr. Rep. & ). * & * & * & 2 & -- & Malawi & * & * & * & -- & -- \\
\hline Chile & * & * & * & 7 & 1 & Malta & * & * & * & -- & -- \\
\hline China† & * & & & -- & -- & Marshall Is. & * & & * & -- & -- \\
\hline Colombia & * & * & * & 2 & -- & Mexico & * & * & * & 1 & -- \\
\hline Congo, D.R. & * & * & * & 16 & 3 & Monaco & * & & * & -- & -- \\
\hline Congo, Rep. of & * & * & & -- & -- & Mozambique & * & & & 1 & -- \\
\hline Costa Rica & * & * & * & 1 & -- & Namibia & * & * & * & -- & -- \\
\hline Cote d'Ivoire & * & * & & -- & -- & Nauru & * & & * & -- & -- \\
\hline Croatia & * & * & * & 5 & 4 & Netherlands & * & * & * & -- & -- \\
\hline Cuba & * & * & * & 7 & 1 & New Zealand & * & * & * & 7 & -- \\
\hline Czech Rep. & & * & * & -- & -- & Nicaragua & * & * & * & 31 & 2 \\
\hline Czechoslovakia & & * & * & 7 & 2 & Nigeria & * & & & 1 & -- \\
\hline Denmark & * & * & * & 1 & -- & Norway & * & * & * & 7 & -- \\
\hline Dominica & * & & * & 1 & 1 & Palau & & & * & 1 & -- \\
\hline Dominican Rep. & * & * & * & 3 & -- & Panama & * & * & * & 5 & 1 \\
\hline Ecuador & * & * & * & 15 & 4 & Papua New G. & * & * & * & 2 & -- \\
\hline El Salvador & * & * & * & 3 & 2 & Paraguay & * & * & * & 2 & 2 \\
\hline Equat'l Guinea & * & * & * & -- & -- & Peru & * & * & * & 14 & 3 \\
\hline Estonia & & * & & -- & -- & Philippines & * & * & * & 14 & -- \\
\hline F.S. Micronesia & * & & * & -- & -- & Poland & * & * & * & 2 & -- \\
\hline Fiji & * & * & & -- & -- & Portugal & * & * & * & -- & -- \\
\hline Finland & * & * & * & -- & -- & Rwanda & * & * & * & 2 & -- \\
\hline France & * & * & * & 23 & 10 & St. Kitts \& Nevis & * & & * & - & -- \\
\hline Gabon & * & * & & -- & -- & St. Lucia & * & & * & -- & -- \\
\hline Germany & & * & * & 2 & 2 & St. Vincent \& Gr. & r. * & & * & 1 & 1 \\
\hline Germany, East & & & * & 9 & 4 & Samoa & * & & * & -- & -- \\
\hline Germany, West & * & * & * & 4 & 1 & San Marino & * & & * & -- & -- \\
\hline Ghana & * & * & * & 4 & 1 & S. Tome \& Prin. & * & & * & -- & -- \\
\hline Great Britain & * & * & * & 26 & 8 & Senegal & * & & & 2 & -- \\
\hline Grenada & * & & * & -- & -- & Seychelles & * & & * & -- & -- \\
\hline
\end{tabular}




\begin{tabular}{|c|c|c|c|c|c|c|c|c|c|c|c|}
\hline State & Chief & Pref. & Prev. & Init'd & Fatal & State & Chief & Pref. & Prev. & Init'd & Fatal \\
\hline Sierra Leone & * & & & 1 & -- & Tonga & * & & * & -- & -- \\
\hline Slovakia & & * & * & -- & -- & Trinidad \& Tob. & * & * & * & -- & -- \\
\hline Slovenia & * & * & * & -- & -- & Tuvalu & * & & * & -- & -- \\
\hline Solomon Is. & * & * & * & -- & -- & Uganda & * & * & * & 23 & 10 \\
\hline South Africa & * & * & * & 11 & -- & Uruguay & * & * & * & -- & -- \\
\hline Spain & * & * & * & 1 & -- & United States & * & * & * & 90 & 30 \\
\hline Suriname & * & & & 2 & -- & Vanuatu & * & * & * & -- & -- \\
\hline Swaziland & & * & & $\overline{1}$ & -- & Venezuela & * & * & * & 15 & -- \\
\hline Sweden & * & * & * & 2 & -- & Vietnam, South & * & & & 29 & 12 \\
\hline Switzerland & * & * & * & 1 & -- & Yugoslavia & * & & & 9 & 6 \\
\hline Taiwan & * & & & 20 & 3 & Zambia & * & * & * & 4 & - \\
\hline Tanzania & * & & & 2 & -- & Zimbabwe & * & * & & 12 & 2 \\
\hline Togo & * & & & -- & -- & & & & & & \\
\hline
\end{tabular}

† Chief executive was Chiang Kai-Shek, prior to breakaway of Taiwan.

Because most Christian states are Western Christian, it is likely that the Western Christian war ethic is the primary driver of the results shown above. And indeed, this supposition is supported empirically. Table 5-2 summarizes the logit coefficients for Western Christianity.

Table 5-4. Summary of Logit Coefficients for Western Christian States.

\begin{tabular}{|c|c|c|c|c|c|c|}
\hline Variable & Model 1 & Model 2 & Model 3 & Model 4 & Model 5 & $\begin{array}{l}\text { App. } \\
\text { Table }\end{array}$ \\
\hline \multicolumn{7}{|c|}{ (Robust SE) } \\
\hline $\begin{array}{l}\text { Western Christian } \\
\text { Chief Exec. (binary) }\end{array}$ & $\begin{array}{l}-.3051^{* *} \\
(.0936)\end{array}$ & $\begin{aligned}-.3442^{\star * *} \\
(.0999)\end{aligned}$ & $\begin{array}{r}-.4235^{\star * *} \\
(.1060)\end{array}$ & $\begin{array}{r}-.4792^{\star * *} \\
(.1160)\end{array}$ & $\begin{array}{r}-.9612^{* * *} \\
(.2000)\end{array}$ & B-66 \\
\hline $\begin{array}{l}\text { Western Christian } \\
\text { Preference (binary) }\end{array}$ & $\begin{array}{l}-.3475^{\star *} \\
(.1059)\end{array}$ & $\begin{array}{r}-.3880^{* * *} \\
(.1119)\end{array}$ & $\begin{aligned}-.4128^{* * *} \\
(.1200)\end{aligned}$ & $\begin{aligned}-.4617^{\star * *} \\
(.1294)\end{aligned}$ & $\begin{array}{c}-1.0717^{* \star *} \\
(.2220)\end{array}$ & B-67 \\
\hline $\begin{array}{l}\text { Western Christian } \\
\text { GRP (every 10\%) }\end{array}$ & $\begin{aligned}-.0728^{\star *} \\
(.0237)\end{aligned}$ & $\begin{aligned}-.0733^{\star \star} & (.0250)\end{aligned}$ & $\begin{aligned}-.0951^{\star \star *} & (.0267)\end{aligned}$ & $\begin{aligned}-.0964^{* * *} & (.0287)\end{aligned}$ & $\begin{aligned}-.2641^{* \star *} & (.0516)\end{aligned}$ & B-68 \\
\hline $\begin{array}{l}\text { Western Christian } \\
\text { Prevalence (binary) }\end{array}$ & $\begin{array}{l}-.1587 \\
(.1150)\end{array}$ & $\begin{array}{l}-.1585 \\
(.1220)\end{array}$ & $\begin{array}{l}-.2528^{\circ} \\
(.1298)\end{array}$ & $\begin{array}{l}-.2697^{\circ} \\
(.1403)\end{array}$ & $\begin{aligned}-.9477^{* * *} \\
(.2447)\end{aligned}$ & B-69 \\
\hline $\begin{array}{l}\text { Western Christian } \\
\text { Pop. (every 10\%) }\end{array}$ & $\begin{array}{r}-.0323^{*} \\
(.0132)\end{array}$ & $\begin{array}{r}-.0318^{*} \\
(.0140)\end{array}$ & $\begin{array}{r}-.0458^{* *} \\
(.0149)\end{array}$ & $\begin{array}{r}-.0475^{\star \star} \\
(.0160) \\
\end{array}$ & $\begin{array}{r}-.1120^{* * *} \\
(.0271)\end{array}$ & B-70 \\
\hline
\end{tabular}

${ }^{\circ} \mathrm{p}<.10^{*} \mathrm{p}<.05^{* *} \mathrm{p}<.01{ }^{* * *} \mathrm{p}<.001$

All coefficients are negative and nearly all of them are statistically significant. As is the case for Christianity overall, a Western Christian chief executive or regime Preference 
has a stronger negative effect than a Western Christian population. The difference is stronger at lower thresholds of armed conflict, in which Preference is about twice as strong as Prevalence and GRP about twice as strong as the percentage of the population (though note that the coefficients for the binary variable Prevalence are not statistically significant at those thresholds). At the highest threshold of armed conflict, the binary Preference coefficient is only about $10 \%$ stronger than the other binary coefficients, though the effect of the Western Christian GRP is still over twice as strong as the percentage of the Western Christian population. Figures 5A and 5B graph the effect of the Western Christian GRP and population, respectively, as they increase. As most Christian states are Western Christian, these results were expected to be similar to those for Christianity overall, and in fact they are.

Figure 5A. Graph of Western Christian GRP.

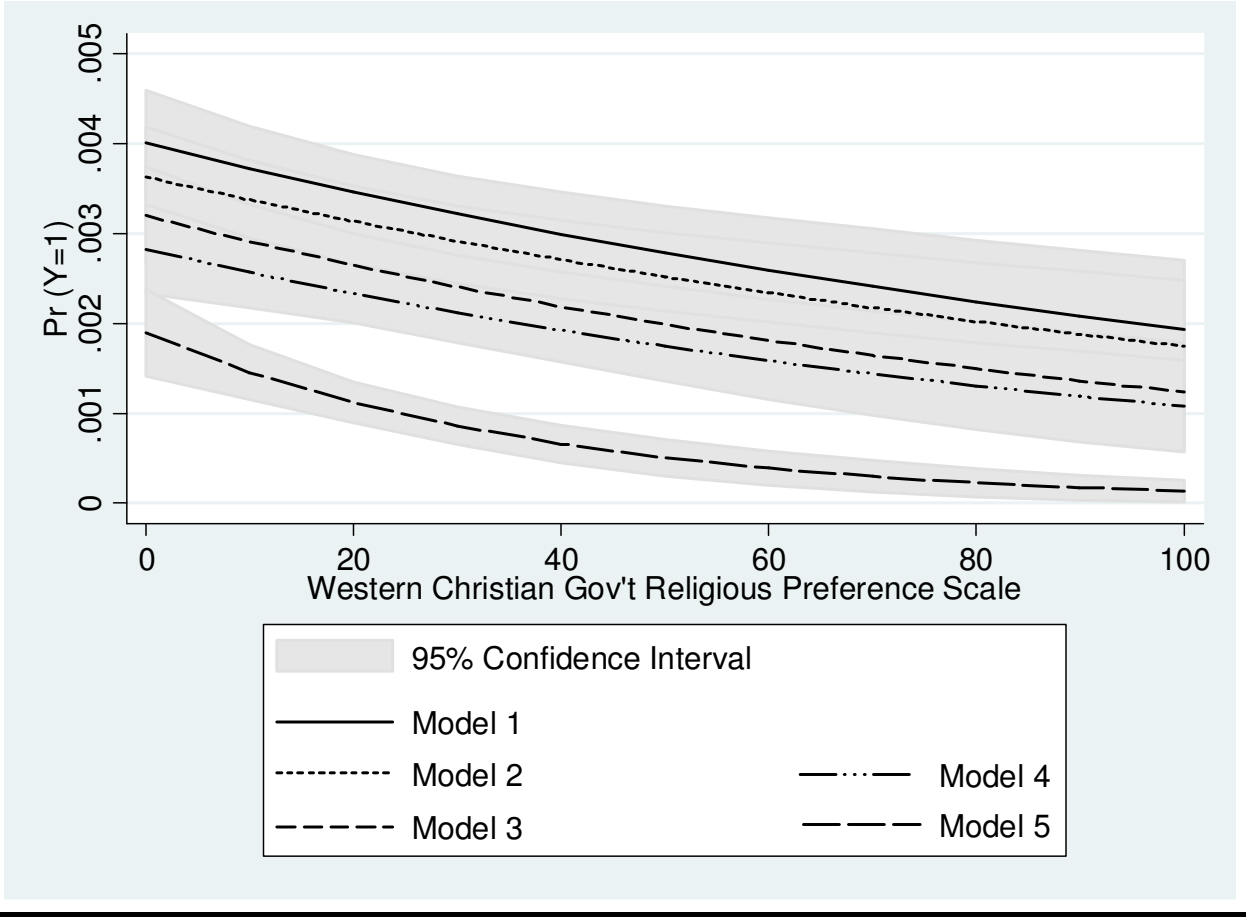


Figure 5B. Graph of Western Christian Population.

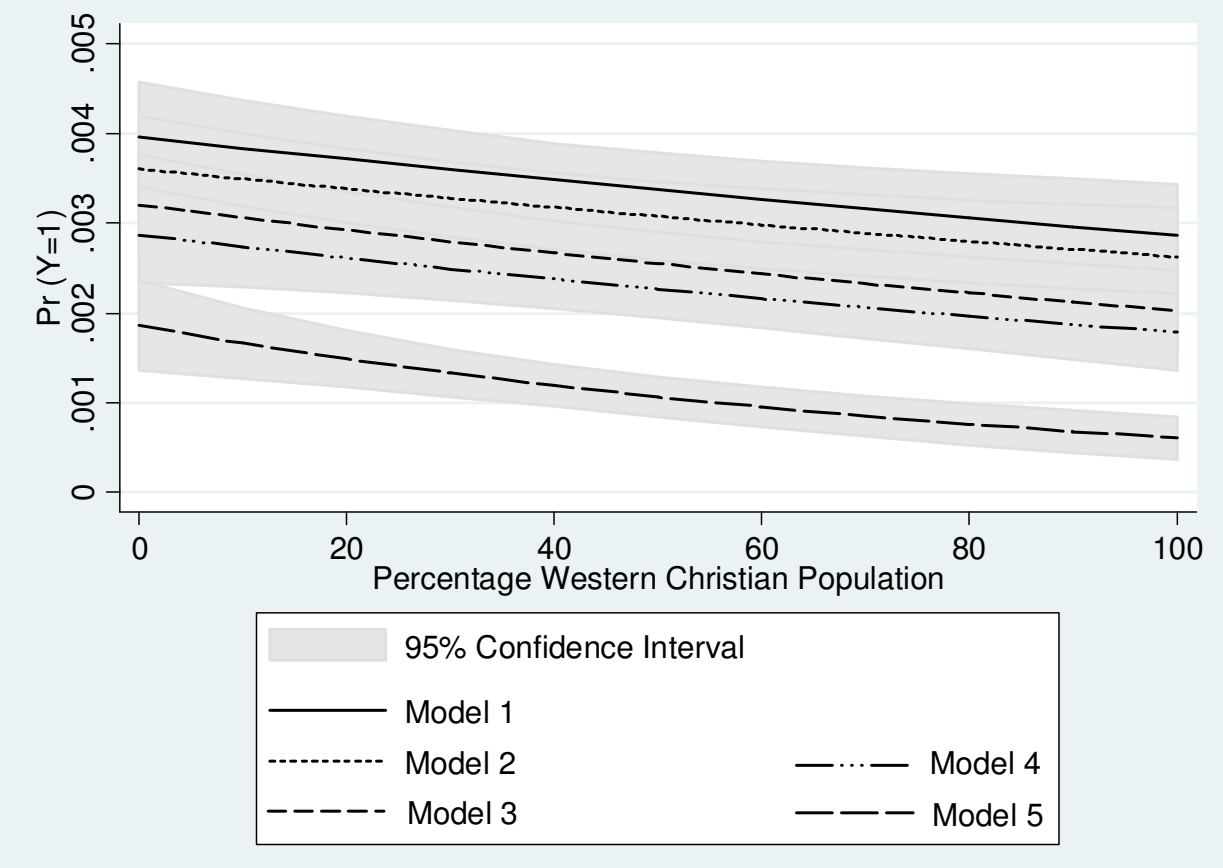

\section{Catholic and Protestant States Compared}

Table 5-5 lists the states that have had Catholic chief executives, regime Preferences, or population Prevalences, and the number of interstate armed conflict they initiated (if any) at the lowest and highest thresholds, while they were Catholic. Table 5-6 provide a similar listing for Protestant states. ${ }^{50}$

\footnotetext{
${ }^{50}$ Several Western states have Protestant majorities, but the percentage of Protestants does not reach the 66.5\% threshold is necessary to code a Protestant Prevalence or Preference; such states are coded as Western Christian. These states include the United States, Canada, the Netherlands, and Germany. As a result, they do not appear in the table of Protestant states.
} 
Table 5-5. List of Catholic States, with Number of Armed Conflicts Initiated at Lowest Threshold (Model 1) and Highest Threshold (Model 5).

\begin{tabular}{|c|c|c|c|c|c|c|c|c|c|c|c|}
\hline State & Chief & Pref. & Prev. & Init'd & Fatal & $\underline{\text { State }}$ & Chief & Pref. & Prev. & Init'd & Fata \\
\hline Andorra & * & * & * & -- & -- & Japan & * & & & -- & -- \\
\hline Angola & * & & & 3 & 2 & Korea, South & * & & & 1 & -- \\
\hline Argentina & * & * & * & 17 & 1 & Lebanon & * & & & 3 & 3 \\
\hline Australia & * & & & -- & -- & Lesotho & * & & & -- & -- \\
\hline Austria & * & * & * & 2 & -- & Liechtenstein & & * & * & -- & -- \\
\hline Belgium & * & * & * & -- & -- & Lithuania & * & * & * & -- & -- \\
\hline Belize & & * & & 5 & -- & Luxembourg & * & * & * & -- & -- \\
\hline Benin & * & & & 2 & -- & Madagascar & * & & & -- & -- \\
\hline Bolivia & * & * & * & - & -- & Malta & * & * & * & -- & -- \\
\hline Bosnia \& Herz. & * & & & -- & -- & Mexico & * & * & * & 1 & -- \\
\hline Brazil & * & * & * & 3 & -- & Monaco & * & & * & -- & -- \\
\hline Bulgaria & * & & & 5 & 4 & Mozambique & * & & & 1 & -- \\
\hline Burkina Faso & * & & & -- & -- & Netherlands & * & & & -- & -- \\
\hline Burundi & & * & * & 3 & -- & New Zealand & * & & & -- & -- \\
\hline Cameroon & * & & & 6 & 3 & Nicaragua & * & * & * & 31 & 2 \\
\hline Canada & * & & & 4 & -- & Panama & * & * & * & 5 & 1 \\
\hline Cape Verde & & * & * & -- & -- & Papua New G. & * & & & -- & -- \\
\hline Central Afr. Rep. & * & & & 1 & -- & Paraguay & * & * & * & 2 & 2 \\
\hline Chile & * & * & * & 7 & 1 & Peru & * & * & * & 14 & 3 \\
\hline Colombia & * & * & * & 2 & -- & Philippines & * & * & * & 14 & -- \\
\hline Congo, Rep. of & * & & & -- & -- & Poland & * & * & * & 2 & -- \\
\hline Costa Rica & * & * & * & 1 & -- & Portugal & * & * & * & -- & -- \\
\hline Cote d'Ivoire & * & * & & -- & -- & Rwanda & * & * & & 2 & -- \\
\hline Croatia & * & * & * & 5 & 4 & St. Lucia & & & * & -- & -- \\
\hline Cuba & * & * & * & 7 & 1 & St. Vincent \& Gr. & . * & & & -- & -- \\
\hline Czech Rep. & & & * & -- & -- & Samoa & * & & & -- & -- \\
\hline Czechoslovakia & & * & * & 7 & 2 & San Marino & * & & * & -- & -- \\
\hline Dominica & * & & * & 1 & 1 & S. Tome \& Prin. & & & * & -- & -- \\
\hline Dominican Rep. & * & * & * & 3 & -- & Senegal & * & & & 2 & -- \\
\hline Ecuador & * & * & * & 15 & 4 & Seychelles & & & * & -- & -- \\
\hline El Salvador & * & * & * & 3 & 2 & Slovakia & & * & * & -- & -- \\
\hline Equat'l Guinea & * & * & * & -- & -- & Slovenia & * & * & * & -- & -- \\
\hline $\mathrm{Fiji}$ & * & & & -- & -- & Solomon Is. & * & & & -- & -- \\
\hline France & * & * & * & 23 & 10 & Spain & * & * & * & 1 & -- \\
\hline Gabon & * & & & -- & -- & Suriname & * & & & 1 & -- \\
\hline Germany, West & * & & & 4 & 1 & Switzerland & * & & & 1 & -- \\
\hline Ghana & * & & & 2 & 1 & Tanzania & * & & & 2 & -- \\
\hline Guatemala & * & * & * & 8 & 2 & Uruguay & * & * & * & -- & -- \\
\hline Haiti & * & * & & 3 & -- & United States & * & & & 2 & -- \\
\hline Honduras & * & * & * & 8 & 1 & Venezuela & * & * & * & 15 & -- \\
\hline Hungary & * & * & * & 6 & 6 & Vietnam, South & * & & & 29 & 12 \\
\hline Ireland & * & * & * & -- & -- & Yugoslavia & * & & & 9 & 6 \\
\hline Italy & * & * & * & 3 & 2 & Zimbabwe & * & & & -- & -- \\
\hline Jamaica & * & & & -- & -- & & & & & & \\
\hline
\end{tabular}


Table 5-6. List of Protestant States, with Number of Armed Conflicts Initiated at Lowest Threshold (Model 1) and Highest Threshold (Model 5).

\begin{tabular}{|c|c|c|c|c|c|c|c|c|c|c|c|}
\hline$\underline{\text { State }}$ & Chief & Pref. & Prev. & $\underline{\text { Init'd }}$ & Fatal & $\underline{\text { State }}$ & $\underline{\text { Chief }}$ & Pref. & \multicolumn{3}{|c|}{ Prev.Init'd Fatal } \\
\hline Antigua \& Barb. & & & * & 1 & 1 & Marshall Is. & * & & * & -- & -- \\
\hline Argentina & * & & & 3 & -- & Namibia & * & * & & -- & -- \\
\hline Australia & * & & & 5 & 2 & Nauru & * & & * & -- & -- \\
\hline Bahamas & * & * & & -- & -- & Netherlands & * & & & -- & -- \\
\hline Barbados & * & * & & 1 & 1 & New Zealand & * & * & & 7 & -- \\
\hline Benin & * & & & -- & -- & Nigeria & * & & & 1 & -- \\
\hline Bolivia & * & & & -- & -- & Norway & * & * & * & 7 & -- \\
\hline Brazil & * & & & 2 & -- & Papua New G. & & * & & 2 & -- \\
\hline Canada & * & & & -- & -- & Paraguay & * & & & -- & -- \\
\hline China† & * & & & -- & -- & Philippines & * & & & 2 & -- \\
\hline Congo, D.R. & * & & & 2 & -- & St. Kitts \& Nevis & & & * & -- & -- \\
\hline Denmark & * & * & * & 1 & -- & St. Lucia & * & & & -- & -- \\
\hline Dominica & * & & & -- & -- & St. Vincent \& Gr. & & & * & 1 & 1 \\
\hline Estonia & & * & & -- & -- & Samoa & * & & * & -- & -- \\
\hline Fiji & * & & & -- & -- & Sierra Leone & * & & & -- & -- \\
\hline Finland & * & * & * & -- & -- & Solomon Is. & * & * & * & -- & -- \\
\hline Germany, East & & & * & 9 & 4 & South Africa & * & & & 11 & -- \\
\hline Germany, West & * & & & -- & -- & Suriname & * & & & 1 & -- \\
\hline Ghana & * & & & 1 & -- & Sweden & * & * & * & 2 & -- \\
\hline Great Britain & * & * & * & 26 & 8 & Switzerland & * & & & -- & -- \\
\hline Grenada & * & & * & -- & -- & Taiwan & * & & & 20 & 3 \\
\hline Guatemala & * & & & 1 & -- & Togo & * & & & -- & -- \\
\hline Hungary & * & & & -- & 1 & Tonga & * & & & -- & -- \\
\hline Iceland & * & * & * & 8 & 2 & Trinidad & * & & & -- & -- \\
\hline Jamaica & & * & * & 1 & 1 & Tuvalu & * & & * & -- & -- \\
\hline Japan & * & & & -- & -- & Uganda & * & & & 10 & 2 \\
\hline Kenya & * & & & 2 & -- & United States & * & & & 88 & 30 \\
\hline Korea, South & * & & & 6 & 1 & Vanuatu & * & * & * & -- & -- \\
\hline Liberia & * & & & -- & -- & Zambia & * & & & 4 & -- \\
\hline Malawi & * & * & & -- & -- & Zimbabwe & * & & & 10 & 2 \\
\hline
\end{tabular}

† Chief executive was Chiang Kai-Shek, prior to breakaway of Taiwan.

A puzzle arises when the coefficients associated with Catholic states are compared to those for Protestant states. Table 5-7 summarizes and compares them. Several coefficients are only statistically significant at the higher (or highest) thresholds of armed conflict. Like those for Christianity generally and Western Christianity, the coefficients for Catholic and Protestant states grow more negative as the threshold for an armed conflict increases - up to five times more negative at the highest threshold than at the lowest. 
Table 5-7. Summary of Logit Coefficients for Catholic \& Protestant States.

\begin{tabular}{|c|c|c|c|c|c|c|}
\hline Variable & Model 1 & Model 2 & Model 3 & Model 4 & Model 5 & $\begin{array}{l}\text { App. } \\
\text { Table }\end{array}$ \\
\hline $\begin{array}{l}\text { Catholic } \\
\text { Chief Exec. (binary) }\end{array}$ & $\begin{array}{l}-.2594^{*} \\
(.1022)\end{array}$ & $\begin{array}{l}-.2517^{\star} \\
(.1068)\end{array}$ & $\begin{array}{r}-.3749^{\star *} \\
(.1181)\end{array}$ & $\begin{array}{r}-.3718^{* *} \\
(.1256)\end{array}$ & $\begin{array}{l}-.7309^{* *} \\
(.2272)\end{array}$ & B-71 \\
\hline $\begin{array}{l}\text { Protestant } \\
\text { Chief Exec. (binary) }\end{array}$ & $\begin{array}{r}-.1335 \\
(.1286) \\
\end{array}$ & $\begin{array}{c}-.2322 \dagger \\
(.1432) \\
\end{array}$ & $\begin{array}{c}-.2170 \dagger \\
(.1445) \\
\end{array}$ & $\begin{array}{r}-.3551^{*} \\
(.1668) \\
\end{array}$ & $\begin{array}{r}-.7160^{* *} \\
(.2695) \\
\end{array}$ & B-76 \\
\hline $\begin{array}{l}\text { Catholic } \\
\text { Preference (binary) }\end{array}$ & $\begin{array}{l}-.1569 \\
(.1145)\end{array}$ & $\begin{array}{l}-.2043^{\circ} \\
(.1202)\end{array}$ & $\begin{array}{l}-.2677^{*} \\
(.1332)\end{array}$ & $\begin{array}{l}-.3376^{*} \\
(.1432)\end{array}$ & $\begin{array}{r}-.9554^{* * *} \\
(.2571)\end{array}$ & B-72 \\
\hline $\begin{array}{l}\text { Protestant } \\
\text { Preference (binary) }\end{array}$ & $\begin{array}{r}-.6459^{* *} \\
(.2131) \\
\end{array}$ & $\begin{array}{r}-.6609^{* *} \\
(.2274) \\
\end{array}$ & $\begin{array}{r}-.7369^{* *} \\
(.2491) \\
\end{array}$ & $\begin{array}{r}-.7619^{* *} \\
(.2733) \\
\end{array}$ & $\begin{array}{r}-1.2931^{* *} \\
(.4606) \\
\end{array}$ & B-77 \\
\hline $\begin{array}{l}\text { Catholic } \\
\text { GRP (every 10\%) }\end{array}$ & $\begin{array}{l}.0141 \\
(.0245)\end{array}$ & $\begin{array}{l}.0105 \\
(.0256)\end{array}$ & $\begin{array}{l}-.0134 \\
(.0285)\end{array}$ & $\begin{array}{l}-.0204 \\
(.0305)\end{array}$ & $\begin{array}{l}-.1657^{* *} \\
(.0604)\end{array}$ & B-73 \\
\hline $\begin{array}{l}\text { Protestant } \\
\text { GRP (every 10\%) }\end{array}$ & $\begin{array}{l}-.0962^{*} \\
(.0393) \\
\end{array}$ & $\begin{array}{l}-.0870^{\star} \\
(.0423) \\
\end{array}$ & $\begin{array}{r}-.1258^{\star *} \\
(.0460) \\
\end{array}$ & $\begin{array}{c}-.1180^{*} \\
(.0509) \\
\end{array}$ & $\begin{array}{l}-.2077^{\star} \\
(.0855) \\
\end{array}$ & B-78 \\
\hline $\begin{array}{l}\text { Catholic } \\
\text { Prevalence (binary) }\end{array}$ & $\begin{array}{l}-.1033 \\
(.1148)\end{array}$ & $\begin{array}{l}-.1285 \\
(.1204)\end{array}$ & $\begin{array}{l}-.2421^{\circ} \\
(.1330)\end{array}$ & $\begin{array}{l}-.2852^{*} \\
(.1426)\end{array}$ & $\begin{array}{r}-.7454^{* *} \\
(.2468)\end{array}$ & B-74 \\
\hline $\begin{array}{l}\text { Protestant } \\
\text { Prevalence (binary) }\end{array}$ & $\begin{array}{r}-.3562^{\circ} \\
(.2137) \\
\end{array}$ & $\begin{array}{l}-.2955 \\
(.2257) \\
\end{array}$ & $\begin{array}{r}-.4139^{\circ} \\
(.2474) \\
\end{array}$ & $\begin{array}{c}-.3962 \dagger \\
(.2698) \\
\end{array}$ & $\begin{array}{l}-.9237^{*} \\
(.4475) \\
\end{array}$ & B-79 \\
\hline $\begin{array}{l}\text { Catholic } \\
\text { Pop. (every 10\%) }\end{array}$ & $\begin{array}{l}-.0156 \\
(.0133)\end{array}$ & $\begin{array}{l}-.0158 \\
(.0140)\end{array}$ & $\begin{array}{l}-.0307^{*} \\
(.0152)\end{array}$ & $\begin{array}{l}-.0324^{*} \\
(.0163)\end{array}$ & $\begin{array}{r}-.0810^{* *} \\
(.0283)\end{array}$ & B-75 \\
\hline $\begin{array}{l}\text { Protestant } \\
\text { Pop. (every 10\%) }\end{array}$ & $\begin{array}{c}-.0344 \dagger \\
(.0215) \\
\end{array}$ & $\begin{array}{r}-.0336 \\
(.0238) \\
\end{array}$ & $\begin{array}{r}-.0371 \dagger \\
(.0238) \\
\end{array}$ & $\begin{array}{r}-.0405 t \\
(.0270) \\
\end{array}$ & $\begin{array}{r}-.1085^{*} \\
(.0439) \\
\end{array}$ & B-80 \\
\hline
\end{tabular}

${ }^{\circ} p<.10{ }^{*} p<.05 \quad{ }^{* *} p<.01{ }^{* * *} p<.001$

$\dagger p<.15$

What is interesting is that most of the coefficients for Protestant states are substantially more negative than those for Catholic states, the major exception being for the chief executive. In the other variables, at the lowest threshold of armed conflict, a Catholic regime Preference or population appears to have no effect on the state's propensity to use force (at least, not with the standard of confidence of the field), but a Protestant Preference or population does have an effect. At the highest threshold of armed conflict, both Catholicism and Protestantism have negative effects on propensity to use force, but the 
effect of a Protestant regime Preference and population appear on average to be about $25 \%$ stronger than that of a Catholic regime Preference and population.

Why this is the case is not entirely clear. While a superficial comparison of Catholic and Protestant states in Tables 5-5 and 5-6 above suggests that the Protestant states are overall less powerful and more democratic than the Catholic states, the regressions performed in this chapter control for those factors. Two other possible explanations present themselves. One is regional effects. Nearly all the states in Latin America are Catholic, making most of the contiguous (and politically relevant) dyads in the American region Catholic also. No other region has such a heavy concentration of Catholic states; perhaps the higher propensity of Catholic states is being driven by other factors in Latin America that makes states more conflict-prone. This potential explanation was tested by adding the binary americandyad control variable to regressions on binary Catholic and Protestant Preference and Prevalence (summarized in Table 5-8).

Table 5-8. Summary of Logit Coefficients for Catholic \& Protestant States, Controlled for American Dyads.

\begin{tabular}{|c|c|c|c|c|c|c|}
\hline Variable & Model 1 & Model 2 & Model 3 & Model 4 & Model 5 & $\begin{array}{l}\text { App. } \\
\text { Table }\end{array}$ \\
\hline \multicolumn{7}{|c|}{ (Robust SE) } \\
\hline $\begin{array}{l}\text { Catholic } \\
\text { Preference (binary) }\end{array}$ & $\begin{array}{r}-.6690^{* * *} \\
(.1474)\end{array}$ & $\begin{array}{r}-.7125^{\star * *} \\
(.1549)\end{array}$ & $\begin{array}{r}-.6870^{* * *} \\
(.1669)\end{array}$ & $\begin{array}{r}-.7402^{* * *} \\
(.1793)\end{array}$ & $\begin{array}{c}-1.2870^{\star * *} \\
(.2964)\end{array}$ & B-81 \\
\hline $\begin{array}{l}\text { Protestant } \\
\text { Preference (binary) }\end{array}$ & $\begin{array}{r}-.5693^{* *} \\
(.2140)\end{array}$ & $\begin{array}{r}-.5910^{* *} \\
(.2283)\end{array}$ & $\begin{array}{r}-.6911^{* *} \\
(.2509)\end{array}$ & $\begin{array}{c}-.7266^{* *} \\
(.2752) \\
\end{array}$ & $\begin{array}{c}-1.3080^{* *} \\
(.4647) \\
\end{array}$ & B-83 \\
\hline $\begin{array}{l}\text { Catholic } \\
\text { Prevalence (binary) }\end{array}$ & $\begin{array}{r}-.6059^{* * *} \\
(.1564)\end{array}$ & $\begin{array}{r}-.6070^{\star * *} \\
(.1637)\end{array}$ & $\begin{array}{r}-.6394^{\star * *} \\
(.1768)\end{array}$ & $\begin{array}{r}-.6374^{\star * *} \\
(.1878)\end{array}$ & $\begin{array}{r}-.9723^{* *} \\
(.2997)\end{array}$ & B-82 \\
\hline $\begin{array}{l}\text { Protestant } \\
\text { Prevalence (binary) }\end{array}$ & $\begin{array}{r}-.2614 \\
(.2156) \\
\end{array}$ & $\begin{array}{l}-.2080 \\
(.2278)\end{array}$ & $\begin{array}{r}-.3613 t \\
(.2500)\end{array}$ & $\begin{array}{l}-.3570 \\
(.2725)\end{array}$ & $\begin{array}{l}-.9444^{*} \\
(.4499)\end{array}$ & B-84 \\
\hline
\end{tabular}

${ }^{\circ} p<.10^{*} p<.05^{* *} p<.01{ }^{* * *} p<.001$

$+p<.15$ 
The result of this test is that the americandyad coefficient is nearly always positive, and always statistically significant except at the highest threshold, suggesting that at lower thresholds, the American region is having some effect. The more important issue is the impact of this test on the difference between Catholic and Protestant propensities to use force. Overall, the constraining effect of Protestantism is found to be stronger than that of Catholicism, but after controlling for the American region, the constraining effect of Protestantism is now substantially weaker at the lower thresholds (and about the same at the highest threshold). This result raises yet more questions, which for reasons of space and scope must be deferred for now.

Another possible explanation may reflect a subtle difference between the Catholic and Protestant just war ethics. The Catholic Catechism (1994: sec. 2309) does not comprehensively restate the just war tradition in Catholic thought, but the American Catholic bishops do in their explorations of the subject (National Conference of Catholic Bishops 1983: paras. 92-94), and we shall assume that this work is representative of the official position of the Vatican. The Catholic just war tradition includes a criterion that is not present the Protestant just war tradition. That criterion is comparative justice: "[W]hile there may be rights and wrongs on all sides of a conflict, to override the presumption against the use of force the injustice suffered by one party must significantly outweigh that suffered by the other" (U.S. Conference of Catholic Bishops 1993: 13). By virtue of this additional criterion, one might expect the Catholic war ethic to be more restrictive than its Protestant counterpart, but perhaps for some reason (on which I would prefer not to speculate here) this criterion has a "loosening" effect instead. 


\section{The Eastern Christian War Ethic}

The focus of this chapter up to this point has been on the war ethic in Western Christianity, primarily because (1) the vast majority of state-years in the system from 1946 through 2001 are Catholic, Protestant, or a mixture of both; and (2) the contemporary war ethics of the two branches are very similar to each other (the Catholic criterion of "Comparative Justice" notwithstanding). Such is not the case for the Eastern Orthodox branch, ${ }^{51}$ the war ethic of which originated from different sources and has developed along a different trajectory. Samuel Huntington's approach of separating the Eastern Orthodox "civilization" from its Western counterpart is appropriate, due to differences in the content of the Eastern Orthodox war ethic, as well as in its influence on state practice. For these reasons, the war ethic in Eastern Orthodoxy should be given separate attention.

Within the Eastern Orthodox clergy today, at least in the English-speaking world, there appears to be an ongoing debate as to whether the Church is pacifist or simply silent (Stoyanov 2009). Alexander Webster has attempted to construct a just war tradition from Eastern Orthodox thought (2003; see also Robinson 2003: 40-61), but even he admits that the just war tradition does not enjoy broad support either in the Orthodox Church in America or in the Eastern Orthodox Church worldwide (2004: 110-1). Webster characterizes the Orthodox war ethic as, at best, beset with "moral confusion," pointing out how a document of the 2000 Jubilee Council of Russian Bishops "swings back and forth

\footnotetext{
${ }^{51}$ Not all Eastern Christian churches are Orthodox, e.g. the Armenian Apostolic church, but since the vast majority of Eastern Christians are Orthodox, the Orthodox war ethic will stand as the representative for that of Eastern Christianity overall.
} 
between militant Russian nationalism and patriotism, on the one hand, and excessive caution about the military on the other" (2004: 112). He further highlights inconsistencies in the thought of the renowned Orthodox pacifist Stanley Harakas, who has been extremely hostile to any military operations yet concedes that the United States must defend the innocent in the wake of 9/11 (Webster 2004: 113-4). Yuri Stoyanov (2009: 206 \& n. 86), on the other hand, regards the Russian bishops' document as the first systematic just war tradition in Eastern Orthodoxy. ${ }^{52}$

It seems that both sides of this debate would agree that no systematic just war tradition developed in Eastern Christianity the same way it developed in the West. Stoyanov attributes this divergence to the differing geopolitical conditions within the Eastern and Western Roman empires; the threat to the West's survival during the time of Augustine forced the development of a war ethic that the East did not need at the time because it was more secure. Thus the Eastern church mostly retained pre-Constantinian Christian attitudes toward war, and its war ethic is based on the writings not of Ambrose and Augustine, but Eusebius, Cyril of Alexandria, John Chrysostom, Athanasius of Alexandria, and Basil the Great (Stoyanov 2009: 168-9).

The $13^{\text {th }}$ Canon of Basil the Great, who predated Augustine by a generation, was especially influential. Basil concedes that killing in the course of warfare is morally distinguishable from killing as a voluntary act of murder, but still deems it "advisable" that soldiers who have killed be refused communion for three years (Stoyanov 2009: 169). This writing forms the basis of the Orthodox view of war as a "lesser evil," in contrast to a view of war as a "lesser good" (Webster 2003, 2004). This doctrine was key

\footnotetext{
${ }^{52}$ In my view, Webster has the stronger claim.
} 
in the Orthodox Church's refusal to honor fallen Byzantine soldiers on par with holy martyrs in the $10^{\text {th }}$ century, even though the Emperor had requested it. The doctrine was periodically confirmed and validated as late as the $14^{\text {th }}$ century (Matthew Blastares, Syntagma kata stoicheon, in Stoyanov 2009: 170-2).

By these indicators, a strong preference for pacifism would appear to have emerged as the dominant war ethic in Eastern Orthodoxy. But as Stoyanov himself notes (2009: 1718), the Church occasionally did make exceptions. One major exception to the Church's refusal to honor Byzantine soldiers took place in the wake of the Byzantine Empire's loss of Constantinople to the Latins during the Fourth Crusade; Patriarch Michael IV Autoreinaos promised remission of sins to Nicene soldiers who died in battle in the campaign to retake the city. The Church also canonized several military figures, such as St. George, St. Demetrius of Thessaloniki, St. Theodore Teron, and St. Theodore Stratelates, and the military aristocracy adopted these saints as their patrons. In addition, as early as 527 , the Byzantine state relied on the Church for support of its military campaigns in matters such as providing chaplains, blessing standards and weapons prior to battle, conducting funerals, and giving ritual thanksgiving after military victory. These factors are not themselves conclusive as to whether the Byzantines developed a holy war ethic during the Crusades as the Latins did, but they do undermine the claim that the Eastern Orthodox Church was consistently pacifist.

In addition, Byzantine political and religious ideologies were commingled in Byzantine political theology. The Emperor — a political leader — was extolled as the vicar of Christ and God's chosen ruler to lead and defend the Christian Roman empire, which itself was an earthly replica of the divine heavenly monarchy. The Emperor was the 
Defender of the True Faith (Stoyanov 2009: 179-80 \& n. 32). Contemporaneous Byzantine military treatises appear to support this conclusion, for they contain advice that reflects the Byzantine Christian stance on warfare, yet without any systematically developed theory for justification of warfare in Christianity. Nor was any attempt to systematize a war ethic made within the Byzantine Church itself (id. 182-3).

More pertinent to the influence of Eastern Orthodoxy on state practice is the canonization of several warrior-princes (id. 184). Grand Prince Alexander Nevsky of Novgorod and Vladimir successfully defended medieval Russia against German and Nordic invaders; Grand Prince Dmitri Donskoi of Moscow, so named for the site of his greatest military victory, defeated the Tatars and was the first prince of Moscow to openly challenge Mongol authority; Prince Stefan Lazar of Serbia led his army against the Ottomans in the ill-fated Battle of Kosovo and his son Prince Stefan Lazarević led military campaigns as an Ottoman vassal. Whether or not they were canonized for their military exploits is disputed, ${ }^{53}$ but the point is that these individuals were political figures and canonized for their political acts. Since hagiography is a valid source of Orthodox tradition, a tradition of commingling church and state-and consequently the commingling of religious and nationalist war ethics — should be expected to emerge in the Eastern Orthodox Church.

\footnotetext{
${ }^{53}$ Paul Robinson (2003: 67) argues that Alexander Nevsky was canonized not for victory in war, but for making peace with the Mongols (which was a humiliating peace for the Russians), and Stoyanov (2009: 185) notes the canonization of peacemaking, pacifist, and martyr princes such as John Vladimir of Duklja, and Boris and Gleb of Kievan Rus.
} 
This in fact is what happened. After the fall of Constantinople in 1453 and the demise of the Byzantine Empire, the situs of Eastern Orthodox political theology migrated to Russia according to the theory that Moscow was the next rightful successor to the Roman imperium (literally, "the Third Rome"). The status of the Russian church was linked to the status of the Russian state; it took the rise of the Russian Empire under Ivan IV (the Terrible) for the Eastern Orthodox Church to elevate the metropolitan of Moscow to the rank of Patriarch (Stoyanov 2009: 188). But the commingling of church and state in Russia did not take the form of theocracy as it had with the prince-bishops in Montenegro (from 1516-1852; id. 192); rather, it took the form of state control over the church. Emperor Peter I (the Great), in his capacity as Defender of Orthodoxy, brought the Russian patriarchate under state control and thereafter the Russian church was administered as a government ministry.

Under state control, Russian Orthodoxy (and Eastern Orthodoxy with it) became more nationalist. As the land of the Third Rome, Russia had already assumed the role of champion for the Orthodox vassals of the Ottoman Empire in Eastern Europe, and this role become more overt after the 1774 Treaty of Kuchuk-Kainardji, in which Catherine the Great secured the right to intervene in Turkish affairs to protect Orthodox interests. ${ }^{54}$ In 1817 Russia secured Serb autonomy from Ottoman rule, under its protection, and in the 1829 Treaty of Adrianople, Russia forced the Ottomans to recognize the autonomy of Greece, Moldavia, and Wallachia as well. ${ }^{55}$ In addition, the Napoleonic Wars took on religious tones in Russia, with Alexander I casting Napoleon as the enemy of Orthodoxy.

\footnotetext{
${ }^{54}$ Treaty of Kuchuk-Kainardji (Russia-Turkey), Jul. 16, 1774, arts. 7-8, 45 CTS 349, 368.

55 Treaty of Peace (Russia-Turkey), Sep. 14, 1829 [Treaty of Adrianople], arts. 5-6, 80 CTS 83, 87.
} 
Such nationalist sentiment is evident in the political theology of the Serbian church as well; the best known Eastern Orthodox work on the ethics of war in Serbia is that of the early $20^{\text {th }}$ century bishop Nikolai Velimirović, whom the Serbian Orthodox Church canonized in 2003. Velimirović claims that the Orthodox military effort in the Balkans from the Battle of Kosovo to World War I (1389-1918) had the backing of Christ in order to protect the faith from encroachment by Islam (Stoyanov 2009: 197-8 \& nn. 58-62).

In the early period of Russia's rise, a concept of just war began to crystallize in the form of legitimate defense and liberation (Stoyanov 2009: 194-9), though unlike the situation of the Western church today in which the just war tradition is intertwined with pacifism, the Russian just war ethic was intertwined with "the belief in the inviolability of frontiers and war as the judgement of God" (id.). Even this low amount of religiouslybased restraint did not last, however, for Peter the Great Westernized Russian military thinking as part of his design to Westernize the Russian empire, and in doing so he secularized that thinking for good. In addition, the Russian church was severely suppressed under the Communists, to be revived briefly by Stalin during World War II only for the purpose of boosting national support and mobilization. Paul Robinson's (2003: 62-75) survey of Russian thought on the just war ethic reveals there to be little independence from the state, and that very little independent thought originates not from the Russian Orthodox Church, but in Russian literature (Tolstoy, Dostoyevsky, Solzhenitsyn) and secular philosophy (Vladimir Solovyev, Ivan Il'in). Despite the fact that these lay works are heavily tinged with religion, Robinson argues persuasively that the dominant war ethic in Russia is simply realism. This finding serves as the basis for my claim that the Eastern Orthodox war ethic, to the extent that there is any coherent one, 
is either realist (war is justifiable in pursuit of the national interest) or simply irrelevant (the Church has no influence on state practice). This claim serves as the basis for my prediction that Eastern Christianity has a weaker effect on state practice than Western Christianity.

This claim is somewhat more difficult to measure reliably than for the rest of Christendom, for states with Orthodox Prevalence or Preference are comparatively few and are concentrated in a single region. Table 5-9 lists the states that have had Eastern Christian chief executives, regime Preferences, and Prevalent populations, along with the number of armed conflicts initiated by those states while they had those characteristics.

Table 5-9. List of Eastern Christian States, with Number of Armed Conflicts Initiated at Lowest Threshold (Model 1) and Highest Threshold (Model 5).

\begin{tabular}{|c|c|c|c|c|c|c|c|c|c|c|c|}
\hline State & $\underline{\text { Chief }}$ & Pref. & Prev. & $\underline{\text { Init'd }}$ & Fatal & State & $\underline{\text { Chief }}$ & Pref. & Prev. & $\underline{\text { Init'd }}$ & Fatal \\
\hline Albania & * & & & 2 & 1 & Georgia & * & * & * & -- & \\
\hline Armenia & * & * & * & 11 & 9 & Greece & * & * & * & 9 & \\
\hline Belarus & & * & * & -- & -- & Macedonia & * & * & * & -- & \\
\hline Bosnia \& Herz. & * & & & -- & -- & Moldova & * & * & * & -- & \\
\hline Bulgaria & * & * & * & 6 & 4 & Romania & * & * & * & 3 & \\
\hline Cyprus & * & * & * & 1 & -- & Russia/USSR & * & * & * & 35 & \\
\hline Eritrea & * & & & 13 & 3 & Ukraine & * & * & * & 1 & \\
\hline Ethiopia & * & & & 7 & 1 & Yugoslavia & * & * & & 8 & \\
\hline
\end{tabular}

† Stalin coded as Orthodox after 1942; Gorbachev coded as Orthodox.

If we assume that the low population of Eastern Christian state-years does not invalidate the results of empirical measuring that category, then those results would seem to support my claim that the Orthodox war ethic has a relatively weak effect on statecraft. Table 510 shows the logit coefficients associated with Eastern Christianity, compared to those for Western Christianity. 
Table 5-10. Summary of Logit Coefficients for Eastern and Western Christian States.

\begin{tabular}{|c|c|c|c|c|c|c|}
\hline Variable & Model 1 & Model 2 & Model 3 & Model 4 & Model 5 & $\begin{array}{l}\text { App. } \\
\text { Table }\end{array}$ \\
\hline $\begin{array}{l}\text { Eastern Christian } \\
\text { Chief Exec. (binary) }\end{array}$ & $\begin{array}{l}-.0234 \\
(.1726)\end{array}$ & $\begin{array}{l}-.0391 \\
(.1829)\end{array}$ & $\begin{array}{l}.0076 \\
(.1873)\end{array}$ & $\begin{array}{l}-.0024 \\
(.2007)\end{array}$ & $\begin{array}{l}.2253 \\
(.2899)\end{array}$ & B-85 \\
\hline $\begin{array}{l}\text { Western Christian } \\
\text { Chief Exec. (binary) }\end{array}$ & $\begin{array}{r}-.3051^{* *} \\
(.0936) \\
\end{array}$ & $\begin{array}{r}-.3442^{\star * *} \\
(.0999) \\
\end{array}$ & $\begin{array}{r}-.4235^{\star * *} \\
(.1060) \\
\end{array}$ & $\begin{array}{r}-.4792^{* \star *} \\
(.1160) \\
\end{array}$ & $\begin{array}{r}-.9612^{* * *} \\
(.2000) \\
\end{array}$ & B-66 \\
\hline $\begin{array}{l}\text { Eastern Christian } \\
\text { Preference (binary) }\end{array}$ & $\begin{array}{l}.0143 \\
(.2146)\end{array}$ & $\begin{array}{l}-.1340 \\
(.2399)\end{array}$ & $\begin{array}{l}.0544 \\
(.2373)\end{array}$ & $\begin{array}{l}-.1199 \\
(.2729)\end{array}$ & $\begin{array}{l}.4362 \\
(.3312)\end{array}$ & B-86 \\
\hline $\begin{array}{l}\text { Western Christian } \\
\text { Preference (binary) }\end{array}$ & $\begin{array}{r}-.3475^{\star *} \\
(.1059) \\
\end{array}$ & $\begin{array}{r}-.3880^{* * *} \\
(.1119) \\
\end{array}$ & $\begin{array}{r}-.4128^{\star \star *} \\
(.1200) \\
\end{array}$ & $\begin{array}{r}-.4617^{\star \star *} \\
(.1294) \\
\end{array}$ & $\begin{array}{c}-1.0717^{* * *} \\
(.2220)\end{array}$ & B-67 \\
\hline $\begin{array}{l}\text { Eastern Christian } \\
\text { GRP (every 10\%) }\end{array}$ & $\begin{array}{l}.0267 \\
(.0327)\end{array}$ & $\begin{array}{l}.0149 \\
(.0359)\end{array}$ & $\begin{array}{l}.0366 \\
(.0359)\end{array}$ & $\begin{array}{l}.0251 \\
(.0402)\end{array}$ & $\begin{array}{l}.0833 \dagger \\
(.0509)\end{array}$ & B-87 \\
\hline $\begin{array}{l}\text { Western Christian } \\
\text { GRP (every 10\%) }\end{array}$ & $\begin{array}{r}-.0728^{* *} \\
(.0237) \\
\end{array}$ & $\begin{array}{r}-.0733^{\star *} \\
(.0250) \\
\end{array}$ & $\begin{array}{r}-.0951^{\star * *} \\
(.0267) \\
\end{array}$ & $\begin{array}{r}-.0964^{\star \star *} \\
(.0287) \\
\end{array}$ & $\begin{array}{r}-.2641^{* * *} \\
(.0516) \\
\end{array}$ & B-68 \\
\hline $\begin{array}{l}\text { Eastern Christian } \\
\text { Prevalence (binary) }\end{array}$ & $\begin{array}{l}-.2244 \\
(.2085)\end{array}$ & $\begin{array}{c}-.2215 \\
(.2177)\end{array}$ & $\begin{array}{l}-.1420 \\
(.2240)\end{array}$ & $\begin{array}{l}-.1238 \\
(.2353)\end{array}$ & $\begin{array}{l}.6009^{*} \\
(.2736)\end{array}$ & B-88 \\
\hline $\begin{array}{l}\text { Western Christian } \\
\text { Prevalence (binary) } \\
\end{array}$ & $\begin{array}{c}-.1587 \\
(.1150) \\
\end{array}$ & $\begin{array}{r}-.1585 \\
(.1220) \\
\end{array}$ & $\begin{array}{l}-.2528^{\circ} \\
(.1298) \\
\end{array}$ & $\begin{array}{r}-.2697^{\circ} \\
(.1403) \\
\end{array}$ & $\begin{array}{r}-.9477^{* * *} \\
(.2447) \\
\end{array}$ & B-69 \\
\hline $\begin{array}{l}\text { Eastern Christian } \\
\text { Pop. (every 10\%) }\end{array}$ & $\begin{array}{l}-.0105 \\
(.0133)\end{array}$ & $\begin{array}{r}-.0134 \\
(.0140)\end{array}$ & $\begin{array}{l}-.0065 \\
(.0152)\end{array}$ & $\begin{array}{r}-.0088 \\
(.0163)\end{array}$ & $\begin{array}{l}.0633^{\circ} \\
(.0283)\end{array}$ & B-89 \\
\hline $\begin{array}{l}\text { Western Christian } \\
\text { Pop. (every } 10 \%)\end{array}$ & $\begin{array}{l}-.0323^{*} \\
(.0215)\end{array}$ & $\begin{array}{l}-.0318^{*} \\
(.0228)\end{array}$ & $\begin{array}{r}-.0458^{* *} \\
(.0240)\end{array}$ & $\begin{array}{r}-.0475^{\star *} \\
(.0259)\end{array}$ & $\begin{array}{r}-.1120^{* * *} \\
(.0332)\end{array}$ & B-70 \\
\hline
\end{tabular}

${ }^{\circ} p<.10{ }^{*} p<.05 \quad{ }^{* *} p<.01{ }^{* *} p<.001$

$\dagger p<.15$

When compared with Western Christianity, the differences in effects of Eastern

Christianity are quite noticeable. The most remarkable finding is that only two of the

Eastern Christian coefficients are statistically significant, and then only at relatively low

levels of significance $(\mathrm{p}<.05$ and $\mathrm{p}<.10)$. This could be simply a symptom of there being too few Eastern Christian state-years for a valid measurement, or it could be a confirmation that Eastern Christianity exercises little influence on state practice (or that the Orthodox war ethic is too incoherent to wield much influence). In nearly every model, Eastern Christianity appears to have no effect on the propensities of states to use force (in 
violation of jus ad bellum). The exception to this overall conclusion is the effect on propensities to resort to deadly force (Model 5, the highest threshold of armed conflict). In that model, a state with an Eastern Christian population (though not Preference or chief executive) is more likely to use force.

The other remarkable finding is that whereas for Western Christianity the coefficients tend to be more negative as the thresholds increase from lowest to highest, in Eastern Christianity the coefficients tend to be more positive. Since so few coefficients are statistically significant, however, I am reluctant to offer any conclusions based on that finding.

One potential explanation for the results above has been considered and refuted: that during most of the time period of this study, the majority of Eastern Christian states were controlled by Communist, and therefore officially Atheist governments, and therefore it was Atheist preferences that influenced the behavior of Orthodox states, not Orthodox preferences. This hypothesis can be tested by using the Atheist Chief Executive variable (athchief1) as an approximation for a Communist chief executive. The results are shown in detail in Appendix B, Tables B-90 through B-93; the existence of an Atheist chief executive makes no appreciable difference to the Eastern Christian coefficients, and the effect of an Atheist chief executive itself is not statistically significant.

\section{Conclusion}

In this chapter I have shown that overall, Christian states are less likely than nonChristian states to initiate interstate armed conflicts (in violation of jus ad bellum). This result is attributable to two factors. First, the result for Christianity overall is being driven 
primarily by Western Christianity, which is the dominant category in Christian stateyears from 1946 through 2001. Second, the war ethic of Western Christianity is more restrictive than those of other religions. I have shown that despite the similar origins and constraints in their respective war ethics, there are differences in the propensities of Catholic and Protestant states to use force. The explanation for these differences is not entirely clear; it may be the regional effects of Latin America, where nearly all the states are Catholic, or it may be that the presence of an additional just war criterion in Catholic thought has the unintended effect of actually loosening the constraint.

I have also shown that of the three major branches of Christianity, the Orthodox branch has the least restrictive war ethic. The reason for this result is also not entirely clear. It might be the effect of too few Eastern Christian state-years to measure with validity, but it also appears likely that the Orthodox war ethic wields less influence on states, either because the Eastern Orthodox Church itself is disengaged from temporal politics or because its war ethic lacks sufficient coherence or consistency for real-world application to statecraft. ${ }^{56}$ I cannot conclude that the Orthodox branch is more militant, because most of the positive coefficients that might serve as the basis for such a claim are not statistically significant. I claim only that the Orthodox war ethic is less constraining than those of the other major branches of Christianity.

Finally, I should make the caveat that these findings do not show that Christian states are unaggressive. Our baseline for comparing the behavior of states is jus ad bellum in contemporary, secular international law (the triggering event is the initiation of an armed conflict in violation of it), and this chapter shows that Christian states are statistically

\footnotetext{
${ }^{56}$ I will make similar findings for the Buddhist war ethic in Chapter 7.
} 
more aggressive than the hypothetical state that complies perfectly with jus ad bellum (as evidenced by the probability of a Christian state violating jus ad bellum being consistently and significantly greater than zero). I suggest that this low but non-zero probability is attributable to three possible factors. One is simply that every state should be expected to violate the rules at some point (see note 48 of this chapter). However, the fact that Christian states are less likely to violate jus ad bellum than non-Christian states suggests that the Christian war ethic overall is more restrictive than that of other religions. Another possible factor is that the secularized body of international law originates from the secularized Westphalian state system, which was founded by Western Christian states. If we suppose that the content of international law has developed in such a way as to be most compatible with the ethics of the dominant sector of the Westphalian system (i.e. the Catholic/Protestant West), then it seems intuitive that Western Christian states would have the easiest time complying with it. What raises the Christian propensity to armed conflict, however, is that the Christian war ethic, despite its restrictive nature, does provide for the possibility of an offensive war given sufficient cause. The Christian just war ethic can legitimize a first strike absent Security Council authorization, which secular jus ad bellum cannot do. This makes the Christian war ethic more permissive than jus ad bellum.

Having explored the religious category with the least permissive war ethic of the three categories examined in this study, we now turn our attention to the category that appears to have the most permissive war ethic: Islam. 
CHAPTER 6

\section{$\underline{\text { THE EFFECT OF ISLAM }}$}

\section{Introduction}

Islam is the Prevalent or Preferred religion in about one quarter of the state-years in the international system from 1946 to 2001, making it the second most prominent world religion after Christianity. As with the previous chapter on Christianity, this chapter will begin with an exploration of the Islamic war ethic. The independent variables for Islam will then be subjected to testing similar to that which was performed on Christianity. I find that when the threshold for defining an armed conflict is low, Islam has no significant effect (statistically or substantively) on the propensity of a state to initiate an armed conflict (in violation of jus ad bellum). However, when the threshold is high, Islam has a positive effect on the same. These findings hold for Islam generally, and for Sunni Islam specifically (which appears to be the primary driver of the results for Islam overall). I do not test Shia or other branches of Islam separately because there are too few state-years with a Muslim but non-Sunni chief executive, Preference, or Prevalence.

The most pervasive question in the security literature on Islam today appears to be whether Islam is (and/or should be) militant or not. Mohammad Ayoob (2008: 1), writing on contemporary political Islam, seeks to show that mainstream Islamist parties, which form the "overwhelming majority" of Islamic political organizations, "by and large abjure violence." But far too much literature is devoted to this question-and among Muslims themselves, not just in the West (Hashmi 1996: 146) — to simply explain away Islamic militarism as a fringe ideology that audacious extremists have forced into the 
limelight. The tension between the just war ethic to justify war in self-defense and the holy war ethic to broaden the sphere of Islam has existed throughout Islamic history (Sachedina 2002: 36). But treatments such as Abdul-Aziz Sachedina's that characterize the holy war ethic as an aberration from the Quranic precepts, engineered by Muslim rulers and jurists to justify territorial expansion, introduce tensions of their own. David Cook (2005: 39-40) complains that Muslim apologists and Western scholars who seek to present Islam "as innocuously as possible" devote greater attention to non-forcible acts of jihad than is warranted by the treatment of jihad in classical Islamic texts. Cook claims that works in Arabic and other Muslim-majority languages present jihad as clearly militant (2005: 43). Furthermore, the Quran itself is a source of tension, for some verses sanction fighting (the Sword Verse(s)) whereas other verses call for reconciliation and/or limit the manner of fighting (the Peace/Forgiveness Verses; Aboul-Enein \& Zuhur 2004: 7). The early Caliphate took the view that the Sword Verses abrogated the Peace Verses — because they were revealed to Muhammad later in time — and Islamic extremists hold that view today (id.: 10-1; see also Kelsay 2007: 3).

There is empirical evidence of the effect of Islamic militarism today. Islam has been shown to have fueled a number of interstate armed conflicts since 1945, including those between Greece and Turkey, Israel and Arab nations, Pakistan and India, and Somalia and Ethiopia (Pipes 1983: 3). Other religions have fueled armed conflicts, of course, but Islam has fueled more than its fair share of domestic conflicts: Of the 42 religious civil wars from 1940 to $2000,80 \%$ of them involved parties that identified themselves with Islam, as opposed to 50\% for Christianity and 16\% for Hinduism (Toft 2007: 97). Monica Duffy Toft attributes this statistic in part to jihad as a structural feature of Islam (id.). In 
this chapter, I take the position that the Islamic war ethic overall is more permissive than its defenders often claim, and this position is supported empirically in the greater propensity of Muslim states to initiate armed conflicts with fatalities than the propensity of non-Muslim states.

\section{$\underline{\text { Islamic Scripture }}$}

A key difference between Christian and Islamic perceptions of their scriptures is that whereas the Bible is a compilation of works authored by persons who Christians believe have been inspired by God, the Quran is a compilation of what Muslims believe to be God's direct dictations to a single person, the prophet Muhammad. The Quran being the direct revelation of God, the words themselves are regarded as sacred, to the point that the Quran is not merely the speech of God, it is God. This is the Traditionalist view of the Quran, which Reza Aslan and others argue has prevailed over the Rationalist view that the Quran is a reflection of God but not God himself (Aslan 2005: 158).

Because the contents of the Quran were revealed and subsequently written down in Arabic, only the original Arabic version is authoritative-and since only the Arabic text is the direct word of God, no translation can ever take its place (Ghunaimi 1968: 5). What gives rise to complications in making the Quran accessible to non-Arabic speakers is what Aslan (2005: 70) calls the "variability of the Arabic language." Aslan provides the example of the last phrase of Q. 4:34, adribuhunna in Arabic, which he claims could be translated as "turn away from them," "go along with them," "have intercourse with them," or "beat them." Amira Sonbol highlights a similar problem with Q. 3:142, in which Muslims are expected to "strive" (jihad) for the sake of God in order to go to 
heaven: The word could mean internal striving to be a better Muslim, striving to create a strong community of believers, or fighting for whatever is determined to be God's cause. "This type of general statement," she writes, "opens the door to all sorts of speculation regarding what striving for 'His cause' means” (Sonbol 2009: 285). This, to Aslan (2005: 70), is the key problem in determining whether Islam is militant or peaceful, misogynistic or gender-equitable; the Arabic text is interpreted according to the interpreter's own ideology. Thus many translators of the Quran tend to insert their own ideologies and apologetics into interpreting the original text (Skreslet \& Skreslet 2006), and translations often have subtle differences that could lead to different conclusions (Ghunaimi 1968: 5). Bassam Tibi (1996) observes that Muslims tend to quote the Quran selectively, in order to support their own interpretations. A further problem particularly affects the interpretation of the Quran in the madrassahs (Islamic schools) in non-Arabic-speaking Muslim countries such as Pakistan and Afghanistan. There, Quranic instruction focuses on pronunciation and rote memorization of the original Arabic version, which is unfamiliar to the students (and archaic even to Arabs). In interpreting the text, students must therefore rely on the expertise and ideological orientation of the instructor-and in the decentralized madrassah system, both can vary greatly (Aboul-Enein \& Zuhru 2004: 9)

Thus the first major challenge for non-Arabic speakers to identifying the content of the Quranic war ethic is to find a translation that is representative of the ideology across large segments of the Muslim population worldwide. This task appears to be especially difficult for English speakers, for many translations reflect the sectarian biases of their translators and not all are widely accepted in Islamdom (Skreslet \& Skreslet 2006: 7-19). The classic 1930 scholarly translation by Muhammad (Marmaduke) Pickthall is archaic 
and difficult to read and the once widely available edition by N.J. Dawood has been heavily criticized for imprudently rearranging the text. The ubiquitous 1917 Muhammad Ali translation presents a gentle interpretation, but the translator was a leader of nonOrthodox sect of Islam (the Ahmadi movement), which in its native Pakistan is regarded officially as a non-Muslim sect. ${ }^{1}$ Translations by Muhammad Asad in 1980 and Ahmed Ali in 1984 are Rationalist interpretations of the text and for this reason would also be deemed unacceptable by the prevailing Traditionalist mainstream. In addition, the Asad and Ahmed Ali translations attempt to neutralize passages that endorse behavior that its translators regard as socially unacceptable today, e.g. beating disobedient wives $(\mathrm{Q}$. 4:34), and they have tampered with certain verses in the text. The 1934-37 translation by the Pakistani barrister Yusuf 'Ali, while widely accepted by English-speaking Muslims, tends more toward mysticism than is orthodox in mainstream Islam, and is written in verse which increases the difficulty of reading it. Several modern scholarly and popular translations, e.g. by Mohammed Khatib in 1986, Muhammad Malik in 1997, and Majid Fakhry in 2000, are endorsed as orthodox by al-Azhar University, but the English is poor and/or the translations too mechanical for intelligibility or are peppered with untranslated Arabic terms. Several modern scholarly translations, e.g. by Mahmoud Ayoub in 1983 and Michael Sells (2002), are incomplete.

Two other translations, by contrast, are useful representations of the ideologies that prevail in the Islamic world today. One is the 1977 translation by Muhammad al-Hilali and Muhammad Khan, which scrupulously separates text from commentary and is

\footnotetext{
${ }^{1}$ The practitioners of the Ahmadi movement revere its founder as a prophet or messianic figure, therefore the movement lies outside the bounds of orthodox Islam.
} 
printed in Saudi Arabia - thus it may be presumed to be an officially sanctioned Sunni traditional orthodox interpretation, however sectarian that interpretation may be. Another translation, by Muhammad Abdel Haleem in 2004, is faithful to normative Islamic tradition but is also more accessible to non-Muslim readers than many. These two translations will serve as the benchmarks for presenting and interpreting Islamic scripture.

Going forward, however, the content of scripture will be presented most often through secondary sources, as Thomas Sizgorich does. Sizgorich (2009) deals with the problem of variability in the Arabic language by emphasizing works of Quranic exegesis rather than the text of the Quran itself. His concern is with how the early Muslims conceptualized the theory and practice of jihad, and the best evidence consists of the exegetic works of the first and second centuries A.H. ( $8^{\text {th }}$ and $9^{\text {th }}$ centuries CE). Similarly, John Kelsay's exploration of "Shari'a reasoning" concentrates heavily on classical juridical and philosophical works (2007: 51-72; see also Kelsay 2006). As contemporary interpretations of Islamic scripture still rely heavily on early Muslim practice, this approach seems sound. Using the Quran itself, argues Sizgorich (2009: 900, n. 6), would require the present-day reader to perform his or her own exegetical reading of the text, a reading that would reflect the reader's own cultural, historical, and confessional circumstances.

\section{Islamic Political Theory and Law as a Backdrop to the Islamic War Ethic}

\section{Islamic Political Philosophy}

Although Sizgorich's approach to Quranic exegesis seems logical given the challenges described above, it must be pointed out that if we interpret the Quran today in the manner 
that Sizgorich suggests, then so did the early Muslims, who as Arabs were already a very warlike people. Islam began essentially as a reformist movement against the oppression resulting from human depravity (Ghunaimi 1968: 20-1). In Islam, human nature is perceived as narrow-minded and deliberately stupid. God has favored humans with the cognitive and volitional capacities necessary to comprehend the purpose of life, yet humans have failed to act on the "natural" guidance that God has given them, because they are too preoccupied with the affairs and pleasures of this world to appreciate the pleasures (and punishments) of the next world, which are beyond anything imaginable in this one (Sachedina 2002: 41). ${ }^{2}$

Islam and Christianity both emphasize the moral responsibility of the individual. But in contrast to Christianity, Islam holds that man can achieve salvation only through his actions, and not by virtue of membership in a select group or because of someone else's supreme sacrifice (Badr 1999: 99). ${ }^{3}$ The path to salvation, in Islam, is obedience to God's law. Fulfillment of the law constitutes happiness in this life, however physically arduous it may seem, by giving those who submit to God's law the inner satisfaction that their next lives will be assured in heaven (Khadduri 1955: 24). Indeed, the word islam in

\footnotetext{
${ }^{2}$ Hashmi (1996: 148-9) puts it differently: the fundamental nature of humankind is "moral innocence, that is, freedom from sin." Everybody is born with a natural knowledge of God's commandments. However, some choose to violate their nature and transgress against God's commandments, and it is these corrupting influences of human society that cause humans' moral awareness to be eroded.

${ }^{3}$ This sentiment reflects Islam's misunderstanding of how salvation is achieved in Christian thought, as if Christians could simply declare their belief that Jesus Christ is their savior and then continue sinning with impunity. Rather, Christians believe that the acceptance of Christ leads to the repentance of sin, but only if that acceptance is supremely genuine.
} 
Arabic means "surrender" or "submission" to the will of God (Kelsay 2007: 9). This is another way in which Islam departs from Christianity, notwithstanding that both religions worship the same universal and omnipotent God: whereas Christianity stresses man's submission to God's love, Islam stresses submission to God's will. Islam seeks to restore humankind to its original condition, in which all people submit to God (Martin 1991: 96) and in doing so achieve salvation.

The cosmology of Islam calls for the pragmatic ordering of submission and service to God, all taking place within a community (umma) founded by the Prophet and modeled on his recollected examples. The Islamic world considers God's kingdom to be achievable on earth, but only within the umma and only after the umma has overcome all opposition (Martin 1991: 107). In Islamic tradition, Muhammad conceived of the umma as a brotherhood "bound by common obligations to a superior divine authority," and membership in the umma is the sole path toward both prosperity in this world and salvation in the next. All other loyalties, tribal or otherwise, are superseded by the brotherhood (Khadduri 1955: 3-4). ${ }^{4}$ But as society is indispensable for the survival of man, and the concept of authority is inherent in the concept of society (for the latter cannot survive without the former), the conception of umma presupposes a body of fundamental laws - in this case, divine commands, issued by a supreme Lawgiver. The umma is necessary to suppress the aggressive and evil propensities of man, and thus the Islamic "state" is born-to the extent that the umma would be analogous to the modern conception of the state (Tibi 1996: 140-1).

\footnotetext{
${ }^{4}$ Citing Q. 3:106 and the Constitution of Medina, which is available online at http://www.constitution.org/ cons/medina/macharter.htm. (Accessed November 25, 2011.)
} 
The Islamic state has path-dependent origins as well, and the historical traditions associated with its formation are important to what John Kelsay (2007: 5) calls "Shari'a reasoning," in ways that are absent in Christian ethical reasoning. What also spawned the original Islamic state was the practical necessity of establishing a "tribe" that was physically as strong as, and could therefore withstand the onslaught of, the surrounding tribes. In pre-Islamic Arabia, the sovereign political entity was the tribe, and to not belong to a tribe was to lack any legal or moral standing; a tribeless person could be robbed, raped, and killed with impunity. Since new converts to Islam could be expected to be ostracized from their own tribes as Muhammad was, it was necessary to build a strong community for the sake of mutual protection (Pipes 1983: 42). The original Islamic state was not only a religious unity but also a political one, ruled by a single government (Donner 1991: 51) under the divine banner.

In contrast to Western theories of social contract between individuals, the Islamic social contract is between each person and God. The Islamic citizen does not seek rights in a contract with an earthly ruler, but rather in a higher authority that binds both ruler and subject, in which the earthly ruler discharges the duties imposed on him by God (Weeramantry 1988: 117). The tendency among later Muslim scholars was to adopt a Hobbesian-like approach to governance, in which a strong state is necessary for the security of its people (Khadduri 1955: 13). The Quran and other traditional sources consistently assert that order must supplant anarchy, even at the cost of imposing tyranny. "Sixty years of tyranny is better than one day's anarchy," Muhammad is reported to have said (quoted in Ayoob 2008: 4). 
In Islamic political theory, the locus of sovereignty resides in the person of God; his sovereignty is absolute and responsible to no one else. God promises to delegate his power of earthly sovereignty to those who believe in him and do good works. That delegate is the imam (priest), and the Islamic political ruler is a delegate of the imam. Therefore, subject to the ruler himself upholding the law and fulfilling his divinely ordained duties, the people have a divinely-mandated duty to obey the ruler (Ghunaimi 1968: $92-3) .{ }^{5}$ In the first Islamic state, both religious and political authority resided in a single person, the prophet Muhammad; the Constitution of Medina declared him the "sole war leader" and granted him political authority over the entire population of Medina, including the Jews. The document also formally recognized Muhammad as the Messenger of God (Aslan 2005: 55; though that office surely was already self-evident to his earliest followers). Muhammad's authority as lawgiver was absolute, as evident in his response to grievances over his declaration that women henceforth would be allowed to own and inherit property: "Those who disobey God and His Messenger . . . will be thrown in to Hell" (Aslan 2005: 62, quoting Q. 4:14).

The Constitution of Medina lapsed upon Muhammad's death; his successor, styled the Caliph, exercised no prophetic function but did retain executive power. This decoupling of religious from political authority forms the basis of the complaint of several scholars of Islamic law that the West has mischaracterized the Islamic state as a "theocracy." Ghunaimi (1968: 91) argues that the Western conception of theocracy, as the concentration of God's authority through a priestly class or king in an autocratic manner, is

\footnotetext{
${ }^{5}$ Khadduri, however, claims that the majority of Muslim scholars have argued that the ruler could not be deposed for any reason, not even for violating the social contract (1955: 12).
} 
"alien" to Islam (his word). Majid Khadduri's (1955: 14-6) objection is that although some authority is directly derived from and exercised by God, other authority is derived from the divine code endowed by God but enforced by the earthly ruler. ${ }^{6}$ However, as Mohammed Ayoob (2008: 14) points out in his examination of the historical Islamic Caliphate, the domains of religion and state could not be completely insulated from each other. This is partly due to the historical precedent for commingling temporal and religious authority (in the Prophet and the first four "righteously guided" caliphs), ${ }^{7}$ and partly due to the moral concerns that intruded into the political sphere being inevitably couched in religious vocabulary (as would be the case in any society in which religion flourishes). Political and religious identities continued to overlap significantly during the Caliphate, with Muslim rulers attempting to use religious titles and institutions as political instruments to legitimize their claim to rule.

The question of whether the ideal Islamic state is theocratic or not appears to have obscured a larger, more fundamental question, which is also more germane to the problematique at hand: To what extent, if any, do Islamic norms of political behavior evolve? The outcome of the conflict between Islamic Rationalism and Islamic Traditionalism in the $9^{\text {th }}$ and $10^{\text {th }}$ centuries CE may shed some light on both questions. Rationalists argued that God, while fundamentally indefinable, exists nevertheless within the framework of human reason. Ibn Rushd (Averroës), for example, asserted that the existence of

\footnotetext{
${ }^{6}$ Khadduri would characterize the Islamic state as a "nomocracy," in which the system of government is based on law.

${ }^{7}$ Caliph Abu Bakr once claimed that the corollary of religious leadership is political leadership (Ghunaimi 1968: 63).
} 
God could be established by human reasoning, apart from divine revelation (Weeramantry 1988: 95). In Islamic Rationalism, all theological arguments had to adhere to principles of rational thought and be subordinate to human reason, even interpretations of the Quran and the traditions of the Prophet (the Sunna). Islamic Traditionalists argued the opposite - that human reason, while important, must be subordinated to the Quran and the Sunna, otherwise people would follow their own wills instead of God's. Human reason was imperfect, faulty, and unstable, whereas the Quran was fixed (by God, who is perfect beyond question) and the prophetic traditions were fixed also (by God's representative, the Prophet; Aslan 2005: 153-4). Thus the Traditionalist thinker Ghazali countered that human intellectual rigor must remain within the boundaries of the major premises of Islam (Weeramantry 1988: 100)_an early Islamic iteration of bounded rationality.

The Rationalist school of thought was not accepted in mainstream Islam, and by the end of the $13^{\text {th }}$ century CE, the Traditionalist school had prevailed in Sunni Islam, partly due to the Inquisition conducted by Caliph Ma'mun, in which Rationalists were persecuted as heretics (Aslan 2005: 158). Islamic Rationalism has yet to recover even today, if the accounts of Reza Aslan (2005: 166-9) accurately represent the sentiments of the Islamic leadership. The consequence of this outcome was to give the orthodox ulama (priesthood) the sole authority to interpret the fixed and immutable text of the Quran, and since an eternal Quran could not be a product of and for only Muhammad's society and not others as well (rather, it had to be for all time), historical context could play no further role in interpreting the Quran (id. 162). The result was to freeze into place those standards that its contemporaneous interpreters claimed —at that moment in time-were 
mandated by God. Those standards became norms of behavior for all time, even if the interpreters themselves were reacting to a circumstance of history, and even if their own (human) logic were flawed.

This is what has happened to Islamic ethics. Contemporary scholarship on Islam is plagued with the "baffling contradictions," as Amira Sonbol (2009: 283) puts it, "between what Islam is purported to say and how various political groups act." would explain that contradiction by deconstructing the discursive history of Islamic ethics, but the triumph of Traditionalism over Rationalism described above would appear to negate the utility of any such deconstruction. As a result, Islamic political theory and Islamic law have remained stagnant, and the Islamic worldview and ethos do not comport with the sociopolitical realities in which Muslims find themselves today (Martin 1991: 109). Rather, the Islamic mainstream seeks to force today's reality to fit the confines of Islamic law as it existed in another time and place (Pipes 1983: 11).

\section{Islamic Law}

The core discipline of Islam is not theology or metaphysics, but law (Weeramantry 1988: 9). In Islam, law begins with the premise of God's unparalleled superiority to all else, thus his unparalleled authority as well. Law emanates from the word of God, passed down through his Prophet Muhammad, and compiled into the Quran. The Quran, in its original $7^{\text {th }}$-century CE Arabic version, is immutable, comprehensive, and in Weera-

\footnotetext{
${ }^{8}$ Furthermore, the rosy pictures of the Islamic conceptions of human dignity, women's rights, individual freedoms, equality before the law, and tolerance, painted by Christopher Weeramantry (1988: chap. 5), do not comport with reality in many Muslim countries today.
} 
mantry's words, "supremely authoritative" (1988: 8). Indeed, the Traditionalist view is that by virtue of being the direct revelation of God, the Quran is God (Aslan 2005: 158).

The Quran is the most authoritative source of Islamic law, but it is not the only source. Other sources include the hadith, which is the collection of oral traditions of other statements and actions attributed to the Prophet, which are not included in the Quran (the body of hadith is collectively referred to as the sunna). Other traditional sources also include qiyas, which is the use of analogy in legal reasoning; and ijtihad, which is independent human reasoning (but which is no longer a valid source of Islamic law today).

After the death of the prophet, several different scholarly approaches to Islamic law emerged and these approaches settled into various schools, four of which have survived in Sunni Islam (and one major school in Shia Islam). ${ }^{9}$ The largest and strongest, the Hanafi School, founded by Abu Hanifah, is notable for its extensive use of analogy (qiyas), its dynamism (allowing the law to change with the times and facts), and the use of ijtihad during its formative stage. Most prominent in South and Central Asia, it is considered the most liberal legal school that remains within the bounds of the Traditionalist paradigm. The Maliki School, founded by Malik Ibn Anas and prominent in West Africa, stresses practical teachings, and relies almost exclusively on the hadith from the Medina period (the period when Muhammad lived in exile in Medina). The predominant legal schools in the epicenter of Islam are more conservative. The Shafi'i School, founded by Muhammad al Shafi'i and which is strong in Egypt, southern Arabia, and

\footnotetext{
${ }^{9}$ Summaries of the major legal schools are taken from Weeramantry 1998: chap. 4; Aslan 2005: 141-84; and Khadduri 1955: 36-7.
} 
Southeast Asia, concentrates on logical reasoning from the Quran and sunna. However, that reasoning is strictly bounded; teleological reasoning (reasoning by reference to the ends of law) is treated as anathema in the Shafi'i School because the purpose of law is treated as a matter for God alone. Law is not derived (to do so would be to substitute man's judgment for God's), but instead must be discovered, based on what God has already revealed. The Hanbali School, founded by Ahmed Ibn Hanbal and which is prominent in Afghanistan and Saudi Arabia (where it is official), is the strictest and most conservative of the four. In this school, the only valid roots of law are the Quran and sunna. The Hanbali School is the most hostile to legal reasoning, for the Quran is divine law and as such exists independently of human reasoning. A hadith, however weak, is preferable to any other source save the Quran itself. The main legal school in Shia Islam is the Jafari School, founded by Ja'far as-Sadiq; it recognizes a different body of hadith than Sunni Islam, and vigorously employs ijtihad (Aslan 2005: 184; Ghunaimi 1968: 1).

The triumph of Islamic Traditionalism over Rationalism has had far-reaching consequences for the development of Islamic law. By the $9^{\text {th }}$ century CE, claims of hadith had proliferated to the point that their authenticity was doubtful, so scholars began to seek out and compile those hadith which in their judgment were the most authentic. In theory, only those hadith whose chains of transmission were reliable were to be retained; they had to be traceable all the way back to the Prophet, with each link in the chain being a morally upright Muslim. However, Reza Aslan (2005: 164-9) shows that major compilers of hadith such Bukhari and Hajjaj actually did not put that ideal into practice. Most of the hadith selected for retention were selected not because their chains of transmission were particularly strong, but because their contents reflected the beliefs of the majority and the 
practices of the community. Hadith were selectively incorporated into the sunna in such a way as to legitimize those beliefs and practices that were already widely accepted by the majority of the ulama, with the goal of creating a sense of Islamic orthodoxy and orthopraxy. Those hadith that did not reflect the majority opinion were eliminated. Furthermore, the ulama de-legitimized any further use of ijtihad, and in doing so closed the door to any further possibility of legal reasoning independent of the Quran and sunna, even if the Quran and sunna were silent on the matter at hand. Thus the major compilers of hadith cited by Aslan were hardly objective, politically or religiously. This practice forms the basis of Aslan's conclusion that the sunna is a far better reflection of the ideology of the $9^{\text {th }}$-century CE priesthood then that of the original, $7^{\text {th }}$-century CE community of Muhammad's followers. As the major legal schools outlined above gradually coalesced into legal institutions, the diversity of ideas and freedom of opinion that characterized their early development eventually succumbed to rigid formalism and a strict form of stare decisis (adherence to legal precedent). By the $12^{\text {th }}$ century CE, the ulama were labeling anyone who did not ascribe to this rigid form of Traditionalism an "unbeliever," thus deepening even further the sanctions associated with challenging the status quo.

The result of these developments is that many of the principles, prescriptions, assumptions, and outlooks of Islam are based on historical circumstances that are radically different from the circumstances in which the Islamic world finds itself today. Islamic law is frozen in an epoch during which the Islamic state was very strong and successful, Islamdom's technology was equivalent or superior to that of its rivals, Islamic higher learning flourished, Islamic military campaigns were largely successful, and Islam itself propagated rapidly (Martin 1991: 109). These features induced a historical perception of 
self-superiority, and that perception has strongly influenced the Islamic perception of Otherness. In Islam, the Other consists of the forces of deception, unbelief, and shirk (the association of other beings with God), as opposed to the forces of the straight path and submission to God; in Islam, there is no more repugnant epithet than to be a labeled a mushrikun (one who commits shirk). Even the other Abrahamic, monotheistic religions (Judaism and Christianity) were viewed as communities that had rejected their prophets and distorted their scriptures (Martin 1991: 97-8).

\section{Dar al-Harb and Dar al-Islam}

This strong separation of Other from Self led to the early juridical division of the world between the dar al-harb (abode of war/conflict) and dar al-islam (the abode of submission, or of Islam; Q. 10:25). ${ }^{10}$ Because the abode of war does not follow God's revealed word and Muhammad's teachings, it can never be rightly ordered toward God; even its best efforts are frustrated by human frailties and misguided endeavors. Within the dar al-harb, justice is always injustice and the natural state is one of conflict. All of these faults are righted in the dar al-islam (Johnson 1997: 49). ${ }^{11}$ As V.S. Naipaul (1981: 368) puts it, "everything outside was impious, impure, infidel.” Daniel Pipes (1983: 3940) suggests an additional contributing factor: the strong delineation of Self from Other

\footnotetext{
${ }^{10}$ On the Quranic roots of this juridical division, see Tibi 1996: 129-30.

${ }^{11}$ James Turner Johnson likens the two abodes to the City of the World and City of God in Augustinian thought. The major differences, however, are that (1) Islam holds that the dar al-islam is achievable on earth, whereas Christianity holds that it is not achievable, and (2) Islam assigns to itself the sole capacity and prerogative to prescribe and create this right order on earth. This second difference appears to be a consequence of the Islamic belief that salvation is achievable through earthly works.
} 
may be a natural consequence of the strong social bond created by any heavily legalistic religion (such as Islam).

Such a worldview is a recipe for Islamic hostility toward non-Islam, whether it be generated by antipathy toward non-believers or by the belief (rational or not) that the dar al-harb is hostile to Islam. As Marshall Hodgson puts it, "Muhammad's prophethood, in fulfilling the monotheistic tendency toward a total religious community, at the same time left his community confronted with that temptation to a spirit of exclusivity that went with any vision of the total community and received appropriate expression in warfare" (quoted in Martin 1991: 107, n. 43). This is what Richard Martin (1991: 108) characterizes as the moral dilemma of Islam: whether or not the dar al-islam must/should be expanded by force. On one hand, it would be a charitable act to create conditions in which more people are assured of salvation instead of fewer (the Augustinian ethic of fraternal correction is not dissimilar), and in any case Muslims would naturally desire to be governed by and under protection of a Muslim political entity. On the other hand, given the distribution of power in the state system today, how can the umma fulfill such a divinely-ordained role—-to conquer the world—without bringing down upon it the wrath of the world?

This tension is evident in the principles of the Islamic law of nations. In Islam, international law is simply an extension of the natural law discovered first by juristtheologians, as was the case for international law in Europe (Ghunaimi 1968: 30). But international law was originally intended as a temporary institution only, as the goal of Islam was to unite the whole world under its banner (Khadduri 1955: 44-5). The focus on Islamic international law thus is not the intercourse between Muslim countries (recall that 
the original umma was a single Muslim state), but between Islamdom and the outside. A few basic principles of Islamic international law are familiar to Westerners, such as pacta sunt servanda (Q. 2:177, 5:1, 9:4, 16:91-2), reciprocity (Q. 2:194, 9:7, 16:126), and the legal personality of non-Muslim entities (Q. 8:72; Badr 1999: 98). However, early Muslim jurists denounced the possibility of perpetual treaties with non-Muslims (and by extension, perpetual peace), citing the Quranic proscription to "take not the Jews and the Christians for friends" (Q. 5:51; Ghunaimi 1968: 160-1). ${ }^{12}$ Furthermore, the Islamic state is permitted to repudiate any treaty with non-Muslims should the interests of the Islamic state dictate it, i.e. when the Islamic state becomes strong enough to defeat the nonMuslims in battle, thus the non-Muslims can no longer enforce the treaty. The passage in Q. 9:5 in which God instructs the Muslims to kill the unbelievers takes place in the context of repudiating treaties with non-believers (Q. 9:1-4). Some modern scholars have thus held that treaties with non-Muslims are not fully binding on Muslims. Ayatollah Khomeini declared his opposition to treaties that contradicted Islamic law (Mayer 1991: 201), ${ }^{13}$ and the former rector of al-Azhar University, Sheikh Mahmud Shaltut, asserted that Muslims are free to denounce a treaty when it causes harm to Muslims that exceed its advantages to Muslims (id.). By that logic, any pacta with non-Muslims only sunt servanda by the non-Muslims, thereby holding Muslims to a different standard of compliance with international law (which serves to severely undermine the principle of reciprocity). Thomas Franck (1995: 16-8) labels this problem the "trumping" principle,

\footnotetext{
${ }^{12}$ Ghunaimi mistakenly cites Q. 9:51.

${ }^{13}$ Mayer notes, however, that Iran did not invoke Islamic law in its memorials to the International Court of Justice justifying its holding American embassy personnel hostage.
} 
and shows how it undermines the fair dealing that is a necessary part of orderly international interaction. This problem forms the basis of Ann Elizabeth Mayer's (1991: 199) assertion that the Islamic world has difficulty accepting modern public international law, for it is not a Muslim but Western (and fundamentally Christian) creation and accepting its authority offends the Islamic theory of the supremacy of Islamic law.

\section{$\underline{\text { Dar al-Suhl }}$}

Several scholars counter-argue that the so-called perpetual state of war between the dar al-islam and the dar al-harb is a myth, long dispelled by centuries of diplomatic relations between the Islamic and non-Islamic states in Europe, Central Asia, and India (Weeramantry 1988: 143; Ghunaimi 1968: 45-6). These arguments neglect the third type of abode constructed by early Muslim jurisconsults: the dar al-suhl (abode of treaty or conciliation). Islamic law deems it permissible to temporarily suspend conflict with nonIslam if doing so serves the interests of Islam. The entry of Islamdom into the Westphalian state system ${ }^{14}$ is better rooted in the tradition of the dar al-suhl, in which Islamdom acknowledges the reality of its material weakness relative to the West, than in claims that Muslim alliances with non-Muslims violate Islamic law (Ghunaimi 1968: 502). Ghunaimi characterizes this event as the beginning of the decline of Islamic international law (id. 53), but I submit that it is better characterized as a temporary abatement of hostilities that do not further Muslim interests at a time when Muslim states are weaker

\footnotetext{
${ }^{14}$ That entry takes place with the inclusion of the Ottoman Empire in the peace settlement that ended the Crimean War. General Treaty for the Re-Establishment of Peace (Austria, France, Great Britain, Prussia, Russia, Sardinia, Turkey), Mar. 30, 1856, [Treaty of Paris], 46 BFSP 8, 114 CTS 409, 410.
} 
(Tibi 1996: 130). Bassam Tibi offers a poignant illustration of this doctrine in the decision of the $19^{\text {th }}$ century Moroccan state to normalize peaceful relations with Europe (id. 134-5). The advisor to the Sultan was reluctant to repudiate the duty to wage war against unbelievers, but was unable to overlook the superior power of the Christians. Therefore, it was in Morocco's temporary interest to accept peaceful relations with nonIslamdom and submit to international standards of law and conduct. Tibi refers to this policy as "conformism."

But the dar al-suhl has its limits; it may allow Islamdom to capitulate to the geopolitical realities of a state system dominated by the West (the Westphalian system) but that does not entail being integrated fully into it. Sheikh Shaltut, who does not disguise his contempt for Westphalian international law, concedes that peaceful coexistence with non-Islamdom should be sanctioned, but only by treatises that do not impinge on Islamic law (Tibi 1996: 136). The reservations of many Muslim states to core provisions of the Convention on the Elimination of All Forms of Discrimination Against Women $(\mathrm{CEDAW})^{15}$ serve as an illustration of this. Many Muslim states ratified the Convention but made reservations to the effect that nothing in the Convention would override Islamic law; this practice prompted several Western states to lodge objections to those reservations, claiming that they are fundamentally incompatible with the object and purpose of the Convention, and therefore the reserving states are not genuinely party to it. ${ }^{16}$ It is not

\footnotetext{
${ }^{15}$ Convention on the Elimination of All Forms of Discrimination Against Women (CEDAW), Dec. 18, 1979, 1249 UNTS 13.

${ }^{16}$ Declarations, Reservations, and Objections to CEDAW. Available online at http://www.un.org/ womenwatch/daw/cedaw/ reservations-country.htm. (Accessed April 9, 2011).
} 
expected that Muslim states would have ratified CEDAW at all if Muslim states

dominated the state system; furthermore, Western concepts of human rights can be expected to permeate the state system only for as long as the West enjoys hegemony. When geopolitical conditions no longer require the dar al-islam to accommodate the dar al-harb, Islamic thought prescribes that such accommodation and conciliation should cease. The struggle for Islamic dominance may be revived whenever deemed necessary (Khadduri 1955: 65).

\section{The Islamic War Ethic}

\section{Islamic Conception of Self-Defense}

The Islamic war ethic is traceable through several epochs (Firestone 1996: 109). In the very earliest period, when Muhammad and his followers were weak, God's revelations ordered him to persuade the unbelievers but not to fight them (Q. 15: 94-5, 16: 125). But when the Muslims fled to Medina and the movement grew stronger, the revelations began to sanction fighting in defense against the aggressors from Mecca and their allies in Medina (Q. 22:39-40, 2:190).

That Islamic jus ad bellum permits the use of force in self-defense is clear and not surprising. The fundamental basis of the right of self-defense in Islam is rooted historically in the oppression of the earliest Muslims in Mecca by the Quraysh tribe, which forced them to flee to Media. As the Muslim movement grew in strength in Medina, its Meccan adversaries stepped up their effort to destroy it (Firestone 1996: 112). Just as the Christian Roman Empire needed a justification for violence to defend itself against 
invaders, so did Muhammad and his followers to defend against an enemy that was increasingly resolved to destroy them. The primary scriptural basis for an Islamic right of self-defense is Q. 22:39-40, which sanctions fighting by those who have been oppressed and even imposes a duty of self-defense (Aslan 2005: 84; Sonbol 2009: 289). Several of the gentler translations of the Sword Verses of the Quran, Q. 2:190-3, 9:5, and 9:29, may be interpreted in this light. Even the Ahmadiyya sect, which explicitly renounces offensive use of force, permits it for the protection of Muslims and their property (Sivan 1998: 175). ${ }^{17}$ In contemporary statecraft, Islam would generally condone violence in response to state repression or foreign occupation (Ayoob 2008: 1). In addition, Islam imposes a duty to defend and protect the weak, i.e. fight for those who cannot defend themselves (Sonbol 2009: 289). ${ }^{18}$

Many contemporary authors on Islam take the position that jihad (striving for God) is undertaken exclusively for defensive reasons, or could even consist of passive activities such as non-recognition (Mayer 1991: 203-4). ${ }^{19}$ Aslan (2005: 84) argues that Quranic passages on slaying polytheists, fighting infidels, etc. (9:5, 9:73, 9:29) are revelations that specifically concern the treatment of the Quraysh tribe of Mecca and their partisans in Medina. Abdulaziz Sachedina (2002: 42) asserts that the actual meaning of the Quran is to impose the duty to stamp out "actively hostile" unbelief, such as the malicious unbelief of the Meccan tribes who were persecuting the earliest Muslims. Aslan and Weeramantry

\footnotetext{
${ }^{17}$ The Ahmadiyya, however, are not considered a mainstream sect of Islam.

${ }^{18}$ Weeramantry (1988: 115) asserts that Muslims have a duty to defend non-Muslims as well, but Sonbol would limit that duty to defending Jews and Christians only.

${ }^{19}$ Citing Sobhi Mahmassani, Hasan Moinuddin, Sheikh Shaltut, Ghunaimi, and Sachedina,
} 
(1988: 114) thus both claim that the Quran warns Muslims against committing acts of persecution and aggression themselves, only to fight back against attacks from others, e.g. in 2:190 (do not "transgress" the limits of fighting) and 16:90 (God enjoins justice; do not kill without right).

However, as Fred Donner (1991: 47) points out, whether the Quran does or does not explicitly justify offensive violence against unbelievers "is really left to the judgment of the exegete" and not all translations of the Quran lend themselves to such a restrictive interpretation of the Islamic war ethic. Whereas Pickthall, Dawood, and Muhammad Ali translate Q. 2:190 as a prohibition of aggression, the more contemporary translations of Haleem, Hilali \& Khan, and Yusuf Ali interpret the same verse as a prohibition of transgression (of limits). The prohibition of aggression is more restrained; it prescribes the use of force for defensive purposes only, i.e. Muslims are not to give the other party cause to defend itself against Muslims. The prohibition of transgression constrains the use of force only within the confines of jus ad bellum and jus in bello that Islam itself prescribes. If, as other Quranic passages suggest, Muslims have broad discretion as to whether to attack non-Muslims by virtue of their religion or are even required to do so, then Islamic jus ad bellum is considerably more permissive than the first group contends, with fewer confines to transgress against. ${ }^{20}$

The translations of Q. 2:191 vary widely in defining that wrongdoing by the enemy which justifies the lesser wrongdoing of killing them. Of the several translations examined in the course of this work, the plurality uses the word "persecution," but others

\footnotetext{
${ }^{20}$ The passage may be interpreted also to speak only to jus in bello (the methods and means of warfare once undertaken), and therefore would contain no constraints on the decision to attack in the first place.
} 
use "tumult and oppression," idolatry, or polytheism and apostasy. In the plurality's interpretation, the persecution or oppression of Muslims would justify war against nonMuslims on account of their material injuries on Muslims, but the acts of idolatry, polytheism, or apostasy would not. In the other interpretations, the causes for defense are much broader. In addition, the phrase translated by Haleem as "drive them out from where they drove you out" (the translations do not vary widely here) is open to the question of whether it imposes limits or not. Does it mean "drive them out only from where they drove you out," or is there greater latitude to expel non-Muslims for the sake of security or religious purity of the $u m m a ?^{21}$

The translations of the passage that articulates the goal to be achieved by fighting, in Q. 2:193, also vary widely. In the Haleem, Pickthall, and Muhammad Ali translations, the goal is to stop "persecution." These translations suggest that the purpose of fighting is defensive, i.e. to relieve Muslims from material oppression by non-Muslims. But the goal of war in the other translations is considerably more transcendental: in Dawood, the goal is to eradicate "idolatry"; in Hilali \& Khan, to eradicate "disbelief and worshipping of others along with Allâh." In Yusuf Ali, the goal is to eradicate "tumult or oppression," which could cover considerable ground, depending on what is cause for "tumult."

The other goal in Q. 2:193, in Haleem's words, is to fight until “worship is devoted to God" (as opposed to entities other than God; cf. Pickthall's translation "religion is for

\footnotetext{
${ }^{21}$ The phrase "kill them wherever you find them," interpreted by the most extremist radicals as a call to hunt down and exterminate non-Muslims, is interpreted by the mainstream as more limiting, for the overall context of the verse is to address whether Muslims may fight during holy times and in holy places (see Haleem translation, note $a$ to $2: 191$ ).
} 
Allah"). ${ }^{22}$ Haleem's translation suggests that the goal of fighting is to propagate monotheism, or put another way, eradicate polytheism; his commentary claims that the verse speaks specifically to worship at the "sacred mosque" (Haleem trans., 2:193 note $c$, apparently meaning the Kaaba at Mecca). Muhammad Ali asserts a considerably softer interpretation of his translation "until . . religion is only for Allāh"; he claims that the phrase means "When persecution ceases, and men are not forced to accept or renounce a religion, being at liberty to profess any religion of the truth of which they are convinced" (Muhammad Ali trans., 2:193 note 193a). Muhammad Ali asserts, incorrectly in my view, that this interpretation must be correct in light of other verses such as 22:40 (fight to resist injustice), ${ }^{23}$ which would be rendered meaningless under any other interpretation of 2:193. But the context of both verses is resistance by Muslims against oppression, religious or otherwise, that is committed by non-Muslims. I submit that what Muhammad Ali really means is that Muslims be at liberty to choose their religions. A claim that Muslims should protect freedom of religion for non-Muslims, especially polytheists, is not persuasive in light of the Quran's overall hostility toward non-Muslims (especially polytheists). Other translations are more overtly militant. Yusuf Ali's translation asserts the goal that "there prevail justice and faith in Allah" (emphasis added), ${ }^{24}$ again suggesting the aim of promoting monotheism and eradicating polytheism. Hilali \& Khan

\footnotetext{
${ }^{22}$ In this work, the word "Allah" is interpreted as "God," i.e. the god that would be worshipped in any monotheistic religion.

${ }^{23}$ Kelsay (2007: 24) and Sonbol (2009: 288) arrive at the same interpretation of Q. 22:40: that fighting is justified to resist injustice. I also agree with this interpretation of 22:40.

24 "Justice and faith" is Yusuf Ali's translation of the Arabic word dīn, which implies many meanings. The syntax of the original Arabic version of 2:193 is "until there is din for Allah."
} 
go further, asserting the goal to be that "(all and every kind of) worship is for Allâh (alone)"- - suggesting that Muslims must fight until all polytheism is eradicated, everywhere. Dawood's translation, “until . . Allah's religion reigns supreme," suggests the goal of making Islam specifically the only religion, or at least the predominant one.

The variations outlined above generate ambiguities as to just what acts are to be “defended" against. Sachedina (2002: 39-42) suggests two types of acts: aggression, and "moral wrong" (Q. 8:39 \& 2:193). If "moral wrong" includes the failure to worship and obey the one true God, as is the position of many scriptural verses and Islamic priestly writings, then the concept of self-defense is broadened beyond what would be considered self-defense by the standard set in today's jus ad bellum. In such a case, Islam then would sanction the use of offensive force to (1) eradicate polytheism, despite a lack of material injury toward Muslims, and (2) eliminate obstacles to the propagation of Islam (Mayer 1991: 205). The prominent Islamic scholar of al-Azhar University in Cairo, Sheikh Shaltut, writes that fighting is justified to repel aggression, but also to "protect the Islamic mission” (Mayer 1991: 204; see also Aboul-Enein \& Zuhur 2004: 11). As Sachedina (2002: 39) puts it, the Quran “also requires Muslims to work toward establishing a just public order. At this point the jihad becomes an offensive endeavor in connection with efforts to bring about the kind of world order the Qur'an envisions." Such goals stray beyond the conventional definition of self-defense against an attack. In addition, the Islamic conception of "aggression" perceives actions which do not constitute the use of force against Islam as hostile nevertheless. This interpretation is evident in two works by international lawyers, one written before the adoption of the UN 
Definition of Aggression and one written afterward. Ghunaimi's 1968 treatment speaks of "ideological aggression":

Islam envisaged aggression only when its ideology is endangered because of state activity. In this case, the Islamic state is to defend the Faith and repel aggression, even by force if necessary. ... [T]he element of violence or the use of armed force is not necessarily required to qualify an act as aggression. Indirect aggression and particularly when an act causes incitement against a certain ideology, may constitute a cause good enough for justifying an act of self-defence. (1968: 209)

Weeramantry, writing in 1988 , holds out the possibility that Islamic law permits force in self-defense against "aggression" that does not involve the direct use of force, such as economic or propaganda "wars" (1988: 162). Such claims severely undermine the position that the Islamic war ethic is strictly defensive.

\section{Jihad and the Permissive Islamic War Ethic}

Once the Muslims in Medina had achieved a position of power, revelations to Muhammad concerning the war ethic were significantly more permissive (Firestone 1996: 109). After the revelations of Q. 2:217 and 2:191, the Muslims were free to raid the Meccans and their caravans. With the revelations of Q. 9:5 and 9:29, among other verses, the Muslims were enjoined to attack their opponents any time, anywhere. Even after Muhammad's final triumph over Mecca, which ended the threat to his movement once and for all, no further revelations ensued, thus the more permissive verses giving 
Muslims much broader discretion to use force than before were never moderated (Firestone 1996: 113).

The core of Islamic jus ad bellum in scripture is the doctrine of jihad. Derived from the Arabic root jahada (exert), the word is usually translated into English as a struggle, striving, or great effort. Strictly speaking, that translation does not necessarily denote an armed struggle, but such has been the historical connotation of the word in the West; indeed, the word "jihad" as a loan-word in English is synonymous with "holy war." It is the word most associated with the tenet that "[a]ny war against unbelievers, whatever its immediate ground, is morally justified" (Tibi 1996: 131).

The verse that appears to have the greatest association with the more permissive interpretation of the Islamic war ethic is Q. 9:5, which is said to have abrogated as many as 124 other Quranic verses (Firestone 1996: 111). A more conservative translation reads:

Then when the Sacred Months have passed, then kill the Mushrikûn [translated elsewhere as "idolators, polytheists, disbelievers in the Oneness of Allâh, pagans, etc.’] wherever you find them, and capture them and besiege them, and lie in wait for them in each and every ambush. But if they repent and perform As-Salât (Iqâmat-as-Salât), and give Zakât, then leave their way free. Verily, Allâh is Oft-Forgiving, Most Merciful. (Q. 9:5, Hilali \& Khan trans.)

The same translation also cites several hadith in support of the early Muslim wars against the non-Muslims. In fairness to Islam, the properly-read context of this verse severely undermines its validity as a basis for jihad against unbelievers, despite the plain meaning of the words. The context is that the polytheists, pagans, idolaters, and unbelievers, 
having previously made treaties with the Muslims, have all violated their agreements by attacking Muslims or supporting others who did. The ninth chapter of the Quran therefore begins with a general release from all of the Muslims' treaty obligations toward nonMuslims—on the grounds that the non-Muslims first breached theirs (Muhammad Ali trans., 9:1 note $a$; Haleem trans., introduction to chap. 9). ${ }^{25}$

In Islam, the juridical-theological meaning of jihad is to exert power in God's path, i.e. spread the belief in God and make his word supreme throughout the world (Khadduri 1955: 55). This interpretation suggests a twofold duty: to propagate Islam as a religion, and to expand the authority of Islamic law. Daniel Pipes argues that the primary purpose of jihad is the latter instead of the former; "to approach God properly, man must live by the Shari'a; because the Shari'a contains provisions which can only be executed by a government, the state has to be in the hands of Muslims; Muslims must therefore control territory" (1983: 44). Islamic jurists regard jihad as the means for establishing Islamic sovereignty, since the reign of God's religion requires the political supremacy of that religion on earth (Ghunaimi 1968: 137).

\section{What Is Jihad, Exactly?}

The source of tension is the question of whether the duty of jihad mandates the use of force to bring about the supremacy of Islam and Islamic law. Some assert that jihad has a

\footnotetext{
${ }^{25}$ A potential counter-argument, taken up more thoroughly elsewhere in this chapter, is derived from 9:4, which directs Muslims to continue to honor treaties with those mushrikûn who have not breached them, until the end of their terms. This passage could be interpreted as a broad injunction to deal honorably with honorable unbelievers, or as a narrow injunction that frees the Muslims from all obligations to them the moment those obligations expire. None of the translations shed any light on that question.
} 
dual meaning; that in its primary religious connotation, it means "the struggle of the soul to overcome the sinful obstacles that keep a person from God" (Aslan 2005: 81). This is the "greater jihad" and it is inward-looking, even passive. Outside of Islamdom, however, jihad is usually associated with its secondary meaning, the "lesser jihad," which is an exertion of force (defensive or offensive). Majid Khadduri interprets the term as follows: In Muslim legal theory, ... it is the duty of the imam as well as every believer not only to see that God's world shall be supreme, but also that no infidel shall deny God or be ungrateful for His favor (ni'am).... The jihad, in other words, is a sanction against polytheism and must be suffered by all non-Muslims who reject Islam. ... The jihad, therefore, may be defined as the litigation between Islam and polytheism; it is also a form of punishment to be inflicted upon Islam's enemies and the renegades from the faith. (1955: 59, italics omitted)

This interpretation of jihad imposes an obligation to destroy polytheism, even if no polytheistic actor has attacked Muslims. I submit that this is a quite plausible interpretation of the Sword Verses of the Quran. All translations of Q. 2:193 state that if the enemy ceases its attacks, then Muslims must also. But the Quran makes an exception to this general injunction: Muslims may continue to fight certain enemies even if those enemies give Muslims no further cause to fight. In the translations of Haleem, Muhammad Ali, and Yusuf Ali, those enemies consist of "aggressors" or "oppressors" or "those who practice oppression," which appears to mean those who continue their repressive ways internally (or perhaps against other actors) despite having desisted from their attacks on the Muslims, i.e. given cause for a "humanitarian intervention" in the 
contemporary international legal sense of the word. But in the Pickthall and Dawood translations, the actors against whom Muslims may continue to fight are "wrongdoers" or "evil-doers," respectively. This terminology raises the question of what activity is to be considered "wrong" or "evil" by Muslims, conferring cause to use force to stop that activity. That question seems to be left open to the interpreter. In the Hilali \& Khan translation, those actors are the zâlimûn, translated as "polytheists, and wrong-doers." My point is that it is by no means certain that polytheists and pagans are not the object of perpetual hostility in the Islamic war ethic, nor is it certain that non-Muslim monotheists are not also "wrong-doers" in the eyes of Islamdom.

I submit that of the two conceptions of jihad (greater and lesser), the lesser jihad is the more accurate interpretation of the Islamic war ethic. The greater jihad, as distinguished from the lesser, is not a Quranic mandate but a juridical construction. The construction of the greater and lesser jihads did not emerge until the $13^{\text {th }}$ century CE (and when it did, it encountered formidable opposition). ${ }^{26} \mathrm{Up}$ until that time, the use of force was far more central to the actual practice of Islam, and as David Cook (2005: 42-3) notes, it is the early Muslim history that is heavily emphasized in Islamic education, not the later. There is no basis for distinguishing the greater and lesser jihad in early Muslim history. The greater jihad is given more treatment today than is warranted in the classical Islamic texts, upon which most Islamic scholarly treatments of the Islamic war ethic are based (see Cook 2005: 39-48).

\footnotetext{
${ }^{26}$ Among its most vehement critics was the scholar Taqi ad-Din Ahmed Ibn Taymiyya, whose extreme conservatism inspired the (now official) Wahhabi movement in Saudi Arabia and is also influential in radical Islam (Sonbol 2009: 297).
} 
Even if it is conceded that the original meaning of jihad was in the "lesser" sense as opposed to the greater, many scholars who are sympathetic to Islam maintain that holy war was not part of that original meaning. John Kelsay (2007: 38) reports on the claim that the intention of Muslim expansion was "beneficent paternalism," not for the purpose of aggrandizing conquest but in order to "open" the conquered territory to what the Muslims believed was the natural state of humankind. Aslan (2005: 84), Sachedina (2002: 42-3), and Ghunaimi (1968: 166-7) all assert that the Sword Verses were actually meant to legitimize defensive force against the original persecutors of the earliest Muslims, i.e. only actively hostile unbelievers (see also Sonbol 2009: 296). Weeramantry (1988: 146) claims that jihad did not always necessarily take the form of actual hostilities; the struggle could be furthered through persuasion (Q. 16:125), or through passive resistance such as non-recognition. These claims of the original meaning of the scriptures might be true, but the method of the earliest Muslims was to impose their authority, not merely invite followers to their religion (Kelsay 2007: 45-6). The procedure, informed by the Quran and hadith, required that the Muslims first invite their opponents to convert to Islam, or in the case of the Scriptuaries (People of the Book, i.e. Jews, Christians, and Sabeans), allow them to peacefully accept Muslim dominion if they agree to pay the jizya (poll tax). If the opponent accepts the invitation or terms, and ceases to make war against the Muslims, the cause for jihad is negated. If they do not, the jihad may commence (Khadduri 1955: 96, citing Q. 17:18 and hadith). In such a circumstance, the harbis (the people of the dar al-harb) have no rights; Muslims may treat them as they wish (killing, enslaving, etc.), subject only to specific Quranic proscriptions from killing women and children (Johnson 1997: 70-1, citing Shaybani’s Siyar). For the Scriptuaries, satisfying 
the conditions necessary to negate the jihad means surrendering their autonomy and right of self-determination. For idolators, even accepting Islam will not prevent them from being forced to leave their homes anyway (Kelsay 2007: 101, quoting Shaybani's Siyar).

Under Muhammad's leadership, the original jihad was undertaken with the goal to unify the Arabs. Perhaps the early Muslims believed that they were acting in the best interests of the Arab people, for the Arabs were prone to tribal warfare and as Weeramantry (1988: 145) puts it, jihad was the medium for spreading the "Pax Islamica" to the dar al-harb (the abode of war). But even if the early Muslims are excused for arrogating to themselves the privilege of unifying the Arabs by force, the writers above assert that the Sword Verses were never intended to mandate, or even legitimize, forcible conversion to Islam. Nor, they claim, did they legitimize the rapid territorial conquest and dominion of the Muslim Arabs outside Arabia. Ghunaimi (1968: 165-78) complains that the militant view of jihad is based on verses of the Quran taken out of context, specifically the context of situations in which verses were revealed to Muhammad. One such claim (out of many) pertains to Q. 2:191, which Hilali \& Khan translate as "kill them [unbelievers] wherever you find them." The context set by the surrounding verses (Q. 2:190-3) is defense against acts of aggression by unbelievers, and 2:192 requires the defenders to stand down when the aggression ceases. Sachedina (2002: 36) asserts that many early Islamic jurists chose to overlook Quranic passages on the moral justification of war (which are more restrained), in favor of other, more permissive passages that legitimized the territorial expansion of the dar al-islam and better captured the “proselytizing spirit” of early Islam (as Weeramantry [1988: 145] puts it). Ghunaimi (1968: 173-4) and Sonbol (2009: 296) both also decry the misapplication of hadith in 
favor of the militant view of jihad, including several hadith that contradict the Quran. Even the classical treatise of Shaybani (1966), who would reduce non-Muslim belligerents to non-persons, does so only in the context of a prior attack by the dar al-harb against the dar al-islam. In his view, war in furtherance of jihad was still permitted only in self-defense-a restrictive interpretation of the Islamic war ethic.

In the first few hundred years of Islamdom, however, it was the more permissive interpretation of the Islamic war ethic that prevailed. The practice of early Muslims is particularly significant to the Islamic war ethic in the present because of the heavy emphasis of early Muslim history in Islamic education today (Cook 2005: 43). The Prophet participated personally in 27 Muslim campaigns and directed another 59, all during the last nine years of his life (a total of about nine military engagements per year). Many of the revelations that today constitute the Quran coincided with military activity, and the victories and defeats associated with Islam's origins all contributed to how the umma defined itself (Cook 2005: 6-7). In addition, the early Muslims inherited a fatalistic determinism from their pre-Islamic Arab culture, with the resulting belief that all events were determined absolutely by God (Trombley 2003: 155). ${ }^{27}$ It was thus natural for the early Muslims to attribute their improbable military successes to divine ordination, and this belief emboldened them further. ${ }^{28}$ Defeats and partial victories were viewed as divine tests of the Muslims' faith and resolve. This belief in their divinely-ordained superiority

\footnotetext{
${ }^{27}$ Citing Watt 1985: 25ff. This influence is evident in everyday Arabic speech today, which is peppered with expressions such as "insha-allah" (God-willing) and "al-hamdu li-llah" (praise be to God).

${ }^{28}$ Especially the Battle of Badr (624 CE), in which only two years after the Hejira (Muhammad's flight from Mecca to Medina), Muhammad's outnumbered forces were able to defeat and slay prominent members of the Quraysh tribe that had persecuted the Muslims in Mecca (Cook 2005: 7).
} 
induced the early Muslims to forcibly unite the Arab tribes (622-632 CE), enforce Muslim unity when several tribes attempted to withdraw from it after the death of Muhammad (the Riddah Wars, 632-633 CE, which the Muslims viewed as a war to punish apostasy), and then to expand the domain of Islam beyond the Arabic-speaking people.

The real expansion of the dar al-islam begun under Caliph Umar, beginning in 634 CE. Umar was a fiery, misogynistic, rigid doctrinaire, known for longing for death in battle because he believed that martyrdom was the surest path to reward in heaven (Aboul-Enein \& Zuhur 2004: 14, citing the Muwatta of Malik). That Islam should be the only religion tolerated in Arabia was Umar's “starting point"; under his reign, the Muslims overran the previously Christian domains of Syria, Egypt, and Armenia (of which only Armenia was able to retain its Christian identity), and over ten years succeeded in conquering Persia and stamping out polytheism there. Twenty years after the defeat of Persia, the Muslim caliphate under the Umayyad dynasty conquered the Magreb and a half-century after that, Spain. The Muslim army commander Uqba bin Nafi is quoted as crying out, after completing the conquest of North Africa, "O God: if the sea had not prevented, I would have coursed forever ..., upholding your faith and fighting all who disbelieved" (quoted in Haddad \& Khashan 2002: 817; emphasis added).

The above history is relevant because much of it takes place even before the Quran was compiled and standardized (653-654 CE), and all of it before the emergence of the standard legal schools outlined earlier in this chapter. The Muwatta of Malik (1980; the founding work of the Maliki school) and Kitab al-kharaj of Abu Yusaf (1979; a prominent work of the Hanafi school) both treated jihad in connection with the task of 
converting the dar al-harb (Syria, Egypt, Persia, and beyond) into the dar al-islam. Prominent compilations of hadith such as the Sahih al-Bukhari (Bukhari 1976) portrayed jihad as a struggle to be waged against unbelievers until they accept Islam, not the inward struggle depicted by proponents of the greater jihad (see Sonbol 2009: 296). The works of Muhammad al-Shafi'i (founder of the Shafi'i school) cast jihad as a struggle against unbelievers simply on the basis of their unbelief; the doctrine of jihad to eradicate unbelief originated with Shafi' 'i. ${ }^{29}$ Indeed, the later in time, the more conservative and militaristic the Islamic legal schools and their treatises: the founder of the most liberal school, Abu Hanifa (died 767 CE), was succeeded by Malik (d. 795), then Shafi'i (d. 820), then Ibn Hanbal (d. 855). Within two hundred years after the death of Muhammad, jihad had become synonymous with war in the legal and hadith literature (Sonbol 2009: 294; Donner 1991: 51; Khadduri 1955: 59). But rather than expanding on the original logic and the historical and literary context of the revelations of the Quran, this body of literature instead rationalized the military expansions recounted above. As Sachedina (2002: 37) puts it, the literature constitutes an "ex post facto legitimation of the early conquests."

By the $10^{\text {th }}$ century CE, the militant doctrine of jihad was so strong that it was able to withstand challenges even from the most prominent classical Islamic thinkers. The defeat of the Rationalism of Averroës has already been mentioned; in addition, the treatment of Islamic jus ad bellum by Abu Nasr al-Farabi (Latinized Alpharabius) is worthy of mention (Butterworth 1990). Writing a century after Shaybani and a half-century after

\footnotetext{
${ }^{29}$ Majid Khadduri, “Translator's Introduction,” in Shaybani 1996: 57-8. The specific work of Shafi'i cited, the Kitab al-Umm, is not available in English. See also Shafi'i 1993.
} 
Shafi'i, Farabi outlined seven just and four unjust purposes of war. Among the just purposes were defense, reforming others, subjecting those who were suited for subjection, and punishing a crime. Among the unjust purposes were self-aggrandizement, conquest for conquest's sake, and pure rage or pleasure. Charles Butterworth (1990) argues that reforming others as a cause for war lends itself to a militant version of jihad against unbelievers by virtue of their unbelief, ${ }^{30}$ but Farabi does not explicitly mention the doctrine of jihad in that sense and it appears that his intent was to link reformatory war to the suppression of apostasy, heresy, and dissidence rather than to force Islam on non-Muslims (Johnson 1997: 72-3). Farabi's approach was novel, partly because it disaggregated religious and political doctrines on the use of force, and partly because the justification for using force was conditioned largely (though not entirely) on the opponents' actions or transgressions, not their beliefs. However, like other Rationalist strains of thought, Farabi's argument did not prevail in his time; the official doctrine of jihad remained as it had been articulated by the jurists and unbelief remained a central element in the relationship of Islam with other states (Johnson 1997: 75).

In addition to the relationship between Islam and non-Islam, jihad also informs the political relationship between Islam and its followers. The classical Islamic jurisprudential literature is based on the assumption that the umma is (or should be) a unitary political community as well as religious, governed by a single Islamic government (Donner 1991: 51). Muslim jurists regarded jihad as the means for establishing God's political supremacy, which is a necessary component of the supreme authority of God's

\footnotetext{
${ }^{30}$ The same argument could be made for subjecting those suited for subjection and punishing a crime.
} 
word (Khadduri 1955: 59-60; Ghunaimi 1968: 137). Jihad was not merely the extension of the abode of Islam, but also the enforcement of politico-religious authority. ${ }^{31}$

Such enforcement began with preserving faith and loyalty to the Caliph. The scriptural basis for this practice is Q. 5:33, which prescribes punishments for those who wage war against God and his Messenger; Kelsay (2007: 120) interprets this passage as a call to secure Islam from apostates and rebels. When Muhammad died in $632 \mathrm{CE}$, several Arab tribes claimed that their oaths of allegiance were annulled-and hence also their tithe obligation. Most Arabs outside Hijaz broke from the central leadership and began to follow local prophets. Muhammad's successor, Abu Bakr, declared war against these "apostates" and embarked on military campaigns against these false/fake prophets (the Riddah Wars, 632-633 CE). Although some tribes continued to profess their beliefs in God and Muhammad's prophethood and claimed to be seeking only political separation rather than religious, Abu Bakr rejected their positions, claiming that "wherever the

${ }^{31}$ Steven Fish (2002) shows a statistical correlation between predominantly Muslim populations and more autocratic Polity and Freedom House scores of states. Fish attributes the effects to reduced economic development (which in his design, negates the statistical significance of Islam), and to the subordination of women, rather than Islam. However, several weaknesses seriously undermine his claim that factors other than Islam are the root causes of autocracy. First, by his own admission, the subordination of women is strong in other countries that are not Muslim, yet the effect of Islam when he controls for gender equality is only moderately reduced (while still statistically significant), not negated entirely. Second, his evidence for ruling out religiosity as a factor is anecdotal and no longer convincing, given that religious regime preferences are now measurable. Third, although this study does not consistently control for economic development, it does control for other factors that I have shown are strongly correlated with economic development, and the effect of Islam is still statistically significant (in some models) nevertheless. Finally, Fish's study covers only the 1990s, whereas my study covers a half-century. 
religious leadership is admitted its corollary is political leadership" (Ghunaimi 1968: 63). The central authorities' position was that those tribes had pledged themselves to the immortal community of God, thus retracting that pledge was a sin against God (Aslan 2005: 118-9). Although the Riddah Wars were more political in character than religious, claims Aslan, they did have the "regrettable consequence" of associating religious apostasy/disunity with political treason. The environment appears to have been not unlike those of Spanish Inquisition and the Reformation/Counter-Reformation.

Jihad may also serve as a cover for nationalist fervor. The "starting point" of Caliph Umar's political strategy, as Ghunaimi (1968: 43) puts it, was that Islam should be the only religion tolerated in Arabia. Since political authority could not be completely dissociated from religious (Ayoob 2008: 14), the propagation and enforcement of Islam through jihad served as the basis for Umar's claim to rule the whole of Arabia. Even if the practice of the Islamic state under Muhammad were geared toward simply unifying the Arabs rather than eradicating non-Islam, as Ghunaimi (1968: 180-3) claims, the practice of the Islamic state under Umar was geared toward both—starting with the deportation of non-Muslims from Hijaz entirely (id. 64). But the nationalist fervor could be specifically Arab as well; Fareed Zakaria (2003: 131), Irshad Manji (2005: 143), and Fouad Ajami (2006) all advance the claim that Islamic militarism is really a religious veneer for Arab militarism. This prospect will be taken up again in the conclusion of this section, as well as the second section of Chapter 8 (pertaining to Anwar Sadat).। 
The Religion of the Other

The position of jihad as the means to enforce politico-religious authority, and as a cover for militant nationalism, might serve as a basis for explaining the anomaly of armed conflicts between Muslim states. Because a fundamental goal of Islam is to unify the world under the Pax Islamica, one should expect little intra-Muslim conflict. However, as will be shown in the section on empirical results, more targets of Muslim states (from 1946 through 2001) were Muslim than of any other religious category. Daniel Pipes (1983: 51) goes as far as arguing that since the demise of the unitary Muslim caliphate in 753 and emergence of independent Muslim states, most Muslim wars in history have been against other Muslims. That claim is not supported empirically in this study; despite Islam being the most frequent religion of targets of Muslim states, non-Muslim targets still outnumber Muslim targets. However, the percentage of Muslim targets is significant enough to warrant examination as to why this might be the case, especially given that the Quran and hadith appear to forbid war among Muslims. One possible explanation is that Muslim states are manipulating religion to serve their political ends (the reverse of the causality that is central to the focus of this study) — state leaders attempt to wield religion as an instrument to legitimize their leadership. Islamdom has been disunited since the Sunni-Shiite split after the death of Muhammad, and especially after the displacement of the single (Umayyad) caliphate in $750 \mathrm{CE}$ in favor of the rival Abbasid dynasty. With no single religious figure to unambiguously legitimize war, Muslim rulers wielded religious and religiously sanctioned titles and institutions, including the waging of jihad, in order to proffer evidence of the legitimacy of their claim to rule the whole of Islamdom. Monica Duffy Toft (2007: 103) proposed this as the 
principal cause of religious civil wars undertaken by Muslims today: "religious outbidding," in which political elites attempt to outdo each other in order to enhance their religious credentials and thereby gain the support they need to counter an immediate threat. Such "outbidding" is currently taking place in several Arab countries in the wake of the Arab Spring, with the fracturing of religious parties into factions that claim to be more Islamic than the others (Shadid \& Kirkpatrick 2011). However, Toft's findings are limited to civil conflict, and for inter-state conflicts I will argue later in this chapter that intra-Muslim armed conflicts appear to be largely attributable to proximity. When that factor is controlled for, Muslim states actually have a statistically lower propensity to use force against other Muslim states.

In comparison, Islamic thought is rather antipathetic toward non-Islam. Islam's treatment of polytheism and paganism has already been mentioned, but other monotheistic religions are also disfavored in Islamic scripture, especially Judaism and Christianity. In Muslim eyes, Jews and Christians have fallen away from the right path, as set by Abraham, whom Muslims regard as the original Muslim. In addition, Islam views the Christian practice of worshipping a triune god (God the Father, Son, and Holy Spirit) as a form of polytheism in disguise. Chapter 2 of the Quran contains numerous obloquies against the Jews and Christians on these grounds. ${ }^{32}$

The scriptural basis for actually fighting Jews and Christians is in Q. 9:29. Muslims are to fight against those who do not believe in God or the Last Day, who do not forbid

\footnotetext{
${ }^{32}$ Jews and Christians are banned from worshipped at the Kaaba as well (Q. 9:28), because their disbelief in the message of Muhammad makes them najasun (impure), just as other mushrikun (polytheists, pagans, idolaters, etc.) are (see esp. Hilali \& Khan translation).
} 
what God and (or through) his messenger Muhammad have forbidden, who have not performed dana (the meaning of which will be discussed shortly), and until they pay the jizya (tax) submissively. Beyond this paraphrasing, the translations are sufficiently varied as to engender questions. One question is what the Arabic word dana is intended to convey. In order to be spared, according to most translations, one must follow, or embrace or acknowledge, the "religion of truth" (which to Muslims, naturally is Islam). The Haleem translation, in contrast, reads "obey the rule of justice," which Haleem (9:29, note $b$ ) claims is a reference to breaking the jizya contract. The second question is whether only one of the criteria above must be satisfied to make a person the object of hostility, or all of them. The third question is whether those four criteria are intended to demarcate one subset of Jews and Christians ("the People of the Book who have committed those offenses") or articulate a justification for fighting all of them ("the People of the Book, who have committed those offenses"). None of the translations are clear on these points, but it would seem highly unlikely that any Jews or Christians could fulfill the third and fourth criteria-forbidding what Muhammad forbids, and embracing the religion of truth, which is Islam-without sacrificing their own religious identities, i.e. capitulating to the very demand that would motivate them to defend themselves against Islam. The plain meaning of Q. 9:29 must be to legitimize war against Christians and Jews in order to secure their submission to Muslim authority and payment of the poll tax; no other interpretation makes sense.

As noted earlier, the nature of the Islamic war ethic as it relates to Christianity and Judaism today is further rooted in Islamic historical tradition. A prominent part of the historical narrative is the "steady deterioration" of relations between the early Muslims in 
Medina and the Jewish tribes there (Kelsay 2007: 25). Islamic history chronicles a series of battles by Muhammad and his early followers for the defense of Medina against the Quraysh (the tribe that dominated Mecca). Several Medinan clans that were Jewish were suspected of clandestinely supporting the Quraysh. One Jewish clan opposed Muhammad openly, and Muhammad's heretofore lenient sentencing of his political opponents to exile rather than the traditional mass execution or enslavement came to an end (Aslan 2005: 89-94). ${ }^{33}$ Accounts of the Jewish tribes in Arabia in sources of Islamic tradition tend to contain rather incendiary language when referring to the Jews, e.g. "noxious" and "hypocrites" (e.g. Subhani n.d.: chap. 43).

In the case of the Christians, several sources trace the origin of Islamic antipathy to the murder of Muhammad's ambassador to the Byzantines (Ghunaimi 1968: 70-2; Watt 1962: 43-4, 108, 345; Ali 1967: 90-1). According to tradition, Muhammad sent Dihyah ibn Khalifah al-Kalbi on a mission to "Caesar" (the Byzantine Emperor), calling on him to accept Islam, and Emperor Heraclius was deeply impressed. On his return journey, the ambassador was carrying Byzantine gifts when he was plundered by the Banu Judham, a tribe in southern Syria. In another account, Muhammad sent an ambassador to the Ghassanid prince at Busra, who was an Arab feudatory of the Byzantine Emperor. The ambassador was "cruelly murdered" by another chief of the same family. Muhammad responded by sending a punitive expedition. This vignette forms the basis of Ghunaimi's (1968: 70-1) claim that the Byzantines are responsible for inaugurating the belligerent

\footnotetext{
${ }^{33}$ Aslan attributes Muhammad's treatment of the Jewish clan as a political event, not motivated by hatred of Judaism, and further notes than Jews were not expelled from Medina until the end of the $7^{\text {th }}$ century CE under Caliph Umar, as part of a larger campaign to Islamicize Arabia.
} 
relationship between Islam and Christianity; Syed Ameer Ali (1967: 90-1) calls the "wanton outrage" the casus belli of Islam against Christendom. Whether these claims are justified or not (and I would argue that they are not ${ }^{34}$ ), the hostility of Ali and other Muslim authors toward non-Islam has roots in Islamic historical tradition as well as scripture.

\section{$\underline{\text { Other Factors }}$}

Several additional factors, not necessarily rooted in religion, may add to the permissive nature of the Islamic war ethic. One may be the natural inability of a universal state to tolerate the existence of any other (Khadduri 1955: 17, 51). Such is the inevitable

\footnotetext{
${ }^{34}$ A closer examination of these accounts just mentioned seriously undermines the attribution of
} responsibility for the raid/murder to the Byzantines. The accounts indicate that the crimes against the ambassador(s) were committed by rogues, and there is no evidence that they were committed at the behest or even acquiescence of the political leadership of either the Byzantine Empire or its Ghassanid vassal. Furthermore, the Ghassanids were Arabs, and Muhammad was already on a quest to unify the Arabs under the Islamic banner, therefore he eventually would have attacked the Byzantine Empire anyway, in order to wrest the Arab vassals from Byzantine control. It appears more likely that the early Muslims used the incident(s) as an excuse to enter into hostilities against Christendom in order to extend their territorial domain, and in doing so create conditions conducive to the further propagation of Islam. In addition, it is interesting to note that Montgomery Watt's (1962) rendition of the episode does not actually comport with the rendition that Ghunaimi attributes to Watt. Furthermore, Ali's work (1967: 218-9) reads as a general polemic on the virtues of Islam and the vices of the Christians and Jews; he singles out Christianity for atrocities such as the Inquisitions, burnings at the stake, and racially motivated lynchings in the United States, while accounts of atrocities by Muslims such as those of the Janissaries, the Armenian genocide, and stonings are conspicuously absent. 
consequence of one political entity claiming an entitlement to dominion over all others. A theory of a universal state recognizes no equal status for other parties; it follows that any law of nations espoused by that state would be predicated not on principles of mutual consent or reciprocity, but rather that state's own interpretation of its political, moral, and religious interests, as the state would regard its own principles as superior to any others. This was the case for the law of ancient Rome, and Muslim authors claim not unreasonably that it was the case for medieval Christendom also. It is also the case for the Muslim law of nations today (Khadduri 1955: 44-5).

A second factor may be the personal incentives of Muslim combatants to achieve martyrdom. The Afterlife offers permanent relief from the harsh realities of life in this world, especially for the pre-Islamic Arabs who lived in the desert and for whom warfare (along with the destruction and injustice that comes with it) was a way of life as natural for them as electoral politics is to us. In Islam, salvation is achieved through earthly works, and death in battle in the service of Islam is considered the surest path to the cleansing of sin and admission into heaven — all others must first face trial before being admitted (Khadduri 1955: 61-2; Cook 2005: 15). ${ }^{35}$ The heavenly rewards for martyrdom are lavish indeed (e.g. Q. 3:14-5; 158, 169-71; see Kelsay 2007: 26; Tibi 1996: 138), especially the sexual pleasures for men, which are described graphically in some hadith literature (Cook 2005: 27-8). ${ }^{36}$ Although there is a biological component to incentives

${ }^{35}$ Cook cites Abdallah bin al-Mubarak, Kitab al-Jihad, an $8^{\text {th }}$ century CE collection of hadith; this work was unavailable to this author.

${ }^{36}$ Brad Thayer and Valerie Hudson (2010) attribute the appeal of suicide terrorism among young Muslim men in part to circumstances that diminish their likelihood of procreating, such as inability to afford to support a wife let alone the traditionally lavish wedding, and in part to a culture of polygyny that reduces 
such as these to participate in jihad, the existence of such incentives at all is rooted in Islamic scripture and priestly writings.

A third factor may be the influence of pre-Islamic and non-Islamic cultures and norms on the development of Islam. It may be significant to the development of the Islamic war ethic that Islam emerged among the Arabs, whom Khadduri, Ghunaimi, Donner, Sachedina, and Bruce Lawrence (1991) all characterize as already a warlike culture. For example, in the harsh climate in which the Arabs lived, caravan raids were considered a legitimate means of wealth-acquisition in pre-Islamic Arabia (provided that no blood was spilled). In the earliest period of Islam, before Muhammad's return to Mecca, Muhammad organized caravan raids and even participated in them, in order to provide much needed funds, garner attention to the movement, and divert wealth away from his Meccan enemies and toward his Medinan friends (Aslan 2005: 82). The doctrine of jihad, writes Khadduri, was not meant to pacify the constantly warring Arab tribes, but rather to channel their warlike nature into building a unified, stronger state (1955: 62). ${ }^{37}$ Islamic theorists such as the $14^{\text {th }}$ century CE historian Ibn Khaldun, who is hailed as the Thucydides of Islam, perceived warfare as intrinsic to history, and never advocated that human beings should expect that warfare cease (see Hashmi 1996: 148). In his and others' views, the problematique of warfare was not whether to fight (non-Muslims), but simply how best to fight (Lawrence 1991: 144).

the number of available women. I suggest, however, that in a society in which young men are often sexually repressed, the male sex drive, acting independently of the urge to procreate, is the stronger motivator.

${ }^{37}$ See also Ghunaimi 1968: 137, on outlawing all other war between Arab tribes in favor of the jihad. 
Several authors have also advanced the proposition that the doctrine of jihad against non-Muslims was socialized into the Islamic state by the war ethics of the empires that surrounded it. Arabia was "sandwiched" (Ghunaimi's word) between the Byzantine and (pre-Islamic) Persian empires; Islamdom emerged in a geopolitical environment of protectorates and suzerains (Ghunaimi 1968: 10). Reza Aslan and Thomas Sizgorich thus argue that the Muslims simply were imitating the behavior of the other grand empires. Aslan (2005: 79-80) goes as far as to claim that it is Western aggression that has made Muslim militants what they are today. Sizgorich (2009: 902-3) makes much of the holy war sentiments of the Byzantines:

When the Muslim armies appeared to claim what was theirs by God's decree, ... they encountered in the Christian Romans [the Byzantines] an empire that was long accustomed to doing the Lord's work with the sword. This, at least, is the contention of most of our early Muslim sources. ... [T] he taking up of the sword against the enemies of God was a practice shared in common between Christian Rome and nascent Islam. Indeed, these [early Muslim] narratives insisted that the sanctified violence undertaken by Heraclius in his wars with the Persians precisely mirrored the holy war waged by Muhammad and his followers against the powerful tribal confederation of Quraysh [the Meccan tribe that persecuted Muhammad], and that the struggle waged in Arabia against unbelief and that waged between Romans and Persians were in fact near duplicates for one another, differentiated only in scale. 
Such arguments, while compelling, do not withstand closer scrutiny. For starters, the jihad against disbelief began as a movement to unify Arabia in religious purity, not to balance against powerful and threatening neighbors. This, in fact, was Muhammad's original calling (Kelsay 2007: 26-7). Secondly, the holy war ethic in Christianity, while prominent during the Crusades, had not yet developed at the time of early Islamic territorial expansion. Third, the Crusades themselves were a Western response to the long history of incursions into Christendom by the Muslims, both in the Byzantine Empire and in Italy. A few specific assertions of Aslan's undermine his argument: First, Aslan is trying to compare the behavior of the Muslims to that of the other theocratic kingdoms around them, but for him to cast the Byzantine Empire as a theocracy is as much a stretch as it would be to cast Saudi Arabia, also a highly religious state, as a theocracy today. Second, in attempting to explain the West's "aggression" against Muslims in the Middle Ages, Aslan claims that the Holy Roman Empire was fractured and that it needed to distinguish itself from the Turks, "who were strangling it from all sides" (2005: 79; emphasis added), yet he has nothing to say to justify why the Turks were doing so. Sizgorich's (2009) claim that early Islamic conquests were socialized by the Byzantines may be somewhat better founded, but still does not withstand closer scrutiny. Although it is true that the Byzantine Emperor Heraclius was religious, and it is also true that Heraclius embarked on many military campaigns, the Byzantine war against the Sassanid Persians had little to do with religion. Heraclius inherited that war, which was the last in a cycle of wars and accords - a cycle begun by the Persians. The Byzantines' immediate motivation for that war was self-defense, and restoration of the status quo ante (including the restoration of Christian relics which the Persians had appropriated). Their 
larger, geopolitical motivation was, of course, the acquisition of power in order to safeguard their security from outside invaders, as was the desire of every state during that period (and according to Realists, still is today). If any war ethic was socialized to the Muslims by the Byzantines and Sassanid Persians, it was that of realism, not holy war. Furthermore, in contrast to the gory depiction of Heraclius's campaigns by Sizgorich (2009: 904-5), Islamic tradition frequently (albeit not consistently) views Heraclius favorably (i.e. receptive to Islam). The early Muslims may have been projecting their own war ethic on Heraclius_-viewing the policies of Heraclius through the lens of their own favorable disposition toward holy war. Sizgorich anticipates this counter-argument, and offers evidence of its fallacy in the form of several contemporaneous Christian works that praised militant piety. He cites three works: one by an unnamed Syriac apologist of the late $8^{\text {th }}$ or early $9^{\text {th }}$ century CE, who praises Muhammad for his willingness to use violence in the service of the one God of Abraham; one by Ambrose of Milan, circa $4^{\text {th }}$ century CE, recalling the recently deceased Emperor Theodosius I of Rome as an “implacable enemy of idolatry and idolaters"; and one by the $10^{\text {th }}$-century CE Eutychios, Bishop of Alexandria, which contains a portrait of Heraclius as ferociously militant. The problem with Sizgorich's evidence is that he cites works that are obscure, especially when compared to the foundational works of the Christian just war ethic by Augustine and Thomas Aquinas. For the above reasons, the claim that the permissive Islamic war ethic is the product of socialization is not persuasive. 


\section{$\underline{\text { Conclusion }}$}

The war ethic described above is evident in public opinion in the Islamic world today. In a survey of Lebanese Muslims conducted after the 9/11 attacks, over one-third of the respondents identified themselves as "radical" to some degree, with $15 \%$ identifying themselves as "highly radical" (Haddad \& Khashan 2002: 820). A "sweeping majority" felt that Arab grievances against the United States warranted the attack, 30\% said they actually supported the attacks, and more than one-third supported a follow-up attack with weapons of mass destruction. Nearly half of the respondents either strongly or moderately approved of the attacks (id. 821). In a series of related studies, Peter Furia and Russell Lucas $(2006,2008)$ examine the causes of unfavorable Arab public opinion toward the United States. They argue that Arab publics approve and disapprove of other states on the bases of their foreign policy behaviors in the Middle East, rather than by virtue of those other states being Muslim, non-Muslim, or non-Arab. While their empirical findings do seem to support Arab disapproval of the U.S. in particular as partly generated by its Israel and Iraq policies (2006: 596; 2008: 195-8), along with Arab disapproval of Turkey (a fellow Muslim state) for largely the same reasons (2006: 599), Furia \& Lucas overstate their findings on the effect of foreign policies and understate or neglect the effects of respondents' own Arab identities. Their study showed that respondents with predominant “Arab consciousnesses" were significantly less likely to approve of several Western countries (France being the notable exception). They did find a specifically "Islamic" consciousness usually to have no statistically significant effect. However, the Arab nation as a whole is overwhelmingly Muslim, the claim of brotherhood within the umma resonates strongly, and Arab nationalism historically has been fueled by Islam. Given 
these factors, Furia and Lucas's claim that Islam does not engender hostility toward the West is weakened and therefore not as convincing as it might have been otherwise. ${ }^{38}$

I therefore argue that the Islamic war ethic is more permissive where states of other religions are concerned, and the primary cause for this is a latent Islamic antipathy toward non-Islam, or at least a sense of political superiority, privilege, or entitlement over the same. The causes for this antipathy are rooted in Islamic scripture (the Quran), the body of classical Islamic literature, and the Islamic historical narrative. Compared to secular jus ad bellum, the Islamic war ethic is considerably more permissive, for jus ad bellum makes no provision for using force in order to achieve Islamic political supremacy or sovereignty over non-Muslims. The empirical results below would seem to support these assessments, for the probability of a Muslim state using force (in violation of jus ad bellum) is high compared to those of states of other religions, and Muslim states are statistically more likely to use force than non-Muslim states.

\section{Empirical Testing of Islam}

As with the previous chapter, we begin the empirical analysis with a survey of the Muslim states. Table 6-1 lists all the states that have had a Muslim chief executive, Muslim Preference, or Muslim Prevalence (all branches combined), along with the

\footnotetext{
${ }^{38}$ Mark Tessler and Michael Robbins (2007) make a similar claim: that among Muslims in Algeria and Jordan, a negative assessment of U.S. foreign policy is correlated with support for terrorism, whereas higher religious involvement and higher support for political Islam are not. Their implication that Islam is not a factor in generating preferences for war, is similarly not persuasive, for Islam is a strong factor in those negative assessments of U.S. foreign policy.
} 
number of interstate armed conflicts they initiated (if any) at the lowest threshold (cwhiact=12) and at the highest (cwfatal=1), while they were Muslim.

Table 6-1. List of Muslim (All) States, with Number of Armed Conflicts Initiated at Lowest Threshold (Model 1) and Highest Threshold (Model 5).

\begin{tabular}{|c|c|c|c|c|c|c|c|c|c|c|c|}
\hline State & Chief & Pref. & Prev. & $\underline{\text { Init'd }}$ & Fatal & $\underline{\text { State }}$ & Chief & Pref. & Prev. & $\underline{\text { Init'd }}$ & Fatal \\
\hline Afghanistan & * & * & * & 25 & 4 & Malaysia & * & * & & 3 & -- \\
\hline Albania & * & * & * & 11 & 6 & Maldives & * & * & * & -- & -- \\
\hline Algeria & * & * & * & 1 & -- & Mali & * & * & * & 4 & 3 \\
\hline Azerbaijan & * & * & * & 2 & -- & Mauritania & * & * & * & 2 & -- \\
\hline Bahrain & * & * & * & -- & -- & Morocco & * & * & * & 14 & 3 \\
\hline Bangladesh & * & * & * & 2 & 1 & Niger & & * & * & 1 & 1 \\
\hline Bosnia \& Herz. & * & & & -- & -- & Nigeria & * & & & 2 & 1 \\
\hline Brunei & * & * & * & -- & -- & Oman & * & * & * & -- & -- \\
\hline Burkina Faso & * & * & & -- & -- & Pakistan & * & * & * & 30 & 21 \\
\hline Cameroon & * & & & 1 & -- & Qatar & * & * & * & 1 & -- \\
\hline Chad & * & * & & 3 & 2 & Saudi Arabia & * & * & * & 20 & 6 \\
\hline Comoros Is. & * & * & * & -- & -- & Senegal & * & * & * & 6 & 3 \\
\hline Djibouti & * & * & * & -- & -- & Sierra Leone & * & * & & 2 & -- \\
\hline Egypt & * & * & * & 38 & 16 & Somalia & * & * & * & 17 & 10 \\
\hline Gabon & * & & & -- & -- & Sudan & * & * & * & 10 & 2 \\
\hline Gambia & * & * & * & -- & -- & Syria & * & * & * & 54 & 29 \\
\hline Guinea & * & * & * & 9 & 3 & Tajikistan & * & * & * & 2 & 2 \\
\hline Indonesia & * & * & * & 15 & 7 & Tunisia & * & * & * & 1 & 1 \\
\hline Iran & * & * & * & 57 & 10 & Turkey & * & * & * & 49 & 25 \\
\hline Iraq & * & * & * & 66 & 38 & Turkmenistan & * & * & * & -- & 1 \\
\hline Jordan & * & * & * & 15 & 22 & United Arab Em. & 1. * & * & * & -- & -- \\
\hline Kazakhstan & * & & * & -- & -- & Uzbekistan & * & * & * & 3 & 2 \\
\hline Kuwait & * & * & * & 2 & -- & Yemen & * & * & * & -- & -- \\
\hline Kyrgyzstan & * & * & * & -- & -- & Yemen, North & * & & * & 11 & 1 \\
\hline Lebanon & & & * & -- & -- & Yemen, South & * & & * & 8 & 1 \\
\hline Liberia & * & & & -- & -- & Yugoslavia & * & & & -- & -- \\
\hline Libya & * & * & * & 25 & -- & Zanzibar & * & & * & -- & -- \\
\hline Malawi & * & & & -- & -- & & & & & & \\
\hline
\end{tabular}

A precursory examination of the table above suggests that Muslim states initiate many more armed conflicts than Christian states. The following table, reproduced from Chapter 4, summarizes the coefficients associated with each measurement of Islam. 
Table 6-2. Summary of Logit Coefficients for Muslim (All) States.

\begin{tabular}{lcccccc} 
Variable & Model 1 & Model 2 & Model 3 & Model 4 & Model 5 & App. \\
\hline & (Robust SE) & & & & & \\
Muslim (all) & .0564 & .0534 & $.2222^{*}$ & $.2373^{*}$ & $.5767^{* *}$ & B-36 \\
Chief Exec. (binary) & $(.0972)$ & $(.1001)$ & $(.1051)$ & $(.1094)$ & $(.1774)$ & \\
Muslim (all) & .0167 & .0120 & $.1862^{\circ}$ & $.1990^{\circ}$ & $.5423^{* *}$ & B-37 \\
Preference (binary) & $(.0992)$ & $(.1022)$ & $(.1070)$ & $(.1112)$ & $(.1759)$ & \\
Muslim (all) & .0100 & .0103 & $.0318^{*}$ & $.0344^{*}$ & $.0632^{* *}$ & B-38 \\
GRP (every 10\%) & $(.0134)$ & $(.0138)$ & $(.0142)$ & $(.0147)$ & $(.0222)$ & \\
Muslim (all) & .0738 & .0625 & $.2540^{*}$ & $.2593^{*}$ & $.5368^{* *}$ & B-39 \\
Prevalence (binary) & $(.0993)$ & $(.1022)$ & $(.1067)$ & $(.1108)$ & $(.1782)$ & \\
Muslim (all) & .0142 & .0127 & $.0346^{* *}$ & $.0349^{* *}$ & $.0696^{* * *}$ & B-40 \\
Pop. (every 10\%) & $(.0115)$ & $(.0119)$ & $(.0125)$ & $(.0130)$ & $(.0206)$ & \\
\hline
\end{tabular}

${ }^{\circ} \mathrm{p}<.10 \quad{ }^{*} \mathrm{p}<.05 \quad{ }^{* *} \mathrm{p}<.01{ }^{* * *} \mathrm{p}<.001$

This table yields several significant findings. First, generally speaking, a Muslim state has a higher propensity than a non-Muslim state to initiate an armed conflict against any state, regardless of that state's religion, and the more homogenously Muslim the state's population or the stronger the government's Preference for Islam, the higher that propensity. This finding stands in contrast to that of the previous chapter, in which a Christian state generally has a lower propensity than a non-Christian state. The second significant finding is that none of the coefficients are statistically significant in the lower thresholds of force necessary to code an act as an initiation of an "armed conflict." From this finding we may conclude that despite the positive coefficients, Islam has no significant effect on a state's propensity to initiate low-level armed conflicts.

We may also conclude, however, that Islam does have a significant effect on a state's propensity to use higher degrees of force, with its strongest effect on the propensity to initiate deadly conflicts. The effects of a Muslim Prevalence are stronger than those of Preference and chief executive in the middle thresholds, but at the highest threshold 
(armed conflict with fatalities) the effect of a Muslim chief executive is the strongest, with Muslim regime Preference and population Prevalence being about the same. This finding suggests that when a Muslim state has a choice between committing a "threat" of force, "show" of force, or "use" of force, it is significantly more likely than a nonMuslim state to use force. This trend may be a reflection of the teleology of jihad: its purpose is not to make an injured party whole and restore the status quo ante, but to extend Islamic dominion over non-Islamdom. Islamic jus ad bellum favors conquest and absorption of the enemy over restorative justice.

Further empirical analysis may be conducted on Sunni Islam specifically. Table 6-3 is a list of Sunni Muslim states and the number of armed conflicts initiated by them. From 1946 to 2001, Sunni states initiated 211 armed conflicts with fatalities, as opposed to 221 for Muslim states overall. The large majority of Muslim states are Sunni Muslim, just as the large majority of Muslim people of Sunni, so this finding suggests that Sunni Islam is the primary driver of Islamic state practice overall (i.e., no other hyper-militant branch is skewing the results for Islam overall). 
Table 6-3. List of Sunni Muslim States, with Number of Armed Conflicts Initiated at Lowest Threshold (Model 1) and Highest Threshold (Model 5).

\begin{tabular}{|c|c|c|c|c|c|c|c|c|c|c|c|}
\hline State & $\underline{\text { Chief }}$ & Pref. & Prev. & Init'd & Fatal & $\underline{\text { State }}$ & Chief & Pref. & Prev. & Init'd & Fatal \\
\hline Afghanistan & * & * & * & 25 & 4 & Maldives & * & * & * & -- & -- \\
\hline Albania & * & * & * & 11 & 6 & Mali & * & * & * & 4 & 3 \\
\hline Algeria & * & * & * & 1 & -- & Mauritania & * & * & * & 2 & -- \\
\hline Bahrain & * & * & * & -- & -- & Morocco & * & * & * & 14 & 3 \\
\hline Bangladesh & * & * & * & 2 & 1 & Niger & & * & * & 1 & 1 \\
\hline Bosnia \& Herz. & * & & & -- & -- & Nigeria & * & & & 2 & 1 \\
\hline Brunei & * & * & * & -- & -- & Oman & & * & & -- & -- \\
\hline Burkina Faso & * & * & & -- & -- & Pakistan & * & * & * & 30 & 21 \\
\hline Cameroon & * & & & 1 & -- & Qatar & * & * & * & 1 & -- \\
\hline Chad & * & * & & 3 & 2 & Saudi Arabia & * & * & * & 20 & 6 \\
\hline Comoros Is. & * & * & * & -- & -- & Senegal & * & & & 4 & 3 \\
\hline Djibouti & * & * & * & -- & -- & Sierra Leone & * & * & & 2 & -- \\
\hline Egypt & * & * & * & 38 & 16 & Somalia & * & * & * & 17 & 10 \\
\hline Gabon & * & & & -- & -- & Sudan & * & * & * & 10 & 2 \\
\hline Gambia & * & * & * & -- & -- & Syria & * & * & * & 54 & 29 \\
\hline Guinea & * & * & * & 9 & 3 & Tajikistan & * & * & * & 2 & 2 \\
\hline Indonesia & * & * & * & 15 & 7 & Tunisia & * & * & * & 1 & 1 \\
\hline Iraq & * & * & & 66 & 38 & Turkey & * & * & * & 49 & 25 \\
\hline Jordan & * & * & * & 15 & 22 & Turkmenistan & * & * & * & -- & 1 \\
\hline Kazakhstan & * & & * & -- & -- & United Arab Em. & * & * & * & -- & -- \\
\hline Kuwait & * & * & * & 2 & -- & Uzbekistan & * & * & * & 3 & 2 \\
\hline Kyrgyzstan & * & * & * & -- & -- & Yemen & & * & * & -- & -- \\
\hline Libya & * & * & * & 25 & -- & Yemen, South & * & & * & 8 & 1 \\
\hline Malawi & * & & & -- & -- & Yugoslavia & * & & & -- & -- \\
\hline Malaysia & * & * & & 3 & -- & Zanzibar & & & * & -- & -- \\
\hline
\end{tabular}

Table 6-4 summarizes the coefficients associated with Sunni Islam, compared with those for Muslim states overall. A Sunni regime Preference has a slightly stronger effect than a Muslim regime Preference overall, and a state with a Sunni chief executive is substantially more likely to initiate a deadly armed conflict than a chief executive of any branch of Islam. On the other hand, a Sunni Muslim population has a substantially weaker effect than a Muslim population overall. The reason for this is presently unclear. 
Table 6-4. Summary of Logit Coefficients for Muslim (All) States, Compared to Logit Coefficients for Sunni Muslim States.

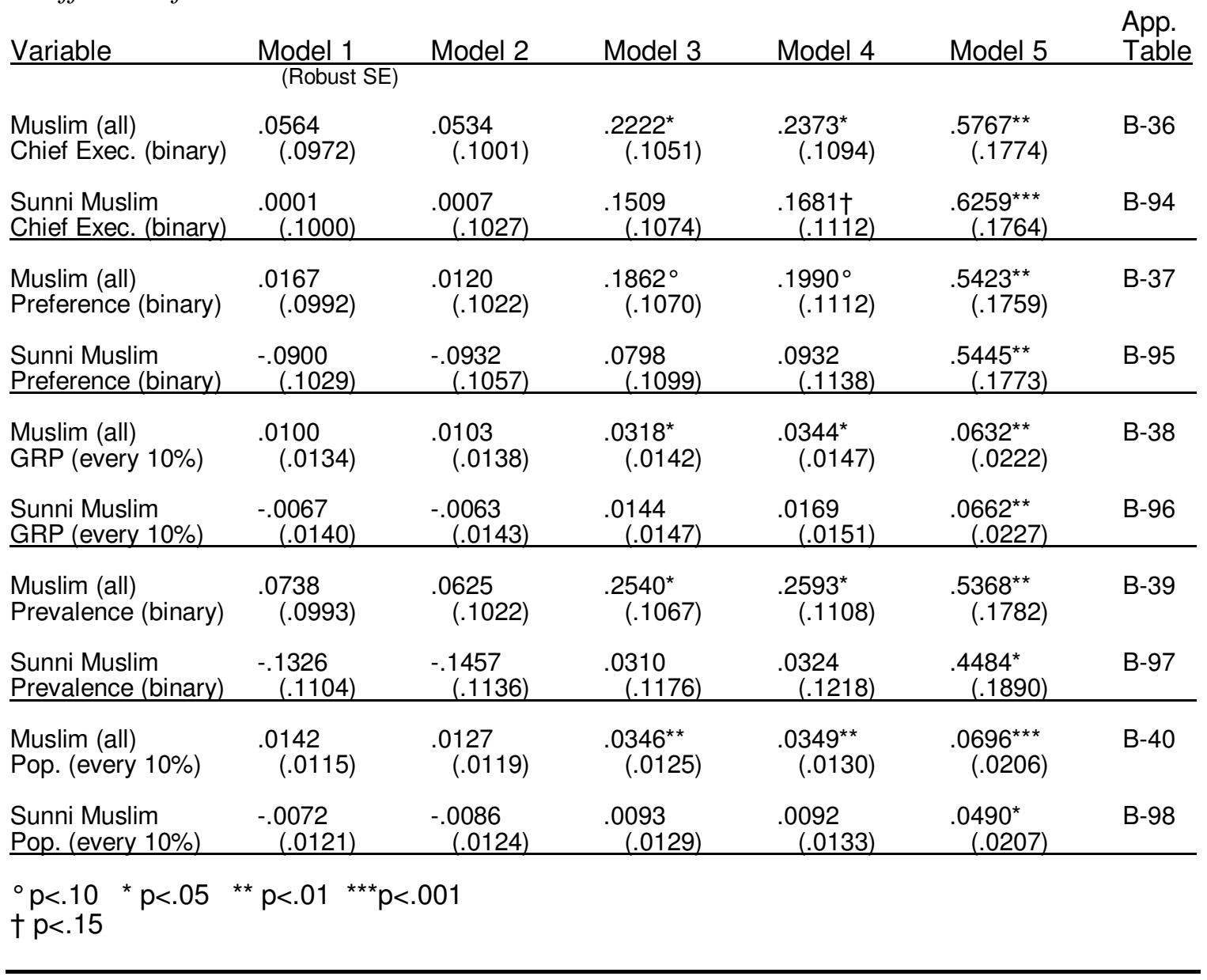

As the permissiveness of the Islamic war ethic is the result of a latent antipathy toward non-Islam, the remainder of this section will be devoted to the propensities of Muslim states to initiate armed conflicts based on the religious identity of the target state. Table 6-5 lists the targets of all armed conflicts initiated by Muslim states from 1946 through 2001, and the number of armed conflicts in which each state was the target. 
Table 6-5. List of Targets of Muslim States, with Number of Armed Conflicts Initiated Against Them at Lowest Threshold (Model 1) and Highest Threshold (Model 5).

\begin{tabular}{|c|c|c|c|c|c|c|c|c|c|}
\hline State & Muslim & Non-Musl. & Low & Fatal & $\underline{\text { State }}$ & Muslim & Non-Musl. & Low & Fatal \\
\hline Afghanistan & * & & 5 & 5 & Liberia & & * & 4 & 2 \\
\hline Algeria & * & & 3 & 3 & Libya & * & & 3 & 1 \\
\hline Armenia & & * & 2 & 1 & Macedonia & & * & 2 & 1 \\
\hline Australia & & * & 3 & 3 & Malaysia & * & & 3 & 1 \\
\hline Azerbaijan & * & & 1 & -- & Mali & * & & 2 & 1 \\
\hline Bahrain & * & & 5 & 1 & Mauritania & * & & 4 & 2 \\
\hline Bulgaria & & * & 2 & -- & Morocco & * & & 1 & -- \\
\hline Burkina Faso & * & & 4 & 3 & Myanmar & & * & 1 & -- \\
\hline Cameroon & * & & 1 & 1 & Niger & * & & 1 & 1 \\
\hline Chad & * & & 10 & -- & Nigeria & * & & 1 & 1 \\
\hline Cote d'Ivoire & & * & 3 & 1 & Oman & * & & 5 & -- \\
\hline Cyprus & & * & 13 & 10 & Pakistan & * & & 17 & 2 \\
\hline Djibouti & * & & 1 & -- & Papua New G. & & * & 4 & -- \\
\hline Egypt & * & & 14 & 3 & Philippines & & * & 2 & -- \\
\hline Ethiopia & & * & 11 & 8 & Qatar & * & & 4 & 1 \\
\hline France & & * & 14 & 6 & Russia & & * & 17 & 7 \\
\hline Gabon & * & & 1 & -- & Saudi Arabia & * & & 17 & 6 \\
\hline Gambia & * & & 2 & -- & Senegal & * & & 1 & -- \\
\hline Georgia & & * & 1 & -- & Sierra Leone & * & & 3 & -- \\
\hline Germany & & * & 1 & 1 & Singapore & & * & 1 & -- \\
\hline Great Britain & & * & 25 & 10 & Spain & & * & 9 & -- \\
\hline Greece & & * & 14 & 8 & Sudan & * & & 5 & 1 \\
\hline Guinea-Bissau & & * & 2 & 1 & Syria & * & & 7 & 6 \\
\hline India & & * & 31 & 22 & Tajikistan & * & & 1 & -- \\
\hline Iran & * & & 23 & 14 & Turkey & * & & 14 & 9 \\
\hline Iraq & * & & 30 & 8 & Uganda & & * & 6 & 2 \\
\hline Israel & & * & 65 & 37 & United Arab Em. & ${ }^{*}$ & & 3 & -- \\
\hline Italy & & * & 3 & -- & United States & & * & 24 & 8 \\
\hline Jordan & * & & 15 & 8 & Yemen & * & & 4 & 2 \\
\hline Kenya & & * & 5 & 1 & Yemen, North & * & & 5 & 1 \\
\hline Kuwait & * & & 19 & 6 & Yemen, South & * & & 4 & -- \\
\hline Kyrgyzstan & * & & 1 & -- & Yugoslavia & & * & 4 & 4 \\
\hline Lebanon & & * & 3 & 1 & & & & & \\
\hline
\end{tabular}

At the lowest threshold, $47 \%$ of the targets of Muslim states were other Muslim states and at the highest threshold, 39\% of them were other Muslim states. However, these statistics do not support a conclusion that Muslim states are equally prone to attacking Muslim states as non-Muslim states, for the results of Table 6-6 show otherwise.

Table 6-6 summarizes the logit coefficients for the effect of a state's religion on its propensity to become the target of a Muslim state. Each coefficient shows how much 
more or less likely a state is the object of attack by a Muslim state, if that state is Muslim as opposed to not Muslim, Judeo-Christian (i.e. Scriptuary) as opposed to not JudeoChristian, and Non-Scriptuary (any religion other than Jewish, Christian, or Islam) as opposed to not Non-Scriptuary.

Table 6-6. Summary of Logit Coefficients for Muslim (All), Judeo-Christian, and NonScriptuary States Being Targets of Muslim (All) States.

\begin{tabular}{|c|c|c|c|c|c|c|}
\hline Variable & Model 1 & Model 2 & Model 3 & Model 4 & Model 5 & $\begin{array}{l}\text { App. } \\
\text { Table }\end{array}$ \\
\hline Target Has: & (Robust SE) & & & & & \\
\hline $\begin{array}{l}\text { Muslim (all) } \\
\text { Chief Exec. (binary) }\end{array}$ & $\begin{array}{l}-.3386^{*} \\
(.1712)\end{array}$ & $\begin{array}{l}-.2760 \dagger \\
(.1752)\end{array}$ & $\begin{array}{r}-.2345 \dagger \dagger \\
(.1793)\end{array}$ & $\begin{array}{l}-.1623 \\
(.1843)\end{array}$ & $\begin{array}{r}-.2680 \\
(.2816)\end{array}$ & B-99 \\
\hline $\begin{array}{l}\text { Muslim (all) } \\
\text { Preference (binary) }\end{array}$ & $\begin{array}{r}-.4748^{\star *} \\
(.1789)\end{array}$ & $\begin{array}{l}-.3732^{*} \\
(.1848)\end{array}$ & $\begin{array}{l}-.3724^{*} \\
(.1868)\end{array}$ & $\begin{array}{r}-.2565 t \dagger \\
(.1939)\end{array}$ & $\begin{array}{l}-.1304 \\
\quad(.2932)\end{array}$ & B-104 \\
\hline $\begin{array}{l}\text { Muslim (all) } \\
\text { Prevalence (binary) }\end{array}$ & $\begin{array}{r}-.5055^{\star *} \\
(.1874) \\
\end{array}$ & $\begin{array}{r}-.4007^{*} \\
(.1925) \\
\end{array}$ & $\begin{array}{r}-.4064^{*} \\
(.1941) \\
\end{array}$ & $\begin{array}{r}-.2879+\uparrow \\
(.1999) \\
\end{array}$ & $\begin{array}{r}-.3631+\dagger \\
(.3096) \\
\end{array}$ & B-109 \\
\hline $\begin{array}{l}\text { Judeo-Christian } \\
\text { Chief Exec. (binary) }\end{array}$ & $\begin{array}{l}.4877^{* *} \\
(.1618)\end{array}$ & $\begin{aligned} .4493^{\star *} \\
(.1666)\end{aligned}$ & $\begin{array}{c}.3560^{*} \\
(.1729)\end{array}$ & $\begin{array}{c}.3073^{\circ} \\
(.1792)\end{array}$ & $\begin{array}{c}.2382 \\
(.2698)\end{array}$ & B-100 \\
\hline $\begin{array}{l}\text { Judeo-Christian } \\
\text { Preference (binary) }\end{array}$ & $\begin{array}{r}.7474^{\star \star \star} \\
(.1799)\end{array}$ & $\begin{array}{r}.6595^{\star \star \star} \\
(.1865)\end{array}$ & $\begin{array}{r}.6406^{\star \star *} \\
(.1914)\end{array}$ & $\begin{array}{l}.5372^{\star \star} \\
(.1996)\end{array}$ & $\begin{array}{r}.3941 \mathrm{t \dagger} \\
(.2921)\end{array}$ & B-105 \\
\hline $\begin{array}{l}\text { Judeo-Christian } \\
\text { Prevalence (binary) }\end{array}$ & $\begin{array}{r}.7874^{\star * *} \\
(.1939) \\
\end{array}$ & $\begin{array}{r}.7003^{\star \star \star} \\
(.1989) \\
\end{array}$ & $\begin{array}{r}.6039^{* *} \\
(.2006) \\
\end{array}$ & $\begin{array}{r}.4975^{\star} \\
(.2063) \\
\end{array}$ & $\begin{array}{c}.4736 \dagger \\
(.3134) \\
\end{array}$ & B-110 \\
\hline $\begin{array}{l}\text { Non-Scriptuary } \\
\text { Chief Exec. (binary) }\end{array}$ & $\begin{array}{l}-.4496 \dagger \\
(.3020)\end{array}$ & $\begin{array}{l}-.4928 \dagger \\
(.3138)\end{array}$ & $\begin{array}{l}-.3335 \\
(.3129)\end{array}$ & $\begin{array}{r}-.3737 \\
(.3261)\end{array}$ & $\begin{array}{l}.0116 \\
(.4060)\end{array}$ & B-103 \\
\hline $\begin{array}{l}\text { Non-Scriptuary } \\
\text { Preference (binary) }\end{array}$ & $\begin{array}{l}-.3920 \dagger \\
(.2852)\end{array}$ & $\begin{array}{r}-.4225 t \dagger \\
(.2969)\end{array}$ & $\begin{array}{r}-.3487 \dagger \dagger \\
(.2955)\end{array}$ & $\begin{array}{r}-.3786+\dagger \\
(.3086)\end{array}$ & $\begin{array}{l}-.3246 \\
(.4176)\end{array}$ & B-108 \\
\hline $\begin{array}{l}\text { Non-Scriptuary } \\
\text { Prevalence (binary) }\end{array}$ & $\begin{array}{c}-.4598 \dagger \\
(.2981) \\
\end{array}$ & $\begin{array}{c}-.4981 \dagger \\
(.3121) \\
\end{array}$ & $\begin{array}{r}-.3295 \\
(.2985) \\
\end{array}$ & $\begin{array}{r}-.3603 \dagger \dagger \\
(.3125) \\
\end{array}$ & $\begin{array}{r}-.0127 \\
(.3910) \\
\end{array}$ & B-113 \\
\hline
\end{tabular}

${ }^{\circ} p<.10 \quad{ }^{*} p<.05 \quad{ }^{* *} p<.01{ }^{* * *} p<.001$

$\dagger p<.15$ †† $p<.25$

These results show that, contrary to Daniel Pipes' assertion mentioned earlier, Muslim states are less likely than non-Muslim states to be attacked by other Muslim states. The coefficients associated with Muslim targets are uniformly negative, but only statistically significant at the lower thresholds of defining an armed conflict (though a Muslim Prevalence still has a negative effect with 75\% confidence). Although the largest 
category of targets of Muslim states consists of other Muslim states, what seems to be driving that statistic is proximity, for the effect of proximity is still relatively strong and significant (the actual coefficients are reproduced in Appendix B) and Muslim states are apparently committing fewer attacks on fellow Muslim states than would be expected given the proximity of many Muslim states to each other.

In contrast to the negative effect of Islam, the effect of a potential target being JudeoChristian (i.e. Scriptuary) is positive. The effect is statistically significant in all except the highest threshold of armed conflict, though again the effects of Preference and Prevalence are still positive with at least $75 \%$ certainty. This finding is consistent with the overall hypothesis that Muslim states are inherently hostile toward non-Muslim states. We shall delve more deeply into this finding momentarily.

One interesting finding is that Non-Scriptuary states are statistically no more or less likely (within the customary standards of confidence in the field) than Scriptuary states to be attacked by Muslim states. The coefficients are all negative, but they would be significant if the standard of confidence were relaxed. The findings suggest, albeit not conclusively, that Muslim states appear overall to be less hostile toward non-Scriptuary states today than in history. This finding is puzzling, for in the classical Islamic war ethic, pagans, polytheists, and other nonbelievers received the harshest treatment. This puzzle will be taken up again momentarily.

It is further interesting to note changes in the effects of several control variables. Proximity and the peace-learning process are both still strong, but not as strong overall as in measurements of propensity to attack (as opposed to being attacked). Defensive alliances remain as irrelevant as ever. But the democratic peace has no effect (dyadic or 
monadic), and more interestingly, the effect of power differential is now statistically significant and usually is strong enough to be noticeable.

When the Scriptuary targets are broken down into their respective religions, the results are even more striking. Table 6-7 summarizes the logit coefficients for the effects of Christianity and Judaism on a state's propensity to be attacked by a Muslim state.

Table 6-7. Summary of Logit Coefficients for Christian (All) and Jewish States Being Targets of Muslim (All) States.

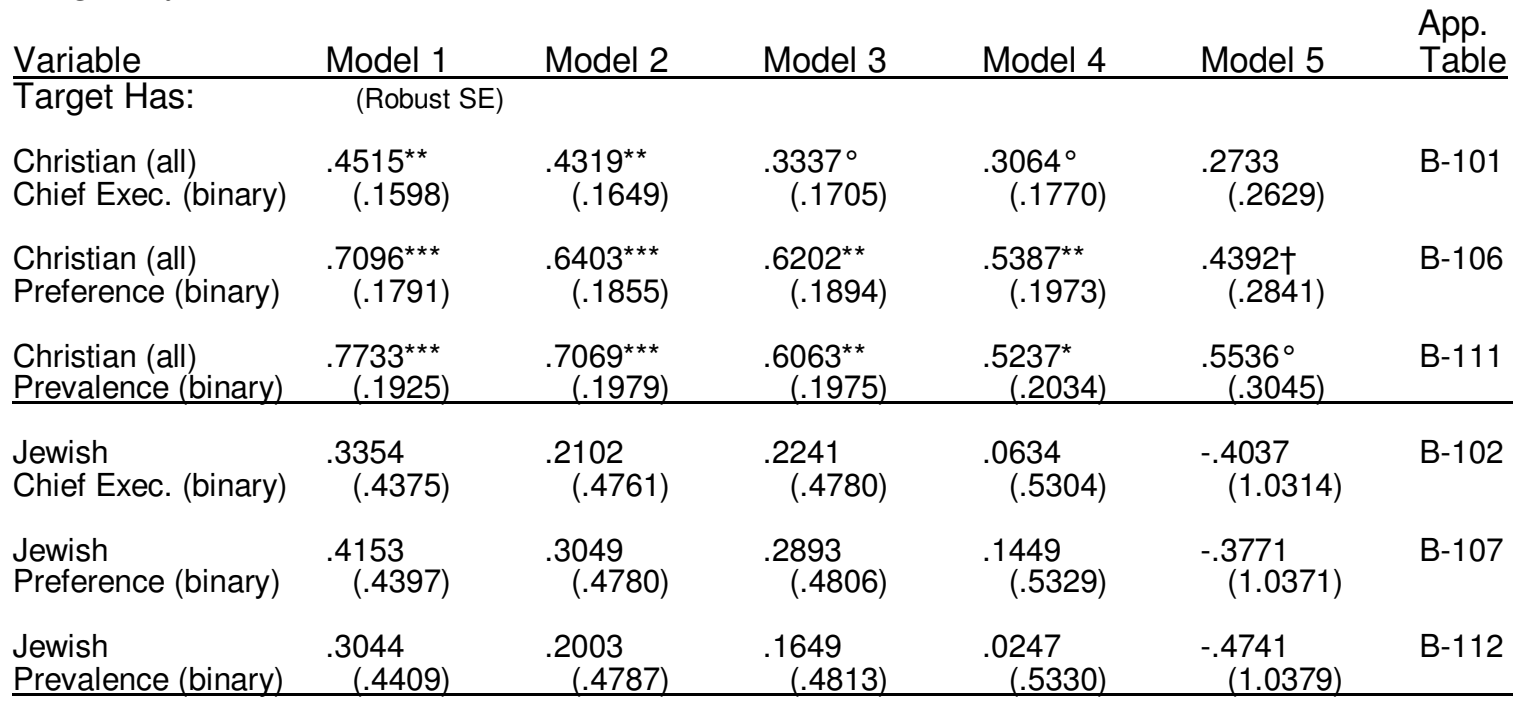

${ }^{\circ} p<.10 \quad{ }^{*} p<.05 \quad{ }^{* *} p<.01{ }^{* * *} p<.001$

$\dagger p<.15$

In all models except the one involving fatalities (Model 5), a Christian state is much more likely than a non-Christian state to be attacked by a Muslim state. This result was expected, given both the content of the classical Islamic war ethic and the logit coefficients already presented for Judeo-Christian states. What was not expected is the finding that Judaism has no effect, in any model or via any operationalization. A Jewish state is statistically no more or less likely to be attacked by a Muslim state than a non-Jewish state. Although every coefficient is positive, none of the confidence intervals are 
anywhere close to meeting the field's standard of certainty. Of course, these results are being driven by the situation of a single state-Israel. ${ }^{39}$ However, despite the well known and well documented hostility of Muslim states toward Israel today and against the Jews in classical Islamic history, and despite the fact that Muslim states have initiated more armed conflicts against Israel than any other state, Israel is not a disproportionately frequent target of Muslim states. This is the case even after controlling for proximity (Israel is surrounded by 5 Muslim states including Saudi Arabia) and the peace-learning process.

The finding just presented raises two important questions. First, why is Israel not a statistically more frequent target? The fact that power differential is now statistically significant at first glance would suggest that Muslim states may not be attacking Israel as often as predicted because overall they are weaker than Israel; the stronger they are vis-àvis Israel, the more likely they should attack (see Appendix B, Tables B-102, B-107, B112). However, this supposition is not supported empirically; in observations in which a Muslim state uses force against Israel, the mean of the logarithm of the ratio of the Muslim state's CINC score to Israel's (Logdircincratio) ranges from only 0.25 at the lowest threshold (Model 1) to -0.003 at the highest (Model 5). A better explanation may be that Israel historically has been successful in defending itself in major wars, despite a lower national capability than its enemies combined. Perhaps Muslim states have been more restrained in attacking Israel because of that record of success, the widespread

\footnotetext{
${ }^{39}$ A few other states have had Jewish chief executives, e.g. France and Switzerland, but those occasions are rare.
} 
belief that Israel has developed nuclear weapons, and its backing by Western powers (see the discussion above on the dar al-suhl).

This latter explanation leads to the other important question: Why do Muslim states attack Christian states statistically more often than states of any other religion, including non-Scriptuaries? A survey of the targeted states in Table 6-5 suggests a potential answer. The Christian states that are most targeted include Cyprus, Greece, Ethiopia, and Russia; these conflicts are likely over Turkish Cyprus (Cyprus and Greece), Ogaden (Ethiopia), and Afghanistan (Russia). Other frequent Christian targets are France, Great Britain, and especially the United States. Each of these states is or has been a supporter of Israel. ${ }^{40}$ Although Muslim hostility toward Israel may not have been the primary motivation for attacking these three states, a latent hostility toward states believed to support Israel in the Arab World has been documented (Furia \& Lucas 2006, 2008; Tessler \& Robbins 2007). In contrast to the Christian states, the only non-Muslim states targeted as often are Israel itself, and India (which is the only non-Scriptuary target). These findings appear to lend at least partial support to claims that Muslim states are hostile to states whose foreign policies are viewed as attacks on the umma (the Muslim community at large).

\section{Conclusion}

This chapter has examined the effect of the Islamic war ethic on the propensity of Muslim states to initiate armed conflicts against other states. Overall, Muslim states have a greater propensity to do so than non-Muslim states and this greater propensity is rooted

\footnotetext{
${ }^{40}$ In a few cases, these states are coded as targets of aggression when in fact they have joined an armed conflict on the side of the original target, e.g. Kuwait during the Gulf War.
} 
in a latent antipathy toward non-Muslims in Islamic scripture, classical writings, and the Islamic historical narrative. However, the effect is not uniform. Muslim states are significantly less likely to attack other Muslim states than they are to attack non-Muslim states (though for higher thresholds of armed conflict, including those with fatalities, that effect is not statistically significant). Muslim states are significantly more likely to attack Christian states than non-Christian states (though at the highest threshold, the effect is statistically significant only for a Christian population). Surprisingly, Jewish and NonScriptuary states are no more or less likely to be attacked by Muslim states than nonJewish and Scriptuary states, respectively. This finding suggests that although a latent antipathy toward these religions still may be present in Islamic thought today, that antipathy has given way to hostility to those religions that Muslims view as more immediately responsible for the present crises or injuries to the Muslim community as a whole (i.e. the Islamic perception of a pattern of Western attacks on and subjugation of Islam). All of this behavior takes place despite Muslim states having agreed to accept restrictions on their rights to resort to use force in contemporary, secular international law (by ratifying the UN Charter and joining the United Nations). The pattern of behavior indicates that Muslim states are acting upon the Islamic war ethic rather than the war ethic promulgated by secular jus ad bellum, just as Christian states have been claimed to act upon the Christian war ethic. The Islamic war ethic is more permissive than those of other religions examined and measured in this study, therefore Muslim states should have a higher propensity than non-Muslim states to initiate armed conflicts (in violation of jus ad bellum), and such is the case. 
We now direct our attention to the third most prominent world religion, Buddhism, and find that in contrast to Christianity and Islam, Buddhism appears to have no effect on the propensity of a state to use force. 


\section{Chapter 7}

\section{THE EFFECT OF BUDDHISM}

\section{Introduction}

The third most prominent religion in international relations is Buddhism, which in one form or another is the Prevalent or Preferred religion in about one-twelfth of the stateyears from 1946 to 2001. The paucity of Buddhist states relative to Christian and Muslim states is one of several factors that have rendered measuring the effect of Buddhism more challenging. The sample size for Buddhist state-years is considerably smaller than that for the other religions studied in this work, which elevates the risk that the results here are driven more by the geopolitical circumstances of particular states that also happen to be Buddhist. One particular challenge is that all Buddhist states are concentrated in a single geographic region (the Asia-Pacific region), raising the possibility that the effect of Buddhism cannot be separated from other geopolitical effects of that particular region. Although regional location can be controlled for, doing so has not yielded much more insight.

A third challenge to measuring the effect of Buddhism is that religion's tendency to intermix with other religions. In Chapter 3 of this work (pages 105-6), I argued that Mahayana Buddhism is so intermingled with Confucianism and Taoism in China and Korea, and with Shinto in Japan, that Buddhism cannot be separated from those other religions. For that reason, I created the religious category "Buddhist Mix," denoting any combination of Buddhist, Confucian, Taoist, and Shinto. In contrast, Buddhism in South and Southeast Asia has not intermingled with other religions to such a degree and thus has retained its "purity," hence the category "Buddhist (Pure)" used in this study. 
Moreover, the three major branches of Buddhism that exist today-Theravada, Mahayana, and Tibetan-have developed different canons (though there are some core commonalities) and those canons are vast compared to those of Christianity and Islam. Being considerably more diverse has made Buddhism considerably less unified, rendering Buddhism more susceptible to the claim that some of its doctrines are less coherent and less consistent than those of its counterparts.

Problems in the coherence and consistency of the Buddhist war ethic may partially explain the inconsistencies in the results of the empirical measurements contained in this chapter. The logit regressions used in the standard models of this study reveal an overall positive correlation of Buddhism with a state's propensity to initiate an interstate armed conflict (in violation of jus ad bellum), but not an armed conflict with fatalities. However, many of the results are not statistically significant. In addition, the results are not always consistent across the several variables that measure religion. For example, the effect of Buddhist chief executive is expected to be similar to that of a Buddhist regime Preference, as it was for Christianity and Islam, yet it is not. Furthermore, when a control variable for Asia-Pacific dyads is introduced, all coefficients lose their statistical significance.

\section{Buddhist Scripture}

The purest, most conservative form of Buddhism is Theravada, which is prominent in Sri Lanka, Burma, Thailand, Laos, Cambodia, and parts of Vietnam. Its canon is known as the Pali Canon, so named for the language in which it was originally written. The Pali Canon, also known as the Tripitaka ("Three Baskets"), is a collection of discourses and/or stories (suttas; in Sanskrit, sütras) by and about the historical Buddha, his 
previous incarnations, and several other figures. The English translation of the Pali Canon is over 20,000 pages long, comprising several dozen volumes, and no single person is known to have translated it in entirety. An outline of the structure of the Pali Canon is provided in Appendix C. The first comprehensive English translation was published by the Pali Text Society (PTS) in England, over several decades beginning in the late $19^{\text {th }}$ century. Those original volumes (which have since been reprinted several times, occasionally into fewer volumes) form the basis of the convention for abbreviating references to the Pali Canon used in English-language treatments of Buddhism today. ${ }^{1} \mathrm{~A}$ new translation by Wisdom Publications is currently in progress; it appears to deviate little from the PTS series in substance, but its language is more accessible to the modern reader, much as the New International Version of the Bible is more accessible to the modern reader than the King James Version. The Wisdom Publications series also includes the conventional references to the PTS series. When quoting the Pali Canon, this work will endeavor to use the Wisdom Publication translations as often as possible.

The other major branch of Buddhism is Mahayana ("Great Vehicle"), which is practiced in China, Taiwan, Korea, and Japan. Its canon is even larger than the Pali Canon and is organized differently. Several parts of the Pali Canon are reproduced in Mahayana scripture, including many of the scriptures that will be cited in this chapter. However, some portions of Mahayana scripture that are said to correspond to the Pali

\footnotetext{
${ }^{1}$ The conventional format is the abbreviation of the division of the individual collection (abbreviations are provided in Appendix C), followed by the volume number of the original PTS translation in lower case Roman numerals, then the page number. For example, section 1 of the Mahāparinibbāna Sutta (sutta 16 of the Dīgha Nikāya) is in volume 2, page 72 of the original PTS translation, and is therefore cited as D ii 72.
} 
Canon are actually significantly different. ${ }^{2}$ Furthermore, the Mahayana branch includes much more material as canon than the Theravada branch; an analogy would be if twothirds of the Bible in one branch of Christianity were regarded as apocryphal in another. The collection of scripture that is most often cited in English-language treatments of Mahayana Buddhism is the Taishō Tripitaka, so named because it was compiled and published in Japan during the Taishō period in traditional Japanese history (i.e. the reign of Emperor Taishō, 1912-1926). The Taishō Tripitaka, which is also outlined in Appendix C, consists of 85 volumes containing nearly 3000 sutras. It is not available in English, despite many citations to it in English-language scholarship. ${ }^{3}$

A third branch of Buddhism, Tibetan Buddhism, is practiced in Tibet and Bhutan and was also exported to Mongolia. Its canon, comprising the Kangyur and the Tengyur, is several hundred volumes and is an amalgamation of Mahayana and Vajrayana text. For lack of enough state-years in which it is prominent, Tibetan Buddhism will not be treated further.

As can be noted from the above survey of Buddhist scripture, Buddhism is highly decentralized, much more so than Christianity or Islam. The commonalities that hold the

\footnotetext{
${ }^{2}$ For example, the Ekottara Āgama in the Mahayana branch to the Anguttara Nikāya in the Theravada branch.

${ }^{3}$ My own citations to the Taisho must necessarily originate from secondary sources, and these sources do not always cite to the Taisho in a consistent manner. The most commonly used format is the volume number in Arabic numerals, followed by page and line numbers, e.g. T. 12 484a8 would mean Taisho, volume 12, page 484, line a8. Occasionally authors cite only the sutra number; e.g. T. 374 means sutra 374 of the Taisho. I shall attempt to avoid confusion by citing to specific volumes and pages/lines using the format T. 12:484a8, and to specific sutras using the format T. \# 374 .
} 
many schools of Buddhism together are the veneration of the historical Buddha; the belief in a cycle of life, death, and reincarnation; the elevation of asceticism; and the belief that good and sinful actions have consequences in both the current and future lives.

\section{The War Ethic in the Pali Canon}

Because the Pali Canon was the original Buddhist scripture, ${ }^{4}$ much of it serves as the core code of Buddhist ethics across the various schools, making it the most appropriate starting point for examining the war ethic in Buddhism. Much of this chapter will be devoted to the Pali Canon as the original scriptural basis for the Buddhist war ethic. A separate section on Mahayana scripture will follow.

The Pali Canon traces the root of all human evil ultimately to sensual pleasure (Mahädukkhakkhandha Sutta, MN 13, secs. 7-15; M i 85-7), i.e. stimulation of the five senses that provoke lust (sight, sound, smell, taste, and touch). Lust for sensual pleasure induces pain and grief on account of the desire to protect one's property and acquire more. It further induces quarreling, conflict, fighting, crime, death, and rebirth in lower states including hell. Lust afflicts everyone, from householders to nobles to kings—and through their kings, lust afflicts nations as well (see Gethin 2007: 71). Although conflict is ultimately rooted in the lust for pleasure, its proximate cause is property. ${ }^{5}$ The Cakkavatti Sïhanāda Sutta, DN 26, sec. 10ff (D iii 65) traces the ills of society to the failure of the otherwise righteous King Dalhanemi to give property to the needy. By that

\footnotetext{
${ }^{4}$ Mahinda Deegalle (2003b: 123) calls the Pali Canon the "most authentic" of all Buddhist sources.

${ }^{5}$ Piyasena Dissanayake (1977: 43) links the above passage in the Pali Canon with others to arrive at the conclusion that property is the root of all conflict. However, the plain language of the Canon indicates that property is merely an instrument of sensual gratification, not a sensual pleasure in and of itself.
} 
one failure, the king allows poverty becomes rampant and the kingdom descends into crime, lasciviousness, and finally murder. ${ }^{6}$

On the international plane, the descent of society is manifested in the insatiable appetite (my word) for conquest. In the Rațtapāla Sutta, MN 82, secs. 41-2 (M ii 71-4), a disciple of the Buddha illustrates this point to King Koravya, asking him what he would do upon being informed of a rich but conquerable kingdom to the east. The King acknowledges that he would in fact conquer it. Asked about other such kingdoms to the south, west, and north, the King's response is the same. The disciple's point is that the wealthy inevitably desire more wealth; the ruler of the sea's near shore covets the far shore as well. The remediation to this state of sinfulness is quite drastic: withdraw from the home life into homelessness, renounce possessions, and seek wisdom over wealth (see also Nakamura 1974: 173). This is the life of the monkhood, which the historical Buddha embraced.

The above may form the basis for the popular conception that Buddhism is a religion of pacifism and asceticism. And despite attempts by several authors to derive a "Buddhist just war theory" by linking Buddhist practice today with modern, Western just-war concepts, it is evident that the plain language of the Pali Canon does embrace total pacifism as the preferred ethic — anything else is sinful and entails negative consequences in the current life or the next one. However, it is also apparent that even Theravada Buddhist scripture is not entirely consistent in this respect, and the inconsistencies render its war ethic less coherent and thus less suitable for practical application.

\footnotetext{
${ }^{6}$ Michael Zimmermann (2006b: 217) claims that society degenerates because the king initially fails to punish thievery. However, in the Pali Canon, the thievery is induced by the poverty resulting from the king's earlier failure to distribute property.
} 


\section{The Ethic of Violence for the Buddhist Monkhood and Laity}

I shall support the claim just made in a series of explorations of the ethics of violence promulgated to the Buddhist monkhood, laity, and monarch, respectively. For the monkhood, the first duty is to refrain from killing and to renounce the "stick and the sword," i.e. to refrain even from doing physical harm without killing. The second duty is to refrain from "taking what is not given," i.e. stealing (Sämañ̃naphala Sutta, DN 2, sec. 43; D i 63). These two duties are reiterated throughout the Pali Canon (e.g. Cülahatthipadopama Sutta, MN 27, sec. 12; M i 179). ${ }^{7}$ For the monkhood, this ethic is absolute; a single infraction, particularly an intentional one, warrants expulsion from the monkhood.

But the Pali Canon also impresses these two duties on the laity as well (Sāleyyaka Sutta, MN 41, sec. 12 [M i 287]; Ghațīkāra Sutta, MN 81, sec. 18 [M ii 51]; Suttanipāta v. 394). No person, from the lowest laborer to the highest ruler, is absolved from the moral culpability for taking life, even under circumstances in which taking life would be widely regarded as necessary. In the Dhānañjāni Sutta, MN 97, secs. 5-15 (M ii 186-8), the venerable Sāriputta visits the brahmin Dhānañjāni and inquires about the brahmin's "diligence" (i.e. in moral living). The brahmin replies:

How can we be diligent, Master Sāriputta, when we have to support our parents, our wife and children, and our slaves, servants, and workers; when we have to do our duty towards our friends and companions, towards our kinsmen and relatives, towards our guests, ... and towards

\footnotetext{
${ }^{7}$ The prohibition from killing even the smallest living things is also prominent in the Vinaya Pitaka, which the section of the Pali Canon detailing the monastic rules of conduct. See Schmithausen 1999: 47.
} 
the king; and when this body must also refreshed and nourished? (sec. 5; Ñāṇamoli \& Bodhi trans.)

The brahmin goes on to lament that even acting contrary to the moral law (the dhamma) for the sake of someone else, seemingly for that person's benefit, would not spare punishment in hell (sec. 15). The strong implication is that even defense of others is condemned. The condemnation of soldiers, whose professional duties may include killing in defense of others, is stated elsewhere quite explicitly. In the Yodhäjivia Sutta, SN 17, sec. 3 (S iv 308-10), a warrior asks the Buddha whether a soldier who dies in battle is reborn in heaven. The Buddha remains silent but the warrior presses the question. Finally the Buddha reluctantly replies that the mere act of going into battle manifests a feeling of hatred and desire to kill and harm others, thus one who dies in battle is reborn in hell.

But lest one despair that there seems to be no escape from the harsher realities of society and life except by withdrawing entirely from the former and even occasionally renouncing the latter, another passage holds out the possibility that one could actually kill without punishment. In the Mahākammavibhanga Sutta, MN 136 (M iii 207ff), the Buddha grants that one could kill and/or commit other sins yet still be reborn in a happy place, and vice versa (that one could refrain from sin and still be reborn in an unhappy place!). In the case of the former, the actor may be punished now or in the future, maybe even in the next rebirth. A person reborn in a happy place despite having sinned either did something good or at the time of death acquired a right view. The inverse is true for having been reborn in an unhappy place despite refraining from sin. The lesson is that not all good and bad results are visible at the time of the act; an act could be prima facie bad yet have an overall good result. This passage would appear to dilute the ethic of absolute pacifism and leave an opening for righteous conduct to include harming or even killing 
when doing so is actually beneficial (e.g. defending others). But this sutta serves to confuse more than it clarifies, for it contains no guidance for defining when killing may be a righteous act. If a seemingly righteous act may result in punishment and a seemingly unrighteous act may not be punished, then the actor is left without a meaningful moral guidance, and virtually anything could be justified.

Even in the face of the inconsistency above, some actors may still choose to follow the precepts of pacifism (and Buddhist mores are chosen by individuals rather than commanded by a godlike entity; Bartholomeusz 2002: 46, citing Obeyesekere). But those actors must eventually face the dilemma of how to respond to an unjust threat to life, or to the need to force someone else to do something in order to achieve a moral result. In the Pali Canon, the Buddha himself is never harmed by anyone (at least, in his current life), but that is due to supernatural interventions against those who offer that harm. Everyone else who is threatened with harm must choose between protection (a sin) and submission (an injustice). The Buddhist ideal seems to be to refrain from using force to protect oneself, relying instead on protection from others. The Ātānātiya Sutta, DN 32 (D iii 194ff), contains verses for the Buddhist monkhood and laity to recite for protection from hostile yakkhas, gandhabbas, and other "non-human" (otherworldly) beings. Such an attack would be warded off by other, presumably righteous non-human beings: "And all the non-human beings, full of rage, would overwhelm him with abuse. Then they would bend down his head like an empty bowl, and they would split his skull into seven pieces" (sec. 8 [D iii 203], Walshe trans., emphasis added). These are verses that the Buddha, having received them from King Vessavana, actually instructs his followers to recite (sec. 12 [D iii 206]). 
This passage serves as another example in which the putatively pacifist Buddhist ethic is rendered incoherent, for it requires the Buddhist monkhood to pray and desire that violence be committed on others. Such a desire is directly antithetical to the Buddhist ideal of non-violence. Granted, the violence is among non-human beings. But if nonviolence is to be the ideal ethic for humankind, then why should it not be so for the nonhuman beings as well—who apparently do not live in nirvana, who interact with humans in this world, and who are no more God than the humans of this world? The answer cannot be that the would-be protectors are simply evil themselves, for then they would not commit the good act of protecting others from harm. Nor can the answer be that they are supremely good, for the Buddha's standard of perfect "goodness" is to renounce violence absolutely.

Further undermining the Buddhist ethic of non-violence are other passages that depict the Buddha as accompanied by a yakkha (which Schmithausen [1999: 56] translates as “demon") who threatens violence against those who resist doing the Buddha's bidding. In the Ambattha Sutta, DN 3, secs. 1.20 (D i 94-5), the Buddha poses an uncomfortable question to Ambatthha and warns him that "[i]f you don't answer, or evade the issue, if you keep silent or go away, your head will split into seven pieces" (Walshe trans.). At that moment, the demon Vijirapāni appears wielding a huge, blazing iron club; Ambatṭha is terrified and answers the question (sec. 1.21). An identical threat is made in the Cūlasaccaka Sutta, MN 35, secs. 13-4 (M i 231-2). ${ }^{8}$ In these passages, the purveyor of a supremely pacifist ethic himself offers violence against someone, in order to force that person to do his bidding. Granted, no violence is actually committed, but it would be

\footnotetext{
${ }^{8}$ In this sutta the demon is not identified by name.
} 
illogical for an ethical system to prohibit the act of violence without also prohibiting the threat of it. Rupert Gethin (2007: 69) tries to explain this inconsistency away by arguing that the Buddha was merely making a factual statement of the outcome of refusing a Tathāgatha such as the Buddha; in warning Ambatțha, the argument goes, Buddha is actually rescuing him from harm. However, no violence would even be threatened if the Buddha did not insist on getting an answer to his question; the Buddha has enough control over the situation to avoid even the threat of harm, yet he does nothing to prevent that threat from being made.

\section{Statecraft and the Ethic of War in the Pali Canon}

The Pali Canon says much about the Buddhist ideal of kingship, i.e. statecraft. We begin with the etiology of kingship in the Aggañña Sutta, DN 27, sec. 20 (D iii 92-3). This sutta depicts a society that has devolved due to greed, lust, appetite, and vanity. Then those beings came together and lamented the arising of these evil things among them: taking what is not given [i.e. stealing], censuring, lying and punishment. And they thought: "Suppose we were to appoint a certain being who would show anger where anger was due, censure those who deserved it, and banish those who deserved banishment! And in return, we would grant him a share of the rice." So they went to the one among them who was the handsomest, the best-looking, and most pleasant and capable, and asked him to do this for them in return for a share of the rice, and he agreed. (Walshe trans.)

Hence the origin of the title $r \bar{a} j \bar{a}$, which means "he who gladdens others with dhamma" (sec. 21; D iii 93). 
In Buddhist political theory, the state is not an end in itself; it is neither moral nor immoral, nor just nor unjust. Rather, the state is an instrument toward some other end. As such, its jurisdiction encompasses all areas of human activity and it has total, awesome power. But the state cannot exist independently of human agency; it is not an abstraction or "thought-construct" (Gokhale 1996: 20), ${ }^{9}$ but can only be exercised by and through people. It is precisely this association of the total power of the state with imperfect human beings that creates the dilemma of statecraft: orderly human existence is not possible without applying the state's power, but that power is easily (and often) misused. In Buddhism, the path toward resolving this dilemma is divine retribution (instead of deterrence) as punishment for the misuse of power. The early Buddhists viewed the world as a rational structure, in which rational laws should prevail and personal moral responsibility was enforced by the "iron law" (Gokhale's words) of cause and effect. In this viewpoint, the state is an instrument not merely for punishment, but for the moral transformation of political man. The solution to the dilemma lies in the morality of a higher order, or dhamma (the Pali word; in Sanskrit, dharma; the word has also been loosely translated as "law").

Thus the early Buddhist attitude toward kingship was one of disquiet, or even fear, regarding its nature and functions (Gokhale 1966: 15-6). In many passages of the Pali Canon, the power of kings is described as calamitous, like a fire or flood, and often exercised with motives of greed and wrath. Yet the attitude is also one of resignation that kingship is "absolutely essential" to the maintenance of order and security, for without it, the world descends to anarchy. Buddhism thus seeks to "tame" the absolute power of

\footnotetext{
${ }^{9}$ This entire restatement of Buddhist political theory is a paraphrasing of Gokhale.
} 
kings by infusing morality into it. The overall theme of the Pali Canon, where it relates to kingship, is to highlight the beneficial role of the king - the provision of internal security, protection from external aggression, and encouragement of moral conduct (Zimmermann 2006b: 223-4).

Beyond the basic functions just described, the function of the king is to morally transform the subjects. The Pali Canon portrays the ideal king as equipped with the best moral and intellectual qualities, who rules according to dhamma (id.). He achieves this by setting the highest example of personal conduct, which is to live a life of purity and contemplation. To fail in this task is to weaken his power and invite social disintegration, the threat of lawlessness, and ultimately loss of security of life and property (Gokhale 1966: 20). According to the Nandiyamiga-Jātaka, J 385 (Ja iii 274), the ideal king rules according to ten virtues: "Alms, morals, charity, justice and penitence, / Peace, mildness, mercy, meekness, patience: / These virtues planted in my soul I feel, / Thence springs up Love and perfect inward weal" (Francis \& Neal trans.). It is inferred from the suttas on the origins of sin, strife, and the devolution of society, recounted above, that a kingdom ruled in accordance with those virtues would enjoy prosperity, internal security, and external security.

That righteous kingship would result in prosperity and a low crime rate is intuitively logical in both the classical liberal and Marxist political theories of the West. But instead of extolling the naturally occurring benefits of righteous kingship, the Pali Canon extols supernaturally occurring benefits. In The Book of the Fours, AN iv, chap. 7, sec. 10 (A ii 74-6), having a righteous king is said to result in the righteousness of ministers, brahmins, householders, townsfolk, and villagers, in that order. The heavenly bodies then "go right in their courses," as do days and nights, months, and seasons, whereas all of these 
things "go wrong" and "are out of joint" when the king is unrighteous. Rain falls seasonably and crops ripen; people are healthy. In the second Rājovāda Jātaka, J 334 (Ja iii $110-2),{ }^{10}$ the king ensures the sweetness of fruits and honey by ruling according to dhamma; as soon as he deviates from righteous rule, the fruits turn bitter.

That external security would flow from adhering to the ten royal virtues, especially mildness, mercy, and meekness, is not so easily derived logically. The Pali Canon does contain vignettes in which non-resistance results in security from aggression and conquest, but that security again is obtained through supernatural means. In the Mahāsilava Jātaka, J 51 (Ja i 132), the kingdom of Kosala is conquered and King Mahāsīlavant refrains from defending the kingdom; the usurper's heart miraculously is moved and he voluntarily restores the king to his rightful rule. In the Seyya Jātaka, J 282 (Ja ii 273-4), a king refuses to fight to protect his kingdom from invasion and is imprisoned by his conqueror. The king's pity for the karmic outcome of his conqueror's sins (he undoubtedly will be reborn in an unhappy place) is so strong that the conqueror is attacked by great physical pain. The conqueror then releases the captive king and returns his kingdom to him. It is probably significant that the vanquished king is none other than the venerated Buddha in a previous rebirth.

The theme of the supernatural king is reinforced the Cakkavatti-Sïhanäda Sutta, DN 26 (D iii 58-79). This sutta, more than any other, is regarded in Theravada Buddhism as the scriptural primer on kingship. ${ }^{11}$ In section 5, the long-lived righteous king Dallhanemi passes on the duties of a righteous monarch: to honor to law, revere it, cherish it, do

\footnotetext{
${ }^{10}$ Another Jātaka with the same name is located at $\mathrm{J} 151$.

${ }^{11}$ The Cakkavatti-Sïhanāda Sutta is reproduced in Mahayana scripture as well, at T. 1:39b4.
} 
homage to it, venerate it, and acknowledge it as master. A righteous king should establish guard, ward, and protection for his household, troops, nobles and vassals, brahmins and householders, town and country folk, ascetics, beasts and birds; allow no crime to prevail and give property to those who are in need; and listen to the counsel of the ascetics (D iii 61). A king who rules in this fashion brings the entire world under his rule. In sections 6 and 7 (D iii 62-3), the king ventures out into the eastern country with his army and is welcomed as its ruler. The king does so also to his south, west, and north, pronouncing "Do not take life. Do not take what is not given. Do not commit sexual misconduct. Do not tell lies. Do not drink strong drink. Be moderate in eating" (Walshe trans.). In each case the result is the same; the country voluntarily welcomes the king as its ruler, the king having conquered not by sword, but by law.

All of the above passages convey the proposition that absolute, perfect pacifism will be rewarded with absolute peace, sometimes by supernatural means. But several inconsistencies in other parts of the Pali Canon serve to undermine the example of the perfectly gentle king. The first inconsistency is in the Cakkavatti-Sihanāda Sutta itself, in that the righteous king goes out with his army (sec. 6). This is no metaphor; the king is accompanied by foot-soldiers, chariots, elephants, and cavalry (the fourfold army in ancient Indian statecraft). The intent of the sutta is to convey that the real emperor is law, not a human king, and that a king who righteously follows the law himself will gain a multitude of followers and therefore will not need to conquer by force. But if that is the case, then why travel with an army? Lambert Schmithausen's (1999: 55) interpretation of this sutta is that the utopian, ideal monarch need not actually use force to rule, but such rule is possible only after applying force to achieve the submission of his followers. However, 
although such force may not necessarily have been deadly, it is force nevertheless, in which harm has been offered to those who do not submit to the king's rule.

Another inconsistency lies in the five powers that are outlined as the basis of kingship in the Tesakuna Jātaka, J 521 ( $\mathrm{J}$ 120-1). In ascending order, those five powers are strength, wealth, counsel, caste, and wisdom. They are open to some variation in interpretation; Gokhale (1966: 17) ${ }^{12}$ interprets the last one as "intelligence" although the PTS translation reads "wisdom," and the first one as "strength of arms" whereas the PTS translation reads "strength of limb." These are not trivial distinctions, for intelligence is hardly synonymous to wisdom and even he feeblest person could wield great military might. Gokhale would characterize a strong army as an important asset, whereas the PTS translation extols only personal physical strength. But in any case, and even granting that strength is only the fifth most important power rather than the first, why is strength (in either form) mentioned as an asset at all? Strength could only be an asset to kingship if the king intends to use it to enforce his will or ward off challenges. Yet the Pali Canon states elsewhere that a perfectly righteous king would have no enemies, no challengers, and even no crime, therefore he should need neither physical strength nor an army.

A third inconsistency consists of several separate passages that, when taken together, suggest that political pacifism is actually impossible to implement, or at best impractical. The Cakkavatti-Sihanāda Sutta, mentioned above, extols the extreme virtues of the cakkavattin, the world-ruling monarch who rules with law (dhamma) rather than force. In the Book of the Twos, AN 2, chap. 6, secs. 1-4 (A i 76), the Buddha questions his monks

\footnotetext{
${ }^{12}$ Gokhale interprets the powers as strength of arms, strength of wealth, strength of ministers, prestige of high birth, and strength of intellect.
} 
on the two types of persons who are born happy, who are born extraordinary, who are mourned upon their deaths, and who are worthy of a shrine, respectively. In each instance, the answer is a Tathăgata (a Fully Enlightened person, i.e. the Buddha) and a cakkavattin. Essentially the Buddha is equating himself with a cakkavattin (Dissana-yake 1977: 94-5). That being the case, it seems likely that only the Buddha could ever actually be a cakkavattin, thus rendering the cakkavattin's standard of morality and enlightenment unachievable by any other person, for the Buddha is unique. Elizabeth Harris documents a similar argument: that for a war to be truly "just," its perpetrator must undertake it with absolute purity of right thought, i.e. absolutely free of greed and hatred, thus only a Buddha (or an arahant) can do this (Harris 2003: 105).

The Buddha himself appears to tacitly acknowledge the difficulty in ruling righteously without using force. In the Māra Suttas, SN 4, chap. 2, sec. 10 (S i 116), the Buddha contemplates whether it is possible to govern righteously without conquering, doing harm and sorrow, or causing the same. The evil demon Māra challenges the Buddha to govern in such a way himself; his plan is to distract the Buddha from his compassion for those suffering from the cruelty of misrule by getting him "absorbed in the fascination of exercising power" (PTS translation, note 1 to sec. 10). But the Buddha refuses to attempt the challenge, saying "And were the mountain all of shimmering gold, not e'en twice reckoned would it be enough for one man's wants" (C.A.F. Rhys Davids trans.). Even the Buddha himself apparently fears the temptations associated with that magnitude of power. It follows that if the Buddha is unsure that even he could rule according to his own ideal, then certainly no one else can.

If the Buddha in his fully enlightened incarnation cannot meet the ideal standard of kingship, then surely he could not have done so in his previous births. This is precisely 
the case in the Müga-pakkha Jātaka, J 538 (Ja vi 1). In this story, Buddha tells of his previous life as Temiya, the only son of a king despite the king having 16,000 wives. As an infant, Temiya was aware that he had been reborn after spending 80,000 years in hell to atone for the sins of mere twenty years of reign as a king in his previous life. Seeing his father go down the same path and being terribly afraid of returning to hell, he chose to avoid exercising any function of kingship whatsoever, by feigning being crippled, deaf, and dumb. When as an adult his true abilities were discovered, he then left the palace to become an ascetic. His father and his queens all renounced their rule in order to join him in his ascetic lifestyle, along with two other putatively conquering kings. All three kingdoms were abandoned, the elephants and horse left to roam wild and the treasuries scattered. At first glance this story seems like a tale of an over-developed society reverting to a simpler, more idyllic existence, but the result of everyone embracing the ideal of the ascetic life (as the Buddha seemingly would desire) would be to destroy the community itself, along with any hope of societal progress. Furthermore, the Jataka omits any mention of the next kingdom that inevitably must have encountered the abandoned three, conquered them, and enslaved their populations. The pursuit of the ideal of total personal and political pacifism left no one behind to maintain the kingdoms and protect their people from harm. This is the third way in which the Pali Canon shows the impossibility or impracticality of the so-called ideal style of kingship.

The tension between the ideal of total pacifism and the practical necessity of force in statecraft is also evident in the Pali Canon's inconsistent treatment of the problem of crime. In the Cakkavatti-Sïhanāda Sutta, summarized above, society degenerates because the king fails in his duty to give property to the needy. In the Kütadanta Sutta, DN 5, secs. 10-12 (D i 134-6), King Mahāvijita's country is beset by thieves and brigands 
ravaging and pillaging the countryside. His chaplain's advice is not to respond with executions and banishments, but to give riches to those who need it. The king follows his chaplain's advice and crime diminishes and revenue grows. Thus the ideal crime prevention, according to the Pali Canon, is to eliminate the need for people to resort to crime by satisfying their material needs. Indeed, the Bhikkā-Parampara Jātaka, J 496 (Ja iv 370), opens with a king finding his court of justice empty, because he himself had renounced sin and kept the ten royal virtues. The message throughout the Pali Canon appears to be that a sinless king will have sinless subjects, and that the very need to punish the crimes of his subjects is a reflection of the king's own sinful life. However, other passages in the Pali Canon undermine the consistency of this message. In the Sumangala Jātaka, J 420 (Ja iii 441-2), and the Somanassa Jātaka, J 505 (Ja iv 451), kings set the example of careful reflection before punishing, rather than acting upon their temporary emotions. Yet according to the ideal standard, the fact that those kings must punish at all means that they themselves have not lived up to the royal virtues, despite their best efforts. Furthermore, I suggest that the solution to the crime wave in the Kütadanta Sutta above was possible only because the king had immense wealth to give in the first place. It seems highly unlikely, given the politics of ancient India, that his kingdom would not have acquired such massive wealth without having to apply force at some point against someone, either in extracting wealth from his own subjects or in conquering other kingdoms.

It is clear from the Pali Canon that the Buddha prefers non-violence. Therefore, when confronted with the question of the morality of a king actually going to war, one would expect the Buddha to explicitly counsel against it, because doing so is sinful and will earn the king a rebirth in hell. However, when confronted with just such a situation in the 
Mahāparinibbāna Sutta, DN 16, secs. 1.1-1.6 (D ii 72-6), the Buddha offers no such counsel. In this sutta, King Ajātasattu of Magadha sends a minister to the Buddha with instructions to inform him that he intends to attack the Vajjians, saying "I will strike the Vajjians who are so powerful and strong, I will cut them off and destroy them, I will bring them to ruin and destruction!" (Walshe trans.). The minister is to report on the Buddha's reaction to this information. The minister does as ordered, and the Buddha replies that as long as the Vajjians continue to live righteously, they "may be expected to prosper and not decline." Now, the sutta does not elaborate on King Ajātasattu's motive for attacking; it could be defense, retribution for a past wrong, preempting the rise of a hostile and belligerent power, or simply personal greed or hatred. But for the Buddha, whose ideal is absolute non-violence regardless of cause or justification, the king's immediate motive should be irrelevant; he should advise the minister that the king should not go to war. Yet he does not.

Several attempts to explain away this problem do not satisfy. Hajime Nakamura's (1974: 175) interpretation of the sutta is that the Buddha actually did counsel against the war, albeit more subtly. Warring against the Vajjians would not achieve the king's purpose, which is to destroy them; therefore, the argument goes, there is no point in the endeavor. But this interpretation is not convincing, for a far better deterrent would be the threat of 80,000 years of torment in hell. The Venerable Pandita's (2011: 138-9) interpretation is that the Buddha refrained from counseling against the war because he did not want his Magadhan followers to get punished for opposing the war, and because he wanted to avoid conferring any advantage to either side. This explanation is also not convincing, for two reasons. First, if the Buddha is important enough for the king to solicit his reaction, then he ought to have sufficient influence to insulate his followers 
from harm. Second, deterring the king's attack does not require the Buddha to reveal the relative strength of the Vajjians, nor would the Buddha invite the king to attack knowing that he would lose in battle. Schmithausen (1999: 50) offers the sutta as evidence that because the Buddha never specifically counsels against the war, he does not actually regard all war as immoral. Such an interpretation, if correct, would render a considerable portion of the Pali Canon - that which elevates political pacifism as the ideal statecraftmeaningless. Recall that the Mahākamma-vibhanga Sutta, MN 136 (M iii 207ff), holds that it actually might be possible to kill without punishment.

At best, the Pali Canon is sending a mixed message as to whether the king must use force or not; at worst, it extols an ideal that is impossible to meet, therefore attempting to do so seems pointless. When actually confronted with the question, in a way that will have immediate, real-life consequences, the Buddha equivocates. These problems undermine the coherence of the ethic of non-violence in the Pali Canon, as well as its prospect for practical application.

Why is the Pali Canon so confused on this subject? One reason might be its tendency to juxtapose the opposing ethical extremes of absolute pacifism and total depravity, and neglecting the vast range of middle ground that exist between the two. For example, the Angulimāla Sutta, MN 86 (M ii 97ff), is the story of the conversion of a notorious murderer who takes such pleasure in killing that he wears his victims' fingers around his neck as a garland. Upon conversion, he is enlightened and embraces total pacifism (going from one extreme to the opposite). The ethic of absolute pacifism is usually contrasted with a depraved lust for killing, e.g. the Cūlkammavibhanga Sutta, MN 135, secs. 5-6 (M iii 203-4). Another example is the Kosala Samyutta, SN 3, chap. 2, secs. 4-5 (S i 82-4), in which the King Ajātasattu of Magadha is depicted as totally evil—“a friend to, an inti- 
mate of, mixed up with, whatever is evil" (C.A.F. Rhys Davids trans.). King Pasenadi of Kosala, in contrast, is "a friend to, an intimate of, mixed up with, whatever is good," i.e. totally good. ${ }^{13}$ It is worth further noting that in the same passage, the "totally good" king uses force to defend his kingdom from attack. Then, having lost the first battle, he launches a new attack against his former victor. Both are significant departures from the pacifist ideal. Finally, we may recall the Ratțapāla Sutta, MN 82, secs. 41-2 (M ii 71-4), in which the remedy for the king's crave for wealth and power is not moderation, but withdrawal from worldly matters entirely. In contrast to the placement of just war theory as a preferred intermediate between holy war and pacifism in Christianity, the scripture of Buddhism appears to tolerate the extremes of both pacifism and raison d'état, while offering no middle ground of its own. ${ }^{14}$ Indeed, Perry Schmidt-Leukel (2004c: 39) even goes as far as to characterize Buddhist pacifism as "radical," yet it seems to be competing with an equally radical strain of militarism.

\section{$\underline{\text { Some Doubtful Claims }}$}

Buddhism may have acquired its present-day reputation as a pacifist religion due to three factors. The first is the historical narrative of the Emperor Ashoka (Aśoka) of the Mauryan Empire, who around 265 BCE completed his dynasty's conquest of the Indian subcontinent by conquering the Kalingas. Ashoka is said to have been quite wicked,

\footnotetext{
${ }^{13}$ The Thanissaro translation online at www.accesstoinsight.org, which has this passage at sections 14-15, reads, "King Ajatasattu has evil friends, evil comrades, evil companions, whereas King Pasenadi has fine friends, fine comrades, fine companions."

${ }^{14}$ For a depiction of a two-dimensional scale of war ethics, from permissive to restrained on the $\mathrm{x}$-axis and from charitable to self-centered on the y-axis, see Brown 2008: 14.
} 
motivated to expand his empire by simple lust for conquest. But after being moved with remorse for the hundred of thousands of deaths on his hands, Ashoka embraced Buddhism and propagated it throughout his empire. After his conversion, his new ethic of statecraft was one of non-violence and compassion, directed toward development, e.g. hospitals and universities; his reign was a golden age in the history of his dynasty. Many treatments of Buddhist statecraft cite the case of Ashoka as evidence of Buddhist pacifism. And to be fair, Ashoka's post-conversion reign is documented in most histories as benign compared to others in his day (Kulke \& Rothermund 1986: 64-70, esp. 70). But several facets of the narrative suggest that Ashoka could never have been as purely pacifist as the Buddhist ideal demands. One is that Ashoka's conversion conveniently took place after his conquest of the Indian subcontinent, beyond which expansion would have been impractical. Having conquered as much as he reasonably could, it was easy for him to then renounce any further conquest. Furthermore, Ashoka is not documented as having restored independence to his conquered lands, including Kalinga, or having repatriated the hundreds of thousands said to have been displaced. In addition, Ashoka never renounced his regnum; he continued to maintain an army, enforce laws, and punish offenders. Despite the relatively enlightened style of rule that is (presumably rightly) attributed to him after his conversion, Ashoka could not have ruled in the style of the cakkavattin in Buddhist scripture.

The second contributor to Buddhism's contemporary reputation for pacifism is the rise in prominence of Walpola Rahula, a Sri Lankan monk regarded as the foremost scholar on Buddhism in the English-speaking world in his day. His best-known work, What the Buddha Taught, advances the claim that Buddhism is entirely pacifist (Rahula 1997: 86). However, his scriptural evidence is mostly limited to the ten royal virtues (mentioned 
above), and to the Dhammapada, which is an anthology of short verses uttered by the Buddha (analogous to a cross between the book of Proverbs and the Sermon on the Mount in the Christian Bible). Perhaps Rahula chose the verses he did because he believed that they would resonate best within his largely Christian audience, e.g. hatred can only be overcome by love (Dhp, v. 5), putting oneself in the other's place (vv. 12930), conquering anger with kindness and wickedness with goodness (v. 223). However, he ignores all the other scripture that is far more relevant to the question of the morality of using force.

The third factor is that several Buddhist pacifists have gained fame for winning the Nobel Peace Prize, including the Dalai Lama of Tibet, the Burmese opposition leader Aung San Suu Kyi, and others (Schmidt-Leukel 2004c: 33-4). These figures have not advocated violence in furtherance of their political aspirations. However, that fact is hardly dispositive evidence that Buddhism is more pacifist than Christianity or Islam, both of which also have pacifist political figures who have won the Nobel Peace Prize. Furthermore, Buddhism has non-pacifist and even militant political figures as well, e.g. in Burma and in Rahula's native Sri Lanka. ${ }^{15}$

Several scholars of the Theravada Buddhist war ethic have advanced the claim that a kind of Buddhist just war theory is rooted in Buddhist scripture. Schmithausen (1999: 47) uses the Angulimāla Sutta (presented above) and other suttas to suggest that Buddhism distinguishes between permissible and impermissible killing, but the suttas that he cites do not support such a claim. Schmithausen's other major claim, on the other hand, which

\footnotetext{
${ }^{15}$ Stanley Tambiah (1992 passim) and Patrick Grant (2009: 81-91) both document the participation of Walpola Rahula in the politicization of a militant form of Buddhism in Sri Lanka.
} 
is that kings supported Buddhism as a code of ethics for their subjects but not for their own political activity (1999: 52-3), would appear to have greater merit. Indeed, the common view of scholars of early Buddhism is that Buddhism took for granted the use of violence by the state (Jerryson \& Juergensmeyer 2010: 13). Damien Keown's (2005: 778) exploration of Buddhist ethics also appears to take for granted the state's justification of using force within its own borders. But in the matter of using force outside the state's borders, Buddhism offers little guidance on such questions as what precisely "pacifists" are opposed to, what distinguishes "violence" from the morally neutral "force," and how to protect innocents from violent criminals. Keown himself offers no answers, instead only highlighting a tension between principle and practice (2005: 83). Xue Yu (2005: 4) also advances the claim that Theravada Buddhist scripture "endorses" (his word) the use of force in self-defense and defense of justice by the laity (though not by the monkhood). His claim is based on the Aggañña Sutta, DN 27 (D iii 80ff), but my reading of that sutta is as a resignation to the use of force, not an endorsement of it. Michael Jerryson (2010) chronicles his observations of "military monks" in southern Thailand, who arm themselves in order to defend the Buddhist community (the sangha) in light of a wave of Islamic terrorist attacks there. The monks' justification: the moral necessity of using force to defend the monastery, its occupants, and Thai Buddhism itself overshadows the moral gravity of murdering a terrorist (2010: 189). The overall theme of Jerryson's chapter, as well as the book in which it is situated, is the claim that Buddhism has as much of a "just war tradition" as other religions. Yet Jerryson also reports a high-ranking monk's dismay over the emergence of the military monks; to him, this development is antithetical to Buddhism (2010: 185-7). 
The simmering and eruption of ethnic conflict between Buddhist Sinhalas and Hindu Tamils in Sri Lanka has spawned a large body of literature on that country, to include literature on the ethic of war and violence in Sri Lankan Buddhism specifically. The most comprehensive is that of the late Tessa Bartholomeusz $(1999,2002)$, who leads the claim that a just war ethic has emerged in modern Sri Lankan Buddhism. She attempts to reconcile the strain of nationalism in Sinhala thought with the claim that although nonviolence is the preferred ethic (or prima facie duty, citing James Childress), a show of strength is sometimes necessary to deter attacks, and actual attacks must be warded off with the application of strength (2001: $38-40)$. She thus argues that the editors of the Pali Canon did not condemn war per se, but only the "mental states that issue into violent behavior" (2001: 52).

However, the scriptures that she cites do not support her claim of a Buddhist "just war" ethic. She invokes the example of the two kings Ajātasattu and Pasenadi in the Kosala Samyutta (S i 82-4), already recounted above. ${ }^{16}$ For the purpose of this analysis, we shall assume that the first-defeated Pasenadi launched a counter-attack to Ajātasattu's previous attack, rather than going into battle to defend his kingdom against a second attack by Ajātasattu (although the scripture is not absolutely clear on this point). That being the case, the scripture does not state that Pasenadi counter-attacked because he had right on his side, only that he counter-attacked to avenge his prior defeat. The point of the scripture was not to morally justify the counter-attack, but to illustrate the consequences of a war of greed; that war begets war, and murder only engenders more murder. In addition, Bartholomeusz refers to Balkrishna Gokhale's citation of the same passage as

\footnotetext{
${ }^{16}$ Elizabeth Harris (2003: 99-100) makes a similar argument.
} 
support for her claim that a Buddhist king should possess a full treasury and a large army (2002: 42, citing Gokhale 1966: 17). However, Gokhale was not making a moral prescription, only a statement of fact; his claim was not that a Buddhist king should possess those two things, but that those things were two widely-held characteristics of a king in early Buddhist political theory.

The centerpiece of Bartholomeusz's claim of a defensive war ethic in Sri Lankan Buddhism is not even in the Pali Canon, but rather in the post-canonical Mahāvamsa, which is a c. $5^{\text {th }}$-century CE Ceylonese text that is venerated as the Sri Lankan national epic. Early in the Mahāvamsa, the Buddha is depicted as having visited the island three times and entrusted the island to the king of the gods (chap. 7, vv. 3-5); this is the foundation for the claim that Sri Lanka is a sacred island to Buddhism. The key scripture is in chapter 25, in which the Buddhist king Dutțagāmani slaughters all the Damila people of the island (she notes the parallel to the modern word Tamil), including the Damila king Elara. At the end of the campaign, Dutțagāmani is unable to celebrate his victory due to his remorse for having killed so many millions of people. ${ }^{17}$ The chapter continues:

When the arahants of Piyangudīpa knew his thought they sent eight arahants to comfort the king. . . 'We are sent by the brotherhood at Piyangudīpa to comfort thee, O lord of men.' And thereon the king said

\footnotetext{
${ }^{17}$ Gananath Obeyesekere (1992) takes the position that Dutțagāmani is remorseful not for slaughtering the Damilas, but for killing King Elara, who is described in many other accounts as a just king, and who Obeyesekere claims was an old man at the time in contrast to Dutțagāmani being in his prime (thus it was not an honorable victory because the fight between the two individuals was not evenly matched). However, the historical narrative upon which the Sinhala war ethic is based is derived from the actual text of the Mahāvaṃsa, and the plain meaning of the text would seem refute Obeyesekere's claim.
} 
again to them: 'How shall there be any comfort for me, $\mathrm{O}$ venerable sirs, since by me was caused the slaughter of a great host numbering millions?'

The arahants reply:

From this deed arises no hindrance in thy way to heaven. Only one and a half human beings have been slain here by thee, $\mathrm{O}$ lord of men. The one had come unto the (three) refuges, the other had taken on himself the five precepts. ${ }^{18}$ Unbelievers and men of evil life were the rest, not more to be esteemed than beasts. But as for thee, thou wilt bring glory to the doctrine of the Buddha in manifold ways; therefore cast away care from thy heart, O ruler of men! (chap. 25, vv. 104-11, Geiger trans.)

With this counsel, King Duțtagāmani was comforted.

The Mahāvaṃsa resonates strongly with the Sinhala in modern Sri Lanka, including with the Buddhist monks there. It is often used as scriptural justification for violence against the Tamils, especially since the rise of the Tamil Tiger terrorists (Bartholomeusz 2001: 32-8). It even has been invoked to justify the 1959 assassination of Prime Minister Bandaranaike as retribution for his reconciliatory policy toward the Tamils (id. 77-88 passim). The popular sentiment is that the presence of such a large proportion of nonBuddhists on a sacred Buddhist island poses a threat to Sri Lankan Buddhism itself; the sentiment is not dissimilar to popular discontent in Saudi Arabia (where the two holiest sites of Islam are located) in the 1990s over the presence of non-Muslim troops there. Richard Gombrich (2006) lends some political psychological support to this contention,

\footnotetext{
${ }^{18}$ The three refuges are the Buddha, the dhamma, and the sangha, i.e. the Buddha, the moral law, and the Buddhist community. The five precepts are the abstention from killing, theft, adultery, lying, and drinking intoxicating liquors.
} 
arguing that the ethnic violence in Sri Lanka has been generated by mutual fear of being a minority — fear on the part of the Tamils because they live under Sinhala jurisdiction, and fear on the part of the Sinhalas because 50 million more Tamils live across the 20-mile strait separating the island from India. In addition, he argues, the ethnic violence is a symptom of anger displacement (striking out in anger at the victim who happens to be most available at the time). These arguments underpin Gombrich's claim that the cause of the ethnic violence in Sri Lanka is nationalism, not Buddhism (but also that Buddhists are no less likely to resort to violence than adherents of other religions). Furthermore, field research by Daniel Kent (2010: 164) reveals that some Sri Lankan soldiers and monks do actually believe that the positive karma resulting from going to war and killing for the common good ("on behalf of the country, people, religion, region, and motherland") outweighs the negative karma that would otherwise result from killing. This sort of focus on the intention of the actor, as opposed to the objective act, is analogous to just-war thinking.

Such focus, however, may also be analogous to holy war thinking, and indeed this is the one major fallacy that most strongly refutes the arguments of Bartholomeusz and others outlined above. The war ethic being adopted in Sri Lanka is not one of just war, but holy war. A war ethic that de-humanizes non-believers, such as that of the Mahāvamisa, cannot be a just war ethic, because it bestows a right to kill based on what the opponent is rather than does (there is no requirement of just cause), and furthermore takes into no account the suffering, dignity, or rights of the opponent (no requirement of 
proportionality or just means). The scriptural basis for the war ethic in Sri Lankan Buddhism does not provide a foundation for just war theory in Theravada Buddhism. ${ }^{19}$

Several other dubious claims of a Buddhist just war tradition have been made intermittently over the last few decades. In 1967, the international legal scholar K.N. Jayatilleke (a Sri Lankan) published an exposition of law in Buddhist doctrine, in which he claims that Buddhism espouses both pacifism and just war, but with pacifism as the superior ideal (1967: 550). His scriptural support is the first Rājovāda Jātaka, J 151 (Ja ii 3-4), in which two kings meet on a narrow road and one must give way to the other, setting up a question of precedence. Finding themselves exactly equal in power, prestige, etc., they examine each others' policies. The first king meets force with force, mildness with mildness, good with good, and evil with evil (which Jayatilleke equates with the just war ethic). The second king conquers wrath with kindness, evil with good, greed with charity, and falsehood with truth (the pacifist ethic). Upon learning this, the first king voluntarily gives way to the second. The problem with Jayatilleke's argument is that his claim of the existence of a legitimate just war tradition in Buddhism is not supported by the scripture he cites. The war ethic of the first king in the Rājovāda Jātaka is not presented as legitimate or just, but inferior. The other scripture that Jayatilleke cites, the Jātakamālā (Āryaśūra 2010), is not even part of the Pali Canon and furthermore does not support the moral legitimacy of using force. The first passage he cites, The Story of Mahābodhi (Kșānti), Jātakamālā 23, sec. 68, states that a prince who disregards and fails

\footnotetext{
${ }^{19}$ On the contrary, Stanley Tambiah (1992), Mahinda Deegalle (2003b), P.D. Premasiri (2006), and Gananath Obeyesekere $(1992,2006)$ have all argued that the Sri Lankan ethic is a gross aberration from the mainstream war ethic in Buddhism. If the Pali Canon did not contain so many inconsistencies that cast doubt on the coherence of the pacifist ethic, then these arguments would be persuasive.
} 
to honor the valor of his military men "will be deserted by victory in battle." This passage is a warning that a prince who slights the military will not earn its loyalty and therefore they will not fight to the best of their ability. This scripture is an admonishment to the prince to treat his people well — the peasants, taxpayers, tradesmen, religious persons, and the army; but it is not an endorsement of the moral legitimacy of using the military force. The second passage that he cites, The Story of Maitrībala (Dāna), Jātakamālā 8, sec. 14, also does not endorse the use of military force to maintain the strength of the kingdom, but in fact endorses the opposite: "On friendliness does his strength rest, not on his motley-bannered army, which he keeps only to comply with custom. . . He protects his land in the proper manner [i.e. by keeping the ten royal virtues]. Righteousness is the rule of his actions" (Speyer trans., emphasis added). Jayatilleke's case that Buddhism recognizes a just war tradition is not persuasive.

Rupert Gethin attempts to reconcile war and Buddhist pacifism by adopting a theory of two modes of dhamma originally proposed by Steven Collins (2007: 71, citing Collins 1998). In first mode, dhamma functions as a "practical moral framework for justice" in which violence is permitted depending on the circumstances, but in any case may not be committed in haste or anger. The second mode is an absolute ethic that makes no compromise for the circumstances. Gethin argues that the second ethic prevailed in early Buddhism and the first ethic emerges only in post-canonical sources (the greater tolerance of Mahayana scripture toward war, outlined below, may be a testament to this theory). The problem with such an approach is that the Pali Canon appears to offer no guidance as to which mode will be applied (by the laity or by the state), and when. Upon closer examination, these two modes of dhamma seem to be fundamentally incompatible with each other, leaving the Buddhist layman — and king — no closer to reconciling the 
genuine needs of statecraft with the absolutist standard of behavior that is demanded in order to reach nirvana. It seems likely, therefore, that the Theravada Buddhist war ethic, incoherent as it is, exerted (and exerts today) little effect on the behavior of states (Schmithausen 1999: 52).

\section{The War Ethic in Mahayana Buddhism}

\section{Mahavana Scripture}

Much but not all of the Pali Canon is incorporated into the Taisho Tripitaka. As in the Pali Canon, the Taisho Tripitaka presents political pacifism as the ideal ethic of statecraft. The Mahāsatyaka-nirgrantha-nirdeśasūtra, T. 9:332a-b, and the Abhidharmakośasastra, T. 12:12b, reproduce the ideal of the cakravartin (the Sanskrit word for the Pali cakkavattin), who need not threaten with force, hurts no one, and renounces weapons, yet is the universal ruler to whom all countries surrender peacefully (Nakamura 1974: 177-8). In the Buddhacarita, chap. 2, sec. 40, T. 17:515a, the father of the historical Buddha, King Suddhodana, is renowned for defeating his enemies by good deeds rather than waging war against them (id. 178). These sutras clearly extol the ideal that a ruler need never use force, or even inflict punishment. Yet the Survarnaprabhāsottama-sütra [The Sutra of Golden Light], T. \#663, a sutra especially used by the Manchu Dynasty in China, predicts supernatural disasters on kingdoms whose kings do not punish evil:

For when a king overlooks an evil deed in his territory and does not inflict appropriate punishment on the evil person, ... wicked acts and quarrels arise in great number in the realm. ... His territory is smitten ... and his realm is destroyed on the arrival of a foreign army ... Unfavourable 
winds will blow; unfavourable showers of rain (will fall); unfavourable (will be) planets and asterisms, likewise moon and sun. Crop, flower, fruit, and seed will not ripen in due season. Famine will arise there where the king is neglectful. (Emmerick trans., pp. 61-2)

Once again, Buddhist scripture is contradictory, sending confusing messages to the practitioners of statecraft. Being a king (which also necessitates being born into a royal family) is supposedly a reward for meritorious conduct in one's previous lives, thus a king should be closer to achieving nirvana than any other person in the kingdom. Yet the king is being demanded to violate the core precepts of Buddhism (especially that of nonviolence) in discharging the official duties of his position - and in doing so, undo his progress toward heaven, perhaps even earn a trip to hell instead.

In the matter of justification of war, the Mahayana scripture is somewhat less incoherent than the Pali Canon, in that a genuine war ethic is identifiable in it. A particularly good summary is the Mahāsatyaka-nirgrantha-putra-vyākarana-sūtra, T. 9:317-65 (T. \#272), which ironically is a sermon not of the Buddha, but of Nirgrantha, the founder of Jainism. ${ }^{20}$ In it, the king is advised to observe the ideal precept of nonkilling, to the point of even disarming (Xue 2005: 5; Nakamura 1974: 180-1). However,

\footnotetext{
${ }^{20}$ Another particularly thorough scripture, the Bodhisattva-gocaropāya-vișaya-virkurvana-nirdeśa-sūtra [BGVVNS], has been explored in some detail by Michael Zimmermann (2000, 2006b) and Stephen Jenkins (Jerryson \& Juergensmeyer 2010: 59-75), and recently translated by Lozang Jamspal (Range of the Bodhisattva, 2011). According to Zimmermann, it is reproduced in the Taisho, at T. 329b10-338c25; the volume number is not stated. However, the BGVVNS is primarily a work of Indian and Tibetan Buddhism and is not well known in East Asia despite its appearance in the Taisho, therefore it will not be treated further.
} 
if his country is invaded anyway despite this policy, then the king's duty is to protect his country and repulse the invaders. If this can be accomplished by peaceful negotiation, arbitration, or even bluffing, then such responses of action are preferred. If those responses are not successful, then the king may fight, but only with restraint, attempting to kill as few people as possible (this is one of the few passages in which an ethic of just war is visible, as opposed to its more militaristic cousin, holy war). But interestingly, the king is to capitulate rather than fight against an equally matched opponent, for doing so would be so destructive to both sides that any victory would be a pyrrhic one. ${ }^{21}$ This provision seems like an invitation for one side to take advantage of the other's morality, and would thus seem to undermine this sutra's ability to wield practical influence.

Several other passages in the Taisho articulate a duty not to attack other countries. The Mahāyana-samnipāta ksitigarbha-daśacakra-sūtra, T. 13:733a, states that a king should not invade other countries; the Brahmajāla-sūtra, T. 24:1005c, forbids using an army "to make profits." The Larger Gandavyūha, T. 10:713a, extols the goal of "bringing forth beatitude and wealth through the concord of all countries" (all of the foregoing passages at Nakamura 1974: 177). Of these three sutras, only the first states there to be a duty actually to defend the kingdom when attacked. That specific duty also is stated in the Saddhamasmrtyu pasthāna-sūtra, T. 17:32a (Nakamura 1974: 178).

As to the duty to exercise restraint, the Larger Gandavyūha implies such a duty in stating that the purpose of conquering the enemy is for the king's own people to live free from fear (id.), suggesting the constraints of necessity and proportionality. In addition, the Mahayana version of the Mahāparinirvāna-sūtra, T. 12:384b8-11, prescribes that

${ }^{21}$ These prescriptions are also contained at T. 50:340b (Deegalle 2009: 67-8). 
although the Buddhist laity should use weapons to defend monks, they should not actually kill anyone. However, another passage at T. 12:460b15-21 states that killing those who discard the Mahayana and promulgate unwholesome doctrines is a less grave offense than killing an animal (Schmithausen 1999: 58)—recall a similar sentiment expressed in the Sri Lankan epic, the Mahāvamsa. The same sutra, at T. 3:383b-384a, declares that there is no reason to observe the five precepts (the first of which is not to kill) if the real law (Buddhism) were in need of protection, and even denounces any observers of the precepts who fail to protect Buddhism as not true Buddhists. The sutra even claims, at T. $16459 \mathrm{a}-460 \mathrm{~b}$, that the Buddha himself put heretic brahmins to death in a previous life, partly to defend Buddhism, and partly out of pity to help the brahmins avoid the punishment they had accrued by slandering Buddhism (Demiéville 2010: 41). ${ }^{22}$ Scriptures such as these would appear to eviscerate the duty of restraint, and are in fact expressions of the holy war ethic, not just war.

\section{$\underline{\text { Recent Episodes of Mahayana Militarism }}$}

Several scholars have documented the development of militaristic war ethics by the Buddhist monkhood in Japan, China, and elsewhere. I should preface this section by acknowledging that the following evidence does not support a contention that all of the Buddhist monkhood in these respective countries are militant all of the time. However,

\footnotetext{
${ }^{22}$ In another early Mahayana text, the Upāyakauśalya Sütra, which does not appear to be part of the Taisho, a bodhisattva kills a man in order to prevent him from killing 500 others, even though he himself will suffer in hell for doing so, out of compassion for the lives of the would-be victims, and out of compassion for the would-be killer in sparing him the same suffering. However, in the sutra, the bodhisattva is not subjected to hell for this act of compassion (Gethin 2007: 70).
} 
the existence of enough such instances in recent history, alongside the communities of proponents of Buddhist pacifism (and of Buddhist just war theory, if that theory has not been debunked here), serves to further undermine the consistency and coherency of the Buddhist war ethic, thus rendering Buddhism that much less likely to actually exert any effect on the decisions of states to use military force.

One body of scholarship in this area takes up the relationship between Zen Buddhism and Japanese militarism before and during the Second World War. Winston King (1993) chronicles the emergence of "warrior Zen," a form of Zen practice specially tailored to bushido (the code of ethics of the samurai), which elevated selfless acceptance of death but also skill in using a sword. The contributions of Zen Buddhism to Japanese militarism were twofold: (1) to instill a personal ethic of selflessness, and (2) to break down the psychological barrier between life and death. The second one is particularly important in my view, for removing the distinction between life and death opens the door to the kind of sophistry that maintains that killing is not killing, as documented in Brian Victoria's work. One such example is the claim that the Buddhist prohibition against killing is a flawed, superficial ethic based on a limited understanding of the relationship between life and death. It is not the soldier but the sword that performs the act of killing; the soldier has no desire to do harm, but the enemy makes himself a victim by the act of appearing (Victoria 2006a: 110, quoting D.T. Suzuki). The sword gives life by killing; "[i]t is the precept forbidding killing that wields the sword" (2006a: 36, quoting Sawaki Kōdō). And further,

[O]f course one should kill, killing as many as possible. One should, fighting hard, kill everyone in the enemy army. The reason for this is that in order to carry compassion and filial obedience through to perfection it is 
necessary to assist good and punish evil. However, in killing one should swallow one's tears, bearing in mind the truth of killing yet not killing. (Victoria 2003: 72, quoting Yasutani Kaku'un)

Victoria documents a consistently militaristic Buddhist institution in Japan between the Meiji Restoration (1868) and 1945. The rise of an ethic of permitting violence in Japan appears to have predated the Meiji Restoration by six centuries, however, beginning with a sect founded by Nichiren in the $13^{\text {th }}$ century CE (Demiéville 2010: 36-41). Victoria (2006a: 152-7) goes on to argue that Japanese Buddhism has been slow to change its militaristic ideology, with only a few sects having acknowledged Japan's responsibility for precipitating World War II in the Pacific.

Xue Yu (2005) documents similar developments in China, though the war ethic there appears to have been less militant than that of Japan. Xue shows that during the war with Japan (1937-1945), Chinese monks abandoned the Buddhist precept of pacifism and embraced war. He claims that the Chinese monkhood actually embraced nationalism (a form of holy war), but the evidence presented in his book does not convincingly support that claim, in my opinion. ${ }^{23}$ Although most of the monkhood's involvement in the war appears to have taken place in the form of medical service, many monks exchanged their robes for uniforms, assisted in the procurement of aircraft, and participated in guerilla warfare (Xue 2005: chap. 4). Given that China was defending itself against an attack, it is not clear that Buddhist monks had adopted a nationalist stance, as opposed to merely a defensive one. Xue's essential claim, which is supportable by his evidence, is that

${ }^{23}$ Brooks Jessup (2008), in his review of Xue's book, also arrives at this conclusion. 
Chinese monks knowingly violated their ethical codes in order to participate in the war effort, and loyalty to the nation prevailed over loyalty to religion. ${ }^{24}$

This phenomenon took place a second time in China with respect to the Korean War (1950-1953); in this instance, Xue's evidence better supports a claim that the Chinese Buddhist war ethic turned nationalist. The new Communist regime viewed the American troops in Korea, as well as its military presence in the Taiwan strait (to deter the People's Republic from invading Taiwan) as a direct threat to China, despite the fact that the U.S. never made any moves toward committing an armed attack on China. Under the influence of the Communist regime, the Chinese Buddhist leadership labeled the United States the "deadly enemy of peace" and called upon the Buddhist community to assist in the Korean War, to "safeguard not only the nation and the world, but also Buddhism" (Xue 2010: 137-9). Buddhist monks joined the armed forces (id. 149-50), and presumably fought in Korea. What is interesting in this particular instance is the evidence that it was the state influencing the Buddhist community, not the reverse. Such appears to have been the case throughout most of Chinese history — the Buddhist "church" submitting to the control of the state (Demiéville 2010: 30). That is not the phenomenon being examined in this work; here we seek to determine the extent to which Buddhism influences the preferences, decisions, and actions of the state. As will be now shown, the empirical

\footnotetext{
${ }^{24}$ The emergence of a defensive war ethic in Chinese Buddhism was not an instantaneous development. A revolutionary streak among the monkhood had been brewing since the time of the Taiping Rebellion (18501864), during which time many Buddhist temples were destroyed and monks and nuns massacred. In the early $20^{\text {th }}$ century, a combination of anti-religious and Christian-inspired movements (so claims Xue) nearly destroyed Buddhism in southern China entirely (Xue 2005: 21). The Japanese invasion may have constituted the additional heat necessary to cause the simmering Buddhist anger to finally boil over.
} 
evidence suggests that Buddhism exerts little influence, if any, on a state's decision to use military force.

\section{Empirical Testing of Buddhism}

In keeping with the format of the other chapters, we begin this section with a survey of Buddhist states. Table 7-1 lists all the states that have had a Buddhist Mix chief executive, Preference, or Prevalence, along with the number of interstate armed conflicts they initiated (if any) at the lowest threshold (cwhiact=12) and at the highest (cwfatal=1), while they were Buddhist Mix. (Recall that the "Buddhist Mix" category consists of Buddhist, Confucianist, Taoist, and Shinto combined; it does not denote only the states in which Buddhism is mixed with another religion.)

Table 7-1. List of Buddhist Mix States, with Number of Armed Conflicts Initiated at Lowest Threshold (Model 1) and Highest Threshold (Model 5).

\begin{tabular}{|c|c|c|c|c|c|c|}
\hline$\underline{\text { State }}$ & $\underline{\text { Chief }}$ & Pref. & Prev. & $\underline{\text { Init'd }}$ & Fatal & Pure/Mix \\
\hline Burma (Myanmar) & * & * & * & 20 & 5 & pure \\
\hline Cambodia & * & * & * & 14 & 6 & pure \\
\hline China & & & * & 134 & 70 & mixed with Confucianism, Tao \\
\hline Japan & * & * & * & 2 & 1 & mixed with Shinto \\
\hline Korea, South† & * & * & & 33 & 9 & mixed with Confucianism \\
\hline Laos & & * & & 4 & -- & pure \\
\hline Mongolia & & & * & 2 & -- & pure \\
\hline Sri Lanka & * & * & * & 1 & -- & pure \\
\hline Taiwan & & * & * & 23 & 4 & mixed with Confucianism, Tao \\
\hline Thailand & * & * & * & 46 & 30 & pure \\
\hline Vietnam (, North) & & & * & 21 & 1 & pure \\
\hline Vietnam, South & & & * & 33 & 14 & pure \\
\hline
\end{tabular}

† The religion of the population of North Korea is coded as Not Religious and its regime Preference as Atheist.

The most immediately interesting feature in Table 7-1 is how short it is compared to similar surveys on Christian and Muslim states. This raises a potential problem with any 
measurement of Buddhism: the fewer the Buddhist states, the less likely that the other characteristics of Buddhist states will vary widely.

With that potential pitfall in mind, we proceed to the probability of a Buddhist state initiating an interstate armed conflict (in violation of jus ad bellum). Table 7-2 is a summary of the logit coefficients associated with the Buddhist Mix category (first presented in Chapter 4), and the Buddhist (Pure) category.

Table 7-2. Summary of Logit Coefficients for Buddhist Mix and Buddhist (Pure) States.

\begin{tabular}{|c|c|c|c|c|c|c|}
\hline Variable & $\frac{\text { Model } 1}{\text { (Robust SE) }}$ & Model 2 & Model 3 & Model 4 & Model 5 & $\begin{array}{l}\text { App. } \\
\text { Table }\end{array}$ \\
\hline $\begin{array}{l}\text { Buddhist Mix } \\
\text { Chief Exec. (binary) }\end{array}$ & $\begin{array}{l}-.0652 \\
(.2258)\end{array}$ & $\begin{array}{l}-.0343 \\
(.2320)\end{array}$ & $\begin{array}{l}-.2702 \\
(.2751)\end{array}$ & $\begin{array}{l}-.2417 \\
(.2863)\end{array}$ & $\begin{array}{l}-.8603 \dagger \\
(.5848)\end{array}$ & B-41 \\
\hline $\begin{array}{l}\text { Buddhist (Pure) } \\
\text { Chief Exec. (binary) }\end{array}$ & $\begin{array}{l}.1108 \\
(.2351) \\
\end{array}$ & $\begin{array}{l}.1116 \\
(.2417) \\
\end{array}$ & $\begin{array}{r}-.0484 \\
(.2800) \\
\end{array}$ & $\begin{array}{r}-.0519 \\
(.2912) \\
\end{array}$ & $\begin{array}{r}-.6159 \\
(.5926) \\
\end{array}$ & B-114 \\
\hline $\begin{array}{l}\text { Buddhist Mix } \\
\text { Preference (binary) }\end{array}$ & $\begin{array}{l}.2538 \dagger \\
(.1764)\end{array}$ & $\begin{array}{l}.3005^{\circ} \\
(.1794)\end{array}$ & $\begin{array}{l}.1272 \\
(.2062)\end{array}$ & $\begin{array}{l}.1850 \\
(.2108)\end{array}$ & $\begin{array}{l}-.4460 \\
(.4197)\end{array}$ & B-42 \\
\hline $\begin{array}{l}\text { Buddhist (Pure) } \\
\text { Preference (binary) }\end{array}$ & $\begin{array}{l}.0430 \\
(.2273) \\
\end{array}$ & $\begin{array}{r}.1061 \\
(.2283) \\
\end{array}$ & $\begin{array}{c}.0329 \\
(.2535) \\
\end{array}$ & $\begin{array}{r}.1166 \\
(.2549) \\
\end{array}$ & $\begin{array}{l}-.4730 \\
(.5154) \\
\end{array}$ & B-115 \\
\hline $\begin{array}{l}\text { Buddhist Mix } \\
\text { GRP }(0-10)\end{array}$ & $\begin{array}{l}.0631^{\circ} \\
(.0324)\end{array}$ & $\begin{array}{l}.0649^{*} \\
(.0329)\end{array}$ & $\begin{array}{l}.0485 \\
(.0387)\end{array}$ & $\begin{array}{l}.0512 \\
(.0397)\end{array}$ & $\begin{array}{l}-.0233 \\
(.0701)\end{array}$ & B-43 \\
\hline $\begin{array}{l}\text { Buddhist (Pure) } \\
\text { GRP }(0-10)\end{array}$ & $\begin{array}{l}.0074 \\
(.0431) \\
\end{array}$ & $\begin{array}{l}.0071 \\
(.0442) \\
\end{array}$ & $\begin{array}{r}.0183 \\
(.0467) \\
\end{array}$ & $\begin{array}{l}.0196 \\
(.0481) \\
\end{array}$ & $\begin{array}{r}-.0394 \\
(.0861) \\
\end{array}$ & B-116 \\
\hline $\begin{array}{l}\text { Buddhist Mix } \\
\text { Prevalence (binary) }\end{array}$ & $\begin{array}{l}.3804^{* *} \\
(.1247)\end{array}$ & $\begin{array}{l}.3916^{* *} \\
(.1292)\end{array}$ & $\begin{array}{l}.2534^{\circ} \\
(.1386)\end{array}$ & $\begin{aligned} .2579^{\circ} \\
(.1450)\end{aligned}$ & $\begin{array}{l}.1954 \\
(.2209)\end{array}$ & B-44 \\
\hline $\begin{array}{l}\text { Buddhist (Pure) } \\
\text { Prevalence (binary) }\end{array}$ & $\begin{array}{r}.4871^{* *} \\
(.1814) \\
\end{array}$ & $\begin{array}{r}.4790^{*} \\
(.1872) \\
\end{array}$ & $\begin{array}{r}.4766^{*} \\
(.1998) \\
\end{array}$ & $\begin{array}{r}.4728^{*} \\
(.2077) \\
\end{array}$ & $\begin{array}{r}.1188 \\
(.3717) \\
\end{array}$ & B-117 \\
\hline $\begin{array}{l}\text { Buddhist Mix } \\
\text { Population (10\%) }\end{array}$ & $\begin{array}{l}.0374^{\star *} \\
(.0136)\end{array}$ & $\begin{array}{l}.0402^{* *} \\
(.0140)\end{array}$ & $\begin{array}{l}.0230 \dagger \\
(.0152)\end{array}$ & $\begin{array}{l}.0256 \dagger \\
(.0158)\end{array}$ & $\begin{array}{l}.0140 \\
(.0250)\end{array}$ & B-45 \\
\hline $\begin{array}{l}\text { Buddhist (Pure) } \\
\text { Population }(10 \%)\end{array}$ & $\begin{array}{l}.0518^{* \star} \\
(.0196)\end{array}$ & $\begin{array}{l}.0541^{* *} \\
(.0199)\end{array}$ & $\begin{array}{l}.0487^{*} \\
(.0220)\end{array}$ & $\begin{array}{l}.0521^{*} \\
(.0224)\end{array}$ & $\begin{array}{l}.0013 \\
(.0435)\end{array}$ & B-118 \\
\hline
\end{tabular}

${ }^{\circ} p<.10 \quad{ }^{*} p<.05 \quad{ }^{* *} p<.01{ }^{* * *} p<.001$

$+p<.15$

Note that few of the coefficients are statistically significant. The effect of a Buddhist population (both Prevalence and percentage of population) is the strongest and most 
significant of the three independent variables, and curiously, the effect of the Buddhist (Pure) category is more strongly positive than that of the Buddhist Mix category. This is the opposite finding than expected. All Buddhist Mix states happen to be Mahayana Buddhist and nearly all Buddhist (Pure) states are Theravada, and Mahayana scripture appears to be more tolerant of the use of force than Theravada scripture. For these two reasons, it was expected that Buddhist Mix states would have a greater propensity to use force than Buddhist (Pure) states. Such is the case for states with Buddhist regime Preferences (though only one coefficient out of ten is statistically significant), but not for states with Buddhist populations. It should be noted also that the results are not very consistent between independent variables, nor are they consistent between models within the same independent variable. The trend in the other religions has been that signs of coefficients are generally uniform across independent variables, and that the propensity to use force steadily increases or decreases between Model 1 and Model 5. That is not the case for the Buddhist Mix or Buddhist (Pure) categories.

These findings could lead to three possible conclusions. One is that there are simply not enough Buddhist state-years in the time period being examined (1946-2001) to provide a sufficiently diverse sample, especially given that the dependent variable measures a rare event. If that is the case, then the defects in these measurements are not curable except by greatly expanding the time period—and since many Buddhist states did not enter the Westphalian state system until the $20^{\text {th }}$ century, sufficient data on their armed conflicts-let alone control variables-is unlikely to be available at this time. The second possible conclusion is that the Buddhist war ethic in scripture-in all schools- 
does not have any significant effect on the practice of Buddhist states. This is a strong possibility, given the exposition of Buddhist scripture in the previous section.

The third possibility is that the effect of Buddhism is being masked by another factor, which is the second-most immediately interesting feature in Table 7-1. All Buddhist states are located in the Asia-Pacific region, therefore most politically relevant dyads involving Asia-Pacific states are with other Asia-Pacific states. This observation raises the possibility that some geopolitical factor within the Asia-Pacific region makes that region more conflict-prone. A regression of the binary variable asiapacificdyad (denoting whether or not both states are in the Asia-Pacific region) reveals a strong and statistically significant correlation for all models except Model 5 (armed conflict with fatalities, the highest threshold)—and the $\mathrm{p}$ value of Model 5 did not miss significance by much. Table 7-3 is a summary of the logit coefficients of the Asia-Pacific dyad as an independent variable, regressed with the standard controls used in this study.

Table 7-3. Summary of Logit Coefficients for Asia-Pacific Dyads.

\begin{tabular}{lcccccc} 
Variable & Model 1 & Model 2 & Model 3 & Model 4 & Model 5 & $\begin{array}{c}\text { App. } \\
\text { Table }\end{array}$ \\
\hline Asia-Pacific & (Robust SE) & & & & & \\
Dyad (binary) & $.5922^{* *}$ & $.6194^{* * *}$ & $.5186^{* * *}$ & $.5512^{* * *}$ & $.2856 \dagger$ & B-119 \\
\hline & $(.1004)$ & $(.1043)$ & $(.1092)$ & $(.1142)$ & $(.1861)$ & \\
\hline
\end{tabular}

${ }^{\circ} p<.10{ }^{*} p<.05{ }^{* *} p<.01{ }^{* * *} p<.001$ $\dagger p<.15$

Except in Model 5, the effect of membership in an Asia-Pacific dyad is stronger than that of any of the variables associated with Buddhism. It is also stronger than most of the controls and quite a few of the variables associated with other religions. 
It would seem to behoove us, therefore, to test the effect of Buddhism while controlling for the Asia-Pacific dyad. The result of doing so is that nearly every coefficient associated with Buddhism turns negative, as summarized in Table 7-4.

Table 7-4. Summary of Logit Coefficients for Buddhist Mix States, Controlling for AsiaPacific Dyads.

\begin{tabular}{|c|c|c|c|c|c|c|}
\hline Variable & Model 1 & Model 2 & Model 3 & Model 4 & Model 5 & $\begin{array}{l}\text { App. } \\
\text { Table }\end{array}$ \\
\hline & (Robust SE) & & & & & \\
\hline $\begin{array}{l}\text { Buddhist Mix } \\
\text { Chief Exec. (binary) }\end{array}$ & $\begin{array}{l}-.4488^{\circ} \\
(.2304)\end{array}$ & $\begin{array}{l}-.4330^{\circ} \\
(.2368)\end{array}$ & $\begin{array}{l}-.6287^{*} \\
(.2799)\end{array}$ & $\begin{array}{l}-.6205^{\star} \\
(.2914)\end{array}$ & $\begin{array}{r}-1.0845^{\circ} \\
(.5874)\end{array}$ & B-120 \\
\hline $\begin{array}{l}\text { Buddhist Mix } \\
\text { Preference (binary) }\end{array}$ & $\begin{array}{l}-.1375 \\
(.1852)\end{array}$ & $\begin{array}{l}-.1064 \\
(.1884)\end{array}$ & $\begin{array}{l}-.2429 \\
(.2166)\end{array}$ & $\begin{array}{l}-.2065 \\
(.2217)\end{array}$ & $\begin{array}{r}-.7134^{\circ} \\
\quad(.4277)\end{array}$ & B-121 \\
\hline $\begin{array}{l}\text { Buddhist Mix } \\
\text { GRP }(0-10)\end{array}$ & $\begin{array}{l}-.0211 \\
(.0361)\end{array}$ & $\begin{array}{l}-.0201 \\
(.0367)\end{array}$ & $\begin{array}{l}-.0325 \\
(.0436)\end{array}$ & $\begin{array}{l}-.0316 \\
(.0448)\end{array}$ & $\begin{array}{l}-.0837 \\
(.0772)\end{array}$ & B-122 \\
\hline $\begin{array}{l}\text { Buddhist Mix } \\
\text { Prevalence (binary) }\end{array}$ & $\begin{array}{l}.0547 \\
(.1370)\end{array}$ & $\begin{array}{l}.0616 \\
(.1425)\end{array}$ & $\begin{array}{l}-.0824 \\
(.1498)\end{array}$ & $\begin{array}{l}-.0878 \\
(.1571)\end{array}$ & $\begin{array}{l}.0093 \\
(.2459)\end{array}$ & B-123 \\
\hline $\begin{array}{l}\text { Buddhist Mix } \\
\text { Population (10\%) }\end{array}$ & $\begin{array}{l}-.0046 \\
(.0154) \\
\end{array}$ & $\begin{array}{r}-.0035 \\
(.0159) \\
\end{array}$ & $\begin{array}{r}-.0173 \\
(.0169) \\
\end{array}$ & $\begin{array}{r}-.0171 \\
(.0176) \\
\end{array}$ & $\begin{array}{l}-.0058 \\
(.0284)\end{array}$ & B-124 \\
\hline
\end{tabular}

${ }^{\circ} p<.10{ }^{*} p<.05{ }^{* *} p<.01{ }^{* * *} p<.001$

The coefficients for the Asia-Pacific dyad dummy variables, which are documented in Appendix B but not reproduced here, are all positive; they range between about .55 and .66 (except in Model 5) and are all highly significant. In Model 5, the effect of the AsiaPacific dyad is significant only for Buddhist regime Preferences (and its coefficient is about .41). Apparently the characteristics of the Asia-Pacific region are having some effect on the propensities of states to use force. But in an odd turn of events, the coefficients for Buddhist Mix Prevalence and population all lose their statistical significance, yet those for a Buddhist Mix chief executive are all now significant where they were not before. It would appear that a state with a chief executive who is Buddhist, Confucian, Taoist, or Shinto is statistically much less likely to use force against another 
state that is not located in the Asia-Pacific region, than a state with a chief executive of a religion other than those four. However, I am concerned that the approach of introducing a dummy variable for Asia-Pacific dyads may not be adequate to distinguish the effects of Buddhism (if any) from the effects of the region, for being a Buddhist state (buddmixchief $1=1$, buddmixpref1=1, or buddmixprev1=1) is a perfect predictor of location in the Asia-Pacific region, therefore it is also strongly correlated with being in an Asia-Pacific dyad (asiapacificdyad=1) due to the dataset containing observations of only politically relevant dyads.

It therefore remains to examine the practice of states within the Asia-Pacific region itself. Table 7-5 summarizes the effects of Buddhism on the use of force solely among Asia-Pacific dyads.

Table 7-5. Summary of Logit Coefficients for Buddhist Mix States, Within Asia-Pacific Region.

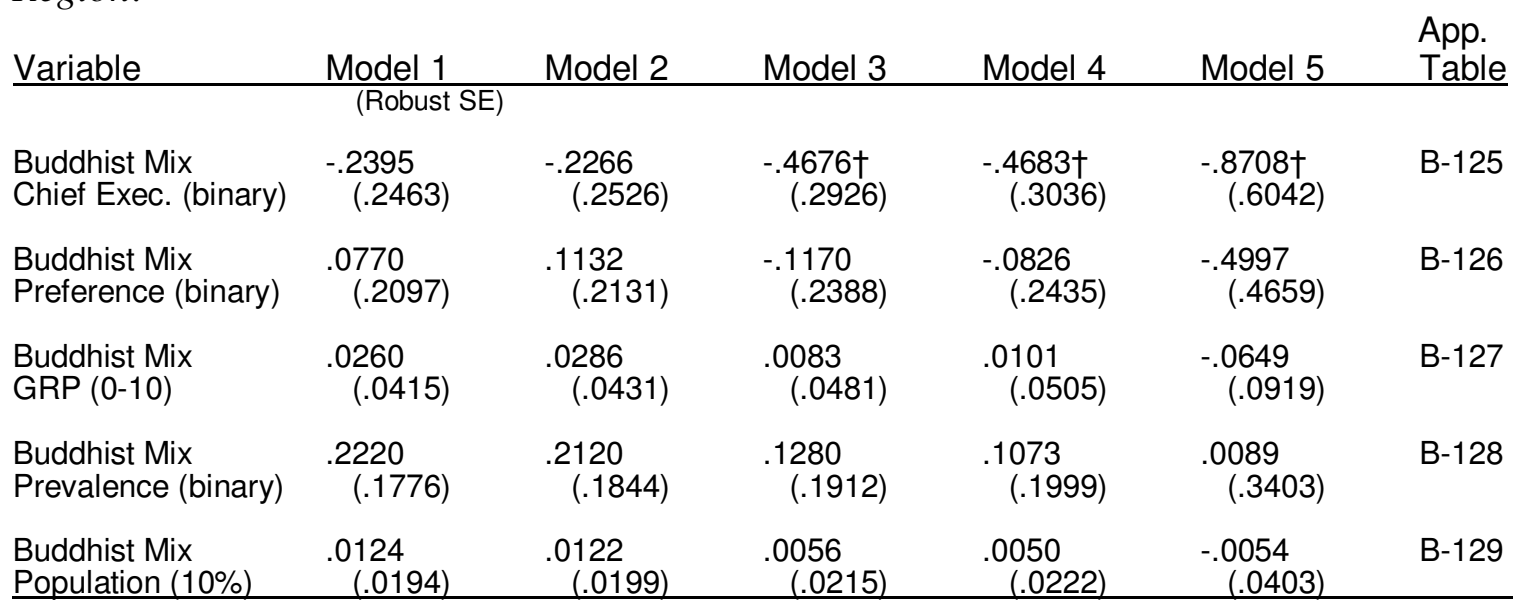

${ }^{\circ} p<.10 \quad{ }^{*} p<.05 \quad{ }^{* *} p<.01{ }^{* * *} p<.001$

$\dagger p<.15$

The Chief Executive coefficients at the higher thresholds of armed conflict just miss statistical significance at $90 \%$ confidence; it is possible that with more observations, a 
negative effect of having a Buddhist chief executive could be identified with greater confidence. However, given the lack of significance according to the conventional standard of the field for confidence, we cannot conclude that Buddhist states are any more or less likely than non-Buddhist states to initiate armed conflicts with other AsiaPacific states. The results are even less promising when only purely Buddhist states are tested, as summarized in Table 7-6.

Table 7-6. Summary of Logit Coefficients for Buddhist (Pure) States, Within Asia-Pacific Region.

\begin{tabular}{|c|c|c|c|c|c|c|}
\hline Variable & Model 1 & Model 2 & Model 3 & Model 4 & Model 5 & $\begin{array}{l}\text { App. } \\
\text { Table }\end{array}$ \\
\hline \multicolumn{7}{|c|}{ (Robust SE) } \\
\hline $\begin{array}{l}\text { Buddhist (Pure) } \\
\text { Chief Exec. (binary) }\end{array}$ & $\begin{array}{l}-.1135 \\
\quad(.2564)\end{array}$ & $\begin{array}{l}-.1129 \\
\quad(.2638)\end{array}$ & $\begin{aligned}-.2958 \\
(.3013)\end{aligned}$ & $\begin{array}{l}-.3076 \\
(.3135)\end{array}$ & $\begin{array}{l}-.7139 \\
\quad(.6349)\end{array}$ & B-130 \\
\hline $\begin{array}{l}\text { Buddhist (Pure) } \\
\text { Preference (binary) }\end{array}$ & $\begin{array}{l}-.2049 \\
(.2524)\end{array}$ & $\begin{array}{l}-.1338 \\
\quad(.2541)\end{array}$ & $\begin{array}{l}-.2253 \\
(.2813)\end{array}$ & $\begin{array}{l}-.1394 \\
(.2835)\end{array}$ & $\begin{array}{l}-.6186 \\
(.5708)\end{array}$ & B-131 \\
\hline $\begin{array}{l}\text { Buddhist (Pure) } \\
\text { GRP }(0-10)\end{array}$ & $\begin{array}{l}-.0258 \\
(.0488)\end{array}$ & $\begin{array}{l}-.0231 \\
(.0504)\end{array}$ & $\begin{aligned}-.0168 \\
(.0527)\end{aligned}$ & $\begin{aligned}-.0129 & (.0546)\end{aligned}$ & $\begin{aligned}-.0612 \\
(.0969)\end{aligned}$ & B-132 \\
\hline $\begin{array}{l}\text { Buddhist (Pure) } \\
\text { Prevalence (binary) }\end{array}$ & $\begin{array}{l}.1999 \\
(.2240)\end{array}$ & $\begin{array}{l}.2130 \\
(.2315)\end{array}$ & $\begin{array}{l}.1672 \\
(.2451)\end{array}$ & $\begin{array}{l}.1802 \\
(.2550)\end{array}$ & $\begin{array}{l}.0186 \\
(.4464)\end{array}$ & B-133 \\
\hline $\begin{array}{l}\text { Buddhist (Pure) } \\
\text { Population }(10 \%)\end{array}$ & $\begin{array}{l}.0158 \\
(.0247) \\
\end{array}$ & $\begin{array}{l}.0189 \\
(.0249) \\
\end{array}$ & $\begin{array}{l}.0149 \\
(.0279) \\
\end{array}$ & $\begin{array}{l}.0186 \\
(.0284) \\
\end{array}$ & $\begin{array}{r}-.0025 \\
(.0545) \\
\end{array}$ & B-134 \\
\hline
\end{tabular}

${ }^{\circ} p<.10 \quad{ }^{*} p<.05 \quad{ }^{* *} p<.01{ }^{* * *} p<.001$

The Buddhist (Pure) coefficients are not consistently lower or higher in value than those of Buddhist states as a whole_-a reflection of the effects of the other East Asian religions as well. Furthermore, not a single coefficient comes close to statistical significance. It would appear that even pure Buddhism (not intermingled with other East Asian religions) has no measurable effect on Buddhist states' propensity to armed conflict within the Asia-Pacific region. 


\section{Conclusion}

In this chapter we have measured empirically the effects of Buddhism on states' propensities to initiate interstate armed conflict (in violation of jus ad bellum), and found none with confidence. This is the result that Lambert Schmithausen (1999) would have predicted, along with others like him who maintain that the Buddhist war ethic has not exerted any influence on leaders of states. This appears to be the case also for states with Buddhist regimes (and regime Preferences) and Buddhist presidents or prime ministers.

However, the foregoing findings, which are not as conclusive as the findings on the effects of Christianity and Islam shown in previous chapters, raise two questions. One question is whether the effects of Buddhism are even measurable. One challenge to the empirical testing has been the paucity of Buddhist state-years relative to the numerous and diverse state-years for Christianity and Islam. The other challenge has been to disaggregate Buddhism from the Asia-Pacific region. This was not a significant problem for Christianity and Islam, since states of those religions are located in several regions.

Assuming that the research design was sound enough to produce valid empirical results despite the challenges outlined above, the second question is why no effect of Buddhism was found. I have argued that although core Buddhist scripture maintains an ideal ethic of absolute non-violence, that ideal is impossible to put into practice. Furthermore, the canons of both major schools (especially the Pali Canon) contain enough selfcontradiction to render the Buddhist war ethic inconsistent or even incoherent. Thus, not only may the governments of Buddhist states not wish to put the Buddhist war ethic into practice, but they also may not be able to do so. Although some Christian and Muslim scripture conflicts with the core war ethics of those respective religions, the level of 
inconsistency is not enough to undermine their overall coherency, whereas it is for the war ethic in Buddhism.

In the explorations of the Christian and Islamic war ethics, it was possible to compare their relative permissiveness to that of secular jus ad bellum (both were found to be more permissive, with the Islamic war ethic being more permissive than the Christian). Such an assessment does not appear to be possible for Buddhism, partly because its war ethic seems to espouse opposing extremes but no middle ground, and partly because no empirical correlation can be found. We cannot conclude that Buddhist states are any more or less likely than non-Buddhist states to violate jus ad bellum; we can only conclude that the probability of their doing so is greater than zero (on the basis of Figures $4 \mathrm{H}$ through 4K in Chapter 4) - putting Buddhist states in good company with states of all religions. The final chapter will attempt to observe the influence of religion on states' decisions to make war or peace in a couple of specific cases. 


\section{CHAPTER 8}

\section{BUSH AND SADAT: TWO ILLUSTRATIONS OF THE EFFECT OF RELIGION}

\section{Introduction}

The many quantitative measurements in the previous chapters are useful for determining the extent and limitations of correlations between a state's religion and its propensity of a state to use force. Such methods are less effective in inferring causality. This chapter will attempt to complement the findings of the other chapters by providing descriptive case studies (see King Keohane \& Verba 1994: 45). Using the technique of "process-tracing," in which the process by which various initial conditions are translated into decisional outcomes is examined closely (id. 226, citing George \& McKeown 1985: 35), this chapter seeks to observe directly the effect of religion on the decisions of states—or more precisely, their chief executives—-to use military force or not. ${ }^{1}$ Two illustrations of this effect are provided: the entrance of the United States into the Gulf War of 1990-1991 against Iraq, and the outbreak of the Yom Kippur War of 1973 and subsequent peace between Egypt and Israel.

\section{George Bush and the Gulf War}

This case study examines the process by which religion influenced the decision of the United States to go to war to liberate Kuwait from Iraqi occupation in January 1991. Iraq is coded as the initiator of the Gulf War in the MID data set, not the U.S., but the case is

\footnotetext{
${ }^{1}$ In these case studies, the observed behavior is the use of military force or not, without regard to jus ad bellum.
} 
useful nevertheless because for the United States the Gulf War was a war of choice. The decision to go to war or not rested ultimately on the shoulders of U.S. President George H.W. Bush. Bush was the chief executive of a state that was $84 \%$ Christian (all denominations combined) and 56\% Protestant, and Bush himself was Protestant. Moreover, Bush was the chief executive of a government with a 25\% GRP for Western Christianity (Catholic and Protestant combined), which is a relatively tepid degree of institutional religious Preference.

On August 2, 1990, after nearly three weeks of saber-rattling and several years of airing its grievances against Kuwait (real or imagined), Iraq invaded and occupied that country and took control of its oil fields. The invasion set off the Gulf War. U.S. forces immediately deployed to Saudi Arabia to deter an Iraqi invasion of that country, and after five months of coalition-building and military buildup, the U.S. led a multilateral counter-invasion to expel Iraqi forces from Kuwait and restore Kuwaiti sovereignty.

\section{Realist Reasons for War with Iraq}

That the United States should desire to spearhead the liberation of Kuwait was quite logical from the realist point of view. Restoring Kuwait's sovereignty—and in doing so, rejecting Iraq's annexation of Kuwait as its newest province-would affirm stability as a paramount value of the international system. ${ }^{2}$ A decisive military victory would directly benefit the U.S. as well: it would showcase to the world the capabilities of the U.S.

\footnotetext{
${ }^{2}$ In legal terms, the principle at work was that of uti possedetis, in which disturbing political boundaries drawn by the European powers during the colonial period is strongly discouraged, however arbitrary those boundaries might be, for the sake of stability of international borders today.
} 
military and free the U.S. psyche from the inhibitions and self-doubt induced by the failures of the Vietnam War and the Iran hostage-rescue attempt. It would also showcase the relevance and utility of U.S. power and hegemony in the new post-Cold War environment, validating the U.S.'s claim to continued global leadership in the face of claims of its decline relative to Japan and Germany. Finally, from the perspective of the militaryindustrial complex, a victory would justify continued high defense spending in the face of calls for cutbacks after the end of the Cold War (Bacevich 2002: 58-9). ${ }^{3}$

The above incentives for the U.S. to undertake the Gulf War were decidedly realist in character, and were natural motivators for war within the Bush Administration, many of whose key national security figures hailed from the Kissingerian school of foreign policy. ${ }^{4}$ Bush's National Security Advisor Brent Scowcroft and Deputy Secretary of State Lawrence Eagleburger both had been protégés of Henry Kissinger and had worked in his private firm as well (Smith 1992: 159, 174), and President Bush himself had been the ambassador to the UN and later to China in the Nixon and Ford Administrations (in which Kissinger had been National Security Advisor and Secretary of State). ${ }^{5}$

However, materialist rationales for war advanced by the Bush Administration in the United States largely centered on the potential for economic harm if Iraq were allowed to keep Kuwait. Kuwait was one of the world's largest exporters of oil, and the threat of another oil shock of the type that rocked the global economy in the 1970s constantly

\footnotetext{
${ }^{3}$ In addition, inserted almost as a footnote, President Bush also cited the protection of American citizens abroad, i.e. those who had been trapped in Kuwait after the invasion (Bush \& Scowcroft 1998: 341).

${ }^{4}$ On the Kissingerian brand of realism, see Smith 1986: chap. 8.

${ }^{5}$ Biographies of Bush contain no evidence that he himself had significant contact with Kissinger or was influenced by him directly.
} 
overshadowed the crisis (Freedman \& Karsh 1993: 180-8). Iraqi President Saddam Hussein was known to prefer higher oil prices (id. 214-5; Bush \& Scowcroft 1998: 349) and the National Security Council (NSC) feared the consequences of Saddam's "unprecedented influence" over the global oil market (Freedman \& Karsh 1993: 74-6)—one of Saddam's grievances against Kuwait was that Kuwaiti overproduction had depressed oil prices. And sure enough, oil prices immediately began to rise after the invasion due to fears that Saddam's next target would be Saudi Arabia (id. 180-1). Bush voiced this concern in a television address to the nation on August 8, 1990 (Bush \& Scowcroft 1993: 340-1), and as late as December 1990, the administration's concern about Saddam controlling Kuwait's oil supplies remained a primary justification of the war to Congress. ${ }^{6}$

Iraqi control of Kuwaiti oil itself would have no direct impact on the U.S. economy, for the chief importers of Kuwaiti oil were Europe and Japan rather than the U.S., and the loss of the Kuwaiti oil market to Iraqi control was therefore not likely to affect U.S. oil imports. But oil imports were not the point; the impact on the U.S. economy would be the global rise in the price of oil that accompanied any fear for the stability of the global oil market. Another oil shock would lead to another recession, and a recession would directly impact the U.S. economy. That was the Bush Administration's point. On October 22, Bush warned how "our jobs, our way of life, our own freedom, would all suffer if control of the world's great oil reserves fell into the hands of that one man, Saddam Hussein" (Freedman \& Karsh 1993: 214-5). Mirroring this concern, Secretary of State James Baker

\footnotetext{
${ }^{6}$ Statement by the Honorable Dick Cheney, Secretary of Defense, Concerning Operation Desert Shield Before the Committee on Armed Services, United States Senate, December 3, 1990. On file with author. I would like to thank Daniel Heimbach for supplying me with this document.
} 
delivered a carefully prepared speech on November 13 , in which he linked the liberation of Kuwait to the standard of living in the United States:

The economic lifeline of the industrial world runs from the Gulf, and we cannot permit a dictator such as this to sit astride that economic lifeline. ... And to bring it down to the level of the average American citizen, let me say that means jobs. If you want to sum it up in one word, it's jobs. Because an economic recession worldwide, caused by the control of one nation, one dictator if you will, of the West's economic lifeline will result in the loss of jobs on the part of American citizens. (Baker 1995: 336)

This statement garnered much attention from the press, and it appears to be the root of the popular attribution of Bush's motivation for war as “jobs, jobs, jobs.” Bush himself did not phrase the rationale this way, but he did endorse it (Bush \& Scowcroft 1998: 399). ${ }^{7}$

\footnotetext{
${ }^{7}$ Several other possible motivations, less prominent at the time, deserve brief mention. One is that Iraq was known to be developing a nuclear arsenal, and on November 22 Bush articulated the concern, in light of Iraq's use of chemical weapons during the Iran-Iraq War, that Saddam would one day use nuclear weapons, saying "He has never possessed a weapon that he hasn't used" (Freedman \& Karsh 1993: 224). The other motivation, advanced by Bush's critics, is personal aggrandizement. It is an old adage in American politics that great Presidents are made by wars; Jean Edward Smith contends that in urging Bush to stiffen his resolve against the invasion early in the crisis, British Prime Minister Margaret Thatcher, herself a successful wartime chief executive, "ignited his urge for greatness, and Bush caught fire" (1992: 71). Smith also argues that a short, successful war would deliver short-term benefits to Bush's presidency by countering the criticism of his lack of vision, diverting attention away from his son Neil's role in the nationwide Savings and Loan debacle, and (Smith implies) lead to successful reelection (id. 77). However, Smith's claim is not persuasive, for it does not comport with the many other accounts of various peace initiatives to Iraq as well as Bush's personal reluctance to resort to war (to be outlined below).
} 
The administration, from Bush on down, believed that advancing these rationales was necessary to gain public support for the war. Bush was being criticized, even heckled, by anti-war protestors who had seized on the slogan "No blood for oil" (Freedman \& Karsh 1993: 214; Baker 1995: 336). By mid-September public opposition to the war had climbed from seven to twenty-three percent (Bush \& Scowcroft 1998: 372). Bush also believed that securing support from Congress was necessary for the war to succeed; although the War Powers Resolution of 1973 gave the President the authority to conduct hostilities for sixty days without Congressional approval, ${ }^{8}$ Bush was unwilling to set a precedent for launching such a monumental undertaking (involving half a million troops) without Congressional support, even if hostilities could be concluded in a short time. Enough members of Congress were sufficiently skeptical, however, to necessitate a long campaign to win them over, especially the Democrats. Beyond the usual partisanship, roots of opposition ranged from budgetary concerns to casualty aversion, particularly the fear of a Vietnam-style quagmire (Bush \& Scowcroft 1998: 358, 372, 389, 398). In addition, Senator Sam Nunn (D-GA) was raising questions about the use of sanctions to coerce Iraq's withdrawal from Kuwait and about the country's military readiness (id. 417). Opposition was being voiced even in military circles; the first military briefing to the NSC on a plan for an offensive operation "sounded unenthusiastic, delivered by people who didn't want to do the job" (id. 380-1). Several former generals, including former Chairman of the Joint Chiefs of Staff Admiral William Crowe, opposed the war in testimony before the Senate Armed Services Committee (id. 417). The Bush Administration had to persuade all of these sectors, using arguments that would resonate with

\footnotetext{
${ }^{8}$ War Powers Resolution, 87 Stat. 555 (1973).
} 
each, such as the consequences of mass layoffs due to a poor economy and the veiled nuclear threat posed by Iraq's WMD programs. Arguments such as these, however necessary it was to make them, instilled a widely-held belief in the public and the media that Bush's true motives were power-based, materialist, or as Andrew Bacevich (2002: 64) puts it, even "crass."

\section{President Bush's Moral Conflict}

Such a belief is misguided. Evidence from histories of the Gulf War, including those written by Bush himself long after any political consequences of such revelations had expired, supports the conclusion that Bush's primary motivators both for and against the war were moral concerns, not material (see also Heimbach 2011). Bush was by no means the enthusiastic warrior that Jean Edward Smith's (1992) treatment of the Gulf War makes him out to be; the evidence shows that Bush's decision to go to war against Iraq was slow and painstaking. ${ }^{9}$

What made his decision so difficult was that Bush found himself having to arbitrate between two competing moral principles that were both fundamental to his ethic of statecraft. One was the goal to stop aggression. Iraq's invasion of Kuwait deeply offended Bush, who had fought and nearly had been killed in World War II in order to uphold the principle of non-aggression (Freedman \& Karsh 1993: 212). Perhaps for that reason, or perhaps because he happened to be reading Martin Gilbert's (1989) history of World War II when the invasion took place (Bush \& Scowcroft 1998: 375), Bush drew an

\footnotetext{
${ }^{9}$ In fact, British Prime Minister Margaret Thatcher and Saudi King Fahd were both stronger advocates of using force than Bush (Bush \& Scowcroft 1998: 319-21).
} 
analogy between Saddam Hussein and Adolf Hitler. ${ }^{10}$ The appeasement of Hitler and the outbreak of World War II had taken place during Bush's formative years, and Bush was unwilling to risk a similar outcome by trying to appease Saddam. "What if Hitler's aggression had been checked earlier on?" he asked in a letter to Cardinal Bernard Law; “how many lives would have been saved?" (Bush 1999: 506). Bush was determined not to allow an unchecked Saddam Hussein to disrupt the post-Cold War world order, which Bush believed would be one of stability and rule of law. As Deputy Secretary of State Lawrence Eagleburger put it, Iraq's invasion “would 'set all the wrong standards' for the post-cold-war world" (Freedman \& Karsh 1993: 76), and Saddam’s “disdain for international law" offended Bush (Bush \& Scowcroft 1998: 374). "No nation," Bush said on November 30, 1990, "should be able to wipe a member state of the United Nations and the Arab League off the face of the earth" (quoted in Smith 1992: 1).

What was even more galling to Bush was the extended pattern of atrocities committed by the Iraqi occupation force in Kuwait, and by the regime in Iraq itself. It was bad enough that Iraq had invaded Kuwait with no plausible justification in international law, but the occupation itself was particularly brutal. Bush himself writes of the information he received and how he reacted to it:

August 9, 1990 (from Bush's memoirs): [The Kuwaiti ambassador to the U.S.] told us how the vaults had been looted of billions of dollars' worth of gold; how women had been raped; and that there was pillaging and plundering. (I also learned from Margaret Thatcher the next day that a stewardess from a British plane had been raped by Iraqi soldiers. The

\footnotetext{
${ }^{10}$ On analogies of crises to other crises that are fresh in the minds of states' leaders, see Khong 1992.
} 
British protested and the Iraqis said one of the men had been shot.) (Bush \& Scowcroft 1998: 341)

September 22 (from his diary): I've just read a horrible intelligence report on the brutal dismembering and dismantling of Kuwait. Shooting citizens when they are stopped in their cars. Exporting what little food there is. Brutalizing the homes. Dismantling the records. ... They quote the Norwegian ambassador, a respected observer, who attested to the brutality and to the horrible intention of this dictator, Saddam Hussein. . . . There is evidence that he's trying to re-populate Kuwait with Iraqi stooges. (Id. 374)

October 20 (in his letter to Jordan's King Hussein): Now, let me tell you what concerns me a lot. ... Saddam Hussein's policy of detaining innocent foreigners-holding them as hostages and staking them out near plants and installations so as to avoid retaliation for his brutality. ... [S] urely you must be shocked and offended by the documented reports of rape, of shooting children for passing out leaflets (and making their parents watch), of the systematical dismantling of Kuwait from the hospitals to the factories and stores. (Bush 1999: 484)

December 18 (from his memoirs): I received an eighty-page Amnesty International report on human rights violations in Kuwait. The report was full of descriptions of specific cases of abuse, documenting the accounts of the most horrible and systematic torture of Kuwaitis. There were 
gruesome accounts of mutilation and rape, as well as arbitrary executions.

I read stories of Iraqi soldiers taking people from their homes and shooting them in front of their families, of people dragged from cars to be beaten and shot, of bodies tossed out into the streets, and Iraqis withholding medical treatment from Kuwaitis and looting medical equipment. (Bush \& Scowcroft 1998: 427)

Bush himself admits that he became "very emotional about the atrocities" (Bush \& Scowcroft 1998: 374), and it was uncharacteristic for Bush to become emotional about anything (Heimbach 2011). By January 1991 he had come to refer to the crisis as the "rape of Kuwait" (Bush 1999: 506). For Bush, the cause against Saddam Hussein had assumed the mantle of "good versus evil, right versus wrong" (Bush \& Scowcroft 1998: 375). This is the portrait of a man who is angry at watching the terrible injustices perpetrated by Saddam Hussein—not so much to the United States or its citizens, as to other countries and their citizens_-and wanting to use his power to stop the suffering.

In hindsight, given his emotions, going to war should have been an easy decision for Bush. But at the time, what made his decision so difficult was that the strong moral impetus for war was impeded by an equally strong moral deterrent: the destruction and loss of life that accompanies war. Bush himself had been an aviator in the Pacific during World War II, and had seen first hand the destruction and loss of life, committed both by him and against him. His plane had been shot down twice and the second time he was the only survivor (Parmet 1997: 52-60). Seeing death around him affected his decisionmaking during the Iraq-Kuwait crisis, as Bush himself notes in his diary entry of October 12: 
Maybe it's from my own experience; maybe it's from the petty officer who was cut in half on the deck when I was standing a few feet away; or the number of pilots in my own squadron who were killed. . . I think my wartime experience does condition me as commander-in-chief and makes me cautious. (Bush \& Scowcroft 1998: 381-2)

Furthermore, Bush had learned statecraft during the Cold War, a time when the conesquences of war with the Soviet Union were so catastrophic that the media "celebrated the careful management of crises and the avoidance of nuclear war as the highest achievements of statecraft" (Barilleaux \& Rozell 2004: 130). Bush's reluctance to go to war over Kuwait was at least partly a reflection of his personal distaste for it.

His reluctance was also a reflection of the casualty projections. The unusually low actual casualty rate for the U.S. during the Gulf War $^{11}$ tends to obscure the fact that prior to the commencement of hostilities the casualty was projected to be much higher. The United States had not fought a major war since the Vietnam War, and many of its troops had never been in actual combat. In contrast, the Iraqi army was battle hardened, having just fought an eight-year war with Iran, and the number of Iraqi troops in the Kuwaiti theatre of operations was estimated to be at least 540,000 (Freedman \& Karsh 1993: 280). By October 1990, projections of U.S. losses ranged from 10,000 to 50,000 (Bush \& Scowcroft 1998: 389), ${ }^{12}$ and those figures weighed heavily on the President, as he writes

\footnotetext{
${ }^{11}$ Out of 541,000 U.S. troops, only 148 were killed in action and 458 were wounded in action (Freedman \& Karsh 1993: 409).

${ }^{12}$ By December 1990the estimated losses varied even more widely, with the political and media opposition to the war touting the higher estimates $(20,000$ by television reporter Robert Novak; 50,000 by former
} 
on October 12: "The thing that weighs on me is sending kids into battle and the lives being lost" (id. 381). Despite Bush reconciling himself to these losses by mid-October (id. 382), the spectre of mass casualties continued to haunt him throughout the crisis. Bush's Thanksgiving Day visit to the troops on November 22 was an emotional event for him; “The marines and sailors all looked so young, and I was thinking, 'May God spare these lives if we have to fight"' (id. 412).

Bush's decision to go to war or not ultimately rode on the choice between two unpleasant prospects: mass U.S. casualties, ${ }^{13}$ and a brutal, unchecked aggressor in the Middle East. A January 22, 1991 letter to Cardinal Law sums up his dilemma and his resolution:

Wait until we hear the real story of the brutality to Kuwait. Before ordering our troops into battle, I thought long and hard about casualties, or, as our severest critics would put it—“body bags.” But as I pondered

Democratic senator George McGovern). In contrast, the military's estimate was 2000 (Bush \& Scowcroft 1998: 425).

${ }^{13}$ His concern for U.S. casualties raises the question of why Bush was not equally concerned for the Iraqi casualties that the war was likely to inflict. No such concern is documented in the written evidence. There are several possible reasons for this. First, Bush may have actually harbored concerns for opposing casualties but chose not to air them in order to avoid criticism from his political base. This alternative seems unlikely, since Bush does not document such concerns in his written works either (in which he has little incentive to hide them). Second, Bush may have believed that he could do little to affect the casualty count of the Iraqi army, but could do a great deal to affect the likelihood of U.S. casualties (by not committing them to offensive combat operations in the first place), so he chose to focus on factors that he could control. Third, Bush may have been indifferent to Iraqi casualties because of the reports of atrocities committed by the Iraqis who were occupying Kuwait. 
that horrible question, I also thought of unchecked aggression, of what would happen if the butcher of Baghdad could emerge the hero. What would that have meant for tomorrow? (Bush 1999: 505)

Bush had decided that the need to restore Kuwait's sovereignty, put an end to the "rape of Kuwait," and prevent further Iraqi aggression outweighed the substantial risk of high American casualties. This was not a choice that he had had to make with respect to Panama in 1989 (Heimbach 2011); U.S. forces had been vastly superior to the Panamanian Defense Force and Chairman of the Joint Chiefs of Staff Colin Powell's projection of "a few dozen" casualties had been the same whether the U.S. invaded Panama or not (Baker 1995: 189). ${ }^{14}$ Bush did none of the agonizing over Panama that he did over Iraq, for the costs of either action or inaction in the Panama crisis were relatively low. But in the Iraq-Kuwait crisis, the costs of both action and inaction were expected to be high. As Powell put it, "This would be the NFL, not a scrimmage" (id. 324). The deliberateness of Bush's decision to go to war reflected the gravity of the likely consequences of doing so.

\section{The Influence of Religion on Bush's Decision}

George Bush is not known for being overtly, publicly religious in the same way as Jimmy Carter (1996, 1997) and Ronald Reagan (2007 passim; Freiling 2000), nor is he a professed "born-again Christian” like his son George W. Bush (2010: 30-4). Bush considered his faith a private matter (Heimbach 2011) and as one reporter on Bush's morality noted, he rarely talked about it (Walsh 1991). However, his morality is firmly grounded

\footnotetext{
${ }^{14}$ In December 1989, Panama had just resumed its campaign of harassing and occasionally killing U.S. military personnel stationed around the Panama Canal (Baker 1995: 177-89).
} 
in Christianity, beginning with his childhood. "My family instilled some concepts in me at a very early age.... They believed very strongly in Christian ethics and helping others, and I've embraced that," he writes (quoted in Smith 1992: 135-6). His parents were devout Episcopalians, regular church attendees, and they infused their faith into their children. ${ }^{15}$ Bush's father often led the family in prayer and read Bible lessons (Parmet 1997: 31). "Our family was very oriented toward religion," says Bush's sister Nancy. "Every day at breakfast time there would be a lesson read from the Bible, and lessons from the parables as applicable to daily life were pointed out and emphasized" (King 1980: 18). Bush carried his faith with him to high school at Phillips Andover Academy, where he was a student deacon during his last two years (King 1980: 16) and was "attentive to chapel services" throughout his time there (Parmet 1997: 31).

Bush carried his faith into adulthood as well. Nicholas King (1980: 35) chronicles Bush's reaction to the end of World War II in the Pacific; while three other Navy couples sharing their house spent the day celebrating, Bush and his wife Barbara went to church to give thanks for the victory. When they relocated to Midland, Texas, they became active in a Presbyterian church, and both taught Sunday school there for a time (Parmet 1997: 79).

Bush remained deeply religious after entering into public service. While President, he had his personal secretary start his day with a bible verse on his desk every morning (Heimbach 2011). Bush's faith also influenced his decisions, including in security matters. In 1986, while serving as Reagan's Vice-President, Bush responded to a letter from Bishop Edmond Browning, the Presiding Bishop of the Episcopal Church (which by

\footnotetext{
${ }^{15}$ Bush also raised his own children in the Episcopal Church (Bush 2010: 30).
} 
then was again Bush's church as well), objecting to the administration's support of the contras in Nicaragua. After defending the policy, Bush closed with a reference to his faith: "[M]y view is not simply official it $[$ sic $]$ is profoundly personal, stemming largely from what my Episcopal faith has taught me" (Bush 1999: 348).

It is Bush's interaction with Bishop Browning during the buildup of forces in the Gulf that is of particular interest in this case study. Bush had discussed the morality of war against Iraq with many spiritual leaders during the Gulf crisis, including Browning, Cardinal Law, televangelists Robert Schuller and Billy Graham, and Pope John Paul II (Walsh 1991). Most of these discussions were by correspondence, and would have been relatively unremarkable, for it is expected that the President of the United States would have some interaction with an American Catholic Cardinal and other influential religious figures in the United States simply by virtue of his office. But Bush's interaction with Bishop Browning is beyond routine; Browning was the Presiding Bishop of Bush's own church, the two had corresponded since the 1980s, and Browning had delivered a homily at Bush's inauguration (Dart 1990).

Browning's opposition to the war came early in the crisis and was unwavering. ${ }^{16}$ On October 5, 1990, Browning issued a statement to the bishops and members of the Episcopal Church, urging Bush to "never give in to the trap of war." His chief concern was the prospect of mass casualties and large-scale destruction in a war, as he saw it, "over cheap oil" (Cornell 1990). He further attempted to link the Gulf crisis with the Palestinian problem (a linkage that Bush emphatically rejected; Connell 1990). Browning was one member of a group of national leaders of mostly mainstream Protestant and Orthodox

\footnotetext{
${ }^{16}$ For a complete statement of Bishop Browning's position, see Browning 1991.
} 
churches in the United States, led by Jim Wallis, the editor of Sojourners Magazine. The Bush Administration believed that Wallis had seized upon the prospect of war in the Gulf to inaugurate a new peace movement (Heimbach 2011). Because of Browning's relationship with Bush, Wallis's group specifically chose Browning to articulate their position directly to the President (Heimbach 2011).

One factor in this group's opposition may have been partisan differences. Of the 18 church officials in Wallis's group, most were from New York or nearby, an area in which the majority are liberal Democrats. Conservative denominations such the Southern Baptist Convention, the Lutheran Church-Missouri Synod, and the Presbyterian Church of America were conspicuously absent from this group. The Catholic Church was also not represented. ${ }^{17}$ It may not be coincidental that the most vocal opposition in Congress also came from Democrats.

But aside from partisan differences, Bush was also clearly dissatisfied with Browning's moral position, citing the moral need to stop the atrocities taking place in Kuwait. Not to be silenced, Browning and other religious leaders sent a new letter to Bush on November 29, calling on him to withdraw any U.S. forces not needed to maintain peace and security in the Persian Gulf, and further asserting that the resort to war as a means of settling international disputes "is in conflict with the teachings of our faith" (St. Louis Post Dispatch 1990). Browning and seventeen other church leaders went on a "peace

\footnotetext{
${ }^{17}$ A Catholic bishop reportedly participated in a news conference of seven church leaders at the Capitol on October 11, 1990, in which they urged the President to rule out war (Stepp 1990). However, the Pope himself appears to have taken the same view as the President, praying for peace but realizing that war may be necessary (Walsh 1991).
} 
pilgrimage" to the Middle East in December, including to Iraq (though he was unable to meet with Saddam Hussein). Browning requested a private meeting with the President, and Bush agreed to meet with him, partly because of his standing as the presiding official of a major American denomination, but also partly because Browning was the presiding official of his own church (Heimbach 2011).

That meeting took place on December 20, with Baker the only other attendee. The meeting was emotional for Bush (Bush \& Scowcroft 1998: 427). Browning told Bush that everyone he had encountered during his trip to the Middle East wanted peace (id. 428). Browning told Bush that he (Bush) had created much fear in the Middle East (Heimbach 2011). War would not serve anyone, he argued, but instead would "find its victims among the poor and voiceless" (Episcopal News Service 1991). Furthermore, he argued, "In no way is the war option going to serve our national interest, because I believe the wrath of the Arab nations following such a catastrophe will be with us for years and years and years to come. ... The Middle East will be scorched beyond belief, and the recovery of such destruction would be almost impossible" (Goldstein 1990). In sum, Browning and the others in Wallis's group harbored the belief that "resort to massive violence to resolve the Gulf crisis would be politically and morally indefensible" (Episcopal News Service 1991).

Bush's response was to give Browning a copy of the Amnesty International report he had received two days earlier, which he said he could not read without complete revulsion (Dart 1990). He asked Browning whether doing nothing, in the face of the atrocities being committed in Kuwait, was morally responsible. "How can you say it is not moral to stop a man who is having children shot in the streets in front of their parents, how can 
you say it is not moral to stop this man?" he asked (Devroy 1991). "How do we handle it when these people are being raped? What would be [your] position in World War II?" (Bush \& Scowcroft 1998: 428).

Browning conceded that the occupation of Kuwait was just cause for war, but that his objection was rooted in the lack of reasonable probability of success (Heimbach 2011). The devastation from war, he replied, would be so significant that war would not regain what was lost (Dart 1990). Turning to the Amnesty report, Browning said, "I'm sure that much of what is in this document is factual, but ... two wrongs don't make a right, that responding in like violence is not going to serve anybody's needs" (Goldstein 1990). Saddam "has to be dealt with," he told Bush, "but I'm still hopeful that [Bush] will see a way other than a military response—one in which the Arab leadership participates in a solution in concert with the United Nations" (Dart 1990).

Browning left the meeting believing that Bush was still struggling with his decision (Goodstein 1990; Cornell 1991). And in fact, he was. The January 15 deadline for Iraqi withdrawal from Kuwait ${ }^{18}$ was still nearly four weeks away, and Bush was still hopeful that Saddam would relent. It did not seem to give him much comfort that more conservative churches ("Evangelicals") largely supported a decision to go to war if a peaceful solution were not possible (Steinfels 1990; Cornell 1991). The difficulty of his decision raises one potential but fallacious objection to my overall argument that Bush's decision ultimately to go to war was influenced by religion. That objection is: If the official position of his own church was so emphatically to refrain from war, then why was Bush so conflicted, and why did he ultimately not follow Bishop Browning's advice?

\footnotetext{
${ }^{18}$ Set by Security Council Resolution 678 (1990).
} 
The answer to that objection is twofold. First, the Bishop gave the President bad advice. The Bishop, like other pacifists before and after him, misused the just war tradition to advance a pacifist position, and misstated the just war criteria. The just war tradition in Western Christianity must be discriminating in order to carry legitimacy (Yoder 1984: 22; Webster \& Cole 2004: 174-5), but that requirement is double-edged. Just as it would be inappropriate to justify every use of force under the just war tradition, so it is equally inappropriate to deny justifying any use of force. Bush, not being familiar with the just war tradition himself, was unable at the time to reconcile Browning's counsel with what he viewed as a moral imperative to alleviate Kuwait's suffering. He struggled with Browning's advice because although Browning's argument had the weight of the highest authority of his own church, it was so morally weak that it did not persuade him, especially in the face of the terrible atrocities being perpetrated by the Iraqi occupyers. James Turner Johnson and George Weigel (1991) rightly show how the mainstream churches in America had made an argument that was so "morally impoverished" (1991: 53) that it constituted exactly the kind of pacifist abuse of the just war theory described above.

Furthermore, Bishop Browning rested his case on the claim that the resulting destructtion of war would eviscerate any possibility of achieving the war's objective. In this respect Browning was flatly wrong; the objective of the war was to expel Iraqi forces from Kuwait and restore Kuwaiti sovereignty. Although further destruction and loss of life on either side was not desirable, avoiding absolutely such things was not the objecttive of the war. To the extent that Browning had any valid objection at all, it would have been not over reasonable prospect of success, but proportionality: that the foreseeable 
destruction and loss of life — then widely believed to be considerable—would outweigh the benefit of achieving the true objectives of the war. In arguing that the war had no reasonable prospect of success, Bishop Browning misstated the just war tradition. ${ }^{19}$

Bush himself was not versed in the just war tradition, nor were any of his closest advisors (Heimbach 2011). However, he was versed in the fundamentals of his own Christian faith, e.g. "Love your neighbor as yourself" (Luke 10:27), and watching his Kuwaiti "neighbors" suffering such terrible injustices caused him distress. He genuinely wanted to help them in some way that was within his power (which, as President of the United States, was considerable); the reason he was hesitant appears to be that he was uncertain whether the criterion of just cause was met—after all, it was not the United States that had been invaded. It seems likely that he also would have believed, at least subconsciously, that the amount foreseeable destruction and loss of life did threaten the legitimacy of the war, for it certainly had the potential to be disproportionate (however, this is only conjecture). What the President needed was someone to articulate his dilemma within a clear moral framework.

That need was fulfilled in the form of the Deputy Executive Secretary of the White House Domestic Policy Council, Daniel Heimbach. This is the second answer to the potential objection lodged above: The President's decision was influenced by religion, but the vehicle of that influence was the religious inclinations of his own staff, not the official echelons of his church. This is an example of Western Christianity influencing the propensity of a state to use force by virtue of that state's Government Religious

\footnotetext{
${ }^{19}$ I shall refrain from speculating whether Browning misstated the just war tradition deliberately or simply did not know it very well.
} 
Preference. Heimbach was a fellow Episcopalian, had a doctorate in Christian Ethics, and had specific expertise in the just war tradition. His reaction to Bishop Browning's visit and to his follow-up letter of January 7 was that the President needed better grounding in the just war tradition than Browning had provided, along with a well-articulated moral justification for the war that he could present to the public (Heimbach 2002, 2011). Heimbach wrote a memorandum to the President, in which he outlined the just war tradition and showed that, contrary to Browning's bad advice, the war was in fact justified. ${ }^{20}$ The memo reached Bush on January 15 , the day of the Security Council's deadline for Iraq to withdraw peacefully from Kuwait. By then, Bush had already reluctantly concluded that war would be necessary, but reading the memo had the effect of "settling his convictions" (Heimbach 2011). Using Heimbach's memo as a template, the President delivered speeches outlining his moral reasoning for the Gulf War and the onslaught of media criticism largely subsided after that (id.).

In Chapters 4 and 5 of this work, I claim that Christian states are less likely to resort to military force than non-Christian states because Christianity has a restraining effect on officials and governments. While the influence of Christianity did not change the outcome from war to no war in this particular case study, it did have a strongly constraining effect. This conclusion is evident from Bush's extreme soul-searching and reluctance to go to war. It is further reflected in the somber and prayerful mood of the White House on

\footnotetext{
${ }^{20}$ The memorandum is reprinted at Heimbach 2002: 458-60. Heimbach borrowed heavily from the Catholic articulation of the just war tradition, particularly the U.S. Catholic Bishops' pastoral letter The Challenge of Peace (National Council of Catholic Bishops 1983), and included a few criteria that most other authors would incorporate into others (Heimbach 2011). However, the memo is a sound restatement of the "general Protestant" war ethic, at least in my judgement.
} 
January 16, the day Bush ordered the war to begin (Bush \& Scowcroft 1998: 450;

Heimbach 2011). ${ }^{21}$ In the ways just described, Christianity had the effect that the empirical measurements of Chapters 4 and 5 predict: it made Bush less likely to go to war than if he had been non-Christian, and consequently Christianity had the effect of making the United States, a Christian state in both Prevalence and Preference, less likely to use force than if the U.S. had been a non-Christian state.

\section{$\underline{\text { Anwar Sadat and War and Peace with Israel }}$}

The case of Egyptian President Anwar Sadat is also useful as an illustration of the effect of religion on Egypt's decision to make war, and then peace, with Israel. Sadat launched the Yom Kippur War against Israel in 1973 (styled the "War of Ramadan" in the Arab world), but in 1979 he negotiated and signed the Egyptian-Israeli Peace Treaty. Sadat was the chief executive of a state with a 91\% Sunni Muslim population in 1973 and 94\% in 1979. In addition, the Egyptian regime had a strong preference for Sunni Islam (60\%), therefore it is expected that Islam would wield a strong effect on Egypt's decisions for war or peace.

In 1973, Egypt began making preparations for a surprise assault on the Israeli forces that had occupied the Sinai peninsula, which is (and was) Egyptian territory, since the Six-Day War of 1967. The assault, which took place on October 6, 1973 (the Jewish holy

\footnotetext{
${ }^{21}$ Bush requested a private prayer service, which took place on January 17. It was originally to be attended only by himself, his secretary, and the White House Staff Prayer Fellowship. He did not want the press to know about the service, but when the list of invitees grew large the service was moved to Fort Myer and the press learned of it (Heimbach 2011).
} 
day of Yom Kippur), was successful; the Egyptians recaptured and held the east bank of the Suez Canal and inflicted heavy losses on the Israelis. However, the Egyptians were unable to push the Israeli forces all the way back to Israel proper. ${ }^{22}$ After superpower intervention, Egypt and Israel concluded a cease-fire in which Egypt retained its territorial (re)gains, and that cease-fire ultimately evolved into a full-fledged peace treaty between the two states, the first between Israel and any Arab state. ${ }^{23}$ It is not surprising that Egypt should choose to go to war with Israel, the sworn enemy of Egypt and much of the rest of the Arab world, especially to recover its own territory from Israeli occupation. But it is surprising, given the widespread opposition to peace with Israel (both domestic and from the other Arab states), that Egypt should choose to enter into a peace treaty with that country. As with the case of the Gulf War, this case study will show that although there were realist, materialist reasons for doing both, the decisions of Egypt—and of its President in particular-were also rooted in Islam.

\section{$\underline{\text { Realist Reasons for War and Peace with Israel }}$}

In the 1970s, Egypt was (and still is) the most populous Arabic-speaking country and it had the largest military; its relative strength in the Arab world is reflected in being the site of both the formation and the headquarters of the Arab League. ${ }^{24}$ Egypt's relative strength made the utter defeat of its armed forces and occupation of its territory (the

\footnotetext{
${ }^{22}$ Egypt claims that this was due to intervention by the United States on behalf of Israel (e.g. Israeli 1985: 129), but Dupuy and Dupuy (1986: 1239) claim it was due to Israeli technological superiority.

${ }^{23}$ Treaty of Peace between the State of Israel and the Arab Republic of Egypt (Egypt-Israel), Mar. 26, 1979, 1138 UNTS 59, 72.

${ }^{24}$ The headquarters was relocated briefly after Egypt's temporary expulsion from the Arab League.
} 
Sinai) — and by a state with a fraction of its size and population—all the more ignominious. Other Arab states had lost territory to Israeli occupation in the 1967 war as well, but Egypt had lost the most. As the leader of the Arab world, Egypt had a strong incentive to militarily defeat Israel in order to recover its territory and reassert its strength (as well as the strength of the Arab world).

In addition, the loss of the Sinai had done considerable economic damage to Egypt. The Israeli occupation of the east bank of the Suez Canal had forced the canal's closure and several major canal cities had been heavily bombed during the War of Attrition (1969-1970), forcing Egypt to evacuate them. The loss of revenue from the Suez Canal and the burden of several hundred thousand displaced persons both severely strained the Egyptian economy. ${ }^{25}$ Regaining control of the canal and pushing Israel out of the Sinai was necessary not only for Egypt's security but also its economic health.

\section{Islamic Incentives for War with Israel}

The ignominy of Egypt's defeat and occupation was a powerful psychological force on the country. Egypt took pride in being a cradle of civilization and an integral part of the Arab world. It had been an Arab nationalist movement that deposed the Britishinfluenced King Farouk and driven out what the nationalists regarded as a British occupation (despite Egypt's formal independence from Great Britain in 1922). Furthermore, Arab nationalism is a strong motivator in the Arab countries' hostility toward Israel since

\footnotetext{
${ }^{25}$ Mohamed Heikal (1975: 55) claims that the Israelis also destroyed the irrigation system around the canal, furthering damaging Egyptian economic production.
} 
Israel's independence. Arab nationalism was certainly a contributor to the ignominy of the Arab defeat in 1967, as well as to Egypt's thirst for redemption in 1973.

But I suggest that the motivators for Egypt (and likely the rest of the Arab world) to make war with Israel consisted not merely of Arab nationalism, but also Islamic nationalism. This may be a counter-intuitive claim, given the strength of the Arab secularist movement in the 1960s—of which Egyptian President Gamal Abdel Nasser had been a major figure. Now, the situation of the Arabic-speaking Palestinians did serve as a strong secular nationalist motive for broader Arab hostility toward Israel (and still does today). However, it was not only Arab states that were hostile toward Israel prior to 1973, but also many non-Arab Muslim states—states that had little or no ethnic affinities toward the Palestinians. This may also seem like a counter-intuitive claim, given that Iran and Turkey did have good relations with Israel (until 1979 and about 2010, respectively). ${ }^{26}$ But up to 1973, Iran and Turkey both also had good relations with the United States, and Iran particularly had cause to balance against the Sunni states in the Middle East. Most other non-Arab Muslim countries with high GRP scores, including those that were aligned with the United States, did not have diplomatic relations with Israel and many did not recognize Israel as a state. These countries included Afghanistan, Bangladesh, Indonesia, Malaysia, and Somalia—all but one of which had Muslim GRP scores of 50\% or higher. ${ }^{27}$ In contrast, Muslim states with GRP scores lower than $50 \%$ did have diplomatic relations with Israel, at least until 1973; these states included Burkina Faso,

\footnotetext{
${ }^{26}$ Iran broke off diplomatic relations with Israel after the Islamic Revolution there; Turkey still has diplomatic relations with Israel.

${ }^{27}$ The GRP score of Afghanistan from 1948 to 1978 is unknown.
} 
Chad, Gambia, Guinea, Mali, Niger, and Sierra Leone. ${ }^{28}$ This (admittedly unscientific) survey suggests that hostility toward Israel was fueled not only by Arab nationalism, but also Islamic nationalism—conscious or subconscious.

As discussed in Chapter 6, Islamic theories of statecraft begin with the assumption of Islamic superiority, which in turn necessitates Islamic strength relative to its neighbors. Islamdom enjoyed such relative strength in its first thousand years, but in 1973 the Islamic world was still quite weak, having only recently reemerged from colonialism and having little indigenous technology. At the time of the outbreak of 1973 war, Arabic was not even yet an official language of the United Nations, despite the emergence of 19 Arabic-speaking independence states in the $20^{\text {th }}$ century. ${ }^{29}$

In addition, the Arab world took great offense at the introduction (imposition, in its view) of Israel into its midst in 1948. As (mostly Muslim) Arabs, the Egyptians were aggrieved, along with much of the rest of the Arab world, at the plight of the Palestinians. The Palestinians, who were Arabic-speaking and also mostly Muslim, were part of the umma and Islamic political theory stresses the importance of unity and brotherhood among all Muslims. Not only this, but the existence of a non-Muslim nation (most Muslims did not recognize Israel as a state) in the heart of the Arab world fundamentally challenged the Islamic paradigm that Islam should enjoy hegemony at least in its own region. Anti-Semitism was likely also a factor in Arab antipathy toward Israel, given the

\footnotetext{
${ }^{28}$ Many of these states broke diplomatic relations with Israel in late 1972 or early 1973 (Guinea did so in 1967); a few have restored them.

${ }^{29}$ Arabic was added as an official language of the United Nations on December 18, 1973. G.A. Res. 3190 (XXVIII).
} 
amount of emphasis on the duplicity and betrayal of the Jewish tribes during the early period of Islam that is placed in the Islamic historical narrative. These factors created an incentive for the Arab world to reassert Islamic hegemony, at least regionally, by defeating Israel at a minimum (and preferably by eradicating it). This does not necessarily make Nasser, Sadat, and other Arab statesmen of that time "Islamist" in the sense that the word is used today; it means only that the Arab pride, wounded by the presence of Israel, was also Islamic pride.

The crushing defeat of Egypt in 1967 was devastating to the country's national identity as well. It had been only 45 years since Egypt had regained its statehood after many centuries of foreign rule. For Egypt to have to suffer yet another foreign occupation, this time at the hands of a Jewish entity with less than a tenth of its population and about a fiftieth of its area, rankled the Egyptians not only as Egyptians and Arabs, but as Muslims. As Sadat's biographer Raphael Israeli (1985: 46) describes it, the Arab defeat in 1967 led to "painful soul-searching." Public discourse was self-condemnatory and scathing, with demonstrations and public trials seeking to blame defeat on someone or something. "Everyone wallowed in a masochistic orgy of self-deprecation" (id.). Egyptians were actually embarrassed of their nationality. A professional colleague of mine has recounted that as a teenager in Great Britain (her father was with the Egyptian embassy there), her parents told her to claim that she was Spanish instead of Egyptian. Mohamed Heikal, a one-time Egyptian official and associate of Sadat, writes:

By 1973 Egypt had almost become the laughing stock of the Arab world. We claimed to be the leader and protector of the Arabs, but gave no lead to our own people and showed ourselves unable to protect our own 
country. . . . Each day that passed was a day of humiliation for Egypt.

(1975: 205)

Egypt's sense of humiliation was not helped by the stated intention of the Israeli Minister of Defense, General Moshe Dayan, to build a new Israeli port and town of Yamit—on Egyptian territory (id.: 22, 205). The result of this national humiliation, writes Israeli (1985: 46), was a "remarkable revival" of Islam and Islamic values in Egypt and in the Arab world in general. At an international conference hosted by al-Azhar University in 1968, scholars argued that "if only Muslims returned to the path of Islam, the 'glorious defeat' of 1967, as one of them bitterly termed it, could be turned into a long-overdue national catharsis." And indeed, the Arab secularist movement began its wane after 1967.

\section{The Effect of Sadat's Faith on His Decision to War}

As is the case with most or all modern states, Egypt's decision to go to war or not ultimately rested with its chief executive. In Egypt's case, that individual was Anwar Sadat. Sadat took pride in his peasant roots, having been born and raised in the Nile delta village Mit Abul-kum, and while President of Egypt he frequently returned there. However, except in his home village, where he often wore traditional garb, Sadat was often "impeccably dressed" in Western-style suits and ties (Israeli 1985: 6, 8, 102). As such, he did not present a distinctly Arab, Muslim, or even non-Western appearance to the outside world, despite his country regarding itself as the epicenter of the Arab world. This practice stands in contrast to the many Arab monarchs and Iranian theocrats who wore (wear) traditional Arab and Middle Eastern dress, as well as to the many secular political officials who seek to distinguish themselves from the West by not wearing ties. 
Sadat was hardly an Islamist, and does not appear to have been overtly religious in his political activity prior to 1967 . But despite his Western appearance, Sadat was a devout Muslim. One of his primary inspirational figures was the teacher of the Quranic Teaching School in his home village, where as a boy he had memorized the Quran (Sadat 1977: 4; Israeli 1980: 2). The piety that Sadat acquired there pervaded the rest of his life (Israeli 1985: 10) and was even heightened during his years in prison (id.: 23; Sadat 1977: 7686). When Islam began to be reasserted after 1967 , Sadat surely must have needed very little convincing.

Sadat's own sense of offense at the foreign occupation of Egypt, first by Great Britain (Sadat 1997: 6; Israeli 1985: 15-6) then by Israel, reflected the sentiment of the Egyptian population as a whole, though after 1967 Sadat displayed his own piety more openly (Israeli 1985: 47). ${ }^{30}$ Sadat personally felt the ignominy of Egypt's defeat; he writes that on June 5, 1967, when Egypt's terrible defeat was known to high government officials but not yet to the general population, he wished he could have "passed away" before the people that were mistakenly celebrating victory learned the truth (Sadat 1977: 176). He further writes how he was "completely overwhelmed by our defeat. It sank into the very fabric of my consciousness so that I relived it day and night" (id.: 184). ${ }^{31}$

\footnotetext{
${ }^{30}$ Sadat frequently used religious language and Quranic quotes in his public statements, including his trademark opening of his speeches with "bismallah" (in the name of God), but such practice is commonplace in the Muslim world (Israeli 1980: 1-2).

${ }^{31}$ Sadat's sense of shame, along with that of his nation, may also have been exacerbated by his own antiSemitic tendencies, which also mirrored the anti-Semitic tendencies of Muslims in general, especially Arabs. Sadat, like many others, often spoke derogatorily of Israel, the Jews, and the Zionists as if they were one and the same (Israeli 1980: 8; idem. 1985: 10, 19-20, 78, 103).
} 
Egypt's defeat in 1967 instilled in Sadat a new purpose. "That Egypt should survive became my dominant passion" (Sadat 1977: 184). Sadat regarded himself as a father figure for the Egyptian nation, and in the village life of his upbringing, one major function of the father is to protect his family's honor. Defeat and occupation were shameful states, erasable only by reversing both. "Better to die honourably," he said, "than to live in humiliation" (quoted in Israeli 1985: 9). He even characterized the liberation of the Sinai as a holy duty, saying "we are required to sacrifice life in order to deserve life" (id. 49). And further, "This is a war for our honour and self-respect" (id. 72). In order to undo the shame, Sadat said, "the whole world, West and East, [had to] see whether or not we're able to liberate our land, whether or not we're able to fight" (id. 75).

Sadat's public statements reveal significant religious fervor on his part in pursuing the goal of reversing Israel's victory over Egypt, and that fervor was infectious. In early 1971, Sadat invoked the idea of jihad against Israel in addressing the International Conference of Islamic Studies:

This country has always resolutely stood in defense of Islam and of the Islamic Holy Places. This country will remain a solid stronghold in defense of the sanctity of Islam, however cruel the sacrifices prove to be. ... Today, we ought to wage war against backwardness the way we are waging war against Zionism and Imperialism. ... The war we are waging these days is the war we have learnt about in the Qur'an. (Quoted in Israeli 1980: 6$)^{32}$

And further, in the first Birthday of the Prophet address of his presidency, in 1971:

\footnotetext{
${ }^{32}$ This is Raphael Israeli's interpretation of the speech.
} 
In this battle that we are waging, we are required to provide ourselves with every weapon possible. ... As I had told you before, Muhammad and his Mission had supplied us with the most potent weapon - Faith. . . Our people has [sic] always ultimately had the upper hand, even though it possessed no weapon other than faith. ... We have learnt a lesson from Muhammad. In the course of history, whenever Arabs unified, they created their culture and occupied their place among nations; but, when they disunited, they were humiliated and they opened an inviting breach to foreigners and Imperialists. (Id.)

Finally, on the Birthday of the Prophet the following year, 1972:

This is a period of mighty trial, first and foremost for our Faith, the Faith of the Mission of the Prophet. We find ourselves in the most difficult ordeal that we could face in our lives. They want to shatter our faith. . . We believe that Allah is on our side. ... We believe, as commanded by Allah, that we are a nation elected above all nations.... We are preparing at present with all we have and with all our might to enter upon the glorious campaign. ... I promise you that at the next Birthday we shall celebrate in this place not only the liberation of our country but also the defeat of Israeli arrogance and rampaging. (Id. 7)

Sadat launched the Yom Kippur War, rolling back Israel's occupation of the Sinai, the following year. In May 1973, when the mobilization of forces began, he ordered the 
Egyptian media to quote "profusely” from the Quran (Israeli 1985: 107) 33 $^{33}$ and enthusiastically backed the new war cry of the Egyptian army_ "Allah akbar" ("God is great"; id. 11, 48). At the central command post on the eve of the war, Sadat participated in taking an oath on the Quran (Heikal 1975: 37). ${ }^{34}$ After the war, the Egyptian media was filled with stories of soldiers claiming to have seen Muhammad himself leading the troops across the canal on a white horse (Israeli 1985: 48), and Sadat himself spoke several times of the "miracles" of the war, which in his view could have materialized only with faith (id. 11).

The prospect of many casualties_-win or lose_-does not appear to have been a concern to Sadat. There are several possible reasons for this, and those reasons are not mutually exclusive. One is that the major cities along the Suez Canal had already been evacuated and the fighting itself was expected to take place in a sparsely populated area (the Sinai desert), therefore civilian casualties were likely to be light at the beginning of the war. On the other hand, however, had it become necessary to liberate by force the towns of El-Arish, Sharm el-Sheikh, and others, which were closer to the Israeli border, civilian casualties likely would have been heavier. There is no evidence that that prospect

\footnotetext{
${ }^{33}$ This was the first of three mobilizations on the Suez Canal that were designed to lull Israel into the false belief that Egypt was merely saber-rattling and not genuinely committed to war. To Israel's surprise, Egypt actually attacked on the third mobilization.

${ }^{34}$ The idea appears to have been initiated by one of Sadat's generals; the oath was for everyone to make his utmost effort.
} 
was a concern for Sadat, who in the run-up to the war often spoke of sacrifice. ${ }^{35}$ Another possible reason is that Sadat believed that the risk of mass casualties suffered by the Egyptian armed forces was mitigated, due to their sheer numbers. However, this explanation is actually unlikely for two reasons. First, the benefit of attacking with an overwhelmingly large force would be the greater likelihood of success, not a reduction of casualties. Second, if Sadat's biographer's assessment of the Yom Kippur War is correct, then Sadat was actually preparing for a protracted war, in which Egyptian forces (and those of other Arab states) could take heavy casualties and still outlast the outnumbered Israelis (Israeli 1985: 105-6).

Sadat seems to have been concerned least of all about the prospect of Israeli casualties. As an Egyptian whose country was partially occupied by Israel, it is expected that he would find it necessary to inflict large-scale casualties on Israeli forces in order to regain territory that under international law rightfully belonged to Egypt. But Sadat's hostility to the Israelis appears to have run deeper than that which their identity as occupiers would have generated. His hostility cannot reasonably have been induced by Israeli atrocities in the Sinai (as Bush's hostility to the Iraqi army was by their atrocities in Kuwait). There is no evidence of reports of atrocities during the occupation; indeed, the Israelis left the Sinai in a better condition than when they arrived. ${ }^{36}$ It seems more

\footnotetext{
${ }^{35}$ For example, in an October 1, 1973 directive to the CINC of the Egyptian armed forces: "[O]nly a people armed with faith in freedom and the willingness to make the necessary sacrifices could have shouldered [the burdens of defeat and occupation by Israel]" (Sadat 1977: 326).

${ }^{36}$ While living in the Sinai from June 1992 to June 1993, I heard many of the locals actually speak in praise of the Israelis, who started industries there. For example, a major boost to the local economy consisted of
} 
likely that Sadat's deeper hostility toward the Israelis was induced by the anti-Semitism that appears to be pervasive among Arab and Muslim states. In addition to Sadat's antiSemitic statements cataloged above, Egyptian soldiers were also given personal booklets containing quotations from the Quran and other Islamic literature urging them to "pursue the Jews and not pity them" (Israeli 1985: 112).

Finally, while Sadat's immediate aim was to regain Egyptian sovereignty over the Sinai, he continued to assume the role of advocate for the Arab cause in general, and for the Palestinians in particular. As Sadat regarded himself as the father-figure for all of Egypt, he also believed that Egypt was "ordained" (in Israeli's words) to be the leader of the Arab world (Israeli 1985: 168), and therefore it was his calling to assert the combined Arab states as the Sixth Power of the world (id. 86, 127). Now, despite his incendiary speeches before the war, ${ }^{37}$ the evidence is unclear as to whether Sadat fervently desired the destruction of Israel itself and/or the Jews, as opposed to merely driving Israeli forces out of Egyptian territory. However, it is clear that Sadat's grievances against Israel were not confined to the defeat and partial occupation of Egypt. In 1971, Sadat rejected entering into a separate peace with Israel, arguing that a necessary aspect of any comprehensive peace with Israel was the settling of grievances of all Arab states in addition to the Palestinian problem (Israeli 1985: 66; see also id. 89). On October 16, 1973, with the war still in progress, Sadat told his parliament that the purpose of the war was not only to recover lands lost in 1967 (he did not specify which lands-Egyptian only, or Jordanian

peach orchards grafted on almond trees so they could grow in the desert—an innovation brought to the region by the Israelis.

${ }^{37}$ E.g. on the Birthday of the Prophet in 1972 (Israeli 1980: 7-8). 
and Syrian as well) but also to restore Palestinian rights (id. 116). These goals are also evident in Sadat's address to the Israeli Knesset in 1977: there would be no separate peace, but a comprehensive peace based on the restoration of Arab lands and Palestinian rights (Sadat 1977: 334-5). Although such sentiments could have been driven partly by a personal craving for the power of hegemony, as Classical Realists would predict, this seems unlikely to have been the case for Sadat—for biographical portraits of him do not depict a man with ambitions for personal political power. His interest in asserting Egyptian (and by extension, Arab and Muslim) power appears to be genuinely driven by his dedication to the well-being of the Arab world—and by extension, the Islamic umma.

Thus, while non-religious factors do generate the expectation that Egypt would eventually resort to war to recover its territory, such an expectation is also influenced by religious factors: the ignominy of defeat and domination by non-Muslims, especially Jews; the need to reassert Muslim hegemony; and the need to relieve the suffering (in Islam's eyes) of other Muslims within the umma. Although Egypt's initiation of the Yom Kippur War was already predictable, and the Arab nationalism that prompted it was difficult to disentangle from Islamic nationalism, I suggest that Islam made the outbreak of the war even more likely than it would otherwise have been.

\section{Islamic Incentives for Peace with Israel}

The outcome of the Yom Kippur War was positive for Egypt, but mixed nevertheless, in that Egypt was unable to recover its territory fully by war. It took a peace initiative for Egypt to complete its recovery. A series of cease-fire agreements culminated in the Egyptian-Israeli peace treaty of 1979, in which Egypt established relations with Israel 
that were at the time unprecedented in the Arab world. At first glance it may be difficult to understand this move, given the fervor (including religious fervor) with which Sadat blasted Israel and the United States before the war. Yet as much as Egypt's initiation of the Yom Kippur War was rooted in the influence of Islam, so was Sadat's initiative to forge a lasting peace with Israel.

Peace with Israel is made possible in Islamic statecraft under the doctrine of the dar al-suhl (the abode of conciliation), which as discussed in Chapter 6 is often overlooked. When Islamdom is too weak relative to the dar al-harb to dominate it, then the conflict may be temporarily suspended if doing so serves the interest of Islam. In the case of Israel, entering into a peace treaty with Israel gained more for Egypt—and for Islamdom—-than continuing to fight. Sadat acknowledged that the Arab world could not destroy Israel, treating Israel as a fait accompli that the Arab world could not undo: I said and I repeat again that Israel is a fact. An Arab President said that he had a plan to wipe Israel out within three hours, but three years or more have elapsed and he has failed to eliminate it. Moreover, twenty years have elapsed and Israel, for from being exterminated, remains a reality and stands firm. (Quoted in Israeli 1985: 141)

Having acknowledged that Egypt could not recover all of its lost territory by force, ${ }^{38}$ Sadat conveyed his willingness to accept a peaceful coexistence with the Jewish state in exchange for the security of its borders, first to U.S. Secretary of State Henry Kissinger on October 10, 1973 (Heikal 1975: 224), then to his parliament on October 16 (Israeli

\footnotetext{
${ }^{38}$ Sadat blamed the United States for this failure as well (Israeli 1985: 129).
} 
1985: 116). ${ }^{39}$ Unable to defeat the Israeli dar al-harb, he was willing to settle for coexistence with an Israeli dar al-suhl.

However, entering into such a settlement first required demonstrating Egyptian strength, or at least shattering Israel's sense of its own invincibility. This is what Sadat believed was the greatest achievement of the war (Israeli 1985: 75). The doctrine of dar al-suhl may presuppose Islamic weakness relative to non-Islamdom, but it does not presuppose Islamic impotence. Any Islamic conciliation with non-Islamdom would have to be reciprocated, otherwise the relationship would become oppressive, which Islamic political theory cannot permit. Having forced Israel to respect Egypt, Sadat could now do likewise; and henceforth his bellicose condemnations of Israel in public speeches ended (id. 133).

In spite of the peace treaty, however, Israel still could not be brought within the dar al-islam. While no longer immediately hostile to Egypt, Israel still lay outside the abode of peace (or of Islam) and Sadat did not abandon his antipathy toward Jews, nor did he counsel other Arab states to do so (Israeli 1980: 11). It took several years for Sadat to be convinced of the need for any more permanent arrangement than a cease-fire, let alone for negotiating with Israel directly (Israeli 1985: 62). It took even longer-until 1978_ for him to come around to the prospect of recognizing the legitimacy of Israel, as opposed to merely its existence (Quandt 1986: 227). Furthermore, as Raphael Israeli points out, Egyptian recognition of Israel and normalization of relations with it was not an irrevoc-

\footnotetext{
${ }^{39}$ Sadat also sought the recovery of other Arab lands as well, along with Palestinian self-determination. It was not until the Camp David peace negotiations in 1978 that Sadat realized that in order to secure the Sinai, he would have to drop the other matters (Quandt 1986: 236).
} 
able measure (1980: 11). Sadat said in 1975, in the same speech in which he acknowledged Egypt's inability to overcome Israel's strength, "Israel is a fact, and anyone who wishes to wipe her out - please go ahead and do it! I assure you that you will have my acclaim" (quoted in Israeli 1985: 141). If Sadat had believed that Egypt and the rest of the Arab world would be able to defeat and dominate Israel in the future without further compromise, he would have advocated precisely that. This position is well rooted in Islamic principles of statecraft; the dar al-suhl is not a perpetual accommodation of nonIslamdom, only a temporary state for as long as Islamdom is unable to dominate the enemy on its own terms.

In sum, Egypt's peace with Israel was made possible by the ethic of war and peace in Islam-but only within its own parameters. Islam made that peace less likely than if Egypt had been a non-Muslim country. The first reason for this is the innate antipathy toward Jews in Islamic tradition, which significantly impeded negotiation with the Jewish state at all, let alone a settlement. The second reason is that the peace with Israel has the potential to unravel if the relative power of the two states is reversed. Israel understood this and needed security from further Egyptian attack in order to withdraw voluntarily; it therefore took a wholesale Egyptian demilitarization of the Sinai (i.e. its own territory) and the promise of a UN peacekeeping force to provide early warning and confidencebuilding measures for Israel to agree to negotiate a peace treaty. ${ }^{40}$

\footnotetext{
${ }^{40}$ Framework for the Conclusion of a Peace Treaty between Egypt and Israel (Egypt-Israel-United States), n.d., reprinted in Quandt 1986: 381-3. The UN force did not materialize because the Soviet Union promised to veto any Security Council resolution providing for such a force. In response, the three countries formed their own international organization, the Multinational Force and Observers, to establish a peacekeeping force. That force still functions today.
} 


\section{Conclusion}

As shown in the two foregoing case studies, chief executives of states can be influenced by religion in a variety of ways. Religion may influence them directly, i.e. through their own personal faiths (as Bush and Sadat both were). Religion may influence them through their advisors, when those advisors are religious. Religion may also influence them through explicitly religious actors, such as churches and other religious organizations and their officials. Religious chief executives, as well as their governments collectively, may be more amenable to influence by these actors, because religious officials may be personally more willing to receive them and correspond with them. Religion may also exert cultural influence on chief executives. Bush being Christian in a country that is mostly Christian, he would have been less persuaded by justifications for or against war that originated from other religious traditions. The same is true for Sadat, being Muslim in a country that is mostly Muslim. Finally, religion may exert influence through public opinion. The decisions for war enjoyed broad public support in both cases, and that support was itself informed by the ethics of war and peace within the publics' respective religions. The overall public satisfaction with Bush's moral justification of the Gulf War in just-war terms—once Bush presented that justification— is evidence of this. Sadat's decision for peace with Israel did not enjoy broad public support, due to the public's antipathy toward Israel—an antipathy generated by Arab nationalism but also, I argue, by Islamic nationalism. That antipathy appears to have been generated by perceptions of Israel's responsibility for injuries toward fellow Muslims, and by an innate hostility toward Jews that is instilled in the classical Islamic historical narrative. 


\section{CONCLUSION}

I submit that my two hypotheses are supported, namely that (1) religion does influence the propensities of states to initiate interstate armed conflicts (in violation of $j u s$ ad bellum), and (2) different religions wield different effects on those propensities. The more religious the state, i.e. the stronger the religious Preference of its governing regime, in any religious category, the greater the state's propensity to do the above. The same is true for religious homogeneity; the greater the proportion of followers of the Prevalent religious category in a state's population, ${ }^{1}$ the greater the state's propensity to violate $j u s$ ad bellum. Put another way, the greater the likelihood that the state will act in accordance with a religious war ethic rather than the war ethic of secular international law. This effect is visible empirically, especially now that secular jus ad bellum is more restrictive than ever before. The Christian and Islamic war ethics are both more permissive than today's secular international law, and that greater permissiveness is evident in the empirical results shown in Chapters 4 through 6. Even the Protestant war ethic, which appears to be one of the most restrictive ethics tested in this work, is more permissive than jus ad bellum — and although the propensity of Protestant states to violate jus ad bellum may be lower than that of states of many other religions, it is still greater than zero.

But beyond the general finding that more religious states are statistically more likely to use force, it cannot be maintained that the effect of religion is uniform. Based on my analyses of their respective war ethics as promulgated in scripture, by the priesthood and through its writings, and by the historical narrative, I conclude that Christianity has a

\footnotetext{
${ }^{1}$ Or more precisely, the state's citizenry.
} 
negative effect on a state's propensity to violate jus ad bellum, Islam has a positive effect, and Buddhism has no effect. Each religion has a distinct war ethic - a code of behavioral principles defining the circumstances in which using military force is morally permissible - and two of these war ethics (Christian and Islamic) legitimize some unilateral resort to force beyond simply defense against an armed attack. I further submit that of those two, the Islamic war ethic is the more permissive one, hence the greater probability that a Muslim state will be the first user of military force in an interstate dispute. The Christian war ethic is more restrictive, hence the lesser probability that a Christian state will do the same (though the Christian war ethic is still more permissive than secular jus ad bellum). The Buddhist war ethic, I have argued, is internally inconsistent and thus impractical for application to statecraft, and the empirical results of testing Buddhism offer some support to that argument (though without the same degree of certainty as my results for Christianity and Islam).

Having drawn the conclusions just stated, I would like to reiterate a few of their limitations. One obvious source of potential criticism is that I have not yet eliminated the possibility of bias in the selection of my data sources and operationalization of my variables. For example, the work done might be criticized for using $\mathrm{COW}$ as the data source for for my dependent variables instead of ICB; using Polity Project measurements of regime type instead of Freedom House; using ordered contiguity levels of proximity instead of great-circle distances between capitals; and using logarithms of peace-years instead of more recently developed approaches to handling the passage of time. I believe that I have explained my rationales in Chapter 3, but I concede that performing a series of 
regressions using the above alternatives would be time well spent. These alternative variables will be introduced in the next phase of the research.

The second caveat that I wish to reiterate is that I make no claim that the war ethic of any religion remains constant over time. It is certainly possible, even probable, that the war ethics of the three religions to which I have devoted chapters - and Christianity in particular-are more permissive or restrictive today then they were, say, 500 years ago, and the same is true for 1000 years ago and beyond. But having limited my claims to the religious war ethics influencing states today, I still maintain that those ethics are rooted in scripture, the priesthood (and especially classic priestly writings), and the historical narrative. My caveat might then lead the reader to wonder how it is possible for me not to claim that religious war ethics have remained constant, given the longevity of scripture, priestly writings, and history. The answer is that all those sources must still be interpreted by individuals and cultures living in the here and now, and different scripture, writings, and history may be emphasized at different times. For this reason, I have also examined more contemporary treatments of religious war ethics, in order to discern which sources are being emphasized today and how they are being interpreted.

In addition, I make no claim that the effect of religion today has the same strength as that of religion even 200 years ago. An implicit assumption in this work has been that the behavior of states is influenced by secular norms as well as religious. The body of international law that regulates the resort to force by states, jus ad bellum, is just such a secular norm, and Louis Henkin's insight that "[i]t is probably the case that almost all nations observe almost all principles of international law and almost all of their obligations 
almost all of the time" (1979: 47, italics removed) seems intuitively correct. ${ }^{2}$ If states generally comply with jus ad bellum, and jus ad bellum were highly permissive (as it was in the $19^{\text {th }}$ century), then we could expect states to use military force more often than during a period in which jus ad bellum is highly restrictive (as it is today). This phenomenon may affect states of all religions.

In response to the potential criticism just set forth, another major component of the next phase of this research will be to test the effects of religion further back in time than 1946. Doing so will enable the testing of and controlling for several epochs of jus ad bellum whereas the date range now covers only a single epoch, and also multiple configurations of the international system whereas the date range now covers only two (bipolar, U.S. and USSR as the poles; and unipolar, U.S. as the pole). However, achieving this goal will be a major undertaking, for two reasons. One is that the necessary data must be collected, especially for the independent variables, and if the study is to reach further back than the COW dataset does, then additional data on the dependent variables must be collected as well (and data on the control variables will likely be unavailable). The other challenge to expanding the scope of this study will be the comparative lack of religious diversity within the Westphalian state system prior to about 1919. Maintaining the validity of measurements of Christianity requires observing a sufficiently large sample of nonChristian states, and according to the datasets known to me at present, there are few such states in the Westphalian system prior to 1919. Islam and Buddhism would be nearly impossible to measure for lack of enough Islamic and Buddhist states to observe (the

\footnotetext{
${ }^{2}$ Chayes and Chayes (1995) further claim that states generally want to comply with the rules of international law.
} 
same problem that afflicts the prospects for measuring Hinduism and Judaism today). But in my view, the problem is not so much the actual lack of non-Christian states, but rather the pro-Westphalian bias of the datasets; they tend to observe only states that are recognized members of the Westphalian state system, ${ }^{3}$ despite the frequent interaction of Westphalian states with state-like entities outside the Westphalian system-not to mention the interaction of non-Westphalian states with each other. This problem is curable, but the cure involves redefining state system membership for the purpose of international relations (though not for international law). The obstacles just described are surmountable, if the goal is to reach back to the beginning of the COW datasets, but they are formidable. I am reluctant to predict whether the obstacles are surmountable if the goal is to go back much further, especially where data on control variables is concerned.

I also anticipate some criticism originating from the most heavily invested stakeholders in the third image. Neorealists and Neoliberals (and even to some extent Neoclassical Realists) are committed to the proposition that international outcomes are generated (primarily) by the pressures, incentives, and constraints of the structure, not the individual characteristics of states and certainly not differences in the ideological preferences of states. And certainly the realist logic is powerful and compelling, and would likely explain even more IR outcomes in a world in which norms did not matter. Based on the empirical results of this study, however, I claim that outcomes are influenced by norms, alongside the materialist factors that are typically studied in the rational-choice sector. However much Waltz's (1979) and Keohane's (1984) seminal works have

\footnotetext{
${ }^{3}$ Furthermore, the COW State System Membership dataset sometimes confuses entry into the Westphalian state system with admission into the United Nations, especially in the case of micro-states.
} 
advanced our knowledge of IR (and they are rightly celebrated for their considerable advancements), it is unfortunate that those works neglected the role of norms so readily.

I submit that the field needs to progress a little more, for it has been too slow to acknowledge (or perhaps, re-acknowledge) the role of ideologies in generating outcomes. Over the last few decades the field has uncovered and studied a variety of characteristics of states that are believed to generate international outcomes: power, regime type, alliances, wealth, trade dependence, the peace-learning process, and proximity—and even if their actual effects are contested, the utility of examining those characteristics do not appear to be widely disputed (and I do not dispute that either). It would behoove the field, however, to devote more attention to the role of ideology, including religious ideology. This work could be situated within a presently far-too-sparse body of literature that examines the effect of ideology on state practice. ${ }^{4}$ One of the major challenges for the constructivist approach to IR, in which ideas are given a prominent place in the problematique, seems to have been how to empirically operationalize and measure an idea. I therefore offer my research design as a model for measuring not only religious ideologies, but secular ideologies as well.

Let me conclude with a final thought, particularly in response to the inevitable objection that I have painted the world's major religions with overly broad strokes, or oversimplified them or even stereotyped them. However, no religion is completely and perfectly pacifist, militant, or moderate; and no war takes place unless someone in a leadership position on one side or the other chooses to precipitate it. States and their leaders are bombarded with a variety of stimuli, but I maintain that decisions of statecraft

\footnotetext{
${ }^{4}$ For another example, see Haas 2005.
} 
are ultimately the product of human agency, as the cases studies of Chapter 8 would seem to attest. Decisions of states may be affected by the configuration of balls on the proverbial global billiard table, but they are not preordained by it. Neither are states' decisions simply the predictable output of the human physiological or psychological programming that generates human responses, preferences, and behavior. The militant tendencies of some war ethics and impossibly pacifist ideals of others, the uncompromising ethics of justice and equally uncompromising ethics of grace, all are transcendable by human choice. Choices of such magnitude as war and peace are made in accordance with the actor's morality (or sometimes lack of it; see Stoessinger 2010; Rummel 1994, 1997). Religion provides the foundation for that morality, and ultimately that is the influence of religion on the onset of armed conflict. 
$\underline{\text { APPENDIX A }}$

\section{CODE BOOK FOR DATA SET}

\section{$\underline{\text { Key }}$}

variablename: description of variable (Source)

Note: The Source identifier states the source of the data in the parameter, not its theoretical origin. A variable that is generated by the author is attributed to the Author, even if the variable is generated from data from other variables or its theoretical foundation is in others' works. For example, the Economic Dependence variable (econdepend) is proposed by Russett and Oneal (2001) and the data for its generation is taken from the Correlates of War and Quality of Government projects. But the actual generation of the variable was carried out by the Author, therefore the source is coded as Author.

\section{Contents of This Appendix}

Observation Identifiers . . . . . . . . . . . . . . . . . . . . . . . 395

Conflict Characteristics . . . . . . . . . . . . . . . . . . . . . 396

Dependent Variables: Raw Data . . . . . . . . . . . . . . . . . . . . 397

Dependent Variables: By Author . . . . . . . . . . . . . . . . . . . . 399

Independent Variables: Religion of Population. . . . . . . . . . . . . . . 402

Independent Variables: Government Religious Preference . . . . . . . . . . 412

Independent Variables: Religion of Chief Executive . . . . . . . . . . . . 423

Control Variables . . . . . . . . . . . . . . . . . . . . . . . . . . 428 


\section{Observation Identifiers}

[1] ccode1: Country Code of State 1 (the observed state in the dyad). (COW)

[2] abbrev1: Three-letter Abbreviation of State 1. (COW)

[3] ccode2: Country Code of State 2 (the unobserved state in the dyad). ( $\mathrm{COW}$ )

[4] abbrev2: Three-letter Abbreviation of State 2. (COW)

[5] year: Year of the observation. (EUGene)

NOTE: The dyadic and state-level characteristics coded for the year are those that existed at 11:59 p.m. on December $31^{\text {st }}$ of the year. 


\section{Conflict Characteristics}

[6] cwkeynum: MID number of the Key Conflict in the dyad-year. (COW, EUGene)

The Key Conflict is the MID with the highest hostility level during the Year.

[7] cwinit: whether State 1 Initiated a MID against State 2 in the Year. (COW, EUGene) Binary: $1=y e s, 0=$ no.

[8] cwinitnm: Number of the MID Initiated by State 1 against State 2 in the Year. (COW, EUGene)

[9] cwdynm: Dyadic MID Number. (COW, EUGene)

[10] cwstyr1: Start Year of the MID for State 1. (COW)

[11] cwstmo1: Start Month of the MID for State 1. (COW)

[12] cwstday 1: Start Day of the MID for State 1. (COW)

[13] cwstyr2: Start Year of the MID for State 2. $(\mathrm{COW})$

[14] cwstmo2: Start Month of the MID for State 2. (COW)

[15] cwstday2: Start Day of the MID for State 2. (COW)

[16] cwendyr1: End Year of the MID for State 1. (COW)

[17] cwendmo1: End Month of the MID for State 1. (COW)

[18] cwendday1: End Day of the MID for State 1. (COW)

[19] cwendyr2: End Year of the MID for State 2. (COW)

[20] cwendmo2: End Month of the MID for State 2. (COW)

[21] cwendday2: End Day of the MID for State 2. (COW) 
Dependent Variables from Other Data Sets (Raw Data)

[22] cworig1: whether State 1 Originated the Dispute of the Key MID. (COW)

Binary: $1=$ yes, $0=$ no.

[23] cworig2: whether State 2 Originated the Dispute of the Key MID. (COW)

Binary: $1=$ yes, $0=$ no.

[24] Cwsidea1: whether State 1 is on Side A of the Key MID, i.e. it was the first to militarize the dispute, or it joined the MID on that side. $(\mathrm{COW})$

Binary: $1=$ yes, $0=$ no.

[25] Cwsidea2: whether State 2 is on Side A of the Key MID, i.e. it was the first to militarize the dispute, or it joined the MID on that side. $(C O W)$

Binary: $1=$ yes, $0=$ no.

[26] cwhiact1: Highest Activity level of State 1 in the Key MID. (COW)

0: no militarized action $\quad 11$ : fortify border

1: threat to use force 12 : border violation

2: threat to blockade 13: blockade

3: threat to occupy territory $\quad 14$ : occupation of territory

4: threat to declare war 15: seizure

5: threat to use CBR weapons 16: attack

6: threat to join war 17 : clash

7: show of force $\quad 18:$ declaration of war

8: alert 19 : use of CBR weapons

9: nuclear alert 20: begin interstate war

10: mobilization 21: join interstate war

[27] cwhiact2: Highest Activity level of State 2 in the Key MID. ( $C O W)$

Same ordered categories as [26] cwhiact 1.

[28] cwhost1: Hostility level reached by State 1 in the Key MID. ( $C O W$ )

1: no militarized action $\quad 4$ : use of force

2: threat to use force $\quad 5:$ war

3: display of force

[29] Cwhost2: Highest Activity level of State 2 in the Key MID. (COW)

Same ordered categories as [28] cwhost1.

[30] cwfatal1: Fatality level reached by State 1 in the Key MID. (COW)

1: none $\quad 4: 101-250$ deaths

2: 1-25 deaths $\quad 5: 501-999$ deaths

3: 26-100 deaths $\quad 6: 1000$ or more deaths 
[31] Cwfatex1: Exact estimate of fatalities incurred by State 1 in the Key MID. (COW)

[32] cwfatal2: Fatality level reached by State 2 in the Key MID. (COW)

Same ordered categories as [30] cwfatal1.

[33] cwfatex2: Exact estimate of fatalities incurred by State 2 in the Key MID. (COW)

[34] Cwrevis1: whether State 1 is the Revisionist State in the Key MID. ( $C O W)$

Binary: $1=y e s, 0=$ no.

[35] cwrevt11: First Revisionist Type of State 1 in the Key MID. (COW)

0: Not applicable 3: Regime/Government

1: Territory 4: Other

2: Policy

[36] cwrevt21: Second Revisionist Type of State 1 in the Key MID. (COW)

Same unordered categories as [35] cwrevt11.

[37] Cwrevis2: whether State 2 is the Revisionist State in the Key MID. (COW) Binary: $1=y e s, 0=$ no.

[38] cwrevt12: First Revisionist Type of State 2 in the Key MID. (COW) Same unordered categories as [35] cwrevt11.

[39] cwrevt22: Second Revisionist Type of State 2 in the Key MID. (COW)

Same unordered categories as [35] cwrevt11. 
$\underline{\text { Dependent Variables by Author }}$

[40] scauth: whether State 1 was on Side A of the Key MID and had authorization from the Security Council to do so. (Author)

Binary: $1=y e s, 0=$ no.

[41] scres: number of the Security Council Resolution that authorized State 1 to be on Side A in the Key MID. (Author)

Only contains data if $[40]$ scauth $=1$.

[42] init 12: whether State 1 Initiated an armed conflict at Highest Activity level 12 or higher; either it was on Side A of the Key MID at HiAct 12 or higher, or it was on Side B but escalated the Key MID from below 12 to 12 or higher. (Author) Binary: $1=y e s, 0=$ no.

[43] init12noauth: whether State 1 Initiated an armed conflict at Highest Activity level 12 or higher (as defined in [42] init12 above) without Security Council authorization. (Author)

Binary: $1=y e s, 0=$ no.

[44] esc12: whether State 1 escalated the MID to Highest Activity level 12 or higher (making it the Initiator of an armed conflict as defined in [42] init12 above), but did not initiate the MID. (Author)

Binary: $1=y e s, 0=$ no.

[45] init 13: whether State 1 Initiated an armed conflict at Highest Activity level 13 or higher; either it was on Side A of the Key MID at HiAct 13 or higher, or it was on Side B but escalated the Key MID from below 13 to 13 or higher. (Author)

Binary: $1=y e s, 0=$ no.

[46] init13noauth: whether State 1 Initiated an armed conflict at Highest Activity level 13 or higher (as defined in [45] init13 above) without Security Council authorization. (Author)

Binary: $1=y e s, 0=$ no.

[47] esc13: whether State 1 escalated the MID to Highest Activity level 13 or higher (making it the Initiator of an armed conflict as defined in [45] init13 above), but did not initiate the MID. (Author)

Binary: $1=y e s, 0=$ no.

[48] init12no15: init12 variable as defined above, but with seizure cases ( [26] cwhiact 1=15) removed. (Author)

Binary: $1=y e s, 0=$ no. 
[49] init12no15noauth: init12 variable as defined above, without Security Council authorization, but with seizure cases ([26] cwhiact $1=15)$ removed. (Author) Binary: $1=y e s, 0=$ no.

[50] esc12no15: whether State 1 escalated the MID to Highest Activity level 12 or higher with seizure cases removed (making it the Initiator of an armed conflict as defined in [48] init12no15 above), but did not initiate the MID. (Author) Binary: $1=$ yes, $0=$ no.

[51] init13no15: init13 variable as defined above, but with seizure cases ( [26] cwhiact $1=15$ ) removed. (Author)

Binary: $1=$ yes, $0=$ no.

[52] init13no15noauth: init13 variable as defined above, without Security Council authorization, but with seizure cases ([26] cwhiact $1=15)$ removed. (Author) Binary: $1=y e s, 0=$ no.

[53] esc13no15: whether State 1 escalated the MID to Highest Activity level 13 or higher with seizure cases removed (making it the Initiator of an armed conflict as defined in [51] init13no15 above), but did not initiate the MID. (Author) Binary: $1=y e s, 0=$ no.

[54] initfatal: whether State 1 Initiated an armed conflict (as defined in [42] init12 above) in which either side incurred fatalities. (Author) Binary: $1=$ yes, $0=$ no.

[55] initfatalnoauth: whether State 1 Initiated an armed conflict (as defined in [42] init12 above) in which either side incurred fatalities, without Security Council authorization. (Author)

Binary: $1=y e s, 0=$ no.

[56] escfatal: whether State 1 escalated the MID to fatalities (making it the Initiator of an armed conflict as defined in [54] initfatal above), but did not initiate the MID. (Author)

Binary: $1=y e s, 0=$ no.

[57] threaton $l_{y}$ : whether State 1 threatened force but did not actually use force, i.e. it was on Side A of the MID, but militarized it at Highest Activity 11 or below. (Author)

Binary: $1=$ yes, $0=$ no. 
[58] hostdlb1: Hostility level of State 1, adjusted by author. (Author)

0 : no hostility ( [26] cwhiact $1=0$ )

1: verbal threat (cwhiact $1=1$ to 6 )

2: show of force but no act of aggression ( $\operatorname{cwhiact} 1=7$ to 11 )

3: use of force (act of aggression) short of war (cwhiact $1=12$ to 17)

4: war, including use of weapons of mass destruction (cwhiact1>=18)

[59] severity1: Severity of Force by State 1. (Author)

11: no actual use of force $([26]$ cwhiact $1<=11)$

12: border violation ( cwhiact $1=12$ )

13: blockade (cwhiact $1=13$ )

14: occupation of territory ( $\operatorname{cwhiact} 1=14$ )

15: seizure (cwhiact $1=15)$

16: attack (cwhiact $1=16)$

17: clash (cwhiact $1=17$ )

18: war, including use of weapons of mass destruction (cwhiact1>=18)

[60] hostd1b2: Hostility level of State 2, adjusted by author. (Author)

Uses [27] cwhiact2. Same ordered categories as [58] hostdlb1.

[61] severity2: Severity of Force by State 2. (Author)

Uses [27] cwhiact2. Same ordered categories as [59] severity1. 
Independent Variables

\section{$\underline{\text { Religion of Population }}$}

[62] prevrelid1: Prevalent Religion of population of State 1 (66.5\% or more of population, or largest segment of population in largely atheist or non-religious state). (Author)

10: Christian (all/generally; all denominations combined, or precise ratio between Orthodox \& Western Christian not known)

11: Western Christian (Catholic, Protestant, \& Mormon combined, or precise ratio between Western Christian denominations not known)

12: Catholic

13: Protestant (including Anglican \& Pentacostal)

14: Eastern Christian

15: Mormon

16: Christian Syncretic

20: Jewish

30: Muslim (all/generally; all branches combined, or precise ratio not known)

31: Sunni Muslim

32: Shia Muslim

33: Other Muslim

40: Hindu

50: Buddhist (pure; i.e. not mixed with Confucian, Tao, or Shinto)

55: Buddhist Mix (mixed with Confucian, Tao, and/or Shinto)

60: East Asian (combined Confucian, Tao, \& Shinto; often mixed with Buddhist)

70: Indigenous (all forms, including especially Animist)

80: None (including Non-denominational \& Agnostic, but not Atheist)

85: Not Religious (None and Atheist combined)

90: Atheist

100: Mixed (generally)

101: Christian-Muslim Mix (2 largest religions Christian \& Muslim)

102: Christian-Indigenous Mix (2 largest religions Christian \& Indigenous)

103: Christian-Hindu Mix (2 largest religions Christian \& Hindu)

104: Muslim-Indigenous Mix (2 largest religions Muslim \& Indigenous, including Syncretic)

105: Muslim-Buddhist Mix (2 largest religions Muslim \& Buddhist)

106: Buddhist-Hindu Mix (2 largest religions Muslim \& Hindu)

107: Buddhist-Indigenous Mix (2 largest religious Buddhist \& Indigenous)

108: Buddhist-Christian Mix (2 largest religions Buddhist \& Christian)

109: East Asian Mix (2 largest religions are East Asian \& something other than Christian) 
[63] prevrelidxtab1: Prevalent Religion of population of State 1 (as defined in [62] prevrelid1 above), with fewer categories in order to facilitate crosstabulation. (Author)

10: Christian

16: Syncretic

20: Jewish

30: Muslim
40: Hindu

55: Buddhist Mix (combined Buddhist \& East Asian)

70: Indigenous

85: Not Religious (combined None \& Atheist)

[64] prevre1110: percentage of population of State 1 that is of the Prevalent religion of State 1 , in units of 10 percent. (Author)

Continuous range $0-10$.

[65] prevrelid2: Prevalent Religion of population of State 2 (66.5\% or more of population, or largest segment of population in largely atheist or non-religious state). (Author)

Same unordered categories as [62] prevrelidl.

[66] prevrelidxtab2: Prevalent Religion of population of State 2 (as defined in prevrelidl above), with fewer categories in order to facilitate cross-tabulation. (Author)

Same unordered categories as [62] prevrelidxtab1.

[67] prevre1210: percentage of population of State 2 that is of the Prevalent religion of State 2, in units of 10 percent. (Author)

Continuous range $0-10$.

[68] judchrprev1: whether Prevalent Religion of State 1 is Judeo-Christian. (Author) Binary: $1=y e s, 0=$ no.

[69] judchrprev2: whether Prevalent Religion of State 2 is Judeo-Christian. (Author) Binary: $1=y e s, 0=$ no.

[70] judchr110: percentage of population of State 1 that is Judeo-Christian, in units of 10 percent. (Author)

Continuous range $0-10$.

[71] judchr210: percentage of population of State 2 that is Judeo-Christian, in units of 10 percent. (Author)

Continuous range $0-10$.

[72] christallprev1: whether Prevalent Religion of State 1 is Christian (any combination of denominations). (Author)

Binary: $1=$ yes, $0=$ no. 
[73] christallprev2: whether Prevalent Religion of State 2 is Christian (any combination of denominations). (Author)

Binary: $1=y e s, 0=$ no.

[74] christal1110: percentage of population of State 1 that is Christian (any combination of denominations), in units of 10 percent. (Author)

Continuous range $0-10$.

[75] christal1210: percentage of population of State 2 that is Christian (any combination of denominations), in units of 10 percent. (Author)

Continuous range $0-10$.

[ 76] christwestprev1: whether Prevalent Religion of State 1 is Western Christian (any combination of Catholic, Protestant, or Mormon). (Author)

Binary: $1=$ yes, $0=$ no.

[77] christwestprev2: whether Prevalent Religion of State 2 is Western Christian (any combination of Catholic, Protestant, or Mormon). (Author)

Binary: $1=y e s, 0=$ no.

[78] christwest110: percentage of population of State 1 that is Western Christian (any combination of Catholic, Protestant, or Mormon), in units of 10 percent. (Author) Continuous range $0-10$.

[79] christwest210: percentage of population of State 2 that is Western Christian (any combination of Catholic, Protestant, or Mormon), in units of 10 percent. (Author) Continuous range $0-10$.

[80] cathprev1: whether Prevalent Religion of State 1 is Catholic. (Author)

Binary: $1=y e s, 0=$ no.

[81] cathprev2: whether Prevalent Religion of State 2 is Catholic. (Author)

Binary: $1=$ yes, $0=$ no.

[82] cath110: percentage of population of State 1 that is Catholic, in units of 10 percent. (Author)

Continuous range $0-10$.

[83] cath210: percentage of population of State 2 that is Catholic, in units of 10 percent. (Author)

Continuous range $0-10$.

[84] protprev1: whether Prevalent Religion of State 1 is Protestant. (Author)

Binary: $1=y e s, 0=$ no. 
[85] protprev2: whether Prevalent Religion of State 2 is Protestant. (Author)

Binary: $1=y e s, 0=$ no.

[86] prot 110: percentage of population of State 1 that is Protestant, in units of 10 percent. (Author)

Continuous range $0-10$.

[87] prot210: percentage of population of State 2 that is Protestant, in units of 10 percent. (Author)

Continuous range $0-10$.

[88] orthprev1: whether Prevalent Religion of State 1 is Eastern Christian. (Author) Binary: $1=y e s, 0=$ no.

[89] orthprev2: whether Prevalent Religion of State 2 is Eastern Christian. (Author) Binary: $1=y e s, 0=$ no.

[90] orth110: percentage of population of State 1 that is Eastern Christian, in units of 10 percent. (Author)

Continuous range $0-10$.

[91] orth210: percentage of population of State 2 that is Eastern Christian, in units of 10 percent. (Author)

Continuous range $0-10$.

[92] mormon110: percentage of population of State 1 that is Mormon, in units of 10 percent. (Author)

Continuous range $0-10$.

[93] mormon210: percentage of population of State 2 that is Mormon, in units of 10 percent. (Author)

Continuous range $0-10$.

[94] christunsp110: percentage of population of State 1 that is Christian Unspecified (denomination not known), in units of 10 percent. (Author)

Continuous range $0-10$.

[95] christunsp210: percentage of population of State 2 that is Christian Unspecified (denomination not known), in units of 10 percent. (Author)

Continuous range 0-10.

[96] syncrprev1: whether Prevalent Religion of State 1 is Christian Syncretic. (Author) Binary: $1=y e s, 0=$ no.

[97] syncrprev2: whether Prevalent Religion of State 2 is Christian Syncretic. (Author) Binary: $1=$ yes, $0=$ no. 
[98] syncr 110: percentage of population of State 1 that is Christian Syncretic, in units of 10 percent. (Author)

Continuous range $0-10$.

[99] syncr 210: percentage of population of State 2 that is Christian Syncretic, in units of 10 percent. (Author)

Continuous range $0-10$.

[100] jewishprev1: whether Prevalent Religion of State 1 is Jewish. (Author) Binary: $1=y e s, 0=$ no.

[101] jewishprev2: whether Prevalent Religion of State 2 is Jewish. (Author) Binary: $1=y e s, 0=$ no.

[102] jewish110: percentage of population of State 1 that is Jewish, in units of 10 percent. (Author)

Continuous range $0-10$.

[103] jewish210: percentage of population of State 2 that is Jewish, in units of 10 percent. (Author)

Continuous range $0-10$.

[104] muslimallprev1: whether Prevalent Religion of State 1 is Muslim (any combination of branches). (Author)

Binary: $1=y e s, 0=$ no.

[105] muslimallprev2: whether Prevalent Religion of State 2 is Muslim (any combination of branches). (Author)

Binary: $1=y e s, 0=$ no.

[106] muslimal1110: percentage of population of State 1 that is Muslim (any combination of branches), in units of 10 percent. (Author)

Continuous range $0-10$.

[107] muslimal1210: percentage of population of State 2 that is Muslim (any combination of branches), in units of 10 percent. (Author)

Continuous range $0-10$.

[108] sunniprev1: whether Prevalent Religion of State 1 is Sunni Muslim. (Author) Binary: $1=y e s, 0=$ no.

[109] sunniprev2: whether Prevalent Religion of State 2 is Sunni Muslim. (Author) Binary: $1=y e s, 0=$ no. 
[110] sunni110: percentage of population of State 1 that is Sunni Muslim, in units of 10 percent. (Author)

Continuous range $0-10$.

[111] sunni210: percentage of population of State 2 that is Sunni Muslim, in units of 10 percent. (Author)

Continuous range $0-10$.

[112] shiaprev1: whether Prevalent Religion of State 1 is Shia Muslim. (Author) Binary: $1=y e s, 0=$ no.

[113] shiaprev2: whether Prevalent Religion of State 2 is Shia Muslim. (Author) Binary: $1=y e s, 0=$ no.

[114] shia110: percentage of population of State 1 that is Shia Muslim, in units of 10 percent. (Author)

Continuous range $0-10$.

[115] shia210: percentage of population of State 2 that is Shia Muslim, in units of 10 percent. (Author)

Continuous range $0-10$.

[116] muslimotherprev1: whether Prevalent Religion of State 1 is Muslim, other than Sunni or Shia. (Author)

Binary: $1=y e s, 0=$ no.

[117] muslimotherprev2: whether Prevalent Religion of State 2 is Muslim, other than Sunni or Shia. (Author)

Binary: $1=\mathrm{yes}, 0=$ no.

[118] muslimother110: percentage of population of State 1 that is Muslim, other than Sunni or Shia, in units of 10 percent. (Author)

Continuous range $0-10$.

[119] muslimother210: percentage of population of State 2 that is Muslim, other than Sunni or Shia, in units of 10 percent. (Author)

Continuous range $0-10$.

[120] ofthebookprev1: whether Prevalent Religion of State 1 is any combination of Christian, Jewish, or Muslim. (Author)

Binary: $1=y e s, 0=$ no.

[121] of thebookprev2: whether Prevalent Religion of State 2 is any combination of Christian, Jewish, or Muslim. (Author)

Binary: $1=y e s, 0=$ no. 
[122] hinduprev1: whether Prevalent Religion of State 1 is Hindu. (Author)

Binary: $1=y e s, 0=$ no.

[123] hinduprev2: whether Prevalent Religion of State 2 is Hindu. (Author) Binary: $1=y e s, 0=$ no.

[124] hindu110: percentage of population of State 1 that is Hindu, in units of 10 percent. (Author)

Continuous range $0-10$.

[125] hindu210: percentage of population of State 2 that is Hindu, in units of 10 percent. (Author)

Continuous range $0-10$.

[126] buddpureprev1: whether Prevalent Religion of State 1 is Buddhist (pure). (Author) Binary: $1=y e s, 0=$ no.

[127] buddpureprev2: whether Prevalent Religion of State 2 is Buddhist (pure). (Author) Binary: $1=$ yes, $0=$ no.

[128] buddpure110: percentage of population of State 1 that is Buddhist (pure), in units of 10 percent. (Author)

Continuous range $0-10$.

[129] buddpure210: percentage of population of State 2 that is Buddhist (pure), in units of 10 percent. (Author)

Continuous range $0-10$.

[130] buddmixprev1: whether Prevalent Religion of State 1 is Buddhist Mix (any combination of Buddhist, Confucian, Tao, and/or Shinto). (Author) Binary: $1=y e s, 0=$ no.

[131] buddmixprev2: whether Prevalent Religion of State 2 is Buddhist Mix (any combination of Buddhist, Confucian, Tao, and/or Shinto). (Author)

Binary: $1=y e s, 0=$ no.

[132] buddmix110: percentage of population of State 1 that is Buddhist Mix (any combination of Buddhist, Confucian, Tao, and/or Shinto), in units of 10 percent. (Author)

Continuous range 0-10.

[133] buddmix210: percentage of population of State 2 that is Buddhist Mix (any combination of Buddhist, Confucian, Tao, and/or Shinto), in units of 10 percent. (Author)

Continuous range $0-10$. 
[134] eaallprev1: whether Prevalent Religion of State 1 is East Asian (Confucian, Tao, or Shinto, whether mixed with Buddhism or not). (Author)

Binary: $1=y e s, 0=$ no.

[135] eallprev2: whether Prevalent Religion of State 2 is East Asian (Confucian, Tao, or Shinto, whether mixed with Buddhism or not). (Author)

Binary: $1=$ yes, $0=$ no.

[136] eaal1110: percentage of population of State 1 that is East Asian (Confucian, Tao, or Shinto, whether mixed with Buddhism or not), in units of 10 percent. (Author) Continuous range $0-10$.

[137] eaal1210: percentage of population of State 2 that is East Asian (Confucian, Tao, or Shinto, whether mixed with Buddhism or not), in units of 10 percent. (Author) Continuous range $0-10$.

[138] conf110: percentage of population of State 1 that is Confucian, in units of 10 percent. (Author)

Continuous range $0-10$.

[139] conf210: percentage of population of State 2 that is Confucian, in units of 10 percent. (Author)

Continuous range $0-10$.

[140] tao110: percentage of population of State 1 that is Tao, in units of 10 percent. (Author)

Continuous range $0-10$.

[141] tao210: percentage of population of State 2 that is Tao, in units of 10 percent. (Author)

Continuous range $0-10$.

[142] shinto110: percentage of population of State 1 that is Shinto, in units of 10 percent. (Author)

Continuous range $0-10$.

[143] shinto210: percentage of population of State 2 that is Shinto, in units of 10 percent. (Author)

Continuous range $0-10$.

[144] indigallprev1: whether Prevalent Religion of State 1 is Indigenous (including Animist). (Author)

Binary: $1=$ yes, $0=$ no. 
[145] indigallprev2: whether Prevalent Religion of State 2 is Indigenous (including Animist). (Author)

Binary: $1=$ yes, $0=$ no.

[146] indigal1110: percentage of population of State 1 that is Indigenous (including Animist), in units of 10 percent. (Author)

Continuous range $0-10$.

[147] indigal1210: percentage of population of State 2 that is Indigenous (including Animist), in units of 10 percent. (Author)

Continuous range $0-10$.

[148] notrelprev1: whether Prevalent Religion of State 1 is Not Religious (including Atheist). (Author)

Binary: $1=$ yes, $0=$ no.

[149] notrelprev2: whether Prevalent Religion of State 2 is Not Religious (including Atheist). (Author)

Binary: $1=$ yes, $0=$ no.

[150] notre1110: percentage of population of State 1 that is Not Religious (including Atheist), in units of 10 percent. (Author)

Continuous range $0-10$.

[151] notre1210: percentage of population of State 2 that is Not Religious (including Atheist), in units of 10 percent. (Author)

Continuous range 0-10.

[152] none110: percentage of population of State 1 that is Non-denominational or Agnostic, but not Atheist, in units of 10 percent. (Author) Continuous range $0-10$.

[153] none210: percentage of population of State 2 that is Non-denominational or Agnostic, but not Atheist, in units of 10 percent. (Author) Continuous range $0-10$.

[154] athprev1: whether Prevalent Religion of State 1 is Atheist. (Author) Binary: $1=y e s, 0=$ no.

[155] athprev2: whether Prevalent Religion of State 2 is Atheist. (Author) Binary: $1=y e s, 0=$ no.

[156] ath110: percentage of population of State 1 that is Atheist, in units of 10 percent. (Author)

Continuous range $0-10$. 
[157] ath210: percentage of population of State 2 that is Atheist, in units of 10 percent. (Author)

Continuous range $0-10$.

[158] unspec110: percentage of population of State 1 that is unknown, in units of 10 percent. (Author)

Continuous range $0-10$.

[159] unspec210: percentage of population of State 2 that is unknown, in units of 10 percent. (Author)

Continuous range $0-10$.

[160] chrchrdyadprev: whether the Prevalent Religion is Christian in both State 1 and State 2. (Author)

Binary: $1=$ yes, $0=$ no.

[161] westeastchrdyadprev: whether the Prevalent Religion is Western Christian in State 1 and Eastern Christian in State 2. (Author)

Binary: $1=y e s, 0=$ no.

[162] eastwestchrdyadprev: whether the Prevalent Religion is Eastern Christian in State 1 and Western Christian in State 2. (Author)

Binary: $1=$ yes, $0=$ no.

[163] chrmusdyadprev: whether the Prevalent Religion is Christian in State 1 and Muslim in State 2. (Author)

Binary: $1=$ yes, $0=$ no.

[164] muschrdyadprev: whether the Prevalent Religion is Muslim in State 1 and Christian in State 2. (Author)

Binary: $1=$ yes, $0=$ no.

[165] mus jewdyadprev: whether the Prevalent Religion is Muslim in State 1 and Jewish in State 2. (Author)

Binary: $1=y e s, 0=$ no.

[166] musmusdyadprev: whether the Prevalent Religion is Muslim in both State 1 and State 2. (Author)

Binary: $1=y e s, 0=$ no.

[167] musbookdyadprev: whether the Prevalent Religion is Muslim in State 1 and Of The Book (any combination of Christian, Jewish, Muslim) in State 2. (Author) Binary: $1=y e s, 0=$ no. 
[168] bookmusdyadprev: whether the Prevalent Religion is Of The Book (any combination of Christian, Jewish, Muslim) in State 1 and Muslim in State 2. (Author)

Binary: $1=$ yes, $0=$ no.

\section{Religious Preference}

[169] prefrelid1: Preferred Religion of the government of State 1. (Author) Same unordered categories as [62] prevrelidl.

[170] prefrelidxtab1: Preferred Religion of the government of State 1, with fewer categories in order to facilitate cross-tabulation. (Author)

Same unordered categories as [63] prevrelidxtab1.

[171] prefrelid2: Preferred Religion of the government of State 2. (Author)

Same unordered categories as [62] prevrelid1.

[172] prefrelidxtab2: Preferred Religion of the government of State 2, with fewer categories in order to facilitate cross-tabulation. (Author)

Same unordered categories as [63] prevrelidxtab1.

[173] prefrel110: Government Religious Preference score of State 1, scaled 0 to 10. (Author)

Average of non-missing scores of the variables for State 1 of [174] constest1, [175] releduc1, [176] amen1, [177] genpriv1, and [178] intol1.

Continuous range $0-10$.

[174] constest1: Constitutional establishment of Preferred religion in State 1. (Author)

4: Official state religion

3: State recognition and protection of Preferred religion

2: No mention of Preferred religion in constitution

1: Separation of religion from governance ("separation of church and state")

0: Government hostility toward religion

[175] releduc1: Religious education of Preferred religion conducted by government of State 1. (Author)

4: Required (non-adherents of Preferred religion may or may not be exempt)

3: Encouraged; provided but individuals may opt out

2: Permitted; provided but individuals must opt in (even if religious education is only permitted for Preferred religion)

1: Funded by government (no further information)

0: Prohibited 
[176] amen1: Amenability of government officials to influence of Preferred religion in State 1. (Author)

4: Highly amenable (includes government religious advisors or officials)

3: Moderately amenable

2: Low amenability, None, or Low resistance

1: Moderately resistant (including prohibition of political activities and other control of religion)

0: Highly resistant (including abolitionist)

[177] genpriv1: General privileges for the Preferred religion in State 1. (Author)

4: Highly discriminatory

3: Moderately discriminatory

2: Slightly discriminatory or Impartial (may be between religions or between religion and secularism)

1: No privileges to any religion

0: Suppression of religion

[178] intol1: Intolerance of practice of any non-Preferred religion in State 1. (Author)

Note: this variable refers to practice of non-Preferred religions, not political activities thereof.

4: Extreme (only Preferred religion is lawful)

3: High (non-Preferred religious institutions must operate quietly; or, high government sanctions against proselytizing by and conversion to Non-Preferred religion; or, extreme suppression of non-Preferred religion)

2: Moderate (practice of non-Preferred religion lawful; but government allows local and/or social sanctions for proselytizing by or conversion to non-Preferred religion; or, severe intolerance of non-indigenous* non-Preferred religions)

1: Low (Indigenous non-Preferred religions are tolerated, but light or moderate restrictions placed on non-Indigenous ones; or, a facially neutral prohibition of all religious proselytizing confers an advantage to the Preferred religion)

0.1: None (free exercise of religion, including non-Indigenous ones, but not sects that the government regards as cults)

0 : Nil (absolutely no suppression of free exercise of religion, even cults)

* An "Indigenous" non-Preferred religion is a non-Preferred religion that has had a substantial and historical-cultural presence in the state for 50 years or longer.

[179] secprefrelid1: Secondary Preferred Religion of the government of State 1. (Author)

Used when GRP score for another religion is non-zero but lower than for primary Preferred religion; usually when primary Preferred religion is Atheist.

Same unordered categories as [62] prevrelid1. 
[180] secprefrel110: Secondary Government Religious Preference score of State 1, scaled 0 to 10 . (Author)

Composite score of components; average of non-missing scores of the variables for State 1 of [181] secconstest1, [182] secreleduc1, [183] secamen1, [184] secgenpriv1, and [185] secintol1.

Continuous range $0-10$.

[181] secconstest1: Constitutional establishment of secondary Preferred religion in State 1. (Author)

Same ordered categories as [174] constest1.

[182] secreleduc1: Religious education of secondary Preferred religion conducted by government of State 1. (Author)

Same ordered categories as [175] releduc1.

[183] secamen1: Amenability of government officials to influence of secondary Preferred religion in State 1. (Author)

Same ordered categories as [176] amen1.

[184] secgenpriv1: General privileges for the secondary Preferred religion in State 1. (Author)

Same ordered categories as [177] genpriv1.

[185] secintol1: Intolerance of practice of any non-Preferred religion in State 1 other than secondary. (Author)

Same ordered categories as [178] intol1.

[186] prefre1210: Government Religious Preference score of State 2, scaled 0 to 10. (Author)

Average of non-missing scores of the variables for State 1 of [187] constest2, [188] releduc2, [189] amen2, [190] genpriv2, and [191] intol2.

Continuous range $0-10$.

[187] constest2: Constitutional establishment of Preferred religion in State 2. (Author) Same ordered categories as [174] constest1.

[188] releduc2: Religious education of Preferred religion conducted by government of State 2. (Author)

Same ordered categories as [175]releduc1.

[189] amen2: Amenability of government officials to influence of Preferred religion in State 2. (Author)

Same ordered categories as [176] amen1.

[190] genpriv2: General privileges for the Preferred religion in State 2. (Author)

Same ordered categories as [177] genpriv1. 
[191] into12: Intolerance of practice of any non-Preferred religion in State 2. (Author) Same ordered categories as [178] intol1.

[192] secprefrelid2: Secondary Preferred Religion of the government of State 2. (Author)

Used when GRP score for another religion is non-zero but lower than for primary Preferred religion; usually when primary Preferred religion is Atheist.

Same unordered categories as [62] prevrelidl.

[193] secprefre1210: Secondary Government Religious Preference score of State 2, scaled 0 to 10 . (Author)

Composite score of components; average of non-missing scores of the variables for State 1 of [194] secconstest2, [195] secreleduc2, [196] secamen2, [197] secgenpriv2, and [198] secintol2.

Continuous range $0-10$.

[194] secconstest2: Constitutional establishment of secondary Preferred religion in State 2. (Author)

Same ordered categories as [174] constest1.

[195] secreleduc2: Religious education of secondary Preferred religion conducted by government of State 2. (Author)

Same ordered categories as [175] releduc1.

[196] secamen2: Amenability of government officials to influence of secondary Preferred religion in State 2. (Author)

Same ordered categories as [176] amen1.

[197] secgenpriv2: General privileges for the secondary Preferred religion in State 2. (Author)

Same ordered categories as [177] genpriv1.

[198] secintol2: Intolerance of practice of any non-Preferred religion in State 2 other than secondary. (Author)

Same ordered categories as [178] intol1.

[199] judchrpref 1: whether Preferred Religion of State 1 is Judeo-Christian. (Author) Binary: $1=y e s, 0=$ no.

[200] judchrpref 2: whether Preferred Religion of State 2 is Judeo-Christian. (Author) Binary: $1=$ yes, $0=$ no.

[201] judchrpref110: Judeo-Christian Government Religious Preference score for State 1, scaled 0 to 10. (Author)

Continuous range $0-10$. 
[202] judchrpref210: Judeo-Christian Government Religious Preference score for State 2, scaled 0 to 10 . (Author)

Continuous range $0-10$.

[203] christallpref 1: whether Preferred Religion of State 1 is Christian (any combination of denominations). (Author)

Binary: $1=$ yes, $0=$ no.

[204] christallpref2: whether Preferred Religion of State 2 is Christian (any combination of denominations). (Author)

Binary: $1=$ yes, $0=$ no.

[205] christallpref110: Christian Government Religious Preference score for State 1, scaled 0 to 10. (Author)

Continuous range $0-10$.

[206] christallpref210: Christian Government Religious Preference score for State 2, scaled 0 to 10 . (Author)

Continuous range $0-10$.

[207] christwestpref 1: whether Preferred Religion of State 1 is Western Christian (any combination of Catholic, Protestant, or Mormon). (Author)

Binary: $1=y e s, 0=$ no.

[208] christwestpref2: whether Preferred Religion of State 2 is Western Christian (any combination of Catholic, Protestant, or Mormon). (Author)

Binary: $1=y e s, 0=$ no.

[209] christwestpref110: Western Christian Government Religious Preference score for State 1, scaled 0 to 10. (Author)

Continuous range $0-10$.

[210] christwestpref210: Western Christian Government Religious Preference score for State 2, scaled 0 to 10. (Author) Continuous range $0-10$.

[211] cathpref1: whether Preferred Religion of State 1 is Catholic. (Author) Binary: $1=y e s, 0=$ no.

[212] cathpref2: whether Preferred Religion of State 2 is Catholic. (Author) Binary: $1=y e s, 0=$ no.

[213] cathpref110: Catholic Government Religious Preference score for State 1, scaled 0 to 10. (Author)

Continuous range 0-10. 
[214] cathpref210: Catholic Government Religious Preference score for State 2, scaled 0 to 10 . (Author)

Continuous range $0-10$.

[215] protpref1: whether Preferred Religion of State 1 is Protestant. (Author)

Binary: $1=y e s, 0=$ no.

[216] protpref2: whether Preferred Religion of State 2 is Protestant. (Author) Binary: $1=y e s, 0=$ no.

[217] protpref110: Protestant Government Religious Preference score for State 1, scaled 0 to 10 . (Author)

Continuous range $0-10$.

[218] protpref210: Protestant Government Religious Preference score for State 2, scaled 0 to 10 . (Author)

Continuous range $0-10$.

[219] orthpref1: whether Preferred Religion of State 1 is Eastern Christian. (Author) Binary: $1=$ yes, $0=$ no.

[220] orthpref2: whether Preferred Religion of State 2 is Eastern Christian. (Author) Binary: $1=$ yes, $0=$ no.

[221] orthpref110: Eastern Christian Government Religious Preference score for State 1 , scaled 0 to 10 . (Author)

Continuous range $0-10$.

[222] orthpref210: Eastern Christian Government Religious Preference score for State 2 , scaled 0 to 10 . (Author)

Continuous range $0-10$.

[223] syncrpref 1: whether Preferred Religion of State 1 is Christian Syncretic. (Author) Binary: $1=y e s, 0=$ no.

[224] syncrpref2: whether Preferred Religion of State 2 is Christian Syncretic. (Author) Binary: $1=$ yes, $0=$ no.

[225] syncrpref110: Christian Syncretic Government Religious Preference score for State 1 , scaled 0 to 10 . (Author) Continuous range $0-10$.

[226] syncrpref210: Christian Syncretic Government Religious Preference score for State 2, scaled 0 to 10 . (Author) Continuous range 0-10. 
[227] jewishpref 1: whether Preferred Religion of State 1 is Jewish. (Author) Binary: $1=$ yes, $0=$ no.

[228] jewishpref2: whether Preferred Religion of State 2 is Jewish. (Author) Binary: $1=$ yes, $0=$ no.

[229] jewishpref110: Jewish Government Religious Preference score for State 1, scaled 0 to 10 . (Author) Continuous range $0-10$.

[230] jewishpref210: Jewish Government Religious Preference score for State 2, scaled 0 to 10 . (Author) Continuous range $0-10$.

[231] muslimallpref1: whether Preferred Religion of State 1 is Muslim (any combination of branches). (Author) Binary: $1=$ yes, $0=$ no.

[232] muslimallpref2: whether Preferred Religion of State 2 is Muslim (any combination of branches). (Author)

Binary: $1=y e s, 0=$ no.

[233] muslimallpref110: Muslim Government Religious Preference score for State 1, scaled 0 to 10. (Author)

Continuous range $0-10$.

[234] muslimallpref210: Muslim Government Religious Preference score for State 2, scaled 0 to 10 . (Author)

Continuous range $0-10$.

[235] sunnipref1: whether Preferred Religion of State 1 is Sunni Muslim. (Author) Binary: $1=y e s, 0=$ no.

[236] sunnipref2: whether Preferred Religion of State 2 is Sunni Muslim. (Author) Binary: $1=y e s, 0=$ no.

[237] sunnipref110: Sunni Government Religious Preference score for State 1, scaled 0 to 10 . (Author) Continuous range $0-10$.

[238] sunnipref210: Sunni Government Religious Preference score for State 2, scaled 0 to 10 . (Author) Continuous range 0-10. 
[239] shiapref1: whether Preferred Religion of State 1 is Shia Muslim. (Author)

Binary: $1=y e s, 0=$ no.

[240] shiapref2: whether Preferred Religion of State 2 is Shia Muslim. (Author) Binary: $1=$ yes, $0=$ no.

[241] shiapref110: Shia Government Religious Preference score for State 1, scaled 0 to 10. (Author)

Continuous range $0-10$.

[242] shiapref210: Shia Government Religious Preference score for State 2, scaled 0 to 10. (Author)

Continuous range $0-10$.

[243] muslimotherpref 1: whether Preferred Religion of State 1 is Muslim, other than Sunni or Shia. (Author)

Binary: $1=$ yes, $0=$ no.

[244] muslimotherpref2: whether Preferred Religion of State 2 is Muslim, other than Sunni or Shia. (Author)

Binary: $1=$ yes, $0=$ no.

[245] muslimotherpref110: Other Muslim Government Religious Preference score for State 1, scaled 0 to 10 . (Author)

Continuous range $0-10$.

[246] muslimotherpref210: Other Muslim Government Religious Preference score for State 2, scaled 0 to 10 . (Author)

Continuous range $0-10$.

[247] ofthebookpref1: whether Preferred Religion of State 1 is any combination of Christian, Jewish, or Muslim. (Author)

Binary: $1=$ yes, $0=$ no.

[248] ofthebookpref2: whether Preferred Religion of State 2 is any combination of Christian, Jewish, or Muslim. (Author)

Binary: $1=$ yes, $0=$ no.

[249] hindupref1: whether Preferred Religion of State 1 is Hindu. (Author) Binary: $1=y e s, 0=$ no.

[250] hindupref2: whether Preferred Religion of State 2 is Hindu. (Author) Binary: $1=y e s, 0=$ no. 
[251] hindupref110: Hindu Government Religious Preference score for State 1, scaled 0 to 10 . (Author)

Continuous range $0-10$.

[252] hindupref210: Hindu Government Religious Preference score for State 2, scaled 0 to 10 . (Author)

Continuous range $0-10$.

[253] buddpurepref 1: whether Preferred Religion of State 1 is Buddhist (pure). (Author) Binary: $1=y e s, 0=$ no.

[254] buddpurepref2: whether Preferred Religion of State 2 is Buddhist (pure). (Author) Binary: $1=y e s, 0=$ no.

[255] buddpurepref110: Buddhist (pure) Government Religious Preference score for State 1, scaled 0 to 10 . (Author)

Continuous range $0-10$.

[256] buddpurepref210: Buddhist (pure) Government Religious Preference score for State 2, scaled 0 to 10. (Author)

Continuous range $0-10$.

[257] buddmixpref1: whether Preferred Religion of State 1 is Buddhist Mix (any combination of Buddhist, Confucian, Tao, and/or Shinto). (Author) Binary: $1=y e s, 0=$ no.

[258] buddmixpref2: whether Preferred Religion of State 2 is Buddhist Mix (any combination of Buddhist, Confucian, Tao, and/or Shinto). (Author) Binary: $1=y e s, 0=$ no.

[259] buddmixpref110: Buddhist Mix (any combination of Buddhist, Confucian, Tao, and/or Shinto)Government Religious Preference score for State 1, scaled 0 to 10. (Author)

Continuous range $0-10$.

[260] buddmixpref210: Buddhist Mix (any combination of Buddhist, Confucian, Tao, and/or Shinto)Government Religious Preference score for State 1, scaled 0 to 10. (Author) Continuous range $0-10$.

[261] eaallpref 1: whether Preferred Religion of State 1 is East Asian (Confucian, Tao, or Shinto, whether mixed with Buddhism or not). (Author)

Binary: $1=$ yes, $0=$ no. 
[262] eaallpref2: whether Preferred Religion of State 2 is East Asian (Confucian, Tao, or Shinto, whether mixed with Buddhism or not). (Author)

Binary: $1=y e s, 0=$ no.

[263] eaallpref110: East Asian Government Religious Preference score for State 1, scaled 0 to 10 . (Author)

Continuous range $0-10$.

[264] eaallpref210: East Asian Government Religious Preference score for State 2, scaled 0 to 10. (Author)

Continuous range $0-10$.

[265] indigallpref1: whether Preferred Religion of State 1 is Indigenous (including Animist). (Author)

Binary: $1=$ yes, $0=$ no.

[266] indigallpref2: whether Preferred Religion of State 2 is Indigenous (including Animist). (Author)

Binary: $1=$ yes, $0=$ no.

[267] indigallpref110: Indigenous (all) Government Religious Preference score for State 1 , scaled 0 to 10 . (Author)

Continuous range $0-10$.

[268] indigallpref210: Indigenous (all) Government Religious Preference score for State 2, scaled 0 to 10 . (Author)

Continuous range $0-10$.

[269] notrelpref1: whether Preferred Religion of State 1 is Not Religious (including Atheist). (Author)

Binary: $1=$ yes, $0=$ no.

[270] notrelpref2: whether Preferred Religion of State 2 is Not Religious (including Atheist). (Author)

Binary: $1=$ yes, $0=$ no.

[271] notrelpref110: Not Religious Government Religious Preference score for State 1, scaled 0 to 10. (Author)

Continuous range $0-10$.

[272] notrelpref210: Not Religious Government Religious Preference score for State 2, scaled 0 to 10. (Author)

Continuous range $0-10$.

[273] athpref 1: whether Preferred Religion of State 1 is Atheist. (Author)

Binary: $1=$ yes, $0=$ no. 
[274] athpref2: whether Preferred Religion of State 2 is Atheist. (Author)

Binary: $1=$ yes, $0=$ no.

[275] athpref110: Atheist Government Religious Preference score for State 1, scaled 0 to 10 . (Author)

Continuous range $0-10$.

[276] athpref210: Atheist Government Religious Preference score for State 2, scaled 0 to 10 . (Author)

Continuous range $0-10$.

[277] chrchrdyadpref: whether the Preferred Religion is Christian in both State 1 and State 2. (Author)

Binary: $1=$ yes, $0=$ no.

[278] westeastchrdyadpref: whether the Preferred Religion is Western Christian in State 1 and Eastern Christian in State 2. (Author)

Binary: $1=$ yes, $0=$ no.

[279] eastwestchrdyadpref: whether the Preferred Religion is Eastern Christian in State 1 and Western Christian in State 2. (Author)

Binary: $1=y e s, 0=$ no.

[280] chrmusdyadpref: whether the Preferred Religion is Christian in State 1 and Muslim in State 2. (Author)

Binary: $1=y e s, 0=$ no.

[281] muschrdyadpref: whether the Preferred Religion is Muslim in State 1 and Christian in State 2. (Author)

Binary: $1=y e s, 0=$ no.

[282] mus jewdyadpref: whether the Preferred Religion is Muslim in State 1 and Jewish in State 2. (Author)

Binary: $1=y e s, 0=$ no.

[283] musmusdyadpref: whether the Preferred Religion is Muslim in both State 1 and State 2. (Author)

Binary: $1=y e s, 0=$ no.

[284] musbookdyadpref: whether the Preferred Religion is Muslim in State 1 and Of The Book (any combination of Christian, Jewish, Muslim) in State 2. (Author)

Binary: $1=$ yes, $0=$ no. 
[285] bookmusdyadpref: whether the Preferred Religion is Of The Book (any combination of Christian, Jewish, Muslim) in State 1 and Muslim in State 2. (Author)

Binary: $1=$ yes, $0=$ no.

\section{Religion of Chief Executive}

[286] chiefname1: Name of the $v$ of State 1 (family or monarchal name). (Author)

[287] chiefrelid1: Religion of Chief Executive of State 1. (Author) Same unordered categories as [62] prevrelid1.

[288] prefrelidxtab2: Religion of Chief Executive of State 1, with fewer categories in order to facilitate cross-tabulation. (Author)

Same unordered categories as [63] prevrelidxtab1.

[289] chiefname2: Name of the Chief Executive of State 2 (family or monarchal name). (Author)

[290] chiefrelid2: Religion of Chief Executive of State 2. (Author)

Same unordered categories as [62] prevrelid1.

[291] prefrelidxtab2: Religion of Chief Executive of State 2, with fewer categories in order to facilitate cross-tabulation. (Author)

Same unordered categories as [63] prevrelidxtab1.

[292] judchrchief1: whether Religion of Chief Executive of State 1 is Judeo-Christian. (Author)

Binary: $1=y e s, 0=$ no.

[293] judchrchief2: whether Religion of Chief Executive of State 2 is Judeo-Christian. (Author)

Binary: $1=$ yes, $0=$ no.

[294] christallchief1: whether Religion of Chief Executive of State 1 is Christian (any denomination). (Author)

Binary: $1=$ yes, $0=$ no.

[295] christallchief2: whether Religion of Chief Executive of State 2 is Christian (any denomination). (Author)

Binary: $1=$ yes, $0=$ no. 
[296] christwestchief1: whether Religion of Chief Executive of State 1 is Western Christian (Catholic, Protestant, or Mormon). (Author)

Binary: $1=y e s, 0=$ no.

[297] christwestchief2: whether Religion of Chief Executive of State 2 is Western Christian (Catholic, Protestant, or Mormon). (Author)

Binary: $1=$ yes, $0=$ no.

[298] cathchief1: whether Religion of Chief Executive of State 1 is Catholic. (Author) Binary: $1=y e s, 0=$ no.

[299] cathchief2: whether Religion of Chief Executive of State 2 is Catholic. (Author) Binary: $1=y e s, 0=$ no.

[300] protchief1: whether Religion of Chief Executive of State 1 is Protestant. (Author) Binary: $1=$ yes, $0=$ no.

[301] protchief2: whether Religion of Chief Executive of State 2 is Protestant. (Author) Binary: $1=$ yes, $0=$ no.

[302] orthchief 1: whether Religion of Chief Executive of State 1 is Eastern Christian. (Author)

Binary: $1=$ yes, $0=$ no.

[303] orthchief2: whether Religion of Chief Executive of State 2 is Eastern Christian. (Author)

Binary: $1=$ yes, $0=$ no.

[304] mormonchief1: whether Religion of Chief Executive of State 1 is Mormon. (Author)

Binary: $1=y e s, 0=$ no.

[305] mormonchief2: whether Religion of Chief Executive of State 2 is Mormon. (Author)

Binary: $1=$ yes, $0=$ no.

[306] syncrchief 1: whether Religion of Chief Executive of State 1 is Christian Syncretic. (Author) Binary: $1=$ yes, $0=$ no.

[307] syncrchief2: whether Religion of Chief Executive of State 2 is Christian Syncretic. (Author) Binary: $1=$ yes, $0=$ no.

[308] jewishchief1: whether Religion of Chief Executive of State 1 is Jewish. (Author) Binary: $1=y e s, 0=$ no. 
[309] jewishchief2: whether Religion of Chief Executive of State 2 is Jewish. (Author) Binary: $1=y e s, 0=$ no.

[310] muslimallchief1: whether Religion of Chief Executive of State 1 is Muslim (any branch). (Author)

Binary: $1=$ yes, $0=$ no.

[311] muslimallchief2: whether Religion of Chief Executive of State 2 is Muslim (any branch). (Author)

Binary: $1=$ yes, $0=$ no.

[312] sunnichief1: whether Religion of Chief Executive of State 1 is Sunni Muslim. (Author)

Binary: $1=$ yes, $0=$ no.

[313] sunnichief2: whether Religion of Chief Executive of State 2 is Sunni Muslim. (Author)

Binary: $1=$ yes, $0=$ no.

[314] shiachief1: whether Religion of Chief Executive of State 1 is Shia Muslim. (Author)

Binary: $1=$ yes, $0=$ no.

[315] shiachief2: whether Religion of Chief Executive of State 2 is Shia Muslim. (Author)

Binary: $1=$ yes, $0=$ no.

[316] muslimotherchief1: whether Religion of Chief Executive of State 1 is Muslim, other than Sunni or Shia. (Author)

Binary: $1=$ yes, $0=$ no.

[317] muslimotherchief2: whether Religion of Chief Executive of State 2 is Muslim, other than Sunni or Shia. (Author)

Binary: $1=y e s, 0=$ no.

[318] ofthebookchief1: whether Religion of Chief Executive of State 1 is Christian, Jewish, or Muslim. (Author)

Binary: $1=$ yes, $0=$ no.

[319] ofthebookchief2: whether Religion of Chief Executive of State 2 is Christian, Jewish, or Muslim. (Author)

Binary: $1=y e s, 0=$ no.

[320] hinduchief 1: whether Religion of Chief Executive of State 1 is Hindu. (Author) Binary: $1=y e s, 0=$ no. 
[321] hinduchief 2: whether Religion of Chief Executive of State 2 is Hindu. (Author) Binary: $1=y e s, 0=$ no.

[322] buddpurechief1: whether Religion of Chief Executive of State 1 is Buddhist (pure). (Author)

Binary: $1=y e s, 0=$ no.

[323] buddpurechief2: whether Religion of Chief Executive of State 2 is Buddhist (pure). (Author)

Binary: $1=$ yes, $0=$ no.

[324] buddmixchief1: whether Religion of Chief Executive of State 1 is Buddhist Mix (Buddhist, Confucian, Tao, and/or Shinto). (Author)

Binary: $1=$ yes, $0=$ no.

[325] buddmixchief2: whether Religion of Chief Executive of State 2 is Buddhist Mix (Buddhist, Confucian, Tao, and/or Shinto). (Author)

Binary: $1=$ yes, $0=$ no.

[326] eaallchief1: whether Religion of Chief Executive of State 1 is East Asian (Confucian, Tao, and/or Shinto, not mixed with Buddhist). (Author) Binary: $1=$ yes, $0=$ no.

[327] eaallchief2: whether Religion of Chief Executive of State 2 is East Asian (Confucian, Tao, and/or Shinto, not mixed with Buddhist). (Author) Binary: $1=$ yes, $0=$ no.

[328] indigallchief1: whether Religion of Chief Executive of State 1 is Indigenous (including Animist). (Author)

Binary: $1=$ yes, $0=$ no.

[329] indigallchief2: whether Religion of Chief Executive of State 2 is Indigenous (including Animist). (Author)

Binary: $1=y e s, 0=$ no.

[330] nonechief1: whether Religion of Chief Executive of State 1 is None (including Agnostic, but not Atheist). (Author)

Binary: $1=y e s, 0=$ no.

[331] nonechief2: whether Religion of Chief Executive of State 2 is None (including Agnostic, but not Atheist). (Author)

Binary: $1=y e s, 0=$ no.

[332] notrelchief1: whether Religion of Chief Executive of State 1 is Not Religious (None, Agnostic, or Atheist). (Author)

Binary: $1=y e s, 0=$ no. 
[333] notrelchief2: whether Religion of Chief Executive of State 2 is Not Religious (None, Agnostic, or Atheist). (Author)

Binary: $1=$ yes, $0=$ no.

[334] athchief1: whether Religion of Chief Executive of State 1 is Atheist. (Author) Binary: $1=$ yes, $0=$ no.

[335] athchief2: whether Religion of Chief Executive of State 2 is Atheist. (Author) Binary: $1=y e s, 0=$ no. 
Control Variables

$\underline{\text { Power }}$

[336] majpow1: whether State 1 is Major Power. (EUGene)

Binary: $1=$ yes, $0=$ no.

[337] majpow2: whether State 1 is Major Power. (EUGene)

Binary: $1=y e s, 0=$ no.

[338] dircincsuperior: Whether Composite Index of National Capability (CINC) of State 1 is 3 times or greater the CINC of State 2 ([341] cinc1/ [348] cinc2>=3). (Author)

Binary: $1=$ yes, $0=$ no.

[339] dircincratio: Directed CINC Ratio of State 1 to State 2. (Author)

Ratio of [341] cinc1 to [348] cinc2.

[340] logdircincratio: Logarithm of Directed CINC Ratio of State 1 to State 2.

(Author)

Natural logarithm of [339] dircincratio.

[341] cinc1: Composite Index of National Capability of State 1. (COW)

Ratio of state's national capability to the global capability of the system; so named because it is composite for State 1 of the following components: [342] milper1, [343]milex1, [344] energy1, [345] irst1, [346] upop1, and [347] tpop1.

[342] milper1: Military Personnel of State 1, in thousands. (COW)

[343] milex1: Military Expenditures of State 1, in thousands of current-year US dollars. $(\mathrm{COW})$

[344] energy 1: Energy consumption of State 1, in thousands of coal-ton equivalents. $(\mathrm{COW})$

[345] irst 1: Iron and Steel production of State 1, in thousands of tons. (COW)

[346] upop1: Urban Population of State 1 (living in cities with population greater than 100,000 , in thousands. (COW)

[347] tpop1: Total Population of State 1, in thousands. (COW)

[348] cinc2: Composite Index of National Capability of State 2. (COW)

Ratio of state's national capability to the global capability of the system; so named because it is composite for State 1 of the following components: [349] milper2, [350] milex2, [351] energy2, [352] irst2, [353] upop2, and [354] tpop2. 
[349] milper2: Military Personnel of State 2, in thousands. (COW)

[350] milex2: Military Expenditures of State 2, in thousands of current-year US dollars. $(\mathrm{COW})$

[351] energy2: Energy consumption of State 2, in thousands of coal-ton equivalents. $(\mathrm{COW})$

[352] irst2: Iron and Steel production of State 2, in thousands of tons. (COW)

[353] upop2: Urban Population of State 2 (living in cities with population greater than 100,000 , in thousands. (COW)

[354] tpop2: Total Population of State 2, in thousands. (COW)

[355] troopqual1: Troop Quality of State 1, in current-year US dollars per soldier. (Author)

Ratio of [343]milex1 to [342]milper1.

[356] troopqual2: Troop Quality of State 2, in current-year US dollars per soldier. (Author)

Ratio of [350]milex2 to [349]milper2.

[357] dirtroopqualratio: Directed Ratio of Troop Quality of State 1 to State 2. (Author)

Ratio of [355] troopqual1 to [356] troopqual2.

[358] logdirtroopqualratio: Logarithm of Directed Ratio of Troop Quality of State 1 to State 2. (Author)

Natural logarithm of [357] dirtroopqualratio.

[359] nuke1: Whether State 1 has nuclear weapons. (Author)

Binary: $1=$ yes, $0=$ no.

[360] nuke2: Whether State 2 has nuclear weapons. (Author)

Binary: $1=$ yes, $0=$ no.

[361] bothnuke: Whether both states have nuclear weapons. (Author)

Binary: $1=$ yes, $0=$ no.

[362] perm51: Whether State 1 is a permanent member of the UN Security Council. (Author)

Binary: $1=$ yes, $0=$ no.

[363] perm51: Whether State 2 is a permanent member of the Security Council. (Author) Binary: $1=$ yes, $0=$ no. 
Regime Type

[364] polity1: Polity score of State 1 , scaled -10 to +10 . (Polity)

Ordered categorical, range -10 to +10 .

[365] polity2: Polity score of State 2, scaled -10 to +10 . (Polity)

Ordered categorical, range -10 to +10 .

[366] polity120: Polity score of State 1, rescaled 0 to 20. (Author)

Ordered categorical, range 0 to 20 .

[367] polity220: Polity score of State 2, rescaled 0 to 20. (Author)

Ordered categorical, range 0 to 20 .

[368] polity21: Polity2 score of State 1, scaled -10 to +10 . (Polity)

Ordered categorical, range -10 to +10 .

[369] polity22: Polity2 score of State 2, scaled -10 to +10 . (Polity)

Ordered categorical, range -10 to +10 .

[370] polity2120: Polity2 score of State 1, rescaled 0 to 20. (Author)

Ordered categorical, range 0 to 20 .

[371] polity2220: Polity2 score of State 2, rescaled 0 to 20. (Author)

Ordered categorical, range 0 to 20.

[372] politydlb1: Adjusted Polity score of State 1, scaled -10 to +10 . (Author) Ordered categorical, range -10 to +10 .

[373] politydlb2: Adjusted Polity score of State 2, scaled -10 to +10 . (Author) Ordered categorical, range -10 to +10 .

[374] politydlb120: Adjusted Polity score of State 1, rescaled 0 to 20. (Author) Ordered categorical, range 0 to 20 .

[375] politydlb220: Adjusted Polity score of State 2, rescaled 0 to 20. (Author) Ordered categorical, range 0 to 20 .

[376] democ17: Whether State 1 is a Democracy, with threshold at +7 or higher in the original scale. (Author)

Binary: $1=y e s, 0=$ no.

[377] democ 27: Whether State 2 is a Democracy, with threshold at +7 or higher in the original scale. (Author)

Binary: $1=y e s, 0=$ no. 
[378] democdyad7: Whether both states in the dyad are Democracies, with threshold at +7 or higher in the original scale. (Author)

Binary: $1=y e s, 0=$ no.

[379] democ18: Whether State 1 is a Democracy, with threshold at +8 or higher in the original scale. (Author)

Binary: $1=$ yes, $0=$ no.

[ 380 ] democ28: Whether State 2 is a Democracy, with threshold at +8 or higher in the original scale. (Author)

Binary: $1=y e s, 0=$ no.

[381] democdyad 7: Whether both states in the dyad are Democracies, with threshold at +8 or higher in the original scale. (Author)

Binary: $1=$ yes, $0=$ no.

[382] dyadlowpolitydlb20: Adjusted Polity score of the less democratic state in the dyad, rescaled 0 to 20. (Author)

Ordered categorical, range 0 to 20 .

[383] dirdyadpolitydlbdiff: Directed Difference of the Adjusted Polity score of State 1 to State 2. (Author)

Range 0 to 20 .

[384] durable1: Duration of the Polity score of State 1 in the observed year, in years. (Polity)

[385] durable2: Duration of the Polity score of State 2 in the observed year, in years. (Polity)

[386] logdurable1: Logarithm of Duration in years of the Polity score of State 1 in the observed year. (Polity)

Natural logarithm of [382] durable1.

[387] logdurable2: Logarithm of Duration in years of the Polity score of State 2 in the observed year. (Polity)

Natural logarithm of [383] durable2. 
$\underline{\text { Alliances }}$

[388] alliancetype: Type of Alliance between states in the dyad. (COW)

4: None 2: Neutrality Pact

3: Entente 1: Defensive

[389] defenseallies: Whether the states in the dyad have a defensive alliance ( [388] alliancetype=1). (COW)

Binary: $1=$ yes, $0=$ no.

\section{Wealth}

[390] maddisongdp1: Angus Maddison's Gross Domestic Product of State 1, in millions of 1990 International Geary-Khamis dollars. (Quality of Government)

[391] maddisongdp2: Angus Maddison's Gross Domestic Product of State 2, in millions of 1990 International Geary-Khamis dollars. (Quality of Government)

[392] dirmaddisongdpratio: Directed Maddison GDP Ratio of State 1 to State 2. (Author)

Ratio of [390] maddisongdp1 to [391] maddisongdp2.

[393] logdirmaddisongdpratio: Logarithm of Directed Maddison GDP Ratio of State 1 to State 2. (Author)

Nautral logarithm of [392] dirmaddisongdpratio.

[394] maddisongdppc1: Angus Maddison's Gross Domestic Product Per Capita of State 1, in millions of 1990 International Geary-Khamis dollars. (Quality of Government)

[395] maddisongdppc2: Angus Maddison's Gross Domestic Product Per Capita of State 2, in millions of 1990 International Geary-Khamis dollars. (Quality of Government)

[396] dirmaddisongdppcratio: Directed Maddison GDPPC Ratio of State 1 to State 2. (Author)

Ratio of [394] maddisongdppc1 to [395] maddisongdppc2.

[397] logdirmaddisongdppcratio: Logarithm of Directed Maddison GDPPC Ratio of State 1 to State 2. (Author)

Natural logarithm of [396] dirmaddisongdppcratio. 


\section{Trade Dependence}

[398] flow1: Imports to State 1 from State 2, in millions of current US dollars. $(\mathrm{COW})$

[399] flow2: Imports to State 2 from State 1, in millions of current US dollars. $(\mathrm{COW})$

[400] imports 1: Total Imports into State 1, in millions of current US dollars. (COW)

[ 401] imports2: Total Imports into State 2, in millions of current US dollars. (COW)

[402] exports1: Total Exports from State 1, in millions of current US dollars. $(\mathrm{COW})$

[403] exports2: Total Exports from State 2, in millions of current US dollars. $(\mathrm{COW})$

[ 404 ] econdepend1: Economic Dependence of State 1 on State 2. (Author)

Sum of ([398] flow1 + [399] flow2), divided by [390] maddisongdp1.

[405] econdepend2: Economic Dependence of State 2 on State 1. (Author)

Sum of ([398] flow1 + [399] flow2), divided by [391] maddisongdp2.

[406] direcondependratio: Directed Economic Dependence Ratio of State 1 to State 2. (Author)

Ratio of [404] econdepend1 to [405] econdepend2.

[407] logdirecondependratio: Logarithm of Directed Economic Dependence Ratio of State 1 to State 2. (Author)

Natural logarithm of [406] direcondependratio.

[408] econopen1: Economic Openness of State 1. (Author)

Sum of ([400] imports1 + [402] exports1), divided by [390] maddisongdp1.

[409] econopen2: Economic Openness of State 2. (Author)

Sum of ([401] imports $2+$ [403] exports2), divided by [391] maddisongdp2.

\section{Peace-Learning Process}

[410] cwpeaceyrs: Number of Years the dyad has gone without a Militarized Interstate Dispute, in years. $(\mathrm{COW})$

[411] logcwpeaceyrs: Logarithm of COW Peace-Years. (Author)

Natural logarithm of [410] cwpeaceyrs. 


\section{Proximity}

[412] contig: Direct Contiguity level between the states in the dyad (metropole to metropole). $(\mathrm{COW})$

6: more than 400 miles of sea. $\quad 3: 12-24$ miles of sea.

5: $150-400$ miles of sea. $\quad 2: 0-12$ miles of sea.

4: 24-150 miles of sea. $\quad$ 1: Contiguous by land.

[413] colcontig: Nearest Colonial Contiguity level between the states in the dyad (between metropole and any colony, or between colonies). (COW)

Same ordered categories as [412] contig.

[414] colony1: COW Code of Colony of State 1 that generates Colonial Contiguity with State 2. $(\mathrm{COW})$

[415] colony2: COW Code of Colony of State 2 that generates Colonial Contiguity with State 1. $(\mathrm{COW})$

[416] closestcontig: Closest Contiguity level between states in the dyad, whether Direct or Colonial. (Author)

Same ordered categories as [412] contig.

[417] landcontig: Whether the states in the dyad have Direct Contiguity by land.

(Author)

Binary: $1=$ yes, $0=$ no.

[418] collandcontig: Whether the states in the dyad have Colonial Contiguity by land.

(Author)

Binary: $1=y e s, 0=$ no.

[419] anylandcontig: Whether the states in the dyad have any Contiguity by land, Direct or Colonial. (Author)

Binary: $1=y e s, 0=$ no.

\section{$\underline{\text { Regional Effects }}$}

[420] americandyad: Whether both states' metropoles are in the Americas. (Author)

Binary: $1=y e s, 0=$ no. Coded 1 if, for both states, ccode $<200$.

[421] europeandyad: Whether both states' metropoles are in Europe. (Author)

Binary: $1=y e s, 0=$ no. Coded 1 if, for both states, ccode $=200$ to 399 , or ccode $=640$ (Turkey).

[422] africandyad: Whether both states' metropoles are in Africa. (Author)

Binary: $1=y e s, 0=$ no. Coded 1 if, for both states, ccode $=400$ to 625 , or $\operatorname{ccode}=651$

(Egypt). 
[423] mideastdyad: Whether both states' metropoles are in the Middle East. (Author) Binary: $1=$ yes, $0=$ no. Coded 1 if, for both states, ccode $=630$ to 699 .

[424] asiapacificdyad: Whether both states' metropoles are in Asia or the Pacific, other than the Middle East. (Author)

Binary: $1=$ yes, $0=$ no. Coded 1 if, for both states, ccode $>=700$, or ccode $=365$ (Russia). 
$\underline{\text { APPENDIX B }}$

$\underline{\text { TABLES }}$

\section{Table of Contents for Appendix B}

Tables for Chapter $3 \ldots 437$

Table B-1

Tables for Chapter 4 . . . . . . 439

Tables B-2 through B-65

Tables for Chapter $5 \ldots 495$

Tables B-66 through B-93

Tables for Chapter $6 \ldots 523$

Tables B-94 through B-113

Tables for Chapter $7 \ldots 543$

Tables B-114 through B-134 
Tables for Chapter 3

Table B-1. Pairwise Correlation of Control Variables.

\begin{tabular}{|c|c|c|c|c|c|c|c|c|c|c|}
\hline $\begin{array}{l}\text { Log } \\
\text { CINC } \\
\text { Ratio }\end{array}$ & $\begin{array}{l}\text { Log } \\
\text { CINC } \\
\text { Ratio } \\
\text { [1.0000] }\end{array}$ & $\begin{array}{l}\text { Log } \\
\text { TQ } \\
\text { Ratio } \\
\end{array}$ & $\begin{array}{l}\text { Nukes } \\
\text { (State 1) }\end{array}$ & $\begin{array}{c}\text { P5 } \\
\text { (State 1) } \\
\end{array}$ & $\begin{array}{l}\text { Low } \\
\text { Polity } \\
\text { LScore } \\
\end{array}$ & $\begin{array}{l}\text { Polity } \\
\text { Score } \\
\text { (State 1) } \\
\end{array}$ & $\begin{array}{l}\text { Defens- } \\
\text { ive } \\
\text { Allies } \\
\end{array}$ & $\begin{array}{l}\text { Log } \\
\text { GDP } \\
\text { Ratio }\end{array}$ & $\begin{array}{l}\text { Log } \\
\text { GDPPC } \\
\text { Ratio } \\
\end{array}$ & $\begin{array}{l}\text { Log Econ. } \\
\text { Depend. } \\
\text { Ratio }\end{array}$ \\
\hline $\begin{array}{l}\text { Log } \\
\text { TQ } \\
\text { Ratio } \\
\end{array}$ & $.6677^{*}$ & [1.0000] & & & & & & & & \\
\hline $\begin{array}{l}\text { Nukes } \\
\text { (State 1) }\end{array}$ & $.6543^{*}$ & $.5277^{\star}$ & {$[1.0000]$} & & & & & & & \\
\hline $\begin{array}{l}\text { P5 } \\
\text { (State 1) }\end{array}$ & $.6580^{*}$ & $.5291^{*}$ & $.9254^{\star}$ & [1.0000] & & & & & & \\
\hline $\begin{array}{l}\text { Low } \\
\text { Polity } \\
\text { Score }\end{array}$ & -.0000 & .0000 & $.0164^{*}$ & .0263 & [1.0000] & & & & & \\
\hline $\begin{array}{l}\text { Polity } \\
\text { Score } \\
\text { (State 1) }\end{array}$ & $.2019^{*}$ & $.3305^{\star}$ & $.2241^{*}$ & $.2533^{*}$ & $.6398^{*}$ & [1.0000] & & & & \\
\hline $\begin{array}{l}\text { Defens- } \\
\text { ive } \\
\text { Allies }\end{array}$ & -.0000 & -.0000 & $-.1195^{*}$ & $-.1077^{\star}$ & $.1844^{*}$ & $.0634^{\star}$ & [1.0000] & & & \\
\hline $\begin{array}{l}\text { Log } \\
\text { GDP } \\
\text { Ratio }\end{array}$ & $.9766^{*}$ & $.7432^{*}$ & $.6754^{*}$ & $.6804^{*}$ & .0000 & $.2681^{*}$ & .0000 & [1.0000] & & \\
\hline $\begin{array}{l}\text { Log } \\
\text { GDPPC } \\
\text { Ratio } \\
\end{array}$ & $.5500^{*}$ & $.8140^{*}$ & $.4376^{*}$ & $.4655^{\star}$ & .0000 & $.4400^{*}$ & -.0000 & $.6700^{*}$ & [1.0000] & \\
\hline $\begin{array}{l}\text { Log Econ } \\
\text { Depend. } \\
\text { Ratio }\end{array}$ & $-.9763^{\star}$ & $-.7424^{*}$ & $-.6757^{*}$ & $-.6832^{\star}$ & .0000 & $-.3106^{*}$ & .0000 & $-1.0000^{*}$ & $-.6971^{*}$ & {$[1.0000]$} \\
\hline $\begin{array}{l}\text { Log } \\
\text { Peace- } \\
\text { Years } \\
\end{array}$ & .0000 & .0000 & $.1164^{*}$ & $.0938^{\star}$ & $.1032^{*}$ & $.0623^{*}$ & $.0762^{\star}$ & -.0000 & .0000 & -.0000 \\
\hline $\begin{array}{l}\text { Closest } \\
\text { Contig. }\end{array}$ & .0000 & .0000 & $.2780^{*}$ & $.2771^{*}$ & $.0418^{*}$ & $.1328^{*}$ & $-.3307^{*}$ & -.0000 & .0000 & -.0000 \\
\hline $\begin{array}{l}\text { Any } \\
\text { Land } \\
\text { Contig. }\end{array}$ & -.0000 & -.0000 & $-.2377^{\star}$ & $-.2383^{*}$ & $-.0723^{\star}$ & $-.1522^{*}$ & $.2674^{\star}$ & .0000 & -.0000 & .0000 \\
\hline
\end{tabular}

${ }^{*} p<.001$

(continued on next page) 
Table B-1 (continued). Pairwise Correlation of Control Variables (continued).

\begin{tabular}{llll} 
& $\begin{array}{l}\text { Log } \\
\text { Peace- } \\
\text { Years }\end{array}$ & $\begin{array}{l}\text { Clos- } \\
\text { est }\end{array}$ & $\begin{array}{l}\text { Any } \\
\text { Contig. } \\
\text { Cond }\end{array}$ \\
Contig. \\
$\begin{array}{l}\text { Peace- } \\
\text { Years }\end{array}$ & {$[1.0000]$} \\
\hline $\begin{array}{lll}\text { Closest } \\
\text { Contig. }\end{array}$ & $.1777^{*}$ & {$[1.0000]$} \\
\hline $\begin{array}{lll}\text { Any } \\
\text { Land }\end{array}$ & $-.1541^{*}$ & $-.9294^{*}$ & {$[1.0000]$} \\
Contig. & & & \\
\hline
\end{tabular}

${ }^{*} p<.001$ 
$\underline{\text { Tables for Chapter } 4}$

Table B-2. Cross-Tabulation of Chief Executive's Religion with Armed Conflict Initiation (Model 1).

\begin{tabular}{|c|c|c|c|c|c|c|}
\hline $\begin{array}{l}\text { init12- } \\
\text { noauth }\end{array}$ & Christian & Muslim & Buddhist Mix & Atheist & Other & TOTAL \\
\hline 0 & $\begin{array}{l}60,758 \\
(60,364.0)\end{array}$ & $\begin{array}{l}18,695 \\
(18,894.5)\end{array}$ & $\begin{array}{l}2,003 \\
(2,063.7)\end{array}$ & $\begin{array}{l}16,721 \\
(16,794.3)\end{array}$ & $\begin{array}{l}7,481 \\
\quad(7,541.4)\end{array}$ & 105,658 \\
\hline 1 & $\begin{array}{l}579 \\
\quad(973.0)\end{array}$ & $\begin{array}{l}504 \\
(304.5)\end{array}$ & $\begin{array}{ll}94 & \\
& \text { (33.3) }\end{array}$ & $\begin{array}{l}344 \\
\quad(270.7)\end{array}$ & $\begin{array}{l}182 \\
(121.6)\end{array}$ & 1,703 \\
\hline & 61,337 & 19,119 & 2,097 & 17,065 & 7,663 & 107,361 \\
\hline
\end{tabular}

Pearson $\chi^{2}(4)=458.2280 \quad p<.001 \quad$ Cramér's $V=.0653$

Table B-3. Cross-Tabulation of Chief Executive's Religion with Armed Conflict Initiation (Model 5).

\begin{tabular}{|c|c|c|c|c|c|c|}
\hline $\begin{array}{c}\text { initfatal- } \\
\text { noauth }\end{array}$ & Christian & Muslim & Buddhist Mix & Atheist & Other & TOTAL \\
\hline 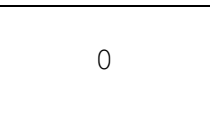 & $\begin{array}{l}60,944 \\
(60,713.6)\end{array}$ & $\begin{array}{l}18,759 \\
(18,857.6)\end{array}$ & $\begin{array}{l}2,013 \\
\quad(2,042.1)\end{array}$ & $\begin{array}{l}16,757 \\
(16,791.7)\end{array}$ & $\begin{array}{l}7,506 \\
(7,574.0)\end{array}$ & 105,979 \\
\hline 1 & $\begin{array}{l}154 \\
(384.4)\end{array}$ & $\begin{array}{l}218 \\
(119.4)\end{array}$ & $\begin{array}{ll}42 & \\
& (12.9) \\
\end{array}$ & $\begin{array}{l}141 \\
\text { (106.3) }\end{array}$ & $\begin{array}{l}116 \\
\quad(48.0)\end{array}$ & 671 \\
\hline & 61,098 & 18,977 & 2,055 & 16,898 & 7,622 & 106,650 \\
\hline
\end{tabular}

Pearson $\chi^{2}(4)=395.2526 \quad p<.001 \quad$ Cramér's $V=.0609$ 
Table B-4. Cross-Tabulation of Religious Preference with Armed Conflict Initiation (Model 1).

\begin{tabular}{|c|c|c|c|c|c|c|}
\hline init12- & Christian & Muslim & Buddhist Mix & Atheist & Other & TOTAL \\
\hline 0 & $\begin{array}{l}60,432 \\
(59,980.5)\end{array}$ & $\begin{array}{l}18,154 \\
(18,328.1)\end{array}$ & $\begin{array}{l}5,315 \\
\quad(5,368.4)\end{array}$ & $\begin{array}{l}18,885 \\
(19,029.0)\end{array}$ & $\begin{array}{l}2,199 \\
\quad(2,279.1)\end{array}$ & 104,985 \\
\hline 1 & $\begin{array}{l}494 \\
\quad(945.5) \\
\end{array}$ & $\begin{array}{l}463 \\
\quad(288.9)\end{array}$ & $\begin{array}{ll}138 & \\
& (84.6) \\
\end{array}$ & $\begin{array}{l}444 \\
\quad(300.0)\end{array}$ & $\begin{array}{l}116 \\
\quad(35.9) \\
\end{array}$ & 1,655 \\
\hline & 60,926 & 18,617 & 5,453 & 19,329 & 2,315 & 106,640 \\
\hline
\end{tabular}

Pearson $\chi^{2}(4)=611.2616 \quad p<.001 \quad$ Cramér's $V=.0757$

Table B-5. Cross-Tabulation of Religious Preference with Armed Conflict Initiation (Model 5).

\begin{tabular}{|c|c|c|c|c|c|c|}
\hline $\begin{array}{l}\text { initfatal- } \\
\text { noauth }\end{array}$ & Christian & Muslim & Buddhist Mix & Atheist & Other & TOTAL \\
\hline 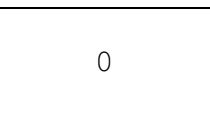 & $\begin{array}{l}60,603 \\
(60,351.8)\end{array}$ & $\begin{array}{l}18,219 \\
(18,319.2)\end{array}$ & $\begin{array}{l}5,324 \\
(5,342.5)\end{array}$ & $\begin{array}{l}18,955 \\
(19,032.7)\end{array}$ & $\begin{array}{l}2,211 \\
\quad(2,265.8)\end{array}$ & 105,312 \\
\hline 1 & $\begin{array}{l}127 \\
(378.2)\end{array}$ & $\begin{array}{l}215 \\
(114.8)\end{array}$ & 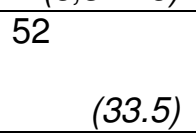 & $\begin{array}{l}197 \\
\text { (119.3) }\end{array}$ & $\begin{array}{l}69 \\
\quad(14.2)\end{array}$ & 660 \\
\hline & 60,730 & 18,434 & 5,376 & 19,152 & 2,280 & 105,972 \\
\hline
\end{tabular}

Pearson $\chi^{2}(4)=529.9755 \quad p<.001 \quad$ Cramér's $V=.0707$ 
Table B-6. Cross-Tabulation of Religious Prevalence with Armed Conflict Initiation (Model 1).

\begin{tabular}{|c|c|c|c|c|c|}
\hline $\begin{array}{l}\text { init } 12- \\
\text { noauth }\end{array}$ & Christian & Muslim & Buddhist Mix & Other & TOTAL \\
\hline 0 & $\begin{array}{l}61,025 \\
\quad(60,566.0)\end{array}$ & $\begin{array}{r}17,393 \\
\quad(17,611.6)\end{array}$ & $\begin{array}{l}12,431 \\
\quad(12,529.6)\end{array}$ & $\begin{array}{r}10,033 \\
\quad(10,174.7)\end{array}$ & 100,882 \\
\hline 1 & $\begin{array}{ll}495 & \\
& (954.0) \\
\end{array}$ & $\begin{array}{ll}496 & \\
& (277.4) \\
\end{array}$ & $\begin{array}{ll}296 & \\
& (197.4) \\
\end{array}$ & $\begin{array}{ll}302 & \\
& (160.3) \\
\end{array}$ & 1,589 \\
\hline & 61,520 & 17,889 & 12,727 & 10,335 & 102,471 \\
\hline
\end{tabular}

Pearson $\chi^{2}(3)=576.6859 \quad p<.001 \quad$ Cramér's $V=.0750$

Table B-7. Cross-Tabulation of Religious Prevalence with Armed Conflict Initiation (Model 5).

\begin{tabular}{|c|c|c|c|c|c|}
\hline $\begin{array}{l}\text { initfatal- } \\
\text { noauth }\end{array}$ & Christian & Muslim & Buddhist Mix & Other & TOTAL \\
\hline 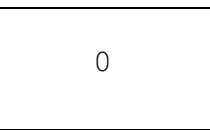 & $\begin{array}{l}61,207 \\
\quad(60,960.7)\end{array}$ & $\begin{array}{l}17,455 \\
\quad(17,560.4)\end{array}$ & $\begin{array}{r}12,425 \\
(12,476.7)\end{array}$ & $\begin{array}{l}10,112 \\
\quad(10,201.2)\end{array}$ & 101,199 \\
\hline 1 & $\begin{array}{ll} & \\
& \\
& (381.3) \\
\end{array}$ & $\begin{array}{ll}217 & \\
& (111.6) \\
\end{array}$ & $\begin{array}{ll} & \\
& \\
& \text { (79.3) } \\
\end{array}$ & $\begin{array}{ll} & \\
& (64.8) \\
\end{array}$ & 643 \\
\hline & 61,348 & 17,672 & 12,556 & 10,266 & 101,842 \\
\hline
\end{tabular}

Pearson $\chi^{2}(3)=415.3560 \quad p<.001 \quad$ Cramér's $V=.0639$ 
Table B-8. Cross-Tabulation of Directed CINC Superiority with Armed Conflict Initiation (Model 1).

\begin{tabular}{|c|c|c|c|}
\hline $\begin{array}{l}\text { init12- } \\
\text { noauth }\end{array}$ & $\ulcorner 3 x$ Superior & 3x Superior & TOTAL \\
\hline 0 & $\begin{array}{r}66,336 \\
(66,464.7)\end{array}$ & $\begin{array}{l}48,245 \\
(48,116.3)\end{array}$ & 114,581 \\
\hline \multirow[t]{2}{*}{1} & $\begin{array}{r}1,156 \\
\quad(1,027.3)\end{array}$ & $\begin{array}{ll}615 & \\
& (743.7)\end{array}$ & 1,771 \\
\hline & 67,492 & 48,860 & 116,352 \\
\hline
\end{tabular}

Pearson $\chi^{2}(1)=38.9894 \quad p<.001 \quad$ Cramér's $V=-.0183$

Table B-9. Cross-Tabulation of Directed CINC Superiority with Armed Conflict Initiation (Model 5).

\begin{tabular}{|c|c|c|c|}
\hline $\begin{array}{l}\text { initfatal- } \\
\text { noauth }\end{array}$ & $r 3 x$ Superior & $3 x$ Superior & TOTAL \\
\hline 0 & $\begin{array}{l}66,563 \\
\quad(66,614.8)\end{array}$ & $\begin{array}{l}48,349 \\
\quad(48,297.2)\end{array}$ & 114,912 \\
\hline \multirow[t]{2}{*}{1} & $\begin{array}{ll}457 \\
\quad(405.2)\end{array}$ & $\begin{array}{ll}242 \\
(293.8)\end{array}$ & 699 \\
\hline & 67,020 & 48,591 & 115,611 \\
\hline
\end{tabular}

Pearson $\chi^{2}(1)=15.8435 \quad p<.001 \quad$ Cramér's V $=-.0117$ 
Table B-10. Cross-Tabulation of Democratic Dyad $(a t+7)$ with Armed Conflict Initiation (Model 1).

\begin{tabular}{|c|r|r|c|}
\hline $\begin{array}{c}\text { init12- } \\
\text { noauth }\end{array}$ & rDemoc. Dyad & Democ. Dyad & TOTAL \\
\hline 0 & \multicolumn{1}{|c|}{$\begin{array}{r}\text { 84,023 } \\
(84,234.4)\end{array}$} & $\begin{array}{r}18,333 \\
(18,121.6)\end{array}$ & 102,356 \\
\hline 1 & 1,617 & 91 & 1,708 \\
\hline & $(1,405.6)$ & $(302.4)$ & 104,064 \\
\hline
\end{tabular}

Pearson $\chi^{2}(1)=182.5659 \quad p<.001 \quad$ Cramér's $V=-.0419$

Table B-11. Cross-Tabulation of Democratic Dyad $(a t+7)$ with Armed Conflict Initiation (Model 5).

\begin{tabular}{|c|c|c|c|}
\hline $\begin{array}{c}\text { initfatal- } \\
\text { noauth }\end{array}$ & rDemoc. Dyad & Democ. Dyad & TOTAL \\
\hline 0 & $\begin{array}{r}84,294 \\
(84,380.3)\end{array}$ & $\begin{array}{r}18,384 \\
(18,297.7)\end{array}$ & 102,678 \\
\hline 1 & $\begin{array}{r}341 \\
(554.7)\end{array}$ & $\begin{array}{r}\text { (120.3) } \\
18,418\end{array}$ & 103,353 \\
\hline
\end{tabular}

Pearson $\chi^{2}(1)=75.8162 \quad p<.001 \quad$ Cramér's $V=-.0271$ 
Table B-12. Cross-Tabulation of Defensive Alliances with Armed Conflict Initiation (Model 1).

\begin{tabular}{|c|c|c|c|}
\hline $\begin{array}{c}\text { init12- } \\
\text { noauth }\end{array}$ & rDef. Alliance & Def. Alliance & TOTAL \\
\hline 0 & $\begin{array}{r}89,557 \\
(89,585.8)\end{array}$ & $\begin{array}{r}21,519 \\
(21,490.2)\end{array}$ & 111,076 \\
\hline 1 & $\begin{array}{r}1,437 \\
(1,408.2)\end{array}$ & $\begin{aligned} 309 \\
(337.8)\end{aligned}$ & 1,746 \\
\hline & 90,994 & 21,828 & 112,822 \\
\hline
\end{tabular}

Pearson $\chi^{2}(1)=3.0930 \quad p=.079 \quad$ Cramér's $V=-.0052$

Table B-13. Cross-Tabulation of Defensive Alliances with Armed Conflict Initiation (Model 5).

\begin{tabular}{|c|c|c|c|}
\hline $\begin{array}{c}\text { initfatal- } \\
\text { noauth }\end{array}$ & rDef. Alliance & Def. Alliance & TOTAL \\
\hline 0 & $\begin{array}{r}89,878 \\
(89,826.5)\end{array}$ & $\begin{array}{r}21,628 \\
(21,579.5)\end{array}$ & 111,406 \\
\hline 1 & $\begin{array}{r}854 \\
(555.5)\end{array}$ & $\begin{aligned}(133.5) \\
21,713\end{aligned}$ & 112,095 \\
\hline
\end{tabular}

Pearson $\chi^{2}(1)=21.9586 \quad p<.001 \quad$ Cramér's $V=-.0140$ 
Table B-14. Cross-Tabulation of 25 Peace-Years with Armed Conflict Initiation (Model 1).

\begin{tabular}{|c|c|c|c|}
\hline $\begin{array}{c}\text { init12- } \\
\text { noauth }\end{array}$ & $<25$ Peace-Yrs. & $25+$ Peace-Yrs. & TOTAL \\
\hline 0 & $\begin{array}{r}70,927 \\
(71,501.0)\end{array}$ & $\begin{array}{r}43,664 \\
(43,090.0)\end{array}$ & 114,591 \\
\hline 1 & $\begin{array}{r}9,679 \\
(1,105.0)\end{array}$ & $(666.0)$ & 1,771 \\
\hline & 72,606 & 43,756 & 116,362 \\
\hline
\end{tabular}

Pearson $\chi^{2}(1)=805.0267 \quad p<.001 \quad$ Cramér's $V=-.0832$

Table B-15. Cross-Tabulation of 25 Peace-Years with Armed Conflict Initiation (Model 5).

\begin{tabular}{|c|c|c|c|}
\hline $\begin{array}{l}\text { initfatal- } \\
\text { noauth }\end{array}$ & $<25$ Peace-Yrs. & $25+$ Peace-Yrs. & TOTAL \\
\hline 0 & $\begin{array}{l}71,225 \\
\quad(71,458.4)\end{array}$ & $\begin{array}{l}43,697 \\
\quad(43,463.6)\end{array}$ & 114,922 \\
\hline \multirow[t]{2}{*}{1} & $\begin{array}{ll}668 & \\
& (434.6) \\
\end{array}$ & $\begin{array}{ll}31 & \\
& (264.4) \\
\end{array}$ & 699 \\
\hline & 71,893 & 43,728 & 115,621 \\
\hline
\end{tabular}

Pearson $\chi^{2}(1)=333.3084 \quad p<.001 \quad$ Cramér's $V=-.0537$ 
Table B-16. Cross-Tabulation of Any Land Contiguity with Armed Conflict Initiation (Model 1).

\begin{tabular}{|c|c|c|c|}
\hline $\begin{array}{c}\text { init12- } \\
\text { noauth }\end{array}$ & rLand Contig. & Land Contig. & TOTAL \\
\hline 0 & $\begin{array}{r}90,120 \\
(89,404.3)\end{array}$ & $\begin{array}{r}24,471 \\
(25,186.7)\end{array}$ & 114,591 \\
\hline 1 & $\begin{array}{r}1,105 \\
(1,381.7)\end{array}$ & 1,771 \\
\hline & 90,786 & 25,576 & 116,362 \\
\hline
\end{tabular}

Pearson $\chi^{2}(1)>1,700 \quad p<.001 \quad$ Cramér's $V=.1213$

Table B-17. Cross-Tabulation of Any Land Contiguity with Armed Conflict Initiation (Model 5).

\begin{tabular}{|c|c|c|c|}
\hline $\begin{array}{c}\text { initfatal- } \\
\text { noauth }\end{array}$ & rLand Contig. & Land Contig. & TOTAL \\
\hline 0 & $\begin{array}{r}90,276 \\
(89,959.8)\end{array}$ & $\begin{array}{r}24,646 \\
(24,962.2)\end{array}$ & 114,922 \\
\hline 1 & $\begin{array}{r}231 \\
(547.2)\end{array}$ & $\begin{aligned}(151.8) \\
\text { (25, }\end{aligned}$ & 699 \\
\hline & 90,507 & 25,114 & 115,621 \\
\hline
\end{tabular}

Pearson $\chi^{2}(1)=846.2024 \quad \mathrm{p}<.001 \quad$ Cramér's $V=.0855$ 
Table B-18. Logits of Religions of Chief Executives Simultaneously.

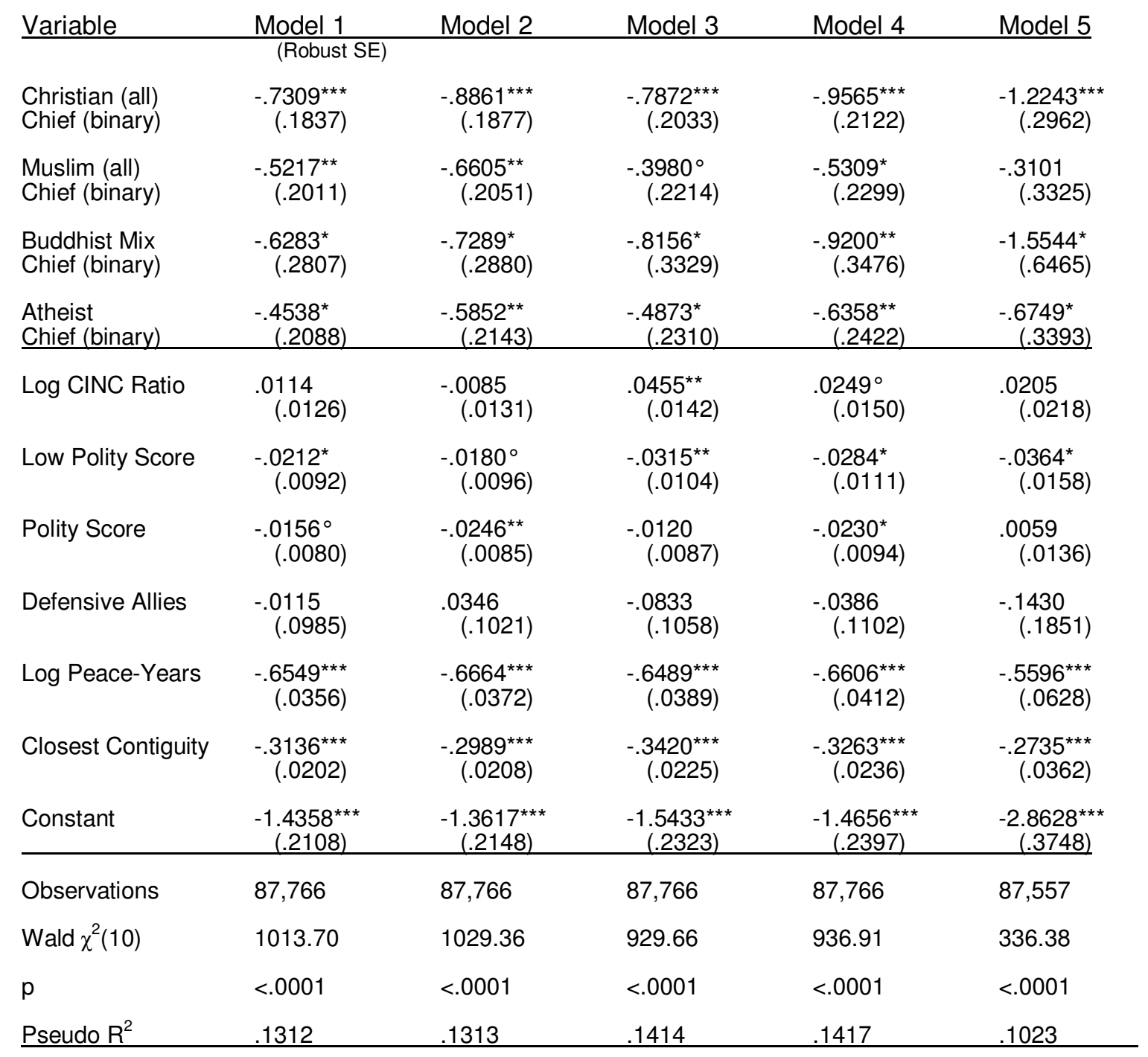

${ }^{\circ} \mathrm{p}<.10{ }^{*} \mathrm{p}<.05{ }^{* *} \mathrm{p}<.01{ }^{* * *} \mathrm{p}<.001$ 
Table B-19. Logits of Binary Religious Preferences Simultaneously.

\begin{tabular}{|c|c|c|c|c|c|}
\hline Variable & Model 1 & Model 2 & Model 3 & Model 4 & Model 5 \\
\hline \multicolumn{6}{|c|}{ (Robust SE) } \\
\hline $\begin{array}{l}\text { Christian (all) } \\
\text { Preference (binary) }\end{array}$ & $\begin{array}{r}-.8203^{* * *} \\
(.2014)\end{array}$ & $\begin{array}{r}-.9061^{\star * *} \\
(.2100)\end{array}$ & $\begin{array}{r}-.7563^{\star \star *} \\
(.2288)\end{array}$ & $\begin{array}{r}-.8174^{* * *} \\
(.2471)\end{array}$ & $\begin{array}{c}-1.2625^{\star * *} \\
(.3421)\end{array}$ \\
\hline $\begin{array}{l}\text { Muslim (all) } \\
\text { Preference (binary) }\end{array}$ & $\begin{array}{l}-.5870^{\star *} \\
(.2054)\end{array}$ & $\begin{array}{l}-.6200^{\star *} \\
(.2114)\end{array}$ & $\begin{array}{l}-.3659 \\
(.2309)\end{array}$ & $\begin{array}{l}-.3510 \\
(.2451)\end{array}$ & $\begin{array}{l}-.1910 \\
(.3344)\end{array}$ \\
\hline $\begin{array}{l}\text { Buddhist Mix } \\
\text { Preference (binary) }\end{array}$ & $\begin{array}{l}-.4186^{\circ} \\
(.2505)\end{array}$ & $\begin{array}{l}-.4167 \\
(.2569)\end{array}$ & $\begin{array}{l}-.4308 \\
(.2908)\end{array}$ & $\begin{aligned}-.3815 \\
(.3047)\end{aligned}$ & $\begin{aligned}-1.1339^{*} \\
(.5090)\end{aligned}$ \\
\hline $\begin{array}{l}\text { Atheist } \\
\text { Preference (binary) }\end{array}$ & $\begin{array}{r}-.4455^{*} \\
(.2178) \\
\end{array}$ & $\begin{array}{r}-.4279^{\circ} \\
(.2244) \\
\end{array}$ & $\begin{array}{r}-.3987 \\
(.2456) \\
\end{array}$ & $\begin{array}{r}-.3450 \\
(.2608) \\
\end{array}$ & $\begin{array}{r}-.2652 \\
(.3636) \\
\end{array}$ \\
\hline Log CINC Ratio & $\begin{array}{l}.0144 \\
(.0129)\end{array}$ & $\begin{array}{l}-.0069 \\
(.0133)\end{array}$ & $\begin{array}{l}.0469^{* *} \\
(.0144)\end{array}$ & $\begin{array}{l}.0243 \\
(.0151)\end{array}$ & $\begin{array}{l}.0028 \\
(.0213)\end{array}$ \\
\hline Low Polity Score & $\begin{array}{l}-.0228^{\star} \\
(.0094)\end{array}$ & $\begin{array}{l}-.0189^{\circ} \\
(.0099)\end{array}$ & $\begin{aligned}-.0342^{\star *} & (.0107)\end{aligned}$ & $\begin{array}{r}-.0303^{\star *} \\
(.0114)\end{array}$ & $\begin{array}{l}-.0379^{*} \\
(.0162)\end{array}$ \\
\hline Polity Score & $\begin{array}{l}-.0150^{\circ} \\
(.0088)\end{array}$ & $\begin{array}{l}-.0203^{*} \\
(.0092)\end{array}$ & $\begin{array}{l}-.0123 \\
(.0095)\end{array}$ & $\begin{aligned}-.0192^{\circ} \\
(.0101)\end{aligned}$ & $\begin{array}{l}.0180 \\
(.0152)\end{array}$ \\
\hline Defensive Allies & $\begin{array}{l}.0071 \\
(.0993)\end{array}$ & $\begin{array}{l}.0526 \\
(.1028)\end{array}$ & $\begin{aligned}-.0732 \\
(.1067)\end{aligned}$ & $\begin{aligned}-.0292 \\
(.1110)\end{aligned}$ & $\begin{array}{l}-.1621 \\
(.1862)\end{array}$ \\
\hline Log Peace-Years & $\begin{array}{r}-.6485^{\star * *} \\
(.0356)\end{array}$ & $\begin{array}{r}-.6627^{* * *} \\
(.0371)\end{array}$ & $\begin{array}{r}-.6472^{* * *} \\
(.0390)\end{array}$ & $\begin{array}{r}-.6628^{* * *} \\
(.0412)\end{array}$ & $\begin{array}{r}-.5752^{* \star *} \\
(.0619)\end{array}$ \\
\hline Closest Contiguity & $\begin{array}{r}-.3086^{* * *} \\
(.0201)\end{array}$ & $\begin{array}{r}-.2953^{* * *} \\
(.0207)\end{array}$ & $\begin{array}{r}-.3331^{* * *} \\
(.0224)\end{array}$ & $\begin{array}{r}-.3190^{\star * *} \\
(.0233)\end{array}$ & $\begin{array}{r}-.2592^{* * *} \\
(.0351)\end{array}$ \\
\hline Constant & $\begin{array}{c}-1.4404^{\star \star *} \\
(.2077) \\
\end{array}$ & $\begin{array}{c}-1.4870^{\star \star *} \\
(.2140) \\
\end{array}$ & $\begin{array}{c}-1.6264^{\star * *} \\
(.2340) \\
\end{array}$ & $\begin{array}{c}-1.7121^{\star * *} \\
(.2476) \\
\end{array}$ & $\begin{array}{c}-3.0522^{\star * *} \\
(.3606) \\
\end{array}$ \\
\hline Observations & 89,770 & 89,770 & 89,770 & 89,770 & 89,572 \\
\hline Wald $\chi^{2}(10)$ & 1038.08 & 1058.14 & 954.88 & 965.28 & 367.14 \\
\hline$p$ & $<.0001$ & $<.0001$ & $<.0001$ & $<.0001$ & $<.0001$ \\
\hline Pseudo $\mathrm{R}^{2}$ & .1319 & .1330 & .1407 & .1420 & .1040 \\
\hline
\end{tabular}

${ }^{\circ} p<.10{ }^{*} p<.05 \quad{ }^{* *} p<.01{ }^{* * *} p<.001$ 
Table B-20. Logits of Binary Religious Prevalences Simultaneously.

\begin{tabular}{|c|c|c|c|c|c|}
\hline Variable & Model 1 & Model 2 & Model 3 & Model 4 & Model 5 \\
\hline $\begin{array}{l}\text { Christian (all) } \\
\text { Prevalence (binary) }\end{array}$ & $\begin{array}{l}-.3113^{*} \\
(.1471)\end{array}$ & $\begin{array}{l}-.3127^{\star} \\
(.1549)\end{array}$ & $\begin{array}{l}-.2908^{\circ} \\
(.1659)\end{array}$ & $\begin{array}{l}-.2831 \\
(.1779)\end{array}$ & $\begin{array}{l}-.5598^{\circ} \\
(.2920)\end{array}$ \\
\hline $\begin{array}{l}\text { Muslim (all) } \\
\text { Prevalence (binary) }\end{array}$ & $\begin{array}{l}-.1289 \\
(.1385)\end{array}$ & $\begin{array}{l}-.1409 \\
(.1434)\end{array}$ & $\begin{array}{l}.0737 \\
(.1528)\end{array}$ & $\begin{array}{l}.0903 \\
(.1608)\end{array}$ & $\begin{array}{l}.2348 \\
(.2453)\end{array}$ \\
\hline $\begin{array}{l}\text { Buddhist Mix } \\
\text { Prevalence (binary) }\end{array}$ & $\begin{array}{l}.1518 \\
(.1553) \\
\end{array}$ & $\begin{array}{r}.1571 \\
(.1617) \\
\end{array}$ & $\begin{array}{l}.1174 \\
(.1716) \\
\end{array}$ & $\begin{array}{l}.1356 \\
(.1812) \\
\end{array}$ & $\begin{array}{l}.0547 \\
(.2818) \\
\end{array}$ \\
\hline Log CINC Ratio & $\begin{array}{l}.0000 \\
(.0128)\end{array}$ & $\begin{array}{l}-.0199 \\
(.0130)\end{array}$ & $\begin{array}{l}.0338^{*} \\
(.0143)\end{array}$ & $\begin{array}{l}.0136 \\
(.0148)\end{array}$ & $\begin{array}{l}.0024 \\
(.0209)\end{array}$ \\
\hline Low Polity Score & $\begin{array}{r}-.0281^{\star *} \\
(.0095)\end{array}$ & $\begin{aligned}-.0241^{\star} \\
(.0100)\end{aligned}$ & $\begin{array}{r}-.0372^{\star \star \star} \\
(.0107)\end{array}$ & $\begin{array}{r}-.0327^{\star \star} \\
(.0114)\end{array}$ & $\begin{array}{l}-.0391^{\star} \\
(.0162)\end{array}$ \\
\hline Polity Score & $\begin{array}{l}-.0137 \\
(.0084)\end{array}$ & $\begin{array}{l}-.0228^{*} \\
(.0090)\end{array}$ & $\begin{array}{l}-.0121 \\
(.0091)\end{array}$ & $\begin{array}{l}-.0233^{*} \\
(.0099)\end{array}$ & $\begin{array}{l}.0033 \\
(.0151)\end{array}$ \\
\hline Defensive Allies & $\begin{array}{l}.0418 \\
(.1046)\end{array}$ & $\begin{array}{l}.0804 \\
(.1086)\end{array}$ & $\begin{array}{l}-.0678 \\
(.1118)\end{array}$ & $\begin{array}{l}-.0329 \\
(.1168)\end{array}$ & $\begin{array}{l}-.0998 \\
(.1912)\end{array}$ \\
\hline Log Peace-Years & $\begin{array}{r}-.6616^{* \star *} \\
(.0362)\end{array}$ & $\begin{array}{r}-.6772^{* * *} \\
(.0379)\end{array}$ & $\begin{array}{r}-.6582^{* * *} \\
(.0394)\end{array}$ & $\begin{array}{r}-.6749^{* * *} \\
(.0417)\end{array}$ & $\begin{array}{r}-.5948^{* * *} \\
(.0623)\end{array}$ \\
\hline Closest Contiguity & $\begin{array}{r}-.3143^{\star * *} \\
(.0210)\end{array}$ & $\begin{array}{r}-.3002^{\star * *} \\
(.0217)\end{array}$ & $\begin{array}{r}-.3378^{* * *} \\
(.0231)\end{array}$ & $\begin{array}{r}-.3229^{* * *} \\
(.0242)\end{array}$ & $\begin{array}{r}-.2557^{\star * \star} \\
(.0363)\end{array}$ \\
\hline Constant & $\begin{array}{c}-1.8159^{* * *} \\
(.1412) \\
\end{array}$ & $\begin{array}{c}-1.8678^{* * *} \\
(.1466) \\
\end{array}$ & $\begin{array}{c}-1.9639^{* * *} \\
(.1554) \\
\end{array}$ & $\begin{array}{c}-2.0328^{\star \star *} \\
(.1631) \\
\end{array}$ & $\begin{array}{c}-3.3644^{* * *} \\
(.2661)\end{array}$ \\
\hline Observations & 83,515 & 83,515 & 83,515 & 83,515 & 83,327 \\
\hline Wald $\chi^{2}(9)$ & 977.70 & 989.77 & 915.52 & 924.78 & 343.33 \\
\hline $\mathrm{p}$ & $<.0001$ & $<.0001$ & $<.0001$ & $<.0001$ & $<.0001$ \\
\hline Pseudo $\mathrm{R}^{2}$ & .1357 & .1367 & .1444 & .1459 & .1015 \\
\hline
\end{tabular}

${ }^{\circ} p<.10{ }^{*} p<.05{ }^{* *} p<.01{ }^{* * *} p<.001$ 
Table B-21. Odds Ratios of GRP Scale of Preferred Religion.

\begin{tabular}{|c|c|c|c|c|c|}
\hline Variable & Model 1 & Model 2 & Model 3 & Model 4 & Model 5 \\
\hline $\begin{array}{l}\text { GRP Scale of } \\
\text { Preferred Religion } \\
\text { (every 10\%) }\end{array}$ & $\begin{array}{c}1.0709^{\star \star \star} \\
(.0180) \\
\end{array}$ & $\begin{array}{c}1.0879^{* * *} \\
(.0193) \\
\end{array}$ & $\begin{array}{c}1.0737^{* * *} \\
(.0195) \\
\end{array}$ & $\begin{array}{c}1.0924^{\star * *} \\
(.0212) \\
\end{array}$ & $\begin{array}{r}1.1085^{\star *} \\
(.0350) \\
\end{array}$ \\
\hline Log CINC Ratio & $\begin{array}{c}1.0118 \\
(.0119)\end{array}$ & $\begin{array}{c}.9920 \\
(.0119)\end{array}$ & $\begin{array}{r}1.0386^{\star \star} \\
(.0135)\end{array}$ & $\begin{array}{c}1.0168 \\
(.0137)\end{array}$ & $\begin{array}{r}.9965 \\
(.0189)\end{array}$ \\
\hline Low Polity Score & $\begin{array}{l}.9760^{* *} \\
(.0089)\end{array}$ & $\begin{array}{l}.9797^{\star} \\
(.0094)\end{array}$ & $\begin{array}{r}.9640^{* * *} \\
(.0099)\end{array}$ & $\begin{array}{c}.9675^{\star \star} \\
(.0105)\end{array}$ & $\begin{array}{c}.9540^{* *} \\
(.0145)\end{array}$ \\
\hline Polity Score & $\begin{array}{c}.9888 \\
(.0077)\end{array}$ & $\begin{array}{l}.9830^{*} \\
(.0082)\end{array}$ & $\begin{array}{l}.9905 \\
(.0082)\end{array}$ & $\begin{array}{c}.9828^{\circ} \\
(.0088)\end{array}$ & $\begin{array}{c}1.0035 \\
(.0128)\end{array}$ \\
\hline Defensive Allies & $\begin{array}{l}.9667 \\
(.0958)\end{array}$ & $\begin{array}{l}1.0001 \\
(.1027)\end{array}$ & $\begin{array}{l}.9056 \\
(.0961)\end{array}$ & $\begin{array}{c}.9372 \\
(.1036)\end{array}$ & $\begin{array}{r}.8055 \\
(.1491)\end{array}$ \\
\hline Log Peace-Years & $\begin{array}{c}.5268^{\star * *} \\
(.0184)\end{array}$ & $\begin{array}{c}.5188^{\star \star *} \\
(.0190)\end{array}$ & $\begin{array}{c}.5276^{\star * *} \\
(.0202)\end{array}$ & $\begin{array}{c}.5187^{\star * *} \\
(.0210)\end{array}$ & $\begin{array}{r}.5621^{\star \star \star} \\
(.0335)\end{array}$ \\
\hline Closest Contiguity & $\begin{array}{r}.7291^{\star * *} \\
(.0147) \\
\end{array}$ & $\begin{array}{r}.7381^{* * *} \\
(.0153) \\
\end{array}$ & $\begin{array}{r}.7076^{\star * \star} \\
(.0157) \\
\end{array}$ & $\begin{array}{c}.7164^{\star \star *} \\
(.0167) \\
\end{array}$ & $\begin{array}{c}.7542^{\star \star \star} \\
(.0263) \\
\end{array}$ \\
\hline Observations & 92,277 & 92,277 & 92,277 & 92,277 & 92,077 \\
\hline Wald $\chi^{2}(7)$ & 1008.31 & 1025.79 & 927.42 & 939.44 & 318.57 \\
\hline$p$ & $<.0001$ & $<.0001$ & $<.0001$ & $<.0001$ & $<.0001$ \\
\hline Pseudo $\mathrm{R}^{2}$ & .1276 & .1290 & .1364 & .1385 & .0931 \\
\hline
\end{tabular}

${ }^{\circ} p<.10{ }^{*} p<.05{ }^{* *} p<.01{ }^{* * *} p<.001$ 
Table B-22. Logit of GRP Scale of Preferred Religion.

\begin{tabular}{|c|c|c|c|c|c|}
\hline Variable & Model 1 & Model 2 & Model 3 & Model 4 & Model 5 \\
\hline $\begin{array}{l}\text { GRP Scale of } \\
\text { Preferred Religion } \\
\text { (every } 10 \%)\end{array}$ & $\begin{array}{r}.0685^{\star \star \star} \\
(.0168) \\
\end{array}$ & $\begin{array}{r}.0842^{* * *} \\
(.0177) \\
\end{array}$ & $\begin{array}{r}.0711^{* * *} \\
(.0181) \\
\end{array}$ & $\begin{array}{r}.0884^{* * *} \\
(.0194) \\
\end{array}$ & $\begin{array}{c}.1030^{* *} \\
(.0316) \\
\end{array}$ \\
\hline Log CINC Ratio & $\begin{array}{c}.0118 \\
(.0118)\end{array}$ & $\begin{array}{l}-.0080 \\
(.0120)\end{array}$ & $\begin{array}{l}.0378^{\star *} \\
(.0130)\end{array}$ & $\begin{array}{l}.0166 \\
(.0135)\end{array}$ & $\begin{array}{l}-.0035 \\
(.0189)\end{array}$ \\
\hline Low Polity Score & $\begin{array}{r}-.0243^{\star *} \\
(.0091)\end{array}$ & $\begin{array}{l}-.0205^{\star} \\
(.0096)\end{array}$ & $\begin{array}{r}-.0367^{* * *} \\
(.0102)\end{array}$ & $\begin{array}{r}-.0330^{\star *} \\
(.0109)\end{array}$ & $\begin{array}{r}-.0471^{\star *} \\
(.0152)\end{array}$ \\
\hline Polity Score & $\begin{array}{l}-.0112 \\
(.0078)\end{array}$ & $\begin{array}{l}-.0171^{*} \\
(.0084)\end{array}$ & $\begin{array}{l}-.0096 \\
(.0083)\end{array}$ & $\begin{array}{r}-.0173 \\
(.0090)\end{array}$ & $\begin{array}{l}.0035 \\
(.0127)\end{array}$ \\
\hline Defensive Allies & $\begin{array}{l}-.0339 \\
(.0991)\end{array}$ & $\begin{array}{l}.0001 \\
(.1027)\end{array}$ & $\begin{array}{l}-.0992 \\
(.1062)\end{array}$ & $\begin{array}{l}-.0649 \\
(.1106)\end{array}$ & $\begin{array}{c}-.2162 \\
(.1851)\end{array}$ \\
\hline Log Peace-Years & $\begin{array}{r}-.6409^{* * *} \\
(.0351)\end{array}$ & $\begin{array}{r}-.6563^{* * *} \\
(.0367)\end{array}$ & $\begin{array}{r}-.6394^{\star \star *} \\
(.0382)\end{array}$ & $\begin{array}{r}-.6564^{\star * *} \\
(.0405)\end{array}$ & $\begin{array}{r}-.5761^{* * *} \\
(.0597)\end{array}$ \\
\hline Closest Contiguity & $\begin{array}{r}-.3160^{\star * *} \\
(.0201)\end{array}$ & $\begin{array}{r}-.3037^{\star * *} \\
(.0208)\end{array}$ & $\begin{array}{r}-.3458^{\star \star *} \\
(.0222)\end{array}$ & $\begin{array}{r}-.3335^{\star \star *} \\
(.0232)\end{array}$ & $\begin{array}{r}-.2821^{* * *} \\
(.0349)\end{array}$ \\
\hline Constant & $\begin{array}{c}-2.5107^{* * *} \\
(.1527) \\
\end{array}$ & $\begin{array}{c}-2.6831^{* \star *} \\
(.1634) \\
\end{array}$ & $\begin{array}{c}-2.5809^{\star * *} \\
(.1621) \\
\end{array}$ & $\begin{array}{c}-2.7625^{\star * *} \\
(.1758) \\
\end{array}$ & $\begin{array}{c}-4.0864^{* * *} \\
(.2873) \\
\end{array}$ \\
\hline Observations & 92,277 & 92,277 & 92,277 & 92,277 & 92,077 \\
\hline Wald $\chi^{2}(7)$ & 1008.31 & 1025.79 & 927.42 & 939.44 & 318.57 \\
\hline$p$ & $<.0001$ & $<.0001$ & $<.0001$ & $<.0001$ & $<.0001$ \\
\hline Pseudo $\mathrm{R}^{2}$ & .1276 & .1290 & .1364 & .1385 & .0931 \\
\hline
\end{tabular}

${ }^{\circ} \mathrm{p}<.10{ }^{*} \mathrm{p}<.05{ }^{* *} \mathrm{p}<.01{ }^{* \star *} \mathrm{p}<.001$ 
Table B-23. Odds Ratios of Proportion of Prevalent Religion.

\begin{tabular}{|c|c|c|c|c|c|}
\hline Variable & Model 1 & Model 2 & Model 3 & Model 4 & Model 5 \\
\hline $\begin{array}{l}\text { Proportion of } \\
\text { Prevalent Religion } \\
\text { (every 10\%) }\end{array}$ & $\begin{array}{l}1.0469 \\
(.0364) \\
\end{array}$ & $\begin{array}{c}1.0485 \\
(.0383) \\
\end{array}$ & $\begin{array}{c}1.0861^{*} \\
(.0425)\end{array}$ & $\begin{array}{r}1.0938^{*} \\
(.0457) \\
\end{array}$ & $\begin{array}{r}1.1372^{*} \\
(.0744) \\
\end{array}$ \\
\hline Log CINC Ratio & $\begin{array}{c}1.0246^{*} \\
(.0117)\end{array}$ & $\begin{array}{c}1.0062 \\
(.0117)\end{array}$ & $\begin{array}{c}1.0550^{* * *} \\
(.0133)\end{array}$ & $\begin{array}{r}1.0350^{\star \star} \\
(.0134)\end{array}$ & $\begin{array}{r}1.0176 \\
(.0190)\end{array}$ \\
\hline Low Polity Score & $\begin{array}{r}.9748^{* *} \\
(.0089)\end{array}$ & $\begin{array}{l}.9778^{*} \\
(.0094)\end{array}$ & $\begin{array}{r}.9636^{\star * *} \\
(.0099)\end{array}$ & $\begin{array}{c}.9664^{\star *} \\
(.0106)\end{array}$ & $\begin{array}{r}.9569^{* *} \\
(.0149)\end{array}$ \\
\hline Polity Score & $\begin{array}{l}.9777^{\star *} \\
(.0072)\end{array}$ & $\begin{array}{c}.9699^{\star * \star} \\
(.0076)\end{array}$ & $\begin{array}{c}.9782^{\star *} \\
(.0076)\end{array}$ & $\begin{array}{c}.9682^{\star * *} \\
(.0081)\end{array}$ & $\begin{array}{l}.9855 \\
(.0118)\end{array}$ \\
\hline Defensive Allies & $\begin{array}{l}.9255 \\
(.0892)\end{array}$ & $\begin{array}{l}.9596 \\
(.0958)\end{array}$ & $\begin{array}{l}.8600 \\
(.0889)\end{array}$ & $\begin{array}{l}.8907 \\
(.0958)\end{array}$ & $\begin{array}{l}.7666 \\
(.1378)\end{array}$ \\
\hline Log Peace-Years & $\begin{array}{r}.5206^{\star * *} \\
(.0177)\end{array}$ & $\begin{array}{r}.5135^{\star * *} \\
(.0182)\end{array}$ & $\begin{array}{r}.5216^{\star * *} \\
(.0193)\end{array}$ & $\begin{array}{r}.5138^{* * *} \\
(.0200)\end{array}$ & $\begin{array}{r}.5630^{\star * *} \\
(.0327)\end{array}$ \\
\hline Closest Contiguity & $\begin{array}{c}.7298^{\star * *} \\
(.0142) \\
\end{array}$ & $\begin{array}{r}.7401^{* * *} \\
(.0149) \\
\end{array}$ & $\begin{array}{c}.7103^{\star * \star} \\
(.0154) \\
\end{array}$ & $\begin{array}{c}.7211^{\star \star \star} \\
(.0163) \\
\end{array}$ & $\begin{array}{c}.7601^{\star \star \star} \\
(.0262) \\
\end{array}$ \\
\hline Observations & 95,418 & 95,418 & 95,418 & 95,418 & 95,197 \\
\hline Wald $\chi^{2}(7)$ & 1062.52 & 1065.76 & 972.09 & 972.05 & 318.67 \\
\hline$p$ & $<.0001$ & $<.0001$ & $<.0001$ & $<.0001$ & $<.0001$ \\
\hline Pseudo $\mathrm{R}^{2}$ & .1302 & .1299 & .1393 & .1395 & .0910 \\
\hline
\end{tabular}

${ }^{\circ} p<.10 \quad{ }^{*} p<.05{ }^{* *} p<.01{ }^{* * *} p<.001$ 
Table B-24. Logit of Proportion of Prevalent Religion.

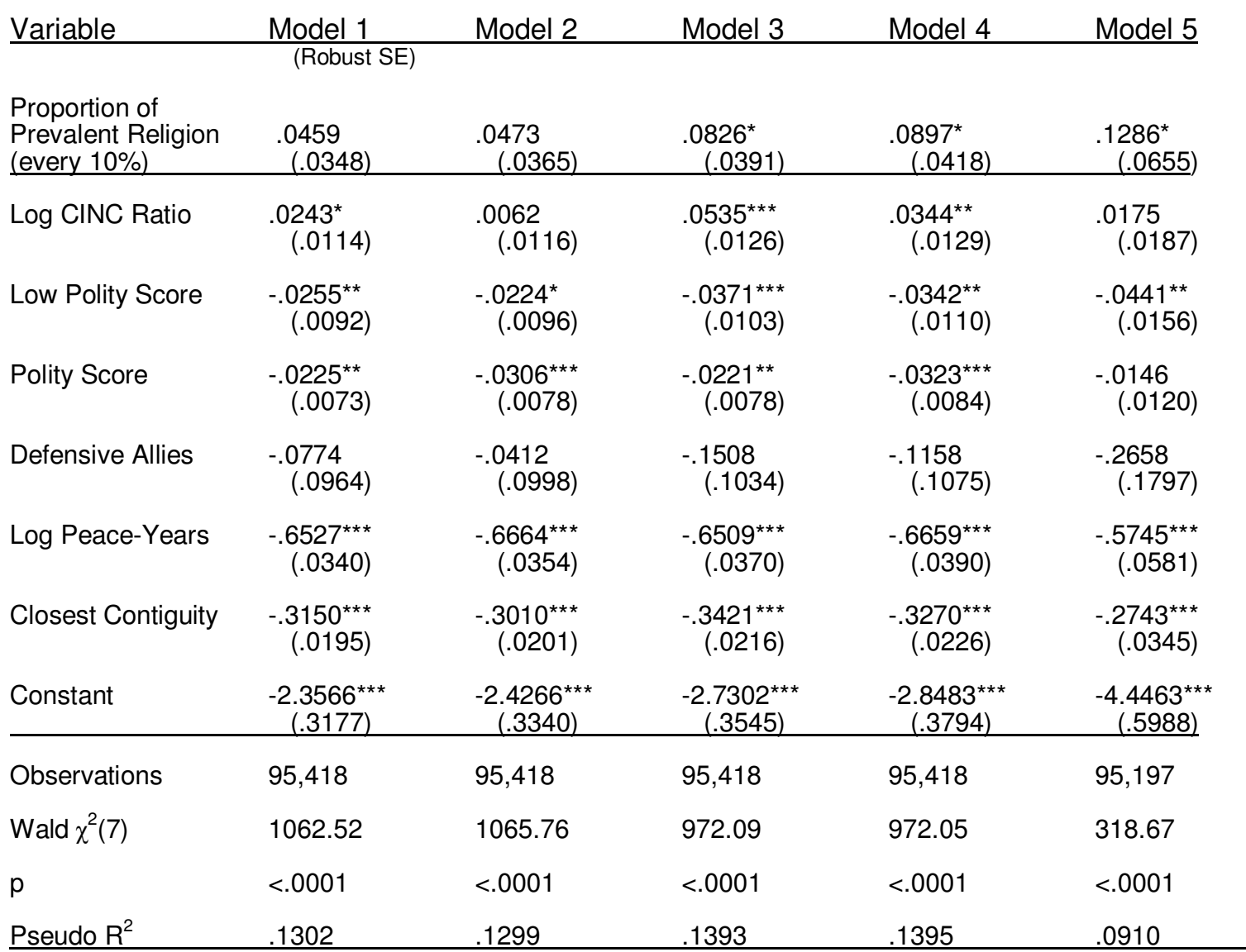

${ }^{\circ} \mathrm{p}<.10{ }^{*} \mathrm{p}<.05{ }^{* *} \mathrm{p}<.01{ }^{* \star *} \mathrm{p}<.001$ 
Table B-25. Logit of Religious Similarity (Religion of Chief Executive).

\begin{tabular}{|c|c|c|c|c|c|}
\hline Variable & Model 1 & Model 2 & Model 3 & Model 4 & Model 5 \\
\hline $\begin{array}{l}\text { Same Religion of } \\
\text { Chief Exec. (binary) } \\
\end{array}$ & $\begin{array}{c}-.3280^{* *} \\
(.1005) \\
\end{array}$ & $\begin{array}{r}-.3750^{\star \star *} \\
(.1053) \\
\end{array}$ & $\begin{array}{r}-.2287^{\star} \\
(.1065) \\
\end{array}$ & $\begin{array}{r}-.2719^{\star} \\
(.1123) \\
\end{array}$ & $\begin{array}{r}-.1056 \\
(.1726) \\
\end{array}$ \\
\hline Log CINC Ratio & $\begin{array}{l}.0187 \\
(.0114)\end{array}$ & $\begin{aligned}-.0013 \\
(.0117)\end{aligned}$ & $\begin{array}{r}.0471^{* * *} \\
(.0126)\end{array}$ & $\begin{array}{l}.0253^{\circ} \\
(.0131)\end{array}$ & $\begin{array}{l}.0149 \\
(.0190)\end{array}$ \\
\hline Low Polity Score & $\begin{array}{l}-.0162^{\circ} \\
(.0093)\end{array}$ & $\begin{array}{l}-.0129 \\
(.0098)\end{array}$ & $\begin{array}{r}-.0288^{\star *} \\
(.0104)\end{array}$ & $\begin{array}{l}-.0258^{*} \\
(.0111)\end{array}$ & $\begin{array}{l}-.0385^{\star} \\
(.0157)\end{array}$ \\
\hline Polity Score & $\begin{aligned}-.0228^{* *} & (.0074)\end{aligned}$ & $\begin{array}{r}-.0315^{\star \star *} \\
(.0079)\end{array}$ & $\begin{array}{r}-.0207^{\star *} \\
(.0079)\end{array}$ & $\begin{array}{r}-.0317^{\star * *} \\
(.0085)\end{array}$ & $\begin{array}{l}-.0110 \\
(.0122)\end{array}$ \\
\hline Defensive Allies & $\begin{array}{l}.0452 \\
(.1069)\end{array}$ & $\begin{array}{l}.1044 \\
(.1106)\end{array}$ & $\begin{array}{l}-.0532 \\
(.1138)\end{array}$ & $\begin{array}{l}.0066 \\
(.1185)\end{array}$ & $\begin{array}{l}-.1727 \\
(.1922)\end{array}$ \\
\hline Log Peace-Years & $\begin{array}{r}-.6811^{* * *} \\
(.0357)\end{array}$ & $\begin{array}{r}-.6956^{* \star *} \\
(.0373)\end{array}$ & $\begin{array}{r}-.6779^{* * *} \\
(.0391)\end{array}$ & $\begin{array}{r}-.6940^{\star * *} \\
(.0413)\end{array}$ & $\begin{array}{r}-.6253^{\star \star *} \\
(.0605)\end{array}$ \\
\hline Closest Contiguity & $\begin{array}{r}-.3072^{* * *} \\
(.0204)\end{array}$ & $\begin{array}{r}-.2932^{\star \star *} \\
(.0211)\end{array}$ & $\begin{array}{r}-.3341^{* \star *} \\
(.0227)\end{array}$ & $\begin{array}{r}-.3187^{\star \star \star} \\
(.0237)\end{array}$ & $\begin{array}{r}-.2703^{* \star *} \\
(.0364)\end{array}$ \\
\hline Constant & $\begin{array}{c}-1.8152^{* \star *} \\
(.0949) \\
\end{array}$ & $\begin{array}{c}-1.8658^{* * *} \\
(.0979) \\
\end{array}$ & $\begin{array}{c}-1.9045^{\star * *} \\
(.1006) \\
\end{array}$ & $\begin{array}{c}-1.9548^{* * *} \\
(.1038) \\
\end{array}$ & $\begin{array}{c}-3.2148^{* * *} \\
(.1659) \\
\end{array}$ \\
\hline Observations & 81,658 & 81,658 & 81,658 & 81,658 & 81,455 \\
\hline Wald $\chi^{2}(7)$ & 1005.08 & 996.38 & 905.41 & 889.98 & 296.69 \\
\hline $\mathrm{p}$ & $<.0001$ & $<.0001$ & $<.0001$ & $<.0001$ & $<.0001$ \\
\hline Pseudo $R^{2}$ & .1306 & .1305 & .1384 & .1381 & .0939 \\
\hline
\end{tabular}

${ }^{\circ} \mathrm{p}<.10{ }^{*} \mathrm{p}<.05{ }^{* *} \mathrm{p}<.01{ }^{* \star *} \mathrm{p}<.001$ 
Table B-26. Logit of Religious Similarity (Religion of Chief Executive) - Christian, Muslim, Buddhist Mix, and Atheist Only.

\begin{tabular}{|c|c|c|c|c|c|}
\hline Variable & Model 1 & Model 2 & Model 3 & Model 4 & Model 5 \\
\hline $\begin{array}{l}\text { Same Religion of } \\
\text { Chief Exec. (binary) }\end{array}$ & $\begin{array}{r}-.2480^{\star *} \\
(.0945) \\
\end{array}$ & $\begin{array}{r}-.2675^{* *} \\
(.0994) \\
\end{array}$ & $\begin{array}{r}-.1745^{\circ} \\
(.1042) \\
\end{array}$ & $\begin{array}{r}-.1873^{\circ} \\
(.1110) \\
\end{array}$ & $\begin{array}{r}-.3329^{\circ} \\
(.1896) \\
\end{array}$ \\
\hline Log CINC Ratio & $\begin{array}{l}.0180 \\
(.0124)\end{array}$ & $\begin{array}{l}-.0053 \\
(.0127)\end{array}$ & $\begin{array}{r}.0545^{\star * *} \\
(.0136)\end{array}$ & $\begin{array}{l}.0291^{*} \\
(.0142)\end{array}$ & $\begin{array}{l}.0280 \\
(.0205)\end{array}$ \\
\hline Low Polity Score & $\begin{array}{l}-.0159 \\
(.0106)\end{array}$ & $\begin{array}{l}-.0112 \\
(.0113)\end{array}$ & $\begin{array}{l}-.0311^{*} \\
(.0121)\end{array}$ & $\begin{array}{l}-.0287^{*} \\
(.0130)\end{array}$ & $\begin{array}{r}-.0327^{\circ} \\
(.0188)\end{array}$ \\
\hline Polity Score & $\begin{array}{r}-.0243^{* *} \\
(.0081)\end{array}$ & $\begin{array}{r}-.0354^{* * *} \\
(.0088)\end{array}$ & $\begin{array}{l}-.0226^{\star *} \\
(.0086)\end{array}$ & $\begin{array}{r}-.0350^{* * *} \\
(.0094)\end{array}$ & $\begin{array}{l}-.0156 \\
(.0134)\end{array}$ \\
\hline Defensive Allies & $\begin{array}{l}.0855 \\
(.1089)\end{array}$ & $\begin{array}{l}.1501 \\
(.1130)\end{array}$ & $\begin{array}{c}-.0154 \\
(.1179)\end{array}$ & $\begin{array}{l}.0468 \\
(.1231)\end{array}$ & $\begin{array}{l}.0576 \\
(.2041)\end{array}$ \\
\hline Log Peace-Years & $\begin{array}{r}-.6589^{* * *} \\
(.0386)\end{array}$ & $\begin{array}{r}-.6719^{* * *} \\
(.0404)\end{array}$ & $\begin{array}{r}-.6588^{\star \star *} \\
(.0420)\end{array}$ & $\begin{array}{r}-.6741^{* * *} \\
(.0445)\end{array}$ & $\begin{array}{r}-.5635^{\star * *} \\
(.0676)\end{array}$ \\
\hline Closest Contiguity & $\begin{array}{r}-.2963^{\star \star *} \\
(.0224)\end{array}$ & $\begin{array}{r}-.2805^{* * *} \\
(.0233)\end{array}$ & $\begin{array}{r}-3288^{* * *} \\
(.0247)\end{array}$ & $\begin{array}{r}-3119^{* * *} \\
(.0259)\end{array}$ & $\begin{array}{r}-.2817^{\star \star *} \\
(.0409)\end{array}$ \\
\hline Constant & $\begin{array}{c}-1.8946^{\star * *} \\
(.1108) \\
\end{array}$ & $\begin{array}{c}-1.9561^{\star \star \star} \\
(.1148) \\
\end{array}$ & $\begin{array}{c}-1.9626^{\star \star *} \\
(.1149) \\
\end{array}$ & $\begin{array}{c}-2.0196^{\star * *} \\
(.1187) \\
\end{array}$ & $\begin{array}{c}-3.2952^{\star * *} \\
(.1832) \\
\end{array}$ \\
\hline Observations & 70,778 & 70,778 & 70,778 & 70,778 & 70,609 \\
\hline Wald $\chi^{2}(7)$ & 789.91 & 796.18 & 736.08 & 733.79 & 251.69 \\
\hline$p$ & $<.0001$ & $<.0001$ & $<.0001$ & $<.0001$ & $<.0001$ \\
\hline Pseudo $\mathrm{R}^{2}$ & .1231 & .1233 & .1331 & .1333 & .0853 \\
\hline
\end{tabular}

${ }^{\circ} p<.10{ }^{*} p<.05 \quad{ }^{* *} p<.01{ }^{* * *} p<.001$ 
Table B-27. Logit of Religious Similarity (Preference).

\begin{tabular}{|c|c|c|c|c|c|}
\hline Variable & Model 1 & Model 2 & Model 3 & Model 4 & Model 5 \\
\hline $\begin{array}{l}\text { Same Religious } \\
\text { Preference (binary) }\end{array}$ & $\begin{array}{c}-.2129^{*} \\
(.0931) \\
\end{array}$ & $\begin{array}{c}-.2078^{*} \\
(.0969) \\
\end{array}$ & $\begin{array}{r}-.1704^{\circ} \\
(.0990) \\
\end{array}$ & $\begin{array}{c}-.1574 \\
(.1037) \\
\end{array}$ & $\begin{array}{c}-.0238 \\
(.1629) \\
\end{array}$ \\
\hline Log CINC Ratio & $\begin{array}{l}.0250^{*} \\
(.0114)\end{array}$ & $\begin{array}{l}.0063 \\
(.0116)\end{array}$ & $\begin{array}{r}.0527^{\star \star *} \\
(.0125)\end{array}$ & $\begin{array}{l}.0326^{*} \\
(.0128)\end{array}$ & $\begin{array}{l}.0140 \\
(.0184)\end{array}$ \\
\hline Low Polity Score & $\begin{array}{c}-.0265^{* *} \\
(.0094)\end{array}$ & $\begin{array}{c}-.0233^{*} \\
(.0100)\end{array}$ & $\begin{array}{r}-.0396^{* * *} \\
(.0106)\end{array}$ & $\begin{array}{c}-.0368^{* *} \\
(.0113)\end{array}$ & $\begin{array}{c}-.0472^{* *} \\
(.0154)\end{array}$ \\
\hline Polity Score & $\begin{array}{r}-.0251^{\star * *} \\
(.0076)\end{array}$ & $\begin{array}{r}-.0336^{\star \star *} \\
(.0081)\end{array}$ & $\begin{array}{c}-.0235^{\star \star} \\
(.0080)\end{array}$ & $\begin{array}{r}-.0342^{\star \star \star} \\
(.0087)\end{array}$ & $\begin{array}{l}-.0129 \\
(.0122)\end{array}$ \\
\hline Defensive Allies & $\begin{array}{c}.0269 \\
(.1041)\end{array}$ & $\begin{array}{l}.0662 \\
(.1081)\end{array}$ & $\begin{array}{l}-.0487 \\
(.1107)\end{array}$ & $\begin{array}{l}-.0104 \\
(.1156)\end{array}$ & $\begin{array}{l}-.2261 \\
(.1921)\end{array}$ \\
\hline Log Peace-Years & $\begin{array}{r}-.6567^{\star \star \star} \\
(.0355)\end{array}$ & $\begin{array}{r}-.6723^{* * *} \\
(.0370)\end{array}$ & $\begin{array}{r}-.6566^{* * *} \\
(.0389)\end{array}$ & $\begin{array}{r}-.6742^{\star \star *} \\
(.0412)\end{array}$ & $\begin{array}{r}-.5874^{\star * *} \\
(.0608)\end{array}$ \\
\hline Closest Contiguity & $\begin{array}{r}-.3211^{* * *} \\
(.0199)\end{array}$ & $\begin{array}{r}-.3054^{\star \star *} \\
(.0205)\end{array}$ & $\begin{array}{r}-.3458^{\star \star *} \\
(.0222)\end{array}$ & $\begin{array}{r}-.3280^{\star * *} \\
(.0231)\end{array}$ & $\begin{array}{r}-.2778^{\star * *} \\
(.0357)\end{array}$ \\
\hline Constant & $\begin{array}{c}-1.8639^{* * *} \\
(.0991) \\
\end{array}$ & $\begin{array}{c}-1.9272^{* * *} \\
(.1021) \\
\end{array}$ & $\begin{array}{c}-1.9437^{* * *} \\
(.1045) \\
\end{array}$ & $\begin{array}{c}-2.0098^{\star * *} \\
(.1078) \\
\end{array}$ & $\begin{array}{c}-3.2947^{* * *} \\
(.1673) \\
\end{array}$ \\
\hline Observations & 91,524 & 91,524 & 91,524 & 91,524 & 91,340 \\
\hline Wald $\chi^{2}(7)$ & 1009.27 & 1007.13 & 916.96 & 909.17 & 299.75 \\
\hline $\mathrm{p}$ & $<.0001$ & $<.0001$ & $<.0001$ & $<.0001$ & $<.0001$ \\
\hline Pseudo $\mathrm{R}^{2}$ & .1295 & .1293 & .1378 & .1379 & .0902 \\
\hline
\end{tabular}

${ }^{\circ} \mathrm{p}<.10{ }^{*} \mathrm{p}<.05{ }^{* *} \mathrm{p}<.01{ }^{* \star *} \mathrm{p}<.001$ 
Table B-28. Logit of Religious Similarity (Preference) - Christian, Muslim, Buddhist Mix, and Atheist Only.

\begin{tabular}{|c|c|c|c|c|c|}
\hline Variable & Model 1 & Model 2 & Model 3 & Model 4 & Model 5 \\
\hline $\begin{array}{l}\text { Same Religious } \\
\text { Preference (binary) }\end{array}$ & $\begin{array}{r}-.4021^{\star * *} \\
(.0981) \\
\end{array}$ & $\begin{array}{r}-.3935^{* * *} \\
(.1029) \\
\end{array}$ & $\begin{array}{r}-.3703^{* * *} \\
(.1083) \\
\end{array}$ & $\begin{array}{c}-.3552^{* *} \\
(.1150) \\
\end{array}$ & $\begin{array}{r}-.2885 \\
(.1943) \\
\end{array}$ \\
\hline Log CINC Ratio & $\begin{array}{l}.0243^{*} \\
(.0117)\end{array}$ & $\begin{array}{l}.0021 \\
(.0119)\end{array}$ & $\begin{array}{r}.0570^{* * *} \\
(.0127)\end{array}$ & $\begin{array}{l}.0325^{\star} \\
(.0131)\end{array}$ & $\begin{array}{l}.0213 \\
(.0187)\end{array}$ \\
\hline Low Polity Score & $\begin{array}{l}-.0184^{\circ} \\
(.0102)\end{array}$ & $\begin{array}{c}-.0160 \\
(.0109)\end{array}$ & $\begin{array}{r}-.0348^{\star \star} \\
(.0116)\end{array}$ & $\begin{array}{l}-.0353^{* *} \\
(.0126)\end{array}$ & $\begin{array}{l}-.0423^{*} \\
(.0183)\end{array}$ \\
\hline Polity Score & $\begin{array}{r}-.0329^{\star \star *} \\
(.0079)\end{array}$ & $\begin{array}{r}-.0421^{* * \star} \\
(.0085)\end{array}$ & $\begin{array}{r}-.0304^{\star \star *} \\
(.0083)\end{array}$ & $\begin{array}{r}-.0406^{\star \star *} \\
(.0090)\end{array}$ & $\begin{array}{r}-.0249^{\circ} \\
(.0129)\end{array}$ \\
\hline Defensive Allies & $\begin{array}{l}.0971 \\
(.1092)\end{array}$ & $\begin{array}{l}.1346 \\
(.1136)\end{array}$ & $\begin{array}{l}.0273 \\
(.1187)\end{array}$ & $\begin{array}{l}.0618 \\
(.1244)\end{array}$ & $\begin{array}{l}-.0890 \\
(.2056)\end{array}$ \\
\hline Log Peace-Years & $\begin{array}{r}-.6548^{\star \star \star} \\
(.0376)\end{array}$ & $\begin{array}{r}-.6718^{\star \star \star} \\
(.0392)\end{array}$ & $\begin{array}{r}-.6512^{\star \star \star} \\
(.0414)\end{array}$ & $\begin{array}{r}-.6712^{\star \star \star} \\
(.0438)\end{array}$ & $\begin{array}{r}-.5674^{\star \star \star} \\
(.0662)\end{array}$ \\
\hline Closest Contiguity & $\begin{array}{r}-.3166^{\star \star *} \\
(.0219)\end{array}$ & $\begin{array}{r}-3012^{* * *} \\
(.0226)\end{array}$ & $\begin{array}{r}-3444^{* * *} \\
(.0239)\end{array}$ & $\begin{array}{r}-3272^{* * *} \\
(.0249)\end{array}$ & $\begin{array}{r}-.2712^{\star \star *} \\
(.0402)\end{array}$ \\
\hline Constant & $\begin{array}{c}-1.6974^{\star \star *} \\
(.1132) \\
\end{array}$ & $\begin{array}{c}-1.7563^{\star \star *} \\
(.1171) \\
\end{array}$ & $\begin{array}{c}-1.7710^{* * *} \\
(.1173) \\
\end{array}$ & $\begin{array}{c}-1.8258^{* * *} \\
(.1209) \\
\end{array}$ & $\begin{array}{c}-3.1683^{* * *} \\
(.1887) \\
\end{array}$ \\
\hline Observations & 80,810 & 80,810 & 80,810 & 80,810 & 80,647 \\
\hline Wald $\chi^{2}(7)$ & 902.93 & 914.75 & 827.84 & 831.11 & 288.12 \\
\hline$p$ & $<.0001$ & $<.0001$ & $<.0001$ & $<.0001$ & $<.0001$ \\
\hline${\text { Pseudo } \mathrm{R}^{2}}$ & .1302 & .1313 & .1392 & .1407 & .0875 \\
\hline
\end{tabular}

${ }^{\circ} p<.10{ }^{*} p<.05{ }^{* *} p<.01{ }^{* * *} p<.001$ 
Table B-29. Logit of Religious Similarity (Prevalence).

\begin{tabular}{|c|c|c|c|c|c|}
\hline Variable & Model 1 & Model 2 & Model 3 & Model 4 & Model 5 \\
\hline $\begin{array}{l}\text { Same Religious } \\
\text { Prevalence (binary) }\end{array}$ & $\begin{array}{c}-.1323 \\
(.0948) \\
\end{array}$ & $\begin{array}{r}-.1539 \\
(.0984) \\
\end{array}$ & $\begin{array}{r}-.0912 \\
(.1027) \\
\end{array}$ & $\begin{array}{r}-.1121 \\
(.1075) \\
\end{array}$ & $\begin{array}{r}-.0162 \\
(.1699) \\
\end{array}$ \\
\hline Log CINC Ratio & $\begin{array}{l}.0224^{*} \\
(.0112)\end{array}$ & $\begin{array}{l}.0044 \\
(.0114)\end{array}$ & $\begin{array}{r}.0496^{\star * *} \\
(.0123)\end{array}$ & $\begin{array}{l}.0302^{*} \\
(.0127)\end{array}$ & $\begin{array}{l}.0112 \\
(.0180)\end{array}$ \\
\hline Low Polity Score & $\begin{array}{l}-.0259^{* *} \\
(.0091)\end{array}$ & $\begin{array}{l}-.0228^{*} \\
(.0096)\end{array}$ & $\begin{array}{r}-.0386^{* * *} \\
(.0103)\end{array}$ & $\begin{array}{l}-.0358^{* *} \\
(.0109)\end{array}$ & $\begin{array}{l}-.0466^{* *} \\
(.0154)\end{array}$ \\
\hline Polity Score & $\begin{array}{r}-.0225^{\star *} \\
(.0073)\end{array}$ & $\begin{array}{r}-.0306^{\star * *} \\
(.0078)\end{array}$ & $\begin{array}{r}-.0216^{\star \star} \\
(.0077)\end{array}$ & $\begin{array}{r}-.0319^{\star \star *} \\
(.0083)\end{array}$ & $\begin{array}{l}-.0141 \\
(.0120)\end{array}$ \\
\hline Defensive Allies & $\begin{array}{l}-.0281 \\
(.0982)\end{array}$ & $\begin{array}{l}.0138 \\
(.1014)\end{array}$ & $\begin{array}{l}-.0957 \\
(.1057)\end{array}$ & $\begin{array}{l}-.0524 \\
(.1096)\end{array}$ & $\begin{array}{l}-.2144 \\
(.1851)\end{array}$ \\
\hline Log Peace-Years & $\begin{array}{r}-.6546^{* * *} \\
(.0340)\end{array}$ & $\begin{array}{r}-.6682^{* * *} \\
(.0354)\end{array}$ & $\begin{array}{r}-.6537^{* * *} \\
(.0370)\end{array}$ & $\begin{array}{r}-.6688^{* * *} \\
(.0390)\end{array}$ & $\begin{array}{r}-.5785^{\star * *} \\
(.0580)\end{array}$ \\
\hline Closest Contiguity & $\begin{array}{r}-.3214^{\star \star *} \\
(.0197)\end{array}$ & $\begin{array}{r}-.3082^{\star \star *} \\
(.0203)\end{array}$ & $\begin{array}{r}-.3474^{\star \star *} \\
(.0219)\end{array}$ & $\begin{array}{r}-.3330^{\star * *} \\
(.0229)\end{array}$ & $\begin{array}{r}-.2781^{* * *} \\
(.0349)\end{array}$ \\
\hline Constant & $\begin{array}{c}-1.9171^{* * *} \\
(.0921) \\
\end{array}$ & $\begin{array}{c}-1.9683^{* * *} \\
(.0944) \\
\end{array}$ & $\begin{array}{c}-1.9824^{* * *} \\
(.0964) \\
\end{array}$ & $\begin{array}{c}-2.0324^{* * *} \\
(.0987) \\
\end{array}$ & $\begin{array}{c}-3.3102^{* * *} \\
(.1549) \\
\end{array}$ \\
\hline Observations & 95,352 & 95,352 & 95,352 & 95,352 & 95,132 \\
\hline Wald $\chi^{2}(7)$ & 1066.85 & 1073.20 & 970.89 & 971.62 & 315.70 \\
\hline $\mathrm{p}$ & $<.0001$ & $<.0001$ & $<.0001$ & $<.0001$ & $<.0001$ \\
\hline Pseudo R ${ }^{2}$ & .1302 & .1300 & .1388 & .1389 & .0898 \\
\hline
\end{tabular}

${ }^{\circ} \mathrm{p}<.10{ }^{*} \mathrm{p}<.05{ }^{* *} \mathrm{p}<.01{ }^{* \star *} \mathrm{p}<.001$ 
Table B-30. Logit of Religious Similarity (Prevalence) - Christian, Muslim, and Buddhist Mix Only.

\begin{tabular}{|c|c|c|c|c|c|}
\hline Variable & Model 1 & Model 2 & Model 3 & Model 4 & Model 5 \\
\hline $\begin{array}{l}\text { Same Religious } \\
\text { Prevalence (binary) }\end{array}$ & $\begin{array}{c}-.1032 \\
(.1402) \\
\end{array}$ & $\begin{array}{l}-.1239 \\
(.1455) \\
\end{array}$ & $\begin{array}{c}-.1232 \\
(.1512) \\
\end{array}$ & $\begin{array}{c}-.1698 \\
(.1570) \\
\end{array}$ & $\begin{array}{r}-.3395 \\
(.2586) \\
\end{array}$ \\
\hline Log CINC Ratio & $\begin{array}{l}.0369^{\star} \\
(.0166)\end{array}$ & $\begin{array}{l}.0151 \\
(.0173)\end{array}$ & $\begin{array}{r}.0763^{* * *} \\
(.0173)\end{array}$ & $\begin{array}{l}.0542^{* *} \\
(.0182)\end{array}$ & $\begin{array}{l}.0582^{*} \\
(.0246)\end{array}$ \\
\hline Low Polity Score & $\begin{array}{l}-.0258^{\star} \\
(.0113)\end{array}$ & $\begin{array}{l}-.0194 \\
(.0120)\end{array}$ & $\begin{array}{r}-.0402^{* *} \\
(.0126)\end{array}$ & $\begin{array}{l}-.0363^{* *} \\
(.0135)\end{array}$ & $\begin{array}{l}-.0404^{*} \\
(.0191)\end{array}$ \\
\hline Polity Score & $\begin{array}{r}-.0363^{* * *} \\
(.0093)\end{array}$ & $\begin{array}{r}-.0501^{\star * *} \\
(.0101)\end{array}$ & $\begin{array}{r}-.0351^{* * *} \\
(.0096)\end{array}$ & $\begin{array}{r}-.0497^{\star * *} \\
(.0105)\end{array}$ & $\begin{array}{l}-.0351^{*} \\
(.0150)\end{array}$ \\
\hline Defensive Allies & $\begin{array}{l}.0293 \\
(.1207)\end{array}$ & $\begin{array}{l}.0856 \\
(.1257)\end{array}$ & $\begin{array}{l}-.0841 \\
(.1300)\end{array}$ & $\begin{array}{l}-.0254 \\
(.1365)\end{array}$ & $\begin{array}{l}-.0419 \\
(.2198)\end{array}$ \\
\hline Log Peace-Years & $\begin{array}{r}-.6080^{* * *} \\
(.0417)\end{array}$ & $\begin{array}{r}-.6195^{\star \star *} \\
(.0435)\end{array}$ & $\begin{array}{r}-.6089^{* * *} \\
(.0454)\end{array}$ & $\begin{array}{r}-.6221^{* * *} \\
(.0478)\end{array}$ & $\begin{array}{r}-.5367^{\star \star *} \\
(.0708)\end{array}$ \\
\hline Closest Contiguity & $\begin{array}{r}-.2956^{\star * *} \\
(.0291)\end{array}$ & $\begin{array}{r}-.2807^{* * *} \\
(.0301)\end{array}$ & $\begin{array}{r}-.3251^{* * *} \\
(.0309)\end{array}$ & $\begin{array}{r}-.3117^{* * *} \\
(.0321)\end{array}$ & $\begin{array}{r}-.2875^{* * *} \\
(.0518)\end{array}$ \\
\hline Constant & $\begin{array}{c}-1.8664^{* * *} \\
(.1687) \\
\end{array}$ & $\begin{array}{c}-1.8999^{* * *} \\
(.1709) \\
\end{array}$ & $\begin{array}{c}-1.8526^{* * *} \\
(.1707) \\
\end{array}$ & $\begin{array}{c}-1.8545^{\star * *} \\
(.1694) \\
\end{array}$ & $\begin{array}{c}-2.9307^{* * *} \\
(.2693)\end{array}$ \\
\hline Observations & 60,282 & 60,282 & 60,282 & 60,282 & 60,147 \\
\hline Wald $\chi^{2}(7)$ & 631.55 & 657.66 & 600.23 & 628.03 & 217.57 \\
\hline $\mathrm{p}$ & $<.0001$ & $<.0001$ & $<.0001$ & $<.0001$ & $<.0001$ \\
\hline Pseudo $\mathrm{R}^{2}$ & .1239 & .1264 & .1346 & .1377 & .0932 \\
\hline
\end{tabular}

${ }^{\circ} p<.10{ }^{*} p<.05{ }^{* *} p<.01{ }^{* * *} p<.001$ 
Table B-31. Logit of Christian Chief Executive.

\begin{tabular}{|c|c|c|c|c|c|}
\hline Variable & Model 1 & Model 2 & Model 3 & Model 4 & Model 5 \\
\hline & (Robust SE) & & & & \\
\hline $\begin{array}{l}\text { Christian (all) } \\
\text { Chief Exec. (binary) }\end{array}$ & $\begin{array}{r}-.2958^{\star *} \\
(.0915) \\
\end{array}$ & $\begin{array}{r}-.3362^{\star * *} \\
(.0972) \\
\end{array}$ & $\begin{array}{r}-.3942^{\star * *} \\
(.1022) \\
\end{array}$ & $\begin{array}{r}-.4468^{\star * \star} \\
(.1108) \\
\end{array}$ & $\begin{array}{r}-.8108^{\star * *} \\
(.1839) \\
\end{array}$ \\
\hline Log CINC Ratio & $\begin{array}{l}.0131 \\
(.0117)\end{array}$ & $\begin{array}{l}-.0071 \\
(.0120)\end{array}$ & $\begin{array}{r}.0430^{* * *} \\
(.0129)\end{array}$ & $\begin{array}{l}.0212 \\
(.0134)\end{array}$ & $\begin{array}{l}.0089 \\
(.0195)\end{array}$ \\
\hline Low Polity Score & $\begin{array}{l}-.0214^{\star} \\
(.0092)\end{array}$ & $\begin{array}{r}-.0184^{\circ} \\
(.0096)\end{array}$ & $\begin{array}{r}-.0332^{\star *} \\
(.0103)\end{array}$ & $\begin{array}{r}-.0305^{\star *} \\
(.0110)\end{array}$ & $\begin{array}{r}-.0410^{\star *} \\
(.0158)\end{array}$ \\
\hline Polity Score & $\begin{array}{l}-.0104 \\
(.0076)\end{array}$ & $\begin{array}{l}-.0174^{\star} \\
(.0081)\end{array}$ & $\begin{array}{l}-.0068 \\
(.0081)\end{array}$ & $\begin{array}{l}-.0156^{\circ} \\
(.0088)\end{array}$ & $\begin{array}{c}.0131 \\
(.0126)\end{array}$ \\
\hline Defensive Allies & $\begin{array}{l}-.0200 \\
(.0980)\end{array}$ & $\begin{array}{l}.0216 \\
(.1015)\end{array}$ & $\begin{array}{l}-.0723 \\
(.1057)\end{array}$ & $\begin{array}{l}-.0298 \\
(.1101)\end{array}$ & $\begin{array}{l}-.0954 \\
(.1882)\end{array}$ \\
\hline Log Peace-Years & $\begin{array}{r}-.6496^{* * *} \\
(.0355)\end{array}$ & $\begin{array}{r}-.6597^{* * *} \\
(.0371)\end{array}$ & $\begin{array}{r}-.6459^{* * *} \\
(.0387)\end{array}$ & $\begin{array}{r}-.6566^{* * *} \\
(.0411)\end{array}$ & $\begin{array}{r}-.5578^{* * *} \\
(.0620)\end{array}$ \\
\hline Closest Contiguity & $\begin{array}{r}-.3142^{* * *} \\
(.0202)\end{array}$ & $\begin{array}{r}-.2999^{\star * *} \\
(.0208)\end{array}$ & $\begin{array}{r}-.3455^{\star * *} \\
(.0224)\end{array}$ & $\begin{array}{r}-.3305^{\star * *} \\
(.0235)\end{array}$ & $\begin{array}{r}-.2836^{\star * *} \\
(.0361)\end{array}$ \\
\hline Constant & $\begin{array}{c}-1.9358^{\star \star \star} \\
(.0928) \\
\end{array}$ & $\begin{array}{c}-1.9963^{\star \star \star} \\
(.0955) \\
\end{array}$ & $\begin{array}{c}-1.9835^{\star \star *} \\
(.0969) \\
\end{array}$ & $\begin{array}{c}-2.0423^{\star \star \star} \\
(.0995) \\
\end{array}$ & $\begin{array}{c}-3.3161^{* * *} \\
(.1616) \\
\end{array}$ \\
\hline Observations & 87,766 & 87,766 & 87,766 & 87,766 & 87,557 \\
\hline Wald $\chi^{2}(7)$ & 1003.78 & 1013.97 & 912.85 & 917.02 & 321.27 \\
\hline$p$ & $<.0001$ & $<.0001$ & $<.0001$ & $<.0001$ & $<.0001$ \\
\hline Pseudo $\mathrm{R}^{2}$ & .1303 & .1299 & .1403 & .1402 & .0983 \\
\hline
\end{tabular}

${ }^{\circ} \mathrm{p}<.10{ }^{*} \mathrm{p}<.05{ }^{* *} \mathrm{p}<.01{ }^{* \star *} \mathrm{p}<.001$ 
Table B-32. Logit of Christian Preference.

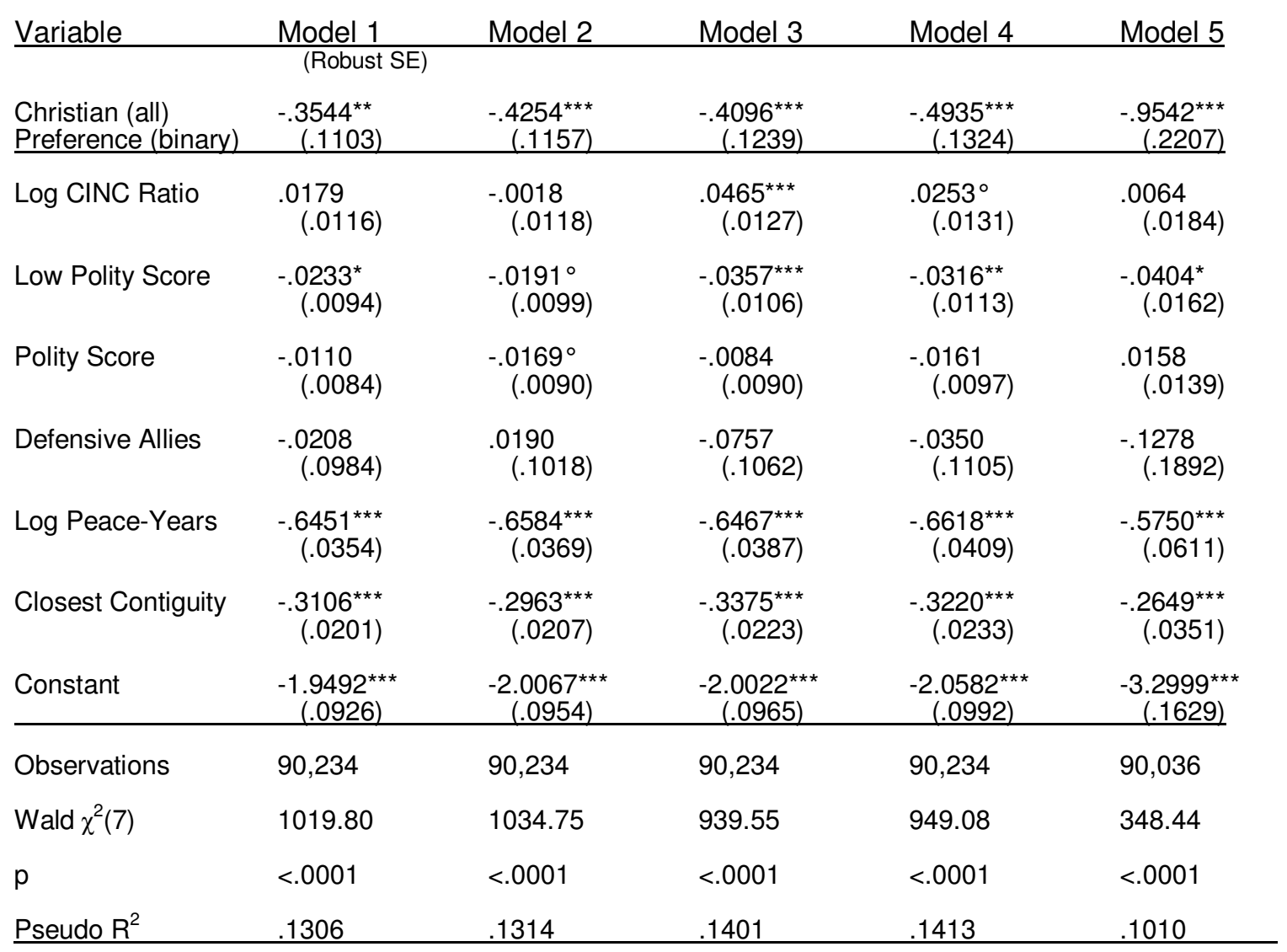

${ }^{\circ} p<.10 \quad{ }^{*} p<.05 \quad{ }^{* *} p<.01{ }^{* * *} p<.001$ 
Table B-33. Logit of Christian GRP Scale.

\begin{tabular}{|c|c|c|c|c|c|}
\hline Variable & Model 1 & Model 2 & Model 3 & Model 4 & Model 5 \\
\hline $\begin{array}{l}\text { Christian (all) } \\
\text { GRP (every 10\%) }\end{array}$ & $\begin{array}{r}-.0620^{* *} \\
(.0234) \\
\end{array}$ & $\begin{array}{r}-.0671^{\star *} \\
(.0246) \\
\end{array}$ & $\begin{array}{r}-.0781^{\star *} \\
(.0261) \\
\end{array}$ & $\begin{array}{r}-.0842^{* *} \\
(.0278) \\
\end{array}$ & $\begin{array}{r}-.2013^{* * *} \\
(.0480) \\
\end{array}$ \\
\hline Log CINC Ratio & $\begin{array}{l}.0172 \\
(.0116)\end{array}$ & $\begin{array}{l}-.0005 \\
(.0118)\end{array}$ & $\begin{array}{r}.0433^{* * *} \\
(.0128)\end{array}$ & $\begin{array}{l}.0247^{\circ} \\
(.0132)\end{array}$ & $\begin{array}{l}.0003 \\
(.0184)\end{array}$ \\
\hline Low Polity Score & $\begin{array}{l}-.0226^{\star} \\
(.0093)\end{array}$ & $\begin{array}{r}-.0189^{\circ} \\
(.0098)\end{array}$ & $\begin{array}{r}-.0345^{\star \star *} \\
(.0104)\end{array}$ & $\begin{array}{c}-.0309^{\star *} \\
(.0111)\end{array}$ & $\begin{array}{c}-.0417^{\star *} \\
(.0159)\end{array}$ \\
\hline Polity Score & $\begin{array}{l}-.0136 \\
(.0085)\end{array}$ & $\begin{array}{l}-.0214^{*} \\
(.0090)\end{array}$ & $\begin{array}{l}-.0104 \\
(.0090)\end{array}$ & $\begin{array}{l}-.0203^{\star} \\
(.0097)\end{array}$ & $\begin{array}{l}.0137 \\
(.0136)\end{array}$ \\
\hline Defensive Allies & $\begin{array}{l}.0030 \\
(.0977)\end{array}$ & $\begin{array}{l}.0441 \\
(.1011)\end{array}$ & $\begin{array}{l}-.0577 \\
(.1051)\end{array}$ & $\begin{array}{l}-.0158 \\
(.1093)\end{array}$ & $\begin{array}{l}-.1206^{\circ} \\
(.1854)\end{array}$ \\
\hline Log Peace-Years & $\begin{array}{r}-.6385^{\star \star \star} \\
(.0352)\end{array}$ & $\begin{array}{r}-.6542^{\star \star \star *} \\
(.0368)\end{array}$ & $\begin{array}{r}-.6356^{\star \star \star} \\
(.0384)\end{array}$ & $\begin{array}{r}-.6531^{* \star *} \\
(.0407)\end{array}$ & $\begin{array}{r}-.5618^{\star \star *} \\
(.0608)\end{array}$ \\
\hline Closest Contiguity & $\begin{array}{r}-.3113^{\star * \star *} \\
(.0202)\end{array}$ & $\begin{array}{r}-.2973^{* \star *} \\
(.0209)\end{array}$ & $\begin{array}{r}-.3409^{* \star \star *} \\
(.0223)\end{array}$ & $\begin{array}{r}-.3264^{\star * *} \\
(.0233)\end{array}$ & $\begin{array}{r}-.2746^{\star \star \star} \\
(.0352)\end{array}$ \\
\hline Constant & $\begin{array}{c}-1.9894^{\star * *} \\
(.0930) \\
\end{array}$ & $\begin{array}{c}-2.0437^{\star \star * *} \\
(.0959) \\
\end{array}$ & $\begin{array}{c}-2.0344^{* * *} \\
(.0962) \\
\end{array}$ & $\begin{array}{c}-2.0861^{\star * *} \\
(.0992) \\
\end{array}$ & $\begin{array}{c}-3.2971^{\star \star *} \\
(.1587) \\
\end{array}$ \\
\hline Observations & 92,277 & 92,277 & 92,277 & 92,277 & 92,077 \\
\hline Wald $\chi^{2}(7)$ & 1010.45 & 1015.43 & 936.89 & 933.77 & 336.18 \\
\hline$p$ & $<.0001$ & $<.0001$ & $<.0001$ & $<.0001$ & $<.0001$ \\
\hline Pseudo $\mathrm{R}^{2}$ & .1268 & .1275 & .1362 & .1374 & .0986 \\
\hline
\end{tabular}

${ }^{\circ} \mathrm{p}<.10{ }^{*} \mathrm{p}<.05{ }^{* *} \mathrm{p}<.01{ }^{* \star *} \mathrm{p}<.001$ 
Table B-34. Logit of Christian Prevalence.

\begin{tabular}{|c|c|c|c|c|c|}
\hline Variable & Model 1 & Model 2 & Model 3 & Model 4 & Model 5 \\
\hline $\begin{array}{l}\text { Christian (all) } \\
\text { Prevalence (binary) }\end{array}$ & $\begin{array}{r}-.2085^{\circ} \\
(.1121) \\
\end{array}$ & $\begin{array}{r}-.2082^{\circ} \\
(.1182) \\
\end{array}$ & $\begin{array}{r}-.2788^{*} \\
(.1250) \\
\end{array}$ & $\begin{array}{c}-.2907^{\star} \\
(.1338) \\
\end{array}$ & $\begin{array}{l}-.5973^{\star} \\
(.2329) \\
\end{array}$ \\
\hline Log CINC Ratio & $\begin{array}{l}.0135 \\
(.0120)\end{array}$ & $\begin{array}{l}-.0071 \\
(.0123)\end{array}$ & $\begin{array}{l}.0399^{* *} \\
(.0130)\end{array}$ & $\begin{array}{l}.0178 \\
(.0134)\end{array}$ & $\begin{array}{l}.0040 \\
(.0187)\end{array}$ \\
\hline Low Polity Score & $\begin{array}{r}-.0267^{\star *} \\
(.0094)\end{array}$ & $\begin{array}{l}-.0230^{*} \\
(.0098)\end{array}$ & $\begin{array}{r}-.0381^{\star * *} \\
(.0106)\end{array}$ & $\begin{array}{r}-.0342^{\star *} \\
(.0113)\end{array}$ & $\begin{array}{l}-.0407^{\star} \\
(.0162)\end{array}$ \\
\hline Polity Score & $\begin{array}{l}-.0152^{\circ} \\
(.0084)\end{array}$ & $\begin{array}{r}-.0237^{* *} \\
(.0090)\end{array}$ & $\begin{array}{l}-.0136 \\
(.0091)\end{array}$ & $\begin{array}{l}-.0243^{*} \\
(.0098)\end{array}$ & $\begin{array}{l}.0004 \\
(.0151)\end{array}$ \\
\hline Defensive Allies & $\begin{array}{l}-.0074 \\
(.1013)\end{array}$ & $\begin{array}{l}.0253 \\
(.1050)\end{array}$ & $\begin{array}{l}-.0724 \\
(.1095)\end{array}$ & $\begin{array}{l}-.0392 \\
(.1142)\end{array}$ & $\begin{array}{l}-.0690 \\
(.1937)\end{array}$ \\
\hline Log Peace-Years & $\begin{array}{r}-.6596^{\star \star \star} \\
(.0358)\end{array}$ & $\begin{array}{r}-.6738^{\star \star \star} \\
(.0374)\end{array}$ & $\begin{array}{r}-.6632^{\star \star \star} \\
(.0389)\end{array}$ & $\begin{array}{r}-.6791^{\star \star *} \\
(.0410)\end{array}$ & $\begin{array}{r}-.5982^{\star * *} \\
(.0618)\end{array}$ \\
\hline Closest Contiguity & $\begin{array}{r}-.3111^{* * *} \\
(.0207)\end{array}$ & $\begin{array}{r}-.2966^{\star \star *} \\
(.0214)\end{array}$ & $\begin{array}{r}-.3350^{\star \star \star \star} \\
(.0228)\end{array}$ & $\begin{array}{r}-.3194^{* * *} \\
(.0238)\end{array}$ & $\begin{array}{r}-.2545^{\star * *} \\
(.0358)\end{array}$ \\
\hline Constant & $\begin{array}{c}-1.9140^{* * *} \\
(.0954)\end{array}$ & $\begin{array}{c}-1.9701^{* * *} \\
(.0980) \\
\end{array}$ & $\begin{array}{c}-1.9514^{\star \star *} \\
(.0987) \\
\end{array}$ & $\begin{array}{c}-2.0043^{* * *} \\
(.1012) \\
\end{array}$ & $\begin{array}{c}-3.2807^{* * *} \\
(.1658)\end{array}$ \\
\hline Observations & 86,651 & 86,651 & 86,651 & 86,651 & 86,452 \\
\hline Wald $\chi^{2}(7)$ & 973.38 & 984.82 & 900.01 & 908.03 & 319.92 \\
\hline$p$ & $<.0001$ & $<.0001$ & $<.0001$ & $<.0001$ & $<.0001$ \\
\hline Pseudo $R^{2}$ & .1323 & .1326 & .1414 & .1423 & .0962 \\
\hline
\end{tabular}

${ }^{\circ} p<.10{ }^{*} p<.05{ }^{* *} p<.01{ }^{* * *} p<.001$ 
Table B-35. Logit of Christian Population.

\begin{tabular}{|c|c|c|c|c|c|}
\hline Variable & Model 1 & Model 2 & Model 3 & Model 4 & Model 5 \\
\hline & (Robust SE) & & & & \\
\hline $\begin{array}{l}\text { Christian (all) } \\
\text { Pop. (every 10\%) }\end{array}$ & $\begin{array}{r}-.0341^{* *} \\
(.0132) \\
\end{array}$ & $\begin{array}{c}-.0342^{*} \\
(.0140) \\
\end{array}$ & $\begin{array}{r}-.0459^{* *} \\
(.0148) \\
\end{array}$ & $\begin{array}{r}-.0478^{* *} \\
(.0158) \\
\end{array}$ & $\begin{array}{r}-.0814^{* *} \\
(.0265) \\
\end{array}$ \\
\hline Log CINC Ratio & $\begin{array}{l}.0218^{\circ} \\
(.0112)\end{array}$ & $\begin{array}{l}.0035 \\
(.0114)\end{array}$ & $\begin{array}{r}.0489^{* * *} \\
(.0122)\end{array}$ & $\begin{array}{l}.0292^{*} \\
(.0126)\end{array}$ & $\begin{array}{l}.0113 \\
(.0177)\end{array}$ \\
\hline Low Polity Score & $\begin{array}{r}-.0243^{* *} \\
(.0093)\end{array}$ & $\begin{array}{c}-.0212^{*} \\
(.0097)\end{array}$ & $\begin{array}{r}-.0358^{* * *} \\
(.0105)\end{array}$ & $\begin{array}{r}-.0329^{* *} \\
(.0111)\end{array}$ & $\begin{array}{c}-.0423^{* *} \\
(.0158)\end{array}$ \\
\hline Polity Score & $\begin{array}{r}-.0142^{\circ} \\
(.0080)\end{array}$ & $\begin{array}{r}-.0224^{* *} \\
(.0086)\end{array}$ & $\begin{array}{l}-.0108 \\
(.0086)\end{array}$ & $\begin{array}{c}-.0208^{*} \\
(.0093)\end{array}$ & $\begin{array}{l}.0051 \\
(.0137)\end{array}$ \\
\hline Defensive Allies & $\begin{array}{l}-.0169 \\
(.0958)\end{array}$ & $\begin{array}{l}.0196 \\
(.0991)\end{array}$ & $\begin{array}{r}-.0639 \\
(.1037)\end{array}$ & $\begin{array}{c}-.0251 \\
(.1079)\end{array}$ & $\begin{array}{l}-.1164 \\
\quad(.1849)\end{array}$ \\
\hline Log Peace-Years & $\begin{array}{r}-.6458^{* * *} \\
(.0341)\end{array}$ & $\begin{array}{r}-.6593^{\star \star \star} \\
(.0356)\end{array}$ & $\begin{array}{r}-.6423^{* \star *} \\
(.0371)\end{array}$ & $\begin{array}{r}-.6568^{\star \star \star} \\
(.0391)\end{array}$ & $\begin{array}{r}-.5598^{\star \star \star} \\
(.0591)\end{array}$ \\
\hline Closest Contiguity & $\begin{array}{r}-.3150^{\star * *} \\
(.0195)\end{array}$ & $\begin{array}{r}-.3012^{* * *} \\
(.0201)\end{array}$ & $\begin{array}{r}-.3423^{* * *} \\
(.0216)\end{array}$ & $\begin{array}{r}-.3276^{* * *} \\
(.0226)\end{array}$ & $\begin{array}{r}-.2731^{* * *} \\
(.0345)\end{array}$ \\
\hline Constant & $\begin{array}{c}-1.9262^{* * *} \\
(.0901)\end{array}$ & $\begin{array}{c}-1.9821^{* * *} \\
(.0928) \\
\end{array}$ & $\begin{array}{c}-1.9707^{* * *} \\
(.0935) \\
\end{array}$ & $\begin{array}{c}-2.0231^{* * *} \\
(.0962) \\
\end{array}$ & $\begin{array}{c}-3.2634^{* * *} \\
(.1517) \\
\end{array}$ \\
\hline Observations & 95,418 & 95,418 & 95,418 & 95,418 & 95,197 \\
\hline Wald $\chi^{2}(7)$ & 1071.02 & 1072.62 & 985.73 & 981.56 & 346.43 \\
\hline$p$ & $<.0001$ & $<.0001$ & $<.0001$ & $<.0001$ & $<.0001$ \\
\hline Pseudo $\mathrm{R}^{2}$ & .1309 & .1307 & .1404 & .1405 & .0942 \\
\hline
\end{tabular}

${ }^{\circ} p<.10{ }^{*} p<.05{ }^{* *} p<.01{ }^{* * *} p<.001$ 
Table B-36. Logit of Muslim Chief Executive.

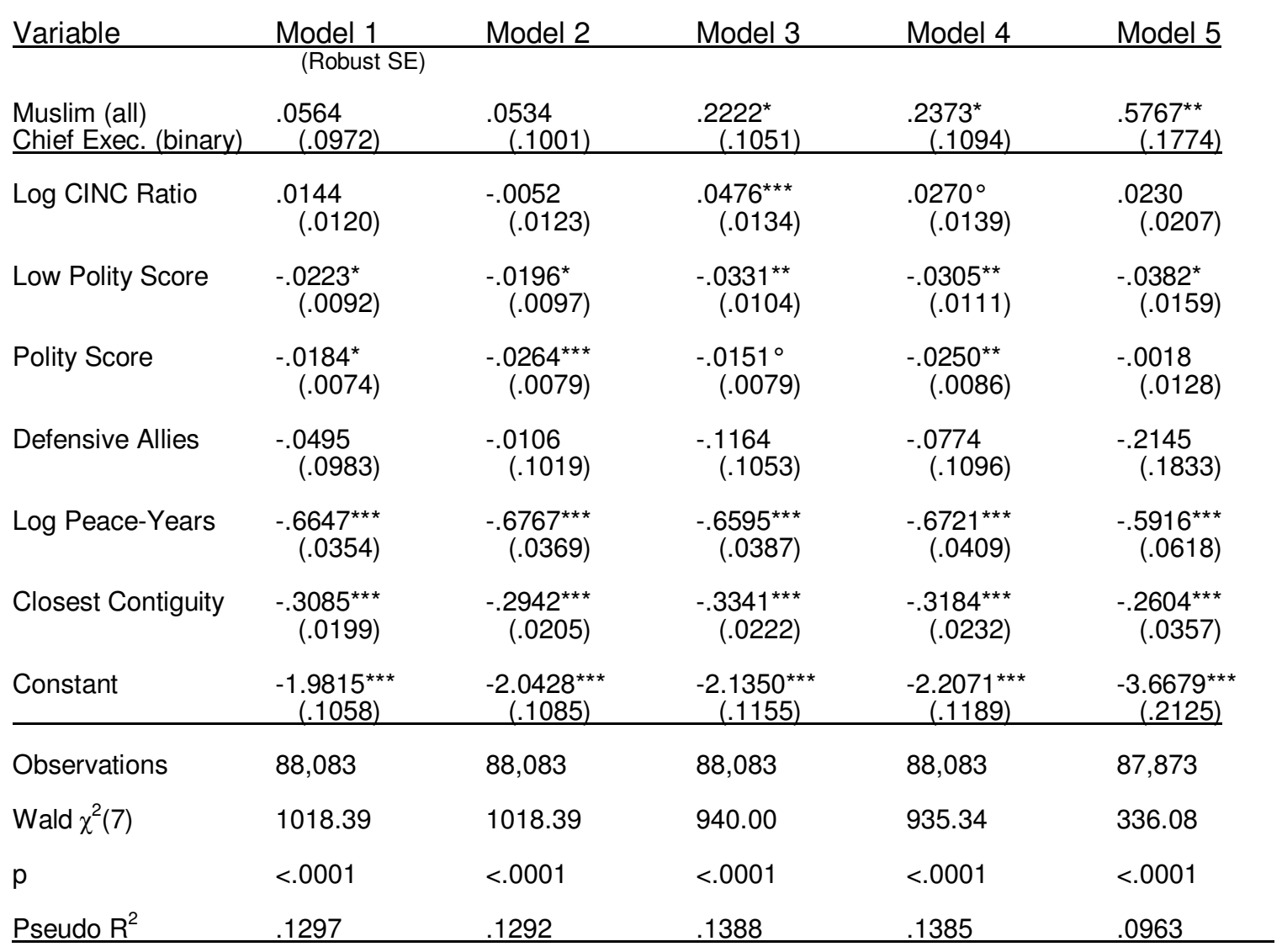

${ }^{\circ} p<.10{ }^{*} p<.05{ }^{* *} p<.01{ }^{* * *} p<.001$ 
Table B-37. Logit of Muslim Preference.

\begin{tabular}{|c|c|c|c|c|c|}
\hline Variable & Model 1 & Model 2 & Model 3 & Model 4 & Model 5 \\
\hline & (Robust SE) & & & & \\
\hline $\begin{array}{l}\text { Muslim (all) } \\
\text { Preference (binary) }\end{array}$ & $\begin{array}{l}.0167 \\
(.0992) \\
\end{array}$ & $\begin{array}{r}.0120 \\
(.1022) \\
\end{array}$ & $\begin{array}{r}.1862^{\circ} \\
(.1070) \\
\end{array}$ & $\begin{array}{c}.1990^{\circ} \\
(.1112) \\
\end{array}$ & $\begin{array}{l}.5423^{* *} \\
(.1759) \\
\end{array}$ \\
\hline Log CINC Ratio & $\begin{array}{l}.0209^{\circ} \\
(.0119)\end{array}$ & $\begin{array}{l}.0021 \\
(.0122)\end{array}$ & $\begin{array}{r}.0533^{\star * *} \\
(.0133)\end{array}$ & $\begin{array}{l}.0337^{\star} \\
(.0138)\end{array}$ & $\begin{array}{l}.0240 \\
(.0201)\end{array}$ \\
\hline Low Polity Score & $\begin{array}{r}-.0253^{\star *} \\
(.0093)\end{array}$ & $\begin{array}{l}-.0224^{*} \\
(.0098)\end{array}$ & $\begin{array}{r}-.0363^{\star * *} \\
(.0105)\end{array}$ & $\begin{array}{r}-.0335^{\star *} \\
(.0112)\end{array}$ & $\begin{array}{r}-.0414^{\star *} \\
(.0159)\end{array}$ \\
\hline Polity Score & $\begin{array}{r}-.0232^{\star *} \\
(.0076)\end{array}$ & $\begin{array}{r}-.0313^{* * *} \\
(.0081)\end{array}$ & $\begin{array}{l}-.0203^{*} \\
(.0081)\end{array}$ & $\begin{array}{r}-.0304^{\star * *} \\
(.0087)\end{array}$ & $\begin{array}{l}-.0086 \\
(.0128)\end{array}$ \\
\hline Defensive Allies & $\begin{array}{l}-.0569 \\
(.0991)\end{array}$ & $\begin{array}{l}-.0169 \\
(.1027)\end{array}$ & $\begin{array}{l}-.1308 \\
(.1061)\end{array}$ & $\begin{array}{l}-.0912 \\
(.1105)\end{array}$ & $\begin{array}{c}-.2613 \\
(.1830)\end{array}$ \\
\hline Log Peace-Years & $\begin{array}{r}-.6525^{\star * *} \\
(.0354)\end{array}$ & $\begin{array}{r}-.6683^{* * *} \\
(.0369)\end{array}$ & $\begin{array}{r}-.6502^{* * *} \\
(.0388)\end{array}$ & $\begin{array}{r}-.6676^{\star * *} \\
(.0410)\end{array}$ & $\begin{array}{r}-.5824^{* * *} \\
(.0614)\end{array}$ \\
\hline Closest Contiguity & $\begin{array}{r}-.3116^{* * *} \\
(.0200)\end{array}$ & $\begin{array}{r}-.2961^{* * *} \\
(.0206)\end{array}$ & $\begin{array}{r}-.3361^{* * *} \\
(.0222)\end{array}$ & $\begin{array}{r}-.3188^{\star * *} \\
(.0232)\end{array}$ & $\begin{array}{r}-.2610^{* * *} \\
(.0349)\end{array}$ \\
\hline Constant & $\begin{array}{c}-1.9643^{\star * *} \\
(.1064) \\
\end{array}$ & $\begin{array}{c}-2.0238^{\star * *} \\
(.1092) \\
\end{array}$ & $\begin{array}{c}-2.1067^{* * *} \\
(.1160) \\
\end{array}$ & $\begin{array}{c}-2.1750^{\star * *} \\
(.1196) \\
\end{array}$ & $\begin{array}{c}-3.5853^{* * *} \\
(.2112) \\
\end{array}$ \\
\hline Observations & 91,036 & 91,036 & 91,036 & 91,036 & 90,838 \\
\hline Wald $\chi^{2}(7)$ & 1017.68 & 1022.46 & 950.72 & 951.92 & 350.63 \\
\hline$p$ & $<.0001$ & $<.0001$ & $<.0001$ & $<.0001$ & $<.0001$ \\
\hline${\text { Pseudo } \mathrm{R}^{2}}^{2}$ & .1289 & .1289 & .1384 & .1388 & .0961 \\
\hline
\end{tabular}

${ }^{\circ} \mathrm{p}<.10{ }^{*} \mathrm{p}<.05{ }^{* *} \mathrm{p}<.01{ }^{* \star *} \mathrm{p}<.001$ 
Table B-38. Logit of Muslim GRP Scale.

\begin{tabular}{|c|c|c|c|c|c|}
\hline Variable & $\begin{array}{l}\text { Model } 1 \\
\text { (Robust SE) }\end{array}$ & Model 2 & Model 3 & Model 4 & Model 5 \\
\hline $\begin{array}{l}\text { Muslim (all) } \\
\text { GRP (every 10\%) }\end{array}$ & $\begin{array}{l}.0100 \\
(.0134) \\
\end{array}$ & $\begin{array}{c}.0103 \\
(.0138) \\
\end{array}$ & $\begin{array}{r}.0318^{*} \\
(.0142) \\
\end{array}$ & $\begin{array}{l}.0344^{*} \\
(.0147) \\
\end{array}$ & $\begin{array}{r}.0632^{\star *} \\
(.0222) \\
\end{array}$ \\
\hline Log CINC Ratio & $\begin{array}{l}.0226^{\circ} \\
(.0119)\end{array}$ & $\begin{array}{l}.0054 \\
(.0121)\end{array}$ & $\begin{array}{r}.0528^{* * *} \\
(.0132)\end{array}$ & $\begin{array}{l}.0350^{*} \\
(.0136)\end{array}$ & $\begin{array}{l}.0202 \\
(.0194)\end{array}$ \\
\hline Low Polity Score & $\begin{array}{l}-.0238^{*} \\
(.0093)\end{array}$ & $\begin{array}{l}-.0202^{\star} \\
(.0098)\end{array}$ & $\begin{array}{r}-.0344^{\star *} \\
(.0105)\end{array}$ & $\begin{array}{r}-.0307^{\star *} \\
(.0111)\end{array}$ & $\begin{array}{r}-.0426^{\star *} \\
(.0156)\end{array}$ \\
\hline Polity Score & $\begin{array}{r}-.0217^{* *} \\
(.0077)\end{array}$ & $\begin{array}{r}-.0301^{* * *} \\
(.0083)\end{array}$ & $\begin{array}{l}-.0185^{*} \\
(.0082)\end{array}$ & $\begin{array}{r}-.0290^{\star *} \\
(.0089)\end{array}$ & $\begin{array}{r}-.0073 \\
(.0129)\end{array}$ \\
\hline Defensive Allies & $\begin{array}{l}-.0251 \\
(.0990)\end{array}$ & $\begin{array}{l}.0138 \\
(.1025)\end{array}$ & $\begin{array}{l}-.1049 \\
(.1058)\end{array}$ & $\begin{array}{l}-.0675 \\
(.1101)\end{array}$ & $\begin{array}{l}-.2354 \\
(.1813)\end{array}$ \\
\hline Log Peace-Years & $\begin{array}{r}-.6432^{* * *} \\
(.0356)\end{array}$ & $\begin{array}{r}-.6594^{* * *} \\
(.0372)\end{array}$ & $\begin{array}{r}-.6368^{* * *} \\
(.0388)\end{array}$ & $\begin{array}{r}-.6543^{* * *} \\
(.0412)\end{array}$ & $\begin{array}{r}-.5678^{\star \star *} \\
(.0615)\end{array}$ \\
\hline Closest Contiguity & $\begin{array}{r}-.3088^{\star * *} \\
(.0200)\end{array}$ & $\begin{array}{r}-.2947^{\star * *} \\
(.0207)\end{array}$ & $\begin{array}{r}-.3361^{* * *} \\
(.0222)\end{array}$ & $\begin{array}{r}-.3213^{* * *} \\
(.0233)\end{array}$ & $\begin{array}{r}-.2676^{* * *} \\
(.0352)\end{array}$ \\
\hline Constant & $\begin{array}{c}-2.0463^{\star * *} \\
(.1057)\end{array}$ & $\begin{array}{c}-2.1029^{\star \star *} \\
(.1087) \\
\end{array}$ & $\begin{array}{c}-2.1815^{\star \star *} \\
(.1143) \\
\end{array}$ & $\begin{array}{c}-2.2455^{\star * *} \\
(.1181) \\
\end{array}$ & $\begin{array}{c}-3.5774^{* \star *} \\
(.1993) \\
\end{array}$ \\
\hline Observations & 92,277 & 92,277 & 92,277 & 92,277 & 92,077 \\
\hline Wald $\chi^{2}(7)$ & 1001.90 & 1006.82 & 939.26 & 940.79 & 335.76 \\
\hline $\mathrm{p}$ & $<.0001$ & $<.0001$ & $<.0001$ & $<.0001$ & $<.0001$ \\
\hline Pseudo $\mathrm{R}^{2}$ & .1257 & .1262 & .1352 & .1363 & .0922 \\
\hline
\end{tabular}

${ }^{\circ} \mathrm{p}<.10{ }^{*} \mathrm{p}<.05{ }^{* *} \mathrm{p}<.01{ }^{* \star *} \mathrm{p}<.001$ 
Table B-39. Logit of Muslim Prevalence.

\begin{tabular}{|c|c|c|c|c|c|}
\hline Variable & Model 1 & Model 2 & Model 3 & Model 4 & Model 5 \\
\hline $\begin{array}{l}\text { Muslim (all) } \\
\text { Prevalence (binary) }\end{array}$ & $\begin{array}{r}.0738 \\
(.0993) \\
\end{array}$ & $\begin{array}{r}.0625 \\
(.1022) \\
\end{array}$ & $\begin{array}{r}.2540^{*} \\
(.1067) \\
\end{array}$ & $\begin{array}{r}.2593^{*} \\
(.1108) \\
\end{array}$ & $\begin{array}{r}.5368^{* *} \\
(.1782) \\
\end{array}$ \\
\hline Log CINC Ratio & $\begin{array}{r}.0191 \\
(.0119)\end{array}$ & $\begin{array}{l}.0002 \\
(.0122)\end{array}$ & $\begin{array}{r}.0494^{\star * *} \\
(.0132)\end{array}$ & $\begin{array}{l}.0296^{*} \\
(.0137)\end{array}$ & $\begin{array}{l}.0183 \\
(.0198)\end{array}$ \\
\hline Low Polity Score & $\begin{array}{c}-.0276^{* *} \\
(.0093)\end{array}$ & $\begin{array}{l}-.0247^{*} \\
(.0098)\end{array}$ & $\begin{array}{r}-.0380^{* * *} \\
(.0105)\end{array}$ & $\begin{array}{l}-.0352^{* *} \\
(.0111)\end{array}$ & $\begin{array}{l}-.0439^{* *} \\
(.0158)\end{array}$ \\
\hline Polity Score & $\begin{array}{l}-.0220^{\star *} \\
(.0075)\end{array}$ & $\begin{array}{r}-.0304^{\star * *} \\
(.0080)\end{array}$ & $\begin{array}{l}-.0193^{*} \\
(.0080)\end{array}$ & $\begin{array}{r}-.0296^{\star \star *} \\
(.0087)\end{array}$ & $\begin{array}{l}-.0081 \\
(.0128)\end{array}$ \\
\hline Defensive Allies & $\begin{array}{l}-.0537 \\
(.0987)\end{array}$ & $\begin{array}{l}-.0127 \\
(.1022)\end{array}$ & $\begin{array}{l}-.1399 \\
(.1054)\end{array}$ & $\begin{array}{l}-.1004 \\
(.1097)\end{array}$ & $\begin{array}{l}-.2461 \\
(.1816)\end{array}$ \\
\hline Log Peace-Years & $\begin{array}{r}-.6528^{* * *} \\
(.0348)\end{array}$ & $\begin{array}{r}-.6698^{* * *} \\
(.0363)\end{array}$ & $\begin{array}{r}-.6455^{\star * *} \\
(.0378)\end{array}$ & $\begin{array}{r}-.6638^{* * *} \\
(.0399)\end{array}$ & $\begin{array}{r}-.5760^{* * *} \\
(.0594)\end{array}$ \\
\hline Closest Contiguity & $\begin{array}{r}-.3127^{\star \star *} \\
(.0200)\end{array}$ & $\begin{array}{r}-.2972^{\star * *} \\
(.0207)\end{array}$ & $\begin{array}{r}-.3372^{\star \star *} \\
(.0222)\end{array}$ & $\begin{array}{r}-.3204^{\star \star *} \\
(.0231)\end{array}$ & $\begin{array}{r}-.2591^{\star * *} \\
(.0352)\end{array}$ \\
\hline Constant & $\begin{array}{c}-1.9570^{* * *} \\
(.1053) \\
\end{array}$ & $\begin{array}{c}-2.0090^{* * *} \\
(.1080)\end{array}$ & $\begin{array}{c}-2.1007^{* * *} \\
(.1141) \\
\end{array}$ & $\begin{array}{c}-2.1600^{* * *} \\
(.1176) \\
\end{array}$ & $\begin{array}{c}-3.5707^{* * *} \\
(.2069) \\
\end{array}$ \\
\hline Observations & 90,441 & 90,441 & 90,441 & 90,441 & 90,233 \\
\hline Wald $\chi^{2}(7)$ & 1043.36 & 1048.90 & 975.80 & 979.38 & 350.16 \\
\hline $\mathrm{p}$ & $<.0001$ & $<.0001$ & $<.0001$ & $<.0001$ & $<.0001$ \\
\hline Pseudo $\mathrm{R}^{2}$ & .1319 & .1323 & .1410 & .1419 & .0957 \\
\hline
\end{tabular}

${ }^{\circ} \mathrm{p}<.10{ }^{*} \mathrm{p}<.05{ }^{* *} \mathrm{p}<.01{ }^{* \star *} \mathrm{p}<.001$ 
Table B-40. Logit of Muslim Population.

\begin{tabular}{|c|c|c|c|c|c|}
\hline Variable & Model 1 & Model 2 & Model 3 & Model 4 & Model 5 \\
\hline & (Robust SE) & & & & \\
\hline $\begin{array}{l}\text { Muslim (all) } \\
\text { Pop. (every 10\%) }\end{array}$ & $\begin{array}{l}.0142 \\
(.0115) \\
\end{array}$ & $\begin{array}{r}.0127 \\
(.0119) \\
\end{array}$ & $\begin{array}{r}.0346^{* *} \\
(.0125) \\
\end{array}$ & $\begin{array}{r}.0349^{\star *} \\
(.0130) \\
\end{array}$ & $\begin{array}{r}.0696^{* * *} \\
(.0206) \\
\end{array}$ \\
\hline Log CINC Ratio & $\begin{array}{l}.0246^{\star} \\
(.0118)\end{array}$ & $\begin{array}{l}.0061 \\
(.0120)\end{array}$ & $\begin{array}{r}.0564^{\star * *} \\
(.0131)\end{array}$ & $\begin{array}{l}.0368^{\star *} \\
(.0136)\end{array}$ & $\begin{array}{l}.0258 \\
(.0198)\end{array}$ \\
\hline Low Polity Score & $\begin{array}{r}-.0253^{\star *} \\
(.0093)\end{array}$ & $\begin{array}{l}-.0224^{*} \\
(.0097)\end{array}$ & $\begin{array}{r}-.0357^{\star * *} \\
(.0104)\end{array}$ & $\begin{array}{r}-.0329^{\star *} \\
(.0111)\end{array}$ & $\begin{array}{r}-.0408^{\star *} \\
(.0157)\end{array}$ \\
\hline Polity Score & $\begin{array}{r}-.0203^{\star *} \\
(.0075)\end{array}$ & $\begin{array}{r}-.0286^{* * *} \\
(.0080)\end{array}$ & $\begin{array}{l}-.0168^{*} \\
(.0080)\end{array}$ & $\begin{array}{r}-.0270^{\star *} \\
(.0087)\end{array}$ & $\begin{array}{l}-.0036 \\
(.0129)\end{array}$ \\
\hline Defensive Allies & $\begin{array}{l}-.0665 \\
(.0967)\end{array}$ & $\begin{array}{l}-.0289 \\
(.1001)\end{array}$ & $\begin{array}{l}-.1397 \\
(.1034)\end{array}$ & $\begin{array}{l}-.1029 \\
(.1076)\end{array}$ & $\begin{array}{l}-.2547 \\
(.1788)\end{array}$ \\
\hline Log Peace-Years & $\begin{array}{r}-.6502^{* * *} \\
(.0343)\end{array}$ & $\begin{array}{r}-.6642^{* * *} \\
(.0357)\end{array}$ & $\begin{array}{r}-.6440^{\star * *} \\
(.0374)\end{array}$ & $\begin{array}{r}-.6589^{* * *} \\
(.0394)\end{array}$ & $\begin{array}{r}-.5598^{* * *} \\
(.0595)\end{array}$ \\
\hline Closest Contiguity & $\begin{array}{r}-.3143^{* * *} \\
(.0194)\end{array}$ & $\begin{array}{r}-.3006^{* * *} \\
(.0200)\end{array}$ & $\begin{array}{r}-.3395^{\star * *} \\
(.0217)\end{array}$ & $\begin{array}{r}-.3246^{\star * *} \\
(.0226)\end{array}$ & $\begin{array}{r}-.2674^{\star * *} \\
(.0347)\end{array}$ \\
\hline Constant & $\begin{array}{c}-2.0320^{* * *} \\
(.1080) \\
\end{array}$ & $\begin{array}{c}-2.0809^{* * *} \\
(.1105) \\
\end{array}$ & $\begin{array}{c}-2.1958^{\star * *} \\
(.1184) \\
\end{array}$ & $\begin{array}{c}-2.2533^{* * *} \\
(.1218) \\
\end{array}$ & $\begin{array}{c}-3.7193^{* * *} \\
(.2153) \\
\end{array}$ \\
\hline Observations & 95,418 & 95,418 & 95,418 & 95,418 & 95,197 \\
\hline Wald $\chi^{2}(7)$ & 1066.68 & 1068.16 & 991.49 & 989.01 & 356.67 \\
\hline$p$ & $<.0001$ & $<.0001$ & $<.0001$ & $<.0001$ & $<.0001$ \\
\hline${\text { Pseudo } \mathrm{R}^{2}}^{2}$ & .1302 & .1299 & . 1399 & .1400 & .0942 \\
\hline
\end{tabular}

${ }^{\circ} \mathrm{p}<.10{ }^{*} \mathrm{p}<.05{ }^{* *} \mathrm{p}<.01{ }^{* \star *} \mathrm{p}<.001$ 
Table B-41. Logit of Buddhist Mix Chief Executive.

\begin{tabular}{|c|c|c|c|c|c|}
\hline Variable & Model 1 & Model 2 & Model 3 & Model 4 & Model 5 \\
\hline $\begin{array}{l}\text { Buddhist Mix } \\
\text { Chief Exec. (binary) }\end{array}$ & $\begin{array}{r}-.0652 \\
(.2258) \\
\end{array}$ & $\begin{array}{r}-.0343 \\
(.2320) \\
\end{array}$ & $\begin{array}{l}-.2702 \\
(.2751) \\
\end{array}$ & $\begin{array}{c}-.2417 \\
(.2863) \\
\end{array}$ & $\begin{array}{c}-.8603 \dagger \\
(.5848) \\
\end{array}$ \\
\hline Log CINC Ratio & $\begin{array}{l}.0128 \\
(.0115)\end{array}$ & $\begin{array}{l}-.0066 \\
(.0118)\end{array}$ & $\begin{array}{l}.0404^{* *} \\
(.0127)\end{array}$ & $\begin{array}{l}.0195 \\
(.0131)\end{array}$ & $\begin{array}{l}.0041 \\
(.0188)\end{array}$ \\
\hline Low Polity Score & $\begin{array}{l}-.0229^{\star} \\
(.0091)\end{array}$ & $\begin{array}{l}-.0201^{*} \\
(.0096)\end{array}$ & $\begin{array}{r}-.0354^{* * *} \\
(.0103)\end{array}$ & $\begin{array}{r}-.0332^{\star *} \\
(.0110)\end{array}$ & $\begin{array}{c}-.0437^{\star *} \\
(.0156)\end{array}$ \\
\hline Polity Score & $\begin{array}{r}-.0191^{\star *} \\
(.0073)\end{array}$ & $\begin{array}{r}-.0271^{\star * *} \\
(.0078)\end{array}$ & $\begin{array}{l}-.0177^{*} \\
(.0077)\end{array}$ & $\begin{array}{r}-.0279^{\star \star *} \\
(.0083)\end{array}$ & $\begin{array}{l}-.0096 \\
(.0121)\end{array}$ \\
\hline Defensive Allies & $\begin{array}{l}-.0492 \\
(.0985)\end{array}$ & $\begin{array}{l}-.0091 \\
(.1021)\end{array}$ & $\begin{array}{c}-.1130 \\
(.1058)\end{array}$ & $\begin{array}{l}-.0716 \\
(.1102)\end{array}$ & $\begin{array}{l}-.2128 \\
(.1860)\end{array}$ \\
\hline Log Peace-Years & $\begin{array}{r}-.6665^{\star * *} \\
(.0349)\end{array}$ & $\begin{array}{r}-.6785^{\star * *} \\
(.0364)\end{array}$ & $\begin{array}{r}-.6670^{\star * *} \\
(.0382)\end{array}$ & $\begin{array}{r}-.6802^{* * *} \\
(.0404)\end{array}$ & $\begin{array}{r}-.6104^{* * *} \\
(.0600)\end{array}$ \\
\hline Closest Contiguity & $\begin{array}{r}-.3093^{* * *} \\
(.0200)\end{array}$ & $\begin{array}{r}-.2949^{* * *} \\
(.0206)\end{array}$ & $\begin{array}{r}-.3378^{\star \star *} \\
(.0222)\end{array}$ & $\begin{array}{r}-.3223^{* * *} \\
(.0232)\end{array}$ & $\begin{array}{r}-.2719^{* \star *} \\
(.0355)\end{array}$ \\
\hline Constant & $\begin{array}{c}-1.9481^{* * *} \\
(.0905) \\
\end{array}$ & $\begin{array}{c}-2.0122^{* * *} \\
(.0932) \\
\end{array}$ & $\begin{array}{c}-1.9997^{\star * *} \\
(.0947) \\
\end{array}$ & $\begin{array}{c}-2.0626^{\star * *} \\
(.0975) \\
\end{array}$ & $\begin{array}{c}-3.2873^{\star * \star} \\
(.1561) \\
\end{array}$ \\
\hline Observations & 88,083 & 88,083 & 88,083 & 88,083 & 87,873 \\
\hline Wald $\chi^{2}(7)$ & 1017.94 & 1017.47 & 925.02 & 919.04 & 294.25 \\
\hline $\mathrm{p}$ & $<.0001$ & $<.0001$ & $<.0001$ & $<.0001$ & $<.0001$ \\
\hline Pseudo $R^{2}$ & .1297 & .1291 & .1383 & .1378 & .0929 \\
\hline
\end{tabular}

${ }^{\circ} p<.10{ }^{*} p<.05 \quad{ }^{* *} p<.01{ }^{* * *} p<.001$

$\dagger p<.15$ 
Table B-42. Logit of Buddhist Mix Preference.

\begin{tabular}{|c|c|c|c|c|c|}
\hline Variable & Model 1 & Model 2 & Model 3 & Model 4 & Model 5 \\
\hline & (Robust SE) & & & & \\
\hline $\begin{array}{l}\text { Buddhist Mix } \\
\text { Preference (binary) }\end{array}$ & $\begin{array}{c}.2538 \dagger \\
(.1764) \\
\end{array}$ & $\begin{array}{l}.3005^{\circ} \\
(.1794) \\
\end{array}$ & $\begin{array}{l}.1272 \\
(.2062) \\
\end{array}$ & $\begin{array}{l}.1850 \\
(.2108) \\
\end{array}$ & $\begin{array}{l}-.4460 \\
(.4197) \\
\end{array}$ \\
\hline Log CINC Ratio & $\begin{array}{l}.0250^{*} \\
(.0115)\end{array}$ & $\begin{array}{l}.0071 \\
(.0118)\end{array}$ & $\begin{array}{r}.0521^{* * *} \\
(.0126)\end{array}$ & $\begin{array}{l}.0331^{*} \\
(.0130)\end{array}$ & $\begin{array}{l}.0094 \\
(.0183)\end{array}$ \\
\hline Low Polity Score & $\begin{array}{l}-.0249^{* *} \\
(.0092)\end{array}$ & $\begin{array}{l}-.0219^{\star} \\
(.0097)\end{array}$ & $\begin{array}{r}-.0377^{\star \star *} \\
(.0104)\end{array}$ & $\begin{array}{l}-.0351^{* *} \\
(.0110)\end{array}$ & $\begin{array}{r}-.0478^{* *} \\
(.0154)\end{array}$ \\
\hline Polity Score & $\begin{array}{l}-.0231^{\star *} \\
(.0075)\end{array}$ & $\begin{array}{r}-.0312^{\star * *} \\
(.0080)\end{array}$ & $\begin{array}{l}-.0218^{\star *} \\
(.0079)\end{array}$ & $\begin{array}{r}-.0321^{* * *} \\
(.0085)\end{array}$ & $\begin{array}{l}-.0131 \\
(.0121)\end{array}$ \\
\hline Defensive Allies & $\begin{array}{l}-.0342 \\
(.0985)\end{array}$ & $\begin{array}{l}.0068 \\
(.1021)\end{array}$ & $\begin{array}{l}-.0990 \\
(.1057)\end{array}$ & $\begin{array}{l}-.0562 \\
(.1101)\end{array}$ & $\begin{array}{l}-.2263 \\
(.1835)\end{array}$ \\
\hline Log Peace-Years & $\begin{array}{r}-.6472^{* * *} \\
(.0348)\end{array}$ & $\begin{array}{r}-.6618^{* * *} \\
(.0362)\end{array}$ & $\begin{array}{r}-.6487^{\star * *} \\
(.0381)\end{array}$ & $\begin{array}{r}-.6652^{* * *} \\
(.0402)\end{array}$ & $\begin{array}{r}-.5857^{* * *} \\
(.0597)\end{array}$ \\
\hline Closest Contiguity & $\begin{array}{r}-.3142^{\star \star *} \\
(.0200)\end{array}$ & $\begin{array}{r}-.2992^{\star * \star} \\
(.0206)\end{array}$ & $\begin{array}{r}-.3414^{\star \star *} \\
(.0221)\end{array}$ & $\begin{array}{r}-.3251^{\star \star *} \\
(.0231)\end{array}$ & $\begin{array}{r}-.2764^{\star \star *} \\
(.0347)\end{array}$ \\
\hline Constant & $\begin{array}{c}-1.9985^{\star \star \star} \\
(.0910) \\
\end{array}$ & $\begin{array}{c}-2.0605^{\star \star \star} \\
(.0937) \\
\end{array}$ & $\begin{array}{c}-2.0481^{* * *} \\
(.0949) \\
\end{array}$ & $\begin{array}{c}-2.1093^{\star \star \star} \\
(.0977) \\
\end{array}$ & $\begin{array}{c}-3.2935^{\star \star *} \\
(.1545) \\
\end{array}$ \\
\hline Observations & 93,210 & 93,210 & 93,210 & 93,210 & 93,007 \\
\hline Wald $\chi^{2}(7)$ & 1026.25 & 1030.90 & 939.00 & 937.51 & 302.34 \\
\hline$p$ & $<.0001$ & $<.0001$ & $<.0001$ & $<.0001$ & $<.0001$ \\
\hline Pseudo $\mathrm{R}^{2}$ & .1283 & .1283 & .1367 & .1370 & .0908 \\
\hline
\end{tabular}

${ }^{\circ} p<.10{ }^{*} p<.05{ }^{* *} p<.01{ }^{* * *} p<.001$ $+p<.15$ 
Table B-43. Logit of Buddhist Mix GRP Scale.

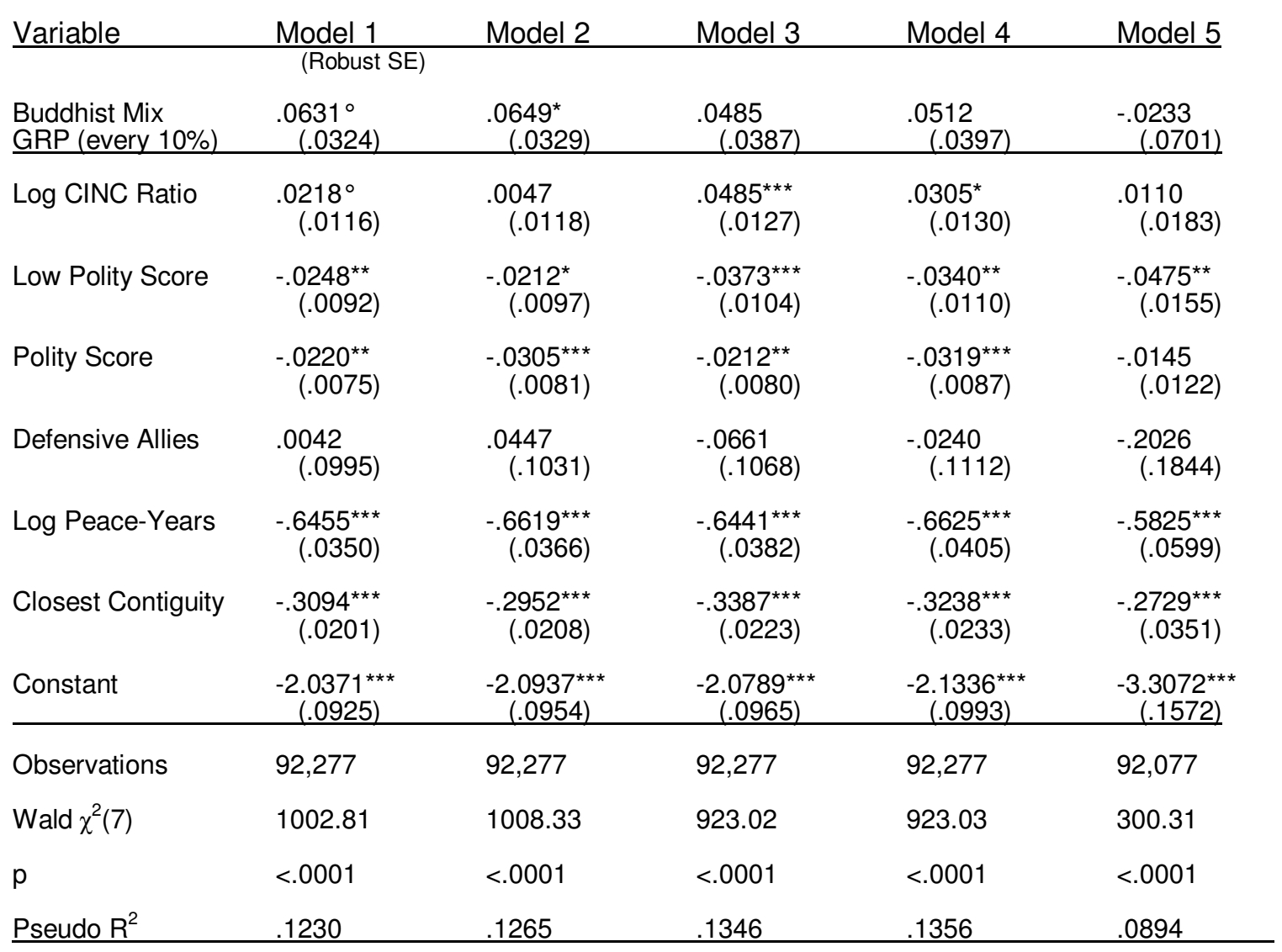

${ }^{\circ} \mathrm{p}<.10{ }^{*} \mathrm{p}<.05{ }^{* *} \mathrm{p}<.01{ }^{* \star *} \mathrm{p}<.001$ 
Table B-44. Logit of Buddhist Mix Prevalence.

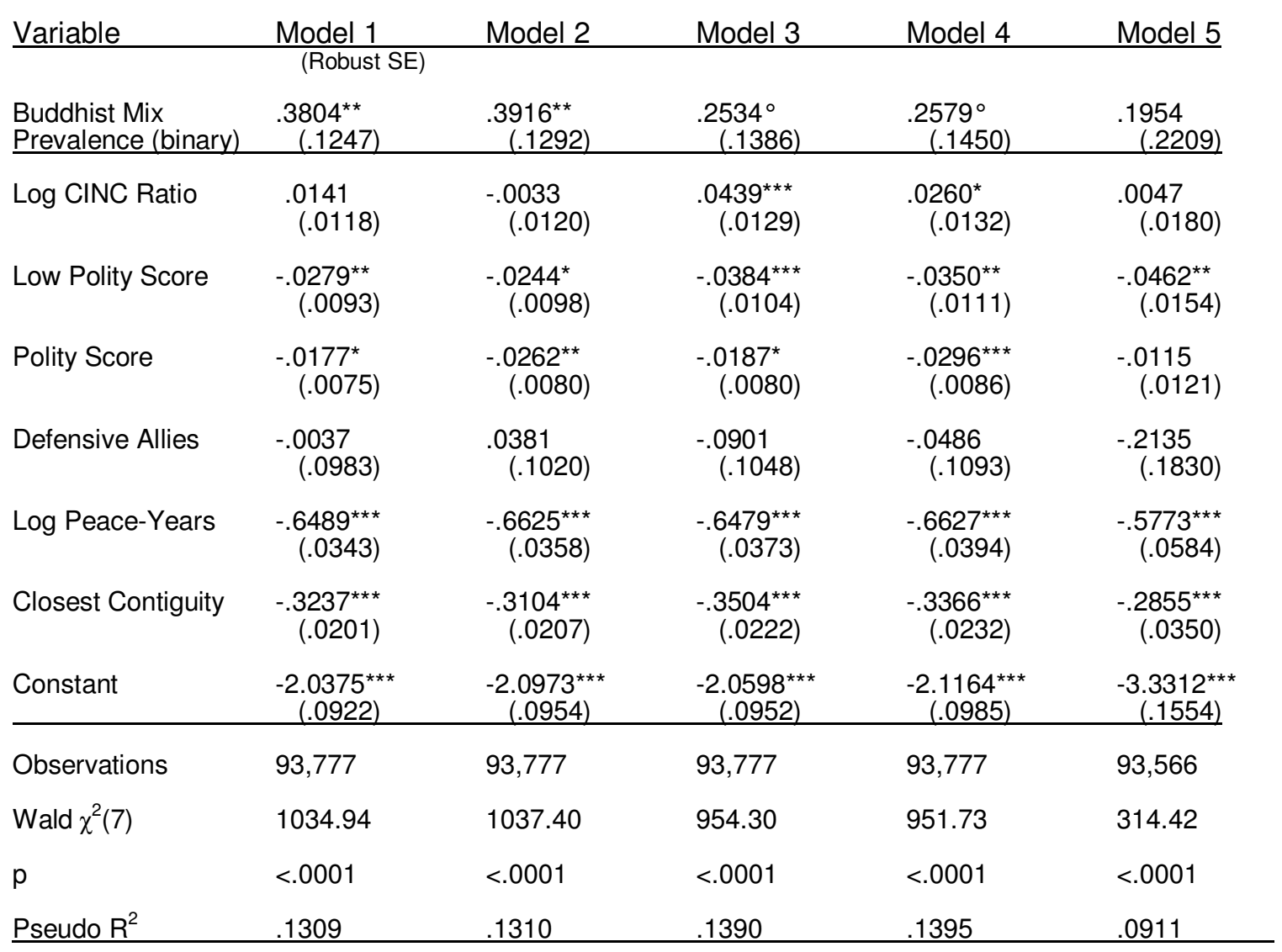

${ }^{\circ} p<.10{ }^{*} p<.05{ }^{* *} p<.01{ }^{* * *} p<.001$ 
Table B-45. Logit of Buddhist Mix Population.

\begin{tabular}{|c|c|c|c|c|c|}
\hline Variable & Model 1 & Model 2 & Model 3 & Model 4 & Model 5 \\
\hline $\begin{array}{l}\text { Buddhist Mix } \\
\text { Pop. (every 10\%) }\end{array}$ & $\begin{array}{r}.0374^{\star *} \\
(.0136) \\
\end{array}$ & $\begin{array}{c}.0402^{* *} \\
(.0140) \\
\end{array}$ & $\begin{array}{l}.0230 \dagger \\
(.0152) \\
\end{array}$ & $\begin{array}{c}.0256 \dagger \\
(.0158)\end{array}$ & $\begin{array}{r}.0140 \\
\quad(.0250) \\
\end{array}$ \\
\hline Log CINC Ratio & $\begin{array}{l}.0155 \\
(.0115)\end{array}$ & $\begin{array}{l}-.0033 \\
(.0117)\end{array}$ & $\begin{array}{r}.0451^{* \star *} \\
(.0127)\end{array}$ & $\begin{array}{l}.0250^{\circ} \\
(.0130)\end{array}$ & $\begin{array}{l}.0085 \\
(.0178)\end{array}$ \\
\hline Low Polity Score & $\begin{array}{c}-.0275^{\star *} \\
(.0092)\end{array}$ & $\begin{array}{l}-.0246^{*} \\
(.0096)\end{array}$ & $\begin{array}{r}-.0396^{* * *} \\
(.0103)\end{array}$ & $\begin{array}{r}-.0370^{* * *} \\
(.0110)\end{array}$ & $\begin{array}{c}-.0471^{* *} \\
(.0154)\end{array}$ \\
\hline Polity Score & $\begin{array}{c}-.0191^{* *} \\
(.0073)\end{array}$ & $\begin{array}{r}-.0271^{\star \star *} \\
(.0078)\end{array}$ & $\begin{array}{c}-.0195^{\star} \\
(.0078)\end{array}$ & $\begin{array}{r}-.0296^{\star * *} \\
(.0084)\end{array}$ & $\begin{array}{l}-.0128 \\
(.0120)\end{array}$ \\
\hline Defensive Allies & $\begin{array}{l}-.0121 \\
(.0978)\end{array}$ & $\begin{array}{c}.0289 \\
(.1014)\end{array}$ & $\begin{array}{l}-.0894 \\
(.1045)\end{array}$ & $\begin{array}{l}-.0476 \\
(.1089)\end{array}$ & $\begin{array}{l}-.2001 \\
(.1829)\end{array}$ \\
\hline Log Peace-Years & $\begin{array}{r}-.6543^{\star * *} \\
(.0338)\end{array}$ & $\begin{array}{r}-.6680^{\star * *} \\
(.0352)\end{array}$ & $\begin{array}{r}-.6530^{\star * *} \\
(.0369)\end{array}$ & $\begin{array}{r}-.6681^{* * *} \\
(.0388)\end{array}$ & $\begin{array}{r}-.5771^{\star \star *} \\
(.0579)\end{array}$ \\
\hline Closest Contiguity & $\begin{array}{r}-.3199^{* * *} \\
(.0196)\end{array}$ & $\begin{array}{r}-.3061^{* * *} \\
(.0202)\end{array}$ & $\begin{array}{r}-.3463^{* * *} \\
(.0218)\end{array}$ & $\begin{array}{r}-.3314^{* * *} \\
(.0227)\end{array}$ & $\begin{array}{r}-.2784^{* * *} \\
(.0346)\end{array}$ \\
\hline Constant & $\begin{array}{c}-2.0177^{\star * *} \\
(.0908) \\
\end{array}$ & $\begin{array}{c}-2.0792^{* * *} \\
(.0940) \\
\end{array}$ & $\begin{array}{c}-2.0473^{* * *} \\
(.0945) \\
\end{array}$ & $\begin{array}{c}-2.1066^{* * *} \\
(.0978) \\
\end{array}$ & $\begin{array}{c}-3.3438^{* * *} \\
(.1554) \\
\end{array}$ \\
\hline Observations & 95,418 & 95,418 & 95,418 & 95,418 & 95,197 \\
\hline Wald $\chi^{2}(7)$ & 1067.82 & 1073.18 & 972.67 & 971.65 & 313.84 \\
\hline $\mathrm{p}$ & $<.0001$ & $<.0001$ & $<.0001$ & $<.0001$ & $<.0001$ \\
\hline Pseudo $R^{2}$ & .1308 & .1307 & .1389 & .1391 & .0896 \\
\hline
\end{tabular}

${ }^{\circ} p<.10{ }^{*} p<.05{ }^{* *} p<.01{ }^{* * *} p<.001$

$\dagger p<.15$ 
Table B-46. Logit of Atheist Chief Executive.

\begin{tabular}{|c|c|c|c|c|c|}
\hline Variable & Model 1 & Model 2 & Model 3 & Model 4 & Model 5 \\
\hline $\begin{array}{l}\text { Atheist } \\
\text { Chief Exec. (binary) }\end{array}$ & $\begin{array}{c}.1354 \\
(.1086) \\
\end{array}$ & $\begin{array}{c}.1420 \\
(.1128) \\
\end{array}$ & $\begin{array}{l}.0645 \\
(.1211) \\
\end{array}$ & $\begin{array}{c}.0532 \\
(.1276) \\
\end{array}$ & $\begin{array}{r}-.0334 \\
(.1981) \\
\end{array}$ \\
\hline Log CINC Ratio & $\begin{array}{l}.0080 \\
(.0122)\end{array}$ & $\begin{array}{l}-.0118 \\
(.0126)\end{array}$ & $\begin{array}{l}.0390^{\star *} \\
(.0137)\end{array}$ & $\begin{array}{l}.0185 \\
(.0143)\end{array}$ & $\begin{array}{l}.0079 \\
(.0200)\end{array}$ \\
\hline Low Polity Score & $\begin{array}{l}-.0238^{* *} \\
(.0092)\end{array}$ & $\begin{array}{l}-.0211^{*} \\
(.0096)\end{array}$ & $\begin{array}{r}-.0359^{\star \star *} \\
(.0104)\end{array}$ & $\begin{array}{r}-.0335^{\star *} \\
(.0110)\end{array}$ & $\begin{array}{r}-.0436^{\star \star} \\
(.0156)\end{array}$ \\
\hline Polity Score & $\begin{array}{l}-.0164^{*} \\
(.0075)\end{array}$ & $\begin{array}{l}-.0244^{* *} \\
(.0079)\end{array}$ & $\begin{array}{l}-.0167^{*} \\
(.0081)\end{array}$ & $\begin{array}{l}-.0271^{* *} \\
(.0086)\end{array}$ & $\begin{array}{l}-.0110 \\
(.0123)\end{array}$ \\
\hline Defensive Allies & $\begin{array}{l}-.0382 \\
(.0977)\end{array}$ & $\begin{array}{l}.0008 \\
(.1012)\end{array}$ & $\begin{array}{l}-.0987 \\
(.1047)\end{array}$ & $\begin{array}{l}-.0589 \\
(.1090)\end{array}$ & $\begin{array}{l}-.1892 \\
(.1833)\end{array}$ \\
\hline Log Peace-Years & $\begin{array}{r}-.6665^{\star * *} \\
(.0350)\end{array}$ & $\begin{array}{r}-.6785^{\star * *} \\
(.0365)\end{array}$ & $\begin{array}{r}-.6663^{* * *} \\
(.0382)\end{array}$ & $\begin{array}{r}-.6797^{* * *} \\
(.0404)\end{array}$ & $\begin{array}{r}-.6089^{* * *} \\
(.0600)\end{array}$ \\
\hline Closest Contiguity & $\begin{array}{r}-.3121^{* * *} \\
(.0201)\end{array}$ & $\begin{array}{r}-.2978^{\star \star \star} \\
(.0207)\end{array}$ & $\begin{array}{r}-.3391^{* * *} \\
(.0224)\end{array}$ & $\begin{array}{r}-.3233^{* * *} \\
(.0234)\end{array}$ & $\begin{array}{r}-.2705^{* * *} \\
(.0358)\end{array}$ \\
\hline Constant & $\begin{array}{c}-1.9877^{* * *} \\
(.0933)\end{array}$ & $\begin{array}{c}-2.0517^{* * *} \\
(.0964)\end{array}$ & $\begin{array}{c}-2.0268^{* * *} \\
(.0970) \\
\end{array}$ & $\begin{array}{c}-2.0858^{* * *} \\
(.1001)\end{array}$ & $\begin{array}{c}-3.3028^{\star * *} \\
(.1608)\end{array}$ \\
\hline Observations & 88,083 & 88,083 & 88,083 & 88,083 & 87,873 \\
\hline Wald $\chi^{2}(7)$ & 1011.48 & 1012.73 & 923.38 & 918.59 & 296.23 \\
\hline $\mathrm{p}$ & $<.0001$ & $<.0001$ & $<.0001$ & $<.0001$ & $<.0001$ \\
\hline Pseudo $\mathrm{R}^{2}$ & .1299 & .1294 & .1382 & .1377 & .0919 \\
\hline
\end{tabular}

${ }^{\circ} p<.10{ }^{*} p<.05{ }^{* *} p<.01{ }^{* * *} p<.001$

$+p<.15$ 
Table B-47. Logit of Atheist Preference.

\begin{tabular}{|c|c|c|c|c|c|}
\hline Variable & $\frac{\text { Model } 1}{\text { (Robust SE) }}$ & Model 2 & Model 3 & Model 4 & Model 5 \\
\hline $\begin{array}{l}\text { Atheist } \\
\text { Preference (binary) }\end{array}$ & $\begin{array}{r}.2389^{*} \\
(.1111) \\
\end{array}$ & $\begin{array}{r}.2962^{* *} \\
(.1137) \\
\end{array}$ & $\begin{array}{r}.1333 \\
(.1231) \\
\end{array}$ & $\begin{array}{r}.1839 \dagger \\
(.1271) \\
\end{array}$ & $\begin{array}{r}.3020 \dagger \\
(.1972) \\
\end{array}$ \\
\hline Log CINC Ratio & $\begin{array}{l}.0139 \\
(.0125)\end{array}$ & $\begin{array}{l}-.0069 \\
(.0128)\end{array}$ & $\begin{array}{l}.0460^{* *} \\
(.0140)\end{array}$ & $\begin{array}{l}.0242^{\circ} \\
(.0146)\end{array}$ & $\begin{array}{l}-.0003 \\
(.0205)\end{array}$ \\
\hline Low Polity Score & $\begin{array}{r}-.0267^{\star *} \\
(.0092)\end{array}$ & $\begin{array}{l}-.0241^{*} \\
(.0097)\end{array}$ & $\begin{array}{r}-.0388^{\star \star *} \\
(.0104)\end{array}$ & $\begin{array}{r}-.0366^{\star \star *} \\
(.0111)\end{array}$ & $\begin{array}{r}-.0497^{\star *} \\
(.0155)\end{array}$ \\
\hline Polity Score & $\begin{array}{r}-.0158^{*} \\
(.0081)\end{array}$ & $\begin{array}{r}-.0223^{\star *} \\
(.0085)\end{array}$ & $\begin{array}{r}-.0177^{*} \\
(.0086)\end{array}$ & $\begin{array}{r}-.0265^{\star *} \\
(.0092)\end{array}$ & $\begin{array}{l}-.0049 \\
(.0132)\end{array}$ \\
\hline Defensive Allies & $\begin{array}{l}-.0312 \\
(.0977)\end{array}$ & $\begin{array}{l}.0098 \\
(.1011)\end{array}$ & $\begin{array}{l}-.0937 \\
(.1046)\end{array}$ & $\begin{array}{l}-.0511 \\
(.1088)\end{array}$ & $\begin{array}{l}-.1840 \\
(.1813)\end{array}$ \\
\hline Log Peace-Years & $\begin{array}{r}-.6497^{* * *} \\
(.0348)\end{array}$ & $\begin{array}{r}-.6649^{* * *} \\
(.0363)\end{array}$ & $\begin{array}{r}-.6502^{\star \star *} \\
(.0381)\end{array}$ & $\begin{array}{r}-.6672^{* * *} \\
(.0402)\end{array}$ & $\begin{array}{r}-.5855^{\star * *} \\
(.0596)\end{array}$ \\
\hline Closest Contiguity & $\begin{array}{r}-.3203^{* * *} \\
(.0199)\end{array}$ & $\begin{array}{r}-.3070^{* * *} \\
(.0204)\end{array}$ & $\begin{array}{r}-.3450^{\star \star *} \\
(.0221)\end{array}$ & $\begin{array}{r}-.3303^{\star * *} \\
(.0230)\end{array}$ & $\begin{array}{r}-.2831^{* * *} \\
(.0345)\end{array}$ \\
\hline Constant & $\begin{array}{c}-2.0684^{* * *} \\
(.0970) \\
\end{array}$ & $\begin{array}{c}-2.1469^{\star * *} \\
(.1005) \\
\end{array}$ & $\begin{array}{c}-2.0884^{* * *} \\
(.1004) \\
\end{array}$ & $\begin{array}{c}-2.1627^{* * *} \\
(.1041) \\
\end{array}$ & $\begin{array}{c}-3.4267^{* * *} \\
(.1658) \\
\end{array}$ \\
\hline Observations & 93,474 & 93,474 & 93,474 & 93,474 & 93,271 \\
\hline Wald $\chi^{2}(7)$ & 1020.32 & 1025.16 & 935.16 & 931.20 & 302.95 \\
\hline$p$ & $<.0001$ & $<.0001$ & $<.0001$ & $<.0001$ & $<.0001$ \\
\hline Pseudo $\mathrm{R}^{2}$ & .1286 & .1288 & .1369 & 1372 & .0912 \\
\hline
\end{tabular}

${ }^{\circ} p<.10{ }^{*} p<.05 \quad{ }^{* *} p<.01{ }^{* * *} p<.001$

$+p<.15$ 
Table B-48. Logit of Atheist GRP Scale.

\begin{tabular}{|c|c|c|c|c|c|}
\hline Variable & Model 1 & Model 2 & Model 3 & Model 4 & Model 5 \\
\hline $\begin{array}{l}\text { Atheist } \\
\text { GRP (every 10\%) }\end{array}$ & $\begin{array}{r}.0263^{*} \\
(.0121) \\
\end{array}$ & $\begin{array}{r}.0335^{\star *} \\
(.0124) \\
\end{array}$ & $\begin{array}{r}.0140 \\
(.0134) \\
\end{array}$ & $\begin{array}{c}.0204 \dagger \\
(.0138) \\
\end{array}$ & $\begin{array}{r}.0367^{\circ} \\
(.0214) \\
\end{array}$ \\
\hline Log CINC Ratio & $\begin{array}{l}.0107 \\
(.0129)\end{array}$ & $\begin{array}{l}-.0097 \\
(.0132)\end{array}$ & $\begin{array}{l}.0423^{\star \star} \\
(.0145)\end{array}$ & $\begin{array}{l}.0213 \\
(.0151)\end{array}$ & $\begin{array}{l}-.0045 \\
(.0211)\end{array}$ \\
\hline Low Polity Score & $\begin{array}{c}-.0261^{* *} \\
(.0092)\end{array}$ & $\begin{array}{l}-.0230^{*} \\
(.0097)\end{array}$ & $\begin{array}{r}-.0380^{* * *} \\
(.0104)\end{array}$ & $\begin{array}{c}-.0351^{* *} \\
(.0111)\end{array}$ & $\begin{array}{r}-.0498^{* *} \\
(.0155)\end{array}$ \\
\hline Polity Score & $\begin{array}{l}-.0160^{*} \\
(.0081)\end{array}$ & $\begin{array}{r}-.0226^{\star *} \\
(.0086)\end{array}$ & $\begin{array}{l}-.0181^{*} \\
(.0087)\end{array}$ & $\begin{array}{r}-.0272^{\star *} \\
(.0093)\end{array}$ & $\begin{array}{l}-.0046 \\
(.0132)\end{array}$ \\
\hline Defensive Allies & $\begin{array}{l}-.0060 \\
(.0983)\end{array}$ & $\begin{array}{l}.0370 \\
(.1019)\end{array}$ & $\begin{array}{l}-.0759 \\
(.1051)\end{array}$ & $\begin{array}{l}-.0317 \\
(.1094)\end{array}$ & $\begin{array}{l}-.1771 \\
(.1825)\end{array}$ \\
\hline Log Peace-Years & $\begin{array}{r}-.6469^{* * *} \\
(.0351)\end{array}$ & $\begin{array}{r}-.6636^{* * *} \\
(.0367)\end{array}$ & $\begin{array}{r}-.6449^{* * *} \\
(.0383)\end{array}$ & $\begin{array}{r}-.6636^{* * *} \\
(.0406)\end{array}$ & $\begin{array}{r}-.5839^{* * *} \\
(.0598)\end{array}$ \\
\hline Closest Contiguity & $\begin{array}{r}-.3157^{\star \star *} \\
(.0200)\end{array}$ & $\begin{array}{r}-.3034^{* * *} \\
(.0206)\end{array}$ & $\begin{array}{r}-.3421^{* * *} \\
(.0222)\end{array}$ & $\begin{array}{r}-.3291^{\star * *} \\
(.0231)\end{array}$ & $\begin{array}{r}-.2820^{\star * *} \\
(.0347)\end{array}$ \\
\hline Constant & $\begin{array}{c}-2.0884^{* * *} \\
(.0982) \\
\end{array}$ & $\begin{array}{c}-2.1663^{* * *} \\
(.1019) \\
\end{array}$ & $\begin{array}{c}-2.0990^{* * *} \\
(.1012)\end{array}$ & $\begin{array}{c}-2.1709^{* * *} \\
(.1051) \\
\end{array}$ & $\begin{array}{c}-3.4320^{* * *} \\
(.1671) \\
\end{array}$ \\
\hline Observations & 92,277 & 92,277 & 92,277 & 92,277 & 92,077 \\
\hline Wald $\chi^{2}(7)$ & 997.37 & 1004.52 & 917.16 & 916.42 & 301.46 \\
\hline $\mathrm{p}$ & $<.0001$ & $<.0001$ & $<.0001$ & $<.0001$ & $<.0001$ \\
\hline Pseudo R ${ }^{2}$ & .1262 & .1271 & .1345 & .1357 & .0904 \\
\hline
\end{tabular}

${ }^{\circ} p<.10{ }^{*} p<.05{ }^{* *} p<.01{ }^{* * *} p<.001$ $+p<.15$ 
Table B-49. Comparison of Logit \& RELogit Regressions (Two Strong Coefficients).

\begin{tabular}{|c|c|c|c|c|}
\hline Variable & $\begin{array}{l}\text { MODEL } 5 \\
\text { Logit }\end{array}$ & RELogit & $\begin{array}{l}\text { MODEL } 5 \\
\text { Logit }\end{array}$ & RELogit \\
\hline $\begin{array}{l}\text { Christian (all) } \\
\text { Preference (binary) }\end{array}$ & $\begin{array}{r}-.9542^{* * *} \\
(.2207)\end{array}$ & $\begin{array}{r}-.9481^{* * *} \\
(.2206)\end{array}$ & & \\
\hline $\begin{array}{l}\text { Muslim (all) } \\
\text { Prevalence (binary) }\end{array}$ & & & $\begin{array}{r}.5368^{\star *} \\
(.1782) \\
\end{array}$ & $\begin{array}{l}.5362^{\star *} \\
(.1781) \\
\end{array}$ \\
\hline Log CINC Ratio & $\begin{array}{l}.0064 \\
(.0184)\end{array}$ & $\begin{array}{l}.0063 \\
(.0184)\end{array}$ & $\begin{array}{l}.0183 \\
(.0198)\end{array}$ & $\begin{array}{l}.0182 \\
(.0198)\end{array}$ \\
\hline Low Polity Score & $\begin{array}{l}-.0404^{\star} \\
(.0162)\end{array}$ & $\begin{array}{l}-.0401^{*} \\
(.0162)\end{array}$ & $\begin{array}{r}-.0439^{\star \star} \\
(.0158)\end{array}$ & $\begin{array}{r}-.0436^{* *} \\
(.0158)\end{array}$ \\
\hline Polity Score & $\begin{array}{l}.0158 \\
(.0139)\end{array}$ & $\begin{array}{l}.0163 \\
(.0139)\end{array}$ & $\begin{array}{l}-.0081 \\
(.0128)\end{array}$ & $\begin{array}{l}-.0077 \\
(.0128)\end{array}$ \\
\hline Defensive Allies & $\begin{array}{l}-.1278 \\
(.1892)\end{array}$ & $\begin{array}{l}-.1211 \\
(.1892)\end{array}$ & $\begin{array}{l}-.2461 \\
(.1816)\end{array}$ & $\begin{array}{l}-.2388 \\
(.1816)\end{array}$ \\
\hline Log Peace-Years & $\begin{array}{r}-.5750^{* * *} \\
(.0611)\end{array}$ & $\begin{array}{r}-.5748^{\star \star *} \\
(.0611)\end{array}$ & $\begin{array}{r}-.5760^{\star * *} \\
(.0594)\end{array}$ & $\begin{array}{r}-.5757^{* * *} \\
(.0594)\end{array}$ \\
\hline Closest Contiguity & $\begin{array}{r}-.2649^{* * *} \\
(.0351)\end{array}$ & $\begin{array}{r}-.2639^{* * *} \\
(.0351)\end{array}$ & $\begin{array}{r}-.2591^{* * *} \\
(.0352)\end{array}$ & $\begin{array}{r}-.2581^{* * *} \\
(.0352)\end{array}$ \\
\hline Constant & $\begin{array}{c}-3.2999^{* * *} \\
(.1629) \\
\end{array}$ & $\begin{array}{c}-3.2914^{\star \star *} \\
(.1629) \\
\end{array}$ & $\begin{array}{c}-3.5707^{\star \star *} \\
(.2069) \\
\end{array}$ & $\begin{array}{c}-3.5603^{\star \star *} \\
(.2069) \\
\end{array}$ \\
\hline Observations & 90,036 & 90,036 & 90,233 & 90,233 \\
\hline
\end{tabular}

${ }^{\circ} p<.10 \quad{ }^{*} p<.05{ }^{* *} p<.01{ }^{* * *} p<.001$ 
Table B-50. Comparison of Logit \& RELogit Regressions (Two Weak Coefficients).

\begin{tabular}{|c|c|c|c|c|}
\hline Variable & $\begin{array}{l}\text { MODEL } 5 \\
\text { Logit }\end{array}$ & RELogit & $\begin{array}{l}\text { MODEL } 5 \\
\text { Logit }\end{array}$ & RELogit \\
\hline $\begin{array}{l}\text { Buddhist Mix } \\
\text { Pop. (every } 10 \% \text { ) }\end{array}$ & $\begin{array}{l}.0140 \\
(.0250)\end{array}$ & $\begin{array}{c}.0159 \\
(.0250)\end{array}$ & & \\
\hline $\begin{array}{l}\text { Atheist } \\
\text { GRP (every 10\%) }\end{array}$ & & & $\begin{array}{l}.0367^{\circ} \\
(.0214) \\
\end{array}$ & $\begin{array}{c}.0375^{\circ} \\
(.0214) \\
\end{array}$ \\
\hline Log CINC Ratio & $\begin{array}{l}.0085 \\
(.0178)\end{array}$ & $\begin{array}{l}.0084 \\
(.0178)\end{array}$ & $\begin{array}{l}-.0045 \\
(.0211)\end{array}$ & $\begin{array}{l}-.0049 \\
(.0211)\end{array}$ \\
\hline Low Polity Score & $\begin{array}{r}-.0471^{\star *} \\
(.0154)\end{array}$ & $\begin{array}{l}-.0468^{\star *} \\
(.0154)\end{array}$ & $\begin{array}{l}-.0498^{\star *} \\
(.0155)\end{array}$ & $\begin{array}{l}-.0495^{\star *} \\
(.0155)\end{array}$ \\
\hline Polity Score & $\begin{array}{l}-.0128 \\
(.0120)\end{array}$ & $\begin{array}{l}-.0122 \\
(.0120)\end{array}$ & $\begin{array}{l}-.0046 \\
(.0132)\end{array}$ & $\begin{array}{l}-.0041 \\
(.0132)\end{array}$ \\
\hline Defensive Allies & $\begin{array}{l}-.2001 \\
(.1829)\end{array}$ & $\begin{array}{l}-.1927 \\
(.1829)\end{array}$ & $\begin{array}{l}-.1771 \\
(.1825)\end{array}$ & $\begin{array}{l}-.1690 \\
(.1825)\end{array}$ \\
\hline Log Peace-Years & $\begin{array}{r}-.5771^{* * *} \\
(.0579)\end{array}$ & $\begin{array}{r}-.5769^{\star * *} \\
(.0579)\end{array}$ & $\begin{array}{r}-.5839^{* * *} \\
(.0598)\end{array}$ & $\begin{array}{r}-.5837^{* * *} \\
(.0598)\end{array}$ \\
\hline Closest Contiguity & $\begin{array}{r}-.2784^{\star * *} \\
(.0346)\end{array}$ & $\begin{array}{r}-.2773^{* * *} \\
(.0346)\end{array}$ & $\begin{array}{r}-.2820^{* * *} \\
(.0347)\end{array}$ & $\begin{array}{r}-.2810^{\star * *} \\
(.0347)\end{array}$ \\
\hline Constant & $\begin{array}{c}-3.3438^{* * *} \\
(.1554) \\
\end{array}$ & $\begin{array}{c}-3.3376^{* * *} \\
(.1554) \\
\end{array}$ & $\begin{array}{c}-3.4320^{* * *} \\
(.1671) \\
\end{array}$ & $\begin{array}{c}-3.4240^{* * *} \\
(.1671) \\
\end{array}$ \\
\hline Observations & 95,197 & 95,197 & 92,077 & 92,077 \\
\hline
\end{tabular}

${ }^{\circ} \mathrm{p}<.10{ }^{*} \mathrm{p}<.05{ }^{* *} \mathrm{p}<.01{ }^{* * *} \mathrm{p}<.001$ 
Table B-51. Comparison of Logit \& RELogit Regressions (Two Middle Coefficients).

\begin{tabular}{|c|c|c|c|c|}
\hline Variable & $\begin{array}{l}\text { MODEL } 5 \\
\text { Logit }\end{array}$ & RELogit & $\begin{array}{l}\text { MODEL } 5 \\
\text { Logit }\end{array}$ & RELogit \\
\hline $\begin{array}{l}\text { Christian (all) } \\
\text { GRP (every 10\%) }\end{array}$ & $\begin{array}{r}-.2013^{\star * \star} \\
(.0480)\end{array}$ & $\begin{array}{r}-.1996^{\star \star *} \\
(.0480)\end{array}$ & & \\
\hline $\begin{array}{l}\text { Buddhist Mix } \\
\text { Prevalence (binary) }\end{array}$ & & & $\begin{array}{r}.1954 \\
(.2209) \\
\end{array}$ & $\begin{array}{r}.2129 \\
(.2209) \\
\end{array}$ \\
\hline Log CINC Ratio & $\begin{array}{l}.0003 \\
(.0184)\end{array}$ & $\begin{array}{l}.0002 \\
(.0184)\end{array}$ & $\begin{array}{l}.0047 \\
(.0180)\end{array}$ & $\begin{array}{l}.0045 \\
(.0180)\end{array}$ \\
\hline Low Polity Score & $\begin{aligned}-.0417^{* *} & (.0159)\end{aligned}$ & $\begin{array}{r}-.0414^{\star *} \\
(.0159)\end{array}$ & $\begin{array}{r}-.0462^{* *} \\
(.0154)\end{array}$ & $\begin{array}{r}-.0459^{\star *} \\
(.0154)\end{array}$ \\
\hline Polity Score & $\begin{array}{l}.0137 \\
(.0136)\end{array}$ & $\begin{array}{l}.0142 \\
(.0136)\end{array}$ & $\begin{array}{l}-.0115 \\
\quad(.0121)\end{array}$ & $\begin{array}{l}-.0110 \\
(.0121)\end{array}$ \\
\hline Defensive Allies & $\begin{array}{l}-.1206 \\
(.1854)\end{array}$ & $\begin{array}{l}-.1138 \\
(.1854)\end{array}$ & $\begin{array}{l}-.2135 \\
(.1830)\end{array}$ & $\begin{array}{l}-.2063 \\
(.1830)\end{array}$ \\
\hline Log Peace-Years & $\begin{array}{r}-.5618^{\star * *} \\
(.0608)\end{array}$ & $\begin{array}{r}-.5616^{\star * *} \\
(.0608)\end{array}$ & $\begin{array}{r}-.5773^{\star \star *} \\
(.0584)\end{array}$ & $\begin{array}{r}-.5771^{* * *} \\
(.0584)\end{array}$ \\
\hline Closest Contiguity & $\begin{array}{r}-.2746^{\star * *} \\
(.0352)\end{array}$ & $\begin{array}{r}-.2735^{\star \star *} \\
(.0352)\end{array}$ & $\begin{array}{r}-.2855^{\star \star *} \\
(.0350)\end{array}$ & $\begin{array}{r}-.2844^{* * *} \\
(.0350)\end{array}$ \\
\hline Constant & $\begin{array}{c}-3.2971^{* * *} \\
(.1587) \\
\end{array}$ & $\begin{array}{c}-3.2888^{\star \star *} \\
(.1587) \\
\end{array}$ & $\begin{array}{c}-3.3312^{* * *} \\
(.1554) \\
\end{array}$ & $\begin{array}{c}-3.3249^{* * *} \\
(.1554) \\
\end{array}$ \\
\hline Observations & 92,077 & 92,077 & 93,566 & 93,566 \\
\hline
\end{tabular}

${ }^{\circ} \mathrm{p}<.10{ }^{*} \mathrm{p}<.05{ }^{* *} \mathrm{p}<.01{ }^{* * *} \mathrm{p}<.001$ 
Table B-52. Comparison of Standard and Alternative Controls, Model 1 (Two Strong Coefficients).

\begin{tabular}{|c|c|c|c|c|}
\hline Variable & $\begin{array}{l}\text { MODEL } 1 \\
\text { Standard }\end{array}$ & Alternative & $\begin{array}{l}\text { MODEL } 1 \\
\text { Standard }\end{array}$ & Alternative \\
\hline $\begin{array}{l}\text { Christian (all) } \\
\text { Preference (binary) }\end{array}$ & $\begin{array}{r}-.3544^{\star *} \\
(.1103)\end{array}$ & $\begin{array}{r}-.3341^{\star \star *} \\
(.0988)\end{array}$ & & \\
\hline $\begin{array}{l}\text { Buddhist Mix } \\
\text { Prevalence (binary) }\end{array}$ & & & $\begin{array}{r}.3804^{* *} \\
(.1247) \\
\end{array}$ & $\begin{array}{r}.2393 \dagger \\
(.1673) \\
\end{array}$ \\
\hline Log CINC Ratio & $\begin{array}{l}.0179 \\
(.0116)\end{array}$ & & $\begin{array}{l}.0141 \\
(.0118)\end{array}$ & \\
\hline Log GDPPC Ratio & & $\begin{array}{l}-.1108^{* *} \\
(.0354)\end{array}$ & & $\begin{array}{r}-.1243^{\star * *} \\
(.0351)\end{array}$ \\
\hline Nuclear (State 1) & & $\begin{array}{r}.4786^{\circ} \\
(.2591)\end{array}$ & & $\begin{array}{l}.5553^{\star} \\
(.2746)\end{array}$ \\
\hline Nuclear (State 2) & & $\begin{array}{l}.1936 \\
(.1273)\end{array}$ & & $\begin{array}{l}.2229^{\circ} \\
(.1274)\end{array}$ \\
\hline Nuclear (Both) & & $\begin{array}{l}.7811^{* *} \\
(.2965)\end{array}$ & & $\begin{array}{l}.7514^{*} \\
(.2989)\end{array}$ \\
\hline P5 & & $\begin{array}{l}-.4634^{\circ} \\
(.2585)\end{array}$ & & $\begin{array}{l}-.5103^{\circ} \\
(.2628)\end{array}$ \\
\hline Low Polity Score & $\begin{array}{l}-.0233^{*} \\
(.0094)\end{array}$ & & $\begin{array}{r}-.0279^{* *} \\
(.0093)\end{array}$ & \\
\hline Polity Score & $\begin{array}{l}-.0110 \\
(.0084)\end{array}$ & & $\begin{array}{l}-.0177^{\star} \\
(.0075)\end{array}$ & \\
\hline Democratic Dyad & & $\begin{array}{r}-.8026^{\star \star *} \\
(.1750)\end{array}$ & & $\begin{array}{r}-.9022^{* \star *} \\
(.1646)\end{array}$ \\
\hline Defensive Allies & $\begin{array}{l}-.0208 \\
(.0984)\end{array}$ & $\begin{array}{l}.2581^{*} \\
(.1080)\end{array}$ & $\begin{array}{l}-.0037 \\
(.0983)\end{array}$ & $\begin{array}{c}.2685^{*} \\
(.1069)\end{array}$ \\
\hline Log Peace-Years & $\begin{array}{r}-.6451^{* * *} \\
(.0354)\end{array}$ & $\begin{array}{r}-.6702^{* * *} \\
(.0381)\end{array}$ & $\begin{array}{r}-.6489^{* * *} \\
(.0343)\end{array}$ & $\begin{array}{r}-.6578^{\star * *} \\
(.0373)\end{array}$ \\
\hline Closest Contiguity & $\begin{array}{r}-.3106^{* * *} \\
(.0201)\end{array}$ & & $\begin{array}{r}-.3237^{* * *} \\
(.0201)\end{array}$ & \\
\hline Any Land Contiguity & & $\begin{array}{c}1.2387^{* * *} \\
(.1104)\end{array}$ & & $\begin{array}{c}1.3464^{* * *} \\
(.1096)\end{array}$ \\
\hline Constant & $\begin{array}{c}-3.2971^{* * *} \\
(.1587) \\
\end{array}$ & $\begin{array}{c}-3.8154^{* * *} \\
(.1264)\end{array}$ & $\begin{array}{c}-3.3312^{* * *} \\
(.1554) \\
\end{array}$ & $\begin{array}{c}-4.1128^{\star \star *} \\
(.1185) \\
\end{array}$ \\
\hline Observations & 90,234 & 81,496 & 93,777 & 84,435 \\
\hline Wald $\chi^{2}(7 \mathrm{Std} / 10 \mathrm{Alt})$ & 1019.80 & 829.63 & 917.16 & 826.83 \\
\hline$p$ & $<.0001$ & $<.0001$ & $<.0001$ & $<.0001$ \\
\hline Pseudo $\mathrm{R}^{2}$ & .1306 & .1232 & .1345 & .1202 \\
\hline
\end{tabular}

${ }^{\circ} p<.10{ }^{*} p<.05 \quad{ }^{* *} p<.01{ }^{* * *} p<.001$

$\dagger p<.20$ 
Table B-53. Comparison of Standard and Alternative Controls, Model 1 (Two Weak Coefficients).

\begin{tabular}{|c|c|c|c|c|}
\hline Variable & $\begin{array}{l}\text { MODEL } 1 \\
\text { Standard }\end{array}$ & Alternative & $\begin{array}{l}\text { MODEL } 1 \\
\text { Standard }\end{array}$ & Alternative \\
\hline $\begin{array}{l}\text { Muslim (all) } \\
\text { GRP (every 10\%) }\end{array}$ & $\begin{array}{l}.0100 \\
(.0134)\end{array}$ & $\begin{array}{l}.0319^{*} \\
(.0146)\end{array}$ & & \\
\hline $\begin{array}{l}\text { Muslim (all) } \\
\text { Population (every } 10 \%\end{array}$ & & & $\begin{array}{l}.0142 \\
(.0115) \\
\end{array}$ & $\begin{array}{r}.0281^{*} \\
(.0122) \\
\end{array}$ \\
\hline Log CINC Ratio & $\begin{array}{l}.0226^{\circ} \\
(.0119)\end{array}$ & & $\begin{array}{l}.0246^{*} \\
(.0118)\end{array}$ & \\
\hline Log GDPPC Ratio & & $\begin{array}{r}-.1345^{\star * *} \\
(.0348)\end{array}$ & & $\begin{array}{r}-.1278^{\star \star *} \\
(.0351)\end{array}$ \\
\hline Nuclear (State 1) & & $\begin{array}{l}.6507^{\star} \\
(.2686)\end{array}$ & & $\begin{array}{l}.6483^{*} \\
(.2680)\end{array}$ \\
\hline Nuclear (State 2) & & $\begin{array}{l}.1606 \\
(.1283)\end{array}$ & & $\begin{array}{l}.1596 \\
(.1274)\end{array}$ \\
\hline Nuclear (Both) & & $\begin{array}{l}.8487^{* *} \\
(.2958)\end{array}$ & & $\begin{array}{l}.8482^{* *} \\
(.2955)\end{array}$ \\
\hline P5 & & $\begin{array}{l}-.5457^{*} \\
(.2677)\end{array}$ & & $\begin{array}{l}-.5263^{\circ} \\
(.2682)\end{array}$ \\
\hline Low Polity Score & $\begin{array}{l}-.0238^{*} \\
(.0093)\end{array}$ & & $\begin{array}{r}-.0253^{* *} \\
(.0093)\end{array}$ & \\
\hline Polity Score & $\begin{array}{r}-.0217^{\star *} \\
(.0077)\end{array}$ & & $\begin{array}{l}-.0203^{\star *} \\
(.0075)\end{array}$ & \\
\hline Democratic Dyad & & $\begin{array}{r}-.8913^{* * *} \\
(.1682)\end{array}$ & & $\begin{array}{r}-.8662^{\star * *} \\
(.1695)\end{array}$ \\
\hline Defensive Allies & $\begin{array}{l}-.0251 \\
(.0990)\end{array}$ & $\begin{array}{c}.2534^{*} \\
(.1076)\end{array}$ & $\begin{array}{l}-.0665 \\
(.0967)\end{array}$ & $\begin{array}{l}.2300^{*} \\
(.1061)\end{array}$ \\
\hline Log Peace-Years & $\begin{array}{r}-.6432^{* * *} \\
(.0356)\end{array}$ & $\begin{array}{r}-.6632^{* * *} \\
(.0380)\end{array}$ & $\begin{array}{r}-.6502^{* * *} \\
(.0343)\end{array}$ & $\begin{array}{r}-.6573^{\star * *} \\
(.0371)\end{array}$ \\
\hline Closest Contiguity & $\begin{array}{r}-.3088^{* * *} \\
(.0200)\end{array}$ & & $\begin{array}{r}-.3143^{* * *} \\
(.0194)\end{array}$ & \\
\hline Any Land Contiguity & & $\begin{array}{c}1.2541^{* * *} \\
(.1098)\end{array}$ & & $\begin{array}{c}1.2907^{* \star *} \\
(.1085)\end{array}$ \\
\hline Constant & $\begin{array}{c}-2.0463^{* * *} \\
(.1057) \\
\end{array}$ & $\begin{array}{c}-4.0768^{\star * *} \\
(.1302) \\
\end{array}$ & $\begin{array}{c}-2.0320 * * * \\
(.1080) \\
\end{array}$ & $\begin{array}{c}-4.1299^{* * *} \\
(.1307) \\
\end{array}$ \\
\hline Observations & 92,277 & 83,794 & 95,418 & 85,944 \\
\hline Wald $\chi^{2}(7 \mathrm{Std} / 10 \mathrm{Alt})$ & 1001.90 & 829.29 & 1066.68 & 855.52 \\
\hline $\mathrm{p}$ & $<.0001$ & $<.0001$ & $<.0001$ & $<.0001$ \\
\hline Pseudo $\mathrm{R}^{2}$ & .1257 & .1200 & .1302 & .1201 \\
\hline
\end{tabular}

${ }^{\circ} p<.10{ }^{*} p<.05 \quad{ }^{* *} p<.01{ }^{* * *} p<.001$ 
Table B-54. Comparison of Standard and Alternative Controls, Model 1 (Two Middle Coefficients).

\begin{tabular}{|c|c|c|c|c|}
\hline Variable & $\begin{array}{l}\text { MODEL } 1 \\
\text { Standard }\end{array}$ & Alternative & $\begin{array}{l}\text { MODEL } 1 \\
\text { Standard }\end{array}$ & Alternative \\
\hline $\begin{array}{l}\text { Christian (all) } \\
\text { GRP (every 10\%) }\end{array}$ & $\begin{array}{r}-.0620^{* *} \\
(.0234)\end{array}$ & $\begin{array}{r}-.0668^{\star *} \\
(.0214)\end{array}$ & & \\
\hline $\begin{array}{l}\text { Atheist } \\
\text { Preference (binary) }\end{array}$ & & & $\begin{array}{r}.2389^{*} \\
(.1111) \\
\end{array}$ & $\begin{array}{c}.2656^{*} \\
(.1243) \\
\end{array}$ \\
\hline Log CINC Ratio & $\begin{array}{l}.0172 \\
(.0116)\end{array}$ & & $\begin{array}{l}.0139 \\
(.0125)\end{array}$ & \\
\hline Log GDPPC Ratio & & $\begin{array}{l}-.1128^{\star *} \\
(.0351)\end{array}$ & & $\begin{array}{r}-.1160^{* * *} \\
(.0336)\end{array}$ \\
\hline Nuclear (State 1) & & $\begin{array}{l}.4973^{\circ} \\
(.2587)\end{array}$ & & $\begin{array}{l}.4961^{\circ} \\
(.2727)\end{array}$ \\
\hline Nuclear (State 2) & & $\begin{array}{l}.1648 \\
(.1267)\end{array}$ & & $\begin{array}{l}.1525 \\
(.1264)\end{array}$ \\
\hline Nuclear (Both) & & $\begin{array}{l}.8326^{* *} \\
(.2959)\end{array}$ & & $\begin{array}{l}.8466^{\star \star} \\
(.2967)\end{array}$ \\
\hline P5 & & $\begin{array}{l}-.4935^{\circ} \\
(.2574)\end{array}$ & & $\begin{array}{l}-.5806^{*} \\
(.2590)\end{array}$ \\
\hline Low Polity Score & $\begin{array}{l}-.0226^{\star} \\
(.0093)\end{array}$ & & $\begin{array}{l}-.0267^{* *} \\
(.0092)\end{array}$ & \\
\hline Polity Score & $\begin{array}{l}-.0136 \\
(.0085)\end{array}$ & & $\begin{array}{l}-.0158^{*} \\
(.0081)\end{array}$ & \\
\hline Democratic Dyad & & $\begin{array}{r}-.8237^{\star \star *} \\
(.1719)\end{array}$ & & $\begin{array}{r}-.8954^{\star * *} \\
(.1656)\end{array}$ \\
\hline Defensive Allies & $\begin{array}{l}.0030 \\
(.0977)\end{array}$ & $\begin{array}{l}.2770^{* \star} \\
(.1070)\end{array}$ & $\begin{array}{l}-.0312 \\
(.0977)\end{array}$ & $\begin{array}{l}.2644^{*} \\
(.1068)\end{array}$ \\
\hline Log Peace-Years & $\begin{array}{r}-.6385^{\star \star *} \\
(.0352)\end{array}$ & $\begin{array}{r}-.6632^{* * *} \\
(.0378)\end{array}$ & $\begin{array}{r}-.6497^{\star * *} \\
(.0348)\end{array}$ & $\begin{array}{r}-.6670^{* * *} \\
(.0374)\end{array}$ \\
\hline Closest Contiguity & $\begin{array}{r}-.3113^{\star * \star} \\
(.0202)\end{array}$ & & $\begin{array}{r}-.3203^{* * *} \\
(.0199)\end{array}$ & \\
\hline Any Land Contiguity & & $\begin{array}{c}1.2400^{* \star *} \\
(.1099)\end{array}$ & & $\begin{array}{c}1.2496^{* \star *} \\
(.1102)\end{array}$ \\
\hline Constant & $\begin{array}{c}-1.9894^{\star \star *} \\
(.0930) \\
\end{array}$ & $\begin{array}{c}-3.8550^{\star \star * *} \\
(.1279) \\
\end{array}$ & $\begin{array}{c}-2.0684^{\star \star *} \\
(.0970) \\
\end{array}$ & $\begin{array}{c}-4.0172^{\star \star *} \\
(.1167) \\
\end{array}$ \\
\hline Observations & 92,277 & 83,794 & 93,474 & 84,607 \\
\hline Wald $\chi^{2}(7 \mathrm{Std} / 10 \mathrm{Alt})$ & 1010.45 & 830.86 & 1020.32 & 814.00 \\
\hline $\mathrm{p}$ & $<.0001$ & $<.0001$ & $<.0001$ & $<.0001$ \\
\hline Pseudo $\mathrm{R}^{2}$ & .1268 & .1209 & .1286 & .1189 \\
\hline
\end{tabular}

${ }^{\circ} p<.10{ }^{*} p<.05{ }^{* *} p<.01{ }^{* * *} p<.001$ 
Table B-55. Comparison of Standard and Alternative Controls, Model 5 (Two Strong Coefficients).

\begin{tabular}{|c|c|c|c|c|}
\hline Variable & $\begin{array}{l}\text { MODEL } 5 \\
\text { Standard }\end{array}$ & Alternative & $\begin{array}{l}\text { MODEL } 5 \\
\text { Standard }\end{array}$ & Alternative \\
\hline $\begin{array}{l}\text { Christian (all) } \\
\text { Preference (binary) }\end{array}$ & $\begin{array}{r}-.9542^{* * *} \\
(.2207)\end{array}$ & $\begin{array}{r}-.6530^{\star * *} \\
(.1827)\end{array}$ & & \\
\hline $\begin{array}{l}\text { Muslim (all) } \\
\text { Prevalence (binary) }\end{array}$ & & & $\begin{array}{r}.5368^{\star *} \\
(.1782) \\
\end{array}$ & $\begin{array}{r}.5498^{\star *} \\
(.1783) \\
\end{array}$ \\
\hline Log CINC Ratio & $\begin{array}{l}.0064 \\
(.0184)\end{array}$ & & $\begin{array}{l}.0183 \\
(.0198)\end{array}$ & \\
\hline Log GDPPC Ratio & & $\begin{array}{l}-.1096^{\circ} \\
(.0630)\end{array}$ & & $\begin{array}{l}-.1304^{*} \\
(.0631)\end{array}$ \\
\hline Nuclear (State 1) & & $\begin{array}{c}.2745 \\
(.3968)\end{array}$ & & $\begin{array}{l}.6074 \\
(.4284)\end{array}$ \\
\hline Nuclear (State 2) & & $\begin{array}{l}-.2105 \\
(.2193)\end{array}$ & & $\begin{array}{l}-.2030 \\
(.2167)\end{array}$ \\
\hline Nuclear (Both) & & $\begin{array}{c}.1379 \\
(.7759)\end{array}$ & & $\begin{array}{l}.2017 \\
(.7735)\end{array}$ \\
\hline P5 & & $\begin{array}{l}-.7154^{\circ} \\
\quad(.4114)\end{array}$ & & $\begin{array}{l}-.9034^{*} \\
(.4466)\end{array}$ \\
\hline Low Polity Score & $\begin{array}{l}-.0404^{*} \\
(.0162)\end{array}$ & & $\begin{array}{r}-.0439^{\star *} \\
(.0158)\end{array}$ & \\
\hline Polity Score & $\begin{array}{l}.0158 \\
(.0139)\end{array}$ & & $\begin{array}{l}-.0081 \\
(.0128)\end{array}$ & \\
\hline Democratic Dyad & & $\begin{array}{r}-1.2001^{* *} \\
(.4165)\end{array}$ & & $\begin{array}{c}-1.3741^{* * *} \\
(.4020)\end{array}$ \\
\hline Defensive Allies & $\begin{array}{l}-.1278 \\
(.1892)\end{array}$ & $\begin{array}{l}-.0506 \\
(.1967)\end{array}$ & $\begin{array}{l}-.2461 \\
(.1816)\end{array}$ & $\begin{array}{l}-.1004 \\
(.1937)\end{array}$ \\
\hline Log Peace-Years & $\begin{array}{r}-.5750^{* * *} \\
(.0611)\end{array}$ & $\begin{array}{r}-.5339^{* * *} \\
(.0682)\end{array}$ & $\begin{array}{r}-.5760^{* * *} \\
(.0594)\end{array}$ & $\begin{array}{r}-.5331^{* * *} \\
(.0662)\end{array}$ \\
\hline Closest Contiguity & $\begin{array}{r}-.2649^{* \star *} \\
(.0351)\end{array}$ & & $\begin{array}{r}-.2591^{* * *} \\
(.0352)\end{array}$ & \\
\hline Any Land Contiguity & & $\begin{array}{c}1.1529^{* \star *} \\
(.1839)\end{array}$ & & $\begin{array}{c}1.1801^{* * *} \\
(.1806)\end{array}$ \\
\hline Constant & $\begin{array}{c}-3.2999^{* * *} \\
(.1629) \\
\end{array}$ & $\begin{array}{c}-4.8125^{\star * *} \\
(.1998) \\
\end{array}$ & $\begin{array}{c}-3.5707^{\star * *} \\
(.2069) \\
\end{array}$ & $\begin{array}{c}-5.2564^{* * *} \\
(.2325) \\
\end{array}$ \\
\hline Observations & 90,036 & 81,331 & 90,233 & 81,173 \\
\hline Wald $\chi^{2}(7 \mathrm{Std} / 9$ Alt $)$ & 348.44 & 256.29 & 350.16 & 280.56 \\
\hline $\mathrm{p}$ & $<.0001$ & $<.0001$ & $<.0001$ & $<.0001$ \\
\hline Pseudo $\mathrm{R}^{2}$ & .1010 & .0995 & .0957 & .1001 \\
\hline
\end{tabular}

${ }^{\circ} p<.10{ }^{*} p<.05{ }^{* *} p<.01{ }^{* * *} p<.001$ 
Table B-56. Comparison of Standard and Alternative Controls, Model 5 (Two Weak Coefficients).

\begin{tabular}{|c|c|c|c|c|}
\hline Variable & $\begin{array}{l}\text { MODEL } 5 \\
\text { Standard }\end{array}$ & Alternative & $\begin{array}{l}\text { MODEL } 5 \\
\text { Standard }\end{array}$ & Alternative \\
\hline $\begin{array}{l}\text { Buddhist Mix } \\
\text { Pop. (every 10\%) }\end{array}$ & $\begin{array}{c}.0140 \\
(.0250)\end{array}$ & $\begin{array}{l}.0890 \\
(.0329)\end{array}$ & & \\
\hline $\begin{array}{l}\text { Atheist } \\
\text { GRP (every 10\%) }\end{array}$ & & & $\begin{array}{r}.0367^{\circ} \\
(.0214) \\
\end{array}$ & $\begin{array}{r}.0453^{\circ} \\
(.0260) \\
\end{array}$ \\
\hline Log CINC Ratio & $\begin{array}{l}.0085 \\
(.0178)\end{array}$ & & $\begin{array}{l}-.0045 \\
(.0211)\end{array}$ & \\
\hline Log GDPPC Ratio & & $\begin{array}{l}-.1436^{*} \\
(.0583)\end{array}$ & & $\begin{array}{l}-.1303^{*} \\
(.0588)\end{array}$ \\
\hline Nuclear (State 1) & & $\begin{array}{l}.4575 \\
(.4507)\end{array}$ & & $\begin{array}{c}.2741 \\
(.4420)\end{array}$ \\
\hline Nuclear (State 2) & & $\begin{array}{l}-.2137 \\
(.2102)\end{array}$ & & $\begin{array}{l}-.2816 \\
(.2142)\end{array}$ \\
\hline Nuclear (Both) & & $\begin{array}{c}.1827 \\
(.7693)\end{array}$ & & $\begin{array}{l}.2508 \\
(.7775)\end{array}$ \\
\hline P5 & & $\begin{array}{l}-.8947^{*} \\
(.4445)\end{array}$ & & $\begin{array}{l}-.9299^{*} \\
(.4186)\end{array}$ \\
\hline Low Polity Score & $\begin{array}{r}-.0471^{\star *} \\
(.0154)\end{array}$ & & $\begin{array}{l}-.0498^{\star *} \\
(.0155)\end{array}$ & \\
\hline Polity Score & $\begin{array}{l}-.0128 \\
(.0120)\end{array}$ & & $\begin{array}{l}-.0046 \\
(.0132)\end{array}$ & \\
\hline Democratic Dyad & & $\begin{array}{c}-1.4965^{\star * *} \\
(.3895)\end{array}$ & & $\begin{array}{c}-1.4422^{* * *} \\
(.3930)\end{array}$ \\
\hline Defensive Allies & $\begin{array}{l}-.2001 \\
(.1829)\end{array}$ & $\begin{array}{l}-.0492 \\
(.1919)\end{array}$ & $\begin{array}{l}-.1771 \\
(.1825)\end{array}$ & $\begin{array}{l}-.0486 \\
(.1949)\end{array}$ \\
\hline Log Peace-Years & $\begin{array}{r}-.5771^{* * *}(.0579)\end{array}$ & $\begin{array}{r}-.5314^{* * *} \\
(.0647)\end{array}$ & $\begin{array}{r}-.5839^{* * *} \\
(.0598)\end{array}$ & $\begin{array}{r}-.5426^{* \star *} \\
(.0664)\end{array}$ \\
\hline Closest Contiguity & $\begin{array}{r}-.2784^{* \star *} \\
(.0346)\end{array}$ & & $\begin{array}{r}-.2820^{\star \star *} \\
(.0347)\end{array}$ & \\
\hline Any Land Contiguity & & $\begin{array}{c}1.2215^{\star \star *} \\
(.1805)\end{array}$ & & $\begin{array}{c}1.1592^{\star * *} \\
(.1797)\end{array}$ \\
\hline Constant & $\begin{array}{c}-3.3438^{* * *} \\
(.1554) \\
\end{array}$ & $\begin{array}{c}-5.1404^{* * *} \\
(.1946) \\
\end{array}$ & $\begin{array}{c}-3.4320^{* * *} \\
(.1671) \\
\end{array}$ & $\begin{array}{c}-5.0915^{\star * *} \\
(.1892) \\
\end{array}$ \\
\hline Observations & 95,197 & 85,765 & 92,077 & 83,626 \\
\hline Wald $\chi^{2}(7 \mathrm{Std} / 10$ Alt $)$ & 313.84 & 241.70 & 301.46 & 227.12 \\
\hline $\mathrm{p}$ & $<.0001$ & $<.0001$ & $<.0001$ & $<.0001$ \\
\hline Pseudo $R^{2}$ & .0896 & .0911 & .0904 & .0932 \\
\hline
\end{tabular}

${ }^{\circ} p<.10{ }^{*} p<.05 \quad{ }^{* *} p<.01{ }^{* * *} p<.001$ 
Table B-57. Comparison of Standard and Alternative Controls, Model 5 (Two Middle Coefficients).

\begin{tabular}{|c|c|c|c|c|}
\hline Variable & $\begin{array}{l}\text { MODEL } 5 \\
\text { Standard }\end{array}$ & Alternative & $\begin{array}{l}\text { MODEL } 5 \\
\text { Standard }\end{array}$ & Alternative \\
\hline $\begin{array}{l}\text { Christian (all) } \\
\text { GRP (every 10\%) }\end{array}$ & $\begin{array}{r}-.2013^{* * *} \\
(.0480)\end{array}$ & $\begin{array}{r}-.1485^{\star \star *} \\
(.0412)\end{array}$ & & \\
\hline $\begin{array}{l}\text { Buddhist Mix } \\
\text { Prevalence (binary) }\end{array}$ & & & $\begin{array}{r}.1954 \\
(.2209) \\
\end{array}$ & $\begin{array}{r}.1756 \\
(.2941) \\
\end{array}$ \\
\hline Log CINC Ratio & $\begin{array}{l}.0003 \\
(.0184)\end{array}$ & & $\begin{array}{l}.0047 \\
(.0180)\end{array}$ & \\
\hline Log GDPPC Ratio & & $\begin{array}{l}-.1048^{\circ} \\
(.0618)\end{array}$ & & $\begin{array}{l}-.1398^{\star} \\
(.0588)\end{array}$ \\
\hline Nuclear (State 1) & & $\begin{array}{l}.2770 \\
(.3920)\end{array}$ & & $\begin{array}{l}.3998 \\
(.4484)\end{array}$ \\
\hline Nuclear (State 2) & & $\begin{array}{l}-.2585 \\
(.2180)\end{array}$ & & $\begin{array}{l}-.2374 \\
(.2137)\end{array}$ \\
\hline Nuclear (Both) & & $\begin{array}{l}.2184 \\
(.7751)\end{array}$ & & $\begin{array}{l}.1928 \\
(.7715)\end{array}$ \\
\hline P5 & & $\begin{array}{l}-.7629^{\circ} \\
(.4072)\end{array}$ & & $\begin{array}{l}-.8730^{*} \\
(.4373)\end{array}$ \\
\hline Low Polity Score & $\begin{array}{l}-.0417^{\star *} \\
(.0159)\end{array}$ & & $\begin{array}{r}-.0462^{\star *} \\
(.0154)\end{array}$ & \\
\hline Polity Score & $\begin{array}{l}.0137 \\
(.0136)\end{array}$ & & $\begin{array}{l}-.0115 \\
(.0121)\end{array}$ & \\
\hline Democratic Dyad & & $\begin{array}{r}-1.2026^{* *} \\
(.4051)\end{array}$ & & $\begin{array}{c}-1.4868^{\star * \star} \\
(.3896)\end{array}$ \\
\hline Defensive Allies & $\begin{array}{l}-.1206 \\
(.1854)\end{array}$ & $\begin{array}{l}-.0292 \\
(.1940)\end{array}$ & $\begin{array}{l}-.2135 \\
(.1830)\end{array}$ & $\begin{array}{l}-.0717 \\
(.1923)\end{array}$ \\
\hline Log Peace-Years & $\begin{array}{r}-.5618^{* * *} \\
(.0608)\end{array}$ & $\begin{array}{r}-.5256^{\star * *} \\
(.0681)\end{array}$ & $\begin{array}{r}-.5773^{\star * *} \\
(.0584)\end{array}$ & $\begin{array}{r}-.5312^{* \star *} \\
(.0653)\end{array}$ \\
\hline Closest Contiguity & $\begin{array}{r}-.2746^{* * *} \\
(.0352)\end{array}$ & & $\begin{array}{r}-.2855^{\star * *} \\
(.0350)\end{array}$ & \\
\hline Any Land Contiguity & & $\begin{array}{c}1.1496^{\star * *} \\
(.1813)\end{array}$ & & $\begin{array}{c}1.2439^{* \star *} \\
(.1827)\end{array}$ \\
\hline Constant & $\begin{array}{c}-3.2971^{* * *} \\
(.1587) \\
\end{array}$ & $\begin{array}{c}-4.8251^{* * *} \\
(.2029) \\
\end{array}$ & $\begin{array}{c}-3.3312^{\star * *} \\
(.1554) \\
\end{array}$ & $\begin{array}{c}-5.1335^{\star * *} \\
(.1972) \\
\end{array}$ \\
\hline Observations & 92,077 & 83,626 & 93,566 & 84,266 \\
\hline Wald $\chi^{2}(7 \mathrm{Std} / 10$ Alt $)$ & 336.18 & 251.88 & 314.42 & 241.18 \\
\hline $\mathrm{p}$ & $<.0001$ & $<.0001$ & $<.0001$ & $<.0001$ \\
\hline Pseudo $\mathrm{R}^{2}$ & .0986 & .0984 & .0911 & .0932 \\
\hline
\end{tabular}

${ }^{\circ} p<.10{ }^{*} p<.05 \quad{ }^{* *} p<.01{ }^{* * *} p<.001$ 
Table B-58. Comparison of Regressions After Adding Regional Controls, Model 1 (Two Strong Coefficients).

\begin{tabular}{|c|c|c|c|c|}
\hline Variable & $\begin{array}{l}\text { MODEL } 1 \\
\text { Standard }\end{array}$ & With Regions & $\begin{array}{l}\text { MODEL } 1 \\
\text { Standard }\end{array}$ & With Regions \\
\hline $\begin{array}{l}\text { Christian (all) } \\
\text { Preference (binary) }\end{array}$ & $\begin{array}{l}-.3544^{* *} \\
(.1103)\end{array}$ & $\begin{array}{r}-.3484^{* *} \\
(.1331)\end{array}$ & & \\
\hline $\begin{array}{l}\text { Buddhist Mix } \\
\text { Prevalence (binary) }\end{array}$ & & & $\begin{array}{c}.3804^{\star *} \\
(.1247) \\
\end{array}$ & $\begin{array}{r}.1241 \\
(.1433) \\
\end{array}$ \\
\hline Log CINC Ratio & $\begin{array}{l}.0179 \\
(.0116)\end{array}$ & $\begin{array}{l}.0177 \\
(.0116)\end{array}$ & $\begin{array}{l}.0141 \\
(.0118)\end{array}$ & $\begin{array}{l}.0173 \\
(.0118)\end{array}$ \\
\hline Low Polity Score & $\begin{array}{l}-.0233^{*} \\
(.0094)\end{array}$ & $\begin{aligned}-.0197^{*} & (.0100)\end{aligned}$ & $\begin{array}{r}-.0279^{\star *} \\
(.0093)\end{array}$ & $\begin{array}{l}-.0233^{*} \\
(.0098)\end{array}$ \\
\hline Polity Score & $\begin{array}{l}-.0110 \\
(.0084)\end{array}$ & $\begin{array}{l}-.0154^{\circ} \\
(.0083)\end{array}$ & $\begin{array}{l}-.0177^{*} \\
(.0075)\end{array}$ & $\begin{array}{r}-.0218^{\star *} \\
(.0076)\end{array}$ \\
\hline Defensive Allies & $\begin{array}{l}-.0208 \\
(.0984)\end{array}$ & $\begin{array}{l}-.3598^{* *} \\
(.1108)\end{array}$ & $\begin{array}{l}-.0037 \\
(.0983)\end{array}$ & $\begin{array}{r}-.3566^{* *} \\
(.1099)\end{array}$ \\
\hline Log Peace-Years & $\begin{array}{r}-.6451^{* \star *} \\
(.0354)\end{array}$ & $\begin{array}{r}-.6343^{\star \star *} \\
(.0352)\end{array}$ & $\begin{array}{r}-.6489^{* * *} \\
(.0343)\end{array}$ & $\begin{array}{r}-.6307^{* * *} \\
(.0344)\end{array}$ \\
\hline Closest Contiguity & $\begin{array}{r}-.3106^{* \star *} \\
(.0201)\end{array}$ & $\begin{array}{r}-.2627^{\star * *} \\
(.0260)\end{array}$ & $\begin{array}{r}-.3237^{\star \star \star} \\
(.0201)\end{array}$ & $\begin{array}{r}-.2717^{\star * \star} \\
(.0260)\end{array}$ \\
\hline American Dyad & & $\begin{array}{c}1.3648^{* * *} \\
(.1838)\end{array}$ & & $\begin{array}{c}1.2139^{* * *} \\
(.1796)\end{array}$ \\
\hline European Dyad & & $\begin{array}{l}.3733^{*} \\
(.1599)\end{array}$ & & $\begin{array}{l}.3678^{*} \\
(.1616)\end{array}$ \\
\hline African Dyad & & $\begin{array}{c}.1388 \\
(.1774)\end{array}$ & & $\begin{array}{c}.1752 \\
(.1693)\end{array}$ \\
\hline Middle Eastern Dyad & & $\begin{array}{r}.8999^{* * *} \\
(.1741)\end{array}$ & & $\begin{array}{r}.9894^{\star * *} \\
(.1716)\end{array}$ \\
\hline Asia-Pacific Dyad & & $\begin{array}{r}.7422^{\star \star \star} \\
(.1531)\end{array}$ & & $\begin{array}{c}.8322^{* * *} \\
(.1524)\end{array}$ \\
\hline Constant & $\begin{array}{c}-1.9492^{* * *} \\
(.0926)\end{array}$ & $\begin{array}{c}-2.4674^{* \star *} \\
(.1778)\end{array}$ & $\begin{array}{c}-2.0375^{\star * *} \\
(.0922)\end{array}$ & $\begin{array}{c}-2.5469^{\star * *} \\
(.1784)\end{array}$ \\
\hline Observations & 90,234 & 90,234 & 93,777 & 93,777 \\
\hline Wald $\chi^{2}(7 \mathrm{Std} / 12 \mathrm{Alt})$ & 1019.80 & 1126.78 & 1034.94 & 1151.50 \\
\hline$p$ & $<.0001$ & $<.0001$ & $<.0001$ & $<.0001$ \\
\hline Pseudo $\mathrm{R}^{2}$ & .1306 & .1429 & .1309 & .1423 \\
\hline
\end{tabular}

${ }^{\circ} p<.10{ }^{*} p<.05 \quad{ }^{* *} p<.01{ }^{* * *} p<.001$ 
Table B-59. Comparison of Regressions After Adding Regional Controls, Model 1 (Two Weak Coefficients).

\begin{tabular}{|c|c|c|c|c|}
\hline Variable & $\begin{array}{l}\text { MODEL } 1 \\
\text { Standard }\end{array}$ & With Regions & $\begin{array}{l}\text { MODEL } 1 \\
\text { Standard }\end{array}$ & With Regions \\
\hline $\begin{array}{l}\text { Muslim (all) } \\
\text { GRP (every 10\%) }\end{array}$ & $\begin{array}{l}.0100 \\
(.0134)\end{array}$ & $\begin{array}{l}.0049 \\
(.0180)\end{array}$ & & \\
\hline \multicolumn{2}{|l|}{$\begin{array}{l}\text { Muslim (all) } \\
\text { Population (every 10\%) }\end{array}$} & & $\begin{array}{r}.0142 \\
(.0115) \\
\end{array}$ & $\begin{array}{r}.0199 \\
(.0144) \\
\end{array}$ \\
\hline Log CINC Ratio & $\begin{array}{l}.0226^{\circ} \\
(.0119)\end{array}$ & $\begin{array}{l}.0201^{\circ} \\
(.0117)\end{array}$ & $\begin{array}{l}.0246^{*} \\
(.0118)\end{array}$ & $\begin{array}{l}.0244^{*} \\
(.0116)\end{array}$ \\
\hline Low Polity Score & $\begin{array}{l}-.0238^{*} \\
(.0093)\end{array}$ & $\begin{array}{l}-.0199^{*} \\
(.0098)\end{array}$ & $\begin{array}{r}-.0253^{\star *} \\
(.0093)\end{array}$ & $\begin{array}{l}-.0222^{*} \\
(.0097)\end{array}$ \\
\hline Polity Score & $\begin{array}{r}-.0217^{\star *} \\
(.0077)\end{array}$ & $\begin{array}{l}-.0240^{\star *} \\
(.0077)\end{array}$ & $\begin{array}{r}-.0203^{\star *} \\
(.0075)\end{array}$ & $\begin{array}{r}-.0223^{\star *} \\
(.0076)\end{array}$ \\
\hline Defensive Allies & $\begin{array}{l}-.0251 \\
(.0990)\end{array}$ & $\begin{array}{l}-.3254^{\star *} \\
(.1119)\end{array}$ & $\begin{array}{l}-.0665 \\
(.0967)\end{array}$ & $\begin{array}{r}-.3606^{* * *} \\
(.1093)\end{array}$ \\
\hline Log Peace-Years & $\begin{array}{r}-.6432^{* * *} \\
(.0356)\end{array}$ & $\begin{array}{r}-.6285^{* * *} \\
(.0351)\end{array}$ & $\begin{array}{r}-.6502^{* * *} \\
(.0343)\end{array}$ & $\begin{array}{r}-.6341^{* * *} \\
(.0340)\end{array}$ \\
\hline Closest Contiguity & $\begin{array}{r}-.3088^{\star * *} \\
(.0200)\end{array}$ & $\begin{array}{r}-.2663^{* * *} \\
(.0261)\end{array}$ & $\begin{array}{r}-.3143^{\star * *} \\
(.0194)\end{array}$ & $\begin{array}{r}-.2622^{* * *} \\
(.0251)\end{array}$ \\
\hline American Dyad & & $\begin{array}{c}1.1751^{* * *} \\
(.1798)\end{array}$ & & $\begin{array}{c}1.2911^{* * *} \\
(.1776)\end{array}$ \\
\hline European Dyad & & $\begin{array}{l}.3407^{\star} \\
(.1632)\end{array}$ & & $\begin{array}{l}.4172^{\star \star} \\
(.1609)\end{array}$ \\
\hline African Dyad & & $\begin{array}{l}.0723 \\
(.1752)\end{array}$ & & $\begin{array}{l}.1829 \\
(.1648)\end{array}$ \\
\hline Middle Eastern Dyad & & $\begin{array}{r}.9392^{* * *} \\
(.2056)\end{array}$ & & $\begin{array}{r}.8893^{* * *} \\
(.1885)\end{array}$ \\
\hline Asia-Pacific Dyad & & $\begin{array}{r}.8402^{* * *} \\
(.1465)\end{array}$ & & $\begin{array}{r}.9146^{* * *} \\
(.1415)\end{array}$ \\
\hline Constant & $\begin{array}{c}-2.0463^{* * *} \\
(.1057) \\
\end{array}$ & $\begin{array}{c}-2.5454^{* * *} \\
(.1836) \\
\end{array}$ & $\begin{array}{c}-2.0320^{* * *} \\
(.1080) \\
\end{array}$ & $\begin{array}{c}-2.6374^{* * *} \\
(.1812) \\
\end{array}$ \\
\hline Observations & 92,277 & 92,277 & 95,418 & 95,418 \\
\hline Wald $\chi^{2}$ (7 Std/12 Alt) & 1001.90 & 1132.11 & 1066.68 & 1192.40 \\
\hline$p$ & $<.0001$ & $<.0001$ & $<.0001$ & $<.0001$ \\
\hline Pseudo $\mathrm{R}^{2}$ & .1257 & .1382 & .1302 & .1429 \\
\hline
\end{tabular}

${ }^{\circ} p<.10{ }^{*} p<.05 \quad{ }^{* *} p<.01{ }^{* * *} p<.001$ 
Table B-60. Comparison of Regressions After Adding Regional Controls, Model 1 (Two Middle Coefficients).

\begin{tabular}{|c|c|c|c|c|}
\hline Variable & $\begin{array}{l}\text { MODEL } 1 \\
\text { Standard }\end{array}$ & With Regions & $\begin{array}{l}\text { MODEL } 1 \\
\text { Standard }\end{array}$ & With Regions \\
\hline $\begin{array}{l}\text { Christian (all) } \\
\text { GRP (every 10\%) }\end{array}$ & $\begin{array}{r}-.0620^{* *} \\
(.0234)\end{array}$ & $\begin{array}{l}-.0573^{*} \\
(.0263)\end{array}$ & & \\
\hline $\begin{array}{l}\text { Atheist } \\
\text { Preference (binary) }\end{array}$ & & & $\begin{array}{r}.2389^{*} \\
(.1111) \\
\end{array}$ & $\begin{array}{r}.3047^{*} \\
(.1337) \\
\end{array}$ \\
\hline Log CINC Ratio & $\begin{array}{l}.0172 \\
(.0116)\end{array}$ & $\begin{array}{l}.0160 \\
(.0117)\end{array}$ & $\begin{array}{l}.0139 \\
(.0125)\end{array}$ & $\begin{array}{l}.0107 \\
(.0128)\end{array}$ \\
\hline Low Polity Score & $\begin{array}{l}-.0226^{*} \\
(.0093)\end{array}$ & $\begin{array}{r}-.0192^{\circ} \\
(.0099)\end{array}$ & $\begin{array}{r}-.0267^{* *} \\
(.0092)\end{array}$ & $\begin{array}{l}-.0199^{*} \\
(.0098)\end{array}$ \\
\hline Polity Score & $\begin{array}{l}-.0136 \\
(.0085)\end{array}$ & $\begin{array}{l}-.0179^{*} \\
(.0083)\end{array}$ & $\begin{array}{l}-.0158^{*} \\
(.0081)\end{array}$ & $\begin{array}{r}-.0156^{\circ} \\
(.0086)\end{array}$ \\
\hline Defensive Allies & $\begin{array}{l}.0030 \\
(.0977)\end{array}$ & $\begin{array}{l}-.3305^{\star *} \\
(.1109)\end{array}$ & $\begin{array}{l}-.0312 \\
\quad(.0977)\end{array}$ & $\begin{array}{r}-.3557^{* *} \\
(.1100)\end{array}$ \\
\hline Log Peace-Years & $\begin{array}{r}-.6385^{* * *} \\
(.0352)\end{array}$ & $\begin{array}{r}-.6268^{* * *} \\
(.0350)\end{array}$ & $\begin{array}{r}-.6497^{* * *} \\
(.0348)\end{array}$ & $\begin{array}{r}-.6312^{* * *} \\
(.0347)\end{array}$ \\
\hline Closest Contiguity & $\begin{array}{r}-.3113^{\star * *} \\
(.0202)\end{array}$ & $\begin{array}{r}-.2671^{* * *} \\
(.0262)\end{array}$ & $\begin{array}{r}-.3203^{* * *} \\
(.0199)\end{array}$ & $\begin{array}{r}-.2736^{\star * *} \\
(.0260)\end{array}$ \\
\hline American Dyad & & $\begin{array}{c}1.3024^{\star * *} \\
(.1828)\end{array}$ & & $\begin{array}{c}1.2311^{* * *} \\
(.1781)\end{array}$ \\
\hline European Dyad & & $\begin{array}{l}.3630^{*} \\
(.1602)\end{array}$ & & $\begin{array}{l}.2761^{\circ} \\
(.1642)\end{array}$ \\
\hline African Dyad & & $\begin{array}{l}.1052 \\
(.1744)\end{array}$ & & $\begin{array}{l}.1781 \\
(.1773)\end{array}$ \\
\hline Middle Eastern Dyad & & $\begin{array}{r}.8929^{* * *} \\
(.1754)\end{array}$ & & $\begin{array}{c}1.0969^{* * *} \\
(.1801)\end{array}$ \\
\hline Asia-Pacific Dyad & & $\begin{array}{r}.7617^{\star * *} \\
(.1528)\end{array}$ & & $\begin{array}{r}.8030^{\star * *} \\
(.1482)\end{array}$ \\
\hline Constant & $\begin{array}{c}-1.9894^{* * *} \\
(.0930) \\
\end{array}$ & $\begin{array}{c}-2.4850^{* * *} \\
(.1795) \\
\end{array}$ & $\begin{array}{c}-2.0684^{* * *} \\
(.0970) \\
\end{array}$ & $\begin{array}{c}-2.6637^{* * *} \\
(.1911) \\
\end{array}$ \\
\hline Observations & 92,277 & 92,277 & 93,474 & 93,474 \\
\hline Wald $\chi^{2}(7 \mathrm{Std} / 12 \mathrm{Alt})$ & 1010.45 & 1124.14 & 1020.32 & 1154.58 \\
\hline$p$ & $<.0001$ & $<.0001$ & $<.0001$ & $<.0001$ \\
\hline Pseudo $\mathrm{R}^{2}$ & .1268 & .1390 & .1286 & .1416 \\
\hline
\end{tabular}

${ }^{\circ} p<.10{ }^{*} p<.05{ }^{* *} p<.01{ }^{* * *} p<.001$ 
Table B-61. Comparison of Regressions After Adding Regional Controls, Model 5 (Two Strong Coefficients).

\begin{tabular}{|c|c|c|c|c|}
\hline Variable & $\begin{array}{l}\text { MODEL } 5 \\
\text { Standard }\end{array}$ & With Regions & $\begin{array}{l}\text { MODEL } 5 \\
\text { Standard }\end{array}$ & With Regions \\
\hline $\begin{array}{l}\text { Christian (all) } \\
\text { Preference (binary) }\end{array}$ & $\begin{array}{r}-.9542^{* * *} \\
(.2207)\end{array}$ & $\begin{array}{r}-.9178^{* * *} \\
(.2521)\end{array}$ & & \\
\hline $\begin{array}{l}\text { Muslim (all) } \\
\text { Prevalence (binary) }\end{array}$ & & & $\begin{array}{c}.5368^{\star \star} \\
(.1782) \\
\end{array}$ & $\begin{array}{r}.4514^{*} \\
(.2236) \\
\end{array}$ \\
\hline Log CINC Ratio & $\begin{array}{l}.0064 \\
(.0184)\end{array}$ & $\begin{array}{l}.0058 \\
(.0190)\end{array}$ & $\begin{array}{l}.0183 \\
(.0198)\end{array}$ & $\begin{array}{c}.0134 \\
(.0201)\end{array}$ \\
\hline Low Polity Score & $\begin{array}{l}-.0404^{*} \\
(.0162)\end{array}$ & $\begin{array}{l}-.0357^{*} \\
(.0163)\end{array}$ & $\begin{array}{r}-.0439^{\star *} \\
(.0158)\end{array}$ & $\begin{aligned}-.0422^{* *} & (.0157)\end{aligned}$ \\
\hline Polity Score & $\begin{array}{l}.0158 \\
(.0139)\end{array}$ & $\begin{array}{l}.0114 \\
(.0141)\end{array}$ & $\begin{array}{l}-.0081 \\
(.0128)\end{array}$ & $\begin{array}{l}-.0089 \\
(.0128)\end{array}$ \\
\hline Defensive Allies & $\begin{array}{l}-.1278 \\
(.1892)\end{array}$ & $\begin{array}{l}-.3967^{*} \\
(.1999)\end{array}$ & $\begin{array}{r}-.2461 \\
(.1816)\end{array}$ & $\begin{array}{r}-.3904^{\circ} \\
(.2022)\end{array}$ \\
\hline Log Peace-Years & $\begin{array}{r}-.5750^{* \star \star} \\
(.0611)\end{array}$ & $\begin{array}{r}-.5561^{\star \star *} \\
(.0622)\end{array}$ & $\begin{array}{r}-.5760^{* * *} \\
(.0594)\end{array}$ & $\begin{array}{r}-.5512^{* \star *} \\
(.0603)\end{array}$ \\
\hline Closest Contiguity & $\begin{array}{r}-.2649^{* \star *} \\
(.0351)\end{array}$ & $\begin{array}{r}-.2387^{\star * *} \\
(.0428)\end{array}$ & $\begin{array}{r}-.2591^{* * *} \\
(.0352)\end{array}$ & $\begin{array}{r}-.2238^{\star * *} \\
(.0415)\end{array}$ \\
\hline American Dyad & & $\begin{array}{l}.7808^{*} \\
(.3510)\end{array}$ & & $\begin{array}{l}.5096 \\
(.3554)\end{array}$ \\
\hline European Dyad & & $\begin{array}{l}.3147 \\
(.2581)\end{array}$ & & $\begin{array}{c}.4174 \\
(.2652)\end{array}$ \\
\hline African Dyad & & $\begin{array}{l}-.0300 \\
(.2966)\end{array}$ & & $\begin{array}{l}-.0174 \\
(.2862)\end{array}$ \\
\hline Middle Eastern Dyad & & $\begin{array}{c}.8426^{* *} \\
(.2623)\end{array}$ & & $\begin{array}{l}.8280^{\star *} \\
(.2831)\end{array}$ \\
\hline Asia-Pacific Dyad & & $\begin{array}{c}.2096 \\
(.2510)\end{array}$ & & $\begin{array}{l}.6100^{* *} \\
(.2346)\end{array}$ \\
\hline Constant & $\begin{array}{c}-3.2999^{\star * * *} \\
(.1629) \\
\end{array}$ & $\begin{array}{c}-3.6017^{* * *} \\
(.2754)\end{array}$ & $\begin{array}{c}-3.5707^{* * *} \\
(.2069) \\
\end{array}$ & $\begin{array}{c}-3.9749^{* * *} \\
(.3027) \\
\end{array}$ \\
\hline Observations & 90,036 & 90,036 & 90,233 & 90,233 \\
\hline Wald $\chi^{2}(7 \mathrm{Std} / 12 \mathrm{Alt})$ & 348.44 & 395.52 & 350.16 & 382.83 \\
\hline$p$ & $<.0001$ & $<.0001$ & $<.0001$ & $<.0001$ \\
\hline Pseudo $\mathrm{R}^{2}$ & .1010 & .1066 & .0957 & .1018 \\
\hline
\end{tabular}

${ }^{\circ} p<.10{ }^{*} p<.05 \quad{ }^{* *} p<.01{ }^{* * *} p<.001$ 
Table B-62. Comparison of Regressions After Adding Regional Controls, Model 5 (Two Weak Coefficients).

\begin{tabular}{|c|c|c|c|c|}
\hline Variable & $\begin{array}{l}\text { MODEL } 5 \\
\text { Standard }\end{array}$ & With Regions & $\begin{array}{l}\text { MODEL } 5 \\
\text { Standard }\end{array}$ & With Regions \\
\hline $\begin{array}{l}\text { Buddhist Mix } \\
\text { Pop. (every } 10 \% \text { ) }\end{array}$ & $\begin{array}{l}.0140 \\
(.0250)\end{array}$ & $\begin{array}{l}.0033 \\
(.0298)\end{array}$ & & \\
\hline $\begin{array}{l}\text { Atheist } \\
\text { GRP (every 10\%) }\end{array}$ & & & $\begin{array}{r}.0367^{\circ} \\
(.0214) \\
\end{array}$ & $\begin{array}{l}.0585^{\circ} \\
(.0306) \\
\end{array}$ \\
\hline Log CINC Ratio & $\begin{array}{l}.0085 \\
(.0178)\end{array}$ & $\begin{array}{l}.0096 \\
(.0184)\end{array}$ & $\begin{array}{r}-.0045 \\
(.0211)\end{array}$ & $\begin{array}{l}-.0146 \\
(.0237)\end{array}$ \\
\hline Low Polity Score & $\begin{array}{r}-.0471^{* *} \\
(.0154)\end{array}$ & $\begin{array}{l}-.0394^{*} \\
(.0156)\end{array}$ & $\begin{array}{l}-.0498^{* *} \\
(.0155)\end{array}$ & $\begin{array}{l}-.0383^{*} \\
(.0157)\end{array}$ \\
\hline Polity Score & $\begin{array}{l}-.0128 \\
(.0120)\end{array}$ & $\begin{array}{l}-.0129 \\
(.0124)\end{array}$ & $\begin{array}{l}-.0046 \\
(.0132)\end{array}$ & $\begin{array}{l}.0032 \\
(.0149)\end{array}$ \\
\hline Defensive Allies & $\begin{array}{l}-.2001 \\
(.1829)\end{array}$ & $\begin{array}{c}-.4067^{*} \\
(.1997)\end{array}$ & $\begin{array}{c}-.1771 \\
(.1825)\end{array}$ & $\begin{array}{c}-.3586^{\circ} \\
(.1997)\end{array}$ \\
\hline Log Peace-Years & $\begin{array}{r}-.5771^{\star * *} \\
(.0579)\end{array}$ & $\begin{array}{r}-.5411^{\star * *} \\
(.0598)\end{array}$ & $\begin{array}{r}-.5839^{* \star *} \\
(.0598)\end{array}$ & $\begin{array}{r}-.5502^{* * *} \\
(.0616)\end{array}$ \\
\hline Closest Contiguity & $\begin{array}{r}-.2784^{\star \star \star} \\
(.0346)\end{array}$ & $\begin{array}{r}-.2400^{\star * *} \\
(.0414)\end{array}$ & $\begin{array}{r}-.2820^{* \star *} \\
(.0347)\end{array}$ & $\begin{array}{r}-.2526^{\star * \star} \\
(.0426)\end{array}$ \\
\hline American Dyad & & $\begin{array}{l}.4015 \\
(.3578)\end{array}$ & & $\begin{array}{l}.3756 \\
(.3549)\end{array}$ \\
\hline European Dyad & & $\begin{array}{c}.3280 \\
(.2598)\end{array}$ & & $\begin{array}{c}.1025 \\
(.2874)\end{array}$ \\
\hline African Dyad & & $\begin{array}{l}.0517 \\
(.2785)\end{array}$ & & $\begin{array}{l}.0616 \\
(.3062)\end{array}$ \\
\hline Middle Eastern Dyad & & $\begin{array}{c}1.1320^{* * *} \\
(.2646)\end{array}$ & & $\begin{array}{c}1.2413^{\star \star *} \\
(.2824)\end{array}$ \\
\hline Asia-Pacific Dyad & & $\begin{array}{l}.5295^{\star} \\
(.2479)\end{array}$ & & $\begin{array}{c}.4536^{\circ} \\
(.2469)\end{array}$ \\
\hline Constant & $\begin{array}{c}-3.3438^{\star * *} \\
(.1554) \\
\end{array}$ & $\begin{array}{c}-3.8168^{* * *} \\
(.2814) \\
\end{array}$ & $\begin{array}{c}-3.4320^{* * *} \\
(.1671) \\
\end{array}$ & $\begin{array}{c}-3.9813^{* * *} \\
(.3097) \\
\end{array}$ \\
\hline Observations & 95,197 & 95,197 & 92,077 & 92,077 \\
\hline Wald $\chi^{2}$ (7 Std/12 Alt) & 313.84 & 363.35 & 301.46 & 358.72 \\
\hline$p$ & $<.0001$ & $<.0001$ & $<.0001$ & $<.0001$ \\
\hline Pseudo $\mathrm{R}^{2}$ & .0896 & .0978 & .0904 & .0996 \\
\hline
\end{tabular}

${ }^{\circ} p<.10{ }^{*} p<.05 \quad{ }^{* *} p<.01{ }^{* * *} p<.001$ 
Table B-63. Comparison of Regressions After Adding Regional Controls, Model 5 (Two Middle Coefficients).

\begin{tabular}{|c|c|c|c|c|}
\hline Variable & $\begin{array}{l}\text { MODEL } 5 \\
\text { Standard }\end{array}$ & With Regions & $\begin{array}{l}\text { MODEL } 5 \\
\text { Standard }\end{array}$ & With Regions \\
\hline $\begin{array}{l}\text { Christian (all) } \\
\text { GRP (every 10\%) }\end{array}$ & $\begin{array}{r}-.2013^{* * *} \\
(.0480)\end{array}$ & $\begin{array}{r}-.1866^{* * *} \\
(.0524)\end{array}$ & & \\
\hline $\begin{array}{l}\text { Buddhist Mix } \\
\text { Prevalence (binary) }\end{array}$ & & & $\begin{array}{r}.1954 \\
(.2209) \\
\end{array}$ & $\begin{array}{r}.0813 \\
(.2572) \\
\end{array}$ \\
\hline Log CINC Ratio & $\begin{array}{l}.0003 \\
(.0184)\end{array}$ & $\begin{array}{l}-.0004 \\
(.0192)\end{array}$ & $\begin{array}{l}.0047 \\
(.0180)\end{array}$ & $\begin{array}{l}.0051 \\
(.0185)\end{array}$ \\
\hline Low Polity Score & $\begin{array}{r}-.0417^{* *} \\
(.0159)\end{array}$ & $\begin{array}{l}-.0375^{\star} \\
(.0160)\end{array}$ & $\begin{array}{l}-.0462^{* *} \\
(.0154)\end{array}$ & $\begin{array}{l}-.0384^{*} \\
(.0157)\end{array}$ \\
\hline Polity Score & $\begin{array}{l}.0137 \\
(.0136)\end{array}$ & $\begin{array}{l}.0091 \\
(.0137)\end{array}$ & $\begin{array}{l}-.0115 \\
(.0121)\end{array}$ & $\begin{array}{l}-.0115 \\
(.0125)\end{array}$ \\
\hline Defensive Allies & $\begin{array}{l}-.1206 \\
(.1854)\end{array}$ & $\begin{array}{c}-.3734^{\circ} \\
(.1981)\end{array}$ & $\begin{array}{l}-.2135 \\
(.1830)\end{array}$ & $\begin{array}{c}-.4108^{*} \\
(.1996)\end{array}$ \\
\hline Log Peace-Years & $\begin{array}{r}-.5618^{\star \star *} \\
(.0608)\end{array}$ & $\begin{array}{r}-.5416^{\star * *} \\
(.0620)\end{array}$ & $\begin{array}{r}-.5773^{* \star *} \\
(.0584)\end{array}$ & $\begin{array}{r}-.5407^{\star * *} \\
(.0603)\end{array}$ \\
\hline Closest Contiguity & $\begin{array}{r}-.2746^{\star \star \star} \\
(.0352)\end{array}$ & $\begin{array}{r}-.2443^{\star * *} \\
(.0427)\end{array}$ & $\begin{array}{r}-.2855^{\star \star \star} \\
(.0350)\end{array}$ & $\begin{array}{r}-.2493^{* \star *} \\
(.0417)\end{array}$ \\
\hline American Dyad & & $\begin{array}{l}.7594^{*} \\
(.3521)\end{array}$ & & $\begin{array}{l}.3704 \\
(.3582)\end{array}$ \\
\hline European Dyad & & $\begin{array}{l}.3609 \\
(.2583)\end{array}$ & & $\begin{array}{l}.2950 \\
(.2609)\end{array}$ \\
\hline African Dyad & & $\begin{array}{l}-.0050 \\
(.2894)\end{array}$ & & $\begin{array}{l}.0214 \\
(.2775)\end{array}$ \\
\hline Middle Eastern Dyad & & $\begin{array}{l}.8550^{* *} \\
(.2647)\end{array}$ & & $\begin{array}{c}1.1099^{\star \star *} \\
(.2636)\end{array}$ \\
\hline Asia-Pacific Dyad & & $\begin{array}{l}.3053 \\
(.2473)\end{array}$ & & $\begin{array}{l}.5533^{\star} \\
(.2481)\end{array}$ \\
\hline Constant & $\begin{array}{c}-3.2971^{* * *} \\
(.1587) \\
\end{array}$ & $\begin{array}{c}-3.6441^{* * *} \\
(.2775) \\
\end{array}$ & $\begin{array}{c}-3.3312^{* * *} \\
(.1554) \\
\end{array}$ & $\begin{array}{c}-3.7847^{* * *} \\
(.2793) \\
\end{array}$ \\
\hline Observations & 92,077 & 92,077 & 93,566 & 93,566 \\
\hline Wald $\chi^{2}$ (7 Std/12 Alt) & 336.18 & 378.75 & 314.42 & 365.75 \\
\hline$p$ & $<.0001$ & $<.0001$ & $<.0001$ & $<.0001$ \\
\hline Pseudo $\mathrm{R}^{2}$ & .0986 & .1040 & .0911 & .0994 \\
\hline
\end{tabular}

${ }^{\circ} p<.10{ }^{*} p<.05{ }^{* *} p<.01{ }^{* * *} p<.001$ 
Table B-64. Comparison of Logit Diagnostics of Variables Regressed Individually (Model 1).

\begin{tabular}{|c|c|c|c|c|}
\hline Variable & Observations & Wald $\chi^{2}(1)$ & $p$ & Pseudo $\mathrm{R}^{2}$ \\
\hline Christian Chief Exec. (binary) & 106,949 & 310.49 & $<.0001$ & .0194 \\
\hline Christian Preference (binary) & 107,138 & 450.82 & $<.0001$ & .0293 \\
\hline Christian GRP (every 10\%) & 109,626 & 332.56 & $<.0001$ & .0258 \\
\hline Christian Prevalence (binary) & 105,708 & 454.60 & $<.0001$ & .0301 \\
\hline Christian Pop. (every 10\%) & 116,147 & 454.73 & $<.0001$ & .0296 \\
\hline Muslim Chief Exec. (binary) & 107,361 & 155.95 & $<.0001$ & .0081 \\
\hline Muslim Preference (binary) & 108,332 & 129.25 & $<.0001$ & .0068 \\
\hline Muslim GRP (every 10\%) & 109,626 & 155.01 & $<.0001$ & .0076 \\
\hline Muslim Prevalence (binary) & 110,478 & 197.48 & $<.0001$ & .0099 \\
\hline Muslim Pop. (every 10\%) & 116,147 & 219.12 & $<.0001$ & .0107 \\
\hline Buddhist Mix Chief Exec. (binary) & 107,361 & 10.67 & .0011 & .0006 \\
\hline Buddhist Mix Preference (binary) & 110,806 & 37.66 & $<.0001$ & .0019 \\
\hline Buddhist Mix GRP (every 10\%) & 109,626 & 76.91 & $<.0001$ & .0032 \\
\hline Buddhist Mix Prevalence (binary) & 114,133 & 62.99 & $<.0001$ & .0032 \\
\hline Buddhist Mix Pop. (every 10\%) & 116,147 & 57.33 & $<.0001$ & .0027 \\
\hline Atheist Chief Exec. (binary) & 107,361 & 23.82 & $<.0001$ & .0013 \\
\hline Atheist Preference (binary) & 111,087 & 91.86 & $<.0001$ & .0048 \\
\hline Atheist GRP (every 10\%) & 109,626 & 72.19 & $<.0001$ & .0038 \\
\hline Log CINC Ratio & 116,268 & 1.22 & .2697 & $<.0001$ \\
\hline Low Polity Score & 104,064 & 284.52 & $<.0001$ & .0203 \\
\hline Polity Score & 109,802 & 271.75 & $<.0001$ & .0155 \\
\hline Defensive Allies & 112,822 & 3.09 & .0788 & .0002 \\
\hline Log Peace-Years & 109,896 & 606.72 & $<.0001$ & .0734 \\
\hline Closest Contiguity & 116,362 & 1481.23 & $<.0001$ & .0899 \\
\hline
\end{tabular}


Table B-65. Comparison of Logit Diagnostics of Variables Regressed Individually (Model 5).

\begin{tabular}{|c|c|c|c|c|}
\hline Variable & Observations & Wald $\chi^{2}(1)$ & $\mathrm{p}$ & Pseudo $\mathrm{R}^{2}$ \\
\hline Christian Chief Exec. (binary) & 106,240 & 234.11 & $<.0001$ & .0364 \\
\hline Christian Preference (binary) & 106,471 & 304.83 & $<.0001$ & .0497 \\
\hline Christian GRP (every 10\%) & 108,989 & 235.71 & $<.0001$ & .0488 \\
\hline Christian Prevalence (binary) & 105,039 & 292.15 & $<.0001$ & .0463 \\
\hline Christian Pop. (every 10\%) & 115,407 & 283.25 & $<.0001$ & .0464 \\
\hline Muslim Chief Exec. (binary) & 106,650 & 94.56 & $<.0001$ & .0104 \\
\hline Muslim Preference (binary) & 107,661 & 103.85 & $<.0001$ & .0114 \\
\hline Muslim GRP (every 10\%) & 108,989 & 107.79 & $<.0001$ & .0106 \\
\hline Muslim Prevalence (binary) & 109,776 & 118.10 & $<.0001$ & .0126 \\
\hline Muslim Pop. (every 10\%) & 115,407 & 131.04 & $<.0001$ & .0131 \\
\hline Buddhist Mix Chief Exec. (binary) & 106,650 & 9.33 & .0023 & .0010 \\
\hline Buddhist Mix Preference (binary) & 110,121 & 11.79 & .0006 & .0013 \\
\hline Buddhist Mix GRP (every 10\%) & 108,989 & 63.53 & $<.0001$ & .0050 \\
\hline Buddhist Mix Prevalence (binary) & 113,432 & 43.66 & $<.0001$ & .0046 \\
\hline Buddhist Mix Pop. (every 10\%) & 115,407 & 40.66 & $<.0001$ & .0041 \\
\hline Atheist Chief Exec. (binary) & 106,650 & 13.40 & .0003 & .0015 \\
\hline Atheist Preference (binary) & 110,402 & 65.72 & $<.0001$ & .0072 \\
\hline Atheist GRP (every $10 \%$ ) & 108,989 & 67.25 & $<.0001$ & .0074 \\
\hline Log CINC Ratio & 115,527 & 3.24 & .0719 & .0001 \\
\hline Low Polity Score & 103,353 & 128.06 & $<.0001$ & .0189 \\
\hline Polity Score & 109,076 & 103.14 & $<.0001$ & .0129 \\
\hline Defensive Allies & 112,095 & 21.44 & $<.0001$ & .0029 \\
\hline Log Peace-Years & 109,666 & 172.61 & $<.0001$ & .0502 \\
\hline Closest Contiguity & 115,621 & 533.64 & $<.0001$ & .0761 \\
\hline
\end{tabular}


Tables for Chapter 5

Table B-66. Logit of Western Christian Chief Executive.

\begin{tabular}{|c|c|c|c|c|c|}
\hline Variable & Model 1 & Model 2 & Model 3 & Model 4 & Model 5 \\
\hline $\begin{array}{l}\text { Western Christian } \\
\text { Chief Exec. (binary) }\end{array}$ & $\begin{array}{r}-.3051^{* *} \\
(.0936) \\
\end{array}$ & $\begin{array}{r}-.3442^{\star * *} \\
(.0999) \\
\end{array}$ & $\begin{array}{r}-.4235^{\star * *} \\
(.1060) \\
\end{array}$ & $\begin{array}{r}-.4792^{* * *} \\
(.1160) \\
\end{array}$ & $\begin{array}{r}-.9612^{* * *} \\
(.2000) \\
\end{array}$ \\
\hline Log CINC Ratio & $\begin{array}{l}.0120 \\
(.0117)\end{array}$ & $\begin{array}{l}-.0084 \\
(.0119)\end{array}$ & $\begin{array}{l}.0413^{* *} \\
(.0129)\end{array}$ & $\begin{array}{l}.0192 \\
(.0134)\end{array}$ & $\begin{array}{l}.0062 \\
(.0194)\end{array}$ \\
\hline Low Polity Score & $\begin{array}{l}-.0228^{*} \\
(.0091)\end{array}$ & $\begin{array}{l}-.0199^{\star} \\
(.0096)\end{array}$ & $\begin{array}{r}-.0351^{* \star *} \\
(.0103)\end{array}$ & $\begin{array}{l}-.0326^{* *} \\
(.0110)\end{array}$ & $\begin{array}{r}-.0447^{* *} \\
(.0157)\end{array}$ \\
\hline Polity Score & $\begin{array}{l}-.0099 \\
(.0076)\end{array}$ & $\begin{array}{l}-.0169^{*} \\
(.0081)\end{array}$ & $\begin{array}{l}-.0057 \\
(.0081)\end{array}$ & $\begin{array}{r}-.0145 \\
(.0088)\end{array}$ & $\begin{array}{l}.0167 \\
(.0128)\end{array}$ \\
\hline Defensive Allies & $\begin{array}{l}-.0061 \\
(.0973)\end{array}$ & $\begin{array}{l}.0364 \\
(.1010)\end{array}$ & $\begin{array}{l}-.0524 \\
(.1054)\end{array}$ & $\begin{array}{l}-.0086 \\
(.1099)\end{array}$ & $\begin{array}{l}-.0454 \\
(.1880)\end{array}$ \\
\hline Log Peace-Years & $\begin{array}{r}-.6469^{* * *} \\
(.0355)\end{array}$ & $\begin{array}{r}-.6567^{\star * *} \\
(.0371)\end{array}$ & $\begin{array}{r}-6422^{* * *} \\
(.0388)\end{array}$ & $\begin{array}{r}-6523^{* * *} \\
(.0411)\end{array}$ & $\begin{array}{r}-.5490^{* * *} \\
(.0624)\end{array}$ \\
\hline Closest Contiguity & $\begin{array}{r}-3138^{* * *} \\
(.0201)\end{array}$ & $\begin{array}{r}-.2996^{* * *} \\
(.0208)\end{array}$ & $\begin{array}{r}-.3448^{* * *} \\
(.0224)\end{array}$ & $\begin{array}{r}-.3299^{* * *} \\
(.0234)\end{array}$ & $\begin{array}{r}-.2817^{* * *} \\
(.0360)\end{array}$ \\
\hline Constant & $\begin{array}{c}-1.9556^{\star \star *} \\
(.0922) \\
\end{array}$ & $\begin{array}{c}-2.0178^{\star \star \star} \\
(.0949) \\
\end{array}$ & $\begin{array}{c}-2.0090^{* * *} \\
(.0966) \\
\end{array}$ & $\begin{array}{c}-2.0694^{* * *} \\
(.0993) \\
\end{array}$ & $\begin{array}{c}-3.3665^{\star \star *} \\
(.1638) \\
\end{array}$ \\
\hline Observations & 87,766 & 87,766 & 87,766 & 87,766 & 87,557 \\
\hline Wald $\chi^{2}(7)$ & 1000.42 & 1009.43 & 911.11 & 916.72 & 330.28 \\
\hline$p$ & $<.0001$ & $<.0001$ & $<.0001$ & $<.0001$ & $<.0001$ \\
\hline Pseudo $\mathrm{R}^{2}$ & .1303 & .1299 & .1405 & .1404 & .1005 \\
\hline
\end{tabular}

${ }^{\circ} p<.10{ }^{*} p<.05{ }^{* *} p<.01{ }^{* * *} p<.001$ 
Table B-67. Logit of Western Christian Preference.

\begin{tabular}{|c|c|c|c|c|c|}
\hline Variable & Model 1 & Model 2 & Model 3 & Model 4 & Model 5 \\
\hline $\begin{array}{l}\text { Western Christian } \\
\text { Preference (binary) }\end{array}$ & $\begin{array}{r}-.3475^{* *} \\
(.1059) \\
\end{array}$ & $\begin{array}{r}-3880^{* * *} \\
(.1119) \\
\end{array}$ & $\begin{array}{r}-.4128^{* * *} \\
(.1200) \\
\end{array}$ & $\begin{array}{r}-.4617^{* * *} \\
(.1294) \\
\end{array}$ & $\begin{array}{c}-1.0717^{* * *} \\
(.2220)\end{array}$ \\
\hline Log CINC Ratio & $\begin{array}{l}.0182 \\
(.0116)\end{array}$ & $\begin{array}{l}-.0013 \\
(.0118)\end{array}$ & $\begin{array}{r}.0468^{* \star \star} \\
(.0127)\end{array}$ & $\begin{array}{l}.0257^{*} \\
(.0131)\end{array}$ & $\begin{array}{l}.0076 \\
(.0184)\end{array}$ \\
\hline Low Polity Score & $\begin{array}{r}-.0250^{* *} \\
(.0093)\end{array}$ & $\begin{array}{l}-.0212^{*} \\
(.0098)\end{array}$ & $\begin{array}{r}-.0379^{* * *} \\
(.0105)\end{array}$ & $\begin{array}{c}-.0342^{* *} \\
(.0112)\end{array}$ & $\begin{array}{c}-.0454^{\star *} \\
(.0160)\end{array}$ \\
\hline Polity Score & $\begin{array}{l}-.0118 \\
(.0082)\end{array}$ & $\begin{array}{l}-.0188^{*} \\
(.0088)\end{array}$ & $\begin{array}{l}-.0089 \\
(.0088)\end{array}$ & $\begin{array}{c}-.0179^{\circ} \\
(.0096)\end{array}$ & $\begin{array}{l}.0174 \\
(.0137)\end{array}$ \\
\hline Defensive Allies & $\begin{array}{l}-.0087 \\
(.0977)\end{array}$ & $\begin{array}{l}.0287 \\
(.1013)\end{array}$ & $\begin{array}{l}-.0607 \\
(.1059)\end{array}$ & $\begin{array}{l}-.0231 \\
(.1104)\end{array}$ & $\begin{array}{l}-.0815 \\
(.1887)\end{array}$ \\
\hline Log Peace-Years & $\begin{array}{r}-.6436^{\star * *} \\
(.0354)\end{array}$ & $\begin{array}{r}-.6573^{\star * *} \\
(.0369)\end{array}$ & $\begin{array}{r}-.6450^{\star \star \star} \\
(.0388)\end{array}$ & $\begin{array}{r}-.6606^{\star * *} \\
(.0409)\end{array}$ & $\begin{array}{r}-.5697^{\star * *} \\
(.0613)\end{array}$ \\
\hline Closest Contiguity & $\begin{array}{r}-.3094^{\star * *} \\
(.0200)\end{array}$ & $\begin{array}{r}-.2952^{\star \star \star} \\
(.0207)\end{array}$ & $\begin{array}{r}-.3360^{\star \star \star} \\
(.0223)\end{array}$ & $\begin{array}{r}-.3206^{\star * *} \\
(.0233)\end{array}$ & $\begin{array}{r}-.2605^{\star \star *} \\
(.0349)\end{array}$ \\
\hline Constant & $\begin{array}{c}-1.9587^{\star * *} \\
(.0927) \\
\end{array}$ & $\begin{array}{c}-2.0157^{\star * *} \\
(.0954)\end{array}$ & $\begin{array}{c}-2.0125^{\star * *} \\
(.0967) \\
\end{array}$ & $\begin{array}{c}-2.0674^{* * *} \\
(.0995) \\
\end{array}$ & $\begin{array}{c}-3.3292^{* * *} \\
(.1654) \\
\end{array}$ \\
\hline Observations & 90,234 & 90,234 & 90,234 & 90,234 & 90,036 \\
\hline Wald $\chi^{2}(7)$ & 1015.37 & 1028.10 & 935.30 & 944.26 & 348.94 \\
\hline$p$ & $<.0001$ & $<.0001$ & $<.0001$ & $<.0001$ & $<.0001$ \\
\hline Pseudo $R^{2}$ & .1306 & .1311 & .1401 & .1410 & .1032 \\
\hline
\end{tabular}

${ }^{\circ} p<.10{ }^{*} p<.05 \quad{ }^{* *} p<.01{ }^{* * *} p<.001$ 
Table B-68. Logit of Western Christian GRP Scale.

\begin{tabular}{|c|c|c|c|c|c|}
\hline Variable & Model 1 & Model 2 & Model 3 & Model 4 & Model 5 \\
\hline $\begin{array}{l}\text { Western Christian } \\
\text { GRP (every 10\%) }\end{array}$ & $\begin{array}{r}-.0728^{* *} \\
(.0237) \\
\end{array}$ & $\begin{array}{r}-.0733^{\star *} \\
(.0250) \\
\end{array}$ & $\begin{array}{r}-.0951^{* * *} \\
(.0267) \\
\end{array}$ & $\begin{array}{r}-.0964^{\star \star *} \\
(.0287) \\
\end{array}$ & $\begin{array}{r}-.2641^{* * *} \\
(.0516) \\
\end{array}$ \\
\hline Log CINC Ratio & $\begin{array}{l}.0173 \\
(.0115)\end{array}$ & $\begin{array}{l}-.0001 \\
(.0117)\end{array}$ & $\begin{array}{r}.0433^{* * *} \\
(.0127)\end{array}$ & $\begin{array}{l}.0249^{\circ} \\
(.0131)\end{array}$ & $\begin{array}{l}.0015 \\
(.0183)\end{array}$ \\
\hline Low Polity Score & $\begin{array}{r}-.0239^{* *} \\
(.0093)\end{array}$ & $\begin{array}{l}-.0203^{*} \\
(.0098)\end{array}$ & $\begin{array}{r}-.0363^{\star \star *} \\
(.0104)\end{array}$ & $\begin{array}{r}-.0329^{\star *} \\
(.0111)\end{array}$ & $\begin{array}{r}-.0462^{\star *} \\
(.0159)\end{array}$ \\
\hline Polity Score & $\begin{array}{l}-.0127 \\
\quad(.0083)\end{array}$ & $\begin{array}{l}-.0212^{*} \\
(.0089)\end{array}$ & $\begin{array}{l}-.0089 \\
(.0089)\end{array}$ & $\begin{array}{l}-.0196^{*} \\
(.0096)\end{array}$ & $\begin{array}{l}.0185 \\
(.0135)\end{array}$ \\
\hline Defensive Allies & $\begin{array}{l}.0217 \\
(.0966)\end{array}$ & $\begin{array}{l}.0604 \\
(.1002)\end{array}$ & $\begin{array}{l}-.0334 \\
(.1043)\end{array}$ & $\begin{array}{l}.0057 \\
(.1087)\end{array}$ & $\begin{array}{l}-.0572 \\
(.1845)\end{array}$ \\
\hline Log Peace-Years & $\begin{array}{r}-.6350^{* * *} \\
(.0352)\end{array}$ & $\begin{array}{r}-.6511^{* * *} \\
(.0368)\end{array}$ & $\begin{array}{r}-.6313^{* * *} \\
(.0384)\end{array}$ & $\begin{array}{r}-.6491^{* * *} \\
(.0407)\end{array}$ & $\begin{array}{r}-.5514^{* * *} \\
(.0612)\end{array}$ \\
\hline Closest Contiguity & $\begin{array}{r}-.3102^{\star * *} \\
(.0201)\end{array}$ & $\begin{array}{r}-.2962^{\star * *} \\
(.0208)\end{array}$ & $\begin{array}{r}-.3394^{* \star *} \\
(.0222)\end{array}$ & $\begin{array}{r}-.3249^{* * *} \\
(.0233)\end{array}$ & $\begin{array}{r}-.2696^{* * *} \\
(.0351)\end{array}$ \\
\hline Constant & $\begin{array}{c}-2.0014^{\star * *} \\
(.0928)\end{array}$ & $\begin{array}{c}-2.0560^{* * *} \\
(.0957)\end{array}$ & $\begin{array}{c}-2.0487^{* * *} \\
(.0965) \\
\end{array}$ & $\begin{array}{c}-2.1001^{* * *} \\
(.0993) \\
\end{array}$ & $\begin{array}{c}-3.3408^{* * \star} \\
(.1622) \\
\end{array}$ \\
\hline Observations & 92,277 & 92,277 & 92,277 & 92,277 & 92,077 \\
\hline Wald $\chi^{2}(7)$ & 1007.04 & 1010.77 & 934.12 & 930.85 & 348.64 \\
\hline$p$ & $<.0001$ & $<.0001$ & $<.0001$ & $<.0001$ & $<.0001$ \\
\hline Pseudo $\mathrm{R}^{2}$ & .1272 & .1276 & .1368 & 1378 & .1031 \\
\hline
\end{tabular}

${ }^{\circ} p<.10 \quad{ }^{*} p<.05{ }^{* *} p<.01{ }^{* * *} p<.001$ 
Table B-69. Logit of Western Christian Prevalence.

\begin{tabular}{|c|c|c|c|c|c|}
\hline Variable & Model 1 & Model 2 & Model 3 & Model 4 & Model 5 \\
\hline & (Robust SE) & & & & \\
\hline $\begin{array}{l}\text { Western Christian } \\
\text { Prevalence (binary) }\end{array}$ & $\begin{array}{r}-.1587 \\
(.1150)\end{array}$ & $\begin{array}{l}-.1585 \\
(.1220)\end{array}$ & $\begin{array}{r}-.2528^{\circ} \\
(.1298)\end{array}$ & $\begin{array}{l}-.2697^{\circ} \\
(.1403)\end{array}$ & $\begin{array}{r}-.9477^{\star * *} \\
(.2447)\end{array}$ \\
\hline Log CINC Ratio & $\begin{array}{l}.0130 \\
(.0121)\end{array}$ & $\begin{array}{l}-.0057 \\
(.0124)\end{array}$ & $\begin{array}{l}.0396^{\star *} \\
(.0131)\end{array}$ & $\begin{array}{l}.0200 \\
(.0135)\end{array}$ & $\begin{array}{l}.0071 \\
(.0188)\end{array}$ \\
\hline Low Polity Score & $\begin{array}{r}-.0283^{* *} \\
(.0093)\end{array}$ & $\begin{array}{c}-.0242^{*} \\
(.0098)\end{array}$ & $\begin{array}{r}-.0392^{* * *} \\
(.0105)\end{array}$ & $\begin{array}{r}-.0348^{* *} \\
(.0112)\end{array}$ & $\begin{array}{r}-.0423^{* *} \\
(.0161)\end{array}$ \\
\hline Polity Score & $\begin{array}{l}-.0169^{*} \\
(.0085)\end{array}$ & $\begin{array}{r}-.0255^{\star *} \\
(.0091)\end{array}$ & $\begin{array}{r}-.0147 \\
(.0092)\end{array}$ & $\begin{array}{l}-.0253^{*} \\
(.0100)\end{array}$ & $\begin{array}{l}.0107 \\
(.0150)\end{array}$ \\
\hline Defensive Allies & $\begin{array}{l}-.0001 \\
(.1014)\end{array}$ & $\begin{array}{l}.0214 \\
(.1056)\end{array}$ & $\begin{array}{l}-.0609 \\
(.1100)\end{array}$ & $\begin{array}{l}-.0402 \\
(.1153)\end{array}$ & $\begin{array}{l}.0216 \\
(.1926)\end{array}$ \\
\hline Log Peace-Years & $\begin{array}{r}-.6625^{* * *} \\
(.0359)\end{array}$ & $\begin{array}{r}-.6697^{* * *} \\
(.0375)\end{array}$ & $\begin{array}{r}-.6690^{* * *} \\
(.0390)\end{array}$ & $\begin{array}{r}-.6765^{\star * *} \\
(.0413)\end{array}$ & $\begin{array}{r}-.5852^{\star \star \star} \\
(.0629)\end{array}$ \\
\hline Closest Contiguity & $\begin{array}{r}-.3094^{* * *} \\
(.0208)\end{array}$ & $\begin{array}{r}-.3003^{* * *} \\
(.0215)\end{array}$ & $\begin{array}{r}-.3335^{\star \star \star} \\
(.0228)\end{array}$ & $\begin{array}{r}-.3247^{* * *} \\
(.0239)\end{array}$ & $\begin{array}{r}-.2478^{* * *} \\
(.0359)\end{array}$ \\
\hline Constant & $\begin{array}{c}-1.9224^{* * *} \\
(.0967)\end{array}$ & $\begin{array}{c}-1.9732^{* * *} \\
(.0994)\end{array}$ & $\begin{array}{c}-1.9568^{* * *} \\
(.1005)\end{array}$ & $\begin{array}{c}-2.0039^{* * *} \\
(.1032)\end{array}$ & $\begin{array}{c}-3.3686^{* * *} \\
(.1734)\end{array}$ \\
\hline Observations & 86,063 & 86,063 & 86,063 & 86,063 & 85,864 \\
\hline Wald $\chi^{2}(7)$ & 960.32 & 968.60 & 889.44 & 893.68 & 316.77 \\
\hline$p$ & $<.0001$ & $<.0001$ & $<.0001$ & $<.0001$ & $<.0001$ \\
\hline Pseudo $\mathrm{R}^{2}$ & .1322 & .1327 & .1420 & .1433 & .1003 \\
\hline
\end{tabular}

${ }^{\circ} p<.10{ }^{*} p<.05{ }^{* *} p<.01{ }^{* * *} p<.001$ 
Table B-70. Logit of Western Christian Population.

\begin{tabular}{|c|c|c|c|c|c|}
\hline Variable & Model 1 & Model 2 & Model 3 & Model 4 & Model 5 \\
\hline & (Robust SE) & & & & \\
\hline $\begin{array}{l}\text { Western Christian } \\
\text { Pop. (every 10\%) }\end{array}$ & $\begin{array}{c}-.0323^{*} \\
(.0132) \\
\end{array}$ & $\begin{array}{c}-.0318^{\star} \\
(.0140) \\
\end{array}$ & $\begin{array}{r}-.0458^{\star \star} \\
(.0149) \\
\end{array}$ & $\begin{array}{r}-.0475^{\star *} \\
(.0160) \\
\end{array}$ & $\begin{array}{r}-.1120^{\star * *} \\
(.0271) \\
\end{array}$ \\
\hline Log CINC Ratio & $\begin{array}{l}.0209^{\circ} \\
(.0111)\end{array}$ & $\begin{array}{l}.0026 \\
(.0113)\end{array}$ & $\begin{array}{r}.0475^{\star * \star} \\
(.0122)\end{array}$ & $\begin{array}{l}.0277^{*} \\
(.0126)\end{array}$ & $\begin{array}{l}.0088 \\
(.0176)\end{array}$ \\
\hline Low Polity Score & $\begin{array}{r}-.0258^{\star *} \\
(.0092)\end{array}$ & $\begin{array}{l}-.0228^{*} \\
(.0097)\end{array}$ & $\begin{array}{r}-.0379^{* * *} \\
(.0104)\end{array}$ & $\begin{array}{l}-.0351^{* *} \\
(.0111)\end{array}$ & $\begin{array}{r}-.0454^{* *} \\
(.0157)\end{array}$ \\
\hline Polity Score & $\begin{array}{l}-.0139^{\circ} \\
(.0081)\end{array}$ & $\begin{array}{l}-.0223^{\star} \\
(.0087)\end{array}$ & $\begin{array}{l}-.0097 \\
(.0087)\end{array}$ & $\begin{array}{l}-.0199^{\star} \\
(.0094)\end{array}$ & $\begin{array}{l}.0136 \\
(.0137)\end{array}$ \\
\hline Defensive Allies & $\begin{array}{l}-.0087 \\
(.0952)\end{array}$ & $\begin{array}{l}.0265 \\
(.0988)\end{array}$ & $\begin{array}{l}-.0501 \\
(.1034)\end{array}$ & $\begin{array}{c}-.0119 \\
(.1079)\end{array}$ & $\begin{array}{l}-.0542 \\
(.1835)\end{array}$ \\
\hline Log Peace-Years & $\begin{array}{r}-.6451^{* * *} \\
(.0341)\end{array}$ & $\begin{array}{r}-.6587^{* * *} \\
(.0355)\end{array}$ & $\begin{array}{r}-.6411^{* * *} \\
(.0371)\end{array}$ & $\begin{array}{r}-.6555^{\star * *} \\
(.0391)\end{array}$ & $\begin{array}{r}-.5510^{* * *} \\
(.0594)\end{array}$ \\
\hline Closest Contiguity & $\begin{array}{r}-.3145^{\star * *} \\
(.0194)\end{array}$ & $\begin{array}{r}-.3008^{\star * *} \\
(.0200)\end{array}$ & $\begin{array}{r}-.3415^{\star * *} \\
(.0216)\end{array}$ & $\begin{array}{r}-.3269^{\star * *} \\
(.0225)\end{array}$ & $\begin{array}{r}-.2699^{\star * *} \\
(.0343)\end{array}$ \\
\hline Constant & $\begin{array}{c}-1.9531^{* * *} \\
(.0892) \\
\end{array}$ & $\begin{array}{c}-2.0087^{\star \star \star} \\
(.0917) \\
\end{array}$ & $\begin{array}{c}-2.0055^{\star \star *} \\
(.0931) \\
\end{array}$ & $\begin{array}{c}-2.0581^{* * *} \\
(.0957)\end{array}$ & $\begin{array}{c}-3.3297^{\star * *} \\
(.1557) \\
\end{array}$ \\
\hline Observations & 95,418 & 95,418 & 95,418 & 95,418 & 95,197 \\
\hline Wald $\chi^{2}(7)$ & 1065.04 & 1065.31 & 977.31 & 972.37 & 348.46 \\
\hline$p$ & $<.0001$ & $<.0001$ & $<.0001$ & $<.0001$ & $<.0001$ \\
\hline Pseudo $\mathrm{R}^{2}$ & .1308 & .1305 & .1404 & .1405 & .0978 \\
\hline
\end{tabular}

${ }^{\circ} \mathrm{p}<.10{ }^{*} \mathrm{p}<.05{ }^{* *} \mathrm{p}<.01{ }^{* \star *} \mathrm{p}<.001$ 
Table B-71. Logit of Catholic Chief Executive.

\begin{tabular}{|c|c|c|c|c|c|}
\hline Variable & Model 1 & Model 2 & Model 3 & Model 4 & Model 5 \\
\hline & (Robust SE) & & & & \\
\hline $\begin{array}{l}\text { Catholic } \\
\text { Chief Exec. (binary) }\end{array}$ & $\begin{array}{r}-.2594^{*} \\
(.1022) \\
\end{array}$ & $\begin{array}{r}-.2517^{*} \\
(.1068) \\
\end{array}$ & $\begin{array}{r}-.3749^{\star *} \\
(.1181) \\
\end{array}$ & $\begin{array}{r}-.3718^{\star *} \\
(.1256) \\
\end{array}$ & $\begin{array}{c}-.7309^{\star *} \\
(.2272) \\
\end{array}$ \\
\hline Log CINC Ratio & $\begin{array}{l}.0052 \\
(.0118)\end{array}$ & $\begin{array}{r}-.0148 \\
(.0121)\end{array}$ & $\begin{array}{l}.0335^{\star} \\
(.0131)\end{array}$ & $\begin{array}{l}.0120 \\
(.0137)\end{array}$ & $\begin{array}{l}-.0012 \\
(.0198)\end{array}$ \\
\hline Low Polity Score & $\begin{array}{l}-.0227^{\star} \\
(.0092)\end{array}$ & $\begin{array}{l}-.0195^{\star} \\
(.0097)\end{array}$ & $\begin{array}{r}-.0358^{\star \star *} \\
(.0104)\end{array}$ & $\begin{array}{r}-.0331^{* *} \\
(.0111)\end{array}$ & $\begin{array}{l}-.0387^{\star} \\
(.0157)\end{array}$ \\
\hline Polity Score & $\begin{array}{c}-.0167^{\star} \\
(.0074)\end{array}$ & $\begin{array}{r}-.0247^{\star \star} \\
(.0078)\end{array}$ & $\begin{array}{r}-.0144^{\circ} \\
(.0078)\end{array}$ & $\begin{array}{c}-.0245^{\star \star} \\
(.0084)\end{array}$ & $\begin{array}{c}-.0060 \\
(.0123)\end{array}$ \\
\hline Defensive Allies & $\begin{array}{l}-.0368 \\
(.0979)\end{array}$ & $\begin{array}{l}-.0035 \\
(.1015)\end{array}$ & $\begin{array}{l}-.0834 \\
(.1057)\end{array}$ & $\begin{array}{l}-.0496 \\
(.1104)\end{array}$ & $\begin{array}{l}-.1189 \\
\quad(.1872)\end{array}$ \\
\hline Log Peace-Years & $\begin{array}{r}-.6467^{* * *} \\
(.0358)\end{array}$ & $\begin{array}{r}-.6577^{* * *} \\
(.0373)\end{array}$ & $\begin{array}{r}-.6401^{* * *} \\
(.0392)\end{array}$ & $\begin{array}{r}-.6514^{\star * *} \\
(.0413)\end{array}$ & $\begin{array}{r}-.5506^{\star * *} \\
(.0624)\end{array}$ \\
\hline Closest Contiguity & $\begin{array}{r}-.3157^{* * *} \\
(.0204)\end{array}$ & $\begin{array}{r}-.3020^{* * *} \\
(.0212)\end{array}$ & $\begin{array}{r}-.3485^{\star * *} \\
(.0227)\end{array}$ & $\begin{array}{r}-.3341^{* * *} \\
(.0238)\end{array}$ & $\begin{array}{r}-.2951^{* * *} \\
(.0366)\end{array}$ \\
\hline Constant & $\begin{array}{c}-1.9365^{\star * *} \\
(.0930)\end{array}$ & $\begin{array}{c}-2.0019^{* * *} \\
(.0957) \\
\end{array}$ & $\begin{array}{c}-1.9865^{\star * *} \\
(.0970) \\
\end{array}$ & $\begin{array}{c}-2.0514^{* * *} \\
(.0997) \\
\end{array}$ & $\begin{array}{c}-3.3033^{\star * *} \\
(.1594) \\
\end{array}$ \\
\hline Observations & 84,810 & 84,810 & 84,810 & 84,810 & 84,605 \\
\hline Wald $\chi^{2}(7)$ & 985.46 & 989.77 & 897.10 & 894.43 & 302.66 \\
\hline$p$ & $<.0001$ & $<.0001$ & $<.0001$ & $<.0001$ & $<.0001$ \\
\hline Pseudo $\mathrm{R}^{2}$ & .1291 & .1285 & .1386 & .1380 & .0943 \\
\hline
\end{tabular}

${ }^{\circ} \mathrm{p}<.10{ }^{*} \mathrm{p}<.05{ }^{* *} \mathrm{p}<.01{ }^{* \star *} \mathrm{p}<.001$ 
Table B-72. Logit of Catholic Preference.

\begin{tabular}{|c|c|c|c|c|c|}
\hline Variable & Model 1 & Model 2 & Model 3 & Model 4 & Model 5 \\
\hline $\begin{array}{l}\text { Catholic } \\
\text { Preference (binary) }\end{array}$ & $\begin{array}{c}-.1569 \\
(.1145) \\
\end{array}$ & $\begin{array}{c}-.2043^{\circ} \\
(.1202) \\
\end{array}$ & $\begin{array}{c}-.2677^{*} \\
(.1332) \\
\end{array}$ & $\begin{array}{c}-.3376^{\star} \\
(.1432) \\
\end{array}$ & $\begin{array}{r}-.9554^{\star * *} \\
(.2571) \\
\end{array}$ \\
\hline Log CINC Ratio & $\begin{array}{l}.0095 \\
(.0125)\end{array}$ & $\begin{array}{l}-.0066 \\
(.0125)\end{array}$ & $\begin{array}{l}.0382^{* *} \\
(.0138)\end{array}$ & $\begin{array}{l}.0206 \\
(.0139)\end{array}$ & $\begin{array}{l}.0040 \\
(.0202)\end{array}$ \\
\hline Low Polity Score & $\begin{array}{l}-.0087 \\
(.0105)\end{array}$ & $\begin{array}{l}-.0063 \\
(.0108)\end{array}$ & $\begin{array}{l}-.0190 \\
(.0118)\end{array}$ & $\begin{array}{l}-.0157 \\
(.0123)\end{array}$ & $\begin{array}{l}-.0228 \\
(.0168)\end{array}$ \\
\hline Polity Score & $\begin{array}{c}-.0289^{* *} \\
(.0088)\end{array}$ & $\begin{array}{r}-.0341^{* \star *} \\
(.0092)\end{array}$ & $\begin{array}{c}-.0269^{\star *} \\
(.0094)\end{array}$ & $\begin{array}{r}-.0343^{\star \star *} \\
(.0100)\end{array}$ & $\begin{array}{l}-.0073 \\
(.0134)\end{array}$ \\
\hline Defensive Allies & $\begin{array}{l}-.0096 \\
(.1018)\end{array}$ & $\begin{array}{l}.0480 \\
(.1050)\end{array}$ & $\begin{array}{l}-.0509 \\
(.1098)\end{array}$ & $\begin{array}{l}.0136 \\
(.1140)\end{array}$ & $\begin{array}{l}-.0060 \\
(.1864)\end{array}$ \\
\hline Log Peace-Years & $\begin{array}{r}-.6564^{* * *} \\
(.0370)\end{array}$ & $\begin{array}{r}-.6623^{* * *} \\
(.0384)\end{array}$ & $\begin{array}{r}-.6583^{* * *} \\
(.0406)\end{array}$ & $\begin{array}{r}-.6639^{* * *} \\
(.0425)\end{array}$ & $\begin{array}{r}-.5708^{* * *} \\
(.0629)\end{array}$ \\
\hline Closest Contiguity & $\begin{array}{r}-.3057^{* * *} \\
(.0215)\end{array}$ & $\begin{array}{r}-.2820^{\star * *} \\
(.0219)\end{array}$ & $\begin{array}{r}-.3401^{* * *} \\
(.0239)\end{array}$ & $\begin{array}{r}-.3132^{\star \star *} \\
(.0245)\end{array}$ & $\begin{array}{r}-.2737^{\star * *} \\
(.0374)\end{array}$ \\
\hline Constant & $\begin{array}{c}-1.9600^{* * *} \\
(.0974) \\
\end{array}$ & $\begin{array}{c}-2.0659^{\star * *} \\
(.1016)\end{array}$ & $\begin{array}{c}-2.0000^{* * *} \\
(.1003)\end{array}$ & $\begin{array}{c}-2.1152^{* * *} \\
(.1052) \\
\end{array}$ & $\begin{array}{c}-3.3399^{* * *} \\
(.1660) \\
\end{array}$ \\
\hline Observations & 75,401 & 75,401 & 75,401 & 75,401 & 75,227 \\
\hline Wald $\chi^{2}(7)$ & 916.17 & 866.41 & 857.75 & 800.47 & 282.08 \\
\hline$p$ & $<.0001$ & $<.0001$ & $<.0001$ & $<.0001$ & $<.0001$ \\
\hline Pseudo $\mathrm{R}^{2}$ & .1288 & .1244 & .1400 & .1349 & .0961 \\
\hline
\end{tabular}

${ }^{\circ} p<.10{ }^{*} p<.05{ }^{* *} p<.01{ }^{* * *} p<.001$ 
Table B-73. Logit of Catholic GRP Scale.

\begin{tabular}{|c|c|c|c|c|c|}
\hline Variable & Model 1 & Model 2 & Model 3 & Model 4 & Model 5 \\
\hline $\begin{array}{l}\text { Catholic } \\
\text { GRP (every 10\%) }\end{array}$ & $\begin{array}{l}.0141 \\
(.0245) \\
\end{array}$ & $\begin{array}{l}.0105 \\
(.0256) \\
\end{array}$ & $\begin{array}{r}-.0134 \\
(.0285) \\
\end{array}$ & $\begin{array}{r}-.0204 \\
(.0305) \\
\end{array}$ & $\begin{array}{r}-.1657^{* *} \\
(.0604) \\
\end{array}$ \\
\hline Log CINC Ratio & $\begin{array}{l}.0221^{\circ} \\
(.0115)\end{array}$ & $\begin{array}{l}.0047 \\
(.0117)\end{array}$ & $\begin{array}{r}.0475^{\star * \star} \\
(.0127)\end{array}$ & $\begin{array}{l}.0292^{*} \\
(.0131)\end{array}$ & $\begin{array}{l}.0049 \\
(.0182)\end{array}$ \\
\hline Low Polity Score & $\begin{array}{r}-.0248^{* *} \\
(.0092)\end{array}$ & $\begin{array}{l}-.0211^{*} \\
(.0097)\end{array}$ & $\begin{array}{r}-.0369^{\star \star *} \\
(.0103)\end{array}$ & $\begin{array}{r}-.0334^{\star *} \\
(.0110)\end{array}$ & $\begin{array}{r}-.0458^{\star \star} \\
(.0154)\end{array}$ \\
\hline Polity Score & $\begin{array}{c}-.0233^{* *} \\
(.0077)\end{array}$ & $\begin{array}{r}-.0316^{\star * *} \\
(.0083)\end{array}$ & $\begin{array}{r}-.0212^{* *} \\
(.0082)\end{array}$ & $\begin{array}{r}-.0316^{\star * *} \\
(.0089)\end{array}$ & $\begin{array}{l}-.0089 \\
(.0123)\end{array}$ \\
\hline Defensive Allies & $\begin{array}{l}-.0319 \\
(.0957)\end{array}$ & $\begin{array}{l}.0110 \\
(.0989)\end{array}$ & $\begin{array}{r}-.0719 \\
(.1037)\end{array}$ & $\begin{array}{r}-.0256 \\
(.1079)\end{array}$ & $\begin{array}{c}-.0812 \\
(.1785)\end{array}$ \\
\hline Log Peace-Years & $\begin{array}{r}-.6475^{\star \star \star} \\
(.0351)\end{array}$ & $\begin{array}{r}-.6634^{\star * *} \\
(.0367)\end{array}$ & $\begin{array}{r}-.6424^{* \star *} \\
(.0384)\end{array}$ & $\begin{array}{r}-.6598^{\star \star \star} \\
(.0407)\end{array}$ & $\begin{array}{r}-.5634^{\star * \star} \\
(.0619)\end{array}$ \\
\hline Closest Contiguity & $\begin{array}{r}-.3093^{* * *} \\
(.0202)\end{array}$ & $\begin{array}{r}-.2952^{\star * *} \\
(.0208)\end{array}$ & $\begin{array}{r}-.3387^{* * *} \\
(.0223)\end{array}$ & $\begin{array}{r}-.3239^{* * *} \\
(.0233)\end{array}$ & $\begin{array}{r}-.2738^{* * *} \\
(.0351)\end{array}$ \\
\hline Constant & $\begin{array}{c}-2.0081^{* * *} \\
(.0919)\end{array}$ & $\begin{array}{c}-2.0637^{* * *} \\
(.0946)\end{array}$ & $\begin{array}{c}-2.0590^{* * *} \\
(.0955)\end{array}$ & $\begin{array}{c}-2.1129^{\star * *} \\
(.0982)\end{array}$ & $\begin{array}{c}-3.3319^{* * *} \\
(.1562)\end{array}$ \\
\hline Observations & 92,277 & 92,277 & 92,277 & 92,277 & 92,077 \\
\hline Wald $\chi^{2}(7)$ & 1000.51 & 1005.87 & 921.29 & 921.51 & 313.31 \\
\hline$p$ & $<.0001$ & $<.0001$ & $<.0001$ & $<.0001$ & $<.0001$ \\
\hline Pseudo $\mathrm{R}^{2}$ & .1257 & .1261 & .1344 & .1354 & .0928 \\
\hline
\end{tabular}

${ }^{\circ} p<.10{ }^{*} p<.05{ }^{* *} p<.01{ }^{* * *} p<.001$ 
Table B-74. Logit of Catholic Prevalence.

\begin{tabular}{|c|c|c|c|c|c|}
\hline Variable & Model 1 & Model 2 & Model 3 & Model 4 & Model 5 \\
\hline $\begin{array}{l}\text { Catholic } \\
\text { Prevalence (binary) }\end{array}$ & $\begin{array}{c}-.1033 \\
(.1148) \\
\end{array}$ & $\begin{array}{l}-.1285 \\
(.1204) \\
\end{array}$ & $\begin{array}{r}-.2421^{\circ} \\
(.1330) \\
\end{array}$ & $\begin{array}{c}-.2852^{\star} \\
(.1426) \\
\end{array}$ & $\begin{array}{r}-.7454^{\star *} \\
(.2468) \\
\end{array}$ \\
\hline Log CINC Ratio & $\begin{array}{l}.0079 \\
(.0127)\end{array}$ & $\begin{array}{l}-.0066 \\
(.0128)\end{array}$ & $\begin{array}{l}.0337^{\star} \\
(.0139)\end{array}$ & $\begin{array}{l}.0184 \\
(.0141)\end{array}$ & $\begin{array}{l}.0016 \\
(.0201)\end{array}$ \\
\hline Low Polity Score & $\begin{array}{l}-.0110 \\
(.0105)\end{array}$ & $\begin{array}{l}-.0079 \\
(.0109)\end{array}$ & $\begin{array}{l}-.0196^{\circ} \\
(.0119)\end{array}$ & $\begin{array}{l}-.0151 \\
(.0123)\end{array}$ & $\begin{array}{l}-.0186 \\
(.0170)\end{array}$ \\
\hline Polity Score & $\begin{array}{r}-.0294^{\star * *} \\
(.0088)\end{array}$ & $\begin{array}{r}-.0355^{\star * *} \\
(.0092)\end{array}$ & $\begin{array}{l}-.0290^{\star *} \\
(.0095)\end{array}$ & $\begin{array}{r}-.0377^{\star * *} \\
(.0101)\end{array}$ & $\begin{array}{l}-.0136 \\
(.0140)\end{array}$ \\
\hline Defensive Allies & $\begin{array}{l}.0308 \\
(.1045)\end{array}$ & $\begin{array}{l}.0762 \\
(.1081)\end{array}$ & $\begin{array}{l}-.0130 \\
(.1120)\end{array}$ & $\begin{array}{l}.0370 \\
(.1166)\end{array}$ & $\begin{array}{l}.0243 \\
(.1906)\end{array}$ \\
\hline Log Peace-Years & $\begin{array}{r}-.6744^{* \star *} \\
(.0373)\end{array}$ & $\begin{array}{r}-.6744^{\star * *} \\
(.0388)\end{array}$ & $\begin{array}{r}-.6814^{* * *} \\
(.0406)\end{array}$ & $\begin{array}{r}-.6800^{\star \star *} \\
(.0427)\end{array}$ & $\begin{array}{r}-.5905^{\star * *} \\
(.0631)\end{array}$ \\
\hline Closest Contiguity & $\begin{array}{r}-.3038^{\star \star \star} \\
(.0221)\end{array}$ & $\begin{array}{r}-.2852^{\star \star \star} \\
(.0226)\end{array}$ & $\begin{array}{r}-.3365^{\star \star *} \\
(.0243)\end{array}$ & $\begin{array}{r}-.3166^{\star \star \star} \\
(.0250)\end{array}$ & $\begin{array}{r}-.2627^{\star * *} \\
(.0380)\end{array}$ \\
\hline Constant & $\begin{array}{c}-1.9449^{* * *} \\
(.1009) \\
\end{array}$ & $\begin{array}{c}-2.0443^{* * *} \\
(.1053) \\
\end{array}$ & $\begin{array}{c}-1.9612^{\star \star *} \\
(.1030) \\
\end{array}$ & $\begin{array}{c}-2.0667^{\star * *} \\
(.1080) \\
\end{array}$ & $\begin{array}{c}-3.3365^{\star \star *} \\
(.1690) \\
\end{array}$ \\
\hline Observations & 73,588 & 73,588 & 73,588 & 73,588 & 73,409 \\
\hline Wald $\chi^{2}(7)$ & 877.34 & 826.57 & 826.97 & 766.61 & 267.92 \\
\hline$p$ & $<.0001$ & $<.0001$ & $<.0001$ & $<.0001$ & $<.0001$ \\
\hline Pseudo $R^{2}$ & .1318 & .1276 & .1437 & .1392 & .0941 \\
\hline
\end{tabular}

${ }^{\circ} p<.10{ }^{*} p<.05{ }^{* *} p<.01{ }^{* * *} p<.001$ 
Table B-75. Logit of Catholic Population.

\begin{tabular}{|c|c|c|c|c|c|}
\hline Variable & Model 1 & Model 2 & Model 3 & Model 4 & Model 5 \\
\hline & (Robust SE) & & & & \\
\hline $\begin{array}{l}\text { Catholic } \\
\text { Pop. (every 10\%) }\end{array}$ & $\begin{array}{r}-.0156 \\
(.0133) \\
\end{array}$ & $\begin{array}{r}-.0158 \\
(.0140)\end{array}$ & $\begin{array}{r}-.0307^{*} \\
(.0152)\end{array}$ & $\begin{array}{r}-.0324^{*} \\
(.0163) \\
\end{array}$ & $\begin{array}{r}-.0810^{* *} \\
(.0283) \\
\end{array}$ \\
\hline Log CINC Ratio & $\begin{array}{l}.0211^{\circ} \\
(.0111)\end{array}$ & $\begin{array}{l}.0029 \\
(.0114)\end{array}$ & $\begin{array}{r}.0473^{\star * *} \\
(.0122)\end{array}$ & $\begin{array}{l}.0278^{*} \\
(.0126)\end{array}$ & $\begin{array}{l}.0069 \\
(.0176)\end{array}$ \\
\hline Low Polity Score & $\begin{array}{r}-.0258^{\star *} \\
(.0092)\end{array}$ & $\begin{array}{l}-.0227^{\star} \\
(.0096)\end{array}$ & $\begin{array}{r}-.0375^{\star \star *} \\
(.0103)\end{array}$ & $\begin{array}{l}-.0347^{* *} \\
(.0109)\end{array}$ & $\begin{array}{r}-.0438^{* *} \\
(.0154)\end{array}$ \\
\hline Polity Score & $\begin{array}{r}-.0206^{\star *} \\
(.0075)\end{array}$ & $\begin{array}{r}-.0287^{* * *} \\
(.0080)\end{array}$ & $\begin{array}{l}-.0183^{*} \\
(.0079)\end{array}$ & $\begin{array}{r}-.0285^{\star * *} \\
(.0086)\end{array}$ & $\begin{array}{l}-.0063 \\
(.0121)\end{array}$ \\
\hline Defensive Allies & $\begin{array}{l}-.0341 \\
(.0945)\end{array}$ & $\begin{array}{l}.0028 \\
(.0979)\end{array}$ & $\begin{array}{l}-.0720 \\
(.1026)\end{array}$ & $\begin{array}{l}-.0325 \\
(.1070)\end{array}$ & $\begin{array}{c}-.1035 \\
(.1799)\end{array}$ \\
\hline Log Peace-Years & $\begin{array}{r}-.6498^{* * *} \\
(.0341)\end{array}$ & $\begin{array}{r}-.6634^{* * *} \\
(.0355)\end{array}$ & $\begin{array}{r}-.6456^{* * *} \\
(.0371)\end{array}$ & $\begin{array}{r}-.6602^{\star * *} \\
(.0391)\end{array}$ & $\begin{array}{r}-.5596^{* * *} \\
(.0595)\end{array}$ \\
\hline Closest Contiguity & $\begin{array}{r}-.3158^{\star \star *} \\
(.0195)\end{array}$ & $\begin{array}{r}-.3018^{\star \star \star} \\
(.0201)\end{array}$ & $\begin{array}{r}-3434^{* * *} \\
(.0217)\end{array}$ & $\begin{array}{r}-.3284^{* * *} \\
(.0226)\end{array}$ & $\begin{array}{r}-.2758^{\star \star *} \\
(.0345)\end{array}$ \\
\hline Constant & $\begin{array}{c}-1.9548^{\star * *} \\
(.0891) \\
\end{array}$ & $\begin{array}{c}-2.0115^{\star \star \star} \\
(.0917) \\
\end{array}$ & $\begin{array}{c}-2.0043^{\star \star \star} \\
(.0927) \\
\end{array}$ & $\begin{array}{c}-2.0592^{\star * *} \\
(.0953) \\
\end{array}$ & $\begin{array}{c}-3.3070^{* \star *} \\
(.1516) \\
\end{array}$ \\
\hline Observations & 95,418 & 95,418 & 95,418 & 95,418 & 95,197 \\
\hline Wald $\chi^{2}(7)$ & 1063.22 & 1065.27 & 974.40 & 970.14 & 328.88 \\
\hline$p$ & $<.0001$ & $<.0001$ & $<.0001$ & $<.0001$ & $<.0001$ \\
\hline Pseudo $\mathrm{R}^{2}$ & .1301 & .1299 & .1393 & .1394 & .0929 \\
\hline
\end{tabular}

${ }^{\circ} \mathrm{p}<.10{ }^{*} \mathrm{p}<.05{ }^{* *} \mathrm{p}<.01{ }^{* \star *} \mathrm{p}<.001$ 
Table B-76. Logit of Protestant Chief Executive.

\begin{tabular}{|c|c|c|c|c|c|}
\hline Variable & Model 1 & Model 2 & Model 3 & Model 4 & Model 5 \\
\hline $\begin{array}{l}\text { Protestant } \\
\text { Chief Exec. (binary) }\end{array}$ & $\begin{array}{r}-.1335 \\
(.1286) \\
\end{array}$ & $\begin{array}{c}-.2322 \dagger \\
(.1432) \\
\end{array}$ & $\begin{array}{r}-.2170 \dagger \\
(.1445) \\
\end{array}$ & $\begin{array}{r}-.3551^{*} \\
(.1668) \\
\end{array}$ & $\begin{array}{r}-.7160^{* *} \\
(.2695) \\
\end{array}$ \\
\hline Log CINC Ratio & $\begin{array}{l}.0099 \\
(.0120)\end{array}$ & $\begin{array}{l}-.0097 \\
(.0123)\end{array}$ & $\begin{array}{l}.0402^{* *} \\
(.0132)\end{array}$ & $\begin{array}{l}.0191 \\
(.0138)\end{array}$ & $\begin{array}{c}.0138 \\
(.0200)\end{array}$ \\
\hline Low Polity Score & $\begin{array}{r}-.0248^{\star *} \\
(.0092)\end{array}$ & $\begin{array}{l}-.0222^{*} \\
(.0097)\end{array}$ & $\begin{array}{r}-.0392^{* * *} \\
(.0104)\end{array}$ & $\begin{array}{r}-.0373^{\star * *} \\
(.0111)\end{array}$ & $\begin{array}{r}-.0458^{* *} \\
(.0157)\end{array}$ \\
\hline Polity Score & $\begin{array}{l}-.0155^{\star} \\
(.0075)\end{array}$ & $\begin{array}{l}-.0218^{* *} \\
(.0080)\end{array}$ & $\begin{array}{l}-.0122 \\
(.0080)\end{array}$ & $\begin{array}{l}-.0200^{\star} \\
(.0086)\end{array}$ & $\begin{array}{l}.0028 \\
(.0123)\end{array}$ \\
\hline Defensive Allies & $\begin{array}{l}-.0746 \\
(.1003)\end{array}$ & $\begin{array}{l}-.0414 \\
(.1040)\end{array}$ & $\begin{array}{l}-.1342 \\
\quad(.1076)\end{array}$ & $\begin{array}{l}-.1011 \\
\quad(.1122)\end{array}$ & $\begin{array}{r}-.2155 \\
(.1899)\end{array}$ \\
\hline Log Peace-Years & $\begin{array}{r}-.6539^{* * *} \\
(.0353)\end{array}$ & $\begin{array}{r}-.6644^{* * *} \\
(.0368)\end{array}$ & $\begin{array}{r}-.6500^{* * *} \\
(.0387)\end{array}$ & $\begin{array}{r}-.6610^{\star * *} \\
(.0408)\end{array}$ & $\begin{array}{r}-.5685^{* * *} \\
(.0603)\end{array}$ \\
\hline Closest Contiguity & $\begin{array}{r}-.3125^{\star * *} \\
(.0202)\end{array}$ & $\begin{array}{r}-.2984^{* * *} \\
(.0210)\end{array}$ & $\begin{array}{r}-.3436^{* * *} \\
(.0224)\end{array}$ & $\begin{array}{r}-.3286^{\star * *} \\
(.0235)\end{array}$ & $\begin{array}{r}-.2844^{* * *} \\
(.0361)\end{array}$ \\
\hline Constant & $\begin{array}{c}-1.9603^{\star * *} \\
(.0921) \\
\end{array}$ & $\begin{array}{c}-2.0255^{\star \star *} \\
(.0949) \\
\end{array}$ & $\begin{array}{c}-2.0212^{* \star *} \\
(.0965) \\
\end{array}$ & $\begin{array}{c}-2.0856^{\star \star *} \\
(.0994) \\
\end{array}$ & $\begin{array}{c}-3.3700^{* \star *} \\
(.1611) \\
\end{array}$ \\
\hline Observations & 84,810 & 84,810 & 84,810 & 84,810 & 84,605 \\
\hline Wald $\chi^{2}(7)$ & 968.58 & 965.67 & 871.66 & 864.37 & 272.67 \\
\hline$p$ & $<.0001$ & $<.0001$ & $<.0001$ & $<.0001$ & $<.0001$ \\
\hline Pseudo $\mathrm{R}^{2}$ & .1284 & .1281 & .1374 & .1373 & .0925 \\
\hline
\end{tabular}

${ }^{\circ} p<.10{ }^{*} p<.05 \quad{ }^{* *} p<.01{ }^{* * *} p<.001$

$+p<.15$ 
Table B-77. Logit of Protestant Preference.

\begin{tabular}{|c|c|c|c|c|c|}
\hline Variable & Model 1 & Model 2 & Model 3 & Model 4 & Model 5 \\
\hline $\begin{array}{l}\text { Protestant } \\
\text { Preference (binary) }\end{array}$ & $\begin{array}{r}-.6459^{* *} \\
(.2131) \\
\end{array}$ & $\begin{array}{r}-.6609^{\star \star} \\
(.2274) \\
\end{array}$ & $\begin{array}{r}-.7369^{\star *} \\
(.2491) \\
\end{array}$ & $\begin{array}{r}-.7619^{\star *} \\
(.2733) \\
\end{array}$ & $\begin{array}{r}-1.2931^{\star *} \\
(.4606)\end{array}$ \\
\hline Log CINC Ratio & $\begin{array}{l}.0104 \\
(.0126)\end{array}$ & $\begin{array}{l}-.0055 \\
(.0127)\end{array}$ & $\begin{array}{l}.0398^{* *} \\
(.0139)\end{array}$ & $\begin{array}{l}.0225 \\
(.0141)\end{array}$ & $\begin{array}{l}.0081 \\
(.0207)\end{array}$ \\
\hline Low Polity Score & $\begin{array}{l}-.0116 \\
(.0105)\end{array}$ & $\begin{array}{l}-.0096 \\
(.0109)\end{array}$ & $\begin{aligned}-.0231^{\circ} & (.0118)\end{aligned}$ & $\begin{array}{l}-.0203 \\
(.0124)\end{array}$ & $\begin{array}{c}-.0312^{\circ} \\
(.0169)\end{array}$ \\
\hline Polity Score & $\begin{array}{l}-.0219^{*} \\
(.0086)\end{array}$ & $\begin{array}{l}-.0276^{\star *} \\
(.0091)\end{array}$ & $\begin{array}{l}-.0206^{*} \\
(.0093)\end{array}$ & $\begin{array}{r}-.0287^{\star *} \\
(.0099)\end{array}$ & $\begin{array}{l}-.0025 \\
(.0137)\end{array}$ \\
\hline Defensive Allies & $\begin{array}{l}-.0455 \\
(.1055)\end{array}$ & $\begin{array}{l}.0037 \\
(.1090)\end{array}$ & $\begin{array}{l}-.1074 \\
(.1120)\end{array}$ & $\begin{array}{l}-.0540 \\
(.1163)\end{array}$ & $\begin{array}{l}-.1750 \\
(.1919)\end{array}$ \\
\hline Log Peace-Years & $\begin{array}{r}-.6604^{\star * *} \\
(.0367)\end{array}$ & $\begin{array}{r}-.6681^{\star * *} \\
(.0380)\end{array}$ & $\begin{array}{r}-.6649^{\star \star \star} \\
(.0402)\end{array}$ & $\begin{array}{r}-.6730^{\star * *} \\
(.0421)\end{array}$ & $\begin{array}{r}-.5954^{\star \star \star} \\
(.0602)\end{array}$ \\
\hline Closest Contiguity & $\begin{array}{r}-.3019^{\star * *} \\
(.0214)\end{array}$ & $\begin{array}{r}-.2785^{\star \star \star} \\
(.0219)\end{array}$ & $\begin{array}{r}-.3360^{\star \star \star} \\
(.0237)\end{array}$ & $\begin{array}{r}-.3095^{\star \star \star} \\
(.0243)\end{array}$ & $\begin{array}{r}-.2688^{\star \star \star} \\
(.0369)\end{array}$ \\
\hline Constant & $\begin{array}{c}-1.9836^{\star * *} \\
(.0982) \\
\end{array}$ & $\begin{array}{c}-2.0864^{\star * *} \\
(.1026) \\
\end{array}$ & $\begin{array}{c}-2.0202^{* * *} \\
(.1006)\end{array}$ & $\begin{array}{c}-2.1307^{* * *} \\
(.1056) \\
\end{array}$ & $\begin{array}{c}-3.3457^{* * *} \\
(.1643)\end{array}$ \\
\hline Observations & 75,401 & 75,401 & 75,401 & 75,401 & 75,227 \\
\hline Wald $\chi^{2}(7)$ & 899.76 & 849.18 & 836.86 & 778.31 & 251.69 \\
\hline $\mathrm{p}$ & $<.0001$ & $<.0001$ & $<.0001$ & $<.0001$ & $<.0001$ \\
\hline Pseudo $R^{2}$ & .1301 & .1255 & .1410 & .1355 & .0939 \\
\hline
\end{tabular}

${ }^{\circ} \mathrm{p}<.10{ }^{*} \mathrm{p}<.05{ }^{* *} \mathrm{p}<.01{ }^{* \star *} \mathrm{p}<.001$ 
Table B-78. Logit of Protestant GRP Scale.

\begin{tabular}{|c|c|c|c|c|c|}
\hline Variable & Model 1 & Model 2 & Model 3 & Model 4 & Model 5 \\
\hline $\begin{array}{l}\text { Protestant } \\
\text { GRP (every 10\%) }\end{array}$ & $\begin{array}{c}-.0962^{*} \\
(.0393) \\
\end{array}$ & $\begin{array}{r}-.0870^{*} \\
(.0423) \\
\end{array}$ & $\begin{array}{r}-.1258^{* *} \\
(.0460) \\
\end{array}$ & $\begin{array}{c}-.1180^{*} \\
(.0509) \\
\end{array}$ & $\begin{array}{c}-.2077^{*} \\
(.0855) \\
\end{array}$ \\
\hline Log CINC Ratio & $\begin{array}{l}.0206^{\circ} \\
(.0116)\end{array}$ & $\begin{array}{l}.0035 \\
(.0118)\end{array}$ & $\begin{array}{r}.0473^{* * *} \\
(.0127)\end{array}$ & $\begin{array}{c}.0293^{*} \\
(.0131)\end{array}$ & $\begin{array}{l}.0095 \\
(.0184)\end{array}$ \\
\hline Low Polity Score & $\begin{array}{r}-.0260^{* *} \\
(.0093)\end{array}$ & $\begin{array}{l}-.0223^{*} \\
(.0098)\end{array}$ & $\begin{array}{r}-.0390^{* \star *} \\
(.0104)\end{array}$ & $\begin{array}{c}-.0356^{* *} \\
(.0111)\end{array}$ & $\begin{array}{c}-.0506^{\star *} \\
(.0156)\end{array}$ \\
\hline Polity Score & $\begin{array}{l}-.0169^{*} \\
(.0077)\end{array}$ & $\begin{array}{r}-.0259^{\star *} \\
(.0083)\end{array}$ & $\begin{array}{r}-.0147^{\circ} \\
(.0081)\end{array}$ & $\begin{array}{c}-.0258^{\star *} \\
(.0089)\end{array}$ & $\begin{array}{l}-.0039 \\
(.0125)\end{array}$ \\
\hline Defensive Allies & $\begin{array}{r}-.0239 \\
(.0986)\end{array}$ & $\begin{array}{r}.0165 \\
(.1021)\end{array}$ & $\begin{array}{l}-.0897 \\
(.1056)\end{array}$ & $\begin{array}{c}-.0479 \\
(.1099)\end{array}$ & $\begin{array}{c}-.2037 \\
(.1840)\end{array}$ \\
\hline Log Peace-Years & $\begin{array}{r}-.6432^{* * *} \\
(.0351)\end{array}$ & $\begin{array}{r}-.6601^{* * *} \\
(.0366)\end{array}$ & $\begin{array}{r}-.6415^{\star * *} \\
(.0383)\end{array}$ & $\begin{array}{r}-.6604^{* * *} \\
(.0405)\end{array}$ & $\begin{array}{r}-.5791^{* * *} \\
(.0597)\end{array}$ \\
\hline Closest Contiguity & $\begin{array}{r}-.3081^{\star * \star} \\
(.0200)\end{array}$ & $\begin{array}{r}-.2941^{* * *} \\
(.0207)\end{array}$ & $\begin{array}{r}-.3368^{\star \star *} \\
(.0221)\end{array}$ & $\begin{array}{r}-.3222^{\star \star *} \\
(.0232)\end{array}$ & $\begin{array}{r}-.2710^{* * *} \\
(.0348)\end{array}$ \\
\hline Constant & $\begin{array}{c}-2.0282^{* * *} \\
(.0923) \\
\end{array}$ & $\begin{array}{c}-2.0812^{* * *} \\
(.0950)\end{array}$ & $\begin{array}{c}-2.0806^{\star * *} \\
(.0958)\end{array}$ & $\begin{array}{c}-2.1310^{\star \star * *} \\
(.0985)\end{array}$ & $\begin{array}{c}-3.3485^{\star * *} \\
(.1552) \\
\end{array}$ \\
\hline Observations & 92,277 & 92,277 & 92,277 & 92,277 & 92,077 \\
\hline Wald $\chi^{2}(7)$ & 989.04 & 992.31 & 908.98 & 905.34 & 291.08 \\
\hline$p$ & $<.0001$ & $<.0001$ & $<.0001$ & $<.0001$ & $<.0001$ \\
\hline Pseudo $\mathrm{R}^{2}$ & .1265 & .1268 & .1357 & .1364 & .0922 \\
\hline
\end{tabular}

${ }^{\circ} p<.10{ }^{*} p<.05{ }^{* *} p<.01{ }^{* * *} p<.001$ 
Table B-79. Logit of Protestant Prevalence.

\begin{tabular}{|c|c|c|c|c|c|}
\hline \multirow[t]{2}{*}{ Variable } & Model 1 & Model 2 & Model 3 & Model 4 & Model 5 \\
\hline & \multicolumn{5}{|l|}{ (Robust SE) } \\
\hline $\begin{array}{l}\text { Protestant } \\
\text { Prevalence (binary) }\end{array}$ & $\begin{array}{r}-.3562^{\circ} \\
(.2137)\end{array}$ & $\begin{array}{r}-.2955 \\
(.2257) \\
\end{array}$ & $\begin{array}{r}-.4139^{\circ} \\
(.2474) \\
\end{array}$ & $\begin{array}{l}-.3962 \dagger \\
(.2698)\end{array}$ & $\begin{array}{l}-.9237^{*} \\
(.4475) \\
\end{array}$ \\
\hline Log CINC Ratio & $\begin{array}{l}.0096 \\
(.0129)\end{array}$ & $\begin{array}{l}-.0050 \\
(.0130)\end{array}$ & $\begin{array}{l}.0362^{\star *} \\
(.0140)\end{array}$ & $\begin{array}{l}.0210 \\
(.0143)\end{array}$ & $\begin{array}{l}.0073 \\
(.0206)\end{array}$ \\
\hline Low Polity Score & $\begin{array}{l}-.0134 \\
(.0105)\end{array}$ & $\begin{array}{l}-.0102 \\
\quad(.0109)\end{array}$ & $\begin{array}{l}-.0234^{*} \\
(.0118)\end{array}$ & $\begin{array}{l}-.0191 \\
(.0124)\end{array}$ & $\begin{array}{l}-.0268 \\
(.0171)\end{array}$ \\
\hline Polity Score & $\begin{array}{r}-.0256^{\star \star} \\
(.0089)\end{array}$ & $\begin{array}{r}-.0329^{\star \star \star} \\
(.0095)\end{array}$ & $\begin{array}{r}-.0264^{\star \star} \\
(.0097)\end{array}$ & $\begin{array}{r}-.0359^{* * *} \\
(.0105)\end{array}$ & $\begin{array}{l}-.0106 \\
(.0148)\end{array}$ \\
\hline Defensive Allies & $\begin{array}{r}.0121 \\
(.1063)\end{array}$ & $\begin{array}{l}.0516 \\
(.1101)\end{array}$ & $\begin{array}{l}-.0604 \\
(.1122)\end{array}$ & $\begin{array}{l}-.0186 \\
(.1167)\end{array}$ & $\begin{array}{l}-.1145 \\
(.1926)\end{array}$ \\
\hline Log Peace-Years & $\begin{array}{r}-.6768^{* * *} \\
(.0372)\end{array}$ & $\begin{array}{r}-.6779^{\star * *} \\
(.0386)\end{array}$ & $\begin{array}{r}-.6876^{\star * *} \\
(.0404)\end{array}$ & $\begin{array}{r}-.6879^{\star * *} \\
(.0425)\end{array}$ & $\begin{array}{r}-.6099^{* * *} \\
(.0609)\end{array}$ \\
\hline Closest Contiguity & $\begin{array}{r}-.3013^{* * *} \\
(.0221)\end{array}$ & $\begin{array}{r}-.2833^{* * *} \\
(.0226)\end{array}$ & $\begin{array}{r}-.3342^{* * *} \\
(.0242)\end{array}$ & $\begin{array}{r}-.3147^{* * *} \\
(.0249)\end{array}$ & $\begin{array}{r}-.2591^{* * *} \\
(.0377)\end{array}$ \\
\hline Constant & $\begin{array}{c}-1.9596^{\star * *} \\
(.1024) \\
\end{array}$ & $\begin{array}{c}-2.0537^{* * *} \\
(.1070) \\
\end{array}$ & $\begin{array}{c}-1.9702^{* * *} \\
(.1043) \\
\end{array}$ & $\begin{array}{c}-2.0713^{\star * \star} \\
(.1096) \\
\end{array}$ & $\begin{array}{c}-3.3426^{* * *} \\
(.1698) \\
\end{array}$ \\
\hline Observations & 73,588 & 73,588 & 73,588 & 73,588 & 73,409 \\
\hline Wald $\chi^{2}(7)$ & 870.36 & 821.89 & 818.80 & 761.18 & 251.79 \\
\hline$p$ & $<.0001$ & $<.0001$ & $<.0001$ & $<.0001$ & $<.0001$ \\
\hline Pseudo $\mathrm{R}^{2}$ & .1322 & .1277 & .1436 & .1389 & .0920 \\
\hline
\end{tabular}

${ }^{\circ} p<.10{ }^{*} p<.05 \quad{ }^{* *} p<.01{ }^{* * *} p<.001$

$\dagger p<.15$ 
Table B-80. Logit of Protestant Population.

\begin{tabular}{|c|c|c|c|c|c|}
\hline Variable & $\begin{array}{l}\text { Model } 1 \\
\text { (Robust SE) }\end{array}$ & Model 2 & Model 3 & Model 4 & Model 5 \\
\hline $\begin{array}{l}\text { Protestant } \\
\text { Pop. (every 10\%) }\end{array}$ & $\begin{array}{c}-.0344 \dagger \\
(.0215) \\
\end{array}$ & $\begin{array}{c}-.0336 \\
(.0238) \\
\end{array}$ & $\begin{array}{c}-.0371 \dagger \\
(.0238) \\
\end{array}$ & $\begin{array}{c}-.0405 \dagger \\
(.0270) \\
\end{array}$ & $\begin{array}{r}-.1085^{*} \\
(.0439) \\
\end{array}$ \\
\hline Log CINC Ratio & $\begin{array}{l}.0229^{*} \\
(.0113)\end{array}$ & $\begin{array}{l}.0045 \\
(.0115)\end{array}$ & $\begin{array}{r}.0501^{* * *} \\
(.0124)\end{array}$ & $\begin{array}{l}.0305^{*} \\
(.0128)\end{array}$ & $\begin{array}{r}.0137 \\
(.0181)\end{array}$ \\
\hline Low Polity Score & $\begin{array}{r}-.0273^{* *} \\
(.0091)\end{array}$ & $\begin{array}{l}-.0243^{*} \\
(.0096)\end{array}$ & $\begin{array}{r}-.0398^{* * *} \\
(.0102)\end{array}$ & $\begin{array}{r}-.0373^{* * *} \\
(.0109)\end{array}$ & $\begin{array}{r}-.0494^{* *} \\
(.0154)\end{array}$ \\
\hline Polity Score & $\begin{array}{l}-.0174^{*} \\
(.0076)\end{array}$ & $\begin{array}{r}-.0257^{\star *} \\
(.0082)\end{array}$ & $\begin{array}{l}-.0163^{*} \\
(.0082)\end{array}$ & $\begin{array}{c}-.0262^{* *} \\
(.0090)\end{array}$ & $\begin{array}{l}-.0001 \\
(.0128)\end{array}$ \\
\hline Defensive Allies & $\begin{array}{l}-.0563 \\
(.0965)\end{array}$ & $\begin{array}{l}-.0197 \\
(.0998)\end{array}$ & $\begin{array}{c}-.1155 \\
(.1034)\end{array}$ & $\begin{array}{c}-.0778 \\
(.1076)\end{array}$ & $\begin{array}{l}-.2088 \\
(.1821)\end{array}$ \\
\hline Log Peace-Years & $\begin{array}{r}-.6536^{\star * *} \\
(.0339)\end{array}$ & $\begin{array}{r}-.6672^{\star * *} \\
(.0353)\end{array}$ & $\begin{array}{r}-.6526^{\star * *} \\
(.0369)\end{array}$ & $\begin{array}{r}-.6677^{\star \star \star} \\
(.0388)\end{array}$ & $\begin{array}{r}-.5780^{\star \star *} \\
(.0579)\end{array}$ \\
\hline Closest Contiguity & $\begin{array}{r}-.3135^{\star \star \star} \\
(.0195)\end{array}$ & $\begin{array}{r}-.2998^{\star * *} \\
(.0201)\end{array}$ & $\begin{array}{r}-.3411^{\star \star *} \\
(.0215)\end{array}$ & $\begin{array}{r}-.3261^{* \star *} \\
(.0225)\end{array}$ & $\begin{array}{r}-.2702^{\star \star \star} \\
(.0343)\end{array}$ \\
\hline Constant & $\begin{array}{c}-1.9654^{* * *} \\
(.0888) \\
\end{array}$ & $\begin{array}{c}-2.0210^{\star \star * *} \\
(.0914)\end{array}$ & $\begin{array}{c}-2.0188^{* * *} \\
(.0925)\end{array}$ & $\begin{array}{c}-2.0729^{\star * *} \\
(.0951)\end{array}$ & $\begin{array}{c}-3.3393^{* * *} \\
(.1521) \\
\end{array}$ \\
\hline Observations & 95,418 & 95,418 & 95,418 & 95,418 & 95,197 \\
\hline Wald $\chi^{2}(7)$ & 1060.00 & 1060.94 & 968.38 & 964.52 & 316.54 \\
\hline$p$ & $<.0001$ & $<.0001$ & $<.0001$ & $<.0001$ & $<.0001$ \\
\hline Pseudo $\mathrm{R}^{2}$ & .1303 & .1300 & .1390 & .1391 & .0920 \\
\hline
\end{tabular}

${ }^{\circ} p<.10 \quad{ }^{*} p<.05 \quad{ }^{* *} p<.01{ }^{* * *} p<.001$

$+p<.15$ 
Table B-81. Logit of Catholic Preference, Controlled for American Dyads.

\begin{tabular}{|c|c|c|c|c|c|}
\hline Variable & Model 1 & Model 2 & Model 3 & Model 4 & Model 5 \\
\hline $\begin{array}{l}\text { Catholic } \\
\text { Preference (binary) }\end{array}$ & $\begin{array}{r}-.6690^{\star * *} \\
(.1474) \\
\end{array}$ & $\begin{array}{r}-.7125^{* * *} \\
(.1549) \\
\end{array}$ & $\begin{array}{r}-.6870^{* * *} \\
(.1669) \\
\end{array}$ & $\begin{array}{r}-.7402^{* * *} \\
(.1793) \\
\end{array}$ & $\begin{array}{c}-1.2870^{\star \star \star} \\
(.2964)\end{array}$ \\
\hline Log CINC Ratio & $\begin{array}{l}.0105 \\
(.0122)\end{array}$ & $\begin{array}{c}-.0053 \\
(.0123)\end{array}$ & $\begin{array}{c}.0386^{* *} \\
(.0136)\end{array}$ & $\begin{array}{l}.0211 \\
(.0138)\end{array}$ & $\begin{array}{l}.0052 \\
(.0199)\end{array}$ \\
\hline Low Polity Score & $\begin{array}{c}-.0082 \\
(.0108)\end{array}$ & $\begin{array}{c}-.0059 \\
(.0111)\end{array}$ & $\begin{array}{c}-.0190 \\
(.0120)\end{array}$ & $\begin{array}{c}-.0158 \\
(.0125)\end{array}$ & $\begin{array}{c}-.0227 \\
(.0170)\end{array}$ \\
\hline Polity Score & $\begin{array}{c}-.0282^{* *} \\
(.0087)\end{array}$ & $\begin{array}{r}-.0335^{\star * *} \\
(.0091)\end{array}$ & $\begin{array}{c}-.0261^{* *} \\
(.0093)\end{array}$ & $\begin{array}{r}-.0336^{\star * *} \\
(.0098)\end{array}$ & $\begin{array}{c}-.0073 \\
(.0133)\end{array}$ \\
\hline Defensive Allies & $\begin{array}{c}-.2467^{\star} \\
(.1128)\end{array}$ & $\begin{array}{c}-.1733 \\
(.1153)\end{array}$ & $\begin{array}{l}-.2167^{\circ} \\
(.1205)\end{array}$ & $\begin{array}{c}-.1310 \\
(.1236)\end{array}$ & $\begin{array}{c}-.1025 \\
(.1972)\end{array}$ \\
\hline Log Peace-Years & $\begin{array}{r}-.6624^{\star \star *} \\
(.0364)\end{array}$ & $\begin{array}{r}-.6676^{\star * *} \\
(.0377)\end{array}$ & $\begin{array}{r}-.6629^{\star * *} \\
(.0400)\end{array}$ & $\begin{array}{r}-.6678^{\star * *} \\
(.0419)\end{array}$ & $\begin{array}{r}-.5737^{* * *} \\
(.0623)\end{array}$ \\
\hline Closest Contiguity & $\begin{array}{r}-.3036^{\star * *} \\
(.0217)\end{array}$ & $\begin{array}{r}-.2803^{\star * *} \\
(.0221)\end{array}$ & $\begin{array}{r}-.3383^{* * *} \\
(.0240)\end{array}$ & $\begin{array}{r}-.3119^{\star * *} \\
(.0246)\end{array}$ & $\begin{array}{r}-.2733^{\star * *} \\
(.0377)\end{array}$ \\
\hline American Dyad & $\begin{array}{c}1.2257^{\star * *} \\
(.1699)\end{array}$ & $\begin{array}{c}1.2003^{* * *} \\
(.1772)\end{array}$ & $\begin{array}{r}.9979^{* * *} \\
(.1973)\end{array}$ & $\begin{array}{r}.9436^{* * *} \\
(.2104)\end{array}$ & $\begin{array}{l}.8352^{*} \\
(.3507)\end{array}$ \\
\hline Constant & $\begin{array}{c}-1.9284^{* * *} \\
(.0963)\end{array}$ & $\begin{array}{c}-2.0349^{\star * *} \\
(.1004)\end{array}$ & $\begin{array}{c}-1.9766^{* * *} \\
(.0997) \\
\end{array}$ & $\begin{array}{c}-2.0934^{\star \star *} \\
(.1046) \\
\end{array}$ & $\begin{array}{c}-3.3254^{* * *} \\
(.1651) \\
\end{array}$ \\
\hline Observations & 75,401 & 75,401 & 75,401 & 75,401 & 75,227 \\
\hline Wald $\chi^{2}(8)$ & 911.24 & 851.22 & 838.85 & 775.66 & 279.28 \\
\hline$p$ & $<.0001$ & $<.0001$ & $<.0001$ & $<.0001$ & $<.0001$ \\
\hline Pseudo $\mathrm{R}^{2}$ & .1348 & .1300 & .1434 & .1378 & .0977 \\
\hline
\end{tabular}

${ }^{\circ} p<.10{ }^{*} p<.05 \quad{ }^{* *} p<.01{ }^{* * *} p<.001$ 
Table B-82. Logit of Catholic Prevalence, Controlled for American Dyads.

\begin{tabular}{|c|c|c|c|c|c|}
\hline Variable & Model 1 & Model 2 & Model 3 & Model 4 & Model 5 \\
\hline $\begin{array}{l}\text { Catholic } \\
\text { Prevalence (binary) }\end{array}$ & $\begin{array}{r}-.6059^{\star * *} \\
(.1564) \\
\end{array}$ & $\begin{array}{r}-.6070^{\star * \star} \\
(.1637) \\
\end{array}$ & $\begin{array}{r}-.6394^{\star \star *} \\
(.1768) \\
\end{array}$ & $\begin{array}{r}-.6374^{\star \star *} \\
(.1878) \\
\end{array}$ & $\begin{array}{r}-.9723^{\star *} \\
(.2997) \\
\end{array}$ \\
\hline Log CINC Ratio & $\begin{array}{l}.0083 \\
(.0124)\end{array}$ & $\begin{array}{l}-.0060 \\
(.0125)\end{array}$ & $\begin{array}{c}.0335^{\star} \\
(.0136)\end{array}$ & $\begin{array}{l}.0183 \\
(.0138)\end{array}$ & $\begin{array}{l}.0021 \\
(.0199)\end{array}$ \\
\hline Low Polity Score & $\begin{array}{l}-.0109 \\
(.0108)\end{array}$ & $\begin{array}{l}-.0079 \\
(.0111)\end{array}$ & $\begin{array}{l}-.0198 \\
(.0121)\end{array}$ & $\begin{array}{c}-.0153 \\
(.0126)\end{array}$ & $\begin{array}{l}-.0186 \\
(.0172)\end{array}$ \\
\hline Polity Score & $\begin{array}{r}-.0288^{\star \star \star} \\
(.0087)\end{array}$ & $\begin{array}{r}-.0350^{\star * *} \\
(.0091)\end{array}$ & $\begin{array}{r}-.0285^{\star \star} \\
(.0094)\end{array}$ & $\begin{array}{r}-.0373^{\star \star *} \\
(.0100)\end{array}$ & $\begin{array}{l}-.0136 \\
(.0140)\end{array}$ \\
\hline Defensive Allies & $\begin{array}{c}-.1927^{\circ} \\
(.1156)\end{array}$ & $\begin{array}{l}-.1277 \\
(.1184)\end{array}$ & $\begin{array}{c}-.1626 \\
(.1220)\end{array}$ & $\begin{array}{c}-.0866 \\
(.1253)\end{array}$ & $\begin{array}{l}-.0515 \\
(.2001)\end{array}$ \\
\hline Log Peace-Years & $\begin{array}{r}-.6813^{* * *} \\
(.0367)\end{array}$ & $\begin{array}{r}-.6806^{* * *} \\
(.0382)\end{array}$ & $\begin{array}{r}-.6864^{* * *} \\
(.0400)\end{array}$ & $\begin{array}{r}-.6842^{* * *} \\
(.0421)\end{array}$ & $\begin{array}{r}-.5929^{* * *} \\
(.0626)\end{array}$ \\
\hline Closest Contiguity & $\begin{array}{r}-.2987^{\star * *} \\
(.0221)\end{array}$ & $\begin{array}{r}-.2808^{* * *} \\
(.0226)\end{array}$ & $\begin{array}{r}-.3324^{\star \star *} \\
(.0243)\end{array}$ & $\begin{array}{r}-.3134^{\star * *} \\
(.0250)\end{array}$ & $\begin{array}{r}-.2610^{\star * *} \\
(.0380)\end{array}$ \\
\hline American Dyad & $\begin{array}{c}1.2179^{\star \star \star} \\
(.1881)\end{array}$ & $\begin{array}{c}1.1551^{* * *} \\
(.1962)\end{array}$ & $\begin{array}{r}.9686^{\star * *} \\
(.2186)\end{array}$ & $\begin{array}{c}.8589^{* * *} \\
(.2327)\end{array}$ & $\begin{array}{l}.6212 \\
(.3924)\end{array}$ \\
\hline Constant & $\begin{array}{c}-1.9101^{* * *} \\
(.0997) \\
\end{array}$ & $\begin{array}{c}-2.0107^{* * *} \\
(.1039) \\
\end{array}$ & $\begin{array}{c}-1.9370^{* * *} \\
(.1024) \\
\end{array}$ & $\begin{array}{c}-2.0451^{* * *} \\
(.1075) \\
\end{array}$ & $\begin{array}{c}-3.3245^{\star * *} \\
(.1686) \\
\end{array}$ \\
\hline Observations & 73,588 & 73,588 & 73,588 & 73,588 & 73,409 \\
\hline Wald $\chi^{2}(8)$ & 873.23 & 813.38 & 809.18 & 746.23 & 261.61 \\
\hline $\mathrm{p}$ & $<.0001$ & $<.0001$ & $<.0001$ & $<.0001$ & $<.0001$ \\
\hline Pseudo $\mathrm{R}^{2}$ & .1374 & .1325 & .1467 & .1415 & .0949 \\
\hline
\end{tabular}

${ }^{\circ} p<.10{ }^{*} p<.05 \quad{ }^{* *} p<.01{ }^{* * *} p<.001$ 
Table B-83. Logit of Protestant Preference, Controlled for American Dyads.

\begin{tabular}{|c|c|c|c|c|c|}
\hline Variable & Model 1 & Model 2 & Model 3 & Model 4 & Model 5 \\
\hline $\begin{array}{l}\text { Protestant } \\
\text { Preference (binary) }\end{array}$ & $\begin{array}{r}-.5693^{* *} \\
(.2140) \\
\end{array}$ & $\begin{array}{c}-.5910^{\star *} \\
(.2283) \\
\end{array}$ & $\begin{array}{r}-.6911^{* *} \\
(.2509) \\
\end{array}$ & $\begin{array}{c}-.7266^{\star *} \\
(.2752) \\
\end{array}$ & $\begin{array}{r}-1.3080^{\star *} \\
(.4647) \\
\end{array}$ \\
\hline Log CINC Ratio & $\begin{array}{l}.0117 \\
(.0125)\end{array}$ & $\begin{array}{c}-.0041 \\
(.0125)\end{array}$ & $\begin{array}{c}.0403^{* *} \\
(.0138)\end{array}$ & $\begin{array}{l}.0230 \\
(.0140)\end{array}$ & $\begin{array}{l}.0079 \\
(.0206)\end{array}$ \\
\hline Low Polity Score & $\begin{array}{l}-.0131 \\
(.0107)\end{array}$ & $\begin{array}{l}-.0110 \\
(.0110)\end{array}$ & $\begin{array}{l}-.0243^{*} \\
(.0119)\end{array}$ & $\begin{array}{l}-.0213^{\circ} \\
(.0124)\end{array}$ & $\begin{array}{l}-.0308^{\circ} \\
(.0168)\end{array}$ \\
\hline Polity Score & $\begin{array}{r}-.0260^{\star *} \\
(.0088)\end{array}$ & $\begin{array}{r}-.0313^{* * *} \\
(.0093)\end{array}$ & $\begin{array}{l}-.0230^{*} \\
(.0094)\end{array}$ & $\begin{array}{r}-.0305^{\star \star} \\
(.0101)\end{array}$ & $\begin{array}{l}-.0017 \\
(.0138)\end{array}$ \\
\hline Defensive Allies & $\begin{array}{c}-.2738^{\star} \\
(.1167)\end{array}$ & $\begin{array}{l}-.2007^{\circ} \\
(.1195)\end{array}$ & $\begin{array}{l}-.2347^{\circ} \\
(.1238)\end{array}$ & $\begin{array}{l}-.1487 \\
(.1272)\end{array}$ & $\begin{array}{c}-.1240 \\
(.2081)\end{array}$ \\
\hline Log Peace-Years & $\begin{array}{r}-.6733^{* * *} \\
(.0362)\end{array}$ & $\begin{array}{r}-.6798^{* * *} \\
(.0375)\end{array}$ & $\begin{array}{r}-.6725^{\star * *} \\
(.0399)\end{array}$ & $\begin{array}{r}-.6788^{* * *} \\
(.0418)\end{array}$ & $\begin{array}{r}-.5925^{\star * *} \\
(.0610)\end{array}$ \\
\hline Closest Contiguity & $\begin{array}{r}-.3003^{* \star *} \\
(.0214)\end{array}$ & $\begin{array}{r}-.2772^{\star \star *} \\
(.0219)\end{array}$ & $\begin{array}{r}-.3349^{\star \star *} \\
(.0237)\end{array}$ & $\begin{array}{r}-.3088^{\star \star *} \\
(.0244)\end{array}$ & $\begin{array}{r}-.2692^{* \star *} \\
(.0369)\end{array}$ \\
\hline American Dyad & $\begin{array}{r}.6983^{* * *} \\
(.1491)\end{array}$ & $\begin{array}{r}.6399^{\star \star *} \\
(.1548)\end{array}$ & $\begin{array}{l}.4328^{*} \\
(.1730)\end{array}$ & $\begin{array}{l}.3365^{\circ} \\
(.1835)\end{array}$ & $\begin{array}{l}-.1931 \\
(.3356)\end{array}$ \\
\hline Constant & $\begin{array}{c}-1.9456^{\star \star *} \\
(.0967) \\
\end{array}$ & $\begin{array}{c}-2.0514^{* * *} \\
(.1009) \\
\end{array}$ & $\begin{array}{c}-1.9974^{* * *} \\
(.1001) \\
\end{array}$ & $\begin{array}{c}-2.1131^{* * *} \\
(.1051) \\
\end{array}$ & $\begin{array}{c}-3.3545^{\star * *} \\
(.1657) \\
\end{array}$ \\
\hline Observations & 75,401 & 75,401 & 75,401 & 75,401 & 75,227 \\
\hline Wald $\chi^{2}(8)$ & 921.46 & 862.42 & 839.66 & 777.53 & 251.92 \\
\hline $\mathrm{p}$ & $<.0001$ & $<.0001$ & $<.0001$ & $<.0001$ & $<.0001$ \\
\hline Pseudo $\mathrm{R}^{2}$ & .1329 & .1278 & .1419 & .1361 & .0940 \\
\hline
\end{tabular}

${ }^{\circ} p<.10{ }^{*} p<.05 \quad{ }^{* *} p<.01{ }^{* * *} p<.001$ 
Table B-84. Logit of Protestant Prevalence, Controlled for American Dyads.

\begin{tabular}{|c|c|c|c|c|c|}
\hline Variable & Model 1 & Model 2 & Model 3 & Model 4 & Model 5 \\
\hline & (Robust SE & & & & \\
\hline $\begin{array}{l}\text { Protestant } \\
\text { Prevalence (binary) }\end{array}$ & $\begin{array}{r}-.2614 \\
(.2156) \\
\end{array}$ & $\begin{array}{r}-.2080 \\
(.2278) \\
\end{array}$ & $\begin{array}{c}-.3613 \dagger \\
(.2500) \\
\end{array}$ & $\begin{array}{r}-.3570 \\
(.2725) \\
\end{array}$ & $\begin{array}{l}-.9444^{*} \\
(.4499) \\
\end{array}$ \\
\hline Log CINC Ratio & $\begin{array}{l}.0103 \\
(.0127)\end{array}$ & $\begin{array}{l}-.0042 \\
(.0128)\end{array}$ & $\begin{array}{l}.0364^{* *} \\
(.0140)\end{array}$ & $\begin{array}{l}.0212 \\
(.0142)\end{array}$ & $\begin{array}{l}.0071 \\
(.0206)\end{array}$ \\
\hline Low Polity Score & $\begin{aligned}-.0151 \\
(.0106)\end{aligned}$ & $\begin{aligned}-.0118 \\
(.0110)\end{aligned}$ & $\begin{array}{l}-.0246^{*} \\
(.0119)\end{array}$ & $\begin{array}{l}-.0200 \\
(.0124)\end{array}$ & $\begin{array}{l}-.0264 \\
(.0170)\end{array}$ \\
\hline Polity Score & $\begin{array}{r}-.0300^{* *} \\
(.0092)\end{array}$ & $\begin{array}{r}-.0369^{* * *} \\
(.0098)\end{array}$ & $\begin{aligned}-.0288^{* *} & (.0100)\end{aligned}$ & $\begin{array}{r}-.0377^{\star \star \star} \\
(.0107)\end{array}$ & $\begin{array}{l}-.0097 \\
(.0151)\end{array}$ \\
\hline Defensive Allies & $\begin{array}{r}-.2107^{\circ} \\
(.1162)\end{array}$ & $\begin{array}{l}-.1468 \\
\quad(.1191)\end{array}$ & $\begin{array}{l}-.1781 \\
(.1227)\end{array}$ & $\begin{array}{l}-.1019 \\
(.1261)\end{array}$ & $\begin{array}{l}-.0588 \\
(.2036)\end{array}$ \\
\hline Log Peace-Years & $\begin{array}{r}-.6910^{\star * *} \\
(.0367)\end{array}$ & $\begin{array}{r}-.6907^{\star * *} \\
(.0381)\end{array}$ & $\begin{array}{r}-.6954^{* * *} \\
(.0401)\end{array}$ & $\begin{array}{r}-.6936^{\star \star *} \\
(.0422)\end{array}$ & $\begin{array}{r}-.6065^{\star * *} \\
(.0619)\end{array}$ \\
\hline Closest Contiguity & $\begin{array}{r}-.2994^{* * *} \\
(.0221)\end{array}$ & $\begin{array}{r}-.2818^{\star * *} \\
(.0227)\end{array}$ & $\begin{array}{r}-.3330^{\star \star *} \\
(.0242)\end{array}$ & $\begin{array}{r}-.3140^{* \star *} \\
(.0250)\end{array}$ & $\begin{array}{r}-.2597^{* * *} \\
(.0378)\end{array}$ \\
\hline American Dyad & $\begin{array}{r}.7177^{* * *} \\
(.1515)\end{array}$ & $\begin{array}{r}.6576^{* * *} \\
(.1574)\end{array}$ & $\begin{array}{l}.4260^{*} \\
(.1762)\end{array}$ & $\begin{array}{c}.3176^{\circ} \\
(.1875)\end{array}$ & $\begin{array}{r}-.2253 \\
(.3394)\end{array}$ \\
\hline Constant & $\begin{array}{c}-1.9183^{* * *} \\
(.1007) \\
\end{array}$ & $\begin{array}{c}-2.0160^{* * *} \\
(.1052) \\
\end{array}$ & $\begin{array}{c}-1.9470^{* * *} \\
(.1039) \\
\end{array}$ & $\begin{array}{c}-2.0542^{* * *} \\
(.1092) \\
\end{array}$ & $\begin{array}{c}-3.3531^{* * *} \\
(.1716) \\
\end{array}$ \\
\hline Observations & 73,588 & 73,588 & 73,588 & 73,588 & 73,409 \\
\hline Wald $\chi^{2}(8)$ & 888.06 & 830.87 & 818.44 & 758.09 & 253.71 \\
\hline$p$ & $<.0001$ & $<.0001$ & $<.0001$ & $<.0001$ & $<.0001$ \\
\hline Pseudo $\mathrm{R}^{2}$ & .1352 & .1302 & .1446 & .1394 & .0922 \\
\hline
\end{tabular}

${ }^{\circ} p<.10{ }^{*} p<.05{ }^{* *} p<.01{ }^{* * *} p<.001$

$+p<.15$ 
Table B-85. Logit of Eastern Christian Chief Executive.

\begin{tabular}{|c|c|c|c|c|c|}
\hline Variable & Model 1 & Model 2 & Model 3 & Model 4 & Model 5 \\
\hline & (Robust SE & & & & \\
\hline $\begin{array}{l}\text { Eastern Christian } \\
\text { Chief Exec. (binary) }\end{array}$ & $\begin{aligned}-.0234 \\
(.1726)\end{aligned}$ & $\begin{array}{l}-.0391 \\
(.1829)\end{array}$ & $\begin{array}{l}.0076 \\
(.1873)\end{array}$ & $\begin{aligned}-.0024 \\
(.2007)\end{aligned}$ & $\begin{array}{l}.2253 \\
(.2899)\end{array}$ \\
\hline Log CINC Ratio & $\begin{array}{l}.0146 \\
(.0117)\end{array}$ & $\begin{aligned}-.0051 \\
(.0120)\end{aligned}$ & $\begin{array}{r}.0444^{* * *} \\
(.0129)\end{array}$ & $\begin{array}{l}.0232^{\circ} \\
(.0134)\end{array}$ & $\begin{array}{l}.0108 \\
(.0194)\end{array}$ \\
\hline Low Polity Score & $\begin{array}{l}-.0229^{*} \\
(.0091)\end{array}$ & $\begin{array}{l}-.0201^{*} \\
(.0095)\end{array}$ & $\begin{array}{r}-.0356^{* * *} \\
(.0103)\end{array}$ & $\begin{array}{r}-.0332^{* *} \\
(.0109)\end{array}$ & $\begin{aligned}-.0459^{* *} \\
(.0157)\end{aligned}$ \\
\hline Polity Score & $\begin{array}{l}-.0180^{*} \\
(.0073)\end{array}$ & $\begin{array}{r}-.0259^{* * *} \\
(.0078)\end{array}$ & $\begin{array}{l}-.0167^{*} \\
(.0078)\end{array}$ & $\begin{array}{r}-.0267^{* *} \\
(.0084)\end{array}$ & $\begin{array}{l}-.0068 \\
(.0122)\end{array}$ \\
\hline Defensive Allies & $\begin{array}{l}-.0447 \\
(.0986)\end{array}$ & $\begin{array}{l}-.0059 \\
(.1024)\end{array}$ & $\begin{array}{l}-.1021 \\
\quad(.1061)\end{array}$ & $\begin{array}{l}-.0616 \\
(.1108)\end{array}$ & $\begin{array}{l}-.1621 \\
\quad(.1867)\end{array}$ \\
\hline Log Peace-Years & $\begin{array}{r}-.6584^{* * *} \\
(.0351)\end{array}$ & $\begin{array}{r}-.6700^{\star * *} \\
(.0366)\end{array}$ & $\begin{array}{r}-.6569^{\star \star \star} \\
(.0384)\end{array}$ & $\begin{array}{r}-.6695^{\star \star \star} \\
(.0405)\end{array}$ & $\begin{array}{r}-.5784^{* \star *} \\
(.0605)\end{array}$ \\
\hline Closest Contiguity & $\begin{array}{r}-.3137^{* * *} \\
(.0201)\end{array}$ & $\begin{array}{r}-.2993^{* * *} \\
(.0208)\end{array}$ & $\begin{array}{r}-.3447^{\star * *} \\
(.0224)\end{array}$ & $\begin{array}{r}-.3292^{* * *} \\
(.0234)\end{array}$ & $\begin{array}{r}-.2849^{\star * *} \\
(.0361)\end{array}$ \\
\hline Constant & $\begin{array}{c}-1.9705^{\star * *} \\
(.0915)\end{array}$ & $\begin{array}{c}-2.0339^{* * *} \\
(.0943) \\
\end{array}$ & $\begin{array}{c}-2.0300^{* * *} \\
(.0960) \\
\end{array}$ & $\begin{array}{c}-2.0930^{* * *} \\
(.0990) \\
\end{array}$ & $\begin{array}{c}-3.3903^{* * *} \\
(.1607) \\
\end{array}$ \\
\hline Observations & 87,766 & 87,766 & 87,766 & 87,766 & 87,557 \\
\hline Wald $\chi^{2}(7)$ & 994.86 & 994.34 & 901.04 & 895.85 & 284.39 \\
\hline$p$ & $<.0001$ & $<.0001$ & $<.0001$ & $<.0001$ & $<.0001$ \\
\hline Pseudo $\mathrm{R}^{2}$ & .1289 & .1281 & .1379 & .1372 & .0901 \\
\hline
\end{tabular}

${ }^{\circ} p<.10{ }^{*} p<.05{ }^{* *} p<.01{ }^{* * *} p<.001$ 
Table B-86. Logit of Eastern Christian Preference.

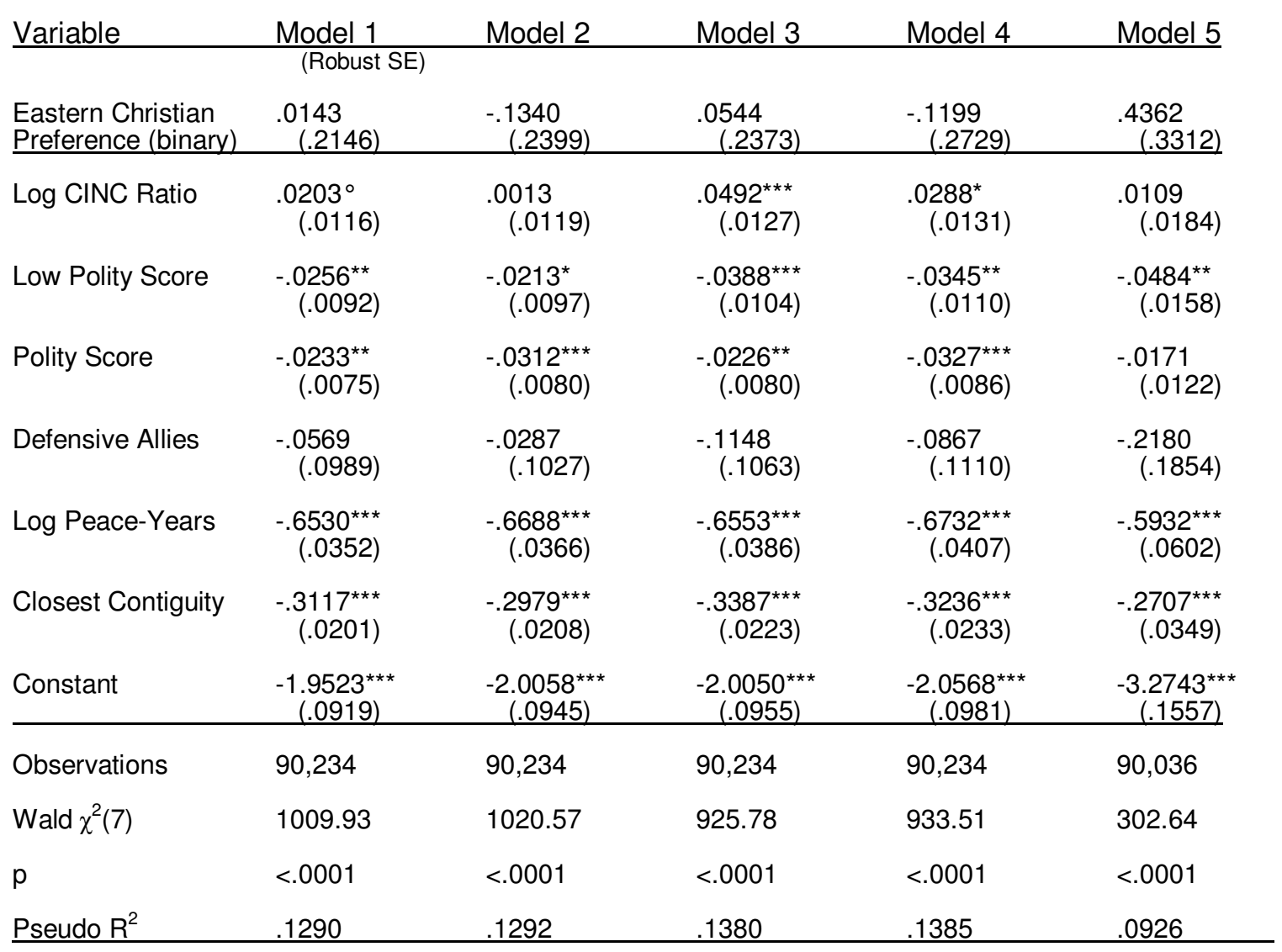

${ }^{\circ} p<.10{ }^{*} p<.05{ }^{* *} p<.01{ }^{* * *} p<.001$ 
Table B-87. Logit of Eastern Christian GRP Scale.

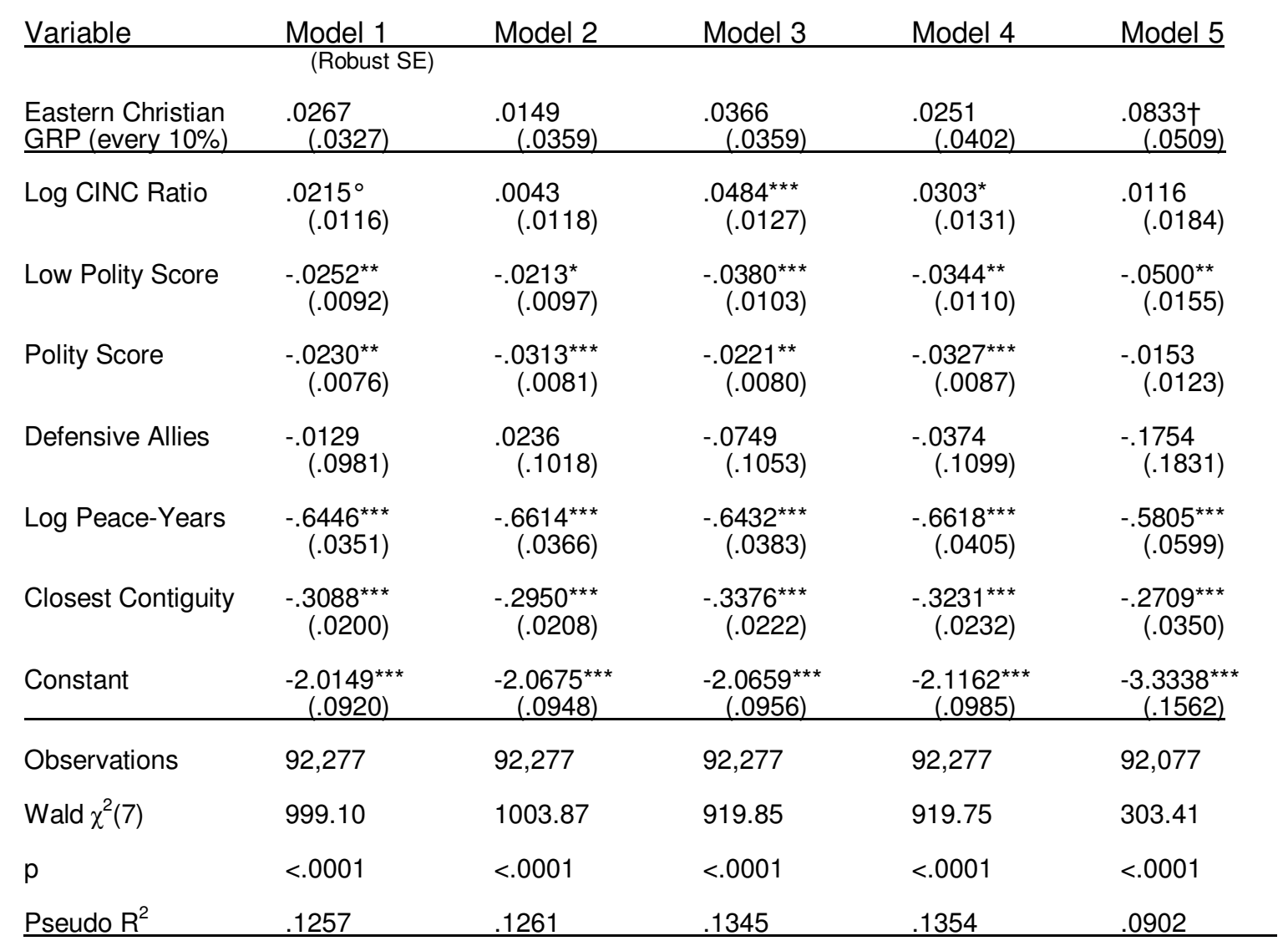

${ }^{\circ} p<.10{ }^{*} p<.05{ }^{* *} p<.01{ }^{* * *} p<.001$

$+p<.15$ 
Table B-88. Logit of Eastern Christian Prevalence.

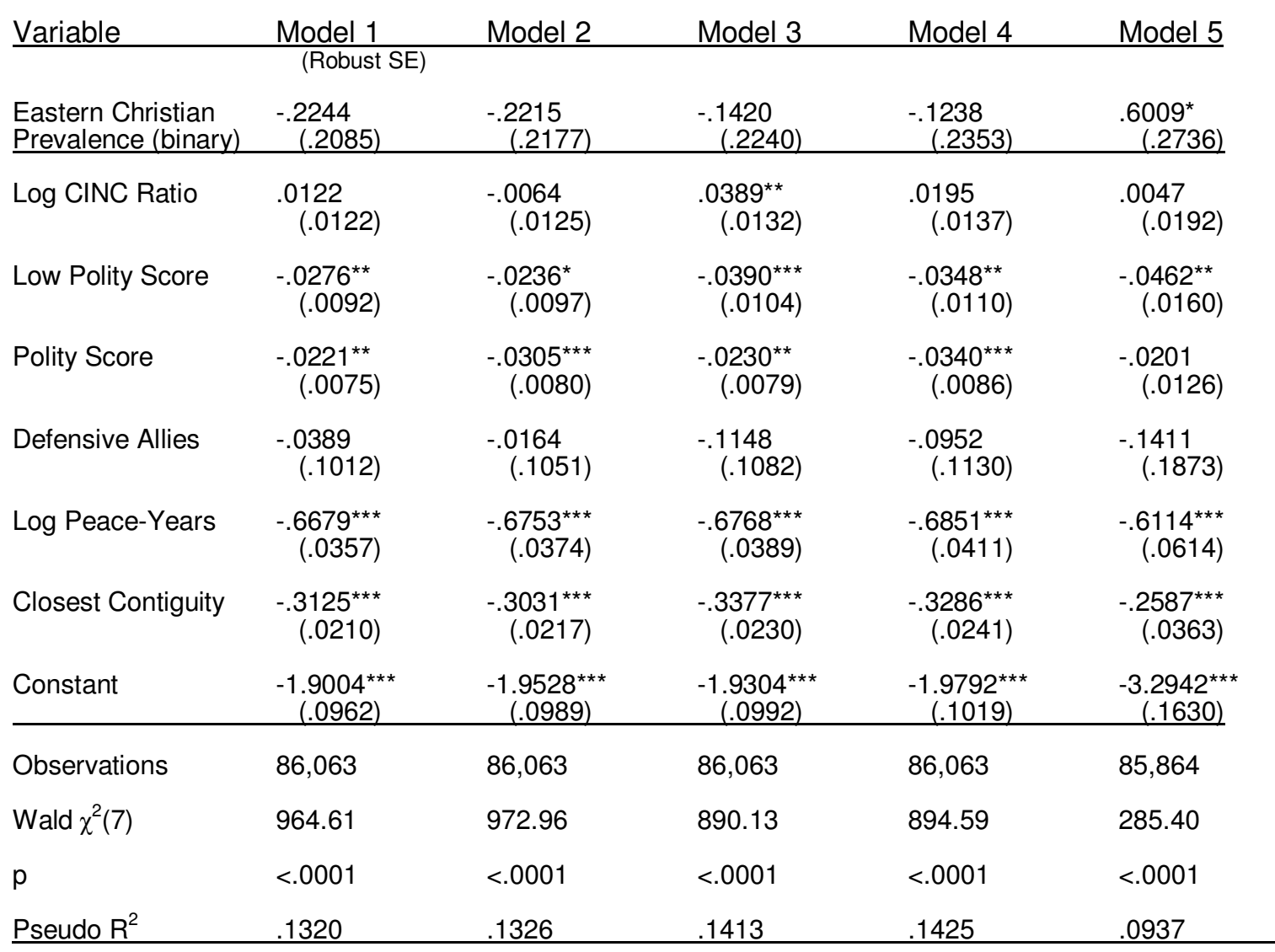

${ }^{\circ} p<.10{ }^{*} p<.05 \quad{ }^{* *} p<.01{ }^{* * *} p<.001$ 
Table B-89. Logit of Eastern Christian Population.

\begin{tabular}{|c|c|c|c|c|c|}
\hline Variable & Model 1 & Model 2 & Model 3 & Model 4 & Model 5 \\
\hline $\begin{array}{l}\text { Eastern Christian } \\
\text { Pop. (every 10\%) }\end{array}$ & $\begin{array}{c}-.0105 \\
(.0215) \\
\end{array}$ & $\begin{array}{c}-.0134 \\
(.0228)\end{array}$ & $\begin{array}{r}-.0065 \\
(.0240) \\
\end{array}$ & $\begin{array}{r}-.0088 \\
(.0259) \\
\end{array}$ & $\begin{array}{r}.0633^{\circ} \\
(.0332) \\
\end{array}$ \\
\hline Log CINC Ratio & $\begin{array}{l}.0222^{*} \\
(.0113)\end{array}$ & $\begin{array}{c}.0041 \\
(.0115)\end{array}$ & $\begin{array}{r}.0494^{* * *} \\
(.0123)\end{array}$ & $\begin{array}{l}.0300^{*} \\
(.0127)\end{array}$ & $\begin{array}{l}.0100 \\
(.0180)\end{array}$ \\
\hline Low Polity Score & $\begin{array}{r}-.0260^{* *} \\
(.0091)\end{array}$ & $\begin{array}{c}-.0229^{*} \\
(.0096)\end{array}$ & $\begin{array}{r}-.0386^{\star * *} \\
(.0103)\end{array}$ & $\begin{array}{r}-.0358^{* * *} \\
(.0109)\end{array}$ & $\begin{array}{c}-.0498^{\star *} \\
(.0155)\end{array}$ \\
\hline Polity Score & $\begin{array}{c}-.0225^{\star *} \\
(.0073)\end{array}$ & $\begin{array}{r}-.0306^{\star * *} \\
(.0078)\end{array}$ & $\begin{array}{r}-.0217^{\star *} \\
(.0078)\end{array}$ & $\begin{array}{r}-.0320^{\star * *} \\
(.0084)\end{array}$ & $\begin{array}{l}-.0128 \\
(.0120)\end{array}$ \\
\hline Defensive Allies & $\begin{array}{l}-.0623 \\
(.0960)\end{array}$ & $\begin{array}{l}-.0262 \\
(.0995)\end{array}$ & $\begin{array}{l}-.1200 \\
(.1029)\end{array}$ & $\begin{array}{l}-.0825 \\
(.1073)\end{array}$ & $\begin{array}{l}-.1921 \\
(.1803)\end{array}$ \\
\hline Log Peace-Years & $\begin{array}{r}-.6540^{\star * *} \\
(.0339)\end{array}$ & $\begin{array}{r}-.6678^{\star * \star} \\
(.0353)\end{array}$ & $\begin{array}{r}-.6528^{\star \star \star} \\
(.0369)\end{array}$ & $\begin{array}{r}-.6680^{\star * *} \\
(.0389)\end{array}$ & $\begin{array}{r}-.5754^{\star \star \star} \\
(.0581)\end{array}$ \\
\hline Closest Contiguity & $\begin{array}{r}-.3161^{\star * *} \\
(.0195)\end{array}$ & $\begin{array}{r}-.3021^{\star \star *} \\
(.0201)\end{array}$ & $\begin{array}{r}-.3438^{\star \star \star} \\
(.0217)\end{array}$ & $\begin{array}{r}-.3287^{\star \star *} \\
(.0226)\end{array}$ & $\begin{array}{r}-.2747^{\star \star \star} \\
(.0345)\end{array}$ \\
\hline Constant & $\begin{array}{c}-1.9511^{* * *} \\
(.0890) \\
\end{array}$ & $\begin{array}{c}-2.0062^{* \star *} \\
(.0917)\end{array}$ & $\begin{array}{c}-2.0073^{* * *} \\
(.0931) \\
\end{array}$ & $\begin{array}{c}-2.0615^{\star \star *} \\
(.0960) \\
\end{array}$ & $\begin{array}{c}-3.3771^{* * *} \\
(.1534)\end{array}$ \\
\hline Observations & 95,418 & 95,418 & 95,418 & 95,418 & 95,197 \\
\hline Wald $\chi^{2}(7)$ & 1066.06 & 1068.39 & 972.42 & 969.72 & 311.20 \\
\hline $\mathrm{p}$ & $<.0001$ & $<.0001$ & $<.0001$ & $<.0001$ & $<.0001$ \\
\hline Pseudo $R^{2}$ & .1300 & .1297 & .1386 & .1387 & .0906 \\
\hline
\end{tabular}

${ }^{\circ} \mathrm{p}<.10{ }^{*} \mathrm{p}<.05{ }^{* *} \mathrm{p}<.01{ }^{* \star *} \mathrm{p}<.001$ 
Table B-90. Logit of Eastern Christian Preference, Controlled for Atheist Chief Executive.

\begin{tabular}{|c|c|c|c|c|c|}
\hline Variable & Model 1 & Model 2 & Model 3 & Model 4 & Model 5 \\
\hline $\begin{array}{l}\text { Eastern Christian } \\
\text { Preference (binary) }\end{array}$ & $\begin{array}{l}-.0275 \\
(.2149)\end{array}$ & $\begin{array}{l}-.1777 \\
(.2403)\end{array}$ & $\begin{array}{l}.0178 \\
(.2376)\end{array}$ & $\begin{array}{l}-.1578 \\
(.2732)\end{array}$ & $\begin{array}{l}.4095 \\
(.3324)\end{array}$ \\
\hline $\begin{array}{l}\text { Atheist } \\
\text { Chief Exec. (binary) }\end{array}$ & $\begin{array}{l}.1015 \\
(.1096)\end{array}$ & $\begin{array}{l}.1059 \\
(.1139)\end{array}$ & $\begin{array}{l}.0284 \\
(.1227) \\
\end{array}$ & $\begin{array}{l}.0141 \\
(.1293) \\
\end{array}$ & $\begin{array}{l}-.1018 \\
(.1994)\end{array}$ \\
\hline Log CINC Ratio & $\begin{array}{l}.0056 \\
(.0126)\end{array}$ & $\begin{array}{l}-.0149 \\
(.0130)\end{array}$ & $\begin{array}{l}.0384^{\star *} \\
(.0141)\end{array}$ & $\begin{array}{l}.0171 \\
(.0148)\end{array}$ & $\begin{array}{l}.0063 \\
(.0206)\end{array}$ \\
\hline Low Polity Score & $\begin{array}{l}-.0225^{\star} \\
(.0093)\end{array}$ & $\begin{aligned}-.0184^{\circ} \\
(.0097)\end{aligned}$ & $\begin{array}{r}-.0354^{\star * *} \\
(.0105)\end{array}$ & $\begin{aligned}-.0313^{* *} \\
(.0111)\end{aligned}$ & $\begin{aligned}-.0453^{* *} & (.0161)\end{aligned}$ \\
\hline Polity Score & $\begin{array}{l}-.0187^{*} \\
(.0078)\end{array}$ & $\begin{array}{l}-.0267^{* *} \\
(.0082)\end{array}$ & $\begin{array}{l}-.0194^{*} \\
(.0084)\end{array}$ & $\begin{array}{r}-.0298^{* * *} \\
(.0089)\end{array}$ & $\begin{array}{l}-.0168 \\
(.0126)\end{array}$ \\
\hline Defensive Allies & $\begin{array}{l}-.0546 \\
(.1001)\end{array}$ & $\begin{aligned}-.0273 \\
(.1040)\end{aligned}$ & $\begin{array}{l}-.1164 \\
\quad(.1075)\end{array}$ & $\begin{array}{l}-.0907 \\
(.1124)\end{array}$ & $\begin{array}{l}-.2056 \\
(.1869)\end{array}$ \\
\hline Log Peace-Years & $\begin{array}{r}-.6668^{* * *} \\
(.0360)\end{array}$ & $\begin{array}{r}-.6809^{* * *} \\
(.0374)\end{array}$ & $\begin{array}{r}-.6692^{* * *} \\
(.0395)\end{array}$ & $\begin{array}{r}-.6850^{* * *} \\
(.0417)\end{array}$ & $\begin{array}{r}-.6183^{* * *} \\
(.0613)\end{array}$ \\
\hline Closest Contiguity & $\begin{array}{r}-.3081^{* * *} \\
(.0206)\end{array}$ & $\begin{array}{r}-.2946^{* * *} \\
(.0213)\end{array}$ & $\begin{array}{r}-.3344^{* * *} \\
(.0229)\end{array}$ & $\begin{array}{r}-.3193^{* * *} \\
(.0240)\end{array}$ & $\begin{array}{r}-.2650^{* * *} \\
(.0361)\end{array}$ \\
\hline Constant & $\begin{array}{c}-1.9525^{\star * *} \\
(.0965) \\
\end{array}$ & $\begin{array}{c}-2.0083^{\star \star *} \\
(.0998) \\
\end{array}$ & $\begin{array}{c}-1.9871^{* * *} \\
(.1002) \\
\end{array}$ & $\begin{array}{c}-2.0360^{\star * \star} \\
(.1036) \\
\end{array}$ & $\begin{array}{c}-3.2091^{* * *} \\
(.1663)\end{array}$ \\
\hline Observations & 83,722 & 83,722 & 83,722 & 83,722 & 83,533 \\
\hline Wald $\chi^{2}(8)$ & 979.59 & 990.58 & 899.10 & 906.41 & 296.05 \\
\hline$p$ & $<.0001$ & $<.0001$ & $<.0001$ & $<.0001$ & $<.0001$ \\
\hline Pseudo $\mathrm{R}^{2}$ & .1298 & .1299 & .1385 & .1388 & .0955 \\
\hline
\end{tabular}

${ }^{\circ} \mathrm{p}<.10 \quad{ }^{*} \mathrm{p}<.05 \quad{ }^{* *} \mathrm{p}<.01{ }^{* * *} \mathrm{p}<.001$ 
Table B-91. Logit of Eastern Christian GRP Scale, Controlled for Atheist Chief Executive.

\begin{tabular}{|c|c|c|c|c|c|}
\hline Variable & Model 1 & Model 2 & Model 3 & Model 4 & Model 5 \\
\hline $\begin{array}{l}\text { Eastern Christian } \\
\text { GRP (every 10\%) }\end{array}$ & $\begin{array}{l}.0211 \\
(.0328)\end{array}$ & $\begin{array}{l}.0090 \\
(.0360)\end{array}$ & $\begin{array}{l}.0321 \\
(.0360)\end{array}$ & $\begin{array}{l}.0203 \\
(.0404)\end{array}$ & $\begin{array}{c}.0806 \dagger \\
(.0511)\end{array}$ \\
\hline $\begin{array}{l}\text { Atheist } \\
\text { Chief Exec. (binary) }\end{array}$ & $\begin{array}{l}.1434 \\
(.1135) \\
\end{array}$ & $\begin{array}{c}.1392 \\
(.1178) \\
\end{array}$ & $\begin{array}{r}.0775 \\
(.1268) \\
\end{array}$ & $\begin{array}{l}.0516 \\
(.1334) \\
\end{array}$ & $\begin{array}{r}-.0381 \\
(.2062) \\
\end{array}$ \\
\hline Log CINC Ratio & $\begin{array}{l}.0064 \\
(.0126)\end{array}$ & $\begin{array}{c}-.0119 \\
(.0129)\end{array}$ & $\begin{array}{l}.0369^{\star *} \\
(.0141)\end{array}$ & $\begin{array}{l}.0185 \\
(.0147)\end{array}$ & $\begin{array}{l}.0058 \\
(.0205)\end{array}$ \\
\hline Low Polity Score & $\begin{array}{l}-.0225^{\star} \\
(.0093)\end{array}$ & $\begin{array}{r}-.0189^{\circ} \\
(.0097)\end{array}$ & $\begin{array}{r}-.0351^{* * *} \\
(.0105)\end{array}$ & $\begin{array}{r}-.0316^{\star \star} \\
(.0111)\end{array}$ & $\begin{array}{r}-.0474^{\star \star} \\
(.0158)\end{array}$ \\
\hline Polity Score & $\begin{array}{l}-.0174^{\star} \\
(.0078)\end{array}$ & $\begin{array}{r}-.0260^{* *} \\
(.0083)\end{array}$ & $\begin{array}{l}-.0177^{*} \\
(.0084)\end{array}$ & $\begin{array}{l}-.0289^{\star *} \\
(.0090)\end{array}$ & $\begin{array}{l}-.0135 \\
(.0127)\end{array}$ \\
\hline Defensive Allies & $\begin{array}{l}.0002 \\
(.0993)\end{array}$ & $\begin{array}{l}.0362 \\
(.1032)\end{array}$ & $\begin{array}{r}-.0643 \\
(.1065)\end{array}$ & $\begin{array}{l}-.0285 \\
(.1112)\end{array}$ & $\begin{array}{c}-.1479 \\
(.1848)\end{array}$ \\
\hline Log Peace-Years & $\begin{array}{r}-.6546^{* * *} \\
(.0359)\end{array}$ & $\begin{array}{r}-.6695^{\star * *} \\
(.0375)\end{array}$ & $\begin{array}{r}-.6530^{* * *} \\
(.0392)\end{array}$ & $\begin{array}{r}-.6694^{* * *} \\
(.0416)\end{array}$ & $\begin{array}{r}-.6011^{* * *} \\
(.0611)\end{array}$ \\
\hline Closest Contiguity & $\begin{array}{r}-.3062^{* * *} \\
(.0206)\end{array}$ & $\begin{array}{r}-.2924^{* * *} \\
(.0213)\end{array}$ & $\begin{array}{r}-.3345^{* * *} \\
(.0229)\end{array}$ & $\begin{array}{r}-.3196^{* * *} \\
(.0240)\end{array}$ & $\begin{array}{r}-.2662^{* * *} \\
(.0362)\end{array}$ \\
\hline Constant & $\begin{array}{c}-2.0368^{\star * *} \\
(.0957) \\
\end{array}$ & $\begin{array}{c}-2.0900^{* * *} \\
(.0990) \\
\end{array}$ & $\begin{array}{c}-2.0733^{* * *} \\
(.0995) \\
\end{array}$ & $\begin{array}{c}-2.1190^{* * *} \\
(.1027) \\
\end{array}$ & $\begin{array}{c}-3.3023^{\star * \star} \\
(.1657) \\
\end{array}$ \\
\hline Observations & 85,471 & 85,471 & 85,471 & 85,471 & 85,280 \\
\hline Wald $\chi^{2}(8)$ & 963.93 & 969.57 & 886.66 & 887.27 & 295.12 \\
\hline $\mathrm{p}$ & $<.0001$ & $<.0001$ & $<.0001$ & $<.0001$ & $<.0001$ \\
\hline Pseudo $\mathrm{R}^{2}$ & .1257 & .1260 & .1342 & .1348 & .0922 \\
\hline
\end{tabular}

${ }^{\circ} p<.10{ }^{*} p<.05{ }^{* *} p<.01{ }^{* * *} p<.001$

$+p<.15$ 
Table B-92. Logit of Eastern Christian Prevalence, Controlled for Atheist Chief Executive.

\begin{tabular}{|c|c|c|c|c|c|}
\hline Variable & Model 1 & Model 2 & Model 3 & Model 4 & Model 5 \\
\hline $\begin{array}{l}\text { Eastern Christian } \\
\text { Prevalence (binary) }\end{array}$ & $\begin{array}{l}-.2859 \\
(.2134)\end{array}$ & $\begin{array}{l}-.2881 \\
(.2233)\end{array}$ & $\begin{array}{l}-.1803 \\
(.2290)\end{array}$ & $\begin{aligned}-.1604 \\
(.2413)\end{aligned}$ & $\begin{array}{l}.6188^{*} \\
(.2834)\end{array}$ \\
\hline $\begin{array}{l}\text { Atheist } \\
\text { Chief Exec. (binary) }\end{array}$ & $\begin{array}{l}.1260 \\
(.1153)\end{array}$ & $\begin{array}{l}.1422 \\
(.1197)\end{array}$ & $\begin{array}{l}.0249 \\
(.1287)\end{array}$ & $\begin{array}{l}.0211 \\
(.1356) \\
\end{array}$ & $\begin{array}{l}-.1755 \\
(.2099) \\
\end{array}$ \\
\hline Log CINC Ratio & $\begin{array}{l}-.0002 \\
(.0132)\end{array}$ & $\begin{array}{l}-.0199 \\
(.0137)\end{array}$ & $\begin{array}{l}.0307^{\star} \\
(.0146)\end{array}$ & $\begin{array}{l}.0110 \\
(.0154)\end{array}$ & $\begin{array}{l}.0057 \\
(.0211)\end{array}$ \\
\hline Low Polity Score & $\begin{array}{l}-.0238^{*} \\
(.0093)\end{array}$ & $\begin{array}{l}-.0199^{*} \\
(.0097)\end{array}$ & $\begin{aligned}-.0346^{* *} & (.0105)\end{aligned}$ & $\begin{aligned}-.0305^{\star *} \\
(.0111)\end{aligned}$ & $\begin{aligned}-.0421^{* *} & (.0162)\end{aligned}$ \\
\hline Polity Score & $\begin{aligned}-.0174^{*} \\
(.0077)\end{aligned}$ & $\begin{array}{l}-.0256^{* *} \\
(.0082)\end{array}$ & $\begin{array}{l}-.0205^{*} \\
(.0084)\end{array}$ & $\begin{array}{r}-.0315^{* * *} \\
(.0090)\end{array}$ & $\begin{array}{l}-.0220^{\circ} \\
(.0132)\end{array}$ \\
\hline Defensive Allies & $\begin{array}{l}-.0209 \\
(.1018)\end{array}$ & $\begin{array}{l}.0058 \\
(.1058)\end{array}$ & $\begin{array}{l}-.1048 \\
(.1086)\end{array}$ & $\begin{aligned}-.0820 \\
(.1135)\end{aligned}$ & $\begin{array}{l}-.1348 \\
(.1879)\end{array}$ \\
\hline Log Peace-Years & $\begin{array}{r}-.6750^{* * *} \\
(.0363)\end{array}$ & $\begin{array}{r}-.6816^{* * *} \\
(.0380)\end{array}$ & $\begin{array}{r}-.6833^{* * *} \\
(.0395)\end{array}$ & $\begin{array}{r}-.6906^{* * *} \\
(.0419)\end{array}$ & $\begin{array}{r}-.6311^{* * *} \\
(.0620)\end{array}$ \\
\hline Closest Contiguity & $\begin{array}{r}-.3086^{* * *} \\
(.0214)\end{array}$ & $\begin{array}{r}-.2993^{* * *} \\
(.0221)\end{array}$ & $\begin{array}{r}-.3330^{* * *} \\
(.0235)\end{array}$ & $\begin{array}{r}-.3237^{* * *} \\
(.0246)\end{array}$ & $\begin{array}{r}-.2494^{* * *} \\
(.0372)\end{array}$ \\
\hline Constant & $\begin{array}{c}-1.9312^{\star * *} \\
(.1004) \\
\end{array}$ & $\begin{array}{c}-1.9928^{\star * *} \\
(.1039) \\
\end{array}$ & $\begin{array}{c}-1.9295^{\star * *} \\
(.1031) \\
\end{array}$ & $\begin{array}{c}-1.9823^{\star \star \star} \\
(.1065) \\
\end{array}$ & $\begin{array}{c}-3.2285^{\star * *} \\
(.1715)\end{array}$ \\
\hline Observations & 80,443 & 80,443 & 80,443 & 80,443 & 80,250 \\
\hline Wald $\chi^{2}(8)$ & 940.43 & 946.45 & 871.41 & 872.72 & 278.73 \\
\hline$p$ & $<.0001$ & $<.0001$ & $<.0001$ & $<.0001$ & $<.0001$ \\
\hline Pseudo $\mathrm{R}^{2}$ & .1319 & .1323 & .1410 & .1420 & .0959 \\
\hline
\end{tabular}

${ }^{\circ} \mathrm{p}<.10 \quad{ }^{*} \mathrm{p}<.05 \quad{ }^{* *} \mathrm{p}<.01{ }^{* * *} \mathrm{p}<.001$ 
Table B-93. Logit of Eastern Christian Population, Controlled for Atheist Chief Executive.

\begin{tabular}{|c|c|c|c|c|c|}
\hline Variable & Model 1 & Model 2 & Model 3 & Model 4 & Model 5 \\
\hline $\begin{array}{l}\text { Eastern Christian } \\
\text { Pop. (every 10\%) }\end{array}$ & $\begin{array}{l}-.0192 \\
(.0220)\end{array}$ & $\begin{aligned}-.0223 \\
(.0234)\end{aligned}$ & $\begin{array}{l}-.0119 \\
(.0245)\end{array}$ & $\begin{aligned}-.0138 \\
(.0264)\end{aligned}$ & $\begin{array}{l}.0649^{\circ} \\
(.0340)\end{array}$ \\
\hline $\begin{array}{l}\text { Atheist } \\
\text { Chief Exec. (binary) }\end{array}$ & $\begin{array}{r}.1403 \\
(.1107) \\
\end{array}$ & $\begin{array}{r}.1491 \\
(.1152)\end{array}$ & $\begin{array}{r}.0650 \\
(.1233)\end{array}$ & $\begin{array}{r}.0551 \\
(.1302)\end{array}$ & $\begin{array}{r}-.0823 \\
(.2027)\end{array}$ \\
\hline Log CINC Ratio & $\begin{array}{l}.0079 \\
(.0122)\end{array}$ & $\begin{array}{l}-.0119 \\
(.0126)\end{array}$ & $\begin{array}{l}.0390^{* *} \\
(.0137)\end{array}$ & $\begin{array}{l}.0184 \\
(.0143)\end{array}$ & $\begin{array}{l}.0090 \\
(.0200)\end{array}$ \\
\hline Low Polity Score & $\begin{array}{l}-.0230^{\star} \\
(.0091)\end{array}$ & $\begin{array}{l}-.0201^{*} \\
(.0096)\end{array}$ & $\begin{array}{r}-.0353^{* * *} \\
(.0103)\end{array}$ & $\begin{aligned}-.0329^{* *} \\
(.0110)\end{aligned}$ & $\begin{aligned}-.0467^{* *} & (.0158)\end{aligned}$ \\
\hline Polity Score & $\begin{array}{l}-.0171^{*} \\
(.0075)\end{array}$ & $\begin{array}{r}-.0250^{* *} \\
(.0079)\end{array}$ & $\begin{array}{l}-.0173^{*} \\
(.0081)\end{array}$ & $\begin{array}{r}-.0277^{* *} \\
(.0086)\end{array}$ & $\begin{aligned}-.0108 \\
(.0124)\end{aligned}$ \\
\hline Defensive Allies & $\begin{array}{l}-.0477 \\
(.0974)\end{array}$ & $\begin{array}{l}-.0095 \\
(.1011)\end{array}$ & $\begin{array}{l}-.1060 \\
(.1044)\end{array}$ & $\begin{array}{l}-.0668 \\
(.1089)\end{array}$ & $\begin{array}{l}-.1657 \\
(.1827)\end{array}$ \\
\hline Log Peace-Years & $\begin{array}{r}-.6691^{* * *} \\
(.0349)\end{array}$ & $\begin{array}{r}-.6813^{* * *} \\
(.0364)\end{array}$ & $\begin{array}{r}-.6687^{* * *} \\
(.0382)\end{array}$ & $\begin{array}{r}-.6821^{* * *} \\
(.0403)\end{array}$ & $\begin{array}{r}-.6083^{* * *} \\
(.0600)\end{array}$ \\
\hline Closest Contiguity & $\begin{array}{r}-.3133^{\star * *} \\
(.0201)\end{array}$ & $\begin{array}{r}-.2991^{* * *} \\
(.0207)\end{array}$ & $\begin{array}{r}-.3400^{* * *} \\
(.0224)\end{array}$ & $\begin{array}{r}-.3243^{\star \star *} \\
(.0234)\end{array}$ & $\begin{array}{r}-.2672^{* \star *} \\
(.0357)\end{array}$ \\
\hline Constant & $\begin{array}{c}-1.9624^{* * *} \\
(.0933) \\
\end{array}$ & $\begin{array}{c}-2.0247^{* * *} \\
(.0966) \\
\end{array}$ & $\begin{array}{c}-2.0063^{* * *} \\
(.0975) \\
\end{array}$ & $\begin{array}{c}-2.0642^{* * *} \\
(.1009) \\
\end{array}$ & $\begin{array}{c}-3.3431^{* * *} \\
(.1624) \\
\end{array}$ \\
\hline Observations & 88,026 & 88,026 & 88,026 & 88,026 & 87,817 \\
\hline Wald $\chi^{2}(8)$ & 1018.17 & 1019.95 & 926.76 & 921.58 & 296.13 \\
\hline$p$ & $<.0001$ & $<.0001$ & $<.0001$ & $<.0001$ & $<.0001$ \\
\hline Pseudo $\mathrm{R}^{2}$ & .1304 & .1299 & .1386 & .1382 & .0934 \\
\hline
\end{tabular}

${ }^{\circ} p<.10{ }^{*} p<.05 \quad{ }^{* *} p<.01{ }^{* * *} p<.001$ 
Tables for Chapter 6

Table B-94. Logit of Sunni Muslim Chief Executive.

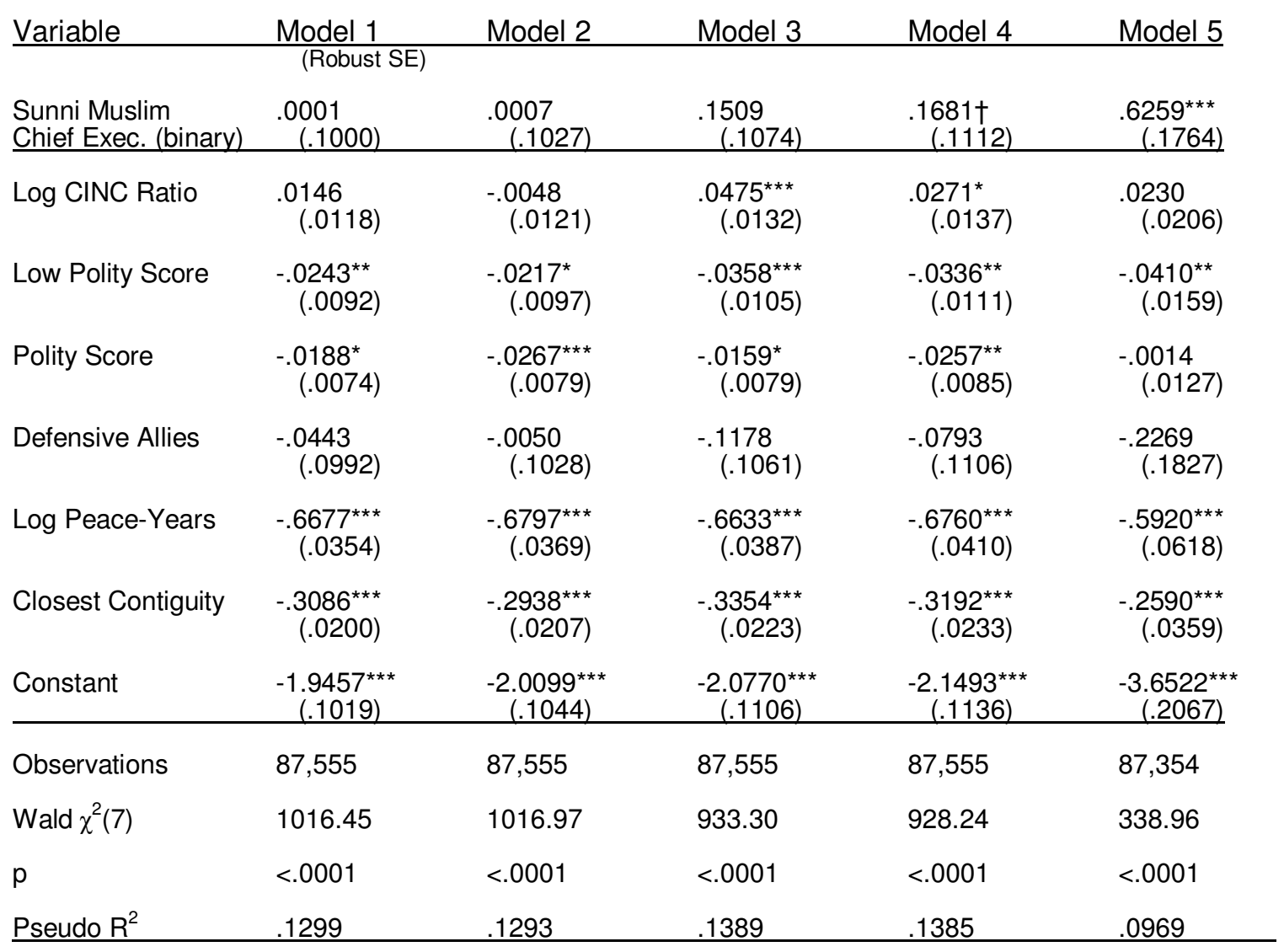

${ }^{\circ} p<.10{ }^{*} p<.05 \quad{ }^{* *} p<.01{ }^{* * *} p<.001$

$+p<.15$ 
Table B-95. Logit of Sunni Muslim Preference.

\begin{tabular}{|c|c|c|c|c|c|}
\hline Variable & Model 1 & Model 2 & Model 3 & Model 4 & Model 5 \\
\hline & (Robust SE) & & & & \\
\hline $\begin{array}{l}\text { Sunni Muslim } \\
\text { Preference (binary) }\end{array}$ & $\begin{array}{r}-.0900 \\
(.1029) \\
\end{array}$ & $\begin{array}{c}-.0932 \\
(.1057) \\
\end{array}$ & $\begin{array}{l}.0798 \\
(.1099) \\
\end{array}$ & $\begin{array}{l}.0932 \\
(.1138) \\
\end{array}$ & $\begin{array}{r}.5445^{\star \star} \\
(.1773) \\
\end{array}$ \\
\hline Log CINC Ratio & $\begin{array}{l}.0183 \\
(.0118)\end{array}$ & $\begin{array}{l}-.0003 \\
(.0121)\end{array}$ & $\begin{array}{r}.0504^{\star \star *} \\
(.0131)\end{array}$ & $\begin{array}{l}.0308^{*} \\
(.0135)\end{array}$ & $\begin{array}{l}.0241 \\
(.0200)\end{array}$ \\
\hline Low Polity Score & $\begin{array}{r}-.0265^{\star *} \\
(.0093)\end{array}$ & $\begin{array}{l}-.0236^{*} \\
(.0098)\end{array}$ & $\begin{array}{r}-.0377^{* * *} \\
(.0105)\end{array}$ & $\begin{array}{l}-.0350^{* *} \\
(.0112)\end{array}$ & $\begin{array}{r}-.0415^{\star *} \\
(.0159)\end{array}$ \\
\hline Polity Score & $\begin{array}{l}-.0243^{\star *} \\
(.0075)\end{array}$ & $\begin{array}{r}-.0324^{\star * *} \\
(.0080)\end{array}$ & $\begin{array}{l}-.0216^{* *} \\
(.0080)\end{array}$ & $\begin{array}{r}-.0317^{\star * *} \\
(.0086)\end{array}$ & $\begin{array}{l}-.0094 \\
(.0126)\end{array}$ \\
\hline Defensive Allies & $\begin{array}{l}-.0459 \\
(.0993)\end{array}$ & $\begin{array}{l}-.0054 \\
(.1029)\end{array}$ & $\begin{array}{l}-.1237 \\
(.1062)\end{array}$ & $\begin{array}{c}-.0840 \\
(.1106)\end{array}$ & $\begin{array}{c}-.2750 \\
(.1829)\end{array}$ \\
\hline Log Peace-Years & $\begin{array}{r}-.6567^{\star \star *} \\
(.0352)\end{array}$ & $\begin{array}{r}-.6726^{\star \star *} \\
(.0368)\end{array}$ & $\begin{array}{r}-.6550^{* \star *} \\
(.0386)\end{array}$ & $\begin{array}{r}-.6726^{\star \star *} \\
(.0408)\end{array}$ & $\begin{array}{r}-.5861^{\star * *} \\
(.0610)\end{array}$ \\
\hline Closest Contiguity & $\begin{array}{r}-.3125^{\star \star *} \\
(.0200)\end{array}$ & $\begin{array}{r}-.2968^{\star \star *} \\
(.0206)\end{array}$ & $\begin{array}{r}-.3379^{* * *} \\
(.0222)\end{array}$ & $\begin{array}{r}-.3206^{* * *} \\
(.0232)\end{array}$ & $\begin{array}{r}-.2625^{\star \star *} \\
(.0350)\end{array}$ \\
\hline Constant & $\begin{array}{c}-1.9113^{\star * \star} \\
(.1027) \\
\end{array}$ & $\begin{array}{c}-1.9720^{\star \star \star} \\
(.1053) \\
\end{array}$ & $\begin{array}{c}-2.0390^{\star \star *} \\
(.1115) \\
\end{array}$ & $\begin{array}{c}-2.1066^{* \star *} \\
(.1147) \\
\end{array}$ & $\begin{array}{c}-3.5473^{\star \star \star} \\
(.2032) \\
\end{array}$ \\
\hline Observations & 90,914 & 90,914 & 90,914 & 90,914 & 90,718 \\
\hline Wald $\chi^{2}(7)$ & 1017.41 & 1022.49 & 942.40 & 943.43 & 350.15 \\
\hline$p$ & $<.0001$ & $<.0001$ & $<.0001$ & $<.0001$ & $<.0001$ \\
\hline Pseudo $\mathrm{R}^{2}$ & .1293 & .1293 & .1383 & .1387 & .0962 \\
\hline
\end{tabular}

${ }^{\circ} p<.10{ }^{*} p<.05{ }^{* *} p<.01{ }^{* * *} p<.001$ 
Table B-96. Logit of Sunni Muslim GRP Scale.

\begin{tabular}{|c|c|c|c|c|c|}
\hline Variable & Model 1 & Model 2 & Model 3 & Model 4 & Model 5 \\
\hline & (Robust SE & & & & \\
\hline $\begin{array}{l}\text { Sunni Muslim } \\
\text { GRP (every 10\%) }\end{array}$ & $\begin{array}{r}-.0067 \\
(.0140) \\
\end{array}$ & $\begin{array}{r}-.0063 \\
(.0143) \\
\end{array}$ & $\begin{array}{l}.0144 \\
(.0147) \\
\end{array}$ & $\begin{array}{l}.0169 \\
(.0151) \\
\end{array}$ & $\begin{array}{l}.0662^{* *} \\
(.0227) \\
\end{array}$ \\
\hline Log CINC Ratio & $\begin{array}{l}.0205^{\circ} \\
(.0118)\end{array}$ & $\begin{array}{l}.0034 \\
(.0120)\end{array}$ & $\begin{array}{r}.0502^{* * *} \\
(.0130)\end{array}$ & $\begin{array}{l}.0324^{*} \\
(.0134)\end{array}$ & $\begin{array}{l}.0208 \\
(.0193)\end{array}$ \\
\hline Low Polity Score & $\begin{array}{r}-.0250^{* *} \\
(.0093)\end{array}$ & $\begin{array}{r}-.0214^{*} \\
(.0098)\end{array}$ & $\begin{array}{r}-.0360^{* * *} \\
(.0105)\end{array}$ & $\begin{array}{r}-.0324^{* *} \\
(.0111)\end{array}$ & $\begin{array}{r}-.0424^{* *} \\
(.0157)\end{array}$ \\
\hline Polity Score & $\begin{array}{r}-.0233^{* *} \\
(.0077)\end{array}$ & $\begin{array}{r}-.0317^{* * *} \\
(.0082)\end{array}$ & $\begin{array}{r}-.0205^{*} \\
(.0081)\end{array}$ & $\begin{array}{r}-.0310^{* * *} \\
(.0088)\end{array}$ & $\begin{array}{l}-.0078 \\
(.0128)\end{array}$ \\
\hline Defensive Allies & $\begin{array}{l}-.0136 \\
(.0991)\end{array}$ & $\begin{array}{l}.0256 \\
(.1026)\end{array}$ & $\begin{array}{r}-.0962 \\
(.1057)\end{array}$ & $\begin{array}{c}-.0587 \\
(.1100)\end{array}$ & $\begin{array}{r}-.2539 \\
(.1810)\end{array}$ \\
\hline Log Peace-Years & $\begin{array}{r}-.6468^{* * *} \\
(.0353)\end{array}$ & $\begin{array}{r}-.6631^{* * *} \\
(.0369)\end{array}$ & $\begin{array}{r}-.6413^{\star * *} \\
(.0386)\end{array}$ & $\begin{array}{r}-.6591^{* * *} \\
(.0409)\end{array}$ & $\begin{array}{r}-.5694^{\star * *} \\
(.0612)\end{array}$ \\
\hline Closest Contiguity & $\begin{array}{r}-.3097^{\star * *} \\
(.0200)\end{array}$ & $\begin{array}{r}-.2955^{\star * *} \\
(.0207)\end{array}$ & $\begin{array}{r}-.3377^{\star * *} \\
(.0222)\end{array}$ & $\begin{array}{r}-.3229^{* * *} \\
(.0233)\end{array}$ & $\begin{array}{r}-.2688^{\star * *} \\
(.0352)\end{array}$ \\
\hline Constant & $\begin{array}{c}-1.9881^{* * *} \\
(.1019)\end{array}$ & $\begin{array}{c}-2.0448^{* * *} \\
(.1046)\end{array}$ & $\begin{array}{c}-2.1052^{* * *} \\
(.1097) \\
\end{array}$ & $\begin{array}{c}-2.1671^{* * *} \\
(.1130) \\
\end{array}$ & $\begin{array}{c}-3.5565^{* * *} \\
(.1945) \\
\end{array}$ \\
\hline Observations & 92,277 & 92,277 & 92,277 & 92,277 & 92,077 \\
\hline Wald $\chi^{2}(7)$ & 999.56 & 1004.46 & 926.27 & 926.87 & 338.43 \\
\hline$p$ & $<.0001$ & $<.0001$ & $<.0001$ & $<.0001$ & $<.0001$ \\
\hline Pseudo $\mathrm{R}^{2}$ & .1257 & .1261 & .1345 & .1356 & .0923 \\
\hline
\end{tabular}

${ }^{\circ} \mathrm{p}<.10{ }^{*} \mathrm{p}<.05{ }^{* *} \mathrm{p}<.01{ }^{* \star *} \mathrm{p}<.001$ 
Table B-97. Logit of Sunni Muslim Prevalence.

\begin{tabular}{|c|c|c|c|c|c|}
\hline Variable & Model 1 & Model 2 & Model 3 & Model 4 & Model 5 \\
\hline & (Robust S & & & & \\
\hline $\begin{array}{l}\text { Sunni Muslim } \\
\text { Prevalence (binary) }\end{array}$ & $\begin{array}{l}-.1326 \\
(.1104)\end{array}$ & $\begin{array}{r}-.1457 \\
(.1136)\end{array}$ & $\begin{array}{l}.0310 \\
(.1176)\end{array}$ & $\begin{array}{l}.0324 \\
(.1218)\end{array}$ & $\begin{array}{l}.4484^{*} \\
(.1890)\end{array}$ \\
\hline Log CINC Ratio & $\begin{array}{l}.0156 \\
(.0121)\end{array}$ & $\begin{array}{l}-.0039 \\
(.0123)\end{array}$ & $\begin{array}{r}.0461^{* * *} \\
(.0135)\end{array}$ & $\begin{array}{l}.0252^{\circ} \\
(.0139)\end{array}$ & $\begin{array}{l}.0109 \\
(.0204)\end{array}$ \\
\hline Low Polity Score & $\begin{array}{r}-.0282^{* *} \\
(.0093)\end{array}$ & $\begin{array}{l}-.0250^{*} \\
(.0098)\end{array}$ & $\begin{array}{r}-.0388^{* * *} \\
(.0105)\end{array}$ & $\begin{array}{l}-.0356^{* *} \\
(.0112)\end{array}$ & $\begin{aligned}-.0426^{* *} \\
(.0157)\end{aligned}$ \\
\hline Polity Score & $\begin{aligned}-.0217^{* *} & (.0075)\end{aligned}$ & $\begin{array}{r}-.0301^{* * *} \\
(.0081)\end{array}$ & $\begin{aligned}-.0191^{*} \\
(.0080)\end{aligned}$ & $\begin{array}{r}-.0296^{* * *} \\
(.0087)\end{array}$ & $\begin{array}{l}-.0052 \\
(.0127)\end{array}$ \\
\hline Defensive Allies & $\begin{array}{l}-.0717 \\
(.1033)\end{array}$ & $\begin{array}{l}-.0410 \\
(.1073)\end{array}$ & $\begin{array}{l}-.1786 \\
(.1112)\end{array}$ & $\begin{array}{l}-.1535 \\
(.1164)\end{array}$ & $\begin{array}{l}-.3389^{\circ} \\
(.1933)\end{array}$ \\
\hline Log Peace-Years & $\begin{array}{r}-.6585^{\star \star *} \\
(.0356)\end{array}$ & $\begin{array}{r}-.6740^{* * *} \\
(.0371)\end{array}$ & $\begin{aligned}-.6510^{* * *} \\
(.0388)\end{aligned}$ & $\begin{array}{r}-.6675^{\star \star *} \\
(.0410)\end{array}$ & $\begin{array}{r}-.5666^{* * *} \\
(.0605)\end{array}$ \\
\hline Closest Contiguity & $\begin{array}{r}-.3190^{* * *} \\
(.0205)\end{array}$ & $\begin{array}{r}-.3045^{\star * *} \\
(.0212)\end{array}$ & $\begin{array}{r}-.3485^{\star * *} \\
(.0227)\end{array}$ & $\begin{array}{r}-.3333^{* * *} \\
(.0238)\end{array}$ & $\begin{array}{r}-.2807^{* * *} \\
(.0357)\end{array}$ \\
\hline Constant & $\begin{array}{c}-1.9066^{* * *} \\
(.1021)\end{array}$ & $\begin{array}{c}-1.9563^{* * *} \\
(.1045) \\
\end{array}$ & $\begin{array}{c}-2.0219^{* * *} \\
(.1099) \\
\end{array}$ & $\begin{array}{c}-2.0747^{* * *} \\
(.1126) \\
\end{array}$ & $\begin{array}{c}-3.5266^{\star * *} \\
(.1999) \\
\end{array}$ \\
\hline Observations & 89,118 & 89,118 & 89,118 & 89,118 & 88,927 \\
\hline Wald $\chi^{2}(7)$ & 983.24 & 993.61 & 899.28 & 907.39 & 318.84 \\
\hline$p$ & $<.0001$ & $<.0001$ & $<.0001$ & $<.0001$ & $<.0001$ \\
\hline Pseudo $\mathrm{R}^{2}$ & .1307 & .1307 & .1390 & .1393 & .0932 \\
\hline
\end{tabular}

${ }^{\circ} p<.10{ }^{*} p<.05{ }^{* *} p<.01{ }^{* * *} p<.001$ 
Table B-98. Logit of Sunni Muslim Population.

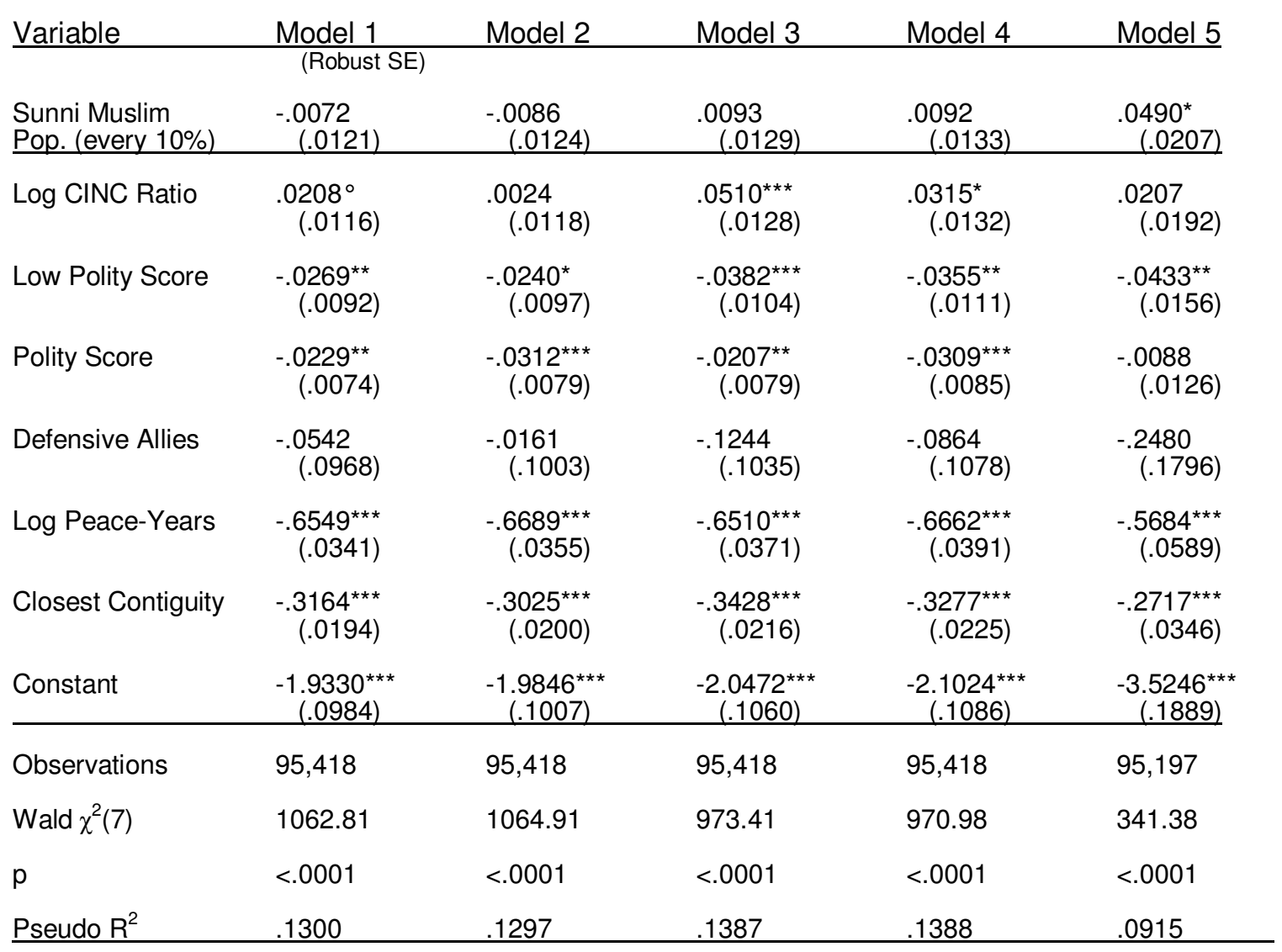

${ }^{\circ} p<.10{ }^{*} p<.05{ }^{* *} p<.01{ }^{* * *} p<.001$ 
Table B-99. Logit of Muslim (All) Chief Executive Being Target of Muslim (All) Chief Executive.

\begin{tabular}{|c|c|c|c|c|c|}
\hline \multirow{2}{*}{\multicolumn{2}{|c|}{$\begin{array}{lc}\text { Variable } & \text { Model } 1 \\
\text { Target has } & \text { (Robust SE) }\end{array}$}} & \multirow{2}{*}{ Model 2} & \multirow[t]{2}{*}{ Model 3} & \multirow[t]{2}{*}{ Model 4} & \multirow[t]{2}{*}{ Model 5} \\
\hline & & & & & \\
\hline $\begin{array}{l}\text { Muslim (all) } \\
\text { Chief Exec. (binary) }\end{array}$ & $\begin{array}{c}-.3386^{\star} \\
(.1712) \\
\end{array}$ & $\begin{array}{c}-.2760 \dagger \\
(.1752) \\
\end{array}$ & $\begin{array}{r}-.2345+\dagger \\
(.1793) \\
\end{array}$ & $\begin{array}{r}-.1623 \\
(.1843) \\
\end{array}$ & $\begin{array}{r}-.2680 \\
(.2816) \\
\end{array}$ \\
\hline Log CINC Ratio & $\begin{array}{c}.1546^{\star * *} \\
(.0326)\end{array}$ & $\begin{array}{r}.1529^{* * *} \\
(.0335)\end{array}$ & $\begin{array}{r}.1814^{\star * *} \\
(.0341)\end{array}$ & $\begin{array}{r}.1807^{\star \star \star} \\
(.0352)\end{array}$ & $\begin{array}{r}.1245^{\star} \\
(.0485)\end{array}$ \\
\hline Low Polity Score & $\begin{array}{l}.0294 \\
(.0257)\end{array}$ & $\begin{array}{c}.0180 \\
(.0267)\end{array}$ & $\begin{array}{c}.0303 \\
(.0263)\end{array}$ & $\begin{array}{c}.0184 \\
(.0274)\end{array}$ & $\begin{array}{c}.0478 \\
(.0367)\end{array}$ \\
\hline Polity Score & $\begin{array}{l}-.0234 \\
(.0187)\end{array}$ & $\begin{array}{l}-.0209 \\
(.0191)\end{array}$ & $\begin{array}{l}-.0200 \\
(.0189)\end{array}$ & $\begin{array}{c}-.0173 \\
(.0193)\end{array}$ & $\begin{array}{c}.0027 \\
(.0291)\end{array}$ \\
\hline Defensive Allies & $\begin{array}{l}-.0252 \\
(.1760)\end{array}$ & $\begin{array}{l}-.0206 \\
(.1796)\end{array}$ & $\begin{array}{c}.0152 \\
(.1804)\end{array}$ & $\begin{array}{c}.0224 \\
(.1844)\end{array}$ & $\begin{array}{c}.2486 \\
(.2724)\end{array}$ \\
\hline Log Peace-Years & $\begin{array}{r}-.5227^{* * *} \\
(.0673)\end{array}$ & $\begin{array}{r}-.5273^{\star * *} \\
(.0694)\end{array}$ & $\begin{array}{r}-.5313^{* \star *} \\
(.0700)\end{array}$ & $\begin{array}{r}-.5368^{* * *} \\
(.0724)\end{array}$ & $\begin{array}{r}-.3282^{* * *} \\
(.0976)\end{array}$ \\
\hline Closest Contiguity & $\begin{array}{r}-.2779^{* * *} \\
(.0447)\end{array}$ & $\begin{array}{r}-.2543^{\star * *} \\
(.0451)\end{array}$ & $\begin{array}{r}-.2669^{* * *} \\
(.0476)\end{array}$ & $\begin{array}{r}-.2402^{* * *} \\
(.0479)\end{array}$ & $\begin{array}{r}-.3002^{* * *} \\
(.0726)\end{array}$ \\
\hline Constant & $\begin{array}{c}-2.0618^{\star * *} \\
(.1996) \\
\end{array}$ & $\begin{array}{c}-2.1660^{* * *} \\
(.2052)\end{array}$ & $\begin{array}{c}-2.2367^{* * *} \\
(.2118) \\
\end{array}$ & $\begin{array}{c}-2.3563^{\star * *} \\
(.2183) \\
\end{array}$ & $\begin{array}{c}-3.6410^{* * *} \\
(.3411) \\
\end{array}$ \\
\hline Observations & 15,310 & 15,310 & 15,310 & 15,310 & 15,240 \\
\hline Wald $\chi^{2}(7)$ & 221.12 & 203.39 & 221.11 & 203.38 & 56.59 \\
\hline$p$ & $<.0001$ & $<.0001$ & $<.0001$ & $<.0001$ & $<.0001$ \\
\hline Pseudo $\mathrm{R}^{2}$ & . 1070 & .1013 & .1133 & .1078 & .0772 \\
\hline
\end{tabular}

${ }^{\circ} p<.10 \quad{ }^{*} p<.05 \quad{ }^{* *} p<.01{ }^{* * *} p<.001$

$\dagger p<.15$ †† $p<.25$ 
Table B-100. Logit of Judeo-Christian Chief Executive Being Target of Muslim (All) Chief Executive.

\begin{tabular}{|c|c|c|c|c|c|}
\hline Variable & Model 1 & Model 2 & Model 3 & Model 4 & Model 5 \\
\hline $\begin{array}{l}\text { Target has } \\
\text { Judeo-Christian } \\
\text { Chief Exec. (binary) } \\
\end{array}$ & $\begin{array}{r}.4877^{\star *} \\
(.1618) \\
\end{array}$ & $\begin{array}{r}.4493^{\star *} \\
(.1666) \\
\end{array}$ & $\begin{array}{c}.3560^{*} \\
(.1729) \\
\end{array}$ & $\begin{array}{c}.3073^{\circ} \\
(.1792) \\
\end{array}$ & $\begin{array}{l}.2382 \\
\quad(.2698) \\
\end{array}$ \\
\hline Log CINC Ratio & $\begin{array}{r}.1475^{\star \star \star} \\
(.0322)\end{array}$ & $\begin{array}{r}.1477^{* * *} \\
(.0330)\end{array}$ & $\begin{array}{r}.1771^{\star * *} \\
(.0336)\end{array}$ & $\begin{array}{r}.1786^{\star * *} \\
(.0345)\end{array}$ & $\begin{array}{r}.1178^{*} \\
(.0487)\end{array}$ \\
\hline Low Polity Score & $\begin{array}{l}.0202 \\
(.0271)\end{array}$ & $\begin{array}{l}.0079 \\
(.0281)\end{array}$ & $\begin{array}{l}.0235 \\
(.0279)\end{array}$ & $\begin{array}{l}.0106 \\
(.0291)\end{array}$ & $\begin{array}{l}.0476 \\
(.0394)\end{array}$ \\
\hline Polity Score & $\begin{array}{c}-.0183 \\
(.0190)\end{array}$ & $\begin{array}{c}-.0160 \\
(.0194)\end{array}$ & $\begin{array}{c}-.0168 \\
(.0193)\end{array}$ & $\begin{array}{c}-.0143 \\
(.0197)\end{array}$ & $\begin{array}{c}.0042 \\
(.0300)\end{array}$ \\
\hline Defensive Allies & $\begin{array}{l}-.0294 \\
(.1704)\end{array}$ & $\begin{array}{l}-.0128 \\
(.1738)\end{array}$ & $\begin{array}{l}.0118 \\
(.1748)\end{array}$ & $\begin{array}{l}.0308 \\
(.1786)\end{array}$ & $\begin{array}{l}.2046 \\
(.2617)\end{array}$ \\
\hline Log Peace-Years & $\begin{array}{r}-.5186^{\star \star *} \\
(.0675)\end{array}$ & $\begin{array}{r}-.5242^{\star * *} \\
(.0696)\end{array}$ & $\begin{array}{r}-.5290^{\star * *} \\
(.0699)\end{array}$ & $\begin{array}{r}-.5357^{\star \star *} \\
(.0723)\end{array}$ & $\begin{array}{r}-.3246^{\star * *} \\
(.0976)\end{array}$ \\
\hline Closest Contiguity & $\begin{array}{r}-.2778^{\star * *} \\
(.0444)\end{array}$ & $\begin{array}{r}-.2555^{\star \star \star} \\
(.0447)\end{array}$ & $\begin{array}{r}-.2677^{\star \star \star} \\
(.0472)\end{array}$ & $\begin{array}{r}-.2426^{\star \star *} \\
(.0475)\end{array}$ & $\begin{array}{r}-.2957^{\star \star \star} \\
(.0711)\end{array}$ \\
\hline Constant & $\begin{array}{c}-2.4212^{\star \star *} \\
(.1807) \\
\end{array}$ & $\begin{array}{c}-2.4716^{\star * *} \\
(.1866) \\
\end{array}$ & $\begin{array}{c}-2.4824^{\star * *} \\
(.1873) \\
\end{array}$ & $\begin{array}{c}-2.5377^{\star \star \star} \\
(.1940) \\
\end{array}$ & $\begin{array}{c}-3.8769^{\star \star *} \\
(.3091)\end{array}$ \\
\hline Observations & 15,294 & 15,294 & 15,294 & 15,294 & 15,224 \\
\hline Wald $\chi^{2}(7)$ & 238.19 & 223.58 & 231.01 & 216.19 & 56.53 \\
\hline$p$ & $<.0001$ & $<.0001$ & $<.0001$ & $<.0001$ & $<.0001$ \\
\hline Pseudo $\mathrm{R}^{2}$ & .1099 & .1041 & .1152 & .1095 & .0774 \\
\hline
\end{tabular}

${ }^{\circ} p<.10 \quad{ }^{*} p<.05 \quad{ }^{* *} p<.01{ }^{* * *} p<.001$

$\dagger p<.15$ †† $p<.25$ 
Table B-101. Logit of Christian (All) Chief Executive Being Target of Muslim (All) Chief Executive.

\begin{tabular}{|c|c|c|c|c|c|}
\hline Variable & Model 1 & Model 2 & Model 3 & Model 4 & Model 5 \\
\hline $\begin{array}{l}\text { Target has } \\
\text { Christian (all) } \\
\text { Chief Exec. (binary) }\end{array}$ & $\begin{array}{r}.4515^{\star *} \\
(.1598) \\
\end{array}$ & $\begin{array}{c}.4319^{\star *} \\
(.1649) \\
\end{array}$ & $\begin{array}{c}.3337^{\circ} \\
(.1705) \\
\end{array}$ & $\begin{array}{r}.3064^{\circ} \\
(.1770) \\
\end{array}$ & $\begin{array}{r}.2733 \\
(.2629) \\
\end{array}$ \\
\hline Log CINC Ratio & $\begin{array}{c}.1490^{\star * *} \\
(.0319)\end{array}$ & $\begin{array}{r}.1492^{* * *} \\
(.0327)\end{array}$ & $\begin{array}{r}.1781^{* \star *} \\
(.0334)\end{array}$ & $\begin{array}{r}.1796^{* * *} \\
(.0344)\end{array}$ & $\begin{array}{l}.1191^{*} \\
(.0485)\end{array}$ \\
\hline Low Polity Score & $\begin{array}{c}.0238 \\
(.0268)\end{array}$ & $\begin{array}{l}.0104 \\
(.0279)\end{array}$ & $\begin{array}{l}.0260 \\
(.0275)\end{array}$ & $\begin{array}{l}.0119 \\
(.0288)\end{array}$ & $\begin{array}{l}.0470 \\
(.0386)\end{array}$ \\
\hline Polity Score & $\begin{array}{c}-.0205 \\
(.0190)\end{array}$ & $\begin{array}{c}-.0178 \\
(.0194)\end{array}$ & $\begin{array}{c}-.0183 \\
(.0193)\end{array}$ & $\begin{array}{c}-.0154 \\
(.0196)\end{array}$ & $\begin{array}{c}.0040 \\
(.0298)\end{array}$ \\
\hline Defensive Allies & $\begin{array}{c}-.0566 \\
(.1693)\end{array}$ & $\begin{array}{c}-.0345 \\
(.1726)\end{array}$ & $\begin{array}{c}-.0066 \\
(.1735)\end{array}$ & $\begin{array}{l}.0186 \\
(.1770)\end{array}$ & $\begin{array}{c}.2029 \\
(.2588)\end{array}$ \\
\hline Log Peace-Years & $\begin{array}{r}-.5213^{\star \star \star} \\
(.0673)\end{array}$ & $\begin{array}{r}-.5269^{\star * *} \\
(.0695)\end{array}$ & $\begin{array}{r}-.5310^{\star \star *} \\
(.0698)\end{array}$ & $\begin{array}{r}-.5376^{\star \star \star} \\
(.0723)\end{array}$ & $\begin{array}{r}-.3259^{\star \star *} \\
(.0976)\end{array}$ \\
\hline Closest Contiguity & $\begin{array}{r}-.2774^{\star \star *} \\
(.0440)\end{array}$ & $\begin{array}{r}-.2559^{\star * *} \\
(.0444)\end{array}$ & $\begin{array}{r}-.2674^{\star \star *} \\
(.0469)\end{array}$ & $\begin{array}{r}-.2432^{\star * \star} \\
(.0473)\end{array}$ & $\begin{array}{r}-.2967^{\star * *} \\
(.0709)\end{array}$ \\
\hline Constant & $\begin{array}{c}-2.3845^{\star * *} \\
(.1783) \\
\end{array}$ & $\begin{array}{c}-2.4416^{\star \star *} \\
(.1837) \\
\end{array}$ & $\begin{array}{c}-2.4581^{\star * *} \\
(.1849) \\
\end{array}$ & $\begin{array}{c}-2.5207^{\star \star *} \\
(.1911) \\
\end{array}$ & $\begin{array}{c}-3.8748^{\star * *} \\
(.3061) \\
\end{array}$ \\
\hline Observations & 15,294 & 15,294 & 15,294 & 15,294 & 15,224 \\
\hline Wald $\chi^{2}(7)$ & 240.78 & 225.33 & 232.58 & 217.07 & 57.34 \\
\hline$p$ & $<.0001$ & $<.0001$ & $<.0001$ & $<.0001$ & $<.0001$ \\
\hline Pseudo $R^{2}$ & .1093 & .1038 & .1149 & .1095 & .0777 \\
\hline $\begin{array}{l}{ }^{\circ} p<.10 \\
\dagger p<.15 \quad \text { †十 } p<.05\end{array}$ & & & & & \\
\hline
\end{tabular}


Table B-102. Logit of Jewish Chief Executive Being Target of Muslim (All) Chief Executive.

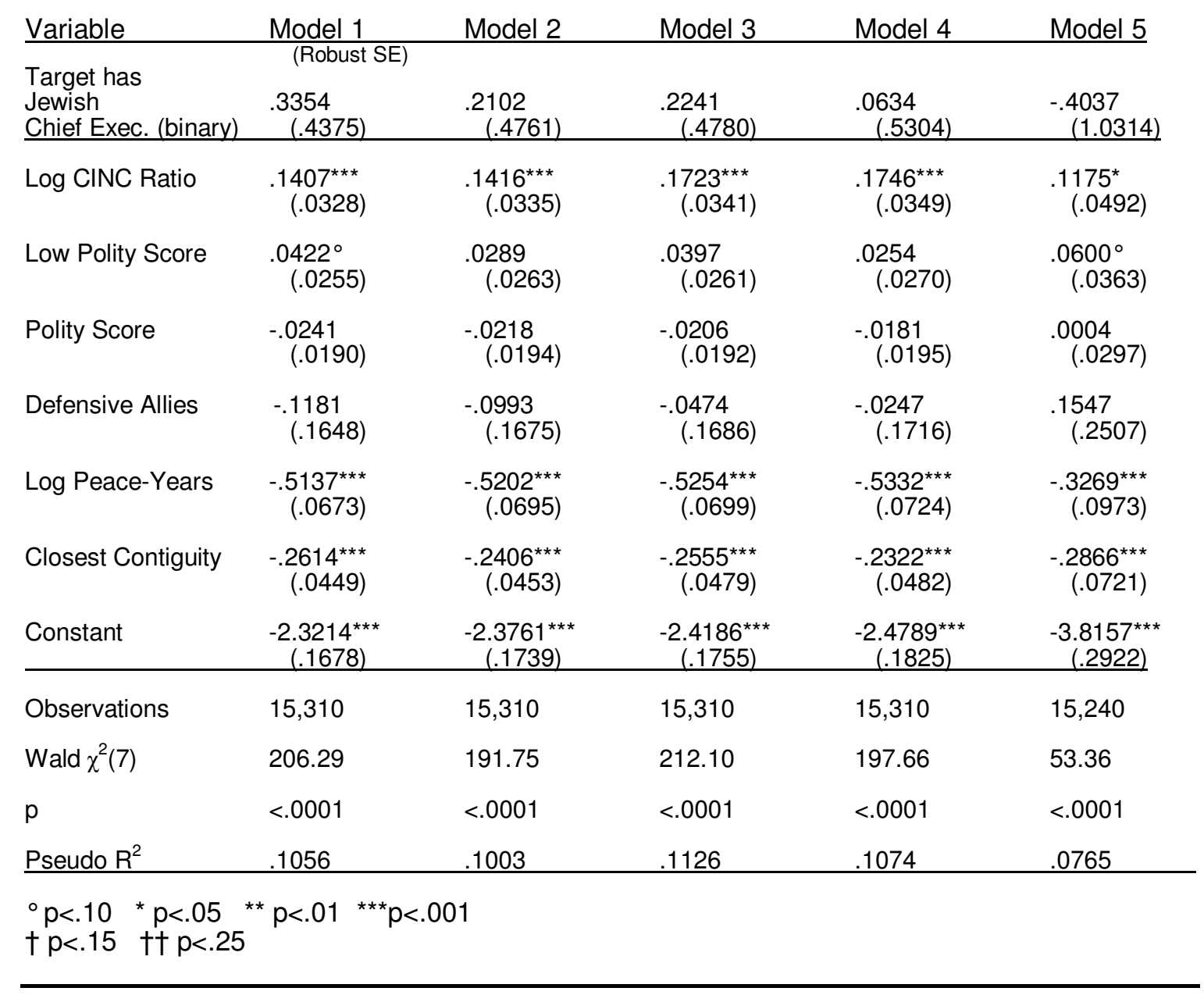


Table B-103. Logit of Non-Scriptuary Chief Executive Being Target of Muslim (All) Chief Executive.

\begin{tabular}{|c|c|c|c|c|c|}
\hline Variable & Model 1 & Model 2 & Model 3 & Model 4 & Model 5 \\
\hline Target has & (Robust SE & & & & \\
\hline $\begin{array}{l}\text { Non-Scriptuary } \\
\text { Chief Exec. (binary) }\end{array}$ & $\begin{array}{c}-.4496 \dagger \\
(.3020) \\
\end{array}$ & $\begin{array}{r}-.4928 \dagger \\
(.3138) \\
\end{array}$ & $\begin{array}{r}-.3335 \\
(.3129) \\
\end{array}$ & $\begin{array}{r}-.3737 \\
(.3261) \\
\end{array}$ & $\begin{array}{c}.0116 \\
\quad(.4060) \\
\end{array}$ \\
\hline Log CINC Ratio & $\begin{array}{c}.1312^{\star \star *} \\
(.0340)\end{array}$ & $\begin{array}{r}.1300^{* * *} \\
(.0350)\end{array}$ & $\begin{array}{r}.1654^{\star \star \star} \\
(.0351)\end{array}$ & $\begin{array}{r}.1657^{\star * *} \\
(.0362)\end{array}$ & $\begin{array}{c}.1178^{*} \\
(.0500)\end{array}$ \\
\hline Low Polity Score & $\begin{array}{c}.0423 \\
(.0258)\end{array}$ & $\begin{array}{c}.0279 \\
(.0267)\end{array}$ & $\begin{array}{c}.0400 \\
(.0263)\end{array}$ & $\begin{array}{l}.0245 \\
(.0272)\end{array}$ & $\begin{array}{l}.0589 \\
(.0363)\end{array}$ \\
\hline Polity Score & $\begin{array}{l}-.0224 \\
(.0195)\end{array}$ & $\begin{array}{c}-.0190 \\
(.0198)\end{array}$ & $\begin{array}{r}-.0196 \\
(.0198)\end{array}$ & $\begin{array}{r}-.0160 \\
(.0201)\end{array}$ & $\begin{array}{l}.0006 \\
(.0304)\end{array}$ \\
\hline Defensive Allies & $\begin{array}{l}-.1755 \\
(.1645)\end{array}$ & $\begin{array}{l}-.1529 \\
(.1673)\end{array}$ & $\begin{array}{l}-.0920 \\
(.1687)\end{array}$ & $\begin{array}{l}-.0647 \\
(.1717)\end{array}$ & $\begin{array}{c}.1591 \\
(.2524)\end{array}$ \\
\hline Log Peace-Years & $\begin{array}{r}-.5100^{\star \star *} \\
(.0673)\end{array}$ & $\begin{array}{r}-.5148^{* \star *} \\
(.0697)\end{array}$ & $\begin{array}{r}-.5227^{\star \star *} \\
(.0700)\end{array}$ & $\begin{array}{r}-.5287^{* \star *} \\
(.0726)\end{array}$ & $\begin{array}{r}-.3263^{\star \star *} \\
(.0971)\end{array}$ \\
\hline Closest Contiguity & $\begin{array}{r}-.2547^{* * *} \\
(.0459)\end{array}$ & $\begin{array}{r}-.2328^{* * *} \\
(.0463)\end{array}$ & $\begin{array}{r}-.2507^{* * *} \\
(.0488)\end{array}$ & $\begin{array}{r}-.2264^{* * *} \\
(.0493)\end{array}$ & $\begin{array}{r}-.2878^{* * *} \\
(.0742)\end{array}$ \\
\hline Constant & $\begin{array}{c}-2.2830^{\star * *} \\
(.1671)\end{array}$ & $\begin{array}{c}-2.3462^{* * *} \\
(.1725) \\
\end{array}$ & $\begin{array}{c}-2.3869^{* * *} \\
(.1746) \\
\end{array}$ & $\begin{array}{c}-2.4564^{\star \star *} \\
(.1808) \\
\end{array}$ & $\begin{array}{c}-3.8173^{\star * *} \\
(.2908) \\
\end{array}$ \\
\hline Observations & 15,294 & 15,294 & 15,294 & 15,294 & 15,224 \\
\hline Wald $\chi^{2}(7)$ & 214.47 & 200.84 & 217.93 & 204.43 & 53.86 \\
\hline$p$ & $<.0001$ & $<.0001$ & $<.0001$ & $<.0001$ & $<.0001$ \\
\hline Pseudo $\mathrm{R}^{2}$ & .1072 & .1023 & .1138 & .1089 & .0766 \\
\hline $\begin{array}{ll}{ }^{\circ} \mathrm{p}<.10 & { }^{*} \mathrm{p}<.05 \\
+\mathrm{p}<.15 & \text { t十 } \mathrm{p}<.25\end{array}$ & & & & & \\
\hline
\end{tabular}


Table B-104. Logit of Muslim (All) Preference Being Target of Muslim (All) Preference.

\begin{tabular}{|c|c|c|c|c|c|}
\hline Variable & Model 1 & Model 2 & Model 3 & Model 4 & Model 5 \\
\hline & (Robust SE) & & & & \\
\hline $\begin{array}{l}\text { Muslim (all) } \\
\text { Preference (binary) }\end{array}$ & $\begin{array}{r}-.4748^{* *} \\
(.1789) \\
\end{array}$ & $\begin{array}{c}-.3732^{*} \\
(.1848) \\
\end{array}$ & $\begin{array}{c}-.3724^{*} \\
(.1868) \\
\end{array}$ & $\begin{array}{r}-.2565 \dagger \dagger \\
(.1939) \\
\end{array}$ & $\begin{array}{r}-.1304 \\
\quad(.2932) \\
\end{array}$ \\
\hline Log CINC Ratio & $\begin{array}{r}.2161^{\star * *} \\
(.0355)\end{array}$ & $\begin{array}{r}.2162^{* * *} \\
(.0365)\end{array}$ & $\begin{array}{r}.2397^{\star * *} \\
(.0365)\end{array}$ & $\begin{array}{r}.2407^{* * *} \\
(.0376)\end{array}$ & $\begin{array}{c}.1507^{\star *} \\
(.0542)\end{array}$ \\
\hline Low Polity Score & $\begin{array}{l}.0326 \\
(.0253)\end{array}$ & $\begin{array}{c}.0238 \\
(.0263)\end{array}$ & $\begin{array}{l}.0326 \\
(.0259)\end{array}$ & $\begin{array}{l}.0235 \\
(.0270)\end{array}$ & $\begin{array}{l}.0793^{*} \\
(.0372)\end{array}$ \\
\hline Polity Score & $\begin{array}{c}-.0220 \\
(.0192)\end{array}$ & $\begin{array}{c}-.0187 \\
(.0197)\end{array}$ & $\begin{array}{c}-.0194 \\
(.0194)\end{array}$ & $\begin{array}{c}-.0159 \\
(.0199)\end{array}$ & $\begin{array}{c}-.0173 \\
(.0319)\end{array}$ \\
\hline Defensive Allies & $\begin{array}{c}-.0354 \\
(.1747)\end{array}$ & $\begin{array}{c}-.0229 \\
(.1787)\end{array}$ & $\begin{array}{l}.0082 \\
(.1789)\end{array}$ & $\begin{array}{l}.0234 \\
(.1833)\end{array}$ & $\begin{array}{l}.1811 \\
(.2642)\end{array}$ \\
\hline Log Peace-Years & $\begin{array}{r}-.5133^{* * *} \\
(.0691)\end{array}$ & $\begin{array}{r}-.5126^{\star \star \star} \\
(.0718)\end{array}$ & $\begin{array}{r}-.5230^{* * *} \\
(.0710)\end{array}$ & $\begin{array}{r}-.5226^{\star \star \star} \\
(.0740)\end{array}$ & $\begin{array}{c}-.3053^{\star *} \\
(.1011)\end{array}$ \\
\hline Closest Contiguity & $\begin{array}{r}-.2654^{\star * *} \\
(.0493)\end{array}$ & $\begin{array}{r}-.2346^{* * *} \\
(.0498)\end{array}$ & $\begin{array}{r}-.2414^{\star * *} \\
(.0506)\end{array}$ & $\begin{array}{r}-.2069^{* * *} \\
(.0508)\end{array}$ & $\begin{array}{c}-.2567^{* *} \\
(.0798)\end{array}$ \\
\hline Constant & $\begin{array}{c}-2.0738^{* * *} \\
(.2248)\end{array}$ & $\begin{array}{c}-2.2454^{* * *} \\
(.2319)\end{array}$ & $\begin{array}{c}-2.2617^{* * *} \\
(.2357) \\
\end{array}$ & $\begin{array}{c}-2.4567^{* * *} \\
(.2436) \\
\end{array}$ & $\begin{array}{c}-3.8674^{* * *} \\
(.3948) \\
\end{array}$ \\
\hline Observations & 15,120 & 15,120 & 15,120 & 15,120 & 15,066 \\
\hline Wald $\chi^{2}(7)$ & 236.71 & 213.91 & 231.60 & 208.58 & 55.29 \\
\hline$p$ & $<.0001$ & $<.0001$ & $<.0001$ & $<.0001$ & $<.0001$ \\
\hline Pseudo $\mathrm{R}^{2}$ & .1154 & .1075 & .1184 & .1110 & .0736 \\
\hline
\end{tabular}

${ }^{\circ} p<.10 \quad{ }^{*} p<.05{ }^{* *} p<.01{ }^{* * *} p<.001$

$\dagger p<.15$ †† $p<.25$ 
Table B-105. Logit of Judeo-Christian Preference Being Target of Muslim (All)

Preference.

\begin{tabular}{|c|c|c|c|c|c|}
\hline Variable & Model 1 & Model 2 & Model 3 & Model 4 & Model 5 \\
\hline $\begin{array}{l}\text { Target has } \\
\text { Judeo-Christian } \\
\text { Preference (binary) }\end{array}$ & $\begin{array}{r}.7474^{\star \star \star} \\
(.1799) \\
\end{array}$ & $\begin{array}{r}.6595^{\star * \star} \\
(.1865) \\
\end{array}$ & $\begin{array}{r}.6406^{* * *} \\
(.1914) \\
\end{array}$ & $\begin{array}{c}.5372^{* *} \\
(.1996) \\
\end{array}$ & $\begin{array}{r}.3941 \dagger \dagger \\
(.2921) \\
\end{array}$ \\
\hline Log CINC Ratio & $\begin{array}{r}.2038^{\star \star \star} \\
(.0357)\end{array}$ & $\begin{array}{c}.2065^{\star * *} \\
(.0366)\end{array}$ & $\begin{array}{c}.2288^{\star \star \star} \\
(.0368)\end{array}$ & $\begin{array}{r}.2329^{* \star *} \\
(.0378)\end{array}$ & $\begin{array}{c}.1472^{\star *} \\
(.0546)\end{array}$ \\
\hline Low Polity Score & $\begin{array}{c}.0073 \\
(.0271)\end{array}$ & $\begin{array}{l}-.0011 \\
\quad(.0282)\end{array}$ & $\begin{array}{c}.0116 \\
(.0287)\end{array}$ & $\begin{array}{l}.0029 \\
(.0300)\end{array}$ & $\begin{array}{l}.0583 \\
(.0409)\end{array}$ \\
\hline Polity Score & $\begin{array}{l}-.0056 \\
(.0190)\end{array}$ & $\begin{array}{l}-.0033 \\
(.0194)\end{array}$ & $\begin{array}{l}-.0087 \\
(.0199)\end{array}$ & $\begin{array}{l}-.0064 \\
(.0204)\end{array}$ & $\begin{array}{l}-.0067 \\
\quad(.0318)\end{array}$ \\
\hline Defensive Allies & $\begin{array}{l}.0207 \\
(.1738)\end{array}$ & $\begin{array}{c}.0434 \\
(.1776)\end{array}$ & $\begin{array}{l}.0606 \\
(.1793)\end{array}$ & $\begin{array}{l}.0860 \\
(.1836)\end{array}$ & $\begin{array}{l}.2490 \\
(.2652)\end{array}$ \\
\hline Log Peace-Years & $\begin{array}{r}-.4955^{\star * *} \\
(.0697)\end{array}$ & $\begin{array}{r}-.4958^{\star \star *} \\
(.0724)\end{array}$ & $\begin{array}{r}-.5213^{\star \star *} \\
(.0715)\end{array}$ & $\begin{array}{r}-.5231^{\star * *} \\
(.0745)\end{array}$ & $\begin{array}{l}-.2871^{* *} \\
(.1018)\end{array}$ \\
\hline Closest Contiguity & $\begin{array}{r}-.2809^{\star * *} \\
(.0478)\end{array}$ & $\begin{array}{r}-.2507^{\star * *} \\
(.0480)\end{array}$ & $\begin{array}{r}-.2524^{\star * *} \\
(.0489)\end{array}$ & $\begin{array}{r}-.2184^{\star * *} \\
(.0489)\end{array}$ & $\begin{array}{r}-.2703^{\star * *} \\
(.0754)\end{array}$ \\
\hline Constant & $\begin{array}{c}-2.5946^{\star * *} \\
(.1938) \\
\end{array}$ & $\begin{array}{c}-2.6734^{* * *} \\
(.2008) \\
\end{array}$ & $\begin{array}{c}-2.6657^{* * *} \\
(.2003) \\
\end{array}$ & $\begin{array}{c}-2.7525^{\star * *} \\
(.2080) \\
\end{array}$ & $\begin{array}{c}-4.0690^{* * *} \\
(.3335) \\
\end{array}$ \\
\hline Observations & 15,139 & 15,139 & 15,139 & 15,139 & 15,085 \\
\hline Wald $\chi^{2}(7)$ & 251.88 & 233.88 & 240.93 & 222.25 & 61.31 \\
\hline$p$ & $<.0001$ & $<.0001$ & $<.0001$ & $<.0001$ & $<.0001$ \\
\hline${\text { Pseudo } \mathrm{R}^{2}}$ & .1185 & .1103 & .1210 & .1131 & .0738 \\
\hline
\end{tabular}

${ }^{\circ} p<.10 \quad{ }^{*} p<.05 \quad{ }^{* *} p<.01{ }^{* * *} p<.001$

$\dagger p<.15$ †† $p<.25$ 
Table B-106. Logit of Christian (All) Preference Being Target of Muslim (All)

Preference.

\begin{tabular}{|c|c|c|c|c|c|}
\hline Variable & Model 1 & Model 2 & Model 3 & Model 4 & Model 5 \\
\hline $\begin{array}{l}\text { Target has } \\
\text { Christian (all) } \\
\text { Preference (binary) }\end{array}$ & $\begin{array}{r}.7096^{\star \star \star} \\
(.1791) \\
\end{array}$ & $\begin{array}{r}.6403^{\star * *} \\
(.1855) \\
\end{array}$ & $\begin{array}{c}.6202^{* *} \\
(.1894) \\
\end{array}$ & $\begin{array}{c}.5387^{\star *} \\
(.1973) \\
\end{array}$ & $\begin{array}{c}.4392 \dagger \\
(.2841) \\
\end{array}$ \\
\hline Log CINC Ratio & $\begin{array}{r}.2055^{\star \star \star} \\
(.0353)\end{array}$ & $\begin{array}{r}.2082^{* * *} \\
(.0362)\end{array}$ & $\begin{array}{r}.2303^{\star * *} \\
(.0365)\end{array}$ & $\begin{array}{r}.2344^{\star * *} \\
(.0375)\end{array}$ & $\begin{array}{c}.1497^{\star *} \\
(.0548)\end{array}$ \\
\hline Low Polity Score & $\begin{array}{l}.0119 \\
(.0268)\end{array}$ & $\begin{array}{l}.0022 \\
(.0279)\end{array}$ & $\begin{array}{l}.0150 \\
(.0283)\end{array}$ & $\begin{array}{l}.0048 \\
(.0296)\end{array}$ & $\begin{array}{c}.0575 \\
(.0399)\end{array}$ \\
\hline Polity Score & $\begin{array}{c}-.0089 \\
(.0190)\end{array}$ & $\begin{array}{l}-.0059 \\
(.0194)\end{array}$ & $\begin{array}{c}-.0113 \\
(.0199)\end{array}$ & $\begin{array}{c}-.0083 \\
(.0203)\end{array}$ & $\begin{array}{c}-.0071 \\
(.0316)\end{array}$ \\
\hline Defensive Allies & $\begin{array}{l}-.0170 \\
(.1725)\end{array}$ & $\begin{array}{l}.0130 \\
(.1762)\end{array}$ & $\begin{array}{l}.0308 \\
(.1777)\end{array}$ & $\begin{array}{l}.0647 \\
(.1818)\end{array}$ & $\begin{array}{c}.2426 \\
(.2625)\end{array}$ \\
\hline Log Peace-Years & $\begin{array}{r}-.5009^{\star \star *} \\
(.0695)\end{array}$ & $\begin{array}{r}-.5003^{\star * *} \\
(.0721)\end{array}$ & $\begin{array}{r}-.5257^{\star \star *} \\
(.0713)\end{array}$ & $\begin{array}{r}-.5265^{\star \star *} \\
(.0743)\end{array}$ & $\begin{array}{c}-.2886^{* *} \\
(.1015)\end{array}$ \\
\hline Closest Contiguity & $\begin{array}{r}-.2802^{\star \star \star} \\
(.0472)\end{array}$ & $\begin{array}{r}-.2512^{\star * \star} \\
(.0474)\end{array}$ & $\begin{array}{r}-.2525^{\star \star *} \\
(.0483)\end{array}$ & $\begin{array}{r}-.2199^{\star * *} \\
(.0483)\end{array}$ & $\begin{array}{r}-.2728^{* * *} \\
(.0752)\end{array}$ \\
\hline Constant & $\begin{array}{c}-2.5429^{\star \star *} \\
(.1917) \\
\end{array}$ & $\begin{array}{c}-2.6309^{\star * *} \\
(.1983) \\
\end{array}$ & $\begin{array}{c}-2.6251^{\star * *} \\
(.1979) \\
\end{array}$ & $\begin{array}{c}-2.7220^{\star \star *} \\
(.2053) \\
\end{array}$ & $\begin{array}{c}-4.0592^{\star * *} \\
(.3312) \\
\end{array}$ \\
\hline Observations & 15,139 & 15,139 & 15,139 & 15,139 & 15,085 \\
\hline Wald $\chi^{2}(7)$ & 255.43 & 237.10 & 243.72 & 224.43 & 62.91 \\
\hline$p$ & $<.0001$ & $<.0001$ & $<.0001$ & $<.0001$ & $<.0001$ \\
\hline Pseudo $\mathrm{R}^{2}$ & .1175 & .1097 & .1205 & .1130 & .0743 \\
\hline
\end{tabular}

${ }^{\circ} p<.10 \quad{ }^{*} p<.05 \quad{ }^{* *} p<.01{ }^{* * *} p<.001$

$\dagger p<.15$ †† $p<.25$ 
Table B-107. Logit of Jewish Preference Being Target of Muslim (All) Preference.

\begin{tabular}{|c|c|c|c|c|c|}
\hline Variable & Model 1 & Model 2 & Model 3 & Model 4 & Model 5 \\
\hline $\begin{array}{l}\text { Target has } \\
\text { Jewish } \\
\text { Preference (binary) }\end{array}$ & $\begin{array}{r}.4153 \\
(.4397) \\
\end{array}$ & $\begin{array}{c}.3049 \\
(.4780) \\
\end{array}$ & $\begin{array}{c}.2893 \\
(.4806) \\
\end{array}$ & $\begin{array}{c}.1449 \\
(.5329) \\
\end{array}$ & $\begin{array}{c}-.3771 \\
(1.0371) \\
\end{array}$ \\
\hline Log CINC Ratio & $\begin{array}{r}.1946^{* * *} \\
(.0354)\end{array}$ & $\begin{array}{r}.1978^{* * *} \\
(.0362)\end{array}$ & $\begin{array}{r}.2209^{* * *} \\
(.0364)\end{array}$ & $\begin{array}{r}.2256^{\star * *} \\
(.0372)\end{array}$ & $\begin{array}{l}.1419^{* *} \\
(.0542)\end{array}$ \\
\hline Low Polity Score & $\begin{array}{l}.0462^{\circ} \\
(.0245)\end{array}$ & $\begin{array}{l}.0339 \\
(.0251)\end{array}$ & $\begin{array}{c}.0460^{\circ} \\
(.0256)\end{array}$ & $\begin{array}{c}.0326 \\
(.0264)\end{array}$ & $\begin{array}{l}.0802^{*} \\
(.0365)\end{array}$ \\
\hline Polity Score & $\begin{array}{c}-.0180 \\
(.0189)\end{array}$ & $\begin{array}{c}-.0146 \\
(.0192)\end{array}$ & $\begin{array}{r}-.0196 \\
(.0197)\end{array}$ & $\begin{array}{c}-.0161 \\
(.0201)\end{array}$ & $\begin{array}{c}-.0150 \\
(.0313)\end{array}$ \\
\hline Defensive Allies & $\begin{array}{c}-.0758 \\
(.1670)\end{array}$ & $\begin{array}{l}-.0410 \\
(.1701)\end{array}$ & $\begin{array}{l}-.0206 \\
(.1713)\end{array}$ & $\begin{array}{r}.0191 \\
(.1747)\end{array}$ & $\begin{array}{l}.1717 \\
(.2556)\end{array}$ \\
\hline Log Peace-Years & $\begin{array}{r}-.4955^{\star * *} \\
(.0688)\end{array}$ & $\begin{array}{r}-.4942^{\star * *} \\
(.0715)\end{array}$ & $\begin{array}{r}-.5192^{\star \star \star} \\
(.0706)\end{array}$ & $\begin{array}{r}-.5191^{\star * \star} \\
(.0737)\end{array}$ & $\begin{array}{c}-.2941^{\star *} \\
(.0997)\end{array}$ \\
\hline Closest Contiguity & $\begin{array}{r}-.2309^{\star \star *} \\
(.0480)\end{array}$ & $\begin{array}{r}-.2072^{\star * *} \\
(.0484)\end{array}$ & $\begin{array}{r}-.2107^{\star \star \star} \\
(.0496)\end{array}$ & $\begin{array}{r}-.1842^{\star \star \star} \\
(.0500)\end{array}$ & $\begin{array}{c}-.2417^{* *} \\
(.0766)\end{array}$ \\
\hline Constant & $\begin{array}{c}-2.5435^{\star * *} \\
(.1784) \\
\end{array}$ & $\begin{array}{c}-2.6347^{\star \star * *} \\
(.1855) \\
\end{array}$ & $\begin{array}{c}-2.6303^{* * *} \\
(.1844) \\
\end{array}$ & $\begin{array}{c}-2.7299^{\star * *} \\
(.1924) \\
\end{array}$ & $\begin{array}{c}-4.0310^{\star * *} \\
(.3099) \\
\end{array}$ \\
\hline Observations & 15,588 & 15,588 & 15,588 & 15,588 & 15,531 \\
\hline Wald $\chi^{2}(7)$ & 201.41 & 185.19 & 202.93 & 186.52 & 50.33 \\
\hline$p$ & $<.0001$ & $<.0001$ & $<.0001$ & $<.0001$ & $<.0001$ \\
\hline Pseudo $R^{2}$ & .1073 & .1008 & .1117 & .1054 & .0686 \\
\hline
\end{tabular}

${ }^{\circ} p<.10{ }^{*} p<.05{ }^{* *} p<.01{ }^{* * *} p<.001$

† $p<.15$ †† $p<.25$ 
Table B-108. Logit of Non-Scriptuary Preference Being Target of Muslim (All)

Preference.

\begin{tabular}{|c|c|c|c|c|c|}
\hline Variable & Model 1 & Model 2 & Model 3 & Model 4 & Model 5 \\
\hline $\begin{array}{l}\text { Target has } \\
\text { Non-Scriptuary } \\
\text { Preference (binary) }\end{array}$ & $\begin{array}{c}-.3920 \dagger \\
(.2852) \\
\end{array}$ & $\begin{array}{r}-.4225 t \dagger \\
(.2969) \\
\end{array}$ & $\begin{array}{r}-.3487+\dagger \\
(.2955) \\
\end{array}$ & $\begin{array}{r}-.3786+\dagger \\
(.3086) \\
\end{array}$ & $\begin{array}{l}-.3246 \\
(.4176) \\
\end{array}$ \\
\hline Log CINC Ratio & $\begin{array}{r}.1890^{* * *} \\
(.0350)\end{array}$ & $\begin{array}{r}.1906^{* * *} \\
(.0360)\end{array}$ & $\begin{array}{r}.2165^{\star * *} \\
(.0356)\end{array}$ & $\begin{array}{r}.2196^{\star \star \star} \\
(.0367)\end{array}$ & $\begin{array}{r}.1330^{*} \\
(.0522)\end{array}$ \\
\hline Low Polity Score & $\begin{array}{c}.0493^{\circ} \\
(.0252)\end{array}$ & $\begin{array}{c}.0359 \\
(.0260)\end{array}$ & $\begin{array}{c}.0463^{\circ} \\
(.0257)\end{array}$ & $\begin{array}{c}.0320 \\
(.0266)\end{array}$ & $\begin{array}{c}.0815^{*} \\
(.0375)\end{array}$ \\
\hline Polity Score & $\begin{array}{l}-.0198 \\
(.0198)\end{array}$ & $\begin{array}{l}-.0158 \\
(.0202)\end{array}$ & $\begin{array}{l}-.0177 \\
(.0201)\end{array}$ & $\begin{array}{l}-.0134 \\
(.0206)\end{array}$ & $\begin{array}{c}-.0151 \\
(.0329)\end{array}$ \\
\hline Defensive Allies & $\begin{array}{l}-.1512 \\
(.1677)\end{array}$ & $\begin{array}{l}-.1136 \\
(.1710)\end{array}$ & $\begin{array}{l}-.0783 \\
(.1707)\end{array}$ & $\begin{array}{l}-.0349 \\
(.1743)\end{array}$ & $\begin{array}{c}.1112 \\
(.2549)\end{array}$ \\
\hline Log Peace-Years & $\begin{array}{r}-.4931^{* * *} \\
(.0687)\end{array}$ & $\begin{array}{r}-.4910^{* \star *} \\
(.0715)\end{array}$ & $\begin{array}{r}-.5028^{\star * \star} \\
(.0705)\end{array}$ & $\begin{array}{r}-.5011^{* * *} \\
(.0737)\end{array}$ & $\begin{array}{l}-.2904^{* *} \\
(.1016)\end{array}$ \\
\hline Closest Contiguity & $\begin{array}{r}-.2289^{* * *} \\
(.0485)\end{array}$ & $\begin{array}{r}-.2045^{\star * *} \\
(.0491)\end{array}$ & $\begin{array}{r}-.2130^{\star * *} \\
(.0501)\end{array}$ & $\begin{array}{r}-.1862^{* * *} \\
(.0507)\end{array}$ & $\begin{array}{r}-.2445^{\star *} \\
(.0781)\end{array}$ \\
\hline Constant & $\begin{array}{c}-2.4743^{* * *} \\
(.1781) \\
\end{array}$ & $\begin{array}{c}-2.5707^{* * *} \\
(.1847) \\
\end{array}$ & $\begin{array}{c}-2.5859^{* * *} \\
(.1832) \\
\end{array}$ & $\begin{array}{c}-2.6922^{* * *} \\
(.1905) \\
\end{array}$ & $\begin{array}{c}-3.9790^{* * *} \\
(.3017) \\
\end{array}$ \\
\hline Observations & 15,369 & 15,369 & 15,369 & 15,369 & 15,312 \\
\hline Wald $\chi^{2}(7)$ & 208.32 & 192.57 & 207.56 & 191.33 & 53.02 \\
\hline$p$ & $<.0001$ & $<.0001$ & $<.0001$ & $<.0001$ & $<.0001$ \\
\hline Pseudo $\mathrm{R}^{2}$ & .1092 & .1028 & .1131 & .1068 & .0705 \\
\hline
\end{tabular}

${ }^{\circ} p<.10 \quad{ }^{*} p<.05 \quad{ }^{* *} p<.01{ }^{* * *} p<.001$

$\dagger p<.15$ †† $p<.25$ 
Table B-109. Logit of Muslim (All) Prevalence Being Target of Muslim (All) Prevalence.

\begin{tabular}{|c|c|c|c|c|c|}
\hline Variable & Model 1 & Model 2 & Model 3 & Model 4 & Model 5 \\
\hline Target has & (Robust SE & & & & \\
\hline $\begin{array}{l}\text { Muslim (all) } \\
\text { Prevalence (binary) }\end{array}$ & $\begin{array}{r}-.5055^{\star *} \\
(.1874) \\
\end{array}$ & $\begin{array}{r}-.4007^{*} \\
(.1925) \\
\end{array}$ & $\begin{array}{r}-.4064^{*} \\
(.1941) \\
\end{array}$ & $\begin{array}{r}-.2879+\dagger \\
(.1999) \\
\end{array}$ & $\begin{array}{r}-.3631 \dagger \dagger \\
(.3096) \\
\end{array}$ \\
\hline Log CINC Ratio & $\begin{array}{r}.1818^{\star * *} \\
(.0356)\end{array}$ & $\begin{array}{r}.1791^{* * *} \\
(.0369)\end{array}$ & $\begin{array}{r}.1992^{* * *} \\
(.0369)\end{array}$ & $\begin{array}{r}.1972^{* * *} \\
(.0383)\end{array}$ & $\begin{array}{l}.1224^{*} \\
(.0532)\end{array}$ \\
\hline Low Polity Score & $\begin{array}{l}.0205 \\
(.0258)\end{array}$ & $\begin{array}{l}.0106 \\
(.0269)\end{array}$ & $\begin{array}{l}.0231 \\
(.0264)\end{array}$ & $\begin{array}{l}.0133 \\
(.0276)\end{array}$ & $\begin{array}{l}.0480 \\
(.0375)\end{array}$ \\
\hline Polity Score & $\begin{aligned}-.0133 \\
(.0187)\end{aligned}$ & $\begin{aligned}-.0097 \\
(.0191)\end{aligned}$ & $\begin{array}{l}-.0113 \\
(.0189)\end{array}$ & $\begin{array}{l}-.0075 \\
(.0194)\end{array}$ & $\begin{array}{l}.0090 \\
(.0296)\end{array}$ \\
\hline Defensive Allies & $\begin{array}{l}-.0234 \\
(.1839)\end{array}$ & $\begin{array}{l}-.0204 \\
(.1875)\end{array}$ & $\begin{array}{l}.0072 \\
(.1875)\end{array}$ & $\begin{array}{l}.0125 \\
(.1914)\end{array}$ & $\begin{array}{l}.3072 \\
(.2836)\end{array}$ \\
\hline Log Peace-Years & $\begin{array}{r}-.5382^{* * *} \\
(.0685)\end{array}$ & $\begin{array}{r}-.5413^{* * *} \\
(.0709)\end{array}$ & $\begin{array}{r}-.5553^{\star * *} \\
(.0700)\end{array}$ & $\begin{array}{r}-.5596^{* * *} \\
(.0727)\end{array}$ & $\begin{array}{r}-.3579^{\star * *} \\
(.1021)\end{array}$ \\
\hline Closest Contiguity & $\begin{array}{r}-.2934^{* * *} \\
(.0477)\end{array}$ & $\begin{array}{r}-.2635^{\star * *} \\
(.0482)\end{array}$ & $\begin{array}{r}-.2713^{\star \star *} \\
(.0490)\end{array}$ & $\begin{array}{r}-.2380^{* * *} \\
(.0493)\end{array}$ & $\begin{array}{r}-.2752^{\star * *} \\
(.0760)\end{array}$ \\
\hline Constant & $\begin{array}{c}-1.8947^{* * *} \\
(.2163)\end{array}$ & $\begin{array}{c}-2.0582^{* * *} \\
(.2227) \\
\end{array}$ & $\begin{array}{c}-2.0598^{* * *} \\
(.2249) \\
\end{array}$ & $\begin{array}{c}-2.2446^{* * *} \\
(.2318)\end{array}$ & $\begin{array}{c}-3.6246^{* * *} \\
(.3622) \\
\end{array}$ \\
\hline Observations & 14,577 & 14,577 & 14,577 & 14,577 & 14,514 \\
\hline Wald $\chi^{2}(7)$ & 233.10 & 209.98 & 231.57 & 208.18 & 61.13 \\
\hline$p$ & $<.0001$ & $<.0001$ & $<.0001$ & $<.0001$ & $<.0001$ \\
\hline Pseudo $\mathrm{R}^{2}$ & .1189 & .1108 & .1216 & .1138 & .0768 \\
\hline
\end{tabular}

${ }^{\circ} p<.10{ }^{*} p<.05 \quad{ }^{* *} p<.01{ }^{* * *} p<.001$

† $p<.15$ †† $p<.25$ 
Table B-110. Logit of Judeo-Christian Prevalence Being Target of Muslim (All)

Prevalence.

\begin{tabular}{|c|c|c|c|c|c|}
\hline Variable & Model 1 & Model 2 & Model 3 & Model 4 & Model 5 \\
\hline $\begin{array}{l}\text { Target has } \\
\text { Judeo-Christian } \\
\text { Prevalence (binary) }\end{array}$ & $\begin{array}{r}.7874^{* * *} \\
(.1939)\end{array}$ & $\begin{array}{r}.7003^{* * *} \\
(.1989) \\
\end{array}$ & $\begin{array}{r}.6039^{\star *} \\
(.2006) \\
\end{array}$ & $\begin{array}{r}.4975^{\star} \\
(.2063) \\
\end{array}$ & $\begin{array}{c}.4736 \dagger \\
(.3134) \\
\end{array}$ \\
\hline Log CINC Ratio & $\begin{array}{r}.1652^{\star \star \star} \\
(.0354)\end{array}$ & $\begin{array}{r}.1651^{* \star *} \\
(.0363)\end{array}$ & $\begin{array}{r}.1819^{\star \star \star} \\
(.0366)\end{array}$ & $\begin{array}{r}.1826^{\star \star \star} \\
(.0376)\end{array}$ & $\begin{array}{l}.1256^{\star} \\
(.0529)\end{array}$ \\
\hline Low Polity Score & $\begin{array}{l}.0101 \\
(.0270)\end{array}$ & $\begin{array}{l}.0010 \\
(.0282)\end{array}$ & $\begin{array}{l}.0205 \\
(.0276)\end{array}$ & $\begin{array}{l}.0118 \\
(.0290)\end{array}$ & $\begin{array}{l}.0521 \\
(.0389)\end{array}$ \\
\hline Polity Score & $\begin{array}{l}-.0084 \\
(.0185)\end{array}$ & $\begin{array}{l}-.0062 \\
(.0190)\end{array}$ & $\begin{array}{l}-.0111 \\
(.0190)\end{array}$ & $\begin{array}{c}-.0090 \\
(.0195)\end{array}$ & $\begin{array}{c}-.0006 \\
(.0295)\end{array}$ \\
\hline Defensive Allies & $\begin{array}{l}.0983 \\
(.1747)\end{array}$ & $\begin{array}{l}.1133 \\
(.1777)\end{array}$ & $\begin{array}{l}.1059 \\
(.1784)\end{array}$ & $\begin{array}{l}.1227 \\
(.1816)\end{array}$ & $\begin{array}{l}.2636 \\
(.2654)\end{array}$ \\
\hline Log Peace-Years & $\begin{array}{r}-.5108^{\star * *} \\
(.0692)\end{array}$ & $\begin{array}{r}-.5172^{* * *} \\
(.0715)\end{array}$ & $\begin{array}{r}-.5347^{* * *} \\
(.0707)\end{array}$ & $\begin{array}{r}-.5427^{* * *} \\
(.0732)\end{array}$ & $\begin{array}{c}-.3256^{\star *} \\
(.0990)\end{array}$ \\
\hline Closest Contiguity & $\begin{array}{r}-.3145^{\star \star \star} \\
(.0469)\end{array}$ & $\begin{array}{r}-.2859^{* * *} \\
(.0471)\end{array}$ & $\begin{array}{r}-.2849^{* * *} \\
(.0476)\end{array}$ & $\begin{array}{r}-.2528^{* * *} \\
(.0475)\end{array}$ & $\begin{array}{r}-.2922^{* * *} \\
(.0718)\end{array}$ \\
\hline Constant & $\begin{array}{c}-2.4639^{* * *} \\
(.1921) \\
\end{array}$ & $\begin{array}{c}-2.5232^{* * *} \\
(.1986) \\
\end{array}$ & $\begin{array}{c}-2.5188^{* * *} \\
(.1949) \\
\end{array}$ & $\begin{array}{c}-2.5849^{* * *} \\
(.2018) \\
\end{array}$ & $\begin{array}{c}-3.9198^{* * *} \\
(.3231) \\
\end{array}$ \\
\hline Observations & 14,715 & 14,715 & 14,715 & 14,715 & 14,652 \\
\hline Wald $\chi^{2}(7)$ & 243.40 & 228.53 & 234.46 & 219.50 & 67.74 \\
\hline$p$ & $<.0001$ & $<.0001$ & $<.0001$ & $<.0001$ & $<.0001$ \\
\hline Pseudo $\mathrm{R}^{2}$ & .1168 & .1094 & .1174 & .1103 & .0771 \\
\hline
\end{tabular}

${ }^{\circ} p<.10{ }^{*} p<.05 \quad{ }^{* *} p<.01{ }^{* * *} p<.001$

† $p<.15$ †† $p<.25$ 
Table B-111. Logit of Christian (All) Prevalence Being Target of Muslim (All)

Prevalence.

\begin{tabular}{|c|c|c|c|c|c|}
\hline Variable & Model 1 & Model 2 & Model 3 & Model 4 & Model 5 \\
\hline $\begin{array}{l}\text { Target has } \\
\text { Christian (all) } \\
\text { Prevalence (binary) }\end{array}$ & $\begin{array}{r}.7733^{* * *} \\
(.1925) \\
\end{array}$ & $\begin{array}{r}.7069^{* * *} \\
(.1979) \\
\end{array}$ & $\begin{array}{r}.6063^{\star *} \\
(.1975) \\
\end{array}$ & $\begin{array}{l}.5237^{\star} \\
(.2034) \\
\end{array}$ & $\begin{array}{l}.5536^{\circ} \\
(.3045) \\
\end{array}$ \\
\hline Log CINC Ratio & $\begin{array}{r}.1674^{\star \star \star} \\
(.0350)\end{array}$ & $\begin{array}{r}.1675^{\star \star *} \\
(.0360)\end{array}$ & $\begin{array}{r}.1837^{\star \star \star} \\
(.0364)\end{array}$ & $\begin{array}{r}.1847^{\star \star \star} \\
(.0374)\end{array}$ & $\begin{array}{l}.1288^{*} \\
(.0530)\end{array}$ \\
\hline Low Polity Score & $\begin{array}{l}.0144 \\
(.0267)\end{array}$ & $\begin{array}{l}.0039 \\
(.0279)\end{array}$ & $\begin{array}{l}.0233 \\
(.0271)\end{array}$ & $\begin{array}{l}.0130 \\
(.0285)\end{array}$ & $\begin{array}{l}.0510 \\
(.0378)\end{array}$ \\
\hline Polity Score & $\begin{array}{l}-.0118 \\
(.0186)\end{array}$ & $\begin{array}{l}-.0090 \\
(.0190)\end{array}$ & $\begin{array}{r}-.0135 \\
(.0191)\end{array}$ & $\begin{array}{c}-.0108 \\
(.0195)\end{array}$ & $\begin{array}{c}-.0016 \\
(.0295)\end{array}$ \\
\hline Defensive Allies & $\begin{array}{l}.0572 \\
(.1720)\end{array}$ & $\begin{array}{l}.0812 \\
(.1751)\end{array}$ & $\begin{array}{l}.0781 \\
(.1757)\end{array}$ & $\begin{array}{l}.1047 \\
(.1790)\end{array}$ & $\begin{array}{l}.2591 \\
(.2608)\end{array}$ \\
\hline Log Peace-Years & $\begin{array}{r}-.5163^{\star * \star} \\
(.0689)\end{array}$ & $\begin{array}{r}-.5219^{* * *} \\
(.0711)\end{array}$ & $\begin{array}{r}-.5386^{* * *} \\
(.0705)\end{array}$ & $\begin{array}{r}-.5456^{* * *} \\
(.0730)\end{array}$ & $\begin{array}{r}-.3272^{* * *} \\
(.0986)\end{array}$ \\
\hline Closest Contiguity & $\begin{array}{r}-.3172^{\star \star \star} \\
(.0464)\end{array}$ & $\begin{array}{r}-.2898^{* * *} \\
(.0466)\end{array}$ & $\begin{array}{r}-.2877^{* * *} \\
(.0470)\end{array}$ & $\begin{array}{r}-.2568^{* * *} \\
(.0468)\end{array}$ & $\begin{array}{r}-.2988^{* * *} \\
(.0717)\end{array}$ \\
\hline Constant & $\begin{array}{c}-2.4065^{\star * *} \\
(.1891) \\
\end{array}$ & $\begin{array}{c}-2.4751^{* * *} \\
(.1954) \\
\end{array}$ & $\begin{array}{c}-2.4790^{* * *} \\
(.1922) \\
\end{array}$ & $\begin{array}{c}-2.5549^{* * *} \\
(.1990) \\
\end{array}$ & $\begin{array}{c}-3.9030^{* * *} \\
(.3196) \\
\end{array}$ \\
\hline Observations & 14,715 & 14,715 & 14,715 & 14,715 & 14,652 \\
\hline Wald $\chi^{2}(7)$ & 246.99 & 231.72 & 237.64 & 222.06 & 69.81 \\
\hline$p$ & $<.0001$ & $<.0001$ & $<.0001$ & $<.0001$ & $<.0001$ \\
\hline Pseudo $\mathrm{R}^{2}$ & .1161 & .1092 & .1172 & .1104 & .0779 \\
\hline
\end{tabular}

${ }^{\circ} p<.10{ }^{*} p<.05{ }^{* *} p<.01{ }^{* * *} p<.001$

$\dagger p<.15$ †† $p<.25$ 
Table B-112. Logit of Jewish Prevalence Being Target of Muslim (All) Prevalence.

\begin{tabular}{|c|c|c|c|c|c|}
\hline Variable & Model 1 & Model 2 & Model 3 & Model 4 & Model 5 \\
\hline $\begin{array}{l}\text { Target has } \\
\text { Jewish } \\
\text { Prevalence (binary) }\end{array}$ & $\begin{array}{c}.3044 \\
(.4409) \\
\end{array}$ & $\begin{array}{c}.2003 \\
(.4787) \\
\end{array}$ & $\begin{array}{c}.1649 \\
(.4813)\end{array}$ & $\begin{array}{l}.0247 \\
(.5330) \\
\end{array}$ & $\begin{array}{l}-.4741 \\
(1.0379)\end{array}$ \\
\hline Log CINC Ratio & $\begin{array}{r}.1574^{\star \star \star} \\
(.0339)\end{array}$ & $\begin{array}{r}.1593^{* * *} \\
(.0348)\end{array}$ & $\begin{array}{r}.1783^{\star * \star} \\
(.0349)\end{array}$ & $\begin{array}{r}.1814^{\star * \star} \\
(.0359)\end{array}$ & $\begin{array}{l}.1087^{\star} \\
(.0502)\end{array}$ \\
\hline Low Polity Score & $\begin{array}{l}.0407 \\
(.0249)\end{array}$ & $\begin{array}{l}.0275 \\
(.0257)\end{array}$ & $\begin{array}{c}.0427^{\circ} \\
(.0256)\end{array}$ & $\begin{array}{l}.0291 \\
(.0265)\end{array}$ & $\begin{array}{c}.0633^{\circ} \\
(.0362)\end{array}$ \\
\hline Polity Score & $\begin{array}{c}-.0141 \\
(.0186)\end{array}$ & $\begin{array}{l}-.0107 \\
(.0189)\end{array}$ & $\begin{array}{l}-.0148 \\
(.0191)\end{array}$ & $\begin{array}{l}-.0112 \\
(.0195)\end{array}$ & $\begin{array}{l}.0042 \\
(.0294)\end{array}$ \\
\hline Defensive Allies & $\begin{array}{l}-.0522 \\
(.1602)\end{array}$ & $\begin{array}{l}-.0167 \\
(.1629)\end{array}$ & $\begin{array}{l}-.0117 \\
(.1636)\end{array}$ & $\begin{array}{l}.0276 \\
(.1665)\end{array}$ & $\begin{array}{l}.2431 \\
(.2424)\end{array}$ \\
\hline Log Peace-Years & $\begin{array}{r}-.5335^{\star \star *} \\
(.0661)\end{array}$ & $\begin{array}{r}-.5369^{\star * \star} \\
(.0685)\end{array}$ & $\begin{array}{r}-.5561^{\star * *} \\
(.0677)\end{array}$ & $\begin{array}{r}-.5609^{\star \star *} \\
(.0703)\end{array}$ & $\begin{array}{r}-.3650^{\star \star *} \\
(.0962)\end{array}$ \\
\hline Closest Contiguity & $\begin{array}{r}-.2640^{* * *} \\
(.0469)\end{array}$ & $\begin{array}{r}-.2409^{\star \star *} \\
(.0473)\end{array}$ & $\begin{array}{r}-.2497^{\star * *} \\
(.0484)\end{array}$ & $\begin{array}{r}-.2244^{\star * *} \\
(.0488)\end{array}$ & $\begin{array}{r}-.2558^{\star * *} \\
(.0741)\end{array}$ \\
\hline Constant & $\begin{array}{c}-2.3549^{* * *} \\
(.1724) \\
\end{array}$ & $\begin{array}{c}-2.4343^{* * *} \\
(.1791) \\
\end{array}$ & $\begin{array}{c}-2.4251^{* * *} \\
(.1765) \\
\end{array}$ & $\begin{array}{c}-2.5107^{\star \star *} \\
(.1838)\end{array}$ & $\begin{array}{c}-3.8931^{* * *} \\
(.2956) \\
\end{array}$ \\
\hline Observations & 15,347 & 15,347 & 15,347 & 15,347 & 15,277 \\
\hline Wald $\chi^{2}(7)$ & 207.14 & 191.07 & 212.90 & 196.61 & 56.26 \\
\hline$p$ & $<.0001$ & $<.0001$ & $<.0001$ & $<.0001$ & $<.0001$ \\
\hline Pseudo $\mathrm{R}^{2}$ & .1132 & .1071 & .1174 & .1115 & .0743 \\
\hline
\end{tabular}

${ }^{\circ} p<.10 \quad{ }^{*} p<.05{ }^{* *} p<.01{ }^{* * *} p<.001$

$\dagger p<.15$ †† $p<.25$ 
Table B-113. Logit of Non-Scriptuary Prevalence Being Target of Muslim (All)

Prevalence.

\begin{tabular}{|c|c|c|c|c|c|}
\hline Variable & Model 1 & Model 2 & Model 3 & Model 4 & Model 5 \\
\hline $\begin{array}{l}\text { Target has } \\
\text { Non-Scriptuary } \\
\text { Prevalence (binary) } \\
\end{array}$ & $\begin{array}{c}-.4598 \dagger \\
(.2981) \\
\end{array}$ & $\begin{array}{c}-.4981 \dagger \\
(.3121) \\
\end{array}$ & $\begin{array}{c}-.3295 \\
(.2985) \\
\end{array}$ & $\begin{array}{r}-.3603+\dagger \\
(.3125) \\
\end{array}$ & $\begin{array}{r}-.0127 \\
\quad(.3910) \\
\end{array}$ \\
\hline Log CINC Ratio & $\begin{array}{r}.1429^{\star * *} \\
(.0339)\end{array}$ & $\begin{array}{r}.1426^{* * *} \\
(.0349)\end{array}$ & $\begin{array}{r}.1673^{\star * \star} \\
(.0348)\end{array}$ & $\begin{array}{r}.1683^{\star \star \star} \\
(.0359)\end{array}$ & $\begin{array}{r}.1160^{*} \\
(.0497)\end{array}$ \\
\hline Low Polity Score & $\begin{array}{l}.0452^{\circ} \\
(.0259)\end{array}$ & $\begin{array}{c}.0311 \\
(.0268)\end{array}$ & $\begin{array}{c}.0451^{\circ} \\
(.0263)\end{array}$ & $\begin{array}{c}.0305 \\
(.0273)\end{array}$ & $\begin{array}{c}.0738^{*} \\
(.0363)\end{array}$ \\
\hline Polity Score & $\begin{array}{l}-.0197 \\
\quad(.0197)\end{array}$ & $\begin{array}{c}-.0162 \\
(.0201)\end{array}$ & $\begin{array}{l}-.0186 \\
(.0199)\end{array}$ & $\begin{array}{l}-.0150 \\
(.0203)\end{array}$ & $\begin{array}{l}-.0061 \\
(.0312)\end{array}$ \\
\hline Defensive Allies & $\begin{array}{l}-.1617 \\
(.1681)\end{array}$ & $\begin{array}{r}-.1314 \\
\quad(.1711)\end{array}$ & $\begin{array}{l}-.0835 \\
(.1711)\end{array}$ & $\begin{array}{l}-.0478 \\
(.1742)\end{array}$ & $\begin{array}{c}.2120 \\
(.2531)\end{array}$ \\
\hline Log Peace-Years & $\begin{array}{r}-.5279^{* \star *} \\
(.0684)\end{array}$ & $\begin{array}{r}-.5344^{* \star *} \\
(.0710)\end{array}$ & $\begin{array}{r}-.5486^{* \star *} \\
(.0700)\end{array}$ & $\begin{array}{r}-.5567^{* * *} \\
(.0728)\end{array}$ & $\begin{array}{r}-.3519^{* * *} \\
(.1012)\end{array}$ \\
\hline Closest Contiguity & $\begin{array}{r}-.2604^{* * *} \\
(.0476)\end{array}$ & $\begin{array}{r}-.2370^{\star \star *} \\
(.0482)\end{array}$ & $\begin{array}{r}-.2441^{* * *} \\
(.0491)\end{array}$ & $\begin{array}{r}-.2184^{* * *} \\
(.0497)\end{array}$ & $\begin{array}{r}-.2531^{* * *} \\
(.0748)\end{array}$ \\
\hline Constant & $\begin{array}{c}-2.2858^{* * *} \\
(.1767) \\
\end{array}$ & $\begin{array}{c}-2.3571^{* * *} \\
(.1832) \\
\end{array}$ & $\begin{array}{c}-2.3881^{* * *} \\
(.1816) \\
\end{array}$ & $\begin{array}{c}-2.4669^{* * *} \\
(.1887) \\
\end{array}$ & $\begin{array}{c}-3.8918^{* * *} \\
(.3029) \\
\end{array}$ \\
\hline Observations & 14,689 & 14,689 & 14,689 & 14,689 & 14,623 \\
\hline Wald $\chi^{2}(7)$ & 206.85 & 193.23 & 208.67 & 194.75 & 56.31 \\
\hline$p$ & $<.0001$ & $<.0001$ & $<.0001$ & $<.0001$ & $<.0001$ \\
\hline Pseudo $\mathrm{R}^{2}$ & . 1127 & . 1072 & .1160 & .1105 & .0748 \\
\hline
\end{tabular}

${ }^{\circ} p<.10 \quad{ }^{*} p<.05 \quad{ }^{* *} p<.01{ }^{* * *} p<.001$

† $p<.15$ †† $p<.25$ 
Tables for Chapter 7

Table B-114. Logit of Buddhist (Pure) Chief Executive.

\begin{tabular}{|c|c|c|c|c|c|}
\hline Variable & $\frac{\text { Model } 1}{\text { (Robust SE) }}$ & Model 2 & Model 3 & Model 4 & Model 5 \\
\hline $\begin{array}{l}\text { Buddhist (Pure) } \\
\text { Chief Exec. (binary) }\end{array}$ & $\begin{array}{l}.1108 \\
(.2351) \\
\end{array}$ & $\begin{array}{l}.1116 \\
(.2417) \\
\end{array}$ & $\begin{array}{r}-.0484 \\
(.2800) \\
\end{array}$ & $\begin{array}{r}-.0519 \\
(.2912) \\
\end{array}$ & $\begin{array}{r}-.6159 \\
(.5926) \\
\end{array}$ \\
\hline Log CINC Ratio & $\begin{array}{l}.0137 \\
(.0116)\end{array}$ & $\begin{array}{l}-.0058 \\
(.0119)\end{array}$ & $\begin{array}{l}.0413^{\star *} \\
(.0127)\end{array}$ & $\begin{array}{l}.0203 \\
(.0132)\end{array}$ & $\begin{array}{l}.0040 \\
(.0189)\end{array}$ \\
\hline Low Polity Score & $\begin{array}{l}-.0229^{\star} \\
(.0091)\end{array}$ & $\begin{array}{l}-.0201^{*} \\
(.0096)\end{array}$ & $\begin{array}{r}-.0354^{\star * *} \\
(.0103)\end{array}$ & $\begin{array}{l}-.0331^{\star *} \\
(.0110)\end{array}$ & $\begin{array}{r}-.0437^{* *} \\
(.0156)\end{array}$ \\
\hline Polity Score & $\begin{array}{c}-.0192^{* *} \\
(.0073)\end{array}$ & $\begin{array}{r}-.0271^{* * *} \\
(.0078)\end{array}$ & $\begin{array}{l}-.0181^{*} \\
(.0078)\end{array}$ & $\begin{array}{r}-.0282^{* * *} \\
(.0083)\end{array}$ & $\begin{array}{l}-.0104 \\
(.0121)\end{array}$ \\
\hline Defensive Allies & $\begin{array}{l}-.0416 \\
(.0988)\end{array}$ & $\begin{array}{l}-.0026 \\
(.1023)\end{array}$ & $\begin{array}{l}-.1047 \\
(.1061)\end{array}$ & $\begin{array}{l}-.0642 \\
(.1104)\end{array}$ & $\begin{array}{l}-.2062 \\
(.1864)\end{array}$ \\
\hline Log Peace-Years & $\begin{array}{r}-.6660^{* * *} \\
(.0349)\end{array}$ & $\begin{array}{r}-.6781^{* * *} \\
(.0365)\end{array}$ & $\begin{array}{r}-.6664^{* * *} \\
(.0383)\end{array}$ & $\begin{array}{r}-.6797^{* * *} \\
(.0404)\end{array}$ & $\begin{array}{r}-.6103^{* * *} \\
(.0600)\end{array}$ \\
\hline Closest Contiguity & $\begin{array}{r}-.3088^{\star \star *} \\
(.0200)\end{array}$ & $\begin{array}{r}-.2944^{\star \star *} \\
(.0207)\end{array}$ & $\begin{array}{r}-.3378^{\star \star *} \\
(.0222)\end{array}$ & $\begin{array}{r}-.3222^{\star \star \star} \\
(.0232)\end{array}$ & $\begin{array}{r}-.2729^{\star \star \star} \\
(.0357)\end{array}$ \\
\hline Constant & $\begin{array}{c}-1.9570^{\star \star *} \\
(.0914) \\
\end{array}$ & $\begin{array}{c}-2.0200^{\star \star \star} \\
(.0940) \\
\end{array}$ & $\begin{array}{c}-2.0072^{\star \star \star} \\
(.0957) \\
\end{array}$ & $\begin{array}{c}-2.0694^{\star \star \star} \\
(.0985) \\
\end{array}$ & $\begin{array}{c}-3.2870^{* \star *} \\
(.1573) \\
\end{array}$ \\
\hline Observations & 88,083 & 88,083 & 88,083 & 88,083 & 87,873 \\
\hline Wald $\chi^{2}(7)$ & 1016.71 & 1017.29 & 924.96 & 920.83 & 295.59 \\
\hline$p$ & $<.0001$ & $<.0001$ & $<.0001$ & $<.0001$ & $<.0001$ \\
\hline Pseudo $\mathrm{R}^{2}$ & .1297 & .1292 & .1381 & .1377 & .0923 \\
\hline
\end{tabular}

${ }^{\circ} \mathrm{p}<.10{ }^{*} \mathrm{p}<.05{ }^{* *} \mathrm{p}<.01{ }^{* \star *} \mathrm{p}<.001$ 
Table B-115. Logit of Buddhist (Pure) Preference.

\begin{tabular}{|c|c|c|c|c|c|}
\hline Variable & Model 1 & Model 2 & Model 3 & Model 4 & Model 5 \\
\hline & & & & & \\
\hline $\begin{array}{l}\text { Buddhist (Pure) } \\
\text { Preference (binary) }\end{array}$ & $\begin{array}{c}.0430 \\
(.2273) \\
\end{array}$ & $\begin{array}{c}.1061 \\
(.2283) \\
\end{array}$ & $\begin{array}{c}.0329 \\
(.2535) \\
\end{array}$ & $\begin{array}{r}.1166 \\
(.2549) \\
\end{array}$ & $\begin{array}{r}-.4730 \\
(.5154) \\
\end{array}$ \\
\hline Log CINC Ratio & $\begin{array}{l}.0234^{*} \\
(.0116)\end{array}$ & $\begin{array}{l}.0055 \\
(.0118)\end{array}$ & $\begin{array}{r}.0514^{\star \star *} \\
(.0127)\end{array}$ & $\begin{array}{l}.0325^{\star} \\
(.0130)\end{array}$ & $\begin{array}{l}.0093 \\
(.0186)\end{array}$ \\
\hline Low Polity Score & $\begin{array}{r}-.0251^{\star *} \\
(.0092)\end{array}$ & $\begin{array}{l}-.0221^{*} \\
(.0097)\end{array}$ & $\begin{array}{r}-.0378^{\star * *} \\
(.0104)\end{array}$ & $\begin{array}{r}-.0352^{\star *} \\
(.0110)\end{array}$ & $\begin{array}{r}-.0477^{\star *} \\
(.0154)\end{array}$ \\
\hline Polity Score & $\begin{array}{r}-.0226^{\star *} \\
(.0075)\end{array}$ & $\begin{array}{r}-.0307^{* * *} \\
(.0080)\end{array}$ & $\begin{array}{r}-.0216^{\star *} \\
(.0079)\end{array}$ & $\begin{array}{r}-.0318^{\star * *} \\
(.0085)\end{array}$ & $\begin{array}{l}-.0135 \\
(.0121)\end{array}$ \\
\hline Defensive Allies & $\begin{array}{l}-.0475 \\
(.0985)\end{array}$ & $\begin{array}{l}-.0067 \\
(.1020)\end{array}$ & $\begin{array}{l}-.1045 \\
(.1057)\end{array}$ & $\begin{array}{l}-.0611 \\
(.1101)\end{array}$ & $\begin{array}{l}-.2249 \\
(.1837)\end{array}$ \\
\hline Log Peace-Years & $\begin{array}{r}-.6482^{* * *} \\
(.0348)\end{array}$ & $\begin{array}{r}-.6630^{\star * *} \\
(.0363)\end{array}$ & $\begin{array}{r}-.6492^{* * *} \\
(.0381)\end{array}$ & $\begin{array}{r}-.6658^{\star * *} \\
(.0402)\end{array}$ & $\begin{array}{r}-.5848^{* * *} \\
(.0596)\end{array}$ \\
\hline Closest Contiguity & $\begin{array}{r}-.3143^{* * *} \\
(.0199)\end{array}$ & $\begin{array}{r}-.2991^{* * *} \\
(.0205)\end{array}$ & $\begin{array}{r}-.3413^{* * *} \\
(.0221)\end{array}$ & $\begin{array}{r}-.3246^{\star * *} \\
(.0231)\end{array}$ & $\begin{array}{r}-.2780^{* * *} \\
(.0348)\end{array}$ \\
\hline Constant & $\begin{array}{c}-1.9846^{* * *} \\
(.0912) \\
\end{array}$ & $\begin{array}{c}-2.0467^{\star * *} \\
(.0940) \\
\end{array}$ & $\begin{array}{c}-2.0424^{\star * *} \\
(.0952) \\
\end{array}$ & $\begin{array}{c}-2.1048^{* * *} \\
(.0982) \\
\end{array}$ & $\begin{array}{c}-3.2920^{* * *} \\
(.1548) \\
\end{array}$ \\
\hline Observations & 93,210 & 93,210 & 93,210 & 93,210 & 93,007 \\
\hline Wald $\chi^{2}(7)$ & 1026.24 & 1028.62 & 939.12 & 936.36 & 303.52 \\
\hline$p$ & $<.0001$ & $<.0001$ & $<.0001$ & $<.0001$ & $<.0001$ \\
\hline${\text { Pseudo } \mathrm{R}^{2}}^{2}$ & .1281 & .1280 & .1367 & .1369 & .0907 \\
\hline
\end{tabular}

${ }^{\circ} \mathrm{p}<.10{ }^{*} \mathrm{p}<.05{ }^{* *} \mathrm{p}<.01{ }^{* \star *} \mathrm{p}<.001$ 
Table B-116. Logit of Buddhist (Pure) GRP Scale.

\begin{tabular}{|c|c|c|c|c|c|}
\hline Variable & Model 1 & Model 2 & Model 3 & Model 4 & Model 5 \\
\hline & (Robust SE) & & & & \\
\hline $\begin{array}{l}\text { Buddhist (Pure) } \\
\text { GRP (every 10\%) }\end{array}$ & $\begin{array}{l}.0074 \\
(.0431) \\
\end{array}$ & $\begin{array}{l}.0071 \\
(.0442) \\
\end{array}$ & $\begin{array}{r}.0183 \\
(.0467) \\
\end{array}$ & $\begin{array}{r}.0196 \\
(.0481) \\
\end{array}$ & $\begin{array}{r}-.0394 \\
(.0861)\end{array}$ \\
\hline Log CINC Ratio & $\begin{array}{l}.0216^{\circ} \\
(.0117)\end{array}$ & $\begin{array}{l}.0044 \\
(.0120)\end{array}$ & $\begin{array}{r}.0488^{\star \star \star} \\
(.0129)\end{array}$ & $\begin{array}{l}.0308^{*} \\
(.0133)\end{array}$ & $\begin{array}{l}.0098 \\
(.0186)\end{array}$ \\
\hline Low Polity Score & $\begin{array}{r}-.0245^{\star *} \\
(.0092)\end{array}$ & $\begin{array}{l}-.0210^{*} \\
(.0097)\end{array}$ & $\begin{array}{r}-.0371^{* \star *} \\
(.0104)\end{array}$ & $\begin{array}{r}-.0338^{\star *} \\
(.0110)\end{array}$ & $\begin{array}{r}-.0476^{\star *} \\
(.0154)\end{array}$ \\
\hline Polity Score & $\begin{array}{r}-.0227^{\star *} \\
(.0075)\end{array}$ & $\begin{array}{r}-.0312^{\star * \star} \\
(.0081)\end{array}$ & $\begin{array}{r}-.0217^{\star *} \\
(.0080)\end{array}$ & $\begin{array}{r}-.0325^{\star * \star} \\
(.0086)\end{array}$ & $\begin{array}{l}-.0143 \\
(.0122)\end{array}$ \\
\hline Defensive Allies & $\begin{array}{l}-.0173 \\
(.0989)\end{array}$ & $\begin{array}{l}.0221 \\
(.1023)\end{array}$ & $\begin{aligned}-.0792 \\
(.1060)\end{aligned}$ & $\begin{aligned}-.0381 \\
(.1102)\end{aligned}$ & $\begin{array}{l}-.2032 \\
(.1841)\end{array}$ \\
\hline Log Peace-Years & $\begin{array}{r}-.6455^{\star * *} \\
(.0351)\end{array}$ & $\begin{array}{r}-.6619^{* * *} \\
(.0367)\end{array}$ & $\begin{array}{r}-.6442^{* * *} \\
(.0383)\end{array}$ & $\begin{array}{r}-.6625^{\star * *} \\
(.0405)\end{array}$ & $\begin{array}{r}-.5825^{\star * *} \\
(.0599)\end{array}$ \\
\hline Closest Contiguity & $\begin{array}{r}-.3092^{* * *} \\
(.0201)\end{array}$ & $\begin{array}{r}-.2951^{* * *} \\
(.0207)\end{array}$ & $\begin{array}{r}-.3381^{* * *} \\
(.0222)\end{array}$ & $\begin{array}{r}-.3232^{* * *} \\
(.0232)\end{array}$ & $\begin{array}{r}-.2739^{* * *} \\
(.0351)\end{array}$ \\
\hline Constant & $\begin{array}{c}-2.0111^{\star \star *} \\
(.0922) \\
\end{array}$ & $\begin{array}{c}-2.0664^{\star * *} \\
(.0949) \\
\end{array}$ & $\begin{array}{c}-2.0631^{\star * *} \\
(.0959) \\
\end{array}$ & $\begin{array}{c}-2.1168^{\star * *} \\
(.0986) \\
\end{array}$ & $\begin{array}{c}-3.3067^{\star * *} \\
(.1559) \\
\end{array}$ \\
\hline Observations & 92,277 & 92,277 & 92,277 & 92,277 & 92,077 \\
\hline Wald $\chi^{2}(7)$ & 1005.18 & 1009.71 & 924.15 & 923.60 & 300.93 \\
\hline$p$ & $<.0001$ & $<.0001$ & $<.0001$ & $<.0001$ & $<.0001$ \\
\hline Pseudo $\mathrm{R}^{2}$ & .1256 & .1261 & .1344 & .1354 & .0895 \\
\hline
\end{tabular}

${ }^{\circ} \mathrm{p}<.10{ }^{*} \mathrm{p}<.05{ }^{* *} \mathrm{p}<.01{ }^{* \star *} \mathrm{p}<.001$ 
Table B-117. Logit of Buddhist (Pure) Prevalence.

\begin{tabular}{|c|c|c|c|c|c|}
\hline Variable & Model 1 & Model 2 & Model 3 & Model 4 & Model 5 \\
\hline $\begin{array}{l}\text { Buddhist (Pure) } \\
\text { Prevalence (binary) }\end{array}$ & $\begin{array}{r}.4871^{* *} \\
(.1814) \\
\end{array}$ & $\begin{array}{c}.4790^{\star} \\
(.1872) \\
\end{array}$ & $\begin{array}{r}.4766^{*} \\
(.1998) \\
\end{array}$ & $\begin{array}{r}.4728^{\star} \\
(.2077) \\
\end{array}$ & $\begin{array}{l}.1188 \\
(.3717) \\
\end{array}$ \\
\hline Log CINC Ratio & $\begin{array}{l}.0264^{*} \\
(.0116)\end{array}$ & $\begin{array}{l}.0093 \\
(.0118)\end{array}$ & $\begin{array}{r}.0536^{\star \star *} \\
(.0126)\end{array}$ & $\begin{array}{l}.0360^{\star *} \\
(.0130)\end{array}$ & $\begin{array}{l}.0097 \\
(.0185)\end{array}$ \\
\hline Low Polity Score & $\begin{array}{r}-.0265^{\star *} \\
(.0093)\end{array}$ & $\begin{array}{l}-.0230^{\star} \\
(.0098)\end{array}$ & $\begin{array}{r}-.0375^{\star * *} \\
(.0104)\end{array}$ & $\begin{array}{r}-.0340^{* *} \\
(.0111)\end{array}$ & $\begin{array}{r}-.0455^{\star *} \\
(.0154)\end{array}$ \\
\hline Polity Score & $\begin{array}{l}-.0212^{* *} \\
(.0075)\end{array}$ & $\begin{array}{r}-.0298^{\star * *} \\
(.0080)\end{array}$ & $\begin{array}{r}-.0211^{\star *} \\
(.0079)\end{array}$ & $\begin{array}{r}-.0320^{\star * *} \\
(.0086)\end{array}$ & $\begin{array}{l}-.0134 \\
(.0121)\end{array}$ \\
\hline Defensive Allies & $\begin{array}{l}-.0227 \\
(.0978)\end{array}$ & $\begin{array}{l}.0174 \\
(.1013)\end{array}$ & $\begin{array}{l}-.0934 \\
(.1047)\end{array}$ & $\begin{array}{l}-.0521 \\
(.1089)\end{array}$ & $\begin{array}{l}-.2310 \\
(.1824)\end{array}$ \\
\hline Log Peace-Years & $\begin{array}{r}-.6473^{\star * *} \\
(.0344)\end{array}$ & $\begin{array}{r}-.6612^{* \star *} \\
(.0359)\end{array}$ & $\begin{array}{r}-.6462^{\star * *} \\
(.0374)\end{array}$ & $\begin{array}{r}-.6613^{\star * *} \\
(.0395)\end{array}$ & $\begin{array}{r}-.5768^{* * *} \\
(.0586)\end{array}$ \\
\hline Closest Contiguity & $\begin{array}{r}-.3154^{* * *} \\
(.0200)\end{array}$ & $\begin{array}{r}-.3018^{* * *} \\
(.0207)\end{array}$ & $\begin{array}{r}-.3440^{* \star *} \\
(.0221)\end{array}$ & $\begin{array}{r}-.3298^{* * *} \\
(.0231)\end{array}$ & $\begin{array}{r}-.2822^{* * *} \\
(.0350)\end{array}$ \\
\hline Constant & $\begin{array}{c}-2.0144^{\star \star *} \\
(.0911) \\
\end{array}$ & $\begin{array}{c}-2.0723^{* * *} \\
(.0939) \\
\end{array}$ & $\begin{array}{c}-2.0581^{* * *} \\
(.0944) \\
\end{array}$ & $\begin{array}{c}-2.1145^{\star * *} \\
(.0973) \\
\end{array}$ & $\begin{array}{c}-3.3089^{* * *} \\
(.1530)\end{array}$ \\
\hline Observations & 93,777 & 93,777 & 93,777 & 93,777 & 93,566 \\
\hline Wald $\chi^{2}(7)$ & 1034.17 & 1034.42 & 957.14 & 953.67 & 311.69 \\
\hline $\mathrm{p}$ & $<.0001$ & $<.0001$ & $<.0001$ & $<.0001$ & $<.0001$ \\
\hline Pseudo $R^{2}$ & .1306 & .1306 & .1393 & .1397 & .0909 \\
\hline
\end{tabular}

${ }^{\circ} p<.10{ }^{*} p<.05 \quad{ }^{* *} p<.01{ }^{* * *} p<.001$ 
Table B-118. Logit of Buddhist (Pure) Population.

\begin{tabular}{|c|c|c|c|c|c|}
\hline Variable & Model 1 & Model 2 & Model 3 & Model 4 & Model 5 \\
\hline $\begin{array}{l}\text { Buddhist (Pure) } \\
\text { Pop. (every 10\%) }\end{array}$ & $\begin{array}{c}.0518^{\star *} \\
(.0196)\end{array}$ & $\begin{array}{r}.0541^{* *} \\
(.0199) \\
\end{array}$ & $\begin{array}{r}.0487^{\star} \\
(.0220) \\
\end{array}$ & $\begin{array}{c}.0521^{*} \\
(.0224) \\
\end{array}$ & $\begin{array}{l}.0013 \\
(.0435) \\
\end{array}$ \\
\hline Log CINC Ratio & $\begin{array}{l}.0265^{\star} \\
(.0114)\end{array}$ & $\begin{array}{l}.0086 \\
(.0116)\end{array}$ & $\begin{array}{r}.0535^{\star \star \star} \\
(.0125)\end{array}$ & $\begin{array}{l}.0345^{\star *} \\
(.0129)\end{array}$ & $\begin{array}{l}.0110 \\
(.0185)\end{array}$ \\
\hline Low Polity Score & $\begin{array}{c}-.0263^{* *} \\
(.0092)\end{array}$ & $\begin{array}{l}-.0233^{*} \\
(.0096)\end{array}$ & $\begin{array}{r}-.0388^{\star * *} \\
(.0103)\end{array}$ & $\begin{array}{r}-.0362^{\star * *} \\
(.0110)\end{array}$ & $\begin{array}{r}-.0467^{\star *} \\
(.0153)\end{array}$ \\
\hline Polity Score & $\begin{array}{c}-.0221^{* *} \\
(.0073)\end{array}$ & $\begin{array}{r}-.0302^{\star * *} \\
(.0078)\end{array}$ & $\begin{array}{c}-.0214^{\star *} \\
(.0078)\end{array}$ & $\begin{array}{r}-.0317^{\star * *} \\
(.0084)\end{array}$ & $\begin{array}{l}-.0140 \\
(.0120)\end{array}$ \\
\hline Defensive Allies & $\begin{array}{l}-.0259 \\
(.0974)\end{array}$ & $\begin{array}{l}.0136 \\
(.1008)\end{array}$ & $\begin{array}{l}-.0876 \\
(.1044)\end{array}$ & $\begin{array}{l}-.0460 \\
(.1086)\end{array}$ & $\begin{array}{l}-.2156 \\
(.1823)\end{array}$ \\
\hline Log Peace-Years & $\begin{array}{r}-.6528^{* * *} \\
(.0339)\end{array}$ & $\begin{array}{r}-.6666^{* \star *} \\
(.0353)\end{array}$ & $\begin{array}{r}-.6515^{\star \star * *} \\
(.0370)\end{array}$ & $\begin{array}{r}-.6668^{\star * *} \\
(.0389)\end{array}$ & $\begin{array}{r}-.5768^{\star \star *} \\
(.0580)\end{array}$ \\
\hline Closest Contiguity & $\begin{array}{r}-.3123^{* * *} \\
(.0196)\end{array}$ & $\begin{array}{r}-.2979^{* * *} \\
(.0202)\end{array}$ & $\begin{array}{r}-.3406^{* * *} \\
(.0217)\end{array}$ & $\begin{array}{r}-.3249^{* * *} \\
(.0227)\end{array}$ & $\begin{array}{r}-.2769^{* * *} \\
(.0346)\end{array}$ \\
\hline Constant & $\begin{array}{c}-2.0019^{\star \star *} \\
(.0899) \\
\end{array}$ & $\begin{array}{c}-2.0616^{* * *} \\
(.0926) \\
\end{array}$ & $\begin{array}{c}-2.0516^{* * *} \\
(.0939) \\
\end{array}$ & $\begin{array}{c}-2.1109^{* * *} \\
(.0967) \\
\end{array}$ & $\begin{array}{c}-3.3243^{* * *} \\
(.1533) \\
\end{array}$ \\
\hline Observations & 95,418 & 95,418 & 95,418 & 95,418 & 95,197 \\
\hline Wald $\chi^{2}(7)$ & 1068.46 & 1072.22 & 975.19 & 974.47 & 312.11 \\
\hline $\mathrm{p}$ & $<.0001$ & $<.0001$ & $<.0001$ & $<.0001$ & $<.0001$ \\
\hline Pseudo $R^{2}$ & .1307 & .1305 & .1392 & .1394 & .0895 \\
\hline
\end{tabular}

${ }^{\circ} p<.10{ }^{*} p<.05{ }^{* *} p<.01{ }^{* * *} p<.001$ 
Table B-119. Logit of Asia-Pacific Dyad.

\begin{tabular}{|c|c|c|c|c|c|}
\hline Variable & Model 1 & Model 2 & Model 3 & Model 4 & Model 5 \\
\hline $\begin{array}{l}\text { Asia-Pacific } \\
\text { Dyad (binary) }\end{array}$ & $\begin{array}{r}.5922^{* * *} \\
(.1004) \\
\end{array}$ & $\begin{array}{r}.6194^{* * *} \\
(.1043) \\
\end{array}$ & $\begin{array}{r}.5186^{\star * *} \\
(.1092) \\
\end{array}$ & $\begin{array}{r}.5512^{* * *} \\
(.1142) \\
\end{array}$ & $\begin{array}{c}.2856 \dagger \\
(.1861) \\
\end{array}$ \\
\hline Log CINC Ratio & $\begin{array}{l}.0205^{\circ} \\
(.0110)\end{array}$ & $\begin{array}{l}.0023 \\
(.0112)\end{array}$ & $\begin{array}{r}.0473^{\star \star \star} \\
(.0120)\end{array}$ & $\begin{array}{l}.0278^{*} \\
(.0124)\end{array}$ & $\begin{array}{l}.0106 \\
(.0178)\end{array}$ \\
\hline Low Polity Score & $\begin{array}{c}-.0245^{\star *} \\
(.0092)\end{array}$ & $\begin{array}{l}-.0212^{*} \\
(.0097)\end{array}$ & $\begin{array}{r}-.0375^{* * *} \\
(.0104)\end{array}$ & $\begin{array}{c}-.0346^{* *} \\
(.0111)\end{array}$ & $\begin{array}{c}-.0459^{* *} \\
(.0155)\end{array}$ \\
\hline Polity Score & $\begin{array}{c}-.0210^{\star *} \\
(.0073)\end{array}$ & $\begin{array}{r}-.0294^{\star * *} \\
(.0078)\end{array}$ & $\begin{array}{r}-.0201^{\star *} \\
(.0078)\end{array}$ & $\begin{array}{r}-.0306^{\star \star *} \\
(.0084)\end{array}$ & $\begin{array}{l}-.0133 \\
(.0120)\end{array}$ \\
\hline Defensive Allies & $\begin{array}{l}.0855 \\
(.1012)\end{array}$ & $\begin{array}{c}.1309 \\
(.1049)\end{array}$ & $\begin{array}{l}.0089 \\
(.1080)\end{array}$ & $\begin{array}{l}.0570 \\
(.1126)\end{array}$ & $\begin{array}{l}-.1529 \\
(.1855)\end{array}$ \\
\hline Log Peace-Years & $\begin{array}{r}-.6449^{* * *} \\
(.0338)\end{array}$ & $\begin{array}{r}-.6582^{* * *} \\
(.0352)\end{array}$ & $\begin{array}{r}-.6444^{* * *} \\
(.0368)\end{array}$ & $\begin{array}{r}-.6589^{* * *} \\
(.0388)\end{array}$ & $\begin{array}{r}-.5712^{* * *} \\
(.0578)\end{array}$ \\
\hline Closest Contiguity & $\begin{array}{r}-.2997^{\star * *} \\
(.0202)\end{array}$ & $\begin{array}{r}-.2846^{\star \star *} \\
(.0208)\end{array}$ & $\begin{array}{r}-.3295^{\star \star *} \\
(.0222)\end{array}$ & $\begin{array}{r}-.3133^{\star * *} \\
(.0232)\end{array}$ & $\begin{array}{r}-.2693^{\star * *} \\
(.0352)\end{array}$ \\
\hline Constant & $\begin{array}{c}-2.1783^{* * *} \\
(.0986) \\
\end{array}$ & $\begin{array}{c}-2.2460^{* * *} \\
(.1019) \\
\end{array}$ & $\begin{array}{c}-2.2042^{* * *} \\
(.1024) \\
\end{array}$ & $\begin{array}{c}-2.2723^{* * *} \\
(.1060) \\
\end{array}$ & $\begin{array}{c}-3.4252^{* * *} \\
(.1599) \\
\end{array}$ \\
\hline Observations & 95,484 & 95,484 & 95,484 & 95,484 & 95,262 \\
\hline Wald $\chi^{2}(7)$ & 1112.47 & 1114.41 & 1005.42 & 1000.94 & 313.47 \\
\hline $\mathrm{p}$ & $<.0001$ & $<.0001$ & $<.0001$ & $<.0001$ & $<.0001$ \\
\hline Pseudo R ${ }^{2}$ & .1336 & .1336 & .1413 & .1417 & .0900 \\
\hline
\end{tabular}

${ }^{\circ} p<.10{ }^{*} p<.05{ }^{* *} p<.01{ }^{* * *} p<.001$

$+p<.15$ 
Table B-120. Logit of Buddhist Mix Chief Executive, Controlled for Asia-Pacific Dyad.

\begin{tabular}{|c|c|c|c|c|c|}
\hline Variable & Model 1 & Model 2 & Model 3 & Model 4 & Model 5 \\
\hline & (Robust S & & & & \\
\hline $\begin{array}{l}\text { Buddhist Mix } \\
\text { Chief Exec. (binary) }\end{array}$ & $\begin{array}{r}-.4488^{\circ} \\
(.2304) \\
\end{array}$ & $\begin{array}{r}-.4330^{\circ} \\
(.2368) \\
\end{array}$ & $\begin{array}{r}-.6287^{*} \\
(.2799) \\
\end{array}$ & $\begin{array}{r}-.6205^{\star} \\
(.2914) \\
\end{array}$ & $\begin{array}{r}-1.0845^{\circ} \\
(.5874) \\
\end{array}$ \\
\hline Log CINC Ratio & $\begin{array}{l}.0095 \\
(.0112)\end{array}$ & $\begin{array}{l}-.0099 \\
(.0115)\end{array}$ & $\begin{array}{l}.0366^{\star *} \\
(.0123)\end{array}$ & $\begin{array}{l}.0156 \\
(.0127)\end{array}$ & $\begin{array}{l}.0025 \\
(.0184)\end{array}$ \\
\hline Low Polity Score & $\begin{array}{l}-.0211^{*} \\
(.0092)\end{array}$ & $\begin{array}{r}-.0180^{\circ} \\
(.0097)\end{array}$ & $\begin{array}{r}-.0342^{\star \star *} \\
(.0104)\end{array}$ & $\begin{array}{l}-.0317^{* *} \\
(.0111)\end{array}$ & $\begin{array}{r}-.0430^{* *} \\
(.0157)\end{array}$ \\
\hline Polity Score & $\begin{array}{l}-.0171^{*} \\
(.0073)\end{array}$ & $\begin{array}{c}-.0254^{\star *} \\
(.0078)\end{array}$ & $\begin{array}{l}-.0155^{\star} \\
(.0077)\end{array}$ & $\begin{array}{r}-.0259^{\star *} \\
(.0083)\end{array}$ & $\begin{array}{l}-.0084 \\
(.0120)\end{array}$ \\
\hline Defensive Allies & $\begin{array}{l}.0926 \\
(.1032)\end{array}$ & $\begin{array}{l}.1405 \\
(.1072)\end{array}$ & $\begin{array}{l}.0177 \\
(.1103)\end{array}$ & $\begin{array}{l}.0691 \\
(.1152)\end{array}$ & $\begin{array}{l}-.1367 \\
(.1901)\end{array}$ \\
\hline Log Peace-Years & $\begin{array}{r}-.6585^{\star * *} \\
(.0349)\end{array}$ & $\begin{array}{r}-.6700^{\star * *} \\
(.0364)\end{array}$ & $\begin{array}{r}-.6596^{* * *} \\
(.0382)\end{array}$ & $\begin{array}{r}-.6722^{* * *} \\
(.0403)\end{array}$ & $\begin{array}{r}-.6049^{* * *} \\
(.0598)\end{array}$ \\
\hline Closest Contiguity & $\begin{array}{r}-.2922^{\star * *} \\
(.0206)\end{array}$ & $\begin{array}{r}-.2768^{\star \star *} \\
(.0213)\end{array}$ & $\begin{array}{r}-.3223^{* * *} \\
(.0227)\end{array}$ & $\begin{array}{r}-.3058^{\star \star \star} \\
(.0238)\end{array}$ & $\begin{array}{r}-.2624^{\star \star *} \\
(.0362)\end{array}$ \\
\hline $\begin{array}{l}\text { Asia-Pacific Dyad } \\
\text { (binary) }\end{array}$ & $\begin{array}{r}.6343^{\star \star \star} \\
(.1046)\end{array}$ & $\begin{array}{r}.6619^{\star \star \star} \\
(.1087)\end{array}$ & $\begin{array}{r}.5781^{\star \star \star} \\
(.1138)\end{array}$ & $\begin{array}{r}.6128^{\star \star \star} \\
(.1193)\end{array}$ & $\begin{array}{l}.3727 \\
(.1930)\end{array}$ \\
\hline Constant & $\begin{array}{c}-2.1709^{\star \star \star} \\
(.1019) \\
\end{array}$ & $\begin{array}{c}-2.2451^{* * *} \\
(.1053) \\
\end{array}$ & $\begin{array}{c}-2.2020^{* \star *} \\
(.1062) \\
\end{array}$ & $\begin{array}{c}-2.2778^{\star * \star} \\
(.1099) \\
\end{array}$ & $\begin{array}{c}-3.4089^{* \star *} \\
(.1668) \\
\end{array}$ \\
\hline Observations & 88,083 & 88,083 & 88,083 & 88,083 & 87,873 \\
\hline Wald $\chi^{2}(8)$ & 1071.80 & 1069.14 & 963.89 & 953.92 & 296.83 \\
\hline$p$ & $<.0001$ & $<.0001$ & $<.0001$ & $<.0001$ & $<.0001$ \\
\hline Pseudo $\mathrm{R}^{2}$ & .1340 & .1338 & .1418 & .1418 & .0941 \\
\hline
\end{tabular}

${ }^{\circ} p<.10{ }^{*} p<.05 \quad{ }^{* *} p<.01{ }^{* * *} p<.001$ 
Table B-121. Logit of Buddhist Mix Preference, Controlled for Asia-Pacific Dyad.

\begin{tabular}{|c|c|c|c|c|c|}
\hline Variable & Model 1 & Model 2 & Model 3 & Model 4 & Model 5 \\
\hline & (Robust SE) & & & & \\
\hline $\begin{array}{l}\text { Buddhist Mix } \\
\text { Preference (binary) }\end{array}$ & $\begin{array}{r}-.1375 \\
(.1852)\end{array}$ & $\begin{array}{r}-.1064 \\
(.1884)\end{array}$ & $\begin{array}{r}-.2429 \\
(.2166) \\
\end{array}$ & $\begin{array}{r}-.2065 \\
(.2217) \\
\end{array}$ & $\begin{array}{r}-.7134^{\circ} \\
(.4277) \\
\end{array}$ \\
\hline Log CINC Ratio & $\begin{array}{l}.0197^{\circ} \\
(.0112)\end{array}$ & $\begin{array}{l}.0017 \\
(.0114)\end{array}$ & $\begin{array}{r}.0462^{* * *} \\
(.0122)\end{array}$ & $\begin{array}{l}.0269^{*} \\
(.0126)\end{array}$ & $\begin{array}{l}.0063 \\
(.0179)\end{array}$ \\
\hline Low Polity Score & $\begin{aligned}-.0234^{*} \\
(.0093)\end{aligned}$ & $\begin{array}{l}-.0201^{*} \\
(.0098)\end{array}$ & $\begin{array}{r}-.0366^{\star * *} \\
(.0105)\end{array}$ & $\begin{array}{r}-.0338^{\star *} \\
(.0111)\end{array}$ & $\begin{aligned}-.0470^{* *} \\
(.0155)\end{aligned}$ \\
\hline Polity Score & $\begin{array}{r}-.0211^{* *} \\
(.0075)\end{array}$ & $\begin{array}{r}-.0295^{\star * *} \\
(.0080)\end{array}$ & $\begin{array}{l}-.0196^{*} \\
(.0079)\end{array}$ & $\begin{array}{r}-.0301^{* * *} \\
(.0085)\end{array}$ & $\begin{array}{l}-.0118 \\
(.0120)\end{array}$ \\
\hline Defensive Allies & $\begin{array}{l}.0823 \\
(.1025)\end{array}$ & $\begin{array}{l}.1300 \\
(.1064)\end{array}$ & $\begin{array}{l}.0100 \\
(.1096)\end{array}$ & $\begin{array}{l}.0614 \\
(.1143)\end{array}$ & $\begin{array}{l}-.1523 \\
(.1866)\end{array}$ \\
\hline Log Peace-Years & $\begin{array}{r}-.6415^{\star * *} \\
(.0347)\end{array}$ & $\begin{array}{r}-.6559^{* * *} \\
(.0362)\end{array}$ & $\begin{array}{r}-.6434^{* * *} \\
(.0380)\end{array}$ & $\begin{array}{r}-.6594^{* * *} \\
(.0401)\end{array}$ & $\begin{array}{r}-.5810^{* * *} \\
(.0595)\end{array}$ \\
\hline Closest Contiguity & $\begin{aligned}-.2991^{* * *} & (.0205)\end{aligned}$ & $\begin{array}{r}-.2834^{* * *} \\
(.0212)\end{array}$ & $\begin{array}{r}-.3274^{* * *} \\
(.0226)\end{array}$ & $\begin{array}{r}-.3104^{* * *} \\
(.0236)\end{array}$ & $\begin{array}{r}-.2669^{* * *} \\
(.0352)\end{array}$ \\
\hline $\begin{array}{l}\text { Asia-Pacific Dyad } \\
\text { (binary) }\end{array}$ & $\begin{array}{r}.6003^{* * *} \\
(.1082)\end{array}$ & $\begin{array}{l}.6277^{* * *} \\
(.1123)\end{array}$ & $\begin{array}{l}.5536^{* * *} \\
(.1181)\end{array}$ & $\begin{array}{r}.5884^{* * *} \\
(.1235)\end{array}$ & $\begin{aligned} .4126^{*} \\
(.1927)\end{aligned}$ \\
\hline Constant & $\begin{array}{c}-2.1838^{\star * *} \\
(.1010) \\
\end{array}$ & $\begin{array}{c}-2.2545^{\star \star *} \\
(.1044) \\
\end{array}$ & $\begin{array}{c}-2.2191^{\star * *} \\
(.1050) \\
\end{array}$ & $\begin{array}{c}-2.2915^{\star * *} \\
(.1086) \\
\end{array}$ & $\begin{array}{c}-3.4130^{\star * *} \\
(.1619) \\
\end{array}$ \\
\hline Observations & 93,210 & 93,210 & 93,210 & 93,210 & 93,007 \\
\hline Wald $\chi^{2}(8)$ & 1078.07 & 1083.39 & 975.54 & 971.97 & 304.61 \\
\hline$p$ & $<.0001$ & $<.0001$ & $<.0001$ & $<.0001$ & $<.0001$ \\
\hline Pseudo $\mathrm{R}^{2}$ & .1318 & .1320 & .1396 & .1402 & .0921 \\
\hline
\end{tabular}

${ }^{\circ} \mathrm{p}<.10 \quad{ }^{*} \mathrm{p}<.05 \quad{ }^{* *} \mathrm{p}<.01{ }^{* * *} \mathrm{p}<.001$ 
Table B-122. Logit of Buddhist Mix GRP Scale, Controlled for Asia-Pacific Dyad.

\begin{tabular}{|c|c|c|c|c|c|}
\hline Variable & Model 1 & Model 2 & Model 3 & Model 4 & Model 5 \\
\hline & (Robust S & & & & \\
\hline $\begin{array}{l}\text { Buddhist Mix } \\
\text { GRP (every 10\%) }\end{array}$ & $\begin{array}{r}-.0211 \\
(.0361) \\
\end{array}$ & $\begin{array}{r}-.0201 \\
(.0367)\end{array}$ & $\begin{array}{r}-.0325 \\
(.0436) \\
\end{array}$ & $\begin{array}{r}-.0316 \\
(.0448) \\
\end{array}$ & $\begin{array}{r}-.0837 \\
(.0772) \\
\end{array}$ \\
\hline Log CINC Ratio & $\begin{array}{l}.0184 \\
(.0113)\end{array}$ & $\begin{array}{l}.0012 \\
(.0115)\end{array}$ & $\begin{array}{r}.0448^{* * *} \\
(.0124)\end{array}$ & $\begin{array}{l}.0266^{*} \\
(.0127)\end{array}$ & $\begin{array}{l}.0095 \\
(.0180)\end{array}$ \\
\hline Low Polity Score & $\begin{array}{l}-.0229^{*} \\
(.0093)\end{array}$ & $\begin{array}{l}-.0191^{\circ} \\
(.0098)\end{array}$ & $\begin{array}{r}-.0359^{* * *} \\
(.0104)\end{array}$ & $\begin{array}{r}-.0324^{\star *} \\
(.0112)\end{array}$ & $\begin{array}{r}-.0464^{\star *} \\
(.0156)\end{array}$ \\
\hline Polity Score & $\begin{array}{r}-.0214^{\star *} \\
(.0075)\end{array}$ & $\begin{array}{r}-.0301^{\star * \star} \\
(.0081)\end{array}$ & $\begin{array}{l}-.0204^{*} \\
(.0080)\end{array}$ & $\begin{array}{r}-.0312^{\star \star \star} \\
(.0087)\end{array}$ & $\begin{array}{l}-.0142 \\
(.0122)\end{array}$ \\
\hline Defensive Allies & $\begin{array}{l}.1114 \\
(.1032)\end{array}$ & $\begin{array}{l}.1570 \\
(.1070)\end{array}$ & $\begin{array}{l}.0325 \\
(.1102)\end{array}$ & $\begin{array}{l}.0808 \\
(.1148)\end{array}$ & $\begin{array}{l}-.1342 \\
\quad(.1874)\end{array}$ \\
\hline Log Peace-Years & $\begin{array}{r}-.6390^{* * *} \\
(.0350)\end{array}$ & $\begin{array}{r}-.6551^{\star * *} \\
(.0366)\end{array}$ & $\begin{array}{r}-.6380^{* * *} \\
(.0382)\end{array}$ & $\begin{array}{r}-.6559^{* * *} \\
(.0404)\end{array}$ & $\begin{array}{r}-.5771^{* * *} \\
(.0596)\end{array}$ \\
\hline Closest Contiguity & $\begin{array}{r}-.2944^{* * *} \\
(.0207)\end{array}$ & $\begin{array}{r}-.2796^{\star * *} \\
(.0214)\end{array}$ & $\begin{array}{r}-.3246^{\star \star *} \\
(.0228)\end{array}$ & $\begin{array}{r}-.3092^{* * *} \\
(.0238)\end{array}$ & $\begin{array}{r}-.2629^{* * *} \\
(.0355)\end{array}$ \\
\hline $\begin{array}{l}\text { Asia-Pacific Dyad } \\
\text { (binary) }\end{array}$ & $\begin{array}{r}.5964^{* * *} \\
(.1105)\end{array}$ & $\begin{array}{r}.6163^{* * *} \\
(.1147)\end{array}$ & $\begin{array}{r}.5463^{* * *} \\
(.1204)\end{array}$ & $\begin{array}{r}.5714^{\star * *} \\
(.1261)\end{array}$ & $\begin{array}{l}.4121^{*} \\
(.1982)\end{array}$ \\
\hline Constant & $\begin{array}{c}-2.2065^{\star * *} \\
(.1018) \\
\end{array}$ & $\begin{array}{c}-2.2694^{\star \star *} \\
(.1051) \\
\end{array}$ & $\begin{array}{c}-2.2333^{\star \star *} \\
(.1054) \\
\end{array}$ & $\begin{array}{c}-2.2958^{\star * *} \\
(.1088) \\
\end{array}$ & $\begin{array}{c}-3.4177^{\star * *} \\
(.1627) \\
\end{array}$ \\
\hline Observations & 92,277 & 92,277 & 92,277 & 92,277 & 92,077 \\
\hline Wald $\chi^{2}(8)$ & 1054.09 & 1055.53 & 957.83 & 951.63 & 302.03 \\
\hline$p$ & $<.0001$ & $<.0001$ & $<.0001$ & $<.0001$ & $<.0001$ \\
\hline Pseudo $\mathrm{R}^{2}$ & .1293 & .1300 & .1373 & .1385 & .0907 \\
\hline
\end{tabular}

${ }^{\circ} \mathrm{p}<.10 \quad{ }^{*} \mathrm{p}<.05 \quad{ }^{* *} \mathrm{p}<.01{ }^{* * *} \mathrm{p}<.001$ 
Table B-123. Logit of Buddhist Mix Prevalence, Controlled for Asia-Pacific Dyad.

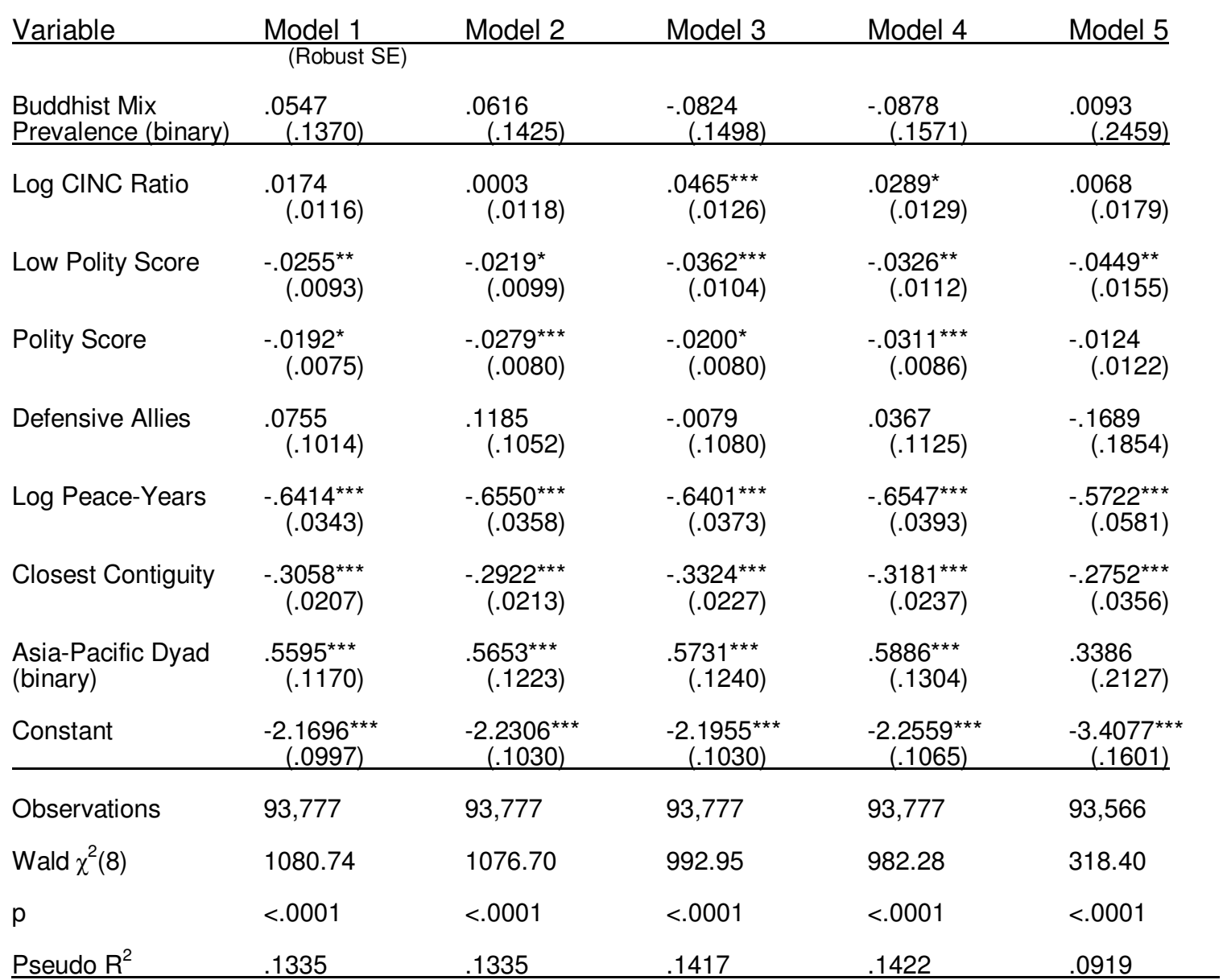

${ }^{\circ} \mathrm{p}<.10 \quad{ }^{*} \mathrm{p}<.05 \quad{ }^{* *} \mathrm{p}<.01{ }^{* * *} \mathrm{p}<.001$ 
Table B-124. Logit of Buddhist Mix Population, Controlled for Asia-Pacific Dyad.

\begin{tabular}{|c|c|c|c|c|c|}
\hline Variable & Model 1 & Model 2 & Model 3 & Model 4 & Model 5 \\
\hline $\begin{array}{l}\text { Buddhist Mix } \\
\text { Pop. (every 10\%) }\end{array}$ & $\begin{array}{c}-.0046 \\
(.0154) \\
\end{array}$ & $\begin{array}{c}-.0035 \\
(.0159) \\
\end{array}$ & $\begin{array}{c}-.0173 \\
(.0169) \\
\end{array}$ & $\begin{array}{c}-.0171 \\
(.0176) \\
\end{array}$ & $\begin{array}{l}-.0058 \\
(.0284) \\
\end{array}$ \\
\hline Log CINC Ratio & $\begin{array}{l}.0210^{\circ} \\
(.0113)\end{array}$ & $\begin{array}{l}.0027 \\
(.0115)\end{array}$ & $\begin{array}{r}.0497^{* * *} \\
(.0124)\end{array}$ & $\begin{array}{l}.0302^{*} \\
(.0127)\end{array}$ & $\begin{array}{l}.0113 \\
(.0177)\end{array}$ \\
\hline Low Polity Score & $\begin{array}{c}-.0244^{\star *} \\
(.0093)\end{array}$ & $\begin{array}{l}-.0211^{*} \\
(.0098)\end{array}$ & $\begin{array}{r}-.0369^{* \star *} \\
(.0104)\end{array}$ & $\begin{array}{r}-.0340^{\star *} \\
(.0111)\end{array}$ & $\begin{array}{c}-.0457^{* *} \\
(.0155)\end{array}$ \\
\hline Polity Score & $\begin{array}{c}-.0216^{\star *} \\
(.0074)\end{array}$ & $\begin{array}{r}-.0299^{\star * *} \\
(.0079)\end{array}$ & $\begin{array}{c}-.0216^{* *} \\
(.0079)\end{array}$ & $\begin{array}{r}-.0321^{* * *} \\
(.0085)\end{array}$ & $\begin{array}{r}-.0140 \\
(.0121)\end{array}$ \\
\hline Defensive Allies & $\begin{array}{l}.0802 \\
(.1013)\end{array}$ & $\begin{array}{l}.1259 \\
(.1051)\end{array}$ & $\begin{array}{l}-.0018 \\
(.1080)\end{array}$ & $\begin{array}{c}.0461 \\
(.1126)\end{array}$ & $\begin{array}{c}-.1583 \\
(.1858)\end{array}$ \\
\hline Log Peace-Years & $\begin{array}{r}-.6462^{\star * \star} \\
(.0338)\end{array}$ & $\begin{array}{r}-.6596^{* \star *} \\
(.0352)\end{array}$ & $\begin{array}{r}-.6451^{* * *} \\
(.0369)\end{array}$ & $\begin{array}{r}-.6597^{* * *} \\
(.0388)\end{array}$ & $\begin{array}{r}-.5725^{* * *} \\
(.0576)\end{array}$ \\
\hline Closest Contiguity & $\begin{array}{r}-.2995^{\star \star *} \\
(.0203)\end{array}$ & $\begin{array}{r}-.2846^{\star * *} \\
(.0209)\end{array}$ & $\begin{array}{r}-.3273^{\star \star *} \\
(.0224)\end{array}$ & $\begin{array}{r}-.3112^{\star * *} \\
(.0233)\end{array}$ & $\begin{array}{r}-.2688^{\star \star *} \\
(.0354)\end{array}$ \\
\hline $\begin{array}{l}\text { Asia-Pacific Dyad } \\
\text { (binary) }\end{array}$ & $\begin{array}{r}.6038^{\star * *} \\
(.1134)\end{array}$ & $\begin{array}{r}.6270^{\star * *} \\
(.1179)\end{array}$ & $\begin{array}{r}.5766^{\star \star \star} \\
(.1214)\end{array}$ & $\begin{array}{r}.6087^{* * *} \\
(.1270)\end{array}$ & $\begin{array}{l}.3019 \\
(.2114)\end{array}$ \\
\hline Constant & $\begin{array}{c}-2.1661^{* * *} \\
(.0989) \\
\end{array}$ & $\begin{array}{c}-2.2340^{* * *} \\
(.1024) \\
\end{array}$ & $\begin{array}{c}-2.1870^{* * *} \\
(.1025) \\
\end{array}$ & $\begin{array}{c}-2.2551^{* * *} \\
(.1063) \\
\end{array}$ & $\begin{array}{c}-3.4132^{* * *} \\
(.1611)\end{array}$ \\
\hline Observations & 95,418 & 95,418 & 95,418 & 95,418 & 95,197 \\
\hline Wald $\chi^{2}(8)$ & 1113.97 & 1114.99 & 1005.36 & 998.54 & 315.81 \\
\hline$p$ & $<.0001$ & $<.0001$ & $<.0001$ & $<.0001$ & $<.0001$ \\
\hline Pseudo $\mathrm{R}^{2}$ & .1339 & .1340 & .1417 & .1422 & .0902 \\
\hline
\end{tabular}

${ }^{\circ} \mathrm{p}<.10 \quad{ }^{*} \mathrm{p}<.05 \quad{ }^{* *} \mathrm{p}<.01{ }^{* * *} \mathrm{p}<.001$ 
Table B-125. Logit of Buddhist Mix Chief Executive, Within Asia-Pacific Region.

\begin{tabular}{|c|c|c|c|c|c|}
\hline Variable & Model 1 & Model 2 & Model 3 & Model 4 & Model 5 \\
\hline & (Robust SE) & & & & \\
\hline $\begin{array}{l}\text { Buddhist Mix } \\
\text { Chief Exec. (binary) }\end{array}$ & $\begin{array}{r}-.2395 \\
(.2463) \\
\end{array}$ & $\begin{aligned}-.2266 \\
(.2526) \\
\end{aligned}$ & $\begin{array}{r}-.4676 \dagger \\
(.2926) \\
\end{array}$ & $\begin{array}{r}-.4683 \dagger \\
(.3036) \\
\end{array}$ & $\begin{array}{r}-.8708 \dagger \\
(.6042) \\
\end{array}$ \\
\hline Log CINC Ratio & $\begin{array}{l}.0268 \\
(.0216)\end{array}$ & $\begin{array}{l}.0132 \\
(.0226)\end{array}$ & $\begin{array}{l}.0325 \\
(.0238)\end{array}$ & $\begin{array}{l}.0164 \\
(.0252)\end{array}$ & $\begin{array}{l}.0082 \\
(.0388)\end{array}$ \\
\hline Low Polity Score & $\begin{array}{l}.0064 \\
(.0259)\end{array}$ & $\begin{array}{l}.0102 \\
(.0267)\end{array}$ & $\begin{array}{l}.0012 \\
(.0293)\end{array}$ & $\begin{array}{l}.0055 \\
(.0304)\end{array}$ & $\begin{array}{l}.0198 \\
(.0491)\end{array}$ \\
\hline Polity Score & $\begin{aligned}-.0288^{\circ} \\
(.0167)\end{aligned}$ & $\begin{array}{l}-.0330^{\circ} \\
(.0173)\end{array}$ & $\begin{aligned}-.0303^{\circ} \\
(.0183)\end{aligned}$ & $\begin{aligned}-.0357^{\circ} \\
(.0192)\end{aligned}$ & $\begin{array}{l}-.0353 \\
(.0328)\end{array}$ \\
\hline Defensive Allies & $\begin{array}{l}-.1953 \\
\quad(.5984)\end{array}$ & $\begin{array}{l}-.1013 \\
\quad(.5990)\end{array}$ & $\begin{array}{r}-.0857 \\
(.6045)\end{array}$ & $\begin{array}{l}.0197 \\
(.6058)\end{array}$ & see note \\
\hline Log Peace-Years & $\begin{array}{r}-.7329^{\star * *} \\
(.0756)\end{array}$ & $\begin{array}{r}-.7393^{\star \star \star} \\
(.0766)\end{array}$ & $\begin{array}{r}-.7171^{* * *} \\
(.0838)\end{array}$ & $\begin{array}{r}-.7239^{* * *} \\
(.0852)\end{array}$ & $\begin{array}{r}-.7465^{\star * *} \\
(.1400)\end{array}$ \\
\hline Closest Contiguity & $\begin{aligned}-.2110^{* * *} \\
(.0396)\end{aligned}$ & $\begin{aligned}-.1965^{* * *} \\
(.0410)\end{aligned}$ & $\begin{array}{r}-.2307^{* * *} \\
(.0448)\end{array}$ & $\begin{aligned}-.2145^{\star * *} & (.0469)\end{aligned}$ & $\begin{aligned}-.2166^{* *} & (.0823)\end{aligned}$ \\
\hline Constant & $\begin{array}{c}-1.6794^{\star * *} \\
(.1742) \\
\end{array}$ & $\begin{array}{c}-1.7655^{\star \star *} \\
(.1751) \\
\end{array}$ & $\begin{array}{c}-1.7979 * \star * \\
(.1917) \\
\end{array}$ & $\begin{array}{c}-1.8923^{\star * *} \\
(.1929) \\
\end{array}$ & $\begin{array}{c}-3.0033^{\star * *} \\
(.3671) \\
\end{array}$ \\
\hline Observations & 7731 & 7731 & 7731 & 7731 & 7448 \\
\hline Wald $\chi^{2}(7)$ & 161.59 & 162.22 & 131.40 & 132.84 & 40.32 [6 dof] \\
\hline$p$ & $<.0001$ & $<.0001$ & $<.0001$ & $<.0001$ & $<.0001$ \\
\hline Pseudo $R^{2}$ & .1134 & .1101 & .1142 & .1105 & .0999 \\
\hline
\end{tabular}

${ }^{\circ} p<.10{ }^{*} p<.05 \quad{ }^{* *} p<.01{ }^{* * *} p<.001$

$\dagger p<.15$

Note: In Model 5, the variable defenseallies=1 predicts failure perfectly, so the variable is omitted. 
Table B-126. Logit of Buddhist Mix Preference, Within Asia-Pacific Region.

\begin{tabular}{|c|c|c|c|c|c|}
\hline Variable & Model 1 & Model 2 & Model 3 & Model 4 & Model 5 \\
\hline $\begin{array}{l}\text { Buddhist Mix } \\
\text { Preference (binary) }\end{array}$ & $\begin{array}{l}.0770 \\
(.2097) \\
\end{array}$ & $\begin{array}{c}.1132 \\
(.2131) \\
\end{array}$ & $\begin{array}{r}-.1170 \\
(.2388) \\
\end{array}$ & $\begin{array}{c}-.0826 \\
(.2435) \\
\end{array}$ & $\begin{array}{l}-.4997 \\
(.4659)\end{array}$ \\
\hline Log CINC Ratio & $\begin{array}{l}.0462^{\star} \\
(.0216)\end{array}$ & $\begin{array}{l}.0347 \\
(.0225)\end{array}$ & $\begin{array}{l}.0454^{\circ} \\
(.0239)\end{array}$ & $\begin{array}{l}.0316 \\
(.0251)\end{array}$ & $\begin{array}{l}.0149 \\
(.0368)\end{array}$ \\
\hline Low Polity Score & $\begin{array}{l}.0189 \\
(.0266)\end{array}$ & $\begin{array}{l}.0218 \\
(.0274)\end{array}$ & $\begin{array}{l}.0146 \\
(.0297)\end{array}$ & $\begin{array}{l}.0178 \\
(.0308)\end{array}$ & $\begin{array}{l}.0271 \\
(.0506)\end{array}$ \\
\hline Polity Score & $\begin{array}{c}-.0380^{\star} \\
(.0185)\end{array}$ & $\begin{array}{l}-.0421^{*} \\
(.0191)\end{array}$ & $\begin{array}{l}-.0401^{*} \\
(.0203)\end{array}$ & $\begin{array}{l}-.0455^{\star} \\
(.0210)\end{array}$ & $\begin{array}{l}-.0468 \\
(.0357)\end{array}$ \\
\hline Defensive Allies & $\begin{array}{l}-.1728 \\
(.6025)\end{array}$ & $\begin{array}{l}-.0738 \\
(.6033)\end{array}$ & $\begin{array}{l}-.0723 \\
(.6076)\end{array}$ & $\begin{array}{l}.0382 \\
(.6090)\end{array}$ & see note \\
\hline Log Peace-Years & $\begin{array}{r}-.7087^{* * *} \\
(.0773)\end{array}$ & $\begin{array}{r}-.7201^{\star * *} \\
(.0784)\end{array}$ & $\begin{array}{r}-.7015^{\star * \star} \\
(.0862)\end{array}$ & $\begin{array}{r}-.7151^{* * *} \\
(.0879)\end{array}$ & $\begin{array}{r}-.7408^{\star \star *} \\
(.1460)\end{array}$ \\
\hline Closest Contiguity & $\begin{array}{r}-.2246^{* * *} \\
(.0415)\end{array}$ & $\begin{array}{r}-.2122^{* * *} \\
(.0431)\end{array}$ & $\begin{array}{r}-.2407^{\star * *} \\
(.0465)\end{array}$ & $\begin{array}{r}-.2269^{* * *} \\
(.0488)\end{array}$ & $\begin{array}{c}-.2517^{* *} \\
(.0844)\end{array}$ \\
\hline Constant & $\begin{array}{c}-1.7687^{* * *} \\
(.1808) \\
\end{array}$ & $\begin{array}{c}-1.8419^{* * *} \\
(.1808) \\
\end{array}$ & $\begin{array}{c}-1.8586^{* * *} \\
(.1978) \\
\end{array}$ & $\begin{array}{c}-1.9360^{* * *} \\
(.1973) \\
\end{array}$ & $\begin{array}{c}-2.8736^{\star \star *} \\
(.3705) \\
\end{array}$ \\
\hline Observations & 7791 & 7791 & 7791 & 7791 & 7503 \\
\hline Wald $\chi^{2}(7)$ & 157.41 & 158.64 & 131.41 & 133.71 & 45.81 [6 dof] \\
\hline $\mathrm{p}$ & $<.0001$ & $<.0001$ & $<.0001$ & $<.0001$ & $<.0001$ \\
\hline Pseudo $\mathrm{R}^{2}$ & .1134 & .1117 & .1136 & .1117 & .1065 \\
\hline
\end{tabular}

${ }^{\circ} \mathrm{p}<.10{ }^{*} \mathrm{p}<.05 \quad{ }^{* *} \mathrm{p}<.01{ }^{* * *} \mathrm{p}<.001$

Note: In Model 5, the variable defenseallies=1 predicts failure perfectly, so the variable is omitted. 
Table B-127. Logit of Buddhist Mix GRP Scale, Within Asia-Pacific Region.

\begin{tabular}{|c|c|c|c|c|c|}
\hline Variable & Model 1 & Model 2 & Model 3 & Model 4 & Model 5 \\
\hline & (Robust SE) & & & & \\
\hline $\begin{array}{l}\text { Buddhist Mix } \\
\text { GRP (every 10\%) }\end{array}$ & $\begin{array}{l}.0260 \\
(.0415) \\
\end{array}$ & $\begin{array}{l}.0286 \\
(.0431) \\
\end{array}$ & $\begin{array}{l}.0083 \\
(.0481) \\
\end{array}$ & $\begin{array}{l}.0101 \\
(.0505) \\
\end{array}$ & $\begin{array}{r}-.0649 \\
(.0919) \\
\end{array}$ \\
\hline Log CINC Ratio & $\begin{array}{l}.0528^{*} \\
(.0223)\end{array}$ & $\begin{array}{l}.0461^{*} \\
(.0232)\end{array}$ & $\begin{array}{l}.0559^{\star} \\
(.0244)\end{array}$ & $\begin{array}{l}.0482^{\circ} \\
(.0256)\end{array}$ & $\begin{array}{l}.0161 \\
(.0379)\end{array}$ \\
\hline Low Polity Score & $\begin{array}{l}.0200 \\
(.0271)\end{array}$ & $\begin{array}{l}.0247 \\
(.0282)\end{array}$ & $\begin{array}{l}.0150 \\
(.0304)\end{array}$ & $\begin{array}{l}.0203 \\
(.0320)\end{array}$ & $\begin{array}{l}.0240 \\
(.0509)\end{array}$ \\
\hline Polity Score & $\begin{array}{l}-.0365^{\circ} \\
(.0188)\end{array}$ & $\begin{array}{l}-.0410^{*} \\
(.0199)\end{array}$ & $\begin{array}{l}-.0407^{\star} \\
(.0207)\end{array}$ & $\begin{array}{l}-.0467^{*} \\
(.0222)\end{array}$ & $\begin{array}{l}-.0505 \\
(.0355)\end{array}$ \\
\hline Defensive Allies & $\begin{array}{l}-.1298 \\
(.6065)\end{array}$ & $\begin{array}{l}-.0302 \\
(.6081)\end{array}$ & $\begin{array}{l}-.0296 \\
(.6148)\end{array}$ & $\begin{array}{l}.0823 \\
(.6173)\end{array}$ & see note \\
\hline Log Peace-Years & $\begin{array}{r}-.7325^{\star * *} \\
(.0793)\end{array}$ & $\begin{array}{r}-.7480^{* * *} \\
(.0813)\end{array}$ & $\begin{array}{r}-.7198^{* \star *} \\
(.0875)\end{array}$ & $\begin{array}{r}-.7378^{* * *} \\
(.0902)\end{array}$ & $\begin{array}{r}-.7478^{* * *} \\
(.1444)\end{array}$ \\
\hline Closest Contiguity & $\begin{array}{r}-.2235^{\star * *} \\
(.0424)\end{array}$ & $\begin{array}{r}-.2173^{* * *} \\
(.0443)\end{array}$ & $\begin{array}{r}-.2466^{* * *} \\
(.0475)\end{array}$ & $\begin{array}{r}-.2415^{* * *} \\
(.0502)\end{array}$ & $\begin{array}{l}-.2624^{* *} \\
(.0862)\end{array}$ \\
\hline Constant & $\begin{array}{c}-1.7869^{\star \star *} \\
(.1881) \\
\end{array}$ & $\begin{array}{c}-1.8515^{\star * *} \\
(.1895) \\
\end{array}$ & $\begin{array}{c}-1.8642^{\star \star *} \\
(.2079) \\
\end{array}$ & $\begin{array}{c}-1.9291^{\star * *} \\
(.2097) \\
\end{array}$ & $\begin{array}{c}-2.7920^{* * *} \\
(.3906) \\
\end{array}$ \\
\hline Observations & 7717 & 7717 & 7717 & 7717 & 7434 \\
\hline Wald $\chi^{2}(7)$ & 157.47 & 161.01 & 135.31 & 139.71 & 46.25 [6 dof] \\
\hline$p$ & $<.0001$ & $<.0001$ & $<.0001$ & $<.0001$ & $<.0001$ \\
\hline Pseudo $\mathrm{R}^{2}$ & .1183 & .1187 & .1191 & .1201 & .1092 \\
\hline
\end{tabular}

${ }^{\circ} \mathrm{p}<.10{ }^{*} \mathrm{p}<.05 \quad{ }^{* *} \mathrm{p}<.01{ }^{* * *} \mathrm{p}<.001$

Note: In Model 5, the variable defenseallies=1 predicts failure perfectly, so the variable is omitted. 
Table B-128. Logit of Buddhist Mix Prevalence, Within Asia-Pacific Region.

\begin{tabular}{|c|c|c|c|c|c|}
\hline Variable & Model 1 & Model 2 & Model 3 & Model 4 & Model 5 \\
\hline $\begin{array}{l}\text { Buddhist Mix } \\
\text { Prevalence (binary) }\end{array}$ & $\begin{array}{l}.2220 \\
(.1776) \\
\end{array}$ & $\begin{array}{l}.2120 \\
(.1844) \\
\end{array}$ & $\begin{array}{l}.1280 \\
(.1912) \\
\end{array}$ & $\begin{array}{c}.1073 \\
(.1999) \\
\end{array}$ & $\begin{array}{l}.0089 \\
(.3403) \\
\end{array}$ \\
\hline Log CINC Ratio & $\begin{array}{l}.0334 \\
(.0226)\end{array}$ & $\begin{array}{l}.0258 \\
(.0236)\end{array}$ & $\begin{array}{l}.0397^{\circ} \\
(.0242)\end{array}$ & $\begin{array}{l}.0314 \\
(.0253)\end{array}$ & $\begin{array}{l}.0169 \\
(.0356)\end{array}$ \\
\hline Low Polity Score & $\begin{array}{l}.0007 \\
(.0288)\end{array}$ & $\begin{array}{l}.0057 \\
(.0302)\end{array}$ & $\begin{array}{l}.0099 \\
(.0310)\end{array}$ & $\begin{array}{l}.0173 \\
(.0328)\end{array}$ & $\begin{array}{l}.0294 \\
(.0508)\end{array}$ \\
\hline Polity Score & $\begin{array}{r}-.0232 \\
(.0177)\end{array}$ & $\begin{array}{l}-.0286 \\
(.0190)\end{array}$ & $\begin{array}{r}-.0318 \\
(.0201)\end{array}$ & $\begin{array}{l}-.0397^{\circ} \\
(.0220)\end{array}$ & $\begin{array}{r}-.0431 \\
(.0359)\end{array}$ \\
\hline Defensive Allies & $\begin{array}{l}-.1526 \\
(.6024)\end{array}$ & $\begin{array}{l}-.0563 \\
(.6039)\end{array}$ & $\begin{array}{l}-.0657 \\
(.6061)\end{array}$ & $\begin{array}{l}.0402 \\
(.6084)\end{array}$ & see note \\
\hline Log Peace-Years & $\begin{array}{r}-.7296^{\star * *} \\
(.0794)\end{array}$ & $\begin{array}{r}-.7397^{\star * \star} \\
(.0815)\end{array}$ & $\begin{array}{r}-.7078^{\star \star *} \\
(.0866)\end{array}$ & $\begin{array}{r}-.7181^{* * *} \\
(.0895)\end{array}$ & $\begin{array}{r}-.7300^{* * *} \\
(.1432)\end{array}$ \\
\hline Closest Contiguity & $\begin{array}{r}-.2304^{\star * *} \\
(.0434)\end{array}$ & $\begin{array}{r}-.2234^{\star * *} \\
(.0456)\end{array}$ & $\begin{array}{r}-.2499^{\star * *} \\
(.0481)\end{array}$ & $\begin{array}{r}-.2438^{\star * *} \\
(.0512)\end{array}$ & $\begin{array}{l}-.2696^{\star *} \\
(.0899)\end{array}$ \\
\hline Constant & $\begin{array}{c}-1.8196^{\star * *} \\
(.2114) \\
\end{array}$ & $\begin{array}{c}-1.8878^{* * *} \\
(.2151) \\
\end{array}$ & $\begin{array}{c}-1.8981^{* * *} \\
(.2250) \\
\end{array}$ & $\begin{array}{c}-1.9672^{* * *} \\
(.2293) \\
\end{array}$ & $\begin{array}{c}-2.9252^{* * *} \\
(.4356)\end{array}$ \\
\hline Observations & 7176 & 7176 & 7176 & 7176 & 6894 \\
\hline Wald $\chi^{2}(7)$ & 155.00 & 157.28 & 131.84 & 134.32 & 46.14 [6 dof] \\
\hline$p$ & $<.0001$ & $<.0001$ & $<.0001$ & $<.0001$ & $<.0001$ \\
\hline Pseudo $\mathrm{R}^{2}$ & .1220 & .1207 & .1191 & .1181 & .1072 \\
\hline
\end{tabular}

${ }^{\circ} \mathrm{p}<.10{ }^{*} \mathrm{p}<.05 \quad{ }^{* *} \mathrm{p}<.01{ }^{* * *} \mathrm{p}<.001$

Note: In Model 5, the variable defenseallies=1 predicts failure perfectly, so the variable is omitted. 
Table B-129. Logit of Buddhist Mix Population, Within Asia-Pacific Region.

\begin{tabular}{|c|c|c|c|c|c|}
\hline Variable & Model 1 & Model 2 & Model 3 & Model 4 & Model 5 \\
\hline & (Robust SE) & & & & \\
\hline $\begin{array}{l}\text { Buddhist Mix } \\
\text { Pop. (every 10\%) }\end{array}$ & $\begin{array}{l}.0124 \\
(.0194) \\
\end{array}$ & $\begin{array}{l}.0122 \\
(.0199) \\
\end{array}$ & $\begin{array}{l}.0056 \\
(.0215) \\
\end{array}$ & $\begin{array}{l}.0050 \\
(.0222) \\
\end{array}$ & $\begin{array}{r}-.0054 \\
(.0403)\end{array}$ \\
\hline Log CINC Ratio & $\begin{array}{l}.0348 \\
(.0215)\end{array}$ & $\begin{array}{l}.0210 \\
(.0224)\end{array}$ & $\begin{array}{l}.0446^{\circ} \\
(.0235)\end{array}$ & $\begin{array}{l}.0286 \\
(.0248)\end{array}$ & $\begin{array}{l}.0264 \\
(.0358)\end{array}$ \\
\hline Low Polity Score & $\begin{array}{l}.0049 \\
(.0264)\end{array}$ & $\begin{array}{l}.0088 \\
(.0271)\end{array}$ & $\begin{array}{l}-.0005 \\
(.0297)\end{array}$ & $\begin{array}{l}.0039 \\
(.0307)\end{array}$ & $\begin{array}{l}.0179 \\
(.0494)\end{array}$ \\
\hline Polity Score & $\begin{aligned}-.0314^{\circ} \\
(.0166)\end{aligned}$ & $\begin{array}{l}-.0358^{*} \\
(.0173)\end{array}$ & $\begin{array}{l}-.0357^{\circ} \\
(.0185)\end{array}$ & $\begin{array}{l}-.0414^{*} \\
(.0195)\end{array}$ & $\begin{array}{l}-.0453 \\
(.0333)\end{array}$ \\
\hline Defensive Allies & $\begin{array}{l}-.1519 \\
(.5972)\end{array}$ & $\begin{array}{l}-.0623 \\
(.5973)\end{array}$ & $\begin{array}{l}-.0399 \\
(.6018)\end{array}$ & $\begin{array}{l}.0621 \\
(.6022)\end{array}$ & see note \\
\hline Log Peace-Years & $\begin{array}{r}-.7443^{* * *} \\
(.0740)\end{array}$ & $\begin{array}{r}-.7511^{* * *} \\
(.0749)\end{array}$ & $\begin{array}{r}-.7284^{* * *} \\
(.0817)\end{array}$ & $\begin{array}{r}-.7357^{* * *} \\
(.0831)\end{array}$ & $\begin{array}{r}-.7244^{* * *} \\
(.1349)\end{array}$ \\
\hline Closest Contiguity & $\begin{array}{r}-.2123^{\star * *} \\
(.0397)\end{array}$ & $\begin{array}{r}-.1985^{\star * *} \\
(.0411)\end{array}$ & $\begin{array}{r}-.2342^{\star * *} \\
(.0449)\end{array}$ & $\begin{array}{r}-.2190^{\star * *} \\
(.0470)\end{array}$ & $\begin{array}{r}-.2319^{* *} \\
(.0836)\end{array}$ \\
\hline Constant & $\begin{array}{c}-1.7466^{\star \star *} \\
(.1985) \\
\end{array}$ & $\begin{array}{c}-1.8253^{\star * *} \\
(.2006) \\
\end{array}$ & $\begin{array}{c}-1.8380^{\star * *} \\
(.2189) \\
\end{array}$ & $\begin{array}{c}-1.9222^{\star * \star} \\
(.2215) \\
\end{array}$ & $\begin{array}{c}-2.9994^{\star * *} \\
(.4374) \\
\end{array}$ \\
\hline Observations & 8156 & 8156 & 8156 & 8156 & 7864 \\
\hline Wald $\chi^{2}(7)$ & 174.62 & 175.92 & 143.62 & 145.65 & 46.18 [6 dof] \\
\hline$p$ & $<.0001$ & $<.0001$ & $<.0001$ & $<.0001$ & $<.0001$ \\
\hline$\underline{\text { Pseudo } \mathrm{R}^{2}}$ & .1178 & .1147 & .1176 & .1141 & .0964 \\
\hline
\end{tabular}

${ }^{\circ} \mathrm{p}<.10{ }^{*} \mathrm{p}<.05 \quad{ }^{* *} \mathrm{p}<.01{ }^{* * *} \mathrm{p}<.001$

Note: In Model 5, the variable defenseallies=1 predicts failure perfectly, so the variable is omitted. 
Table B-130. Logit of Buddhist (Pure) Chief Executive, Within Asia-Pacific Region.

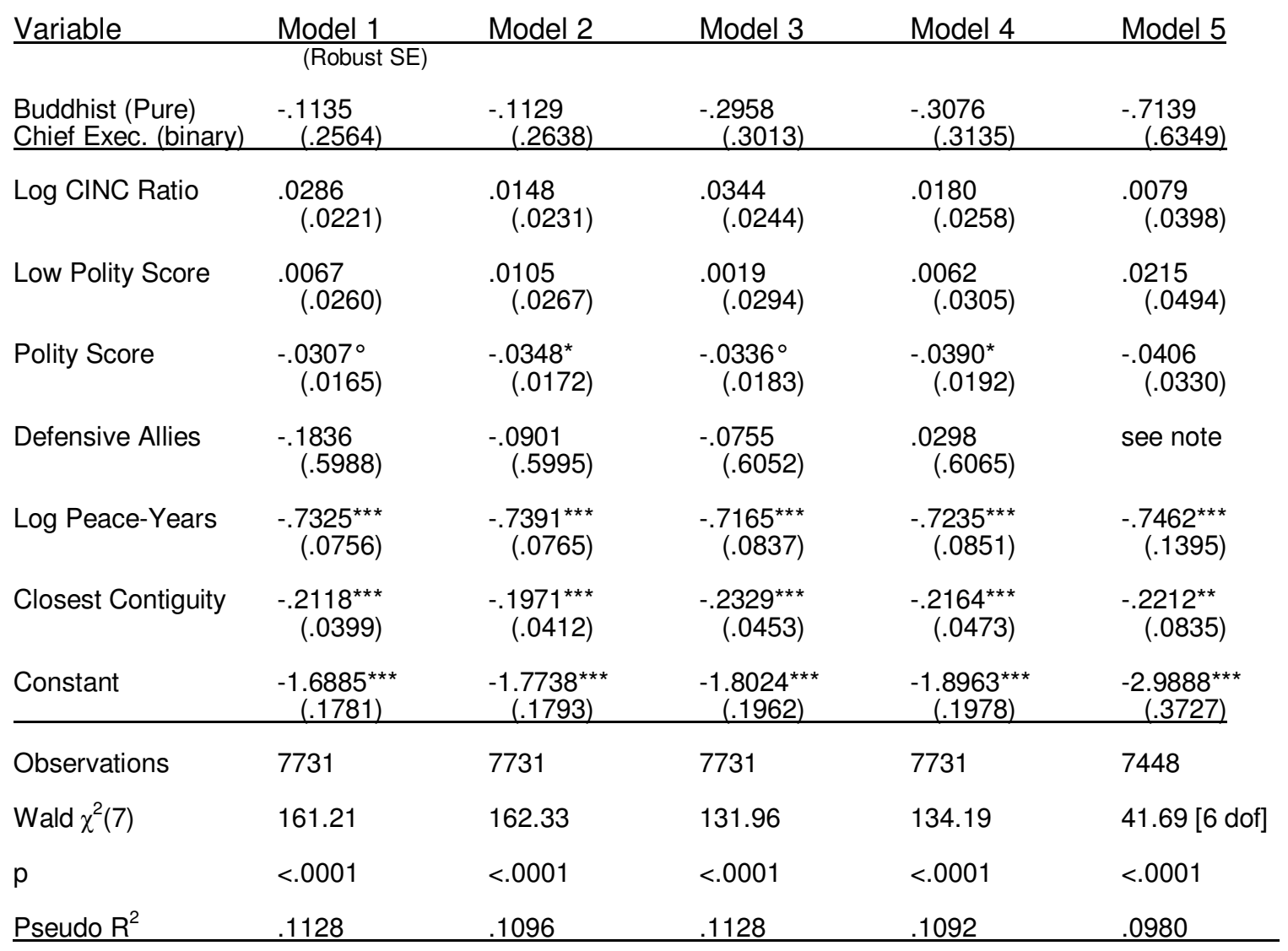

${ }^{\circ} \mathrm{p}<.10{ }^{*} \mathrm{p}<.05 \quad{ }^{* *} \mathrm{p}<.01{ }^{* \star *} \mathrm{p}<.001$

Note: In Model 5, the variable defenseallies=1 predicts failure perfectly, so the variable is omitted. 
Table B-131. Logit of Buddhist (Pure) Preference, Within Asia-Pacific Region.

\begin{tabular}{|c|c|c|c|c|c|}
\hline Variable & Model 1 & Model 2 & Model 3 & Model 4 & Model 5 \\
\hline $\begin{array}{l}\text { Buddhist (Pure) } \\
\text { Preference (binary) }\end{array}$ & $\begin{array}{r}-.2049 \\
(.2524) \\
\end{array}$ & $\begin{array}{r}-.1338 \\
(.2541) \\
\end{array}$ & $\begin{array}{r}-.2253 \\
(.2813) \\
\end{array}$ & $\begin{array}{r}-.1394 \\
(.2835) \\
\end{array}$ & $\begin{array}{r}-.6186 \\
(.5708) \\
\end{array}$ \\
\hline Log CINC Ratio & $\begin{array}{l}.0374^{\circ} \\
(.0226)\end{array}$ & $\begin{array}{l}.0267 \\
(.0234)\end{array}$ & $\begin{array}{l}.0430^{\circ} \\
(.0250)\end{array}$ & $\begin{array}{l}.0303 \\
(.0261)\end{array}$ & $\begin{array}{l}.0145 \\
(.0396)\end{array}$ \\
\hline Low Polity Score & $\begin{array}{l}.0192 \\
(.0265)\end{array}$ & $\begin{array}{l}.0220 \\
(.0273)\end{array}$ & $\begin{array}{l}.0152 \\
(.0297)\end{array}$ & $\begin{array}{l}.0182 \\
(.0308)\end{array}$ & $\begin{array}{l}.0289 \\
(.0506)\end{array}$ \\
\hline Polity Score & $\begin{array}{l}-.0371^{*} \\
(.0181)\end{array}$ & $\begin{array}{l}-.0410^{*} \\
(.0188)\end{array}$ & $\begin{array}{l}-.0410^{*} \\
(.0201)\end{array}$ & $\begin{array}{l}-.0461^{*} \\
(.0209)\end{array}$ & $\begin{array}{l}-.0502 \\
(.0355)\end{array}$ \\
\hline Defensive Allies & $\begin{array}{l}-.2296 \\
(.6016)\end{array}$ & $\begin{array}{l}-.1259 \\
(.6027)\end{array}$ & $\begin{array}{l}-.0954 \\
(.6088)\end{array}$ & $\begin{array}{l}.0249 \\
(.6107)\end{array}$ & see note \\
\hline Log Peace-Years & $\begin{array}{r}-.7074^{\star * *} \\
(.0774)\end{array}$ & $\begin{array}{r}-.7196^{\star * *} \\
(.0785)\end{array}$ & $\begin{array}{r}-.6988^{* \star *} \\
(.0860)\end{array}$ & $\begin{array}{r}-.7132^{\star \star *} \\
(.0876)\end{array}$ & $\begin{array}{r}-.7319^{\star * *} \\
(.1444)\end{array}$ \\
\hline Closest Contiguity & $\begin{array}{r}-.2302^{* * *} \\
(.0414)\end{array}$ & $\begin{array}{r}-.2161^{\star * *} \\
(.0431)\end{array}$ & $\begin{array}{r}-.2462^{* \star *} \\
(.0469)\end{array}$ & $\begin{array}{r}-.2303^{\star * *} \\
(.0493)\end{array}$ & $\begin{array}{l}-.2650^{\star *} \\
(.0870)\end{array}$ \\
\hline Constant & $\begin{array}{c}-1.7063^{\star * *} \\
(.1780) \\
\end{array}$ & $\begin{array}{c}-1.7862^{* * *} \\
(.1802) \\
\end{array}$ & $\begin{array}{c}-1.8339^{* * *} \\
(.1967) \\
\end{array}$ & $\begin{array}{c}-1.9225^{* * *} \\
(.1997) \\
\end{array}$ & $\begin{array}{c}-2.8502^{* * *} \\
(.3692) \\
\end{array}$ \\
\hline Observations & 7791 & 7791 & 7791 & 7791 & 7503 \\
\hline Wald $\chi^{2}(7)$ & 159.27 & 159.07 & 131.35 & 133.10 & 43.57 [6 dof] \\
\hline$p$ & $<.0001$ & $<.0001$ & $<.0001$ & $<.0001$ & $<.0001$ \\
\hline Pseudo $\mathrm{R}^{2}$ & .1138 & .1117 & .1140 & .1118 & - 1070 \\
\hline
\end{tabular}

${ }^{\circ} \mathrm{p}<.10{ }^{*} \mathrm{p}<.05 \quad{ }^{* *} \mathrm{p}<.01{ }^{* * *} \mathrm{p}<.001$

Note: In Model 5, the variable defenseallies=1 predicts failure perfectly, so the variable is omitted. 
Table B-132. Logit of Buddhist (Pure) GRP Scale, Within Asia-Pacific Region.

\begin{tabular}{|c|c|c|c|c|c|}
\hline Variable & Model 1 & Model 2 & Model 3 & Model 4 & Model 5 \\
\hline $\begin{array}{l}\text { Buddhist (Pure) } \\
\text { GRP (every 10\%) }\end{array}$ & $\begin{array}{r}-.0258 \\
(.0488) \\
\end{array}$ & $\begin{array}{r}-.0231 \\
(.0504) \\
\end{array}$ & $\begin{array}{r}-.0168 \\
(.0527) \\
\end{array}$ & $\begin{array}{r}-.0129 \\
(.0546) \\
\end{array}$ & $\begin{array}{c}-.0612 \\
(.0969) \\
\end{array}$ \\
\hline Log CINC Ratio & $\begin{array}{l}.0460^{*} \\
(.0232)\end{array}$ & $\begin{array}{l}.0393 \\
(.0241)\end{array}$ & $\begin{array}{l}.0525^{\star} \\
(.0254)\end{array}$ & $\begin{array}{l}.0451^{\circ} \\
(.0267)\end{array}$ & $\begin{array}{l}.0135 \\
(.0400)\end{array}$ \\
\hline Low Polity Score & $\begin{array}{l}.0208 \\
(.0271)\end{array}$ & $\begin{array}{l}.0254 \\
(.0282)\end{array}$ & $\begin{array}{l}.0154 \\
(.0304)\end{array}$ & $\begin{array}{l}.0206 \\
(.0320)\end{array}$ & $\begin{array}{l}.0245 \\
(.0510)\end{array}$ \\
\hline Polity Score & $\begin{array}{r}-.0367^{\circ} \\
(.0188)\end{array}$ & $\begin{array}{c}-.0412^{\star} \\
(.0199)\end{array}$ & $\begin{array}{c}-.0408^{*} \\
(.0207)\end{array}$ & $\begin{array}{c}-.0468^{\star} \\
(.0222)\end{array}$ & $\begin{array}{l}-.0501 \\
(.0354)\end{array}$ \\
\hline Defensive Allies & $\begin{array}{l}-.1706 \\
(.6036)\end{array}$ & $\begin{array}{l}-.0705 \\
(.6054)\end{array}$ & $\begin{array}{l}-.0508 \\
(.6105)\end{array}$ & $\begin{array}{l}.0635 \\
(.6131)\end{array}$ & see note \\
\hline Log Peace-Years & $\begin{array}{r}-.7297^{\star * *} \\
(.0799)\end{array}$ & $\begin{array}{r}-.7453^{\star \star *} \\
(.0819)\end{array}$ & $\begin{array}{r}-.7182^{\star * *} \\
(.0879)\end{array}$ & $\begin{array}{r}-.7365^{\star \star *} \\
(.0907)\end{array}$ & $\begin{array}{r}-.7451^{* * *} \\
(.1438)\end{array}$ \\
\hline Closest Contiguity & $\begin{array}{r}-.2289^{\star * *} \\
(.0420)\end{array}$ & $\begin{array}{r}-.2226^{\star * *} \\
(.0438)\end{array}$ & $\begin{array}{r}-.2494^{* * *} \\
(.0473)\end{array}$ & $\begin{array}{r}-.2440^{\star \star *} \\
(.0499)\end{array}$ & $\begin{array}{c}-.2653^{\star *} \\
(.0866)\end{array}$ \\
\hline Constant & $\begin{array}{c}-1.7208^{\star * *} \\
(.1806) \\
\end{array}$ & $\begin{array}{c}-1.7835^{\star * *} \\
(.1819) \\
\end{array}$ & $\begin{array}{c}-1.8348^{* * *} \\
(.1981) \\
\end{array}$ & $\begin{array}{c}-1.9005^{\star \star *} \\
(.1996) \\
\end{array}$ & $\begin{array}{c}-2.8246^{* * *} \\
(.3682) \\
\end{array}$ \\
\hline Observations & 7717 & 7717 & 7717 & 7717 & 7434 \\
\hline Wald $\chi^{2}(7)$ & 164.16 & 166.48 & 137.36 & 141.40 & 45.38 [6 dof] \\
\hline $\mathrm{p}$ & $<.0001$ & $<.0001$ & $<.0001$ & $<.0001$ & $<.0001$ \\
\hline Pseudo $\mathrm{R}^{2}$ & .1183 & .1186 & .1192 & .1202 & .1091 \\
\hline
\end{tabular}

${ }^{\circ} \mathrm{p}<.10{ }^{*} \mathrm{p}<.05 \quad{ }^{* *} \mathrm{p}<.01{ }^{* * *} \mathrm{p}<.001$

Note: In Model 5, the variable defenseallies=1 predicts failure perfectly, so the variable is omitted. 
Table B-133. Logit of Buddhist (Pure) Prevalence, Within Asia-Pacific Region.

\begin{tabular}{|c|c|c|c|c|c|}
\hline Variable & Model 1 & Model 2 & Model 3 & Model 4 & Model 5 \\
\hline $\begin{array}{l}\text { Buddhist (Pure) } \\
\text { Prevalence (binary) }\end{array}$ & $\begin{array}{c}.1999 \\
(.2240) \\
\end{array}$ & $\begin{array}{r}.2130 \\
(.2315) \\
\end{array}$ & $\begin{array}{l}.1672 \\
(.2451) \\
\end{array}$ & $\begin{array}{l}.1802 \\
(.2550) \\
\end{array}$ & $\begin{array}{c}.0186 \\
(.4464) \\
\end{array}$ \\
\hline Log CINC Ratio & $\begin{array}{l}.0448^{\circ} \\
(.0237)\end{array}$ & $\begin{array}{l}.0376 \\
(.0245)\end{array}$ & $\begin{array}{l}.0486^{\circ} \\
(.0258)\end{array}$ & $\begin{array}{l}.0405 \\
(.0269)\end{array}$ & $\begin{array}{l}.0178 \\
(.0397)\end{array}$ \\
\hline Low Polity Score & $\begin{array}{l}-.0009 \\
(.0291)\end{array}$ & $\begin{array}{l}.0041 \\
(.0305)\end{array}$ & $\begin{array}{l}.0088 \\
(.0313)\end{array}$ & $\begin{array}{l}.0162 \\
(.0333)\end{array}$ & $\begin{array}{l}.0293 \\
(.0512)\end{array}$ \\
\hline Polity Score & $\begin{array}{l}-.0251 \\
(.0180)\end{array}$ & $\begin{array}{l}-.0303 \\
(.0193)\end{array}$ & $\begin{array}{l}-.0328 \\
(.0203)\end{array}$ & $\begin{array}{l}-.0404^{\circ} \\
(.0222)\end{array}$ & $\begin{aligned}-.0432 \\
(.0361)\end{aligned}$ \\
\hline Defensive Allies & $\begin{array}{l}-.1505 \\
(.6015)\end{array}$ & $\begin{array}{l}-.0489 \\
(.6032)\end{array}$ & $\begin{array}{l}-.0565 \\
(.6074)\end{array}$ & $\begin{array}{l}.0562 \\
(.6100)\end{array}$ & see note \\
\hline Log Peace-Years & $\begin{array}{r}-.7326^{* * *} \\
(.0797)\end{array}$ & $\begin{array}{r}-.7428^{* * *} \\
(.0818)\end{array}$ & $\begin{array}{r}-.7100^{\star * *} \\
(.0868)\end{array}$ & $\begin{array}{r}-.7204^{* * *} \\
(.0896)\end{array}$ & $\begin{array}{r}-.7301^{* * *} \\
(.1423)\end{array}$ \\
\hline Closest Contiguity & $\begin{array}{r}-.2279^{* * *} \\
(.0433)\end{array}$ & $\begin{array}{r}-.2204^{* * *} \\
(.0454)\end{array}$ & $\begin{array}{r}-.2473^{* * *} \\
(.0481)\end{array}$ & $\begin{array}{r}-.2405^{* * *} \\
(.0511)\end{array}$ & $\begin{array}{l}-.2692^{* *} \\
(.0904)\end{array}$ \\
\hline Constant & $\begin{array}{c}-1.7460^{\star \star \star} \\
(.1881) \\
\end{array}$ & $\begin{array}{c}-1.8249^{* * *} \\
(.1914) \\
\end{array}$ & $\begin{array}{c}-1.8717^{* * *} \\
(.2020)\end{array}$ & $\begin{array}{c}-1.9579^{\star \star *} \\
(.2063) \\
\end{array}$ & $\begin{array}{c}-2.9255^{\star * *} \\
(.3891) \\
\end{array}$ \\
\hline Observations & 7176 & 7176 & 7176 & 7176 & 6894 \\
\hline Wald $\chi^{2}(7)$ & 150.85 & 152.73 & 129.28 & 131.86 & 47.68 [6 dof] \\
\hline $\mathrm{p}$ & $<.0001$ & $<.0001$ & $<.0001$ & $<.0001$ & $<.0001$ \\
\hline Pseudo $\mathrm{R}^{2}$ & .1215 & .1204 & .1191 & .1183 & .1072 \\
\hline
\end{tabular}

${ }^{\circ} \mathrm{p}<.10{ }^{*} \mathrm{p}<.05 \quad{ }^{* *} \mathrm{p}<.01{ }^{* * *} \mathrm{p}<.001$

Note: In Model 5, the variable defenseallies=1 predicts failure perfectly, so the variable is omitted. 
Table B-134. Logit of Buddhist (Pure) Population, Within Asia-Pacific Region.

\begin{tabular}{|c|c|c|c|c|c|}
\hline Variable & Model 1 & Model 2 & Model 3 & Model 4 & Model 5 \\
\hline $\begin{array}{l}\text { Buddhist (Pure) } \\
\text { Pop. (every 10\%) }\end{array}$ & $\begin{array}{l}.0158 \\
(.0247) \\
\end{array}$ & $\begin{array}{l}.0189 \\
(.0249) \\
\end{array}$ & $\begin{array}{c}.0149 \\
(.0279) \\
\end{array}$ & $\begin{array}{l}.0186 \\
(.0284) \\
\end{array}$ & $\begin{array}{l}-.0025 \\
(.0545) \\
\end{array}$ \\
\hline Log CINC Ratio & $\begin{array}{c}.0420^{\circ} \\
(.0226)\end{array}$ & $\begin{array}{l}.0293 \\
(.0234)\end{array}$ & $\begin{array}{l}.0508^{\star} \\
(.0253)\end{array}$ & $\begin{array}{l}.0360 \\
(.0264)\end{array}$ & $\begin{array}{l}.0247 \\
(.0412)\end{array}$ \\
\hline Low Polity Score & $\begin{array}{c}.0041 \\
(.0265)\end{array}$ & $\begin{array}{l}.0079 \\
(.0273)\end{array}$ & $\begin{array}{l}-.0011 \\
(.0300)\end{array}$ & $\begin{array}{l}.0031 \\
(.0312)\end{array}$ & $\begin{array}{l}.0181 \\
(.0497)\end{array}$ \\
\hline Polity Score & $\begin{array}{c}-.0322^{\circ} \\
(.0168)\end{array}$ & $\begin{array}{c}-.0363^{*} \\
(.0175)\end{array}$ & $\begin{array}{c}-.0358^{\circ} \\
(.0187)\end{array}$ & $\begin{array}{c}-.0414^{*} \\
(.0197)\end{array}$ & $\begin{array}{c}-.0448 \\
(.0335)\end{array}$ \\
\hline Defensive Allies & $\begin{array}{c}-.1428 \\
(.5973)\end{array}$ & $\begin{array}{c}-.0464 \\
(.5976)\end{array}$ & $\begin{array}{l}-.0229 \\
(.6035)\end{array}$ & $\begin{array}{l}.0876 \\
(.6043)\end{array}$ & see note \\
\hline Log Peace-Years & $\begin{array}{r}-.7457^{* * *} \\
(.0742)\end{array}$ & $\begin{array}{r}-.7529^{\star * *} \\
(.0751)\end{array}$ & $\begin{array}{r}-.7296^{\star * *} \\
(.0818)\end{array}$ & $\begin{array}{r}-.7374^{* * *} \\
(.0831)\end{array}$ & $\begin{array}{r}-.7244^{* \star *} \\
(.1342)\end{array}$ \\
\hline Closest Contiguity & $\begin{array}{r}-.2100^{\star * *} \\
(.0395)\end{array}$ & $\begin{array}{r}-.1953^{\star * *} \\
(.0408)\end{array}$ & $\begin{array}{r}-.2313^{* * *} \\
(.0448)\end{array}$ & $\begin{array}{r}-.2150^{\star * *} \\
(.0468)\end{array}$ & $\begin{array}{c}-.2317^{\star *} \\
(.0839)\end{array}$ \\
\hline Constant & $\begin{array}{c}-1.7251^{* * *} \\
(.1788) \\
\end{array}$ & $\begin{array}{c}-1.8141^{* * *} \\
(.1810) \\
\end{array}$ & $\begin{array}{c}-1.8499^{* * *} \\
(.1986) \\
\end{array}$ & $\begin{array}{c}-1.9486^{* * *} \\
(.2018) \\
\end{array}$ & $\begin{array}{c}-3.0208^{* * *} \\
(.3949) \\
\end{array}$ \\
\hline Observations & 8156 & 8156 & 8156 & 8156 & 7864 \\
\hline Wald $\chi^{2}(7)$ & 173.27 & 174.10 & 142.52 & 144.57 & 48.41 [6 dof] \\
\hline $\mathrm{p}$ & $<.0001$ & $<.0001$ & $<.0001$ & $<.0001$ & $<.0001$ \\
\hline Pseudo $\mathrm{R}^{2}$ & .1178 & .1148 & .1178 & .1144 & .0964 \\
\hline
\end{tabular}

${ }^{\circ} \mathrm{p}<.10{ }^{*} \mathrm{p}<.05 \quad{ }^{* *} \mathrm{p}<.01{ }^{* * *} \mathrm{p}<.001$

Note: In Model 5, the variable defenseallies=1 predicts failure perfectly, so the variable is omitted. 


\section{$\underline{\text { APPENDIX C }}$}

ORGANIZATION OF RELIGIOUS SCRIPTURES

\section{The Bible, in Western Christianity}

\section{$\underline{\text { Old Testament }}$}

$\underline{\text { Pentateuch }}$

Genesis (Gen)

Exodus (Ex)

Leviticus (Lev)

Numbers (Num)

Deuteronomy (Deut)

Histories

Joshua (Josh)

Judges (Judg)

Ruth (Ruth)

First Samuel (1 Sam)

Second Samuel (2 Sam)

First Kings (1 Kings)

Second Kings (2 Kings)

First Chronicles (1 Chr)

Second Chronicles (2 Chr)

Ezra (Ezra)

Nehemiah (Neh)

Tobit (Tob) [Cath. only]

Judith (Jdt) [Cath. only]

Esther (Esth)

First Maccabees (1 Macc)

[Cath. only]

Second Maccabees (2 Macc)

[Cath. only]

Poetical/Wisdom Books

Job (Job)

Psalms (Ps)
Proverbs (Prov)

Ecclesiastes (Eccl)

Song of Solomon (Song) [or, Song of Songs]

Wisdom of Solomon (Wis)

[Cath. only]

Sirach (Sir) [Cath. only; or,

Ecclesiasticus]

Major Prophets

Isaiah (Isa)

Jeremiah (Jer)

Lamentations (Lam)

Baruch (Bar) [Cath. only]

Ezekiel (Ezek)

Daniel (Dan)

Minor Prophets

Hosea (Hos)

Joel (Joel)

Amos (Am)

Obadiah $(\mathrm{Ob})$

Jonah (Jon)

Micah (Mic)

Nahum (Nah)

Habakkuk (Hab)

Zephaniah (Zeph)

Haggai (Hag)

Zechariah (Zech)

Malachi (Mal)

\section{$\underline{\text { New Testament }}$}

Gospels

Matthew (Mt)

Mark (Mk)

Luke (Lk)

John (Jn)
Act of the Apostles (Acts)

Letters/Epistles

Romans (Rom)

First Corinthians (1 Cor)

Second Corinthians (2 Cor) 
Letters/Epistles (continued)

Galatians (Gal)

Ephesians (Eph)

Philippians (Phil)

Colossians (Col)

First Thessalonians (1 Thess)

Second Thessalonians (2 Thess)

First Timothy (1 Tim)

Second Timothy (2 Tim)

Titus (Titus)
Philemon (Philem)

Hebrews (Heb)

James (Jas)

First Peter (1 Pet)

Second Peter (2 Pet)

First John (1 Jn)

Second John (2 Jn)

Third John (3 Jn)

Jude (Jude)

Revelation (Rev)

All non-canonical books in the Protestant bible are occasionally inserted between the Old and New Testaments as the Apocrypha.

\section{The Bible, in Orthodox Christianity}

\section{Old Testament}

Pentateuch

Genesis (Gen)

Exodus (Ex)

Leviticus (Lev)

Numbers (Num)

Deuteronomy (Deut)

Histories

Joshua (Josh)

Judges (Judg)

Ruth (Ruth)

First Samuel (1 Sam)

Second Samuel (2 Sam)

First Kings (1 Kings)

Second Kings (2 Kings)

First Chronicles (1 Chr)

Second Chronicles (2 Chr)

First Esdras (1 Esd)

Second Esdras (2 Esd) [or, Ezra-

Nehemiah]

Tobit (Tob)

Judith (Jdt)

Esther (Esth)

First Maccabees (1 Macc)

Second Maccabees (2 Macc)

Third Maccabees (3 Macc)
Poetical/Wisdom Books

Psalms (Ps)

Prayer of Manasseh (Pr Man)

Job (Job)

Proverbs (Prov)

Ecclesiastes (Eccl)

Song of Solomon (Song) [or, Song of Songs]

Wisdom [of Solomon] (Wis)

Sirach (Sir) [or, Ecclesiasticus]

Minor Prophets

Hosea (Hos)

Amos (Am)

Micah (Mic)

Joel (Joel)

Obadiah (Ob)

Jonah (Jon)

Nahum (Nah)

Habakkuk (Hab)

Zephaniah (Zeph)

Haggai (Hag)

Zachariah (Zach)

Malachi (Mal)

Major Prophets

Isaiah (Isa) 
Major Prophets (continued)

Jeremiah (Jer)

Baruch (Bar)

Lamentations (Lam)

Letter of Jeremiah (Let Jer)

Ezekiel (Ezek)

Daniel (Dan)

Appendix

Fourth Maccabees (4 Macc)

\section{New Testament}

Gospels

Matthew (Mt)

Mark (Mk)

Luke (Lk)

John (Jn)

Act of the Apostles (Acts)

Letters/Epistles

Romans (Rom)

First Corinthians (1 Cor)

Second Corinthians (2 Cor)

Galatians (Gal)

Ephesians (Eph)

Philippians (Phil)

Colossians (Col)

First Thessalonians (1 Thess)
Letters/Epistles (continued)

Second Thessalonians (2 Thess)

First Timothy (1 Tim)

Second Timothy (2 Tim)

Titus (Titus)

Philemon (Philem)

Hebrews (Heb)

James (Jas)

First Peter (1 Pet)

Second Peter (2 Pet)

First John (1 Jn)

Second John (2 Jn)

Third John (3 Jn)

Jude (Jude)

Revelation (Rev)

\section{The Qur'an}

The Quran is organized into 114 numbered chapters or süras. 
The Pali Canon (Pali Text Society abbrev.; sutta reference abbrev., if any)

NOTE: Abbreviation is that of the original Pali Text Society translations, followed by the conventional abbreviation for referencing specific suttas, if any.

Vinaya Pitaka (Vin) [The Basket of the Discipline]

Suttavibhanga (--; SVibh)

Khandhaka

Mahavagga (--; Mv)

Cullavagga $(--; \mathrm{Cv})$

$\underline{\text { Parivara }}$

Sutta Pitaka [The Basket of Discourses]

Dīgha Nikāya (D; DN) [The Long Discourses]

Majjhima Nikāya (M; MN) [The Middle Length Discourses]

Samyutta Nikāya (S; SN) [The Grouped Discourses]

Anguttara Nikāya (A; AN) [Numerical or Gradual Discourses]

Khuddaka Nikāya [Division of Short Books]

Khuddakapātha (Khp) [The Short Passages]

Dhammapada (Dhp) [The Path of Dhamma]

Udāna (Ud) [Exclamations]

Itivuttaka (It) [The Thus-Saids]

Suttanipāta (Sn) [The Group of Discourses]

Vimānavatthu (Vv) [Stories of the Mansions]

Petavatthu [Stories of the Hungry Ghosts]

Theragāthā (Th) [Stories of the Elder Monks]

Therīgāthā (Thī) [Stories of the Elder Nuns]

Jätaka (Ja; J) [Birth Stories]

Niddesa (Nidd) [Exposition]

Patisambhidāmagga (Pațis) [Path of Discrimination]

Apadāna (Ap) [Stories]

Buddhavamsa (Bv) [History of the Buddhas]

Cariyāpitaka (Cp) [The Basket of Conduct]

Nettippakarana (Nett) [Burmese canon only]

Petakopadesa (Peț) [Burmese only]

Milindapañha (Mil) [The Questions of Milinda; Burmese only]

Abhidhamma Pitaka [The Basket of Abhidhamma]

Dhammasangan̄ (Dhs) [Enumeration of Phenomena]

Vibhanga (Vibh) [The Book of Treatises]

Dhātu-kathā [Discussion with Reference to the Elements]

Puggalapaññiti [Description of Individuals]

Kathā-vatthu [Points of Controversy]

Yamaka [The Book of Pairs]

Patthana [The Book of Relations] 
The Taishō Tripitaka

\begin{tabular}{|c|c|c|}
\hline Volume(s) & $\underline{\text { Sutra Nos. }}$ & $\underline{\text { Sanskrit Name [English Name] }}$ \\
\hline $1-2$ & $\overline{1-151}$ & 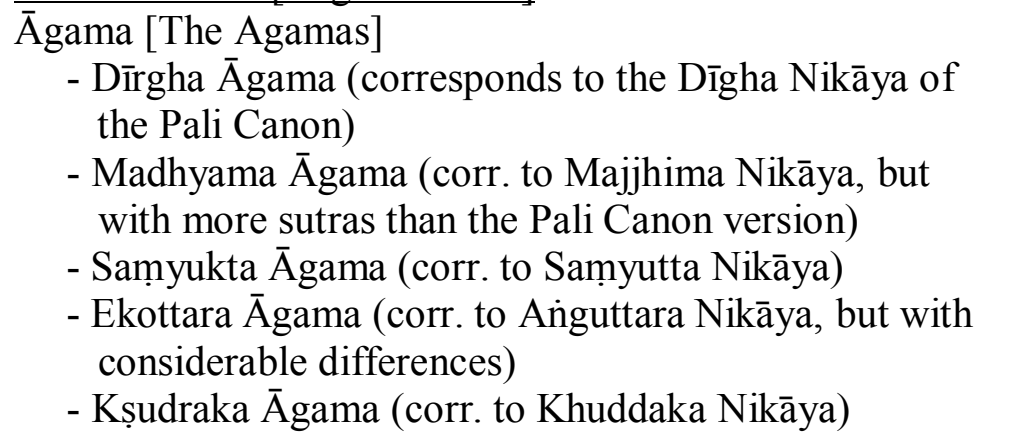 \\
\hline $3-4$ & $152-219$ & Jātaka [Birth Stories] \\
\hline $5-8$ & $220-261$ & Prajñapāramitā [Perfection of Wisdom] \\
\hline $9 \mathrm{a}$ & $262-277$ & Saddharma Punḍarika [The Lotus Sutra] \\
\hline $9 b-10$ & $278-309$ & Avatamsaka [Flower Garland] \\
\hline $11-12 \mathrm{a}$ & $310-373$ & Ratnakūṭa [Jewel Peak] \\
\hline $12 \mathrm{~b}$ & $374-396$ & Nirvāṇa [The Parinirvana] \\
\hline 13 & $397-424$ & Mahāsannipāta [The Great Collection] \\
\hline $14-17$ & $425-847$ & Sūtrasannipāta [Collected Sutras] \\
\hline $18-21$ & $848-1420$ & Tantra [Esoteric Teachings] \\
\hline $22-24$ & $1421-1504$ & Vinaya [Monastic Discipline] \\
\hline $25-26 a$ & $1505-1535$ & Sūtravyākaraṇa [Sutra Explanations] \\
\hline $26 b-29$ & $1536-1563$ & $\begin{array}{l}\text { Abhidharma [Systematic Analyses] (does not correspond to } \\
\text { the Abhidhamma Pitaka of the Pali Canon) }\end{array}$ \\
\hline $30 \mathrm{a}$ & $1564-1578$ & Mādhyamaka [Madhyamaka] \\
\hline $30 b-32$ & $1579-1627$ & Yogācāra [Yogacara] \\
\hline 32 & $1628-1692$ & Śāstra [Treatises] \\
\hline $33-39$ & $1693-1803$ & Sūtravibhāṣa [Sutra Clarifications] \\
\hline $40 \mathrm{a}$ & $1804-1815$ & Vinayavibhāṣa [Vinaya Clarifications] \\
\hline $40 b-44 a$ & $1816-1850$ & Śāstravibhāṣa [Treatise Clarifications] \\
\hline $44 b-48$ & $1851-2025$ & Sarvasamaya [Sectarian Teachings] \\
\hline Volume(s) & Sutra Nos. & Japanese Name [English Name] \\
\hline $49-52$ & $\overline{2026-2120}$ & Shiden-bu [Histories] \\
\hline $53-54 a$ & $2121-2136$ & Jii-bu [Collected Matters] \\
\hline $54 \mathrm{~b}$ & $2137-2144$ & Gekyō-bu [Non-Buddhist Teachings] \\
\hline 55 & $2145-2184$ & Mokuroku-bu [Catalogs] \\
\hline $56-83$ & $2185-2700$ & Zokukyōsho-bu [Japanese Commentaries] \\
\hline Volume(s) & $\underline{\text { Sutra Nos. }}$ & Sanskrit Name [English Name] \\
\hline 84 & $2701-2731$ & Siddham [Siddham] \\
\hline Volume(s) & $\underline{\text { Sutra Nos. }}$ & Japanese Name [English Name] \\
\hline $85 \mathrm{a}$ & $2732-2864$ & Koitsu-bu [Ancient] \\
\hline $85 b$ & $2865-2920$ & Giji-bu [Doubtful] \\
\hline
\end{tabular}




\section{BIBLIOGRAPHY}

Abou el Fadl, Khaled. 2005. The Great Theft: Wrestling Islam from the Extremists. New York: HarperOne.

Aboul-Enein, Youssef H. \& Sherifa Zuhur. 2004. Islamic Rulings on Warfare. Strategic Studies Institute monograph. Carlisle, PA: U.S. Army War College.

Abu Yusaf [Yaqub ibn Ibrahim al-Ansari]. $\left[8^{\text {th }}\right.$ c. CE] 1979. Kitab-ul-kharaj: Islamic Revenue Code. Trans. Abid Ahmad Ali. Rev. Abdul Hameed Siddiqui. Lahore: Islamic Book Centre.

Abu Zahra, Muhammad. 1961. Concept of War in Islam. Trans. Muhammad al-Hady \& Taha Omar. Cairo: Société Orientale de Publicité-Press.

Acharya, Amitav \& Barry Buzan, eds. 2009. Non-Western International Relations Theory: Perspective on and beyond Asia. New York: Routledge.

Acock, Alan C. 2008. A Gentle Introduction to Stata. $2^{\text {nd }}$ ed. College Station, TX: Stata Press.

Ajami, Fouad. 2006. The Foreigner's Gift: The Americans, the Arabs, and the Iraqis in Iraq. New York: Free Press.

Ali, Syed Ameer. [1922] 1967. The Spirit of Islam: A History of the Evolution and Ideals of Islam with a Life of the Prophet. London: Methuen \& Co., Ltd.

Allen, Douglas, ed. 1992. Religion and Political Conflict in South Asia: India, Pakistan, and Sri Lanka. Westport, CT: Greenwood Press.

Allen, Joseph J., ed. 1981. Orthodox Synthesis: The Unity of Theological Thought. Crestwood, NY: St. Vladimir's Seminary Press. 
Almond, Gabriel A. 1956. “Comparative Political Systems.” Journal of Politics 18(3): 391-409.

Almond, Gabriel A. \& Sidney Verba. 1963. The Civil Culture: Political Attitudes and Democracy in Five Nations. Princeton: Princeton University Press.

Ameer Ali, Syed. See Ali, Syed Ameer.

Angell, Norman. 1913. The Great Illusion: A Study of the Relation of Military Power to National Advantage. $4^{\text {th }}$ rev. ed. New York: G.P. Putnam's Sons.

Appleby, R. Scott. 2000. The Ambivalence of the Sacred: Religion, Violence, and Reconciliation. New York: Littlefield.

—. 2003. "Serving Two Masters? Affirming Religious Belief and Human Rights in a Pluralistic World.” In The Sacred and the Sovereign: Religion and International Politics, ed. John D. Carlson \& Eric C. Owens, 170-195. Washington: Georgetown University Press.

Aquinas, Thomas. [1274] 1952. The Summa Theologica. Trans. Fathers of the English Dominican Province. Rev. Daniel J. Sullivan. 2 Vols [Vols. 19-20 of Great Books of the Western World, ed. Robert Maynard Hutchins]. Chicago: Encyclopædia Britannica.

Arend, Anthony Clark \& Robert J. Beck. 1993. International Law and the Use of Force: Beyond the Charter Paradigm. New York: Routledge.

Art, Robert J. 1980. “To What Ends Military Power?” International Security 4(4): 3-35.

Āryaśūra, Venerable. 2010. Jātakamālā or Garland of Birth Stories. Trans. J.S. Speyer. Ed. Ānandajoti Bhikkhu. Available online at http://www.ancient-buddhist-texts.net/ English-Texts/Garland-of-Birth-Stories/index.htm. (Accessed December 29, 2011.)

Aslan, Reza. 2005. No God But God: The Origins, Evolutions, and Future of Islam. New York: Random House. 
Augustine, Bishop of Hippo. [c. 413-423 CE] 1952. The City of God [De Civitate Dei].

Trans. Marcus Dods. In Great Books of the Western World, Volume 18: Augustine, ed. Robert Maynard Hutchins, 127-618. Chicago: Encyclopædia Britannica.

—. [398 CE] 1990. Answer to Faustus, a Manichean [Contra Faustum

Manichaeum]. Trans. Roland Teske, S.J., ed. Boniface Ramsey. Hyde Park, NY: New City Press.

- 1996. The Political Writings of St. Augustine. Ed. Henry Paolucci. Washington: Regnery Publishing.

—. 2001a. Augustine: Political Writings. Ed. E.M. Atkins \& R.J. Dodaro. Cambridge: Cambridge University Press.

—. [n.d.] 2001b. “Sermon 302: On the Feast of St. Laurence.” In Augustine:

Political Writings, ed. E.M. Atkins \& R.J. Dodaro, 107-119. Cambridge: Cambridge University Press.

—. [c. $411 \mathrm{CE}$ ] 2001c. "Letter 138: Augustine to Marcellinus." In Augustine: Political Writings, ed. E.M. Atkins \& R.J. Dodaro, 30-43. Cambridge: Cambridge University Press.

Austin, William G. \& Stephen Worchel, eds. The Social Psychology of Intergroup Relations. Monterey, CA: Brooks/Cole.

Ayoob, Mohammed. 2008. The Many Faces of Political Islam: Religion and Politics in the Muslim World. Ann Arbor: University of Michigan Press.

Bacevich, Andrew J. 2002. American Empire: The Realities and Consequences of U.S. Diplomacy. Cambridge, MA: Harvard University Press.

Badr, Gamal M. 1999. “A Survey of Islamic International Law.” In Religion and International Law, ed. Mark W. Janis \& Carolyn Evans, 95-101. The Hague: Kluwer Law International. 
Bainton, Roland H. 1960. Christian Attitudes Toward War and Peace: A Historical Survey and Critical Re-evaluation. Nashville: Abingdon Press.

Baker, James A. III, with Thomas M. DeFrank. 1995. The Politics of Diplomacy: Revolution, War \& Peace, 1989-1992. New York: G. P. Putnam's Sons.

Baldwin, David A., ed. 1993. Neorealism and Neoliberalism: The Contemporary Debate. New York: Columbia University Press.

Banerjee, Sikata.1999. Warriors in Politics: Hindu Nationalism, Violence, and the Shiv Sena in India. Boulder, CO: Westview Press.

Barbieri, Katherine, Omar Keshk \& Brian Pollins. 2008. Correlates of War Project Trade Data Set Codebook, Version 2.0. Available online at http://www.correlatesofwar.org. (Accessed July 17, 2011.)

—. 2009. “Trading Data: Evaluating Our Assumptions and Coding Rules.” Conflict Management and Peace Science 26(5): 471-491.

Barilleaux, Ryan J. \& Mark J. Rozell. 2004. Power and Prudence: The Presidency of George H.W. Bush. College Station, TX: Texas A\&M University Press.

Barthomeusz, Tessa [J]. 1999. "In Defense of Dharma: Just-War Ideology in Buddhist Sri Lanka." Journal of Buddhist Ethics 6: 1-16. Reprinted in The Ethics of War in Asian Civilizations: A Comparative Perspective, ed. Torkel Brekke, 145-158 (New York: Routledge: 2006).

- 2002. In Defense of Dharma: Just-War Ideology in Buddhist Sri Lanka. New York: RoutledgeCurzon.

Beardsley, Kyle \& Victor Asal. 2009. "Winning with the Bomb." Journal of Conflict Resolution 53(2): 278-301.

Bederman, David J. 2001. International Law in Antiquity. Cambridge: Cambridge University Press. 
Bell, Daniel M., Jr. 2009. Just War as Christian Discipleship: Recentering the Tradition in the Church Rather than the State. Grand Rapids, MI: Brazos Press.

Belli, Pierino. [1563] 1936. A Treatise on Military Matters and Warfare [De Re Militari et Belli Tractatus]. Trans. Herbert C. Hutting. 2 Vols. Oxford: Clarendon Press.

Bellin, Eva. 2008. "Faith in Politics.” World Politics 60(2): 315-347.

Bennett, D. Scott \& Allan Stam. 2000. “EUGene: A Conceptual Manual.” International Interactions 26(2): 179-204.

Berger, Peter L. 1968. “A Bleak Outlook Is Seen for Religion.” New York Times, February 25: 3.

1999. "The Desecularization of the World: A Global Overview." In The Desecularization of the World: Resurgent Religion and World Politics, ed. Peter L. Berger, 1-18. Grand Rapids, MI: William B. Eerdsmans.

The Bible.

Douay-Rheims Version (DR): The Holy Bible, Douay-Rheims Version. 2009. Ed. Richard Challoner. Charlotte, NC: Saint Benedict Press. Also available online at http://www.drbo.org/index.htm. (Accessed November 15, 2011.)

Jerusalem Bible (JB): The Jerusalem Bible, Reader's Edition. 1968. Ed. Alexander Jones. Garden City, NY: Doubleday.

King James Version (KJV): The Holy Bible, Containing the Old and New Testaments: Translated out of the Original Tongues and with the Former Translations Diligently Compared \& Revised. N.d. New York: American Bible Society.

Knox translation (Knox): The Holy Bible: A Translation from the Latin Vulgate in the Light of the Hebrew and Greek Originals. 1950. Ed. Ronald Knox. New York: Sheed \& Ward. 
Living Bible (LB): The Living Bible. 1971. Carol Stream, IL: Tyndale House Publishers.

New American Bible (NAB): The New American Bible, Translated from the Original Languages with Critical Use of All Ancient Sources and the Revised New Testament. 1991. Pasadena, CA: Fireside Bible Publishers. Also available online at http://www.vatican.va/archive/ENG0839/_INDEX.HTM. (Accessed November 15, 2011).

New International Version (NIV): The Quest Study Bible, New International Version. 1997. Grand Rapids, MI: Zondervan.

New Living Translation (NLT): Holy Bible, New Living Translation. 2004. Wheaton, IL: Tyndale House Publishers.

New Revised Standard Version (NRSV): The New Oxford Annotated Bible. 2001. $3^{\text {rd }}$ ed. Ed. Michael D. Coogan. New York: Oxford University Press.

Revised Standard Version (RSV): The Old and New Testaments of The Holy Bible, Revised Standard Version. 1971. $2^{\text {nd }}$ ed. Dallas: The Melton Book Company.

Revised Standard Version-Catholic Edition (RSV-CE): The Holy Bible, Containing the Old and New Testaments, Revised Standard Version Catholic Edition. 1966. Ed. Catholic Biblical Association of Great Britain. San Francisco: Ignatius Press.

Biddle, Stephen. 1994. Military Power: Explaining Victory and Defeat in Modern Battle. Princeton: Princeton University Press.

Bin Laden, Osama. 1996. "Declaration of War Against the Americans." In Osama bin Laden: America's Enemy in His Own Words, ed. Randall B. Hamud, J.D., 32-59. San Diego: Nadeem Publishing. 1998. "Fatwa of Jihad (Holy War) Against Americans." In Osama bin Laden: America's Enemy in His Own Words, ed. Randall B. Hamud, J.D., 60-63. San Diego: Nadeem Publishing. 
Blainey, Geoffrey. 1988. The Causes of War. $3^{\text {rd }}$ ed. New York: The Free Press.

Bleiker, Roland \& Emma Hutchison. 2008. "Fear No More: Emotions and World Politics.” Review of International Studies 34(Special Issue 1): 115-135.

Bodin, Jean. [1576] 1955. Six Books of the Commonwealth. Ed. \& Trans. M.J. Tooley. New York: Macmillan.

Bonfils, Henri. 1914. Manuel de Droit International Public. $7^{\text {th }}$ ed. Ed. Paul Fauchille. Paris: Arthur Rousseau.

Bose, Meena \& Rosanna Perotti, eds. 2002. From Cold War to New World Order: The Foreign Policy of George H.W. Bush. Westport, CT: Greenwood Press

Boulding, Kenneth. 1962. Conflict and Defense: A General Theory. New York: Harper \& Row.

Bownas, G. [1959] 1997. "Shintō." In Encyclopedia of the World's Religions, ed. R.C. Zaehner, 342-356. New York: Barnes \& Noble Books.

Brahimi, Alia. 2011. Jihad and Just War in the War on Terror. New York: Oxford University Press.

Brecher, Michael \& Jonathan Wilkenfeld. 2000. A Study of Crisis. Ann Arbor: University of Michigan Press.

Brekke, Torkel, ed. 2006. The Ethics of War in Asian Civilizations: A Comparative Perspective. New York: Routledge.

Bremer, Stuart A. 1980. "National Capabilities and War Proneness." In The Correlates of War II: Testing Some Realipolitik Models, ed. J. David Singer, 57-82. New York: Free Press.

— 1992. "Dangerous Dyads: Conditions Affecting the Likelihood of Interstate War, 1816-1965." Journal of Conflict Resolution 36(2): 309-341. 
British Foreign and State Papers [BFSP]. c1815-1977. 170 Vols. London: H.M.S.O.

Brown, Davis. 2004. "Iraq and the 800-Pound Gorilla Revisited: Good and Bad Faith, and Humanitarian Intervention." Hastings International and Comparative Law Review 28(1): 1-24.

- 2008. The Sword, the Cross, and the Eagle: The American Christian Just War Tradition. Lanham, MD: Rowman \& Littlefield.

— ed. 2011. The Just War Tradition and the Continuing Challenges to World Public Order. Special Issue of Journal of Military Ethics 10(3).

Browning, Edmond L. 1991. "The Church and War." Washington Post, January 12: A21.

Brownlie, Ian. 1963. International Law and the Use of Force by States. Oxford: Clarendon Press.

—. 2001. "International Law and the Use of Force by States Revisited." Australian Yearbook of International Law 21: 21-37.

Bueno de Mesquita, Bruce. 1981. The War Trap. New Haven: Yale University Press.

Bueno de Mesquita, Bruce \& David Lalman. 1992. War and Reason: Domestic and International Imperatives. New Haven: Yale University Press.

Bueno de Mesquita, Bruce, James D. Morrow, Randolph M. Siverson \& Alastair Smith. 1999. “An Institutional Explanation of the Democratic Peace." American Political Science Review 93(4): 791-807.

—. 2004. "Testing Novel Implications from the Selectorate Theory of War." World Politics 56(3): 363-388.

al-Bukhari, Muhammad ibn Ismail. [9 ${ }^{\text {th }}$ c. CE] 1976. Sāhih al-Bukhāri: The Translations of the Meanings of Sahih al-Bukhari, Arabic-English. Trans. Muhammad Muhsin Khan. 9 Vols. Medina, Saudi Arabia: Islamic University. 
Bull, Hedley. 1977. The Anarchical Society: A Study of Order in World Politics. New York: Columbia University Press.

Burley, Anne-Marie Slaughter. See Slaughter, Anne-Marie.

Bush, George. 1999. All the Best, George Bush: My Life in Letters and Other Writings. New York: Touchstone.

Bush, George \& Brent Scowcroft. 1998. A World Transformed. New York: Vintage Books.

Bush, George W. 2010. Decision Points. New York: Crown Publishers.

Butterworth, Charles E. 1990. “Al-Fârâbî’s Statecraft : War and the Well-Ordered Regime." In Cross, Crescent and Sword: The Justification of War in Western and Islamic Tradition, ed. James Turner Johnson \& John Kelsay, 79-100. Westport, CT: Greenwood Press.

Byrnes, Timothy A. \& Peter J. Katzenstein, eds. 2006. Religion in an Expanding Europe. Cambridge: Cambridge University Press.

Cadoux, C. John. [1919] 1982. The Early Christian Attitude to War: A Contribution to the History of Christian Ethics. New York: Seabury Press.

Cady, Linell E., ed. 2006. Religion and Conflict in South and Southeast Asia: Disrupting Violence. New York: Routledge.

Cahill, Lisa Sowle. 1994. Love Your Enemies: Discipleship, Pacifism, and Just War Theory. Minneapolis: Fortress Press.

Calhoun Commission, First. 1944. "The Relation of the Church to the War in the Light of the Christian Faith.” Social Action 10(10): 3-79.

Calhoun Commission, Second. 1946. "Atomic Warfare and the Christian Faith.” Social Action, May 15: 5-24. 
Calvin, John. [1536] 1948. Institutes of the Christian Religion. Trans. John Allen. 2 Vols. Philadelphia: Presbyterian Board of Christian Education.

Caprioli, Mary \& Peter F. Trumbore. 2006. "First Use of Violent Force in Militarized Interstate Disputes, 1980-2001.” Journal of Peace Research 43(6): 741-749.

Carr, Edward Hallett. [1939] 1964. The Twenty Years' Crisis, 1919-1939: An Introduction to the Study of International Relations. New York: Harper \& Row.

Carlson, John D. \& Eric C. Owens, eds. 2003. The Sacred and the Sovereign: Religion and International Politics. Washington: Georgetown University Press.

Carter, David B. \& Curtis S. Signorino. 2010. "Back to the Future: Modeling Time Dependence in Binary Data.” Political Analysis 18(3): 271-292.

Carter, Jimmy. 1996. Living Faith. New York: Three Rivers Press.

- 1997. Sources of Strength: Meditations on Scripture for a Living Faith. New York: Times Books.

Cashman, Greg. 1993. What Causes War? An Introduction to Theories of International Conflict. Lanham, MD: Lexington Books.

Catechism of the Catholic Church. 1994. Liguori, MO: Liguori Publications. Also available online at http://www.vatican.va/archive/ENG0015/P81.HTM. (Accessed February 3, 2011.)

Cederman, Lars-Erik. 2001. "Back to Kant: Reinterpreting the Democratic Peace as a Macrohistorical Learning Process.” American Political Science Review 95(1): 15-31.

Central Intelligence Agency. 1976-1980. National Basic Intelligence Factbook. Washington: Central Intelligence Agency.

- 1981-2008. The World Factbook. Washington: Central Intelligence Agency. 
Chan, Steve. "Mirror, Mirror on the Wall . . A Are the Freer Countries More Pacific?" Journal of Conflict Resolution 28(4): 617-648.

Charles, J. Daryl. 2005. Between Pacifism and Jihad. Just War and Christian Tradition. Downers Grove, IL: InterVarsity Press.

—. 2010. "Pacifists, Patriots, or Both? Second Thoughts on Pre-Constantinian Early-Christian Attitudes toward Soldiering and War.” Logos 13(2): 17-55.

Charles, J. Daryl \& Timothy J. Demy. 2010. War, Peace, and Christianity: Questions and Answers from a Just-War Perspective. Wheaton, IL: Crossway.

Chayes, Abram \& Antonia Handler Chayes. 1995. The New Sovereignty: Compliance with International Regulatory Agreements. Cambridge, MA: Harvard University Press.

Checkel, Jeffrey T. "The Constructivist Turn in International Relations Theory." World Politics 50(2): 324-348.

Chesterman, Simon. 2001. Just War or Just Peace? Humanitarian Intervention and International Law. New York: Oxford University Press.

Childress, James F. 1982. Moral Responsibility in Conflicts: Essays on Nonviolence, War, and Conscience. Baton Rouge, LA: Louisiana State University Press. 1991. "Contemporary Pacifism: Its Major Types and Possible Contributions to Discourse About War." In The American Search for Peace: Moral Reasoning, Religious Hope, and National Security, ed. George Weigel \& John P. Langan, S.J., 109-131.Washington: Georgetown University Press.

Chiozza, Giacomo. 2002. "Is There a Clash of Civilizations? Evidence of Patterns of International Conflict Involvement, 1946-97.” Journal of Peace Research 39(6): 711734. 
Cicero, Marcus Tullius. [44 BCE] 1961. De Officiis [On Moral Duties]. Trans. Walter Miller. Cambridge, MA: Harvard University Press. 1998a. The Republic and the Laws. Trans. Niall Rudd. Ed. Jonathan Powell \& Niall Rudd. Oxford: Oxford University Press.

—. [51 BCE] 1998b. The Republic [De Re Publica]. Trans. Niall Rudd. In The Republic and the Laws, ed. Jonathan Powell \& Niall Rudd, 1-94. Oxford: Oxford University Press.

von Clauswitz, Carl. [1832] 1993. On War. Ed. \& trans. Michael Howard \& Peter Paret. New York: Alfred A. Knopf.

Coffey, J.I. \& Charles T. Mathewes, eds. 2002. Religion, Law and the Role of Force: A Study of Their Influence on Conflict and on Conflict Resolution. Ardsley, NY: Transnational Publishers.

Cole, Darrell. 1999. “Thomas Aquinas on Virtuous Warfare.” Journal of Religious Ethics 27(1): 57-80.

- 2002. When God Says War Is Right: The Christian's Perspective on When and How to Fight. Colorado Springs, CO: WaterBrook Press.

—. 2011. "War and Intention." Journal of Military Ethics 10(3): 174-191.

Collins, Steven. 1998. Nirvana and Other Buddhist Felicities: Utopias of the Pali Imaginaire. Cambridge: Cambridge University Press.

Connell, Christopher. 1990. "Episcopal Bishop Urges Bush to Eschew War." Associated Press, December 20.

The Consolidated Treaty Series [CTS]. 1969-1981. Ed. Clive Parry. 231 Vols. Dobbs Ferry, NY: Oceana Publications.

Conze, Edward. [1959] 1997. "Buddhism: The Mahāyana." In Encyclopedia of the World's Religions, ed. R.C. Zaehner, 293-317. New York: Barnes \& Noble Books. 
Cook, David. 1997. “Moral Apocalyptic in Islam.” Studia Islamica 86: 37-69.

- 2003. Studies in Muslim Apocalyptic. Princeton: Darwin Press.

— 2004. "The Implications of 'Martyrdom Operations' for Contemporary Islam. Journal of Religious Ethics 32(1): 129-151.

- 2005. Understanding Jihad. Berkeley: University of California Press.

- 2007. Martyrdom in Islam. Cambridge: Cambridge University Press.

Copeland Dale C. 1996. "Economic Interdependence and War: A Theory of Trade Expectations." International Security 20(4): 5-41.

—. 2000a. "The Constructivist Challenge to Structural Realism.” International Security 25(2): 187-212.

—. 2000b. The Origins of Major War. Ithaca, NY: Cornell University Press.

Cornell, George W. 1990. "Head of Bush's Church Urges Peaceful Gulf Solution." Associated Press, October 5.

—. 1991. "No War, Mainline Churches Plead, but Others Add Counterpoint." Associated Press, January 11.

Correlates of War Project. 2004. State System Membership List, v2004.1. Available online at http://www.correlatesofwar.org. (Accessed July 17, 2011.)

-2010. National Material Capabilities Data Documentation, Version 4.0. Available online at http://www.correlatesofwar.org. (Accessed July 16, 2011.)

Correlates of War 2 Project. 2003. Colonial/Dependency Contiguity Data, 1816-2002. Version 3.0. Available online at http://www.correlatesofwar.org. (Accessed July 17, 2011.) 
Crawford, Neta C. 2000. "The Passion of World Politics: Propositions on Emotion and Emotional Relationships.” International Security 24(4): 116-156.

Dai, Xinyuan. 2008. International Institutions and National Policies. Cambridge: Cambridge University Press.

Damasio, Antonio R. 1994. Descartes' Error: Emotion, Reason, and the Human Brain. New York: Putnam.

Daniels, Joseph P. 2005. "Religious Affiliation and Individual International-Policy Preferences in the United States." International Interactions 31(4): 273-301.

Danilenko, G[ennady] M[ikhailovich]. 1993. Law-Making in the International Community. Dordrecht: Martinus Nijhoff.

Dark, K.R. 2000. Religion and International Relations. New York: Palgrave Macmillan.

Dart, John. 1990. "Church Leader Points to Bush's Moral Dilemma." Los Angeles Times, December 22.

Davis, George B. 1916. The Elements of International Law. $4^{\text {th }}$ ed. Rev. Gordon E. Sherman. New York: Harper \& Bros.

Dearey, Paul. 2003. "Catholicism and the Just War Tradition: The Experience of Moral Value in Warfare." In Just War in Comparative Perspective, ed. Paul Robinson, 2439. Burlington, VT: Ashgate.

Deegalle, Mahinda. 2003a. "Theravada Attitudes Toward Violence." Journal of Buddhist Ethics 10: 82-93.

—. 2003b. "Is Violence Justified in Theravāda Buddhism?" Ecumenical Review 55(2): 122-131. , ed. 2006. Buddhism, Conflict and Violence in Modern Sri Lanka. New York: Routledge. 
— 2009. "Norms of War in Theravada Buddhism." In World Religions and Norms of War, ed. Vesselin Popovski, Gregory M. Reichberg \& Nicholas Turner, 60-86. Tokyo: United Nations University Press.

Delaney, Carol. 2010. "The Fundamental Violence of the Abrahamic Religions." In Religion, Fundamentalism, and Violence: An Interdisciplinary Dialogue, ed. Andrew L. Gluck, 53-68. Scranton, PA: University of Scranton Press.

Demiéville, Paul. 2010. "Buddhism and War.” Trans. Michelle Kendall. In Buddhist Warfare, ed. Michael K. Jerryson \& Mark Juergensmeyer, 17-58. New York: Oxford University Press. Reprint of "Le bouddhisme et la guerre: Post-scriptum à l'histoire des moines guerriers du Japan de Gaston Renondeau," in Mélanges publiés par l'Institut des Hautes Études chinoises, vol. 1, 347-385 (Paris: Presses Universitaires de France, 1957).

Desch, Michael C. 1998. "Culture Clash: Assessing the Importance of Ideas in Security Studies." International Security 23(1): 141-170.

Dessler, David. 1989. "What's at Stake in the Agent-Structure Debate?" International Organization 43(3): 441-473.

Devroy, Ann. 1991. "Describing Moral Debate, Bush Spellbinds Audience." Washington Post, January 26: A1.

Diehl, Paul F. 1985. "Contiguity and Military Escalation in Major Power Rivalries, 18161980.” Journal of Politics 47(4): 1203-1211.

Diehl, Paul F. \& Gary Goertz. 1988. "Territorial Changes and Militarized Conflict." Journal of Conflict Resolution 32(1): 103-122.

Dissanayake, Piyasena. 1977. Political Thoughts of the Buddha. Colombo: Ratnakara Press. 
Documents of the United Nations Conference on International Organization, San Francisco, 1945. 1945-1946. 16 Vols. London: United Nations Information Organization.

Donner, Fred M[cGraw]. 1981. The Early Islamic Conquests. Princeton: Princeton University Press.

. 1991. "The Sources of Islamic Conceptions of War." In Just War and Jihad: Historical and Theoretical Perspectives on War and Peace in Western and Islamic Traditions, ed. John Kelsay \& James Turner Johnson, 31-69. Westport, CT: Greenwood Press.

- 2010. Muhammad and the Believers: At the Origins of Islam. Cambridge, MA: Belknap Press.

Dorn, A. Walter. 2010. Justifications for War and Peace in the World Religions: Part III: Comparison of Scriptures from Seven World Religions. Defence Research Report, Contract Report 2010-36. Toronto: Defence Research \& Development Canada.

Doyle, Michael W. 1983. "Kant, Liberal Legacies, and Foreign Affairs [Part I]." Philosophy and Public Affairs 12(3): 205-235.

Dun Commission. 1950. "The Christian Conscience and Atomic War." Christianity and Conscience, December 11: 161-168.

Dupuy, R. Ernest \& Trevor N. Dupuy. 1986. The Encyclopedia of Military History, from 3500 B.C. to the Present. $2^{\text {nd }}$ rev. ed. New York: Harper \& Row.

Durant, Will. 1944. The Story of Civilization, Volume 3. Caesar and Christ: A History of Roman Civilization and of Christianity from their Beginnings to A.D. 325. New York: MJF Books.

Eberle, Christopher. 2006. "Religion, Pacifism, and the Doctrine of Restraint." Journal of Religious Ethics 34(2): 203-224. 
Edkins, Jenny. 2003. Trauma and the Memory of Politics. Cambridge: Cambridge University Press.

Eliade, Mircea. 1954. Mythe de l'éternel retour [The Myth of the Eternal Return]. Trans. Willard R. Trask. New York: Pantheon Books.

- 1959. The Sacred and the Profane: The Nature of Religion. Trans. Willard R. Trask. New York: Harcourt Brace.

Elshtain, Jean Bethke. 2003. Just War Against Terror: The Burden of American Power in a Violent World. New York: Basic Books.

Episcopal Church. 1999. "Remarks by the President Bishop on the NATO bombing Campaign.” March 26. Available online at www.episcopalchurch.org/1275 1329_ENG_HTM.htm. (Accessed January 11, 2008.)

Episcopal Diocese of Washington. 1987. The Nuclear Dilemma: A Christian Search for Understanding. Cincinnati: Forward Movement Publications.

Episcopal News Service. 1991. "Church Leaders Return from Middle East Peace Pilgrimage Urging Peaceful Solution in Gulf." Episcopal News Service, January 11: no. 91002. Available online at http://www.episcopalarchives.org/cgi/bin/ENS/ ENSpress_release.pl?pr_number=91002. (Accessed February 24, 2010.)

Eppstein, John. 1935. The Catholic Tradition of the Law of Nations. London: Burns Oates \& Washbourne.

Erlanger, Steven \& Scott Shane. 2011. “As Horrors Emerge, Norway Charges Christian Extremist.” New York Times, July 24, New York ed.: A1.

Esposito, John L. 2002. Unholy War: Terror in the Name of Islam. New York: Oxford University Press. 
Evangelical Lutheran Church in America. 1999. "Statement by the President Bishop on the Crisis in the Balkans.” April 9. Available online at www.elca.org/ob/kosovo.html. (Accessed January 11, 2008.)

Falk, Richard A. \& Samuel S. Kim, eds. 1980. The War System: An Interdisciplinary Approach. Boulder, CO: Westview Press.

Farber, Henry S. \& Joanne Gowa. 1994. "Polities and Peace.” International Security 20(2): 123-146.

Fattah, Khaled \& K.M. Fierke. 2009. "A Clash of Emotions: The Politics of Humiliation and Political Violence in the Middle East." European Journal of International Relations 15(1): 67-93.

Fearon, James D. 1995. "Rationalist Explanations for War.” International Organization 49(3): 379-414.

Fee, Gordon D. \& Douglas Stuart. 2003. How to Read the Bible for All Its Worth. $3^{\text {rd }}$ ed. Grand Rapids, MI: Zondervan.

Feng, Huiyun. 2005. "The Operational Code of Mao Zedong: Defensive or Offensive Realist?" Security Studies 14(4): 637-662.

Fiala, Andrew. 2008. The Just War Myth: The Moral Illusions of War. Lanham, MD: Rowman \& Littlefield.

Finnemore, Martha. 1996. National Interest in International Society. Ithaca, NY: Cornell University Press.

— 2003. The Purpose of Intervention: Changing Beliefs about the Use of Force. Ithaca, NY: Cornell University Press.

Firestone, Reuven. 1996. "Conceptions of Holy War in Biblical and Qur'ānic Tradition." Journal of Religious Ethics 24(1): 99-123.

Fish, M. Steven. 2002. "Islam and Authoritarianism.” World Politics 55(1): 4-37. 
Fontes Historiae Iuris Gentium [FHIG]. 1995. Ed. Wilhelm G. Grewe. 3 Vols. Berlin: Walter de Gruyter.

Ford, John C., S.J. 1944. "The Morality of Obliteration Bombing." Theological Studies 5(3): 261-309.

Fox, Jonathan. 1999. "Do Religious Institutions Support Violence or the Status Quo?" Studies in Conflict \& Terrorism 22: 119-139.

—. 2001a. "Religious Causes of International Intervention in Ethnic Conflicts." International Politics 38: 515-532.

—. 2001b. "Religion as an Overlooked Element of International Relations." International Studies Review 3(3): 53-73.

—. 2002. "Ethnic Minorities and the Clash of Civilizations: A Quantitative Analysis of Huntington's Thesis.” British Journal of Political Science 32(3): 415-434.

- 2008. A World Survey of Religion and the State. Cambridge: Cambridge University Press.

Fox, Jonathan \& Shmuel Sandler. 2004. Bringing Religion into International Relations. New York: Palgrave Macmillan.

—, eds. 2006. Religion in World Conflict. London: Routledge.

Franck, Thomas M. 1970. "Who Killed Article 2(4)? Or: Changing Norms Governing the Use of Force by States.” American Journal of International Law 64: 809-837.

- 1990. The Power of Legitimacy Among Nations. New York: Oxford University Press.

—. 1995. Fairness in International Law and Institutions. New York: Oxford University Press. 
-1999. The Empowered Self: Law and Society in the Age of Individualism. New York: Oxford University Press.

- 2002. Recourse to Force: State Action Against Threats and Armed Attacks. Cambridge: Cambridge University Press.

Freedman, Lawrence \& Efraim Karsh. 1993. The Gulf Conflict 1990-1991: Diplomacy and War in the New World Order. Princeton: Princeton University Press.

Freedom House. 2011. Freedom in the World, Comparative and Historical Data. Available online at http://www.freedomhouse.org/template.cfm?page=439. (Accessed July 17, 2011.)

Freiling, Tom. 2000. Reagan's God and Country. A President's Moral Compass: His Beliefs on God, Religious Freedom, the Sanctity of Life and More. Ann Arbor: Servant Publications.

Friday, Karl. 2006. "Might Makes Right: Just War and Just Warfare in Early Medieval Japan." In The Ethics of War in Asian Civilizations: A Comparative Perspective, ed. Torkel Brekke, 159-184. New York: Routledge.

Fuller, Graham E. 2004. The Future of Political Islam. New York: Palgrave Macmillan.

Furia, Peter A. \& Russell E. Lucas. 2006. "Determinants of Arab Public Opinion on Foreign Relations.” International Studies Quarterly 50(3): 585-605.

- 2008. "Arab Muslim Attitudes Toward the West: Cultural, Social, and Political Explanations." International Interactions 34(2): 186-207.

Gelpi, Christopher. 2003. The Power of Legitimacy: Assessing the Role of Norms in Crisis Bargaining. Princeton: Princeton University Press.

Gentili, Alberico. [1612] 1933. The Law of War in Three Books [De Iure Belli Libri Tres]. Trans. John C. Rolfe. 2 Vols. Oxford: Clarendon Press. 
George, Alexander L. 1969. “The 'Operational Code': A Neglected Approach to the Study of Political Leaders and Decision-Making." International Studies Quarterly 13(2): 190-222.

George, Alexander L. \& Timothy J. McKeown. 1985. "Case Studies and Theories of Organizational Decision Making." Advances in Information Processing in Organizations 2: 21-58.

Gethin, Rupert. 2007. "Buddhist Monks, Buddhist Kings, Buddhist Violence: On the Early Buddhist Attitudes to Violence." In Religion and Violence in South Asia: Theory and Practice, ed. John R. Hinnells \& Richard King, 62-82. New York: Routledge.

Ghosn, Faten, Glenn Palmer \& Stuart Bremer. 2004. "The MID3 Data Set, 1993-2001: Procedures, Coding Rules, and Description." Conflict Management and Peace Science 21(2): 133-154.

al-Ghunaimi, Mohammed Talaat. 1968. The Muslim Conception of International Law and the Western Approach. The Hague: Martinus Nijhoff.

Gibler, Douglas M. 2008. International Military Alliances, 1648-2008. Washington: Congressional Quarterly Press.

Gibler, Douglas M. \& Meredith Sarkees. 2004. "Measuring Alliances: The Correlates of War Formal Interstate Alliance Data Set.” Journal of Peace Research 41(2): 211-222.

Gibler, Douglas M. \& Scott Wolford. 2006. “Alliances, Then Democracy: An Examination of the Relationships Between Regime Type and Alliance Formation." Journal of Conflict Resolution 50(1): 129-153.

Gilbert, Martin. 1989. The Second World War: A Complete History. New York: Holt.

Gill, Anthony. 1998. Rendering unto Caesar: The Catholic Church and the State in Latin America. Chicago: University of Chicago Press. 
Gilpin, Robert. 1981. War and Change in World Politics. Cambridge: Cambridge University Press.

Gleditsch, Kristian Skrede. 2002. "Expanded Trade and GDP Data." Journal of Conflict Resolution 46(5): 712-724.

Gluck, Andrew L. 2010. Religion, Fundamentalism, and Violence: An Interdisciplinary Dialogue. Scranton, PA: University of Scranton Press.

Gochman, Charles S. \& Alan Ned Sabrosky, eds. 1990. Prisoners of War: Nation-States in the Modern Era. Lexington, MA: Lexington Books.

Goemans, Henk E, Kristian Skrede Gleditsch, \& Giacomo Chiozza. 2009. "Introducing Archigos: A Dataset of Political Leaders." Journal of Peace Research 46(2): 269283.

Gokhale, Balkrishna G. 1966. "Early Buddhist Kingship.” Journal of Asian Studies 26(1): $15-22$.

Goldgeier, James M. 1997. "Psychology and Security.” Security Studies 6(4): 137-166.

Goldstein, Joshua. 1998. Long Cycles: Prosperity and War in the Modern Era. New Haven: Yale University Press.

Goldstein, Laurie. 1990. "U.S. Church Leaders Urge Against Gulf War; After Visit to Middle East, Group Says Using Military Force on Iraq Would Be Hypocritical." Washington Post, December 22: A11.

Gombrich, Richard. 2006. "Is the Sri Lankan War a Buddhist Fundamentalism?" In Buddhism, Conflict and Violence in Modern Sri Lanka, ed. Mahinda Deegalle, 22-37. New York: Routledge.

Gombrich, Richard \& Gananath Obeyesekere. 1988. Buddhism Transformed: Religious Change in Sri Lanka. Princeton: Princeton University Press. 
Graham, A.C. [1959] 1997. "Confucianism.” In Encyclopedia of the World's Religions, ed. R.C. Zaehner, 357-373. New York: Barnes \& Noble Books.

Grant, Patrick. 2009. Buddhism and Ethnic Conflict in Sri Lanka. Albany, NY: State University of New York Press.

Grewe, Wilhelm G. 2000. The Epochs of International Law. Rev. ed. Trans. Michael Byers. Berlin: Walter de Gruyter.

Grieco, Joseph. 1988. "Anarchy and the Limits of Cooperation: A Realist Critique of the Newest Liberal Institutionalism.” International Organization 42(3): 485-507. Reprinted in Neorealism and Neoliberalism: The Contemporary Debate, ed. David A. Baldwin, 116-142 (New York: Columbia University Press, 1993).

Grotius, Hugo. [1646] 1925. De Jure Belli ac Pacis Libri Tres [The Law of War and Peace in Three Books]. 1646 ed. Trans. Francis W. Kelsey. 2 Vols. Oxford: Clarendon Press.

Gruber, Lloyd. 2000. Ruling the World: Power Politics and the Rise of Supranational Institutions. Princeton: Princeton University Press.

Haas, Mark L. 2005. The Ideological Origins of Great Power Politics, 1789-1989. Ithaca, NY: Cornell University Press.

Haas, Michael. 1980. "Societal Approaches to the Study of War." In The War System: An Interdisciplinary Approach, ed. Richard A. Falk \& Samuel S. Kim, 347-368. Boulder, CO: Westview Press.

Haddad, Simon \& Hilal Khashan. 2002. "Islam and Terrorism: Lebanese Muslim Views on September 11." Journal of Conflict Resolution 46(6): 812-828.

Hall, William E. 1890. A Treatise on International Law. $3^{\text {rd }}$ ed. Oxford, Clarendon Press.

Hamud, Randall B., J.D., ed. 2005. Osama bin Laden: America's Enemy in His Own Words. San Diego: Nadeem Publishing. 
Hanson, Eric O. 2006. Religion and Politics in the International System Today. Cambridge: Cambridge University Press.

Harakas, Stanley [S]. 1981. "The Morality of War." In Orthodox Synthesis: The Unity of Theological Thought, ed. Joseph J. Allen, 67-96. Crestwood, NY: St. Vladimir's Seminary Press.

- 1999. Wholeness of Faith and Life: Orthodox Christian Ethics. Part One: Patristic Ethics. Brookline, MA: Holy Cross Orthodox Press.

—. 2002. "Thinking about Peace and War as Orthodox Christians." Praxis [Greek Orthodox Archdiocese of America] 3(1): 26-27.

Harris, Elizabeth J. 2003. "Buddhism and the Justification of War: A Case Study from Sri Lanka." In Just War in Comparative Perspective, ed. Paul Robinson, 93-108. Burlington, VT: Ashgate.

Harsanyi, Andrew. 1989. "Just War Traditions: Ancient and Medieval." In Peace, War and God's Justice, ed. Thomas D. Parker \& Brian J. Fraser, 39-50. Toronto: United Church Publishing House.

Hasenclever, Andreas \& Volker Rittberger. 2000. "Does Religion Make a Difference? Theoretical Approaches to Impact of Faith on Political Conflict." Millennium 29(3): 641-674.

Hashmi, Sohail H. 1996. "Interpreting the Islamic Ethics of War and Peace.” In The Ethics of War and Peace: Religious and Secular Perspectives, ed. Terry Nardin, 146166. Princeton: Princeton University Press ed. 2002. Islamic Political Ethics: Civil Society, Pluralism, and Conflict. Princeton: Princeton University Press.

Hashmi, Sohail H. \& Steven P. Lee, eds. 2004. Ethics and Weapons of Mass Destruction: Religious and Secular Perspectives. Cambridge: Cambridge University Press. 
Hassner, Ron E. 2009. War on Sacred Grounds. Ithaca, NY: Cornell University Press.

Hasson, Kevin J. 2004. "Neither Sacred nor Secular: A Public Anthropology of Human Dignity, Religious Freedom, and Security." In Religion and Security: The New Nexus in International Relations, ed. Robert A. Seiple \& Dennis R. Hoover, 151-161. Lanham, MD: Rowman \& Littlefield.

Hauerwas, Stanley. 1983. The Peaceable Kingdom: A Primer in Christian Ethics. Notre Dame, IN: University of Notre Dame Press.

-1985. Against the Nations: War and Survival in a Liberal Society. Notre Dame, IN: University of Notre Dame Press.

1988. "Epilogue.” In Paul Ramsey, Speak Up for Just War or Pacifism: A Critique of the United Methodist Bishops' Pastoral Letter “In Defense of Creation." University Park, PA: Pennsylvania State University Press.

- 2011. War and the American Difference: Theological Reflections on Violence and National Identity. Grand Rapids, MI: Baker Academic.

Haynes, Jeffrey. 2005. "Religion and International Relations after '9/11."” Democratization 12(3): 398-413.

- 2007. An Introduction to International Relations and Religion. Harlow: Pearson Education Ltd.

Heck, Paul L. 2004. “Jihad Revisited.” Journal of Religious Ethics 32(1): 95-128.

Hehir, J. Bryan. 1982. "The Just-War Ethic and Catholic Theology: Dynamics of Change and Continuity." In War or Peace?: The Search for New Answers, ed. Thomas A. Shannon, 15-39. Maryknoll, NY: Orbis.

—. 1992. "Just War Theory in a Post-Cold War World." Journal of Religious Ethics 20(2): 237-257. 
Heikal, Mohammed. 1975. The Road to Ramadan. New York: Quadrangle/New York Times Book Co.

Heimbach, Daniel R. 2002. "The Bush Just War Doctrine: Genesis and Application of the President's Moral Leadership in the Persian Gulf War." In From Cold War to New World Order: The Foreign Policy of George H.W. Bush, ed. Meena Bose \& Rosanna Perotti, 441-464. Westport, CT: Greenwood Press.

— 2008. "Distinguishing Just War from Crusade: Is Regime Change a Just Cause for Just War?" In War in the Bible and Terrorism in the Twenty-First Century, ed. Richard S. Hess \& Elmer A. Martens, 79-92. Winona Lake, IN: Eisenbrauns.

- 2011. Personal interview with author, November 30, Southeastern Baptist Theological Seminary, Wake Forest, North Carolina. Notes on file with author.

Henderson, Errol A. 1997. "Culture or Contiguity: Ethnic Conflict, the Similarity of States, and the Onset of War, 1820-1989." Journal of Conflict Resolution 41(5): 649668.

Henderson, Errol A. \& Richard Tucker. 2001. "Clear and Present Strangers: The Clash of Civilizations and International Conflict.” International Studies Quarterly 45(2): 317338.

Henkin, Louis. 1979. How Nations Behave: Law and Foreign Policy. $2^{\text {nd }}$ ed. New York: Columbia University Press.

Hermann, Margaret G. \& Thomas W. Milburn, eds. 1977. A Psychological Examination of Political Leaders. New York: Free Press.

Hess, Richard S. \& Elmer A. Martens, eds. 2008. War in the Bible and Terrorism in the Twenty-First Century. Winona Lake, IN: Eisenbrauns.

Hinnells, John R. \& Richard King, eds. 2007. Religion and Violence in South Asia: Theory and Practice. New York: Routledge. 
Hobbes, Thomas. [1651] 1985. Leviathan. Ed. C.B. Macpherson. New York: Penguin Books.

Hobson, John M. 2000. The State and International Relations. Cambridge: Cambridge University Press.

Hocking, William Ernest. 1928. The Meaning of God in Human Experience. New Haven: Yale University Press.

Holmes, Arthur F., ed. 2003. War and Christian Ethics. $2^{\text {nd }}$ ed. Grand Rapids, MI: Baker Academic.

Holsti, Kalevi J. 1991. Peace and War: Armed Conflicts and International Order 16481989. Cambridge: Cambridge University Press.

Holsti, Ole. 1967. "Cognitive Dynamics and Images of the Enemy.” In Image and Reality in World Politics, ed. John C. Farrell \& Asa P. Smith, 16-39. New York: Columbia University Press.

Hoover, Dennis R. 2004. "Introduction: Religion Gets Real.” In Religion and Security: The New Nexus in International Relations, ed. Robert A. Seiple \& Dennis R. Hoover, 1-7. Lanham, MD: Rowman \& Littlefield.

Hopf, Ted. 1998. "The Promise of Constructivism in International Relations Theory." International Security 23(1): 171-200.

Horowitz, Michael. 2009. "The Spread of Nuclear Weapons and International Conflict: Does Experience Matter?” Journal of Conflict Resolution 53(2): 234-257.

Houben, Jan E.M. \& Karel R. van Kooij, eds. 1999. Violence Denied: Violence, NonViolence and the Rationalization of Violence in South Asian Cultural History. Leiden: Brill. 
Hudson, Valerie M. \& Kerry M. Kartchner, eds. 1995. Moral Perspectives on U.S. Security Policy: Views from the LDS Community. Provo, UT: Brigham Young University, Kennedy Center Publications.

Hui, Victoria Tin-bor. 2004. "Toward a Dynamic Theory of International Politics: Insights from Comparing Ancient China and Early Modern Europe." International Organization 58(1): 175-205.

Huntington, Samuel P. 1993. "The Clash of Civilizations." Foreign Affairs 72(3): 22-49.

- 1996. The Clash of Civilizations and the Remaking of World Order. New York: Simon \& Schuster.

Hurd, Elizabeth Shakman. 2008. The Politics of Secularism in International Relations. Princeton: Princeton University Press.

—. 2011. "Secularism and International Relations Theory." In Religion and International Relations Theory, ed. Jack Snyder, 60-90. New York: Columbia University Press.

Hutchison, Emma. 2010. "Trauma and the Politics of Emotions: Constituting Identity, Security and Community after the Bali Bombing." International Relations 24(1): 6586.

Hymans, Jacques E.C. 2006. The Psychology of Nuclear Proliferations: Identity, Emotions, and Foreign Policy. Cambridge: Cambridge University Press.

Ikenberry, G. John. 2001. After Victory: Institutions, Strategic Restraint, and the Rebuilding of Order After Major Wars. Princeton: Princeton University Press.

Information Please Almanac. 1947-1981. New York: Simon \& Schuster.

Israeli, Raphael. 1980. "The Role of Islam in President Sadat's Thought." Jerusalem Journal of International Relations 4(4): 1-12. 
— with Carol Bardenstein. 1985. Man of Defiance: A Political Biography of Anwar Sadat. Totowa, NJ: Barnes \& Noble Books.

Janis, Irving L. \& Leon Mann. 1977. Decision-Making: A Psychological Analysis of Conflict, Choice and Commitment. New York: Free Press.

Janis, Mark W. 1999a. “Introduction.” In Religion and International Law, ed. Mark W. Janis \& Carolyn Evans, xi-xiii. The Hague: Kluwer Law International. . 1999b. "Religion and the Literature of International Law: Some Standard Texts." In Religion and International Law, ed. Mark W. Janis \& Carolyn Evans, 121-143. The Hague: Kluwer Law International.

Janis, Mark W. \& Carolyn Evans, eds. 1999. Religion and International Law. The Hague: Kluwer Law International.

Jayatilleke, K.N. 1962. Buddhism and Peace. Kandy, Sri Lanka: Buddhist Publication Society.

- 1967. "The Principles of Law in Buddhist Doctrine." Recueil des Cours de l'Academie de Droit International de la Haye 120: 441-565.

Jerryson, Michael. 2010. "Militarizing Buddhism: Violence in Southern Thailand.” In Buddhist Warfare, ed. Michael K. Jerryson \& Mark Juergensmeyer, 179-209. New York: Oxford University Press.

Jerryson, Michael K. \& Mark Juergensmeyer, eds. 2010. Buddhist Warfare. New York: Oxford University Press.

Jervis, Robert. 1968. "Hypotheses on Misperception.” World Politics 20(3): 454-479.

—. 1978. "Cooperation Under the Security Dilemma." World Politics 30(2): 167213. 
Jessup, Brooks. 2008. "Review of Buddhism, War, and Nationalism: Chinese Monks in the Struggle against Japanese Aggression, 1931-1945." Journal of Buddhist Ethics 15: R17-R22.

Johnson, James Turner. 1975. Ideology, Reason, and the Limitation of War: Religious and Secular Concepts 1200-1740. Princeton: Princeton University Press.

- 1981. Just War Tradition and the Restraint of War: A Moral and Historical Inquiry. Princeton: Princeton University Press.

_. 1984. Can Modern War Be Just? New Haven: Yale University Press.

— 1987. The Quest for Peace: Three Moral Traditions in Western Cultural History. Princeton: Princeton University Press.

- 1997. The Holy War Idea in Western and Islamic Traditions. University Park, PA: Pennsylvania State University Press.

_. 1999. Morality and Contemporary Warfare. New Haven: Yale University Press.

- 2005. The War to Oust Saddam Hussein: Just War and the New Face of Conflict. Lanham, MD: Rowman and Littlefield.

Johnson, James Turner \& John Kelsay, eds. 1990. Cross, Crescent and Sword: The Justification of War in Western and Islamic Tradition. Westport, CT: Greenwood Press.

Johnson, James Turner \& George Weigel. 1991. Just War and the Gulf War. Lanham, MD: University Press of America.

Johnston, Douglas \& Cynthia Sampson, eds. 1994. Religion, the Missing Dimension of Statecraft. New York: Oxford University Press.

Jones, Daniel M., Stuart A. Bremer \& J. David Singer. 1996. "Militarized Interstate Disputes, 1816-1992: Rationale, Coding Rules, and Empirical Patterns." Conflict Management and Peace Science 15(2): 163-213. 
Juergensmeyer, Mark. 1993. The New Cold War? Religious Nationalism Confronts the Secular State. Berkeley, University of California Press. . 2000. Terror in the Mind of God: The Global Rise of Religious Violence. Berkeley, University of California Press. ed. 2006. The Oxford Handbook of Global Religions. New York: Oxford University Press.

Kahneman, Daniel \& Amos Tversky. 1979. "Prospect Theory: An Analysis of Decision Under Risk.” Econometrica 47(2): 263-292.

Kalyvas, Stathis. 1996. The Rise of Christian Democracy in Europe. Ithaca, NY: Cornell University Press.

Kant, Immanuel. [1795] 1991. "Perpetual Peace.” Trans. H.B. Nisbet. In Kant: Political Writings, $2^{\text {nd }}$ enl. ed., ed. Hans Reiss, 93-130. Cambridge: Cambridge University Press.

Kartchner, Kerry M. \& Valerie M. Hudson, eds. 2004. Wielding the Sword While Proclaiming Peace: Views from the LDS Community on Reconciling the Demands of National Security with the Imperatives of Revealed Truth. Provo, UT: Brigham Young University, David M. Kennedy Center for International Studies.

Katzenstein, Peter J., ed. 1996. The Culture of National Security: Norms and Identity in World Politics. New York: Columbia University Press.

Katzenstein, Peter J. \& Timothy A. Byrnes. 2006. "Transnational Religion in an Expanding Europe." Perspectives on Politics 4(4): 679-694.

Kauppi, Mark V. \& Paul R. Viotti. 1992. The Global Philosophers: World Politics in Western Thought. New York: Lexington Books.

Keck, Margaret E. \& Kathryn Sikkink. 1998. Activists Beyond Borders: Advocacy Networks in International Politics. Ithaca, NY: Cornell University Press. 
Kelsay, John. 1990. "Religion, Morality, and the Governance of War: The Case of Classical Islam.” Journal of Religious Ethics 18(2): 123-139.

1993. Islam and War: A Study in Comparative Ethics. Louisville, KY:

Westminster/John Knox Press.

_ 2003. "Al-Shaybani and the Islamic Law of War." Journal of Military Ethics 2(1): $63-75$.

. 2006. "Islamic Tradition and the Justice of War." In The Ethics of War in Asian

Civilizations: A Comparative Perspective, ed. Torkel Brekke, 81-110. New York:

Routledge

—. 2007. Arguing the Just War in Islam. Cambridge, MA: Harvard University Press.

Kelsay, John \& James Turner Johnson, eds. 1991. Just War and Jihad: Historical and Theoretical Perspectives on War and Peace in Western and Islamic Traditions. Westport, CT: Greenwood Press.

Kent, Daniel. 2008. Shelter for You Nirvana for our Sons: Buddhist Belief and Practice in the Sri Lankan Army. Ph.D. Dissertation, University of Virginia.

—. 2010. "Onward Buddhist Soldiers: Preaching to the Sri Lankan Army." In Buddhist Warfare, ed. Michael K. Jerryson \& Mark Juergensmeyer, 157-178. New York: Oxford University Press.

Keohane, Robert O. 1982. “The Demand for International Regimes.” International Organization 36(2): 325-355.

- 1984. After Hegemony: Cooperation and Discord in the World Political Economy. Princeton: Princeton University Press. 1989. International Institutions and State Power: Essays in International Relations Theory. Boulder, CO: Westview Press. 
Keown, Damien. 2005. Buddhist Ethics: A Very Short Introduction. New York: Oxford University Press.

Kepel, Gilles. 1994. The Revenge of God. Trans. Alan Braley. University Park, PA: Pennsylvania State University Press.

- 2004. The War for Muslim Minds: Islam and West. Trans. Pascale Ghazaleh. Cambridge, MA: Belknap Press

Kepel, Gilles \& Anthony F. Roberts. 2002. Jihad: The Trail of Political Islam. London: I.B. Tauris \& Co.

Kettel, Steven. 2012. “Has Political Science Ignored Religion?” PS: Political Science \& Politics 45(1): 93-100.

Khadduri, Majid. 1955. War and Peace in the Law of Islam. Baltimore: Johns Hopkins Press.

—. 1984. The Islamic Conception of Justice. Baltimore: Johns Hopkins Press.

Khong, Yuen Foong. 1992. Analogies at War: Korea, Munich, Dien Bien Phu, and the Vietnam Decisions of 1965. Princeton: Princeton University Press.

Kierkegaard, Søren. [1848] 1997. Christelige Taler [Christian Discourses]. Ed. \& trans. Howard V. Hong \& Edna H. Hong. Princeton: Princeton University Press.

King, Gary, Robert O. Keohane, \& Sidney Verba. 1994. Designing Social Inquiry: Scientific Inference in Qualitative Research. Princeton: Princeton University Press.

King, Gary \& Langche Zeng. 2001a. "Explaining Rare Events in International Relations." International Organization 55(3): 693-715.

—. 2001b. "Logistic Regression in Rare Events Data.” Political Analysis 9(2): 137163.

King, Nicholas. 1980. George Bush: A Biography. New York: Dodd, Mead \& Co. 
King, Sallie B. 2006. “An Engaged Buddhist Response to John Rawls's The Law of Peoples." Journal of Religious Ethics 34(4): 637-661.

King, Winston L. 1993. Zen and the Way of the Sword: Arming the Samurai Psyche. New York: Oxford University Press.

Kisala, Robert. 2009. "Norms of War in Japanese Religion." In World Religions and Norms of War, ed. Vesselin Popovski, Gregory M. Reichberg \& Nicholas Turner, 87105. Tokyo: United Nations University Press.

Kitagawa, Joseph M. 1990. Religion in Japanese History. New York: Columbia University Press.

Kohn, George Childs. 1999. Dictionary of Wars. Rev. ed. New York: Checkmark Books. Koplow, Michael J. 2011. "Value Judgment: Why Do Americans Support Israel?" Security Studies 20(2): 266-302.

The Koran. See The Quran.

Krasner, Stephen D. 1982. "Structural Causes and Regime Consequences: Regimes as Intervening Variables." International Organization 36(2): 185-205. Reprinted in International Regimes, ed. Stephen D. Krasner, 1-22 (Ithaca, NY: Cornell University Press, 1983).

— ed. 1983. International Regimes. Ithaca, NY: Cornell University Press.

Kratochwil, Friedrich V. 1989. Rules, Norms, and Decisions: On the Conditions of Practical and Legal Reasoning in International Relations and Domestic Affairs. Cambridge: Cambridge University Press.

Kubálková, Vendulka. 2000. “Towards an International Political Theology.” Millennium 29(3): 675-704.

Kulke, Hermann \& Dietmar Rothermund. 1986. A History of India. New York: Dorset Press. 
Küng, Hans. 1997. Weltethos für Weltpolitik und Weltwirtschaft [A Global Ethic for Global Politics and Economics]. Trans. John Bowden. London: SCM Press.

Kurth, James. 1998. "The Protestant Deformation and American Foreign Policy." Orbis 42(2): 221-239.

Labs, Eric J. 1997. "Beyond Victory: Offensive Realism and the Expansion of War Aims." Security Studies 6(4): 1-49.

Lai, Brian. 2006. "An Empirical Examination of Religion and Conflict in the Middle East, 1950-1992." Foreign Policy Analysis 2: 21-36.

Laitin, David D. 1978. "Religion, Political Culture, and the Weberian Tradition." World Politics 30(4): 563-592.

Lancaster, Lewis. 2006. “Korean Religious Society.” In The Oxford Handbook of Global Religions, ed. Mark Juergensmeyer, 155-160. New York: Oxford University Press

Langan, John [P.], S.J. 1984. “The Elements of St. Augustine's Just War Theory.” Journal of Religious Ethics 12(1): 19-38.

_. 1991. "The Western Moral Tradition on War: Christian Theology and Warfare." In Just War and Jihad: Historical and Theoretical Perspectives on War and Peace in Western and Islamic Traditions, ed. John Kelsay \& James Turner Johnson, 71-90. Westport, CT: Greenwood Press.

—. 1998. "The Catholic Vision of World Affairs." Orbis 42(2): 241-261.

Lapid, Yosef \& Friedrich Kratochwil, eds. 1996. The Return of Culture and Identity in IR Theory. Boulder, CO: Lynne Rienner.

Lawrence, Bruce. 1991. "Holy War (Jihad) in Islamic Religion and Nation-State Ideologies." In Just War and Jihad: Historical and Theoretical Perspectives on War and Peace in Western and Islamic Traditions, ed. John Kelsay \& James Turner Johnson, 141-160. Westport, CT: Greenwood Press. 
Lawrence, T.J. 1915. The Principles of International Law. $6^{\text {th }}$ ed. Boston: D.C. Heath \& Co.

Lebow, Richard Ned. 1981. Between Peace and War: The Nature of International Crises. Baltimore: Johns Hopkins Press.

- 2008. A Cultural Theory of International Relations. Cambridge: Cambridge University Press.

Ledet, Richard. 2006. “The Quality of Government Institute's Cross-Sectional and CrossSectional Time Series Dataset." APSA-CP Newsletter 17(2): 29-31.

van Leeuwen, Arend Theodoor. 1964. Christianity in World History: The Meeting of the Faiths of East and West. Trans. H.H. Hoskins. New York: Scribners.

da Legnano, Giovanni. [1360] 1917. On War, on Reprisals, and on Duelling [De Bello, de Represaliis et de Duello]. Ed. Thomas Erkine Holland. Trans. James Leslie Brierly. Oxford: Oxford University Press.

Leites, Nathan. 1953. A Study of Bolshevism. Glencoe, IL: Free Press.

Levy, Jack S. 1983a. War in the Modern Great Power System, 1495-1975. Lexington, KY: The University Press of Kentucky.

- 1983b. "Misperception and the Causes of War: Theoretical Linkages and Analytical Problems." World Politics 36(1): 76-99.

- 1989a. "Domestic Politics and War." In The Origin and Prevention of Major Wars, ed. Robert I Rotberg \& Theodore K. Rabb, 79-99. New York: Cambridge University Press.

_ 1989b. "The Causes of War: A Review of Theories and Evidence." In Behavior, Society, and Nuclear War, ed. Philip E. Tetlock et al., 209-333. New York: Oxford University Press. 
Levy, Jack S. \& William R. Thompson. 2005. "Hegemonic Threats and Great-Power Balancing in Europe, 1495-1999." Security Studies 14(1): 1-33.

Lewis, Bernard. 2002. What Went Wrong? The Clash Between Islam and Modernity in the Middle East. New York: Oxford University Press.

- 2003. The Crisis of Islam: Holy War and Unholy Terror. New York: Random House.

Liddell Hart, Basil. 1939. The Defense of Britain. London: Faber \& Faber.

Limouris, Gannadios, ed. 1990. Justice, Peace and the Integrity of Creation: Insights from Orthodoxy. Geneva: WCC Publications.

Lipson, Charles. 2003. Reliable Partners: How Democracies Have Made A Separate Peace. Princeton: Princeton University Press.

Lobell, Steven E, Norrin M. Ripsman \& Jeffrey W. Taliaferro, eds. 2009. Neoclassical Realism, the State, and Foreign Policy. Cambridge: Cambridge University Press.

Locke, John. [1689] 2003. “A Letter Concerning Toleration.” In Two Treatises of Government and A Letter Concerning Toleration, ed. Ian Shapiro, 211-254. New Haven: Yale University Press.

Long, Edward LeRoy, Jr. 1968. War and Conscience in America. Philadelphia: Westminster Press.

Lovin, Robin W. 1995. Reinhold Niebuhr and Christian Realism. Cambridge: Cambridge University Pres.

—. 2003. "The Future of Sovereignty: A Christian Realist Perspective." In The Sacred and the Sovereign: Religion and International Politics, ed. John D. Carlson \& Eric C. Owens, 154-169. Washington: Georgetown University Press.

Löwenheim, Oded \& Gadi Heimann. 2008. "Revenge in International Politics.” Security Studies 17(4): 685-724. 
Lugo, Luis E., ed. 1996. Sovereignty at the Crossroads? Morality and International Politics in the Post-Cold War Era. Lanham, MD: Rowman \& Littlefield.

Luther, Martin. [1523] 1974a. "Temporal Authority: To What Extent It Should Be Obeyed.” Trans. J.J. Schindel. Rev. Walther I. Brandt. In Luther: Selected Political Writings, ed. J.M. Porter, 51-69. Philadelphia: Fortress Press.

—. [1526] 1974b. "Whether Soldiers, Too, Can Be Saved." Trans. Charles M. Jacobs. Rev. Robert C. Schultz. In Luther: Selected Political Writings, ed. J.M. Porter, 101-119. Philadelphia: Fortress Press.

—. [1525] 1974c. "Against the Robbing and Murdering Hordes of Peasants." Trans. Charles M. Jacobs. Rev. Robert C. Schultz. In Luther: Selected Political Writings, ed. J.M. Porter, 85-88. Philadelphia: Fortress Press.

Lutheran Church in America. 1984. Peace and Politics: Adopted by the Twelfth Biennial Convention. New York: Lutheran Church in America.

Luttwak, Edward. 1994. "The Missing Dimension.” In Religion, the Missing Dimension of Statecraft, ed. Douglas Johnston \& Cynthia Sampson, 8-19. New York: Oxford University Press.

Machiavelli, Niccolò. [c. 1517] 1950a. Discourses on the First Ten Books of Titus Livius. Trans. Christian E. Detmold. In The Prince and the Discourses, ed. Max Lerner, 99540. New York: Random House.

—. [1532] 1950b. The Prince. Trans. Luigi Ricci. Rev. E.R.P. Vincent. In The Prince and the Discourses, ed. Max Lerner, 4-98. New York: Random House.

Macksey, Charles. 1912. "War.” In The Catholic Encyclopedia. New York: Robert Appleton Company. Available online at http://www.newadvent.org/cathen/ 15546c.htm. (Accessed February 3, 2011.)

Maddison, Angus. 2003. The World Economy: Historical Statistics. Paris: OECD Development Centre. 
The Mahāvamsa: or, The Great Chronicle of Ceylon. 1912. Trans. Wilhelm Geiger with Mabel Haynes Bode. London: Pali Text Society.

Major Peace Treaties of Modern History [MPT]. 2002. Ed. Fred L. Israel \& Michael P. Kelly. 6 Vols. Philadelphia: Chelsea House Publishers.

Malik [ibn Anas], Imam [Abu Abdallah]. [8 ${ }^{\text {th }}$ c. CE] 1980. Muwatta'. Trans. Muhammad Rahimuddin. Lahore: Sh. Muhammad Ashraf.

Manji, Irshad. 2005. The Trouble with Islam Today. New York: St. Martin's Press.

Mann, Charles C. 2011. “The Birth of Religion.” National Geographic, June: 35-58.

Manor, James, ed. 1984. Sri Lanka: In Change and Crisis. London: Croom Helm.

Maoz, Zeev. 1997. "The Controversy over the Democratic Peace: Rearguard Action or Cracks in the Wall?" International Security 22(1): 162-198.

Maoz, Zeev \& Nasrin Abdolali. 1989. "Regime Types and International Conflict, 18161976." Journal of Conflict Resolution 33(1): 3-35.

Maoz, Zeev \& Bruce Russett. 1993. "Normative and Structural Causes of Democratic Peace, 1946-1986.” American Political Science Review 87(3): 624-638.

Marshall, Monty G., Ted Robert Gurr \& Keith Jaggers. 2010. Polity ${ }^{T M}$ IV Project: Political Regime Characteristics and Transitions, 1800-2009, Dataset Users' Manual. Available online at http://www.systemicpeace.org/inscr/ p4manualv2009.pdf. (Accessed July 17, 2011.)

Martin, Richard C. 1991. "The Religious Foundations of War, Peace, and Statecraft in Islam." In Just War and Jihad: Historical and Theoretical Perspectives on War and Peace in Western and Islamic Traditions, ed. John Kelsay \& James Turner Johnson, 91-117. Westport, CT: Greenwood Press.

Maslow, A[braham] H. 1943. "A Theory of Human Motivation." Psychological Review 50(4): 370-396. 
Mason, Roger A., ed. 1994. John Knox: On Rebellion. Cambridge: Cambridge University Press.

Mayer, Ann Elizabeth. 1991. "War and Peace in the Islamic Tradition and International Law." In Just War and Jihad: Historical and Theoretical Perspectives on War and Peace in Western and Islamic Traditions, ed. John Kelsay \& James Turner Johnson, 195-226. Westport, CT: Greenwood Press.

Maynard, Elizabeth A., Richard L. Gorsuch \& Jeffrey P. Bjorck. 2001. "Religious Coping Style, Concept of God, and Personal Religious Variables in Threat, Loss, and Challenge Situations.” Journal for the Scientific Study of Religion 40(1): 65-74.

McDermott, Rose. 2004. "Prospect Theory in Political Science: Gain and Losses from the First Decade.” Political Psychology 25(2): 289-312.

—. 2011. "The Biological Bases for Aggressiveness and Non-Aggressiveness in Presidents." Paper presented at the Miller Center/Security Studies Conference "From Clinton to Bush to Obama: What We Have Learned about Presidents and Foreign Policy," University of Virginia, October 27-28.

McDougal, Myres S. \& Florentino P. Feliciano. 1961. Law and Minimum World Public Order. New Haven: Yale University Press.

McDougall, Walter A. 1998. "Religion in World Affairs: Introduction.” Orbis: A Journal of World Affairs 42(2): 159-170.

McGreal, Ian P., ed. 1995. Great Thinkers of the Eastern World. New York: Harper Collins.

Mearsheimer, John J. 1989. "Assessing the conventional Balance: The 3:1 Rule and Its Critics." International Security 13(4): 54-89. 1990. "Back to the Future: Instability in Europe After the Cold War." International Security 15(1): 5-56. 
—. 2001. The Tragedy of Great Power Politics. New York: W.W. Norton.

Mercer, Jonathan. 1995. “Anarchy and Identity." International Organization 49(2): 229252.

— 2006. "Human Nature and the First Image: Emotion in International Politics." Journal of International Relations and Development 9(3): 288-303.

—. 2010. "Emotional Beliefs.” International Organization 64(1): 1-31.

Midlarsky, Manus. 1974. "Power, Uncertainty and the Onset of International Violence." Journal of Conflict Resolution 18(3): 395-431.

Miller, Richard B. 1991. Interpretations of Conflict: Ethics, Pacifism, and the Just-War Tradition. Chicago: University of Chicago Press.

, ed. 1992. War in the Twentieth Century: Source in Theological Ethics. Louisville, KY: Westminster/John Knox Press.

Milner, Helen. 1991. "The Assumption of Anarchy in International Relations Theory: A Critique." Review of International Studies 17: 67-85. Reprinted in Neorealism and Neoliberalism: The Contemporary Debate, ed. David A. Baldwin, 143-169. New York: Columbia University Press, 1993.

Mintz, Alex. 2005. "The Method-of-Analysis Problem in International Relations.” In New Directions for International Relations: Confronting the Method-of-Analysis Problem, ed. Alex Mintz \& Bruce Russett, 1-30. Lanham, MD: Lexington Books.

Mintz, Alex \& Bruce Russett, eds. 2005. New Directions for International Relations: Confronting the Method-of-Analysis Problem. Lanham, MD: Lexington Books.

Modelski, George. 1964. "Kautilya: Foreign Policy and International System in the Ancient Hindu World.” American Political Science Review 58(3): 549-560.

Moore, John Norton. 2004. Solving the War Puzzle. Durham, NC: Carolina Academic Press. 
Morgenthau, Hans. 2006. Politics Among Nations. $7^{\text {th }}$ ed. Rev. Kenneth W. Thompson \& W. David Clinton. New York: McGraw-Hill.

Morkevicius, Valerie Ona. 2009. "Norms of War in Protestant Christianity.” In World Religions and Norms of War, ed. Vesselin Popovski, Gregory M. Reichberg \& Nicholas Turner, 220-254. Tokyo: United Nations University Press.

—. 2011. Unholy Alliance: Just War Traditions as Power Politics. Ann Arbor: ProQuest.

Morris, Clarence, ed. 1959. The Great Legal Philosophers: Selected Readings in Jurisprudence. Philadelphia: University of Pennsylvania Press.

Mousseau, Michael. 2009. "The Social Market Roots of Democratic Peace." International Security 33(4): 52-86.

Mueller, John. 1989. Retreat from Doomsday: The Obsolescence of Major War. New York: Basic Books.

Murphy, Sean D. 1996. Humanitarian Intervention: The United Nations in an Evolving World Order. Philadelphia: University of Pennsylvania Press.

Murray, John Courtney, S.J. 1959a. Morality and Modern Warfare. New York: Council on Religion and International Affairs.

— 1959b. "Remarks on the Moral Problem of War." Theological Studies 20(1): 4061.

Nafziger, James A.R. 1999. "The Functions of Religion in the International Legal System.” In Religion and International Law, ed. Mark W. Janis \& Carolyn Evans, 155-176. The Hague: Kluwer Law International.

Naipaul, V.S. 1981. Among the Believers: An Islamic Journey. New York: Alfred A. Knopf. 
Nakamura, Hajime. 1974. "Violence and Nonviolence in Buddhism." In Violence and Aggression in the History of Ideas, ed. Philip P. Wiener \& John Fisher, 173-186. New Brunswick, NJ: Rutgers University Press.

Nardin, Terry, ed. 1996. The Ethics of War and Peace: Religious and Secular Perspectives. Princeton: Princeton University Press.

National Conference of Catholic Bishops. 1983. The Challenge of Peace: God's Promise and Our Response. Washington: United States Catholic Conference.

Nawaz, M.K. 1957. “The Law of Nations in Ancient India.” Indian Year Book of International Affairs 6: 172-188.

Neff, Stephen C. 2005. War and the Law of Nations: A General History. Cambridge: Cambridge University Press.

Nexon, Daniel H. 2011. "Religion and International Relations: No Leap of Faith Required." In Religion and International Relations Theory, ed. Jack Snyder, 141-167. New York: Columbia University Press.

Niebuhr, H. Richard. [1932] 1992a. "The Grace of Doing Nothing." In War in the Twentieth Century: Sources in Theological Ethics, ed. Richard B. Miller, 6-11. Louisville, KY: Westminster/John Knox Press.

—. [1942] 1992b. "War as the Judgment of God." In War in the Twentieth Century: Sources in Theological Ethics, ed. Richard B. Miller, 47-55. Louisville, KY: Westminster/John Knox Press.

—. [1943] 1992c. "War as Crucifixion." In War in the Twentieth Century: Sources in Theological Ethics, ed. Richard B. Miller, 63-70. Louisville, KY: Westminster/ John Knox Press.

Niebuhr, Reinhold. 1940. Christianity and Power Politics. New York: Charles Scribner's Sons. 
1959. The Structure of Nations and Empires. New York: Charles Scribner's

Sons.

. [1932] 1992a. "Must We Do Nothing?" In War in the Twentieth Century:

Sources in Theological Ethics, ed. Richard B. Miller, 12-18. Louisville, KY:

Westminster/John Knox Press.

— [1940] 1992b. "Why the Christian Church Is Not Pacifist." In War in the

Twentieth Century: Sources in Theological Ethics, ed. Richard B. Miller, 28-46.

Louisville, KY: Westminster/John Knox Press.

—. [1932] 2001. Moral Man and Immoral Society. 2 Vols. Louisville, KY:

Westminster John Knox Press.

Norris, Pippa \& Ronald Inglehart. 2004. Sacred and Secular: Religion and Politics Worldwide. Cambridge: Cambridge University Press.

Novak, Michael et al. 2011. "Religion at the Ballot Box." New York Times Online, October 30. Available online at http://www.nytimes.com/roomfordebate/2011/10/ 30/the-role-of-religion-in-the-2012-election. (Accessed November 2, 2011.)

Nussbaum, Arthur. 1954. A Concise History of the Law of Nations. Rev. ed. New York: Macmillan.

Nyitray, Vivian-Lee. 2006. "Traditional Chinese Religious Society.” In The Oxford Handbook of Global Religions, ed. Mark Juergensmeyer, 115-123. New York: Oxford University Press.

Obeyesekere, Gananath. 1992. "Dutțagāmaṇ̄ and the Buddhist Conscience." In Religion and Political Conflict in South Asia: India, Pakistan, and Sri Lanka, ed. Douglas Allen, 135-160. Westport, CT: Greenwood Press. 2006. "Buddhism, Ethnicity, and Identity: A Problem in Buddhist History." In Buddhism, Conflict and Violence in Modern Sri Lanka, ed. Mahinda Deegale, 134162. New York: Routledge. 
O’Brien, William V. 1967. Nuclear War, Deterrence and Morality. Westminster, MD: Newman Press.

1969. War and/or Survival. Garden City, NY: Doubleday. 1979. U.S. Military Intervention: Law and Morality. Beverly Hills, CA: Sage.

. 1981. The Conduct of Just and Limited War. New York: Praeger.

1983. "Just-War Doctrine in a Nuclear Context." Theological Studies 44(2): 191-

220.

- 1991. Law and Morality in Israel's War with the PLO. New York: Routledge.

O’Brien, William V. \& John Langan, eds. 1986. The Nuclear Dilemma and the Just War Tradition. Lexington, MA: Lexington Books.

O’Donovan, Oliver. 2003. The Just War Revisited. Cambridge: Cambridge University Press.

Oneal, John R. \& James Lee Ray. 1997. "New Tests of the Democratic Peace: Controlling for Economic Interdependence, 1950-85." Political Research Quarterly 50(4): 751-775.

Onuf, Nicholas Greenwood. 1989. World of Our Making: Rules and Rule in Social Theory and International Relations. Columbia, SC: University of South Carolina Press.

Oppenheim, L[assa]. 1912. International Law. $2^{\text {nd }}$ ed. 2 vols. London: Longmans, Greene \& Co.

Oren, Ido. 1990. “The War Proneness of Alliances.” Journal of Conflict Resolution 34(2): 208-233.

Organski, A.F.K. \& Jacek Kugler. 1981. The War Ledger. Chicago: University of Chicago Press. 
Osiander, Andreas. 2000. "Religion and Politics in Western Civilisation: The Ancient World as Matrix and Mirror of the Modern.” Millennium 29(3): 761-790.

Otis, Pauletta. 2004. "Religion and War in the Twenty-first Century." In Religion and Security: The New Nexus in International Relations, ed. Robert A. Seiple \& Dennis R. Hoover, 11-24. Lanham, MD: Rowman \& Littlefield.

Owen, John M., [IV]. 1994. "How Liberalism Produces Democratic Peace.” International Security 19(2): 87-125.

— 1997. Liberal Peace, Liberal War: American Politics and International Security. Ithaca, NY: Cornell University Press.

. 2010. The Clash of Ideas in World Politics: Transnational Networks, States, and Regime Change, 1510-2010. Princeton: Princeton University Press.

Owen, John M., IV \& J. Judd Owen, eds. 2010. Religion, the Enlightenment, and the New Global Order. New York: Columbia University Press.

Pagden, Anthony. 2003. Peoples and Empires. New York: Modern Library.

Pagden, Anthony \& Jeremy Lawrance, eds. 1991. Vitoria: Political Writings. Cambridge: Cambridge University Press.

The Pali Canon.

Dīgha Nikāya:

Thus Have I Heard: The Long Discourses of the Buddha, Dīgha Nikāya. 1987. Trans. Maurice Walshe. London: Wisdom Publications.

Dialogues of the Buddha. 1956-1957. Trans. T.W. Rhys Davids. 3 Vols. London: Pali Text Society. 
Majjhima Nikāya:

The Middle Length Discourses of the Buddha: A New Translation of the Majjhima Nikāya. 1995. Trans. Bhikkhu Ñaṇamoli \& Bikkhu Bodhi. Boston: Wisdom Publications.

The Collection of the Middle Length Sayings (Majjhima Nikāya). 1954-1959. Trans.

I.B. Horner. 3 Vols. London: Pali Text Society.

Sampyutta Nikāya:

The Book of the Kindred Sayings (Sayyutta-Nikāya) or Grouped Suttas. 1950-1956.

Trans. [C.A.F.] Rhys Davids \& F.H. Woodward. 5 Vols. London: Pali Text Society.

Anguttara Nikāya:

The Book of the Gradual Sayings (Anguttara-Nikāya) or More-Numbered Suttas. 1952-1960. Trans. F.L. Woodward. 5 Vols. London: Pali Text Society.

Dhammapada:

The Dhammapada: Verses and Stories. 1990. Trans. Daw Mya Tin. Sarnath, Varanasi, India: Central Institute of Higher Tibetan Studies.

Suttanipāta:

The Sutta-Nipāta. 1985. Trans. H. Saddhattissa. London: Curzon Press.

Jātaka:

The Jātaka: or, Stories of the Buddha's Former Births. 1957. Ed. E.B. Cowell. Trans. Robert Chalmers, W.H.D. Rouse, H.T. Francis, R.A. Neil, \& E.B. Cowell. 3 Vols. [originally 6 Vols.]. London: Pali Text Society.

Pandita, Venerable. 2011. "The Buddha and the Māgadha-Vajjī War.” Journal of Buddhist Ethics 18: 125-144. 
Parker, Thomas D. \& Brian J. Fraser, eds. 1989. Peace, War and God's Justice. Toronto: United Church Publishing House.

Parmet, Herbert S. 1997. George Bush: The Life of a Lone Star Yankee. New York: Lisa Drew/Scribner.

Pearce, Susanna. 2006. “Religious Rage.” In Religion in World Conflict, ed. Jonathan Fox \& Shmuel Sandler. London: Routledge.

Petito, Fabio \& Pavlos Hatzopoulos, eds. 2003. Religion in International Relations: The Return from Exile. New York: Palgrave Macmillan.

Phillipson, Coleman. [1911] 2001. The International Law and Custom of Ancient Greece and Rome. 2 Vols. Buffalo: William S. Hein \& Co.

Philpott, Daniel. 2000. “The Religious Roots of Modern International Relations.” World Politics 52(2): 206-245.

- 2001. Revolutions in Sovereignty: How Ideas Shaped Modern International Relations. Princeton: Princeton University Press.

—. 2002. "The Challenge of September 11 to Secularism in International Relations." World Politics 55(1): 66-95.

—. 2007. "Explaining the Political Ambivalence of Religion." American Political Science Review 101(3): 505-525.

Pickering, Jeffrey \& William R. Thompson. "Stability in a Fragmenting World: Interstate Military Force, 1946-1988.” Political Research Quarterly 51(1): 241-263.

Pipes, Daniel. 1983. In the Path of God: Islam and Political Power. New York: Basic Books.

Plato. [c. 380 BCE] 1992. Republic. Trans. G.M.A. Grube. Rev. C.D.C. Reeve. Indianapolis: Hackett. 
Popovski, Vesselin, Gregory M. Reichberg \& Nicholas Turner, eds. 2009. World Religions and Norms of War. Tokyo: United Nations University Press.

Porter, J.M., ed. 1974a. Luther: Selected Political Writings. Philadelphia: Fortress Press. 1974b. "The Political Thought of Martin Luther." In Luther: Selected Political Writings, ed. J.M. Porter, 1-24. Philadelphia: Fortress Press.

Premasiri, P.D. 2003. “The Place for a Righteous War in Buddhism.” Journal of Buddhist Ethics 10: 153-166.

—. 2006. “A 'Righteous War' in Buddhism?” In Buddhism, Conflict and Violence in Modern Sri Lanka, ed. Mahinda Deegalle, 78-85. New York: Routledge.

Presbyterian Church (USA). 1988. Christian Obedience in a Nuclear Age: A Policy Statement Adopted by the $200^{\text {th }}$ General Assembly. Louisville, KY: Office of the General Assembly, Presbyterian Church (USA).

- 2004. Book of Confessions. Louisville, KY: Office of the General Assembly, Presbyterian Church (USA). Available online at http://oga.pcusa.org/publications/ boc.pdf. (Accessed November 16, 2011).

Ptolemy of Lucca. [c. 1301] 1997. On the Government of Rulers [De Regimine Principum]. Trans. James M. Blythe. Philadelphia: University of Pennsylvania Press.

Pye, Lucien W. \& Sidney Verba, eds. 1965. Political Culture and Political Development. Princeton: Princeton University Press.

Quackenbush, Stephen L. \& Michael Rudy. "Evaluating the Monadic Democratic Peace." Conflict Management and Peace Science 26(3): 268-285.

Quandt, William B. 1986. Camp David: Peacemaking and Politics. Washington: Brookings Institution. 
The Quran.

(Ahmed Ali) Al-Qur'ān: A Contemporary Translation. [1984] 2001. Trans. Ahmed Ali. Princeton: Princeton University Press.

(Asad) The Message of the Qur'ān. 1980. Trans. Muhammad Asad. Gibraltar: Dar alAndalus.

(Ayoub) The Awesome News: Interpretation of Juz' 'Amma, the Last Part of the Qur'an. [1983] 1997. Trans. Mahmoud M. Ayoub. N.p.: World Islamic Call Society.

(Dawood) The Koran. [1956] 1974. $4^{\text {th }}$ rev. ed. Trans. N.J. Dawood. New York: Penguin Books.

(Fakhry) An Interpretation of the Qur'an: English Translation of the Meanings, A Bilingual Text. [2000] 2004. Trans. Majid Fakhry. New York: New York University Press.

(Haleem) The Qur'an: English Translation and Parallel Arabic Text. [2004] 2010. Rev. ed. Trans. M.A.S. Abdel Haleem. New York: Oxford University Press.

(Hilali \& Khan) Translation of the Meanings of the Noble Qur'an in the English Language. [1977] 1998/9 (1419 AH). Trans. Muhammad Taqî-ud-Dîn Al-Hilâlî \& Muhmmad Muhsin Khân. Medina, Saudi Arabia: King Fahd Complex for the Printing of the Holy Qur'an.

(Khatib) The Bounteous Koran: A Translation of Meaning and Commentary. 1986. Trans. Mohammad M. Khatib. London: Macmillan.

(Malik) English Translation of the Meaning of al-Qur'an: The Guidance for Mankind. [1997] 1998. $2^{\text {nd }}$ ed. Trans. Muhammad Farooq-i-Azam Malik. Houston: Institute of Islamic Knowledge. 
(Muhammad Ali) The Holy Qur'ān: Arabic Text with English Translation and Commentary. [1917] 2002. New 2002 ed. Trans. Maulana Muhammad Ali. Dublin, OH: Ahmadiyya Anjuman Isha'at Islam Lahore.

(Pickthall) The Meaning of the Glorious Koran. [1930] N.d. Trans. Mohammad Marmaduke Pickthall. New York: Mentor.

(Yusuf 'Ali) The Meaning of the Holy Qur'ān. [1934-37] 2009. $11^{\text {th }}$ ed. Trans. 'Abdullah Yūsuf ‘Alī. Beltsville, MD: Amana Publications.

Rahula, Walpola. [1959] 1997. What the Buddha Taught. Oxford: Oneworld Publications.

Ramaiah, G. Sundara, K. Ravi, and S.D.A. Joga Rao, eds. 1991. Buddhism and Peace: An Inter Disciplinary Study, Essays in Honour of His Holiness the Dalai Lama. Visakhapatnam, India: Andhra University Press.

Ramaswamy, T.N. 2007. Essentials of Indian Statecraft: Kautilya's Arthasastra for Contemporary Readers. New Delhi: Munshiram Hanoharlal Publishers.

Ramsey, Paul. 1961. War and the Christian Conscience: How Shall Modern War Be Conducted Justly? Durham, NC: Duke University Press.

— 1968. The Just War: Force and Political Responsibility. New York: Charles Scribner's Sons.

The Range of the Bodhisattva, A Mahāyāna Sūtra [Bodhisattva-gocaropāya-vișayavirkurvaṇa-nirdeśa-sūtra]. 2011. Trans. Lozang Jamspal. New York: American Institute of Buddhist Studies, Columbia University.

Rasler, Karen \& William R. Thompson. 2000. "Explaining Rivalry Escalation to War: Space, Position, and Contiguity in the Major Power Subsystem.” International Studies Quarterly 44(3): 503-530. 
Rauchhaus, Robert. 2009. "Evaluating the Nuclear Peace Hypothesis: A Quantitative Approach.” Journal of Conflict Resolution 53(2): 258-277.

Ray, James Lee. 1990. "Friends as Foes: International Conflict and Wars Between Formal Allies." In Prisoners of War: Nation-States in the Modern Era, ed. Charles S. Gochman \& Alan Ned Sabrosky. Lexington, MA: Lexington Books.

_ 1993. "Wars Between Democracies: Rare, or Nonexistent?" International Interactions 18(3): 251-276.

—. 2003. "Explaining Interstate Conflict and War: What Should Be Controlled For?" Conflict Management and Peace Science 20(1): 1-31.

Reagan, Ronald. 2007. The Reagan Diaries. Ed. Douglas Brinkley. New York: HarperCollins.

Reed, Charles \& David Ryall, eds. 2007. The Price of Peace: Just War in the TwentyFirst Century. Cambridge: Cambridge University Press.

Reichberg, Gregory M. 2009. "Norms of War in Catholic Christianity." In World Religions and Norms of War, ed. Vesselin Popovski, Gregory M. Reichberg \& Nicholas Turner, 142-165. Tokyo: United Nations University Press.

Reichberg, Gregory M., Henrik Syse, \& Endre Begby, eds. 2006. The Ethics of War: Classic and Contemporary Readings. Malden, MA: Blackwell Publishing.

Reiss, Hans, ed. 1991. Kant: Political Writings. $2^{\text {nd }}$ enl. ed. Cambridge: Cambridge University Press.

Reiter, Dan \& Allan C. Stam. 2002. Democracies at War. Princeton: Princeton University Press.

Reus-Smit, Christian. 1997. "The Constitutional Structure of International Society and the Nature of Fundamental Institutions.” International Organization 51(4): 555-589. 
-1999. The Moral Purpose of the State: Culture, Social Identity, and Institutional Rationality in International Relations. Princeton: Princeton University Press.

Richardson, Lewis F. 1960. Statistics of Deadly Quarrels. Ed. Quincy Wright \& Carl C. Lienau. Pittsburgh: The Boxwood Press.

Robinson, Paul, ed. 2003. Just War in Comparative Perspective. Burlington, VT: Ashgate.

Robinson, Richard H. [1959] 1997. "Buddhism: In China and Japan.” In Encyclopedia of the World's Religions, ed. R.C. Zaehner, 318-341. New York: Barnes \& Noble Books.

Rose, Gideon. 1998. “Neoclassical Realism and Theories of Foreign Policy.” World Politics 51(1): 144-172.

Ross, Andrew A.G. 2006. "Coming in from the Cold: Constructivism and Emotions." European Journal of International Relations 12(2): 197-222.

Rousseau, David L., Christopher Gelpi, Dan Reiter \& Paul Huth. 1996. “Assessing the Dyadic Nature of the Democratic Peace, 1918-88." American Political Science Review 90(3): 512-533.

Rousseau, Jean-Jacques. [1762] 2002. The Social Contract. In The Social Contract and The First and Second Discourses, ed. Susan Dunn, 149-254. New Haven: Yale University Press.

Rubin, Barry. 1994. "Religion and International Affairs." In Religion, the Missing Dimension of Statecraft, ed. Douglas Johnston \& Cynthia Sampson, 20-36. New York: Oxford University Press.

Ruggie, John Gerard. 1983. "Continuity and Transformation in the World Polity: Toward a Neorealist Synthesis.” World Politics 35(2): 261-285. 
- 1998a. Constructing the World Polity: Essays on International Institutionalization. New York: Routledge. 1998b. "What Makes the World Hang Together? Neo-Utilitarianism and the Social Constructivist Challenge.” International Organization 52(4): 855-885. Reprinted in John Gerard Ruggie, Constructing the World Polity: Essays on International Institutionalization, 1-39 (New York: Routledge).

Rummel, R.J. 1983. "Libertarianism and International Violence.” Journal of Conflict Resolution 27(1): 27-71.

—. 1994. Death by Government. New Brunswick, NJ: Transaction Publishers. . 1995. "Democracies ARE Less Warlike Than Other Regimes." European Journal of International Relations 1(4): 457-479.

- 1997. Power Kills: Democracy as a Method of Nonviolence. New Brunswick, NJ: Transaction Publishers.

Russell, Frederick. 1975. The Just War in the Middle Ages. Cambridge: Cambridge University Press.

Russett, Bruce, ed. 1972. Peace, War, and Numbers. Beverly Hills, CA: Sage.

—1993. Grasping the Democratic Peace: Principles for a Post-Cold War World. Princeton: Princeton University Press.

Russett, Bruce \& John Oneal. 2001. Triangulating Peace: Democracy, Interdependence, and International Organizations. New York: W.W. Norton.

Russett, Bruce M., John R. Oneal, \& Michaelene Cox. 2000. "Clash of Civilizations, or Realism and Liberalism Déjà Vu? Some Evidence." Journal of Peace Research 37(5): 583-608. 
Sachedina, Abdulaziz A. 2002. "From Defensive to Offensive Warfare: The Use and Abuse of Jihad in the Muslim World." In Religion, Law and the Role of Force: A Study of Their Influence on Conflict and on Conflict Resolution, ed. J.I. Coffey \& Charles T. Mathewes, 23-37. Ardsley, NY: Transnational Publishers.

el-Sadat, Anwar. 1977. In Search of Identity: An Autobiography. New York: Harper \& Row.

St. Louis Post-Dispatch. 1990. "Church Leaders Oppose Gulf War Letter Implores Bush to Seek 'Negotiated; Political Solution."” St. Louis Post-Dispatch, December 1: 10A.

Sandal, Nukhet A. \& Patrick James. 2011. "Religion and International Relations Theory: Towards a Mutual Understanding." European Journal of International Relations 17(1): 3-25.

Sasley, Brent E. 2011. “Theorizing States' Emotions.” International Studies Review 13(3): 452-476.

Saunders, Harold H. 2004. "Relational Realism: Toward a New Political Paradigm for Security." In Religion and Security: The New Nexus in International Relations, ed. Robert A. Seiple \& Dennis R. Hoover, 163-174. Lanham, MD: Rowman \& Littlefield.

Saurette, Paul. 2006. "You Dissin Me? Humiliation and Post 9/11 Global Politics." Review of International Studies 32(3): 495-522.

Schachter, Oscar. 1984. "The Right of States to Use Armed Force.” Michigan Law Review 82: 1620-1646.

- 1991. International Law in Theory and Practice. Dordrecht, Netherlands: Martinus Nijhoff Publishers.

Schleiermacher, Friedrich. [1830-31] 1976. Der Christliche Glaube [The Christian Faith]. $2^{\text {nd }}$ ed. Ed. \& trans. H.R. Mackintosh \& J.S. Stewart. Philadelphia: Fortress Press. 
Schmidt-Leukel, Perry, ed. 2004a. War and Peace in World Religions: The Gerald Weisfeld Lectures 2003. London, SCM Press.

Schmidt-Leukel, Perry. 2004b. "“Part of the Problem, Part of the Solution': An Introduction." In War and Peace in World Religions: The Gerald Weisfeld Lectures 2003, ed. Perry Schmidt-Leukel, 1-8. London, SCM Press.

—. 2004c. "War and Peace in Buddhism." In War and Peace in World Religions: The Gerald Weisfeld Lectures 2003, ed. Perry Schmidt-Leukel, 33-56. London, SCM Press.

Schmithausen, Lambert. 1999. “Aspects of the Buddhist Attitude Towards War.” In Violence Denied: Violence, Non-Violence and the Rationalization of Violence in South Asian Cultural History, ed. Jan E.M. Houben \& Karel R. van Kooij, 45-67. Leiden: Brill.

Schwartz, Regina M. 1997. The Curse of Cain: The Violent Legacy of Monotheism. Chicago: University of Chicago Press.

Schweller, Randall L. 1994. "Bandwagoning for Profit: Bringing the Revisionist State Back In.” International Security 19(1): 72-107. 1996. "Neorealism's Status-Quo Bias: What Security Dilemma?" Security Studies 5(3): 90-121.

- 2006. Unanswered Threats: Political Constraints on the Balance of Power. Princeton: Princeton University Press.

Scott, James Brown. 1934. The Spanish Origin of International Law: Francisco de Vitoria and his Law of Nations. Oxford: Clarendon Press.

Seiple, Robert A. \& Dennis R. Hoover. 2004. Religion and Security: The New Nexus in International Relations. Lanham, MD: Rowman \& Littlefield. 
Sells, Michael. 2002. Approaching the Qur'an: The Early Revelations. Ashland, OR: White Cloud Press.

Senese, Paul D. 2005. "Territory, Contiguity, and International Conflict: Assessing a New Joint Explanation.” American Journal of Political Science 49(4): 769-779.

Sereni, Angelo Piero. 1943. The Italian Conception of International Law. New York: Columbia University Press.

Seul, Jeffrey R. 1999. “'Ours Is the Way of God': Religion, Identity, and Intergroup Conflict." Journal of Peace Research 36(5): 553-569.

Shadid, Anthony \& David D. Kirkpatrick. 2011. "Activists in Arab World Vie to Define Islamic State." New York Times Online, September 30.

Shafi’'i, Muhammad ibn Idris. [c. 800 CE] 1993. Al-Shāfi ‘’’’s Risāla: Treatise on the Foundations of Islamic Jurisprudence. Trans. Majid Khadduri. Cambridge: Islamic Texts Society.

Shah, Timothy Samuel \& Daniel Philpott. 2011. "The Fall and Rise of Religion in International Relations History and Theory." In Religion and International Relations Theory, ed. Jack Snyder, 24-59. New York: Columbia University Press.

Shani, Ornit. 2007. Communalism, Caste and Hindu Nationalism: The Violence in Gujarat. Cambridge: Cambridge University Press.

Shannon, Thomas A., ed. 1982. War or Peace?: The Search for New Answers. Maryknoll, NY: Orbis.

Shaw, Malcolm N. 2003. International Law. $5^{\text {th }}$ ed. Cambridge: Cambridge University Press.

Shaybani. [c. 800] 1966. The Islamic Law of Nations: Shaybāni’s Siyar. Ed. \& trans. Majid Khadduri. Baltimore: Johns Hopkins Press. 
Singer, J. David, ed. 1980. The Correlates of War II: Testing Some Realipolitik Models. New York: Free Press. 1988. "Reconstructing the Correlates of War Dataset on Material Capabilities of States, 1816-1985." International Interactions 14(2): 115-132.

Singer, J. David, Stuart Bremer \& John Stuckey. 1972. "Capability Distribution, Uncertainty, and Major Power War, 1820-1965." In Peace, War, and Numbers, ed. Bruce Russett, 19-48. Beverly Hills, CA: Sage.

Singer, J. David \& Melvin Small. 1972. The Wages of War, 1816-1965: A Statistical Handbook. New York: John Wiley \& Sons.

Sivan, Emmanuel 1998. "The Holy War Tradition in Islam.” Orbis 42(2): 171-194.

Sizgorich, Thomas. 2008. Violence and Belief in Late Antiquity: Militant Devotion in Christianity and Islam. Philadelphia: University of Pennsylvania Press.

—. 2009. "Sanctified Violence: Monotheist Militancy as the Tie That Bound Christian Rome and Islam." Journal of the American Academy of Religion 77(4): 895-921.

Skelley, Joseph Morrison. 2009. Political Islam from Mohammed to Ahmadinejad: Defenders, Detractors, and Definitions. Santa Barbara, CA: Praeger Security International.

Skreslet, Paula Youngman \& Rebecca Skreslet. 2006. The Literature of Islam: A Guide to the Primary Sources in English Translation. Lanham, MD: Scarecrow Press.

Slaughter, Anne-Marie. 1993. [as Anne-Marie Slaughter Burley] "International Law and International Relations Theory: A Dual Agenda." American Journal of International Law 87: 205-239.

- 2004. A New World Order. Princeton: Princeton University Press. 
Small, Melvin \& J. David Singer. 1976. "The War-Proneness of Democratic Regimes, 1816-1965." Jerusalem Journal of International Relations 1(4): 50-69.

Smith, F.E. [Lord Stowell]. 1911. International Law. $4^{\text {th }}$ ed. Ed. J. Wylie. London: J.M. Dent \& Sons.

Smith, Huston. 1958. The Religions of Man. New York: Harper Press.

Smith, Jean Edward. 1992. George Bush's War. New York: Henry Holt \& Co.

Smith, Michael Joseph. 1986. Realist Thought from Weber to Kissinger. Baton Rouge, LA: Louisiana University press.

Smith, Tony. 2000. Foreign Attachments: The Power of Ethnic Groups in the Making of American Foreign Policy. Cambridge, MA: Harvard University Press.

Smith, Wilfred Cantwell. 1991. The Meaning and End of Religion. Minneapolis: Fortress Press.

Snyder, Jack. 1991. Myths of Empire: Domestic Politics and International Ambition. Ithaca, NY: Cornell University Press. , ed. 2011a. Religion and International Relations Theory. New York: Columbia University Press.

—. 2011b. "Introduction." In Religion and International Relations Theory, ed. Jack Snyder, 1-23. New York: Columbia University Press.

Sonbol, Amira. 2009. "Norms of War in Sunni Islam." In World Religions and Norms of War, ed. Vesselin Popovski, Gregory M. Reichberg \& Nicholas Turner, 282-302. Tokyo: United Nations University Press.

Sorabji, Richard \& David Rodin, eds. 2006. The Ethics of War: Shared Problems in Different Traditions. Burlington, VT: Ashgate. 
Souva, Mark \& Brandon Prins. 2006. "The Liberal Peace Revisited: The Role of Democracy, Dependence, and Development in Militarized Interstate Dispute Initiation, 1950-1999." International Interactions 32(2): 183-200.

Stark, Rodney. 1999. “Secularization, R.I.P.” Sociology of Religion 60(3): 249-273.

- 2001a. One True God: Historical Consequences of Monotheism. Princeton: Princeton University Press.

—. 2001b. "Gods, Rituals, and the Moral Order," Journal for the Scientific Study of Religion 40(4): 619-636.

- 2005. The Victory of Reason: How Christianity Led to Freedom, Capitalism, and Western Success. New York: Random House.

Starr, Harvey. 1978. “'Opportunity' and 'Willingness' as Ordering Concepts in the Study of Wars." International Interactions 4(4): 363-387.

—. 2005. "Territory, Proximity, and Spatiality: The Geography of International Conflict.” International Studies Review 7(3): 387-406.

Starr, Harvey \& Benjamin A. Most. 1976. "The Substance and Study of Borders in International Relations Research.” International Studies Quarterly 20(4): 581-620.

—. 1978. “A Return Journey: Richardson, 'Frontiers,' and Wars in the 1946-65 Era." Journal of Conflict Resolution 22(3): 441-467.

Steinfels, Peter. 1990. "Church Leaders Voice Doubts on U.S. Gulf Policy.” New York Times, October 12: A1.

Stelmachowicz, Michael J., ed. 1986. Peace and the Just War Tradition: Lutheran Perspectives in the Nuclear Age. New York: Lutheran Council in the USA.

Stepp, Laura Sessions. 1990. "Religious Leaders Urge Bush to Rule Out Force in Gulf." Washington Post, October 12: A16. 
Stinnett, Douglas M., Jaroslav Tir, Philip Schafter, Paul F. Diehl \& Charles Gochman. 2002. "The Correlates of War Project Direct Contiguity Data, Version 3." Conflict Management and Peace Science 19(2): 58-66.

Stoessinger, John G. 2010. Why Nations Go to War. $11^{\text {th }}$ ed. Boston: Wadsworth.

Stoyanov, Yuri. 2009. "Norms of War in Eastern Orthodox Christianity." In World Religions and Norms of War, ed. Vesselin Popovski, Gregory M. Reichberg \& Nicholas Turner, 166-219. Tokyo: United Nations University Press.

Strassler, Robert B., ed. 1998. The Landmark Thucydides: A Comprehensive Guide to the Peloponnesian War. New York: Touchstone.

Strobel, Lee. 1998. The Case for Christ: A Journalist's Personal Investigation of the Evidence of Jesus. Grand Rapids, MI: Zondervan.

- 2004. The Case for a Creator: A Journalist Investigates Scientific Evidence That Points Toward God. Grand Rapids, MI: Zondervan.

Suárez, Francisco, S.J. 1944a. Selections from Three Works of Francisco Suárez, S.J. Ed. \& trans. Gwladys L. Williams, Ammi Brown \& John Waldron. 2 Vols. Oxford: Clarendon Press.

—. [1621] 1944b. "On the Means Which May Be Used for the Conversion and Coercion of Unbelievers Who Are Not Apostates." Disputation 18 of $A$ Work on the Three Theological Virtues Faith, Hope and Charity. In Selections from Three Works of Francisco Suárez, S.J., ed. \& trans. Gwladys L. Williams, Ammi Brown \& John Waldron, vol. 2, 737-795. Oxford: Clarendon Press.

—. [1621] 1944c. "On War [De bello]." Disputation 13 of $A$ Work on the Three Theological Virtues Faith, Hope and Charity. In Selections from Three Works of Francisco Suárez, S.J., ed. \& trans. Gwladys L. Williams, Ammi Brown \& John Waldron, vol. 2, 800-865. Oxford: Clarendon Press. 
Subhani, Ayatullah Ja'far. N.d. The Message. Karachi: Islamic Seminary Publications. Available online at http://www.al-islam.org/message/. (Accessed April 22, 2011.)

Sucharov, Mira. 2011. "Values, Identity, and Israel Advocacy." Foreign Policy Analysis 7(4): 361-379.

The Sūtra of Golden Light. 1970. Trans. R.E. Emmerick. London: Luzac \& Company Ltd.

Swedlow, Brendon. 2011. “A Cultural Theory of Politics: Editor's Introduction: Cultural Theory's Contributions to Political Science.” Political Science and Politics 44(4): 703-710.

Taishō shinshū daizōkyō [The Taishō Tripitaka]. 1924-1932. Ed. Takakusu Junjirō \& Watanabe Kaigyoku. Tokyo: Taishō issaikyō kankōkai.

Tajfel, Henri \& John C. Turner. 1979. “An Integrative Theory of Intergroup Relations.” In The Social Psychology of Intergroup Relations, ed. William G. Austin \& Stephen Worchel. Monterey, CA: Brooks/Cole.

Tambiah, Stanley Jeyaraja. 1992. Buddhism Betrayed? Religion, Politics, and Violence in Sri Lanka. Chicago: University of Chicago Press.

Tappert, Theodore G., ed. 1959. The Book of Concord: The Confessions of the Evangelical Lutheran Church. Trans. Theodore G. Tappert, Jarolsav Pelikan, Robert H. Fischer, \& Arthur C. Piepkorn. Philadelphia: Muhlenberg Press.

Teorell, Jan, Marcus Samanni, Sören Holmberg \& Bo Rothstein. 2011. The Quality of Government Dataset, version 6Apr11. Göteborg: Quality of Government Institute. Available online at http://www.qog.pol.gu.se. (Accessed July 17, 2011).

Tesón, Fernando R. 2005. Humanitarian Intervention: An Inquiry into Law and Morality. $3^{\text {rd }}$ ed. Ardsley-on-Hudson, NY: Transnational Publishers. 
Tessler, Mark \& Michael D.H. Robbins. 2007. "What Leads Some Ordinary Arab Men and Women to Approve of Terrorist Acts Against the United States?” Journal of Conflict Resolution 51(2): 305-328.

Tetlock, Philip E., Jo L. Husbands, Robert Jervis, Paul C. Stern, \& Charles Tilly, eds. 1989. Behavior, Society, and Nuclear War. New York: Oxford University Press.

Thayer, Bradley A. \& Valerie M. Hudson. 2010. "Sex and the Shaheed: Insights from the Life Sciences on Islamic Suicide Terrorism.” International Security 34(4): 37-62.

Thomas, Scott M. 2000a. "Religion and International Conflict." In Religion and International Relations, ed. K.R. Dark, 1-23. New York: Palgrave Macmillan.

_ 2000b. "Taking Religious and Cultural Pluralism Seriously: The Global Resurgence of Religion and the Transformation of International Society." Millennium 29(3): 815-841.

- 2005. The Global Resurgence of Religion and the Transformation of International Relations: The Struggle for the Soul of the Twenty-First Century. New York: Palgrave Macmillan.

Thucydides. [c. 404 BCE] 1998. History of the Peloponnesian War. In The Landmark Thucydides: A Comprehensive Guide to the Peloponnesian War, ed. Robert B. Strassler, trans. Richard Crawley, 1-548. New York: Touchstone.

Tibi, Bassam. 1996. "War and Peace in Islam.” In The Ethics of War and Peace: Religious and Secular Perspectives, ed. Terry Nardin, 128-145. Princeton: Princeton University Press.

- 2002. The Challenge of Fundamentalism: Political Islam and the New World Disorder. Updated ed. Berkeley: University of California Press.

- 2007. Political Islam, World Politics, and Europe: Democratic Peace and EuroIslam Versus Global Jihad. New York: Routledge. 
- 2009. Islam's Predicament with Modernity: Religious Reform and Cultural Change. New York: Routledge.

Tickner, Arlene B. \& Ole Wæver, eds. 2009. International Relations Scholarship Around the World. New York: Routledge.

Tilakaretne, Asanga. 2003. "The Role of the Sangha in the Conflict in Sri Lanka." Journal of Buddhist Ethics 10: 167-191.

Toft, Monica Duffy. 2002/3. "Indivisible Territory, Geographic Concentration, and Ethnic War." Security Studies 12(2): 82-119.

—. 2007. "Getting Religion? The Puzzling Case of Islam and Civil War." International Security 31(4): 97-131.

Toft, Monica Duffy, Daniel Philpott, \& Timothy Samuel Shah. 2011. God's Century: Resurgent Religion and Global Politics. New York: W.W. Norton.

Toynbee, Arnold Joseph. 1947. Christianity and Civilization. Wallingford, PA: Pendle Hill.

Trombley, Frank R. 2003. "The Arabs, the Byzantine State and the Islamic Law of War (fiqh al-jihad) $\left(7^{\text {th }}-10^{\text {th }}\right.$ Centuries CE)." In Just War in Comparative Perspective, ed. Paul Robinson, 153-166. Burlington, VT: Ashgate

Tucker, Robert W. 1953. "Faith, Reason, and Power Politics." World Politics 5(3): 392413.

Tusicisny, Andrej. 2004. “Civilizational Conflicts: More Frequent, Longer, and Bloodier?" Journal of Peace Research 41(4): 485-498.

United Methodist Church. 2004. The Book of Discipline of the United Methodist Church, 2004. Nashville: United Methodist Publishing House.

United Methodist Council of Bishops. 1986. In Defense of Creation: The Nuclear Crisis and a Just Peace. Nashville: Graded Press. 
United Nations Statistics Division, Economic Statistics Branch. 2009. National Accounts

Statistics Database. Available at http://unstats.un.org/unsd/snaama/ introduction.asp. (Accessed July 17, 2011.)

United Nations Treaty Series. 1947- . New York: United Nations.

United States Conference of Catholic Bishops. 1993. The Harvest of Justice Is Sown in Peace. Washington: United States Conference of Catholic Bishops. . 1999. "Statement of President." March 24. Available online at www.usccb.org/ comm/archives/1999/99-064a.shtml. (Accessed January 11, 2008.)

United States Department of State. 1999-2009. Annual Report on International Religious Freedom. Available at http://www.state.gov/g/drl/rls/irf/index.htm. (Accessed January 1, 2011.)

Vasquez, John A. 1995. "Why Do Neighbors Fight? Proximity, Interaction, or Territoriality." Journal of Peace Research 32(3): 277-293.

de Vattel, Emer. [1758] 1995. The Law of Nations or the Principles of Natural Law. Trans. Charles G. Fenwick. 3 Vols. Buffalo: William S. Hein \& Co.

Viorst, Milton. 1965. The Great Documents of Western Civilization. New York: Barnes \& Noble Books.

Victoria, Brian Daizen. 2003. Zen War Stories. New York: RoutledgeCurzon.

- 2006a. Zen at War. $2^{\text {nd }}$ ed. Lanham, MD: Rowman \& Littlefield.

—. 2006b. "D.T. Suzuki and Japanese Militarism: Supporter or Opponent?” In Buddhism and Violence, ed. Michael Zimmermann, 159-194. Bhairahawa, Nepal: Lumbini International Research Institute.

—. 2010. “A Buddhological Critique of 'Soldier-Zen' in Wartime Japan.” In Buddhist Warfare, ed. Michael K. Jerryson \& Mark Juergensmeyer, 105-130. New York: Oxford University Press. 
Viswanatha, S.V. 1925. International Law in Ancient India. Bombay: Longmans, Green \& Co.

Vitoria, Francisco. [1539] 1991a. "De Indis [On the American Indians]." In Vitoria: Political Writings, ed. Anthony Pagden \& Jeremy Lawrance, 231-292. Cambridge: Cambridge University Press.

— . [1539] 1991b. "De Indis Relectio Posterior, sive de iure belli [On the Law of War]." In Vitoria: Political Writings, ed. Anthony Pagden \& Jeremy Lawrance, 293327. Cambridge: Cambridge University Press.

Wald, Kenneth D. \& Clyde Wilcox. 2006. “Getting Religion: Has Political Science Rediscovered the Faith Factor?" American Political Science Review 100(4): 523-529.

Waldron, Arthur. 1998. "Religious Revivals in Communist China." Orbis 42(2): 325334.

Walker, Stephen G. 1990. "The Evolution of Operational Code Analysis.” Political Psychology 11(2): 403-418.

Walker, Stephen G., Mark Schafer, \& Michael D. Young. 1999. "Presidential Operational Codes and Foreign Policy Conflicts in the Post-Cold War World.” Journal of Conflict Resolution 43(5): 610-625.

Walker, Thomas Alfred. 1895. A Manual of Public International Law. Cambridge: Cambridge University Press.

Walsh, Kenneth T. 1991. "Bush's 'Just War' Doctrine.” U.S. News and World Report 110(4) (February 4): 52.

Walt, Stephen M. 1987. The Origins of Alliances. Ithaca, NY: Cornell University Press.

Waltz, Kenneth N. 1959. Man, the State and War: A Theoretical Analysis. New York: Columbia University Press. 1979. Theory of International Politics. New York: McGraw-Hill. 
— 1981. The Spread of Nuclear Weapons: More May Be Better. Adelphi Papers, No. 171. London: International Institute of Strategic Studies.

—. 2003. "More May Be Better." In The Spread of Nuclear Weapons: A Debate Renewed, ed. Scott D. Sagan \& Kenneth N. Waltz, 3-45. New York: W.W. Norton. Warner, Carolyn. 2000. Confessions of an Interest Group: The Catholic Church and Political Parties in Europe. Princeton: Princeton University Press.

Waters, David. 2010. “God gap' impedes U.S. foreign policy, study says.” Washington Post, February 24: A2.

Watson, Alan. 1996. Jesus and the Law. Athens, GA: University of Georgia Press.

Watt, W[illiam] Montgomery. 1962. Muhammad at Medina. Oxford, Clarendon Press.

— 1985. Islamic Philosophy and Theory. Edinburgh: Edinburgh University Press.

Weber, Max. [1922] 1958a. "The Social Psychology of the World Religions." Trans. H.H. Gerth \& C. Wright Mills. In From Max Weber: Essays in Sociology, ed. H.H. Gerth \& C. Wright Mills, 267-301. New York: Oxford University Press.

- [1905] 1958b. The Protestant Ethic and the Spirit of Capitalism. Trans. Talcott Parsons. New York: Scribner.

—. [1922] 1963. Sociology of Religion. Trans. Ephraim Fischoff. Boston: Beacon Press.

Webster, Alexander F.C. 1986. "Just War and Holy War: Two Case Studies in Comparative Christian Ethics.” Christian Scholar's Review 15(4): 358-361.

— 1999. The Pacific Option: The Moral Argument Against War in Eastern Orthodox Theology. Lanham, MD: International Scholars Publications.

—. 2003. "Justifiable War as a 'Lesser Good' in Eastern Orthodox Moral Tradition.” St. Vladimir's Theological Quarterly 47(1): 3-58. 
Webster, Alexander F.C. \& Darrell Cole. 2004. The Virtue of War: Reclaiming the Classic Christian Traditions East and West. Salisbury, MA: Regina Orthodox Press.

Weede, Erich. 1984. "Democracy and War Involvement.” Journal of Conflict Resolution 28(4): 649-664.

—. 1989. "Extended Deterrence, Superpower Control, and Militarized Interstate Disputes, 1962-76." Journal of Peace Research 26(1): 7-17.

Weeks, Jessica L. 2008. “Autocratic Audience Costs: Regime Type and Signaling Resolve." International Organization 62(1): 35-64.

Weeramantry, C[hristopher] G. 1988. Islamic Jurisprudence. An International Perspective. New York: St. Martin's Press.

Weigel, George. 1987. Tranquillitas Ordinis: The Present Failure and Future Promise of American Catholic Thought on War and Peace. New York: Oxford University Press.

-1989. American Interests, American Purpose: Moral Reasoning and U.S. Foreign Policy. New York: Praeger.

. 1994. Idealism Without Illusions: U.S. Foreign Policy in the 1990s. Wilmington, DE: ISI Books.

- 2003. "Moral Clarity in a Time of War." In War and Christian Ethics, $2^{\text {nd }}$ ed., ed. Arthur F. Holmes, 373-390. Grand Rapids, MI: Baker Academic.

-2007a. Faith, Reason, and the War Against Jihadism: A Call to Action. New York: Doubleday Religion.

. 2007b. "The Development of Just War Thinking in the Post-Cold War World: An American Perspective." In The Price of Peace: Just War in the Twenty-First Century, ed. Charles Reed \& David Ryall, 19-36. Cambridge: Cambridge University Press. 
Weigel, George \& John P. Langan, S.J., eds. 1991. The American Search for Peace:

Moral Reasoning, Religious Hope, and National Security. Washington: Georgetown University Press.

Wendt, Alexander E. 1987. “The Agent-Structure Problem in International Relations Theory." International Organization 41(3): 335-370.

1992. "Anarchy Is What States Make of It: The Social Construction of Power Politics.” International Organization 46(2): 391-425.

—. 1995. “Constructing International Politics.” International Security 20(1): 71-81.

— 1999. Social Theory of International Politics. Cambridge: Cambridge University Press.

Westlake, John. 1907. International Law. 2 vols. Cambridge: Cambridge University Press.

Wheaton, Henry. [1866] 1936. Elements of International Law. $8^{\text {th }}$ ed., ed. Richard Henry Dana. Washington: Carnegie Endowment for International Peace.

Wheeler, Nicholas J. 2001. Saving Strangers: Humanitarian Intervention in International Society. New York: Oxford University Press.

Wiener, Philip P. \& John Fisher, eds. 1974. Violence and Aggression in the History of Ideas. New Brunswick, NJ: Rutgers University Press.

Wildavsky, Aaron. 1987. "Choosing Preferences by Constructing Institutions: A Cultural Theory of Preference Formation." American Political Science Review 81(1): 3-21.

Wilson, George Grafton \& George Fox Tucker. 1901. International Law. $2^{\text {nd }}$ ed. New York: Silver, Burdett \& Co.

Winter, David G. \& Abagail J. Stewart. 1977. "Content Analysis as a Technique for Assessing Political Leaders." In A Psychological Examination of Political Leaders, ed. Margaret G. Hermann \& Thomas W. Milburn, 28-61. New York: Free Press. 
Wollebæk Toset, Hans Petter, Nils Petter Gleditsch, and Håvard Hegre. 2000. "Shared Rivers and Interstate Conflict.” Political Geography 19(8): 971-996.

The World Almanac and Book of Facts. 1968-1995. Mahwah, NJ: World Almanac.

World Values Survey Association. 2009. World Values Survey 1981-2008 Official Aggregate v. 20090901. Madrid: ASEP/JDS. Available online at http:// www.wvsevsdb.com/wvs/WVSData.jsp?Idioma=I. (Accessed July 22, 2011.)

Xue Yu. 2005. Buddhism, War, and Nationalism: Chinese Monks in the Struggle against Japanese Aggressions, 1931-1945. New York: Routledge.

— 2010. "Buddhists in China during the Korean War (1951-1953)." In Buddhist Warfare, ed. Michael K. Jerryson \& Mark Juergensmeyer, 131-156. New York: Oxford University Press.

Yoder, John Howard. 1984. When War Is Unjust: Being Honest in Just-War Thinking. Minneapolis: Augsburg Publishing House. 1994. The Politics of Jesus: Vicit Agnus Noster. $2^{\text {nd }}$ ed. Grand Rapids, MI: William B. Eerdmans.

- 2009. The War of the Lamb: The Ethics of Nonviolence and Peacemaking. Ed. Glenn Harold Stassen, Mark Thiessen Nation, \& Matt Hamsher. Grand Rapids, MI: Brazos Press.

Yu, Xue. See Xue Yu.

Zaehner, R.C, ed. [1959] 1997. Encyclopedia of the World's Religions [formerly The Hutchinson Encyclopedia of Living Faiths, $4^{\text {th }}$ ed.]. New York: Barnes \& Noble Books.

Zakaria, Fareed. 2003. The Future of Freedom: Illiberal Democracy at Home and Abroad. New York: W.W. Norton. 2008. The Post-American World. New York: W.W. Norton. 
Zimmermann, Michael. 2000. “A Mahāyānist Criticism of Arthaśāstra: The Chapter on Royal Ethics in the Bodhisattva-gocaropāya-vișaya-vikurvaṇa-nirdeśa-sütra." In Annual of the International Research Institute for Advanced Buddhology at Soka University, for the Academic Year 1999, 177-211. Tokyo: International Research Institute for Advanced Buddhology, Soka University. Available online at www.iriab.soka.ac.jp/orc/Publications/ARIRIAB/pdf/ARIRIAB-03.pdf. (Accessed December 15, 2011.) , ed. 2006a. Buddhism and Violence. Bhairahawa, Nepal: Lumbini International Research Institute. . 2006b. "Only a Fool Becomes a King: Buddhist Stances on Punishment." In Buddhism and Violence, ed. Michael Zimmermann, 213-242. Bhairahawa, Nepal: Lumbini International Research Institute. 